UCRL- $-53689-88$

DE89 012801

\title{
Institutional Research and Development
}

Lawrence Livermore National Laboratory 


\section{Icknowledgments}

The Institutional Research and Development (IR\&D) Program for FY X8 $u$ ats direcled by John Holarichler. Assistant to the Director for IR\&D. Jeannic Maniz served as Research Manager for the IR\&D Program. The following people formed the ptiblication staff for the FY88 IR\&D report:

Scientific Editor

Gordon L. Siruble

Publication Editor

Liluren de Vore

Editors

Designer

Artists

Composition

Cover Photograph
A. Paul Adye
Robert D. Kirvel
Gloria M. Lawler
Coralyn K. MlcGregor
Timothy M. Peck
Judyth K. Frono
Sondra Reid
Palmer T. Van Dyke

John M. Zych

Rober Caldwell

John Danielson

Lynn M. Costa

Julia Z. Deal

Barbara Edwards

Kirk Hadley

Kathryn C. House

George A. Kitrinos

Frank Marquez

Merry Oman

Phyllis Thomas

Louisa Cardoza

Don Gonzalez

We thank George F. Bing. Jane T. Staehle. and Mary Ann Esser for caretul reading of the entire manuscript. 


\section{Contents Intruduction}

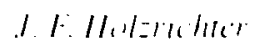

\section{Exploratory Research}

Biotechnolog!

11. L. Me'mle/w/m

Plant Molecular Genetic: Capabilits at L.L VL.

r. Y. I/arshum and I. II. Shrm!

Scanning Tunneling Microwcop! of Biolongical Samples

k. Bathorm and II Sis'khats.

Port-Labeled DNA Adeduch

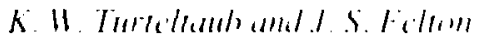

(hemistry and Materials Sicience

4

T.T. Susihura

Peritron Studien of High-Temperature Supercondactors

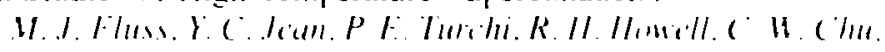
and t. L. Harh

Readise-Element Eflect Siludied L ing fon Implantation

II. F. King and K. S C (iralhemshi

Veu Method for Calculating the Electronic Structure of Soldo

A. (iomis

Site-Specific Chemistry Ling Synchrotron Radiation

I. Ilings

X-Ra! Thin Films

T. Hi. Burlocels:

Phomalctiated Heterogeneous Callalysis on Aerogels

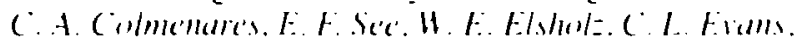

M. Comler and R. (iare')

\section{Computation}

R.R. Brrohers

Closure Modeling of Plasma Turbulence

A. E. Konige's, HI. P. Dammerik, and C. E. Leirh

An Automatic Programming System for Solving Partial

Differential Equations

D. Balaban. I. Girharini. and H. (iriaman

An Expert Sy'stem for Tuning Accelerators

H. Brand, D Lager. R Se'arfus. H Matrer I Hermander. and F. Cofficild

Architecture Studies with SISAL.

$$
\text { I. T. Fin }
$$

Parallel Pacudurandom Vumber (ienerallion

$$
\text { h. DIIII }
$$

Farth Siciences

1. Silmart=

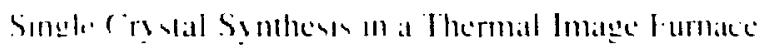

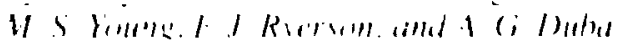

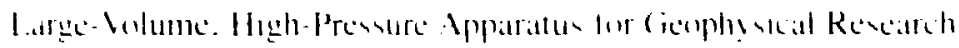




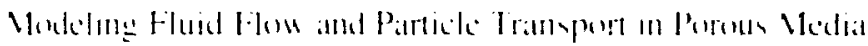

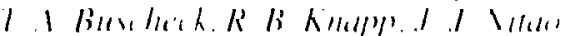

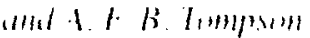

Me:asuring pH in Concentrated Electrolves

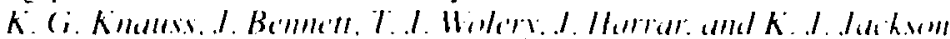

In-Simu Downhole Mleasurements

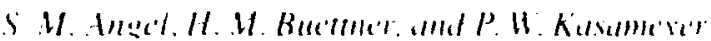

Scoimolongeal and Geochemical Studies in Northern Califorma

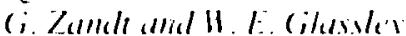

Incorporatina Equation-of -State Modeh in DYNADD

1. A. (ilc'mll

Engineering

I. A. Latrallithi

Surtace Breakdown Induced by I.arge Transient Fields

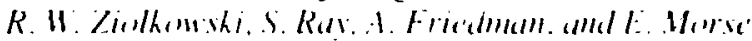

Ductile Ginding of Brinle Malcrials

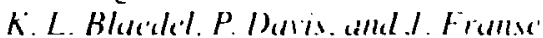

Membership in the NCSU Precision Engineering Center

411

41

$+2$

4.3

$+1$

45

47

$5(1)$

I. F. Stumers and E. R. Mo \%me

Nuclear Chemistry

D. A. Laich

Vew Techniques for Measuring Isolopic Ratios

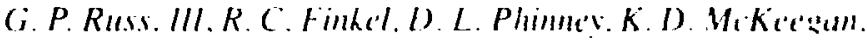

I. M. Bazan. alld M. H. Caffe'

Cismochemistry Research

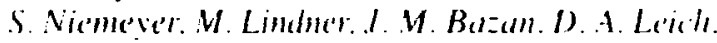

allal C;. P. Rusis. Ill

Liltrasensitive Laser Spectroscopy

R. I. Silva and R. E Rusiss

Measuring the Beta-Decay End Point of Atomlc Trinum

H. Sirift. D. Do'mam. and .I. Engelage'

Measuring the Thermodynamic Properties of Actinide Elements

P. A. Baisden, R. J. Silva, P. M. Gramt, R. A. Torre's.

and C.E. A. Palme'

\section{Physics}

\section{B. Tarter}

Magnetic Fusion Modeling

A. Friedman

Insulator-to-Metal Tramsition in Xenon

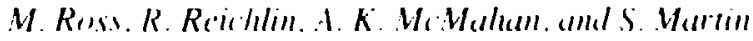

Adranced High-Velocits Two-Stage Light-(ian (iun

il. I. Nellis

Muon-Caltily aed Fusion

B. I. H/der and II I III/ham

Quark Searcin

( Hellolichis

Biomedical and Fonirommental Applicintom al deceleranor

Mats Spectromeirs

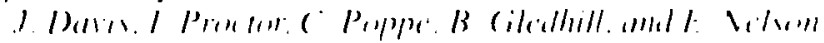

(6)

62

6.3

$6+$

1.5

67

(1) 


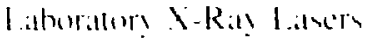

71

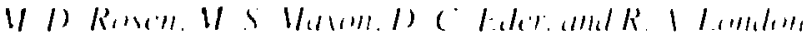

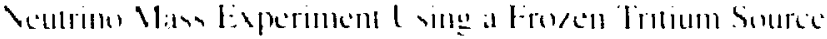

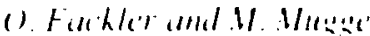

Vuclear Shape leomers as Calldidates for a CiammatRat latser H. Il ins

The Femomecond l alser Project

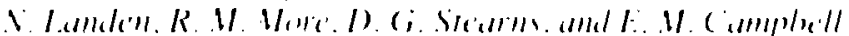

Multiphoton Interatetion of Intense Latsers with Aloms

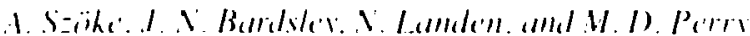

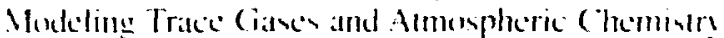

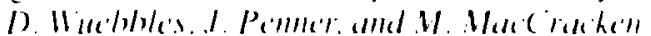

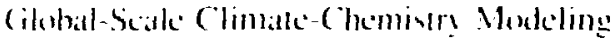

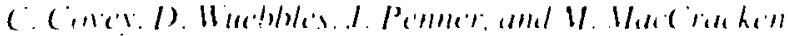

Director's Initiatives

(i. L. S Sm $/$ h/.

Burlogical and Ecologeical Feflectsul Vuckear Watr

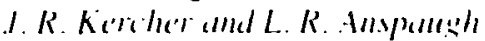

Monocilonal Antiboly Research and Instrumentation M. Limderlam

Microbial Genetic Engineering Biolechnolog!

F. (idllial andl l. I. Fin

Methane-Conversion Ensomes

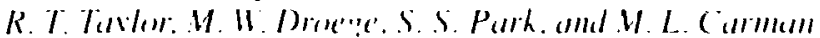

Culturing Thermophilic Microorganisms from cienthermal Fluids

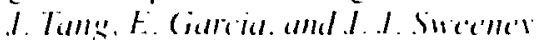

C.S. Eneroy Supply and Demand I. Borle

Relativistic KJutron Rezearch for High-Gradient Accelerators

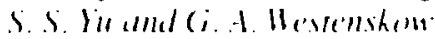

thanced Technologien for (jroming Large ()plical Cryulats

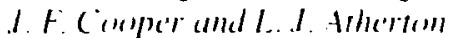

Diode Arraly Development

R. if. Solar-. D. C. Mundinger. R. I. Betuh. Wi F. Kraphe'. and W. I. Benent

Development of $X$-Ray Laser Hollograph!

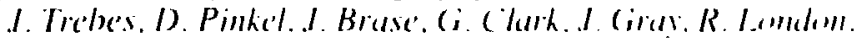
D. Mathens. D. Pe'ters. M. Rosen. P. Ian trodalt. and T. Yarke's

High-Resolution Imaging

I. I. Dewis, N. A. Hawic. amd I P. I. In'th

Compict Torus Acceleralur

(' II. Harmam almal I. H. Hammor

computer-Aided Design Towh for Very-Latge. Scate Integrathon

II. S. Sirnll

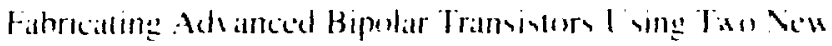

Tichnolugicen

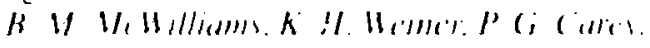$$
\text { amal I II Sismum }
$$

57

73

75

77

74

$x !$

$S 2$

sx

91

บ3

46

47

49

1010

1117

112

115 


\section{Individual Awards}

Individual Awards

$$
\text { K. I. Haril }
$$

Vuclear Magnetic Rembiance Anats sis and Molecular Modelang

(I) Prolamine

$$
\text { R. L. Ballwm. R. Hard. amd A. Hal }
$$

Application af Accelerator Malss Spectrometry "w Marine Ecolog!s

$$
\text { R. B. Spicer amd I. Bancer }
$$

Flunrescence Detection and Quantitication of Gienc Expression M. G. Pallavitini

Scanning Tunneling Microscop!

If. L. Bell. R. Balhenn. T. Behhe' II. I. Siehhalus.

T. Hilsull ald M Salmernm

Sy nthesis of Dense Energetic Material l sing Poly mer Supports

A. R. Minhell

Multilater Gratings for $\mathrm{J} n=0$ Spectroscops

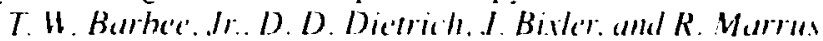

Montc Carlo Alomic Kinelics Calculations

J. R. Alhritum.B. (i. Hilsm. and T. Thumwm

Micropole Lindulator Insertion Devices

A. Tour. P. Comba, J. Humer. R. Homadr, R. Taldhun.

1). Hhelan. and G. Hesconskm

Pressure Effects in High-Temperature Superconductors

B. Bommer. M. Yommg. R. Reichlin. F. Rierwn. and G. Smirh

Lising Geochemical Modeling to Investigalte the Paleocology of Closed

Basin Lakes in the East African Rift During the Plio-Pleistocene

K. I. Jacksom

Almospheric Compensation Algorithms for Imaging

J. P. Filch. T. H. Lamrence and D. M. Gowdman

Thermally and fon-Assisted Elching of Tungsten and Molyhdenum

D. E. Miller, H. J. Sicinalss, and M. Balowh

Miniature Vacuum Tuhes for Harsh Environments

H. I. Orvis. C. F. M. Comagh. D. R. Ciarlo. and I. H. He'

Development af an Induction Linac Cyclotron Autoresonance Maser

M. Caplan.J. K. Boyd. A. Salup. R. R. Srome.

and $C$. Thrwinglom

Generation of High Electrical Polentials in Plasma for Appication

to the Mirrortron

R. F. Past, S. Domglass, T. Weisgraher, and S. Fallabella

Microcalorimeters for X-Ray Spectroscopy

E. Silier. S. Labon: F. Ginulding. N. Madden. D. Lamdis.

I. Be'man. E. Haller. and I. Rullader

Chass: in Amplitied Spontaneous Emission

I. C Ciarrivem. H. Nathel. and R. Y. Chial

Algorithms for the Lamb Shift in High-Z Hydrogen- and

Helium-Like Ions

1. I snivle'mant

Density Fluctuations in the Big Bang and the Dark Matter Problem

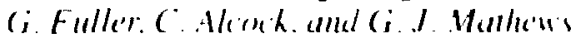

Multiphoum lonization of Aloms in Strong Fields

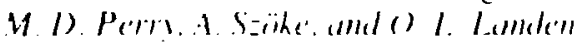

174

$1+1$

$1+4$

146

148

150

152

154

158

161 


\section{Lniversity of California Institutes}

Alomic Physers Studes al he L.BL. F(CRIS

175

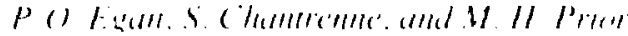

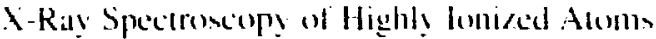

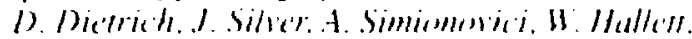

1. H. Laming. amd Si Led

A Multiple-Object Spectrograph for Astronomical Oherenations C. I. Hailer, I. P. Brodic, and R. F. Sichart

Theoretical Studies of High-Temperature Superconductors N. Himler alld M. Ross

Laser Cooling of Positronium

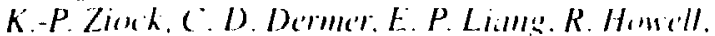

K. M. Imlle's. andF Masmentu

Cniversity of California Institutes

Institute of (reophỵsics and Planetary Physics

Aalysis of the Mt. Lewis Earthyuake and Prior Activity

$1198(1-1986)$ Usine Digital Seismic Data K. C. Me Nalls. G. Zundt. amel $G$. Ne'som

Mapping Changes of Crustal Heterogeneities R. S. Wh. (;. Zandt, anul (i. Nolsom)

Telesermic-Converied Waves in the Long Valley Caldera H. Prothero. Jr. G. Zandt. and L. Steck

Crustal Fault Zone Study with the Law rence Livermore

Scismic Network 1. Iidale. G. Zamdt. G. Nelsen, and D. Gartia-Cionzales

Seismic Altenuation firm Earthquake and Explosion Sources

S. Hough. I. Andersom. and H. Pallon

Crustal Genesis and Recrucling in Northwestem Mexico K. Came'ron, S. Nit'me'ver, and G. Nim:

Geologic Application of Discrete-Particle Models for Earth Materials R. Shreve. O. Wallon. and T. Drake'

Isotopic Analysis of Microscopic Domains in Garnet Porphyrobiasts from Sri Lanka

I. Rernolds. W. Gilassler. and t. I. Irwin

Trace-Element and Isotope Geochemistry of Cretaceous/fertian

Boundary Sediments

S. Margolis. G. P. Russ. III, and E. Dochmo'

Nondestructive Gamma-Ray Analysis of Uranium-Series Nuclides

in Volcanic Rocks

J. D. Mardongall. R. Finhel. and K. Rubin

Stable lsolope Ratios of Reactive Metals in Seawaler

A. R. Fle'gal and S. Nic'me'a')

Multiwavelength Study of the Continuum in Active Gatactic Nuclei

M. Mulhan aind I). Band

Modeling Supernova Spectra

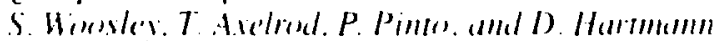

Veutron-Rich Nucleosynthesis

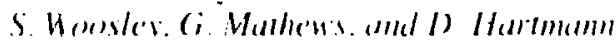

High-Spatial-Resolution Detecturs for Hard-X-Ra! Inaging

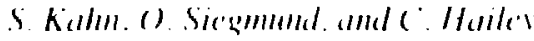

187

$18 x$

19(1)

191

192

177

$17 x$

180

182

90

193

194

195

196

197

198

149

2(K)

201

2(1)

201.3

214 


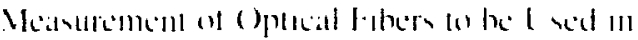

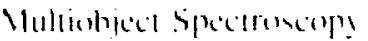

$\underline{215}$

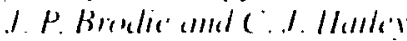

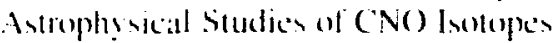

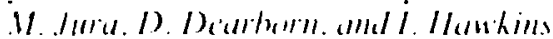

$\underline{2}(16$

The Incertac at Astruphssics and Particle Phssics

$\underline{2} 17$

I. Silk. I). Dawhelln. allal (i. Ruttelt

Plismat tserophysics

?IX

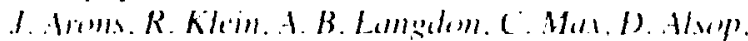

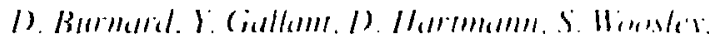
alld A. Lahhur

Frilctal Dust Girams

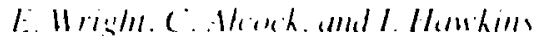

Stalistical Mechanics and Phase Equilihria al homic and Cienphysical

Siscoms all High Pressurc

M. Buknomski. H. Rass, an!l L. Simmde

Dynamic High-Pressure Symthesis of High-Temperature

Superconductors and Ferromagnels

M. R. Maple', H. Neliis, I. Nemmerier C. Seamam. and J. Markirt

Melting and Other Phase Tramsitions of Solids all High Pressures M. Ni(a) D. Yollum, M. Rass. and B. Bater

Conductivity of Mantle Rocks al Subsolidus Temperatures

S. Comstable and A. Duha

Measurement of Elastic Constants up to $20(1)(1) \mathrm{K}$

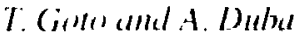

Emision Spectra tron Simple Shockied Solids

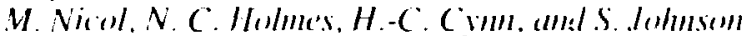

Transilion-Melal Oxides and Silicales al Ultrahigh Pressures

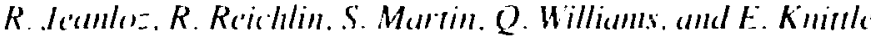

Institute for Scientific Computing Research

A. G. Smiriga

Physics Algorithms for Massively Parallel Computers

M. Colvin. A. Ladd. D. Frenkel, G. Sugivama. and B. Alder

Computer Model of Motion Detection in the Vertebrate Retina

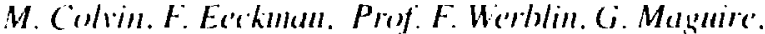

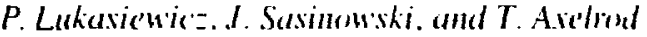

Advanced Algorithms in Computational Fluid Dynamics

E. G. Purke't, S. Baden, P. Colella. L. F. He'mlersem. and $M$. Hiliamic

Plasma Physics Research Institutc

I. Kille'c'n

The Davis Diverted Tokamak

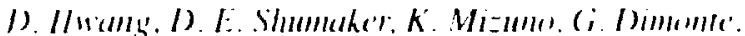

B. I. ('ma'll. I) Flimmer. alld T. Hillid'

Joint LLANL/L'CB Particle-Simulation Project

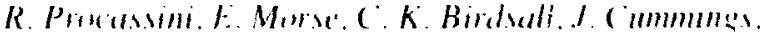

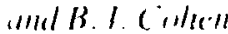

Inense Lower-Hybrid Wave Penetration into Matenetiacd

Fusion Plasmal 
Program for Analytical Cytology $\quad 225$

B. II Mavi!l

Red Cell Density and Aging

226

L. Corcush, R. Lamgleris, R. tonse'n, and M. Clark

Detecting Somatic Cell Mutations Using the Glycophorin-A Assaly

S. Saks. W. L. Bighe'c. R. H. Ionse'n, E. C. Cadman, and H. Jatfe

Viability of Primary Human Breast Cancers

H.S. Smith. I. W. Gras. B. H. Mavall, and B.-M. Linng

Human Brain Tumors Classified by Cytonetry

I. Murovic I. H. Gros and T. Hoshino

Molecular Regulation of Complement Activation

G. A. Iaris, R. Lamghois, and I. M. Griffiss

IR\&D Resource Requirements

Author Index
FY 88 Budget for the Institutional Research and Development Program

Author Index 


\section{Introduction}

\author{
J. F. Holzichter
}

The Laboratory is Institutional Rexairch and Development (IR\&D) Program was established in logt to loster exploratory work to atd ance scituce and lechnology. disciplinary research to develop imovative solutions to problens in various scientific tields, and long-term interdisciplinary research to support our national defense and energy missions. In FY88, the IR\&D Program was funded by a $2 \%$ assessment on the Laboratory's operating budget. Our policy is to use these funds for researching innovative ideas in LLNL's areas of expertise and for developing new areas of expertise that inc perceive to be in the national interest.

We support four categories of research. The first. Explordtory Research. is managed by Laboratory departments and divisions to promote pioneering work in the various scientific disciplines (biomedical and environmental sciences. chemistry and materials science. computations. earth sciences. engineering. nuclear chemistry, and physics). The second. Director`s Initiatives, is devoled to a few larger projects selected by the Laboratory Director.

The third. Individual Awards, supports promising research outside the usual programmatic channels; funds are awarded on the basis of scientilic excellence. potential impact. and leverage for future funding. In FY88. 151 applications tor individual grants were submitted. and 26 were funded.

The fourth category, University of California (UC) Institules, arises from the Laboratory's role in the nation 's academic and research establishment and our collaboration with many UC campuses and universities nationwide. The IR\&D Program has provided support to begin several joint LaboratoryUniversity research groups that enable bring LLNL and UC scientists together to focus effort on important scientific problems of mutual interest.

The IR\&D Program is managed for the Laboratory Director by a special assistal.: who chairs the IR\&D Review Committee. The other nembers of the Review Cornmittee are senior LLNL scientists. engineers. and managers with areas of expertise that span the range of scientific disciplines pursued at the Laboratory. The Individual Award proposals and projects are evaluated by the IR\&D Review Committee, a group of prominent Laboratory scientists and engineers.

For FY88, the total IR\&D budget was $\$ 18$ million: \$6 million for Exploratory Research, \$6.5 million for Director`s Initiatives, $\$ 3.2$ million for Individual Awards, and $\$ 2$ million for the UC Institutes.

The technical and scientific accomplishments of each project and of each institute funded this year are presented in this report. The projects were selected because they are expected to advance research in important areas that are too basic or too time consuming to be funded by the developmental programs or because they are somewhat risky projects that have the promise of high payoff.

We are continually reappraising the IR\&D Program. In parlicular. we seek new candidates for the Director's Initiatives, and we constantly reassess the work in progress. Each ycar, we make adjustments to further the Laboratory's policy of using the IR\&D Program to fund innovative ideas with high potential for enhancing programmatic activities of national importance. 


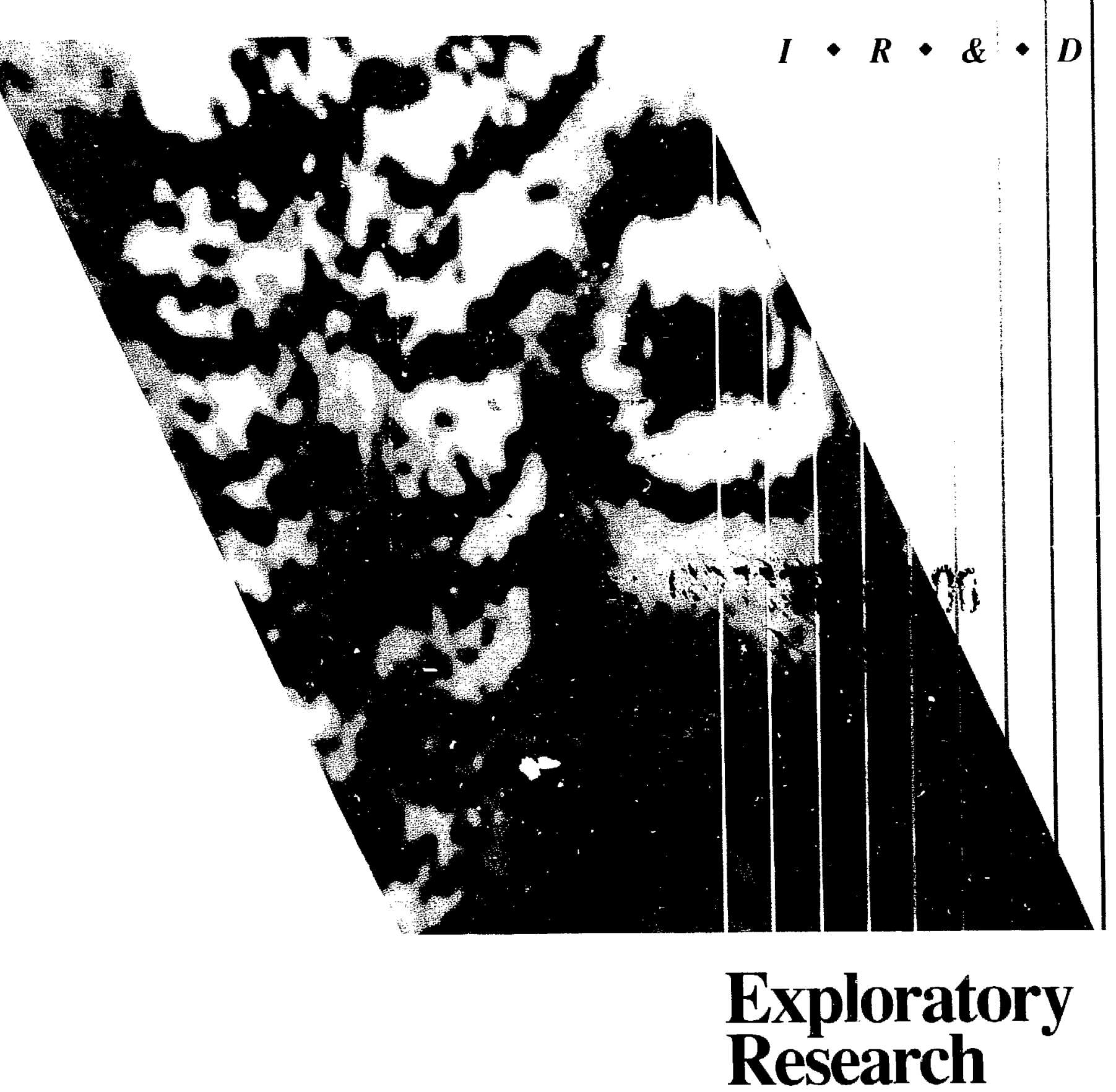

Lawrence Livermore National Laboratory 


\section{Biotechnolog!}

M. L. Mendelsohn
IR\&D fund for the Bioncedical and Em irommental Renearch Program

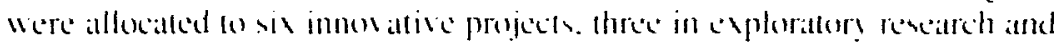

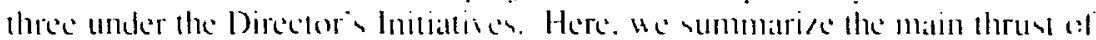
each of these atcivilies.

Exploratory restarch was conducted lo develop a plant molecuiar gentetics capability at LL.NL. Wo established a small facility for studying plant molecular genetics that includes rooms for plant grow ht. areas for plant culture. and the begimnings of a recombinant DNA laboratory. The bassic lechniques lor handling and culturing plants. for isolating DNA. and for creating gernetis variants are now operational.

We are also doing innovative work with the scamning unneling mieroseore o image biological molecules. particularly DNA. We have already whtained dramatic, previously unatlainable. high-resoltation images showing the threedimensional atomic structure of double-stranded DNA. This neu athility 10 obtain atomic-level imageses of hiological structures promises to greally advance the field of molecular research.

In our third exploratory research project. we are applying the technique of post-labeling with phosphorus-32 for the detcetion of DNA adducts r building: blocks of DNA that have heen modified by the binding of electrophilic chemical species). This method results in distinctive spol palterns or fingerprints for the compounds of interest that are of greal value in studying the genotoxicity of exolic chemicals. We are applying the post-labeling assay to the potent. mutagenic, heteroćyclic amines found in cooked foods. such is fried ground bect, that are typical of the Western human diet.

For the Director's Initiatives, we are studying the biological and ecological effects of nuclear war. Specilically. we are using experimental data and model simulations to examine the combined effects of low temperature and low levels of light, which have been projected to follow a nuclear exchange, at the plant. community, and regional levels. For some of the plants studied. computer simulations correctly predict the experimentally observed effects. For others. predictions have failed because the plants have discontinuous or switch-like mechanisms that were not previously known. Research at the regional level of resolution for both agricultural and natural ecosystems comprises a new field in ecology and should yield large returns.

For our research on monoclonal antibodies, we are pursuing two approaches to develop new immunochemical sensors for environmental monitoring. The first makes use of the surface acoustic (or Lamb) wave to detect oscillatory changes in thin films secondary to the binding of antibody molecules; we are testing such devices that have been designed onto silicon chips. The second approach exploits the evanescent wave to yuantify antibody fluorescence in the zone immediately adjacent to the surface of an optical tiber: our goal in this project is to fabricale real-time. portable assay systems for detecting environmental pollutants.

In our last IR\&D project. we have used recombinant DNA lechnicpues Io transfer the gene responsible for the first enzymatic step in the assimilation of

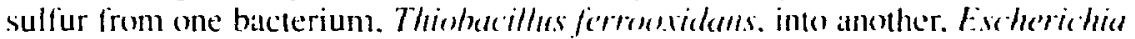
colli. This gene has now been made to function in the new setting. and we are

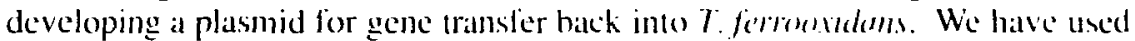
a similar technique for the gene that converts toxic selenale into nontoxic selenium. This gene hats been transferred from (lastrilimm pastetriamm into $E$. coll and has been characterised and mate on lundion in the new sething.

In FY8X. the Biomedical and Environmen al Research Paogram received

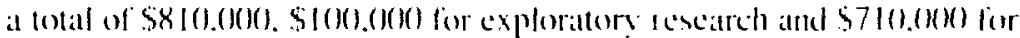
Directors foltiatives projects. 


\section{Plant Molecular Cenetics (alpability at L.I.NI.}

\author{
Principal Insestigaturs: Y. Y. Marchant \\ and .I. H. Shinn
}

\section{We are applying recent advances in plant molecular genetics and biotechnology to minimize the impact of energy-related stressors on plants. One application is the development of plants that are resistant to or tolerant of specific air pollutants.}

W chatc creatlod a small tacilis tior studsing plant molcoular senteric in the Envirommental Sciencer Dirinion. ()ar tikilia? includer renme tor plant grow th and laboratories for lisstec culture and recombinant DNA rexearch. In iniltal

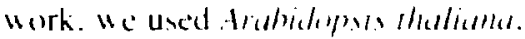
a small annual weed. as a model ten organism. This ycar. We estahlished hasic lechnicyues for handling this plant in culture and for iscolating and separaling DVA.t. and we hegan work on creating phenosyic and genompic varianls. Our long-lems whiective is to geneticalls engineer enhanced colerance do ensironmental stressors. such as o/onte. in cecomomically inportant plants.

In general. mulants halve heen used by researchers as experimemlal uorls to probe the relation betw een protein structure and function. (1) determine the order of events diring differentiation and morphogenesis. ard to define the roles of specific proteins and protein assemblics in the cell. In particular. mutants from algate and higher plants have been important in recent studies of biochemical. biophyvical. and structural aspects of pholosinthesic phenomena. The in vive efficaly at an appropriate mutation can he determined hy in villo assils at the genc product. making porsible the comparting of twa organisms that ditfer by uls ane protein. Ones the role al the mutation has heen charaterised. the propertices at a mulant can then be reproduced comsiscently.

The tirst sepent our project involinge t. thatialla was Io screcon mutagen-expoxed seed populations and idemitis mutant indis iduals that can withatand comstant exponure high levels of asone by some hichemical mechanism (such as all increase in the relative istome propurtions of superoxide dismutasel. We then sienened presumplive mutints fur several gencratiom to emsure homo/sgusils of the mutation and theretoy eliminale spurisus senetic diversits. We have adopled a procedure for serow ing 1. rhaliana based on slandardized technigues. and we hate lested and moditied various methods for handling this plant as genetic malerial.

We successull: Iransformed sterile plants of A. Ahaliana by

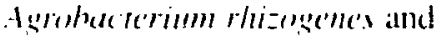
obtained hairy root cultures 1.Marchant. Iogs: Flores er al. I $48 x$ I.

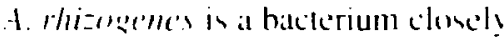
related lo the calusallise angent al crown gall discasc. Virulence is conterred by latẹce plasmids. which

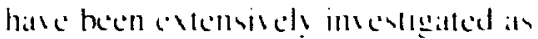
cecturs fir usc in platne genclic

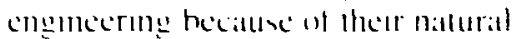

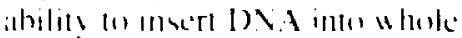

plants. Cicnetlcall! tramstiomed

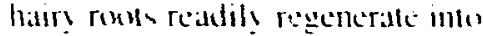
whole plant that tramsmit the DNA wheir proseny. He are altempting lo regeneralle whole plants from Irallolimiced A. Rhaliana.

Finalls. we isolated A Mathath DNA decording lo published procedures and repeated the procedures for charatcterising its relaticly amall haploid genome. which consiss of approximales $7 \times 11^{-}$balse palise.

\section{Keferences}

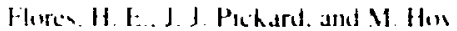

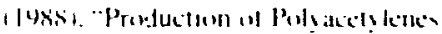
and Thopence in Hetereyluphic and

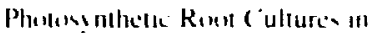

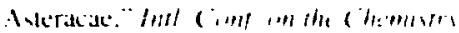

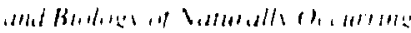

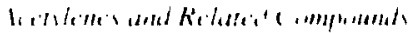

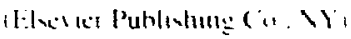

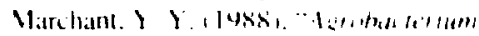

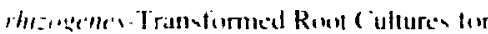

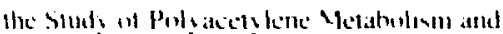

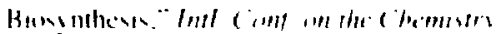

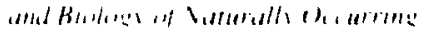

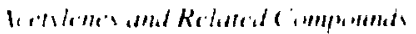

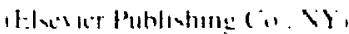




\section{Scanning Tunneling Mlicroscops of Biological Samples}

\author{
Principal Insestigatur: R. Balhorn \\ (i-Insemtigalar: II. Viekhaus
}

\section{We are developing the instrumentation and methodologies needed to apply scanning tunneling microscopy to the analysis of biological materials at the atomic level of resolution.}

$\mathrm{T}$ he recent desclepment it the sathman!

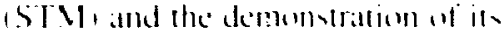
capahilate for imagng molecular

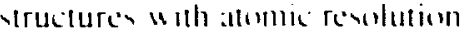
prowdede tremendenus promanc for fulure stadien in moleculat hiologe! Incengallurs who hate uned this microcenpe halle finall! uciecded an vindalieang individual metallic atom and organic molecules. The process iv acomplished by localling the atomicall sharp tip of the STM prohe a lew lemb al al mamemeder ahose a sample. samning the ared containing atoms or molecules. and measuring the current producid at electrom, tumnel ateross the sap between the lip and the outer selectronic surtide at a ramples iltoms.

When we tiegast war propect. the onls hiologecal samples that had heerl esatmined with the STM were sirus particles and isolated. douhlcstranded DNA. Veither study. however. provided images even approatching the atomic level of resolution. The primary goal of our study was to prepare hiological samples relevant to ongoing studies in the Bionedical Sciences Division and to des ise methods for inlaging the atomic sructure of these samples using the STM comstrucled hi rescarchers an 1.L VI , ( hemest amd Malcrals Sicence Department. We

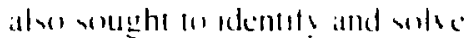
pectal prohleme that meght he cherumlered in tmatsms sample an

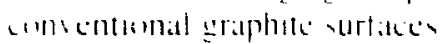

Me prepared samples lor analsus that barted in holh -1/2. and

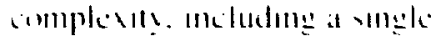
sranded fratement af i) \t. a folded

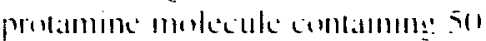

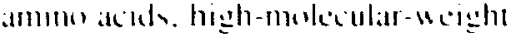
deuble-stranded IDN.-1. and a yerms chromation parricle aceral micromelers long and ano micrometers wide. The hulk al an! clfort. homeser. Mas directed tow ard imateing the altmic aructure af diuble-viranded DNA. We realized that once the capabilit! for imatging

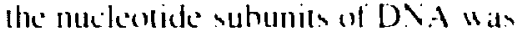
atlatimed. an entirels new "electronic" approatch fir seyuencing DNA could he developed, autumated, and applicel w the anal! siv of cer! lon! DXt fritgments.

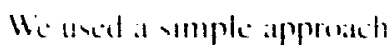
for arym: 1$) \backslash 1$ all the surface of sraphlte an prepare double-stramded

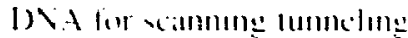
mormalpr. He ha:

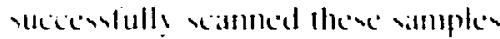
wome a tapered. atomicalls varp prohe. Although wc hasc anls heoum lo lea:n what tators comtrol optimal atmple and tip preparation, on curtern meahosk have produceal images of 1) $\mathrm{A}$ atl ncar-atomic resolution ace fignure l) hal are the hes in the womld. In tuturc ellints.

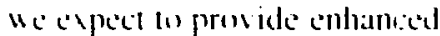
image at the alomic level at reselutum that ean be uned lo identiti individual hase pairs

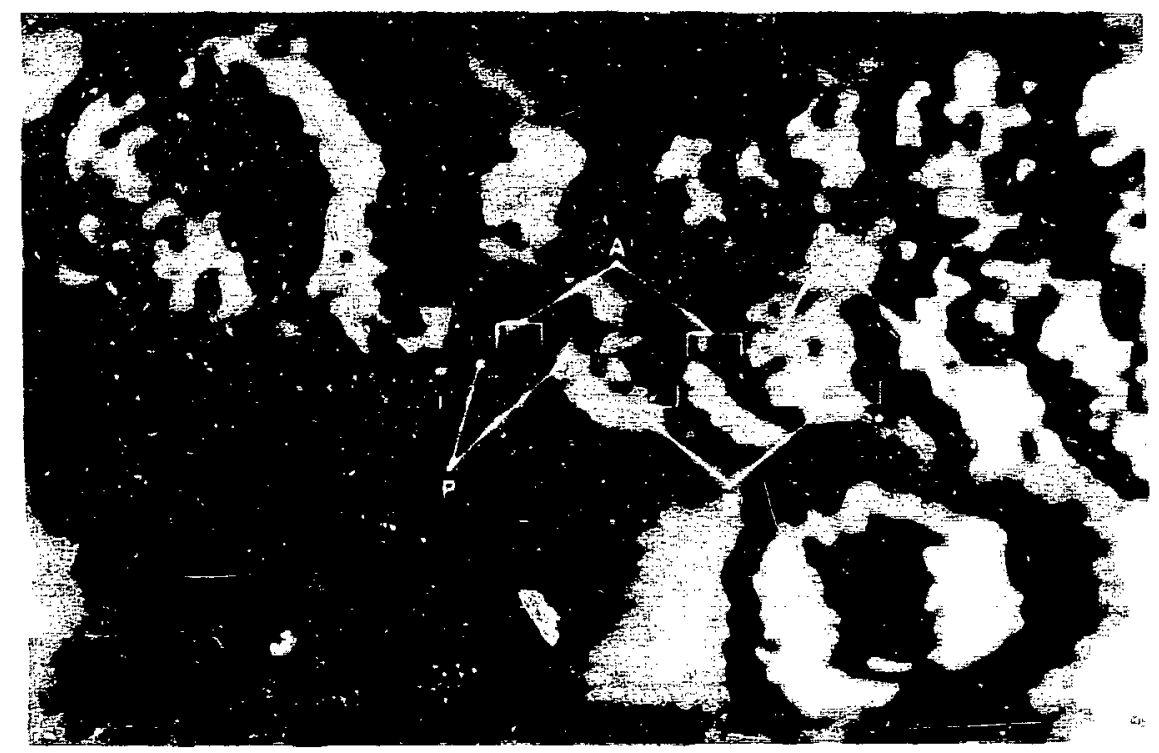

Figure 1. IVt image of calf thymus ohtained using scanning tunneling microscopt. This image clearis resols es the two indisidual phosphodiester strands

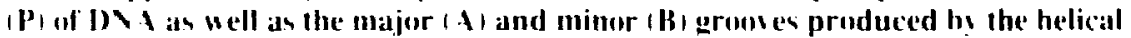
coiling of the two strands. 


\section{Post-l abeled I) II Idducts}

\author{
Principal Insentigalors: K. II. I urledtatuh
} and I. T. Filtun

$\mathrm{O}$

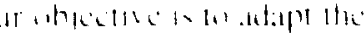

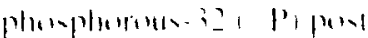

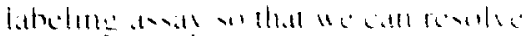

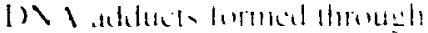

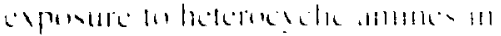

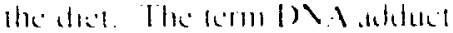

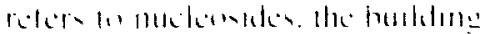

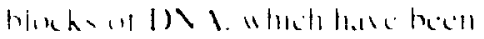
mondeded he the holdmen

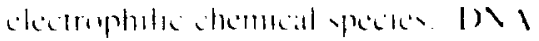

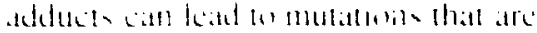

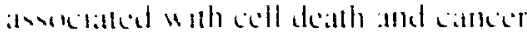

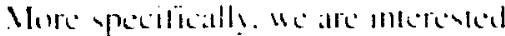

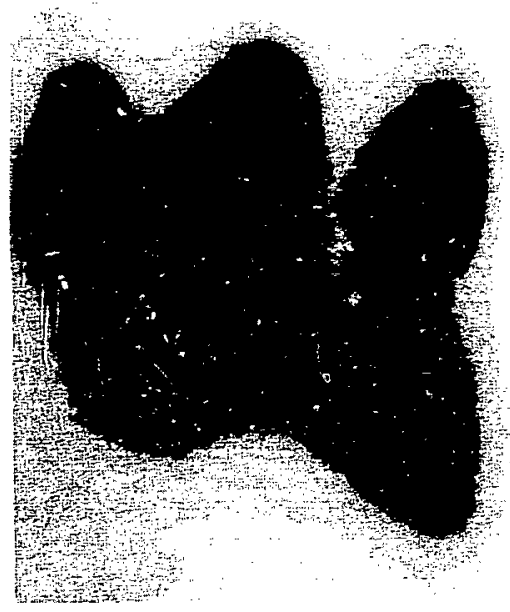

Figure 1. DNi from Salmenella bacteria modified b: the IQ mutagen. This DNA was digested to nucleotiden. labeled with "'p. and resolved using four-dimensional thin-laser chromatographs. I nder such conditions. onls WM addlucts remain. The visihle. werlapping upots correspond to the adducts. The intensits of such sposs can be yuantified and then used to ntuds the rebaltions amone adducks ceposare. and discase.

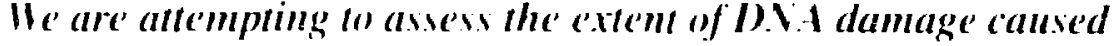 through exposare to a group of heterocyclic amine's found in cootied foods typical of the Western diet.}

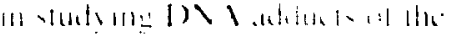

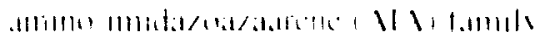

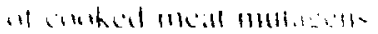

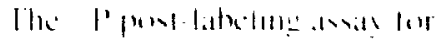

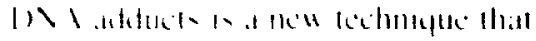

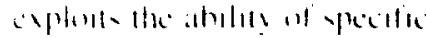

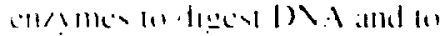
lahel mo revaltant molemale

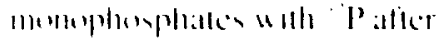

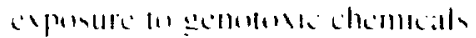

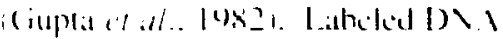

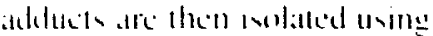
mulndamemsomal thin-laser

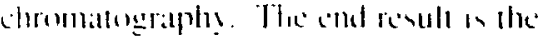

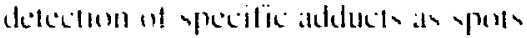

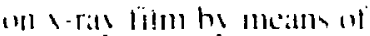

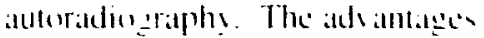
offered ho this technigute are hesh

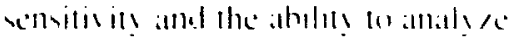

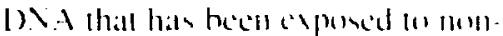

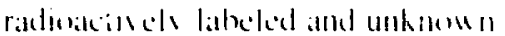
chemicals. Siach adsantagen make the

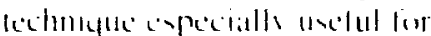

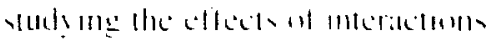

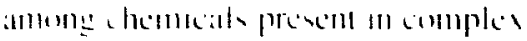

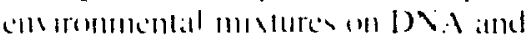
for momitorimg human exponere lo

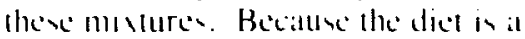
comples misture. the cehnigue is idealls stlled fortuding the edfects of dict an humang genetic mallerial amb the

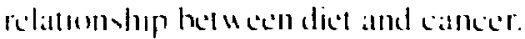

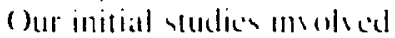

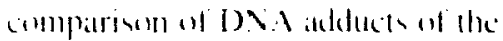

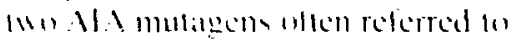

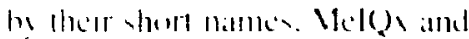

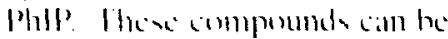

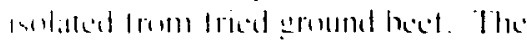

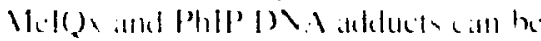

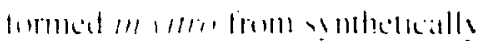

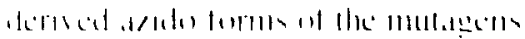

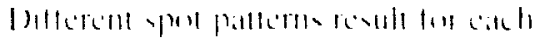

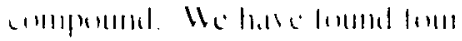

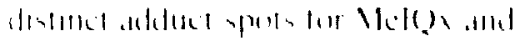

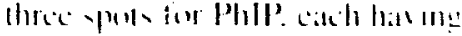

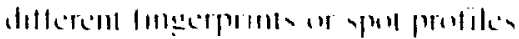

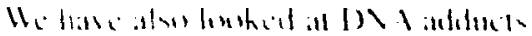

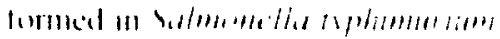

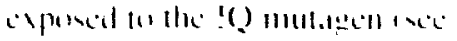

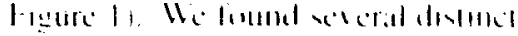
addest yous

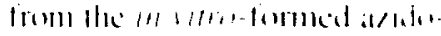

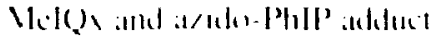
similaris.

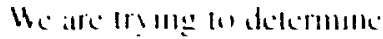

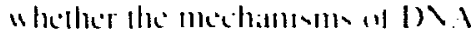
maditicallum m matmmals. hatclerial.

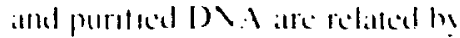
comparme you pallems from mace. b.stmemellad hakteriat. and I) 1

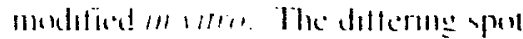

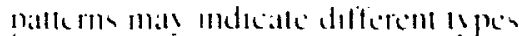

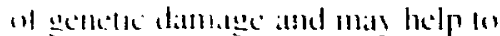
eylat:m the sarsine pollenes of the

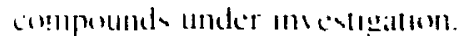

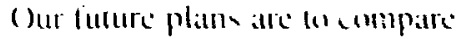
the resuld whtaned in our curremt

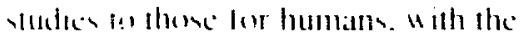
hope of identitions appropralle

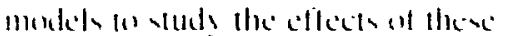
and wher mutasene an luman DX:A In addition. the methodolons viond

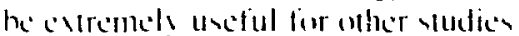
in the lahoraturs o homledical and cols irmmental research pronam. Fir cample. me arcas af currenl applicallom

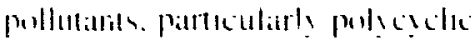
aromatic h!drocathoms an lish from Sin Francisen Ball.

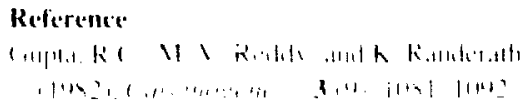

Reference

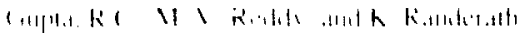

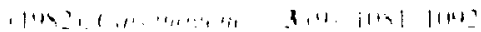




\section{Chemistry and Materials Science}

1. 1. Sugihara

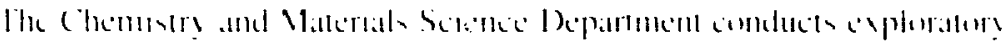

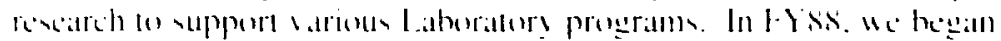

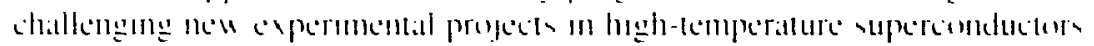

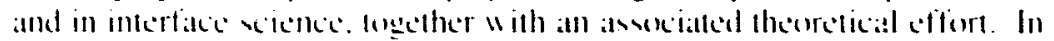

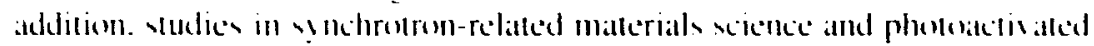
hedrogenation reactions "ere continued from Fyx?.

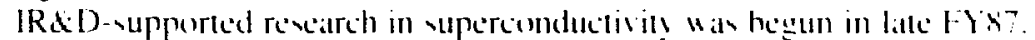

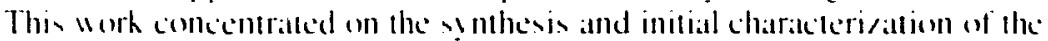

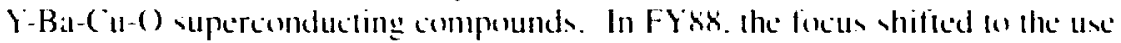

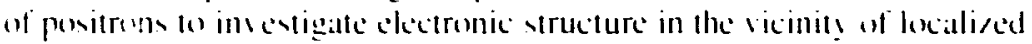

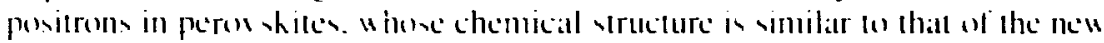
supercondectors. Our first experiments insestegteded positron lifetime ats at function of lemperature and the angular correlation of annihilation radiation. Results show that changes in clectron density accompans the normal-tosuperconducting transition in the high-icmperature superconductors.

To improse our understanding of athesion and honding of materials. Wc are investigating the properties of interfitedes. In FY8x. we initialled a new project to study the diffusion of oxygen anions in the lattice and along grain houndaries in sintered polyerstats of metal oxides. In contrast to initial expectations. anions were found to diffuse signilicantly more rapidly than callions.

A lirst-principles theoretical study. directly related to both superconductors and interfitcial phenomena. Was initiated to describe the electronic structure of ystems with reduced symmetry, such as surtaces and interfaces. This gear. We developed a formalism that exploits the properties of systems with semi-infinite periodicit!.

In synchrotron-related science. the capabilitien developed in FY 87 for highresolution $x$-ray absorption studies extended $x$-ray absorption fine structure or EXAFS. and $x$-ray absorption near-edge structure or XANES / were used 10 investigate superconductor properties and to probe interfaces of nearmonolayer thickness. In another wnehrotron-related project. multilayer diflraction gratings were found of be well suited for use as high-resolution monochromators in the expersmentally difficult energy region of a teu hundred (1) a few thousiand $\mathrm{E}$ (electron volts).

Also in FYXX. a proof-ol-principle experiment was conducted to demonstrate that carbon monoxide (plus hydrogen gas) can be catalytically converted to hydrocarbon at room temperature by photoactivation. This new process involves the use of an aterogel doped with uranyl ion.

The Chemistry and Materials Science Department received $\$ 1.0113 .010(1)$ in IR\&D funds in FY 88 . 


\section{Positron Studies of High-Temperature Superconductors}

\author{
Priscepal Insestigators: M. J. Fluss \\ and Y. C. Jean \\ (in-Insentigaturs: P'. F.. Turchi.
}

R. H. How ell. ('. II. ( hu. and 1. 1. II achs

$\mathrm{T}$ here is no unisersally atcepted mechamivm wexplain the obacration of superconducting materials " ith critical temperatturen greater than .30 K. the upper limit that can he altributed to conventional electron-phonon interatetion. The positron is particularly uneful for probing the changes in electronic structure that mal he associaled with the superconducting mechanism.

Ponitronu are casily implanted into samples by the use of radiosisosopic sources. We studied the amnihilation propertices of posiirons. from a scidium-22 acetate source sandu iched between sarious samples of high-critical-temperature ( $T$ ). superconducting perowsile materials. Positrons from sodium-2 2 are rapidly thermalized $(\sim 2$ ps) in the solid sample. where they either propagate as delocalized particles (analogous to electrons in their ground statel or become trapped in regions where there is a potential minimum (such as oxygen vacancies or vacancy clustersi. Our objective wats to determine how the positron might be sensitive to changes accompanying the onsel of superconductivity in the perosiskite milterials.

We studied the temperature dependence of the positron lifetime and the spatially averaged electron-momentum distribution in one-, two-, and three-layered perovskite superconductors. These experiments revealed that, at the onset of superconductivity, the electronic structure of each material undergoes similar changes attributable to a common characteristic of the superconducting mechanism in this class of materials.

Our work comsisled of imo lypes of experiments: determining the positron lifetime, and meationing the electron-momentum distrihution for those electroms sampled by the positron-electron annihilation process. The experiments were catrried out as at function of ienperature for three materials: $\left(\mathrm{L}, \mathrm{Sr}_{1}, \mathrm{CuO}_{i}\right.$. YBa, $\mathrm{Cu}, \mathrm{O} \ldots$ and $\mathrm{T}_{1}, \mathrm{Ca}_{2} \mathrm{~B}_{2} \mathrm{Cu}_{\mathrm{O}} \mathrm{O}$, . They are representative of one-- IHO-. and three-layer perorskite muterials. respectively. The two types of experiment: provided different but complementary information.

To meatsure the positron lifetins. we used the I. 28 -MeV gatmma raly from the exciled state of neon-2 the positron-decay product of sodium-22) to start an ultrafast clock. which was then stopped by the detection of the annihilation event (the 5ll-keV ganima ray). To measure the spatially averaged momentum distribution of the annihilating positron-electron pairs. we used a solid-state intrinsic germaniun detector in Dopplerhroadening experimlents.

In the lifetime measurements, the diflerent states of the positron call be resolved because they appear as terme in the datat. which are represented as a sum of exponentials

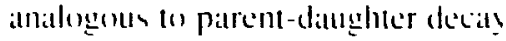

whemes. In the momentum meiturements. however. different valtes of the positron appear ats a sum of lincar lerms. giclding an overall average momentum distrihution.

Figure I shous the lemperature vartiation of the deduced positron Bloch-state lifetime for the three high- $T$ materials studied. The intensity of the shorr-lived component from which these data are derived was found to vary only a few percent over the entire temperature range. The positron lifelime exhibits a strong temperature dependence for $T<T$ but not for $T>T$. This temperature dependence appears to increase systematically from the onelayer to the three-layer material. Also noteworthy is the similarity of the temperature dependence of the oxitron lifetime to that of the superconducting gap. The relatively large lifetime change ohserved for the three-layer $\mathrm{Tl}_{2} \mathrm{Ca}_{2} \mathrm{Ba}_{2} \mathrm{Cu}_{3} \mathrm{O}_{12}$, material appears 10 indicate that there is a significant change in the charge distribution associated with the onset of superconductivity. Since almost all theories make predictions ahout the nature and location of the charge carriers cusually holess in these materials. we hope that the redictions of such theories will 


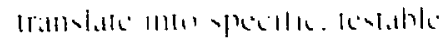

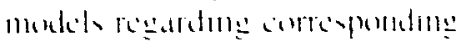

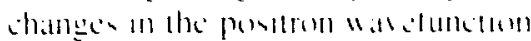
ilnelli.

()ur mcidyrement of the edectronmomentum distrihution whatimed from Doppler-broademm! sycrimente prom ded complementars

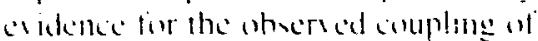

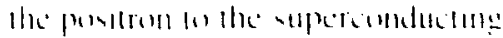

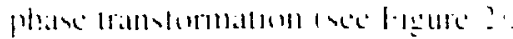
The kemperatere dependemse at the clectrom-momentum distrhutum.

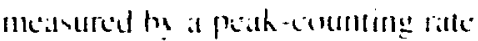
parameler of the $511-h e^{\prime}$ gammat-ral line the s paramelere, is almom

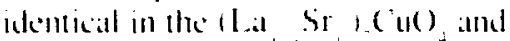

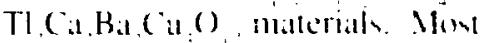

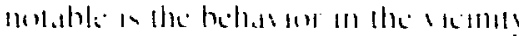

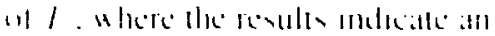
molabe an the high-monicmlum

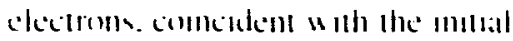
increase in the ponitron liletimet.

()ur resulis supporr carlicer

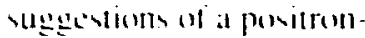

sepercondetis i!s interactute mechanism common to the

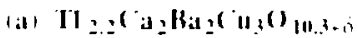

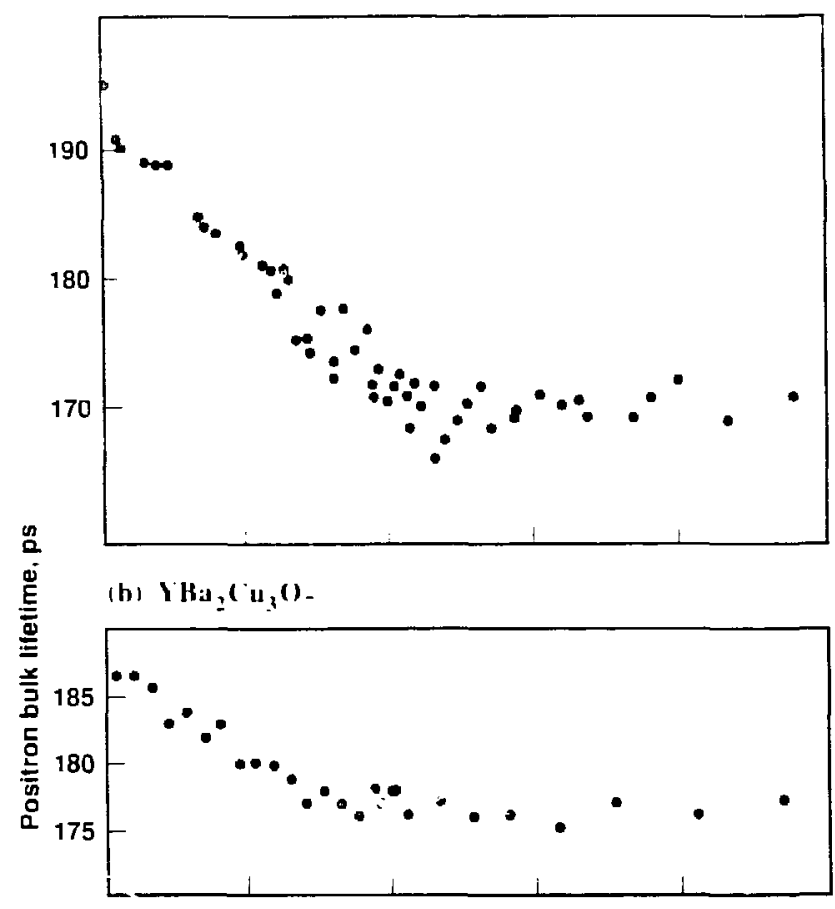

(c) L.a..85 $\mathrm{Sir}_{0.15}(\mathrm{Cu}) \mathrm{C}_{4}$

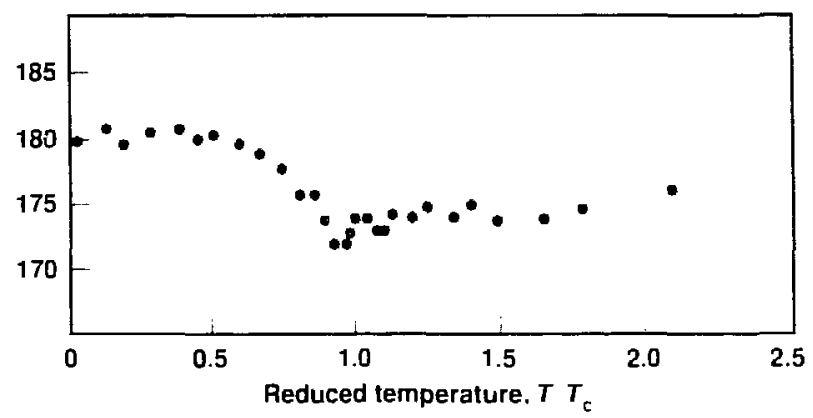

Figure 1. A comparison of the positron Bloch-state lifetimes for three classes of peros skite superconductors.

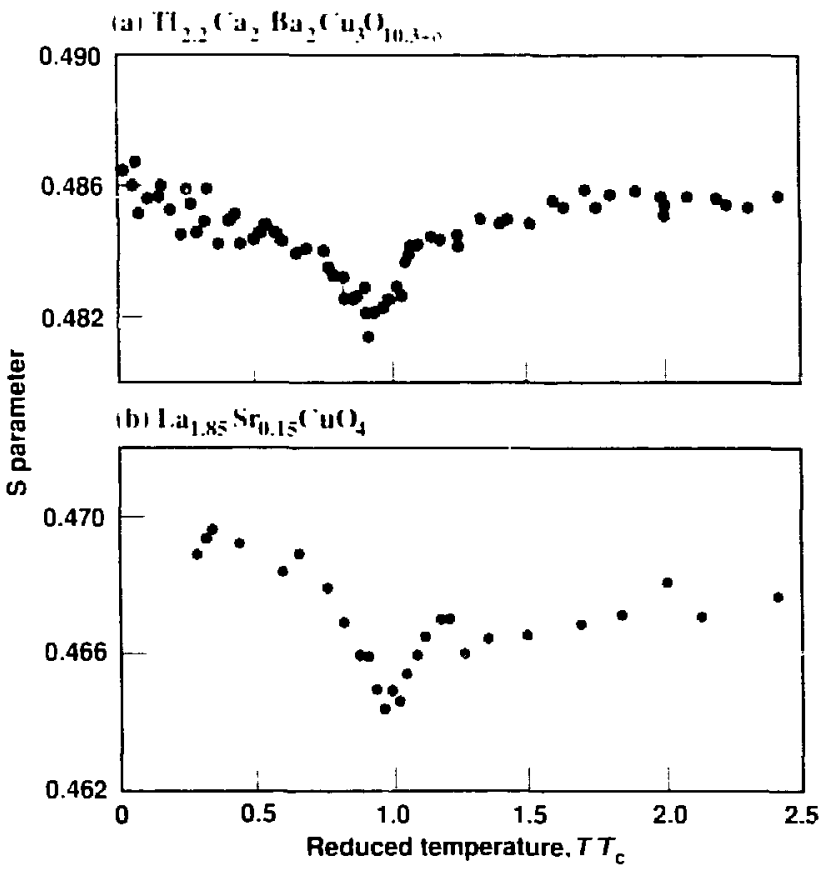

Figure 2. Doppler-broadening $S$ parameter as a function of temperature in $\mathrm{TI}_{2.2}\left(\mathrm{Ca}_{2} \mathrm{Ha}_{2}\left(\mathrm{Cu}_{3} \mathrm{O}\right)_{10.3+5}\right.$ and La I.K5 $\mathrm{Sr}_{0.15} \mathrm{Cu()_{4 }}$ 


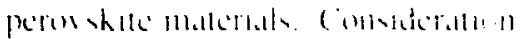
of both the hitedme and Depplere datla

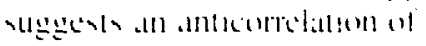
positrons with clectroms als well ats at porsible enincident redistribution af electromic vructure as 7 decreases helow $I$. Ans present or future theory of superconduclisil! will probathly hatse te account for the datia. and. in this sense. our experiments should help to guide the deselopment of at theoretical understatsding of superconductivit! at high temperatures.

\section{Refirencilen}

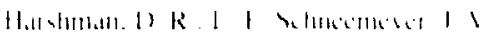

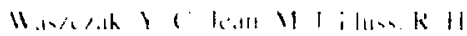

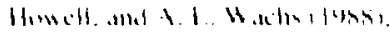

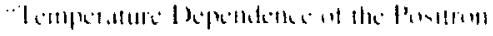

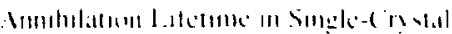

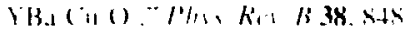

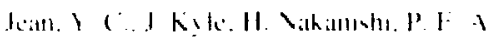

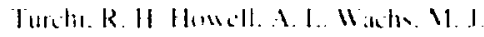

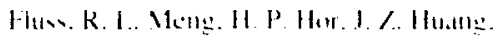

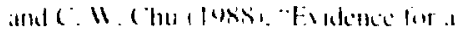
(immmen bleh-Temperature

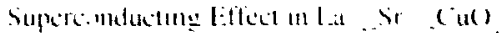

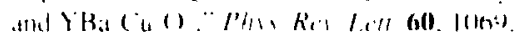

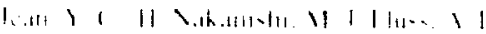

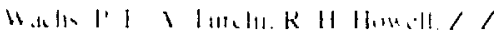

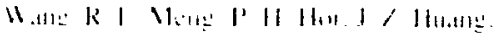

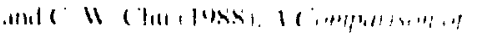

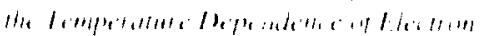

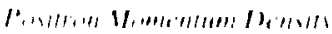

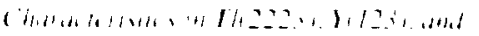

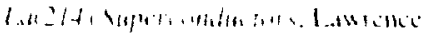

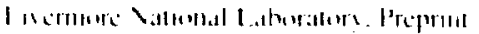

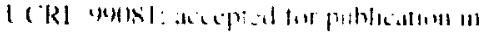

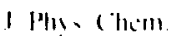

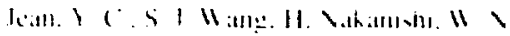

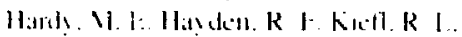

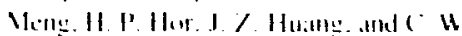

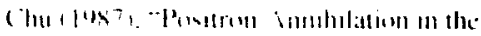
Hegh- lemperature Sujersombletur

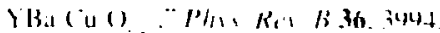




\section{Reactive-Flement Effect Studied L'sing Ion Implantation}

\author{
P'riscipal Insentigatur: 11. F. Kings
}

lo-Insendigatur: h. S. lirabewhi

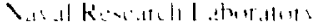

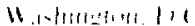

$\mathrm{I}$

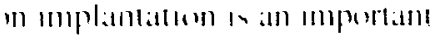
kchmeyte for trallate metal surtides subgested wh hog

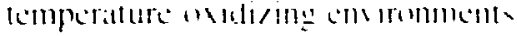

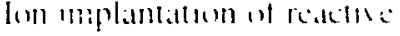

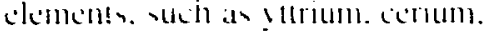
therium. and hat num. cant @late rixe Io a larger reduction on wide gerest th ratle thatr that whecred in matleriat allouged un itin reature clements. Thin kednnique is also ideal for insestigating mechaniome that result in the reartive-element elfect

We halse inserlyated the etfed of reacribe-clement ion implantation on high-lemperature osidation ent high-purit! metal allow that lorm Cro lascers. Presious reports

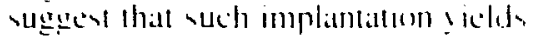
three henclicial effects: stmulation of the earls formation of a continusus single-phase proteclive oxide laver. reduction in the grous th rate of chromia. and enhinced oxide adhesion compared to addition-frec matterials

Wic uned Rutherfiord

backicaltering spectroncops. electron microncons. and ecoundars-ion mas spectroncons tSIMSi to imestigate the axidation hinetice and elemental di-tributiom that wolde during ovidation of $\mathrm{Fe}-2+\mathrm{wl}^{\prime}$; $\mathrm{Cr}$ implanted with btritum son dowe 1 (1) $1,11^{\circ} .3 \cdot 10^{\circ}$. and

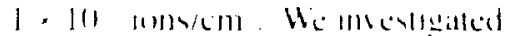
micrustructural and merochemieal

Wh have investigated the effect of vetrium-ion implantation on the high-temperature oxidation of Fe-24C r using Rutherford backscattering spectroseops, secondary-ion mass spectroscopy. and electron microscopy. We have applied analytical tools to determine the spatial distribution of yttrium, the microstructure of the oxidc, and the contribution of oxygen transport to the oxidation process.

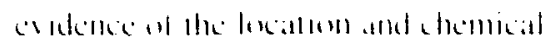

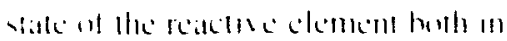
the male and th the melat. Me Hen compared like ctleck al mo

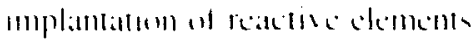
with the eflects al allon me atsd

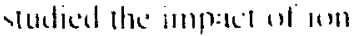

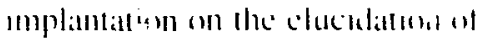
reatide-celement mechanisms.

Three regioms ot a sample uere inplanled with 1.50-kel' !ltriam ans at the Vatsal Rexearch Lahorallor! cach with one af the thres ion dones. Rutherford halch seallering

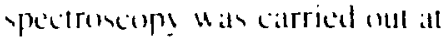
the landem accelerator facilit! at Areonnc Vallianal I_ahoralors using

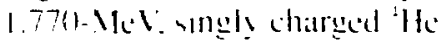
ium helure oxidallion and aller meremental modation timen 115.111.

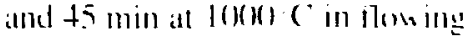
oxigen.

Our results indicate that inn implantation affects axidation behatior in two ways. When the near-surface coricentration of implanted reative element in the alloy is helom at critical level. mos of the implanted clement will he ferund sear the waide/metal intertice lillowing asidation. Shose lhis critcal lexel. most of the implamted clement will he firdnd mear the midedear mertake. The eritical comcontration is probahly relanded to formallion of at secomd plathe in the

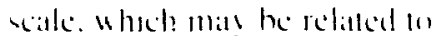
formatlom on a secomd phase on the

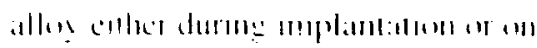

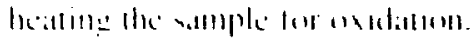

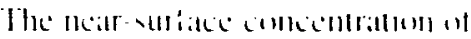

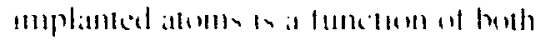

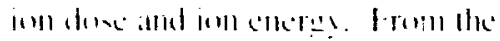
folerallare. we entathlisheal the ant

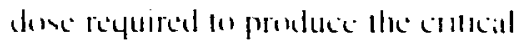

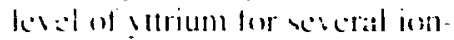
implantation encragles. Thes relatuen is plotled in Figure I. Faldation of strimu componition profiles calculated tor eath of the experime:alal cances indicates that the criticall concentrallom condel he a !ltrium comecontralism at the surlate of ahout I at." or a peash yltrium concentration ol about o at.'; . curses lor holh of the criceria cisleulatei for Illrium implantalion of Fe-24c $\mathrm{r}$ are homen in Figure 1. Besond the exe concentratioms. cither precipitation at the surfate could heogin. or nearly 50 vol'; of the intermetallic stlride could furm hencath the surface. Fommation of thex precipilates in the alls! depends on the thermal hioters of the implatnted samples and the

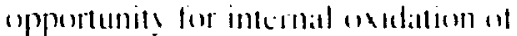
sllriumt. We propose thall. for domes abore the critical dane the elfect that is ohsersed is mot the reactio clemene efted bs its mos strice

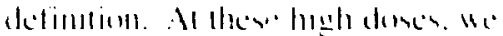
belice that secoldel-plase formation

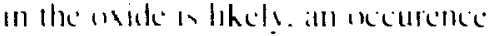
that in mol whereded in allus ysems 


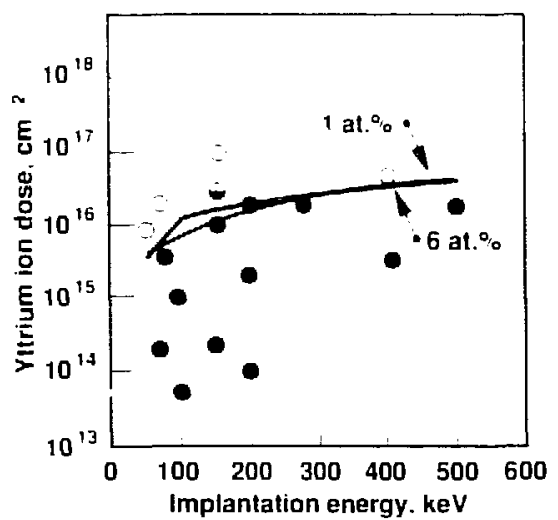

Figure 1. Y Ytrium ion dose as a function of implantation energ.. Solid points indicate that the implant was found at the oxide metal interface: open points indicate the implant was found near the oxide/gas interface. The black curve shows the ion dose needed to produce a peak yttrium concentration of 6 at. $\%$ : the colored curve shows the dose required to produce a surface yttrium concentration of 1 at. \%

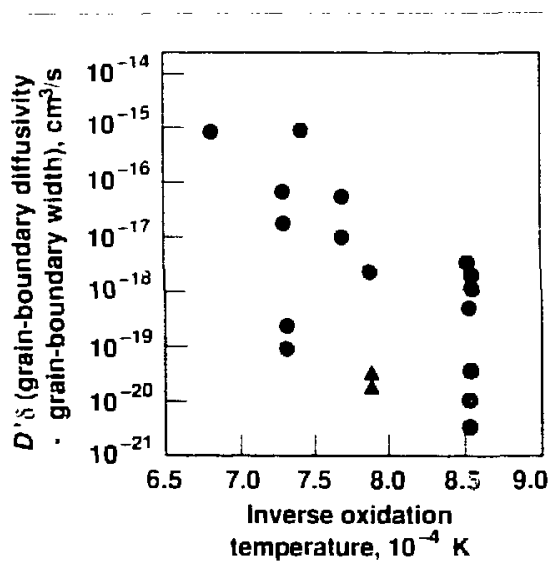

Figure 2. $D^{\prime} \delta$ vaiues deduced from previous experiments (black data points) and from our work (colored data points) plotted as a function of inverse oxidation temperature. The text gives a detailed discussion of this figure.

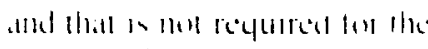

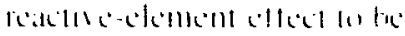

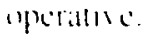

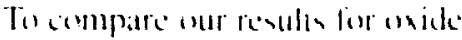
gromb hinclice and literature data on the grom the of ( 1 () with cation and anion diftusion measurements. "16 comverted the experimental values of $k_{1}$. the parabolic ratle enmatat. (1) 、alues at $l)^{\prime} \delta$. the product al grain houndar! dittusivity and grain houndary width. uning the procedure cescribed by Park it al. 11087 , Thome reseatrchers ansumed that the comtrihution of anion diffusion to the growth of (ro, filmw wats negligible In a reciont study hy King and Park (198x). anion diflusivities in the lantice and allong grain boundariess were meisured on :intered polyerystals of $\mathrm{Cr}_{2} \mathrm{O}$; and $\mathrm{Cr}_{2} \mathrm{O}$; doped with 01.019 we; Y, O, ai $1100 \mathrm{C}$ and at the oxygun partial presisure corresponding to that of the $\mathrm{Cr} / \mathrm{Cr}_{2} \mathrm{O}$; squilibrium at that temperature.

Results demonsitrated that under the same conditions, anion diffusion is significanty taster than caltion diffusion.

Figure 2 shows $D^{\prime} \delta$ versus inverse tentperature from the arailable literature, including the $D^{\prime} \delta$ values from cation (Park of al.. 1987, and anion (King and Park. 1488) tracer diffusion siudies. The values for $D^{\prime} \delta$ deduced irom $k_{\text {, }}$, measurements are spread over two orders of magnitude. All values for $D^{\prime} \delta$. except those deduced from the current implantation experiment and the experiments of Pivan ef al. (1980). are higher than the values measured for eation grain houndary transport in $\mathrm{Cr}, \mathrm{O}$, and $\mathrm{Cr}()_{\text {a doped }}$ with $\mathrm{Y}_{2} \mathrm{O}$, at $\left.1 \overline{\mathrm{I}} \mathrm{O}\right) \mathrm{C}$. This indicalles that cation grain boundary diftusion is lar for slow lo explain ohserved oxide grouth rates in unimplanted sampless. These dalla alre comsistent with the anion grain boundars diffusion data of $\mathrm{k}$ ing and Park 1 1988 . The widation raltes al the implanted samples in this studt and

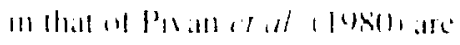

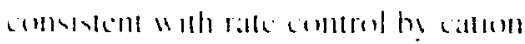
ditiunim.

There applatrs a he a critical Implantation deme ahose which at change in the axidatton hehat ion af ihe allon in absersed Below the critical dose. the mplant is localled Ilear the oxide/motal interfiace. in this regime. the readive-element eflect duc lo implantation $w$ ih

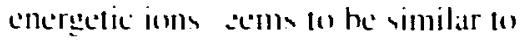
eflects observed due to alloging wh ith reative elements. Homerer. in allows, the reatcolive element is not found in such high concintrations in the axide layers texcept over yttrides) as in implanted samples. and implantation gives risc (1) al barger reduction in growth ralle compared to alloying. Ion implantation produces a uniform distribution of reactive element whereas alloving ofien results in second-phase formation in the base metal. Lniform distribution of a reactive element does not appear lo be necessary lor the alloy to exhibit the reactive-element effect. Ahove the critical dose. the implant is located near the gas/oxide interface. Chromia on unimplanted allogs groms at rates comsistent with aniom grain houndary diffusion.

Chromia on implanted alloys groms at ralles consistent with caltion grain houndary diffusion. SIMS data suggest that yttrium reduces the inward trinsport of oxygen through a chromia scale. and all high enough concentrations. it can trap a significant portion of the imuardiy migralling oxygen.

\section{References}

Parh. J. H. W. I: King. amß' S. I. Rohhman

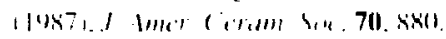

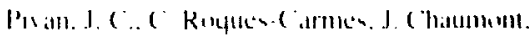

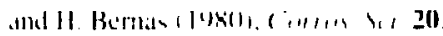
14) $1 \%$ ?

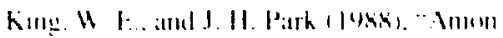

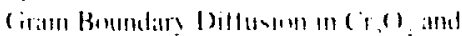

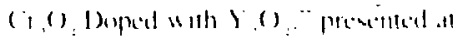

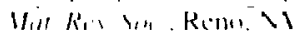




\section{New Method for Calculating the Electronic Structure of Solids}

l'rincipal lnsestigater: A. lionis
We are developing a computer code to determine the electronic structure of materials with full or lon' symmetry (e.g., surfaces and interfaces). This information will help us understand the role played by the electronic structure in such complex phenomena as corrosion, ductility, adhesion, and bonding.
$\mathrm{T}$ he calculation whe thelromic structure of mallier tor the studs (i) malleral propertic ias heen decloped almese coclusidel on the hasis of Blach o theorem. which atsoumes the exiskince of tull translatemal invariances. However. use of this method for materials with

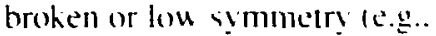
inpuritics surfices, grain boundariess requires esther the inposition of approximate and illdetined houndary conditions on the comesponding Schrödinger equation (supercells, slabs) or extreme computational complexity.

We are develoing an altemative approach based on the concept of semi-infinite periodicits (Zhang and Gonis. 1988) instead of translational invariance. Our new method replates expansions in reciprocal space and the associated integrations with a self-consistent eyuation to determine electronic structure. Semi-infinite periodicity is delined as the periodic repetition of a basic unit or set of units along a given direction starting at a given point. Examples of systems with semi-intinite periodicity include a linear. semi-intinite periodic arrangement of atomis (where the basic repeatling unit is an atome or onc of the luo parts formed upon severing o! a periodic malerial along a cleavise plane 1 were the repeallng unil is either an alomic menolatere or a eet of such latyers. A hroud range of y scoms. from peraske bulk malerials a luist-andlill grain herundaries. can be licused as hat ing parts characterised hy somi-intinite perindicity: in late this vicu encempasses all structures cxiept those characterized by structural disorder (i.c*.. amorphous mallerials) or quasi-periodicity.

Our neu approach. called realspace, multiple scattering theory (RSMST, (Zhang and Gonis, 1488), is hased on a reformulation of ordinary seattering theory developed originally hy Gonis (1986). It is rigorously applicable to all systems consisting of parts with semi-intinite periodicity. including. for example. surfacies, grain houndaries. atnd pure? translationally invariant materials. It is not confined to cells of spherical symmetry but can trea: potential cells of arbitrary shape (Gonis and Zhang. 19881. The RS-MST is straightforward (o) program and prescribes a well-detined process for achieving and testing convergence. However. it is also computationally intensive. requiring the storage capabilities of Cray-lype

supercomputers.

This year. we developed the computer code to the point that we cian reproduce. for a given potential. the electronic structures af pure hulk materials obtained by conventional theorics. With this colle. ue uere afou able w determine. for the first timce ever. the selectronic structures certain surfale and interfiac sysems. Typical resule of RS-MST calculations are shown in Figure 1. The solid black curves show the cotectronic density of states (DOSs) for bulk elemental eopper as calculated with a commonly used Bloch s-theorem method (Moruzzi ('t al.. 1978). and the shatded regions represent the DOSs obtained using RS-MST (a) for bulk copper and (b) al a (10())/( I1I) planar copper intertace. The RS-MST calculation in (a) closely reproduces the reciprocal-space calculations: differenoss ar: attribuled to a lack of conversence. The interface DOS (b) shows a nearly complete loss of structure and has a somewtial narrower bandwidth than the DOS for the bulk material (a). The firsl effect is due to an expected loss of translational invariance, and the second effiect reflects the decreased coordination at the site at which the DOS was calculated.

Athough the RS-MST needs to be improved and refined. it does provide an answer to a long-sianding problem in electronic-stricelure calculations. namkly how to determine houndars conditions om al cluster of sices lo represent properly the infinite medium surrounding the 
lat Bulh copper

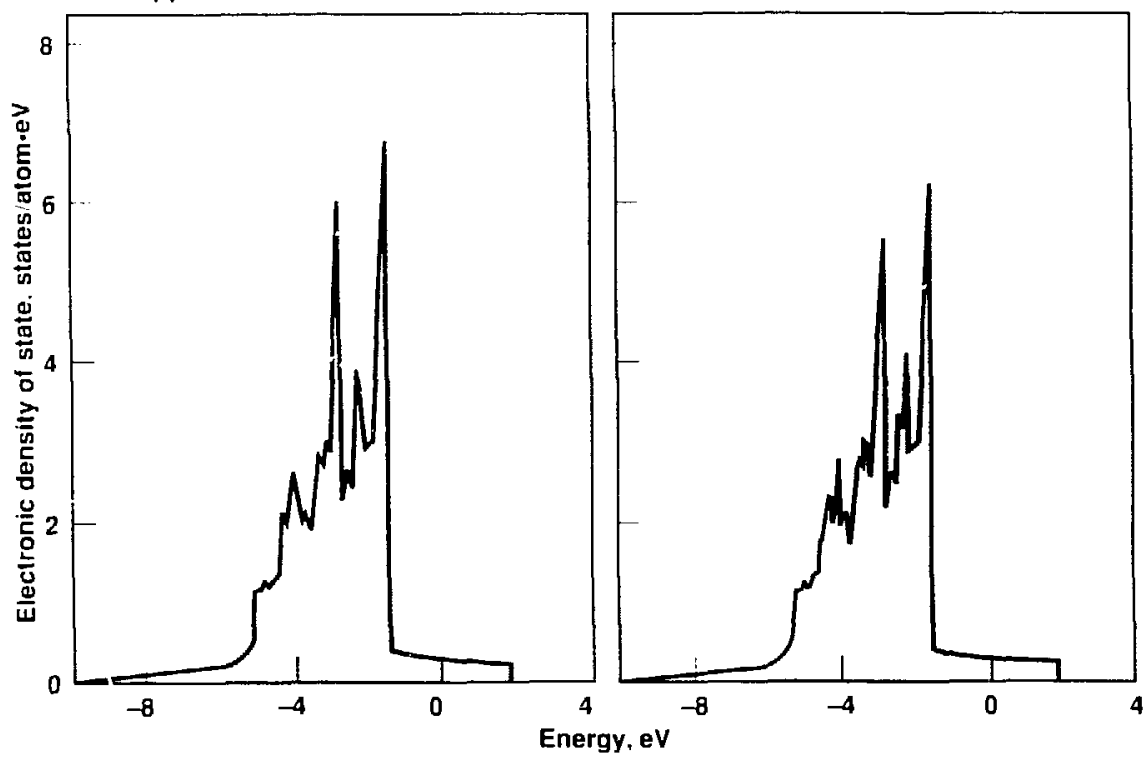

Figure 1. Iocal electronic density of states ( D)( SSis) of bulk eiemental copper calculated with a commonly used Hloch's-theorem method (solid blach curves) and with our RS-MST method ishaded areas) for bulk copper (a) and at a $11001 /(111)$ planar copper interlace (b).

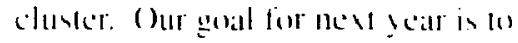
colculd the code to allow the xelfcombinkent determinallion of chareses. polemtials. and total energics. We are also working to reduce the storage and computing timess reyuired.

\section{References}

(inmis $\therefore$ 11486). "Multple Siallerin!" Treatment af Surlaces and lnertikes."

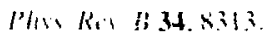

(iums. A.. and X. - C. Zhang 1988 .

"Electronic-Siructure Methend tor (iencral

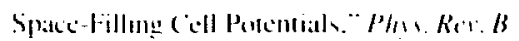
38. 35 th.

Moru/n. V. L... J. F. Franh. and a. R.

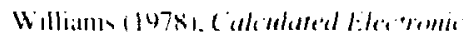

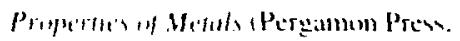
NYi.

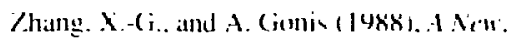

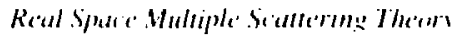

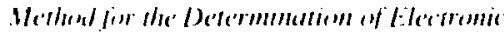
Sirmelure. Law rence Livermore National Laboratory. Preprint, l:CKL_-448/4: submitles (1) Phir. Hev. B. 


\section{Site-Specific Chemistry Using Synchrotron Radiation}

Principal Insestigator: .J. Wing

$\mathrm{O}$ ur sudies combine the use of wnchrotron raddiation as al light source and $x$-raty athsorption spectroseoply ats a structural probe. the performed a variets of $x$-raly absorption experiments on Beamline $111-2$ at the Sianford Sinchrotron Radiation Laboratory sorn after it becance operational in vovember 1987. We will resume running experimemts at the Brookhaven Nattional Symchrotron Light Source when that ficcility returns to normal operation after a phatse-Il construction uperade.

Our experiments included: - Studies of rare-earth substitutions in superconduceing $\mathrm{YBa}_{2} \mathrm{Cu}_{2} \mathrm{O}$. materials.

- Sile-selective detection using the technique of optical extended $x$-rily absorption fine structure (EXAFS). - Interface structure of a monolayer of Hi on a multilayer structure. - Investigations of $\mathrm{Cr}^{\text {i- }}$ ions in fluoride laser crystals.

- Measurement of the wiggler-beam profile with a charge-coupled device imager. Our two-dimensional images. such as that shown in Figure 1 , are the first recorded of any synchrotron beam.

Due to space constraints. we highlight only a few of our findings.

Substitution of trivalent rareearth elements for $\mathrm{Y}$ in $\mathrm{YB} \mathrm{a}_{,} \mathrm{Cu}, \mathrm{O}$ has little effect on superconductivity: whereals $\operatorname{Pr}$ and Th, which hate an accessible letravalent stalte. either lower the eritical temperature (T ) or destron superconductivit!. The
We have performed $x$-ray absorption experiments to study the site-specific chemistry of selected constituent elements in optical materials, laser crystals, high-temperature superconductors, and an ultrathin film on a multilayer structure. yuestion is whether tace elfect is due to valence. In an atlempt (o) determine valences. He measured L-codge spectra for the following compounds:

- Pr Y, Ba, Cu, O, whercer $=0.2$. 0. t. and ().6.

- Cid Y, Ba, Cu, O. where $1=0.5$ and !.. ().

- HoBa, Cu, O..
The Gid and Ho compounds were () $)$ K supercomductors. whereas the $T$ of the Pr compounds was $\sim 80 \mathrm{k}$. - +1$) \mathrm{K}$. and nomsuperconducting for $r=0.2 .(1.4$, and (1.6. respectively.

Our results show that in $\mathrm{Pr}$ super mductors. the valence is $3+$ : however. there is evidence of some splitting in the final state. In contrast. there is no such splitting on

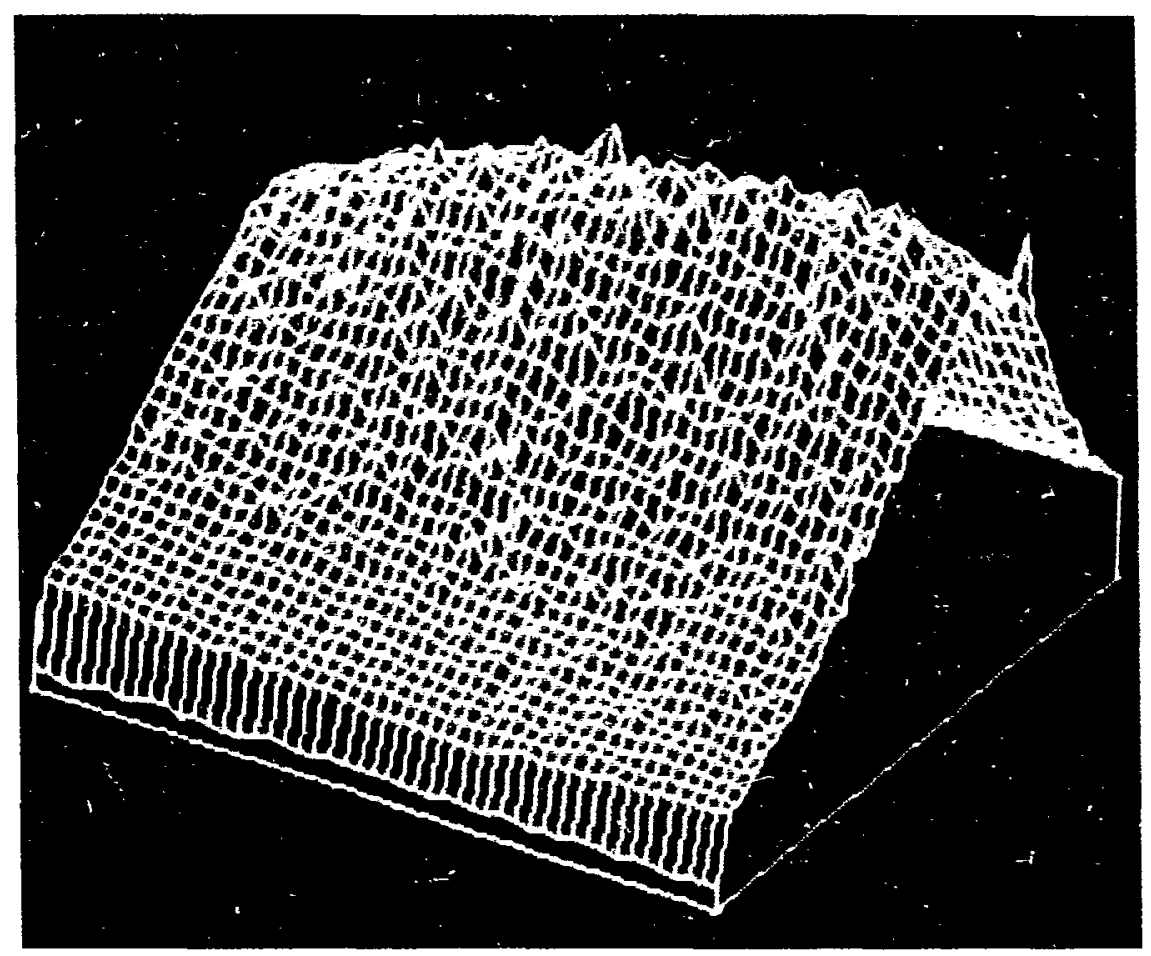

Figure 1. Surface plot of the intensity profile from Beamline $10-2$ of the Sianford Synchrotron Radiation I aboratory, operating at a wiggler field strength of $14 \mathrm{k}$; with focusing. The image span is approximately $1 \mathrm{~mm}$ to either side of the horizontaf center. This image is the first recorded of an! synchrotron beam. 
the high-enersy vide of the white line for the Gid or Ho datia. Both $L$ spectrat of the Gid-and $\mathrm{Ho}$-substituted superconducting matterials were identical to well-known trivalent model compounds of Gd and $\mathrm{Ho}$.

In an exploratory effort. we examined the sensitivity of EXAFS to structures at near-monoliver thickness. We measured the $L$; speitrum of a 0.5-nm-thick Hit film deposited on at $\mathrm{Pt} / \mathrm{C}$ multilayer with a period of $3.17 \mathrm{~nm}$. Figure 2al shows the experimental spectrunt. whi:h is a composite of eight scans of the $\mathrm{Hf}$ $L$-edge EXAFS. These data were taken at a grazing angle of $0.5^{\circ}$.

(a) Original data

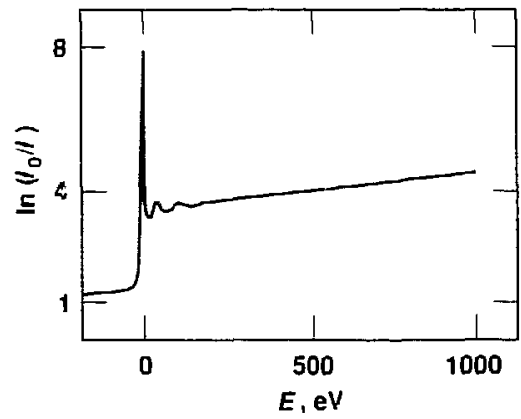

(c) Fourier transform

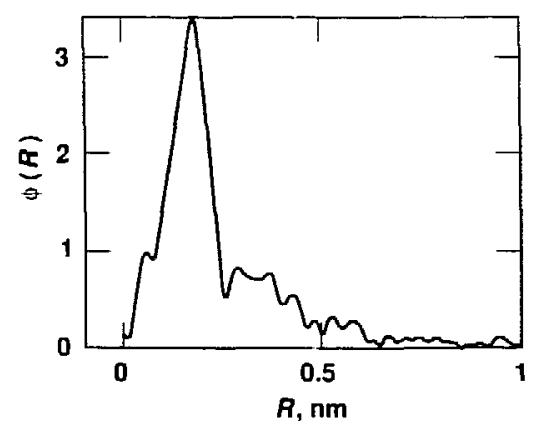

restluing in an effectise Hi layer thickness of $-57 \mathrm{~nm}$. Figure ?h shows the normalized EXAFS signal. detined ats $\chi(k)$. Figure 20 shows the Fourier transform of $\chi(k)$ to yichl a radial structure function $\phi(R)$ thal reveals a series of radial peaks al various distances $R$ from the central atom. Figure $2 \mathrm{~d}$ shows the inverse transform in the region around the central-absorbing $\mathrm{HI}$ atom. where $\chi^{l}(k)$ refers to the filtered data.

Our results indicate that the nearest neighbors of the Hi atoms are iow-Z species. The atomic species is probably carbon because the Hf layer was overcoated with $1.0 \mathrm{~nm}$ of

(b) Normalized signal

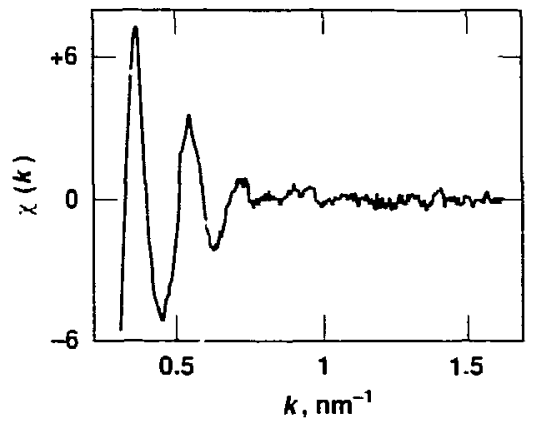

(d) Inverse transform

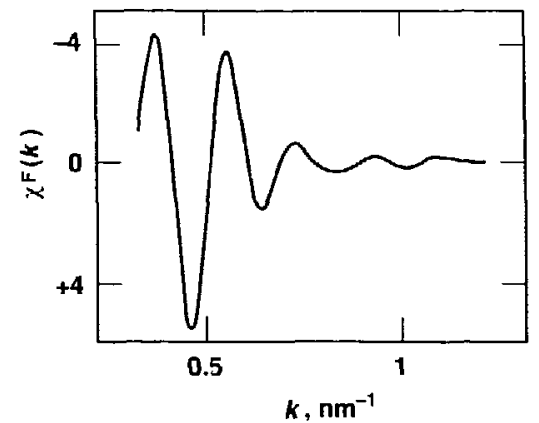

amorphous carbon to stabilise the mexal algainst oxidation. The position of the raddial peak at $k=0.17 \mathrm{~mm}$ indicaltes that there is no $\mathrm{Hi}-\mathrm{HI}^{\circ}$ correlation (in the pure metal. the $\mathrm{Hf}$-Hf distance is $10.32 \mathrm{~nm}$. Our main conclusion is that high-quality EXAFS spectra may be oblained at monolayer coverages on moderately large-areat samples. The intensity available at Beamline (1)-2 allows us to project measurements to a fraction of a monolaver.

In the coming year. we will uxe synchrotron radiation 10 investigalte the honding and locial atomic stricture of several advanced materials. Our studies will include valence and site occupancy of $3 d$ metal ions in high- $T$ superconductors. $\mathrm{Cr}^{3+}$ and $\mathrm{Nd}^{3+}$ ions in laser crystals and glasses. sol-gel intermediates and products, fossil fuels and catalysts, optical detection for valence selectivity. and exciledstate structures. We also plan to use time-resolved $x$-ray diffraction and/or energy-dispersive EXAFS to investigate chemical dynamics and phase transformation on a subsecond time scale. We will investigate solidstate reactions al high temperature and in situ structures of thin films and interfaces.

\section{Reference}

Stantiord Sym hrouron Radiarion Lahoratom Acriviay Reporr 1 1987). Stanturd Synthrolron Radiation Laboralor:. Stanford. CA. Repor \$\$/(1). pp. 67. 114 . 1201, and 121 .

Figure 2. (a) Experimental scan of hafnium $L_{3}$-edge EXAFS for $0.5 \mathrm{~nm}$ of hafnium on a $\mathrm{Pt} / \mathrm{C}$ multilayer. The energy scale is plotted with respect to the hafnium $L$-edge's first inflection of Hf metal at $9561 \mathrm{eV}$ as zero. (b) The normalized EXAFS signal. (c) Fourier transform and (d) inverse transform of the normaized signal in the region from 0.02 to $0.24 \mathrm{~nm}$ about the central absorbing $\mathrm{Hf}$ atom. 


\section{X-Ray Thin Films}

P'rincipal lnvestigator: I. H. Barbee..jr.

$\mathrm{M}$ ulitayer structures, such reflection or antiretlection coatings. Herc developed more than 50 years ago for studying infrared. visible, and ultraviolet light. However. multilayer structures of sufficient quality for optical applications in the $x$-raly, soft-x-ray, and extreme-ultraviolet (EUV) ranges. where wavelengths are 10 to 10.000 times shorter, have only been fabricated during the past decade. Simple reflective diffraction gratings were developed in the early 1900 s and are now a standard dispersive element used in moderate- to highresolution optics. The in-plane scale of diffraction gratings ranges from 300 to $5000 \mathrm{~nm}$; in contrast, the indepth microstructural scale typical of multilayers is from 1 to $40 \mathrm{~nm}$. Our challenge was to design advanced reflective optical elements that focus, disperse, and otherwise manipulate short-wavelength light.

We have prepared multilayer diffraction gratings by multisource magnetron-sputter deposition onto 2000-nm-period laminar amplitude grating substrates. The grating structures were anisotropically etched in (110) single-crystal silicon patterned using standard microlithography techniques. We fabricated multilayers of tungsten/carbon. rhodium/carionn. molybdenum/silicon. and $3(14$ stainless-stecl/silicon. with periods of $2.5620 \mathrm{~nm}$. onto these diffracion-

Multilayers are man-made microstructures that are periodic in depth and can be applied as $x$-ray, soft-x-ray, and extremeultraviolet optics; diffraction gratings are man-made microstructures that are periodic in plane and have been used as optical elements for most of this century. We have combined these two optical elements and demonstrated that their unique properties can advance our experimental capabilities in shortwavelength spectral regions.

grating substratces and characterized them at the Stanford Symchrotron Radiation Laboratory.

Figure 1 is al schematic cross section of a multilayer grating. The gratting consists of t7at-lopped hats with width $d^{\prime \prime} / 2$ and period $d_{4}^{\prime \prime}$. We deposit multilityers with a geometric period $d_{0}$ onto these bars. Light is incident from the left at a graking angle $\theta$. called the Bragg angle, and is diffracted in a specular manner by the multilayer at an exit angle $\theta$ relative to the multilayer in the zero grating order $(m=0)$. Interference of light diffracted by the multilayers on cach grating har results in inlensily maxima at angles mo relative to the ecro order, where $m= \pm 1.2 .3 . \ldots$

The comvolution of diffractive properties of the two periodic structures results in a relation between the grating-order dispersion angles $m \phi$ and the geometric parameters of the multiliyer and grating structures. The resulting analytical relation is

$\sin \phi=\frac{2 m d^{\prime}}{m d^{\prime \prime}}$.

where $m$ is the grating order. $d$ ' is the refraction-corrected multilayer

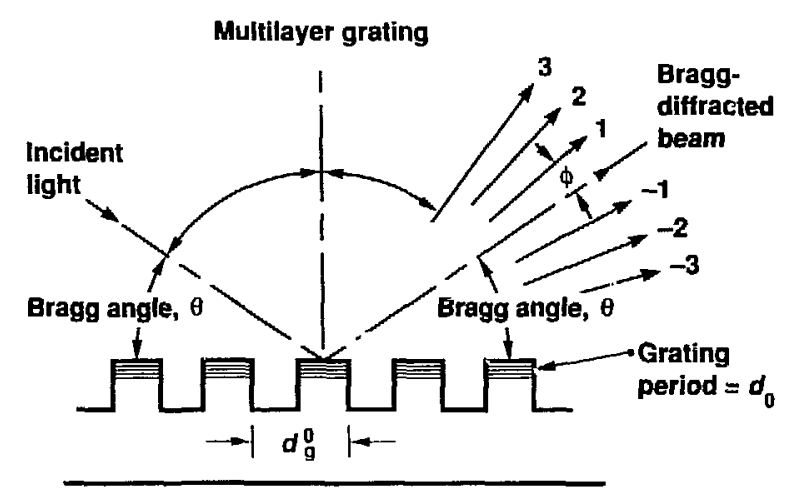

$m= \pm 1, \pm 2, \pm 3$ = order of grating-dispersed Bragg light
Figure 1. Cross section of a multilayer diffraction grating. Flat-topped grating bars have a width $d^{\prime \prime} / 2$ and a period $d_{p}^{\prime \prime}$. Multilayers with a geometric period $d_{n}$ are deposited onto these bars. Iight is incident from the left at a grazing angle $\theta$. typically called the Bragg angle. Diffracted beams are shown on the right. 


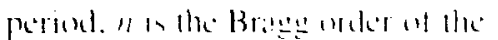
mulabaser-doldracked light. and a the eratum: perowd.

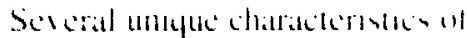

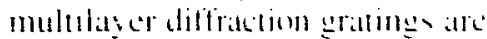
apparent from this revult. Firs. the dispersion antele o in comstam hecaunc it is independent of the angle "1t incidence $\theta$ or the watelength of light that is Brigge-ditfracked hy the multilaser. Second the multiliter gratling xeparater Brages orders of the multilater-diffrateded light hecatte the dispersion angle o in imereds proportional we 11 . Third. hecause angle o is independent on watslength. the gratting atre comstam-resolution divperaton eliment for al gicill gentmetr. Fourth. the epeciticity of the relation anumo o. d'. and d" show no in

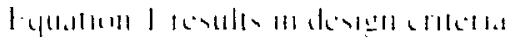

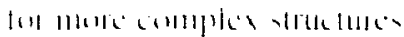

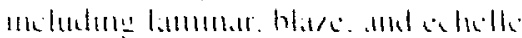

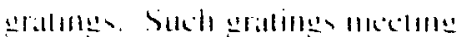
the exerterlat will. in semeral. prentere Britg-!reflecked light that

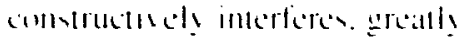

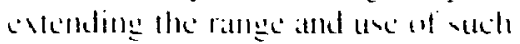
optical elentems. Thi propert!

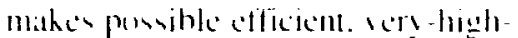
rexiluten dispersion elements in the whi-rat and I: l r ranger

Hi hate ured at mulitalyer strating as the recond elemem in at

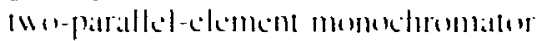

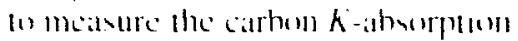

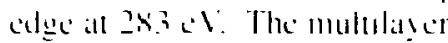

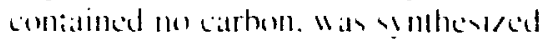
trom 304 vaink we vel and vilicon. and had a peried of $5.5 \mathrm{~mm}$. The perind of the gratling subutratc "

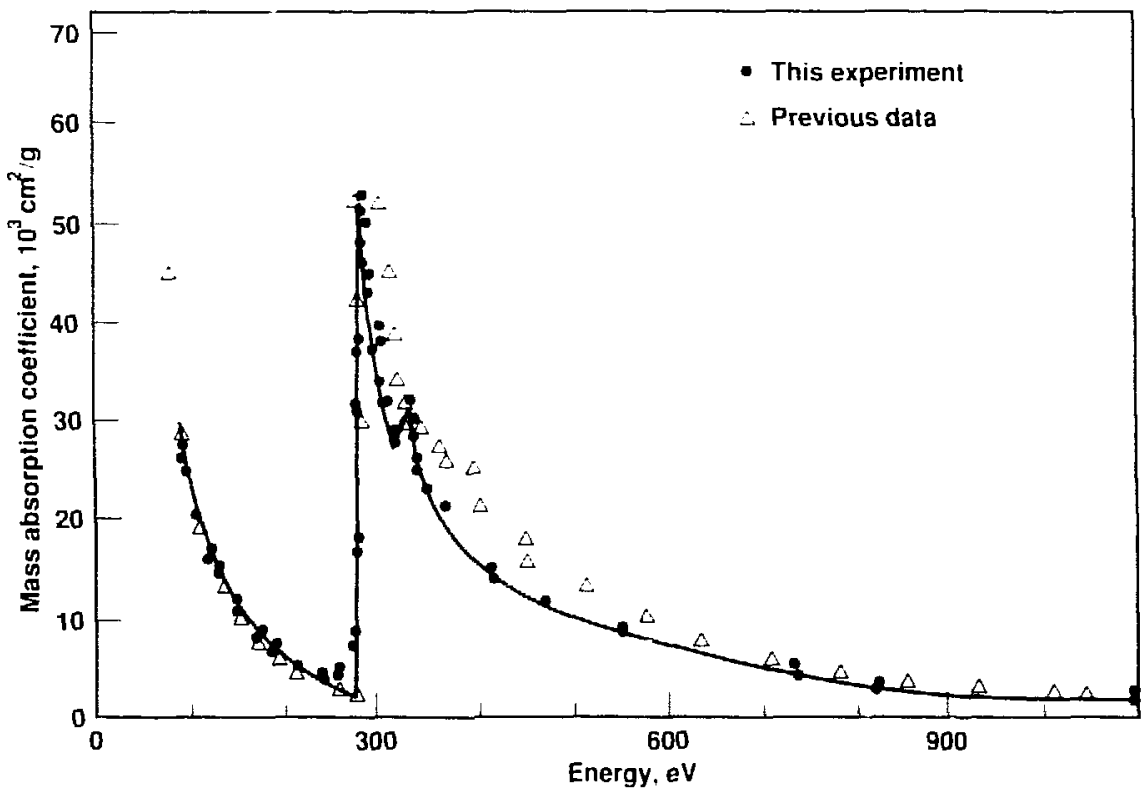

Figure 2. Hass absorption coefficient of carbon measured via a multilayer graling $\left(d^{0}=\mathbf{2 0 0 0} \mathrm{nm} l\right.$ as the second element in a two-parallel-crystal monochromator for energies of 95 to $1100 \mathrm{el}$. The experimentally ubserved structure at approximalely 3.30 el probably signifies the presence of small microcrystalline regions in the carbon foil. These are the first measurements obtained with a multilaver multilayer grating in a simple. two-parallel-crystal monochromator.

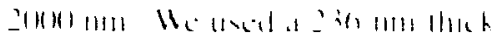

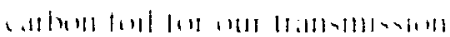

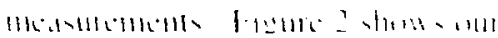

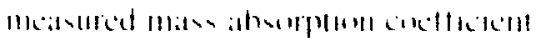

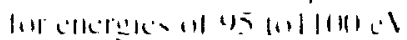

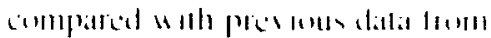

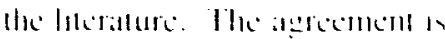

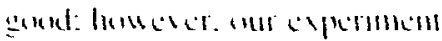

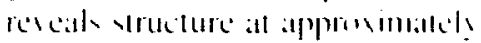

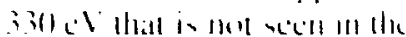

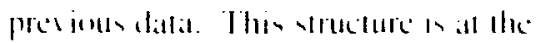

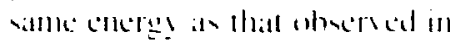

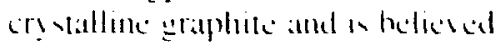

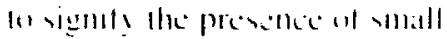

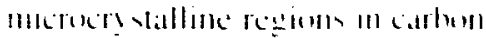
foil. Thene atre the forl measurements ohlatmed will a

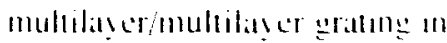
a simple. I momolirmator. ()ur datla demonstratce the unique capabilites al such ad allcod aplic

\section{References}

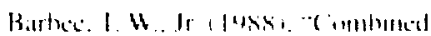

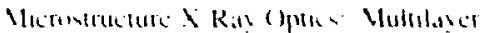

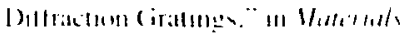

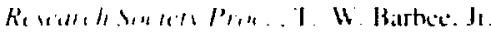

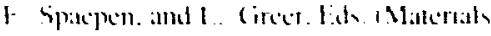

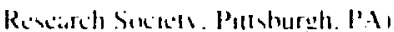
Vill. $1113 . \mathrm{p} .3117$

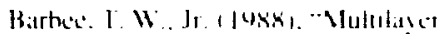

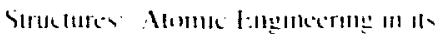

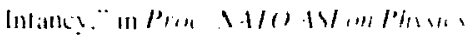

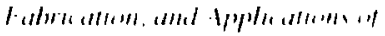

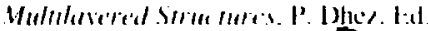

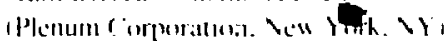

Barhes: I. W.. Jr. Aluskt. "The I xed

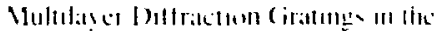
Dekmunathen al X-Rat. Soff $\mathrm{X}$ Kats and

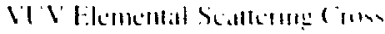

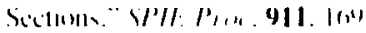

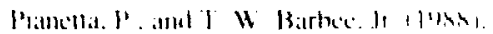

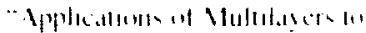

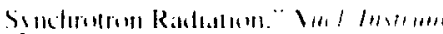
$1 / 1 / m, 1226 .+41$

Wither. I H 6 . It. I 11 R.rrhes II K K

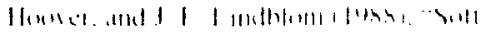

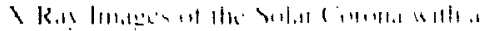

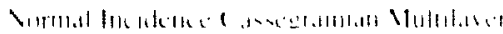

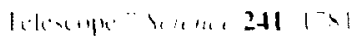




\section{Photoactivatted Heterogeneous Catalysis on terogels}

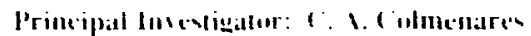

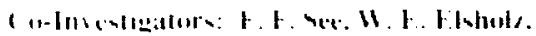

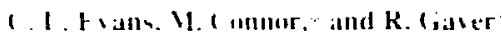

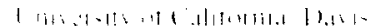

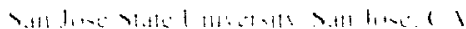

W - hate developed all chere!

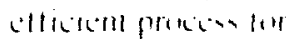

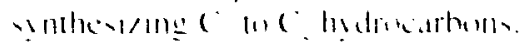

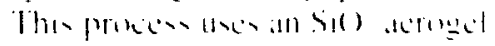
deped wah (1) ancataly the

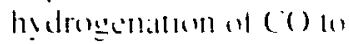

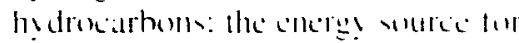
the reatctum in smolated sunleght

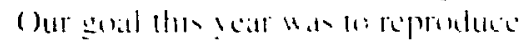
nur f)

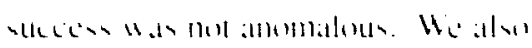

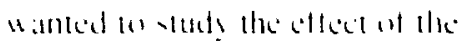

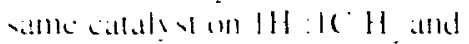

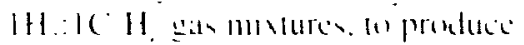

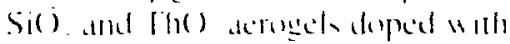

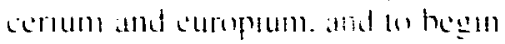

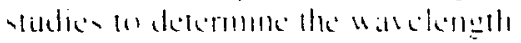

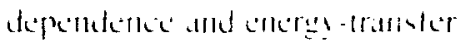

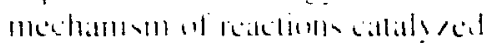
by deped acreses.

For the cataty- Sio, aleroged "with at densily of $5(1-101) \mathrm{m}: / \mathrm{cm}^{\circ} \mathrm{arc}$ produced and doped $\mathrm{xith} 0.45 \mathrm{wt}$; (6). . There doped iterogel dieplat and matntain an intene lluoresecence. indicating the persintence of the uran! ion. Spectromcop! reveals that the uranium on the aterogel matntatus at $6+$ exidatlon state. contirming the continucel preserice of the uram!l ion.

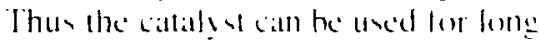

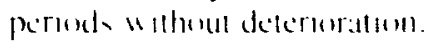

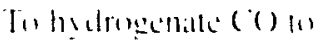

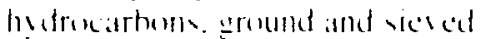

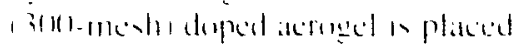

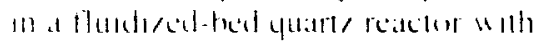

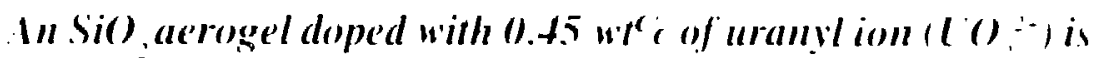
an effective photocatalys for symthesting $C$, to $C$, hydrocarbons from $2 H_{2}: I C O$ and $1 H_{2}: I C, H_{,}$gas mixtures. This catalyst also produces ethylenc and traces of methanc from a $I H_{2}: I C, H_{1}$ gas mixture.

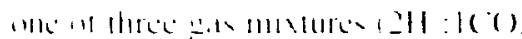

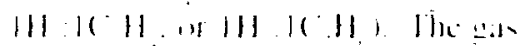

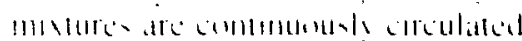

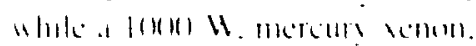

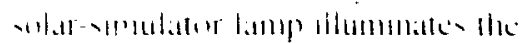

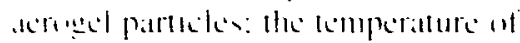

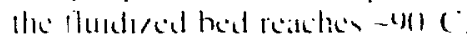

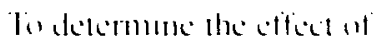
tomperature. we repeatled the process

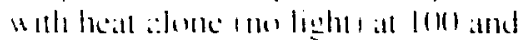
z(11) (5) The !

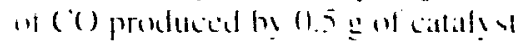

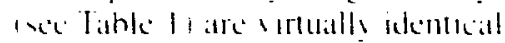
where oblaned on tysit. The

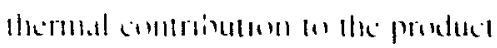
y

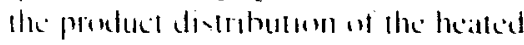
reactum ditlet trom that ot the

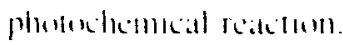

Wie alo conlirmed the effect of the uraml dopant. A photuchemical (xperiment uning plain SiO), ateroged produced predominaml! athane and methance and ant unidentified prendect In yualltitices about ten time lower that for the uram!l-foped aterogel.

Lish. we deternined the effect of light intemsit! on the
Table 1. Distribution of $\mathrm{CO}$ hydrogenation products by weight percent (determined by gas ct.rumatography).

\begin{tabular}{|c|c|c|c|c|}
\hline \multirow[b]{2}{*}{ Products } & \multirow{2}{*}{$\begin{array}{l}\text { Light } \\
\text { exposure, } \\
54 \text { h }\end{array}$} & \multicolumn{3}{|c|}{ Heat exposure } \\
\hline & & $\begin{array}{l}\overline{100^{\circ} \mathrm{C}} \\
21 \mathrm{~h}\end{array}$ & & $\begin{array}{l}200^{\circ} \mathrm{C} \\
24 \mathrm{~h}\end{array}$ \\
\hline Methane & 62.57 & - & - & 3.13 \\
\hline Ethylene & 13.41 & +4.39 & & 22.65 \\
\hline Ethane & 9.67 & 51.61 & & 35.57 \\
\hline Propesin: & - & - & & - \\
\hline Propane & 9.114 & - & & - \\
\hline Methano! & - & - & & 11.23 \\
\hline Isobutane & 2.21 & - & & - \\
\hline 1-butene & - & - & & 10.52 \\
\hline$N$-butane & 2.64 & - & & 16.90 \\
\hline$N$-pentane & 0.42 & - & & - \\
\hline$C_{\text {g }}$ bydrocarbons $*$ & - & - & & - \\
\hline$\% \mathrm{C}$ conversion & -1.1 & $2 \times 111^{+}$ & & $7 \times 111$ \\
\hline
\end{tabular}

*Detected hut not meisured yuantitatively. 


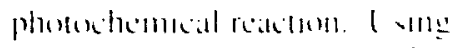

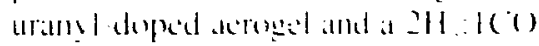

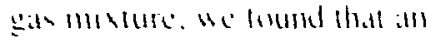
increase an inlensal from ofl (a) 5+1) If rased the methame theld livetold hut only doubled the yeld of the ofleer products.

In onter photextemicial syperiments. We uned urimyl-doped arogel with mivtures al it $: 1 \mathrm{C}, \mathrm{H}$,

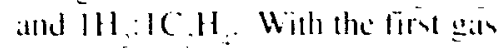

mancere the matm product wat

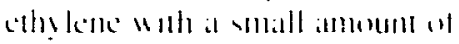
methats. With the acomal gas mivare, the matin products were methatke, shatke, propance bulance. pentance hesalne. and an unidentilied prosluct heliceded to be actanc. Full yeantitative results arce mol led at atilathle. hut we repeatled the $x$ cyperiments and abtained identical yualiative results.

Alter much work. we halle descluped a proceses un probluce

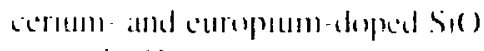

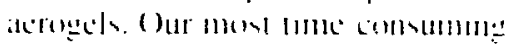

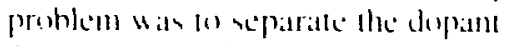
from the alerogel in the find state of the process. He hate yed la lest these aterogels for catalytic activil!

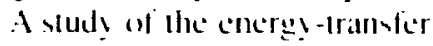
mechamism of reaclions callalyed hy doped ateregels vats adepted as a dectoral project hy M1. Comner. a

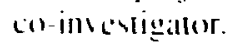




\section{Computation}

R. K. Burchers

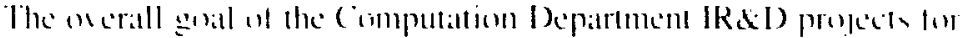

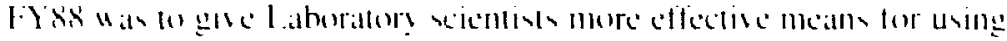

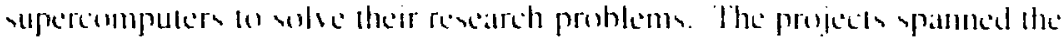
spectrum from dired applications an batsic reseatrch. Our reseatrchers strone to understind the nature of the calleulations that must he performed and to identify allemate approaches to them that might perform better on specitic computer architectures. We also addressed the Ways in which scientists inferate with computers. The design. writing, and debugging of programs is time-consuming

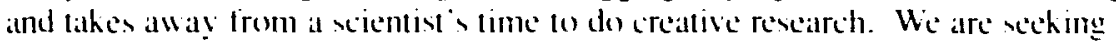
wats 10 help them create working programs faster and more reliably. In addition. we are evaluating the difficulties of dealing with new: ad anted compuler architectures. particularly parallel mathines. We are continually working lo increase the efficiency with which Laboratory computing resturces are used: we have major efforts in optimising compilers. making libraries efficient. and improving the design of operating systems. An integral part of this work is evaluating the performance of various computer architectures executing specific programs.

In the area of applications. considerable progress hals heen made in developing a program to model strongly turbulent processes in plasma physics by the methods of fluid-turbulence closure theory. The challenge here is io increatse computational efficiency while still considering most of the important physics in these processes.

In two other projects. we are developing knowledge-based engineering techmiques to give users a simpler and more powerful way of interacting with computers. In one project. we have developed new schenes. or knowledge bases. for representing information that will simplify the translation of partial differentlal equations and problem specifications into programs for solving them. The knowledge hase heing developed for mathematical analysis allows us to represent functions and operators in a deep context. not merely as the solely syntactic objects of traditional symbolic-manipulation systems. In the other project. we are developing the know ledge-hased programming techniques that can atsiume much of the operational and tuning responsibility for such complex experimental facilities as the 1 aboratory : Advanced Test Accelerator and Experimental Test Accelerator. This project has succeeded not only with traditional heuristic approaches that provide qualitative help but also with approaches that base diagnosis and tuning on conclusions drawn from a yuantitalive model.

Another pair of projects deals with parallel computing. We report on work toward developing the simulation model needed to explore a wide variety of multiprocessor architectures. Informative execution traces for hypothetical systems are combined with studies on the current SISAL runtime system to help us understand how parallelism works and why it sometime:i fails. In the last project. we are working to identify quantitative statistical measures of parallel random number generalors and lo develop ways of improving these generators for more demanding applications. We can nou recommend parallal methods for generating up to several hundred streame of pesedorandom numbers.

In FY Y 8 . the Computation Departument received $\$ 728.9100)$ in IR\&D funds. 


\section{Closure Modeling of Plasma Turbulence}

\author{
Principal Investigator: A. E. kuniges \\ (n-Insestigatturs: W. P. Dannesik \\ and (. F.. l.eith
}

S trong turhulence in at leading: camdidate lo explain anomalous Iramplort and thus lom of conffincment in lokatmath plasmas. Such turthulence cian he descritad hs at conpled wet of monlincar eyuation. that rexemble the Viater-Stokes equattion of thuid dynamices. Civided he the atcecen of clesure models in fluid problems. we hase made a perturbative approsimation that models the influenere of the nonlinear lerms on the statistical land thus transport-related) properties of the turhulent sistem. However. Muid theories must be substantially modified ind rederived in order to incorporate properties of the plasma equattions that are not contained in Navier-Stokes turbulence mokeling. These propertien include the occurrence of complex ficld yuantitice the presence of linear damping and driving via complex linear terms. and the nondiagonal coupling of two or more field quantities in the system.

In FY88. W' concentrated on developing a closure theory that is both applicable to plasmal turbulence and amenable to numerical solution. Approximations based on the physics of the turbulent steady state can be useful for simplifying the numerical computation. In particular. through numerical simulations. we showed that the application of the fluctuation-

Turbulence closures can predict turbulent flow properties and aid our understanding of the underlying physics. The goal of our project is to derive and numerically implement closure models for turbulence in tokamak plasmas.

dismipation relatton is reatsonathle for at damped and driven ssisem in

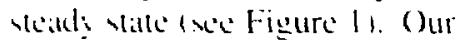
current schence incorporales this approximation and in so doing eliminates a comly integrallion present in full direct-interatetionapproximation (DI.A) calculaltoms. Wie also began lo develop al procedure based on Palde approximalles that lurther alcelerates the computation.

In FY89. we will lest these numerical schemes by applying them lo lokimak turbulence equations that contain driving and damping.

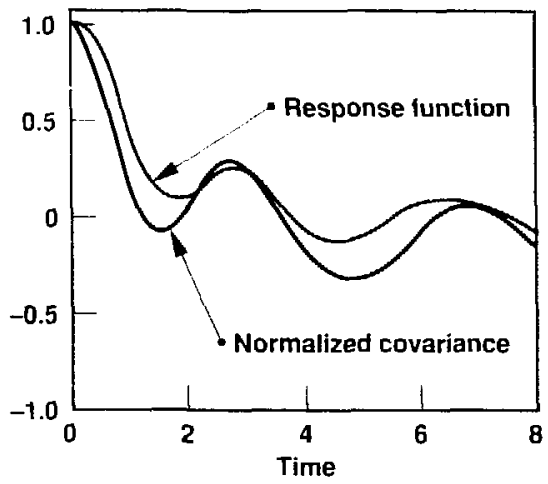

Figure 1. Demonstration of the fluctuation-dissipation relation for a turbulent drift-wave problem. The agreement of the two curves allows us to replace the two-time covariance with the response function.

\section{Refierences}

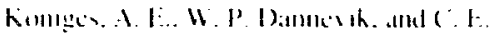

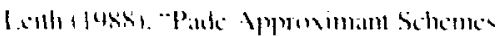

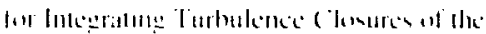

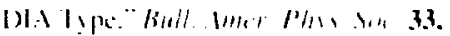
21121 .

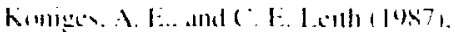

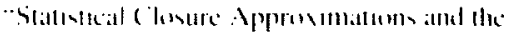

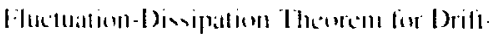
Nave Inleratction." P/m, Fmik 30. 3165.

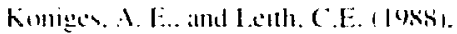

"Parallel Proxcestmy al Random Number Gionerallon fur Mlonte Carlu Turbulence

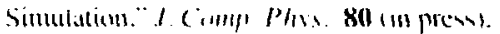


An Iutomatic Programming System for Solving Partial
Differential Equations

Principal Inventioalturs: 1). Baliaban. I. Ciarbarini. and WI (iriemants

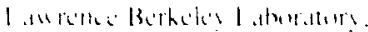
Retheles 6 (')

$\mathrm{O}$ ur goal is bicreatle an atutomatlic prong:amming ?hem that gencrates numerical discretiration sehemes for partial differential exuation (PDE) problems, thus climinating the ledium and human crome inherent in the mathematical manipulations and programming normally involved in crating PDE simulatioms. Initially. the sstem will he usctul to engineers 1 ho need to sinulate well-understond physical problems w ith dincretiration schemes that woukd previously hate heen tow comls werice. A nomlinear heat equation in spherical coordinatce and three space dimemsions is ane example of such a problem.

To hegin with, we want to he able to derive numerical schemes for parabolic equations such ats the reaction diftusion cyuation with complex chemistry. for nonlinear wave equations such as those describing smooth acoustic or seismic walles. and for electromagnetic systems deneribed by Maxwell seyuations. Latler. als the automatic programming "ystem hecomes more sophisticated. it will

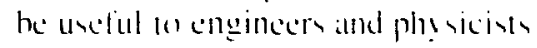
ab ho are developing unustal of
The goal of our project is to improve the productivity of scientists and engincers who develop numerical simulations. for physical problems described by partial differential equations (PDEs). This is to be done by first developing a knowledge base for mathematical analysis and then building an automatic programming system on that knowledge base that will create numerical simulators for PDEs. complex discretifation sethemes for less routine problems. such als those detined hy Eukr's equation or by magnetohydrodynamic eyuations that maty have discontimuous solutions.

There are a variely of ways o crealte an allotomatic programming syem for PDEs soe the hox "Aulomitic Programming Systems lor PDEs" on the following page). We have chosen the following steps to implement our system:

- Develop a uniform scheme for representing continuous-phỵics prohlems that can he implemented in a computer program.

- Develop a uniform scheme that represents the process of deriving al discretization scheme from a comtinuous description.

- Develop advanced symholicmanipulation capabilities to implement the derivation.

We have developed a redational model of continuous-physies knowledge centered on comserved quamities and comservation lalus. Initially, this model delined whersables. densities. currents, and

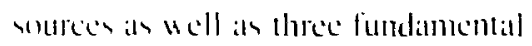

relations al curremt. density. and the conservation law that related them (1) onc another and contained information about the materials heing modeled. All of this knowledge is represented in standard vector calculus form.

The discretization schemes are derived systematically and mechanically. Stokes theorem is used to creale discrete forms of the conservation laws. The partitioning of the domain on which the physical problem is defined provides a framework for defining al stsem of equations from the discrete conservation lats. The discretization scheme is then essentially this system of equations.

Much of the multidimensional calculus in our automatic programming systeja is represented functionally by the mathematicalanalysis knowiledece base currenty heing implemented. (That is. functions and operators are treated much as they are in functional atrily sis: there alre no variatbles. and expressions are represented as compremitions of functions.) This hmom ledge balse is heing huilt an a layer over the traditional symolic- 
manipulation system MAPL.F. In this way. mant new and powertul symbolic-manipulation capabilitios ate being added without recreating existing ones.

In traditional symbolicmanipulation systems. sone comstructs such as operallors and complicaled tur :tions must be expressed as programs in the symbolic-manipulation language. Changing expressions involving these constructs then entails restructuring programs. Our symbolic-manipulation capabilities are powertul enough to allow us to represent these constructs ats functions. not programs. Thus. we will be able to manipulate and simplify more complex expressions that contain them.

In FY88. we extended our automatic programming system by placing it in the uniform tramework of differentiable manifolds. We did this for four reasens. First. it provideria systemaltic way 10 compute high-dimensional surface integrals, which are the basis of our approach to deriving discretization schemes. Second. discretization schemes can then be derived in the same way for many different coordinale systems because manifold theory allows physical systems to be described independently of their coordinates. Third. a wider class of physics problems can be described. Differential manifolds provide the most natural setting for the mathenatical objects used to model continuous physical systems. This single formalism can describe such diverse physical systems as electrodynamic, reaction diffusion. quantum mechanic. and fluid systems. Finally: differential manifolds allow us to deal with coniplex domain geometries. For example. a domain might best be dexcribed by a patchworh of different courdinate shems. or it might have a comples boundary.

A new implementation of the mathematical-analysis knewledge balse is nearly tinished. It has a much more general and complete theoretical foundation. Which was needed to handle the more abstract differential geometry fommalism that we are now using. A novel scheme hatsed on Currying composition operators was completed for manipulating higher-order functions. This scheme is the basis of our implententation and enables us on systematically represent and manipulate operators f functions of functions).

Significant progress was also made on our relational model for continuous physics. The question of how a PDE corresponds wo the tensor of conserved quantities was at least partially solved for the casc of

\section{Automatic Programming Systems for PDEs}

Current automatic programming systems for PDE problems follow a variety of approaches. Some start with a problem's continuous description; others start with its discrete description. Some systems work from conservation laws; others work from the PDEs derived from those laws. Some use symbolic manipulation to derive all or parts of the discretization scheme; others use artificial intelligence techniques to classify the class of problem being solved and to fill program templates that implement the discretization scheme.

Each approach reflects the desired properties of the simulation that is created by the automatic programming system. Systems that use template filling are likely to produce a very efficient code but one that is applicable only to narrow classes of problems. Systems that start with discrete problem descriptions are also likely to generate efficient codes, but the codes are often complicated to use because the user must deal with both the continuous problem and its discrete approximation. Systems that deal with PDEs directly may have a harder time generating conservative discretization schemes (that is, schemes consistent with conservation laws), whereas systems that deal with conservation laws will not handle more abstract PDEs.

Our automatic programming system starts with a continuous description of a problem in terms of conservation laws and derives its discretization schemes from this description. Consequently, our system is relatively easy to use and is applicable to a wide variety of problems. It always generates conservative discretization schemes. However, these schemes may require some work to make them numerically efficient. 


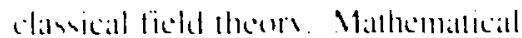
model for mant contmuour whem caln be expresed in lemm of at manifold. in structure, and the Hodege -mapping. Examples include Maxwell e cyuations for

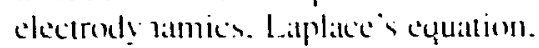
and the heal and walle cyuttions.

The'e models are expresed in lems of differential forms orer manifold that represent conservalton latus for the wylem that are independent if malerial propertices. The propertices are expressed by relationship hetucen vtale variables for the mbem and conserved currems thall appear in conservation latus. In mant cisces. this relattomship call he exprened in the metric structure associaled a ith the manifolds, dangent space. This relationship is rellected in the Hodge tmapping. which is desemined by the metric.
A latrectam col comtinueur plysic model bate the linm

$d F=11 . d \div=I$.

The exe equations ance syuivalent to a PDE mokel fur the system. The metric structure determines the PDE class celliptic. paratolic, or hyperholice. Table I gives the relationship heiween the metric and PDE class for the citse where $F$ is the anc-finrm $f=d /$ and $J=0$. A single covariant expression represents all PDE clasises.

The highese priority for Fy89 will he fo uperade our current implementation of the mathematicalanalysis know ledge base to the point where it can compute general surface integrals. To do this. we will have o expand the knowledge hatse to hatndle manifolds. tangent bundles, and pull

\section{Table 1. The PDE corresponding to the covariant expression * $d * d f=0$ is deter- mined by the metric structure.}

$\begin{array}{llll}\text { Domain of } f & \begin{array}{l}\text { Metric on the } \\ \text { domain of } f\end{array} & \text { Equivalent PDE } & \text { PDE class } \\ \text { Space and time } & \text { Lorentz } & \frac{\partial^{2} f}{\partial t^{2}}-\Delta f=0 & \text { Hyperbolic } \\ \text { Space and time } & \text { Singular } & \frac{\partial f}{\partial t}-\Delta f=0 & \text { Parabolic } \\ \text { Space only } & \text { Riemannian } & \Delta f=0 & \text { Elliptic }\end{array}$

baths. This expansion will delat the atutomatic derisation of the first discretization schemes at lew months. However. heing able to do general surlate integration will mean that high-dimensionality discretization schemes will be immediately derivathle.

We hope to have the implementation ready to derive some schemes for simple electrolynamic systems carly in FY89. Discrete approximations for simple lluid dynamies systems should follow shortly. At this point. we will hegin using FIDIL a finite-difference language extension to Fortram) to implement the atomatically derived schemes.

\section{References}

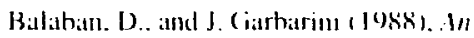

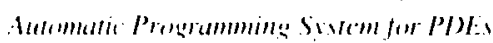

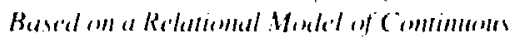

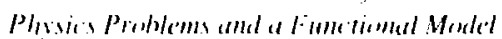

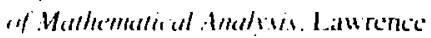
Livermore Naliomal L aboratory. Repurn L ( RL - 53805 .

Cireiman. W.. D. Balaban. M. Durs, and J. Ciarbarini (1987), "Knowledec Representations for the Automatic Gencration of Numerical Simulators lior

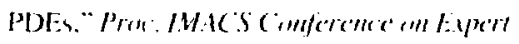
Sistems for Numerical compuring. Barcelona. Spain. June 2-4.

Olwell. K.. D. Balaban. and J. Garbarini (I)Rki. Discrele Aludeses of PI)ts lotined inl Re'ctamgular Latrices. Lawrence Livermore National L aboratory. Reporl LiCID-21598. 


\section{An Expert System for Tuning Accelerators}

\author{
Principal Investigators: H. Brand. \\ D. I ager, K. Scarfus, II. Maurer. \\ J. Hernande\%, and F. Couffield
}

$\mathrm{W}$ a are applying hom ledgrehatsed whems (KBS) echniques a the problem of tuning and combolling an induction lincar alcecleratur and is bealn-tranyput sstem. Our initial effirts hate focused on developing KBS echmiques for the beam-lramsport system of the Advanced Test Accelerator (ATA): this work is also directly applicable to the next-gencration mathine. the Experimental Test Accoleraltur (ETA-II). This year. "re completed the interlate with the ATA's diagnoutic subs stem and hase nearly completed the inlertace with the: control subsystem.

We are insestigating both a heuristic and a model-based approach. The heuristic approach mimics the diagnosis and tuning done by an expert human operator. It can be applied to any instrument for which there is operational and luning expertise. The model-bisied approach. on the other hand. operates a numerical simulation code and compares code-simulated results with curren vlachine performance for diagnosis and tuning. This approach holds much promise but is limited (o) machines whose operations sin he simulated by numerical models.

To support hoth the heuristic and model-based approaches. "le have developed a " smatt" object-oriented representallon ol an alceclerator and

The machines used for modern experimental research are becoming increasingly complex, and there is a pressing need for automation techniques to provide high-level control of these machines to complement and supplement human control. We are developing a knowledge-based expert system to handle many of the tuning tasks and operational responsibilities for induction linear accelerators. $U$ se of an expert system should greatly increase the available highquality beam time.

jo heam-tramyport w bem and hats uncel this representation to madel the ATA heamline. This representation is "smart" in that it includes procedural hnow ledge viat the data-driven programming paradigm. For cxample. it atummatically compleken the description of the heamline as soom as the minimum required information is avalable. It also includes procedural knowledege that couples the model to the diagnomic subsystem intertates so that datla in acyuired as reyuired and when requested: a similar coupling exists with the control subs stem interfice so that changes to the model can be alutomaticall! propatgated to the control subsystem.

The heuristic approach uses a hierarchical scheme, dubbed MDS lor monitored decision seript. 10 describe the accelerator operation and tuning procedures. Unlike earlier seripts (e.g.. Barr and Feigenbaum. $1981)$ that only permit a linear sequence of events. our MDSs allow decision-based branches and lonps. They also allow conditions an be monitored periodically for cxecptions or errors) (luring execution of the script. and the include an exception/error-handling capability a cope with exceptions from the monitored conditions and errors signaled by the actions laten for MDSis called from within the ecript.

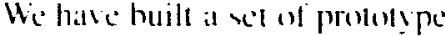
MlDS that can tume part of the ATA

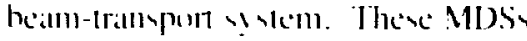
use the object-roriconted mitehine represcentation to reatsem ahout the beamline and wo identity choices as lo which secring masncts an adjus on align the heam. Actual adjustment of the stecring magnets is donc by a I niplex optimisation algorithm that call operate in the presence of measurement noise. This ststem has heen demonstrated suceessfull both on the simulator and on the ATA.

Signilicant work has also heen completed in support of the numerical model-based approalch. Dr. M. Lee of the Stanford Linear Accelerallor Center is assisting us as a consultant. Dr. Lee and his colleague. S. Clearwater. are pioneers in the application of knowledgebased systems that use beamline simulation codes and actual beamI rajeclory data in off-line analyses. We halve alse procured (and are awailing delivery of) a slate-olthe-art accelerator-and heamlinemoleling corde.

In the mean times, using a simple heamline model. us are extending the worh of lece and ckearm iller a) Iwo dimemsioms, an action necessitated by the solenoidal heaml transport sysem used on the FEA-II and som lo be imstalled on the ATA. This wath differs from that of lece and clearwater in that it uses at model 


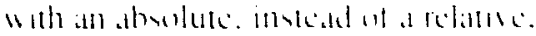
condintats corordinalle-s sem model producer results ditedls compariale to theme eneraled by the beam-ponition

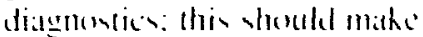
analeis moth eanier and lead on al

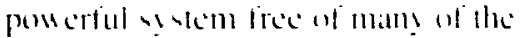
mistithes that can be imrotaced when

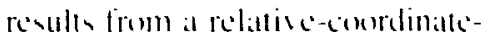
ytem model ate diredt companed "ith meatured beam paramelers.

He hate ured the simple heatmline mokel w lind regioms "ithin the heamline where the model and the heam-dianguric measuremems agree. Figure I hom, stath a region for a simulated sction of the ATA heamline. Our next sep will be to une the know kedere-bilsed sylem to search for the areas where regiom of enoul tit ahut fo redentiti the fatult! parts in the heamline that account for discrepancies hetween the itclual heamline and the model. In this wats. we will he athe to merge

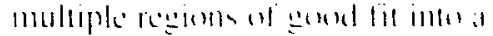
- mele region correring he whote he:alnhllle.

Increanced funding from the Bealm Renarde Project for frye "ill collable we wamplete the

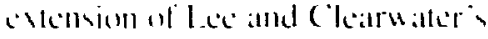

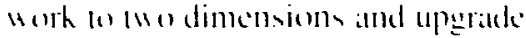
the whem into an on-line. real-time

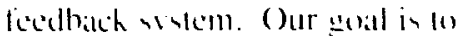
mathe thi "slem Litpathe of designing. running. alnd andily , ang

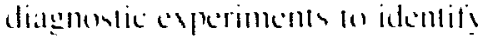
fauls heamline componems and on determine the mpe of tialte. This infermattion would then he led bitch into the mumerical model on that operatlon and luning of the acceleralur could continue in the degraded enviromment. Al present. the major obstate appears to be the abilits of the numerical model lo simulate the many typen of pomsible fauls te.g. misalignment in any or all of on axes. field winding shorts. elc.l.

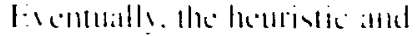
model-bascd alpproaldes will be combered. The hourdic approath uning MIss will excreine high-level operational control and moniturins. The NISS w ill prepare the accelerattor and heamline for latrious cyperiments. monitor its performantes. and adjust for part failures when ponsible. The mokelbared approach will were as the luning and diagnosece "inlelligence" in the yntem. Fatulty or misaligned part and diagmostic will be localled he intelligent une al a numerical model. and tuning parameter will he derived directly from the model after it has hecen updaled lo account for whaterer latuls are identified.

\section{Refierence}

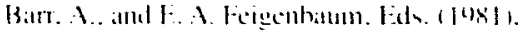

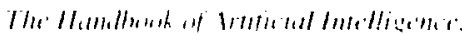

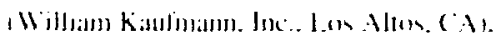

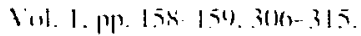

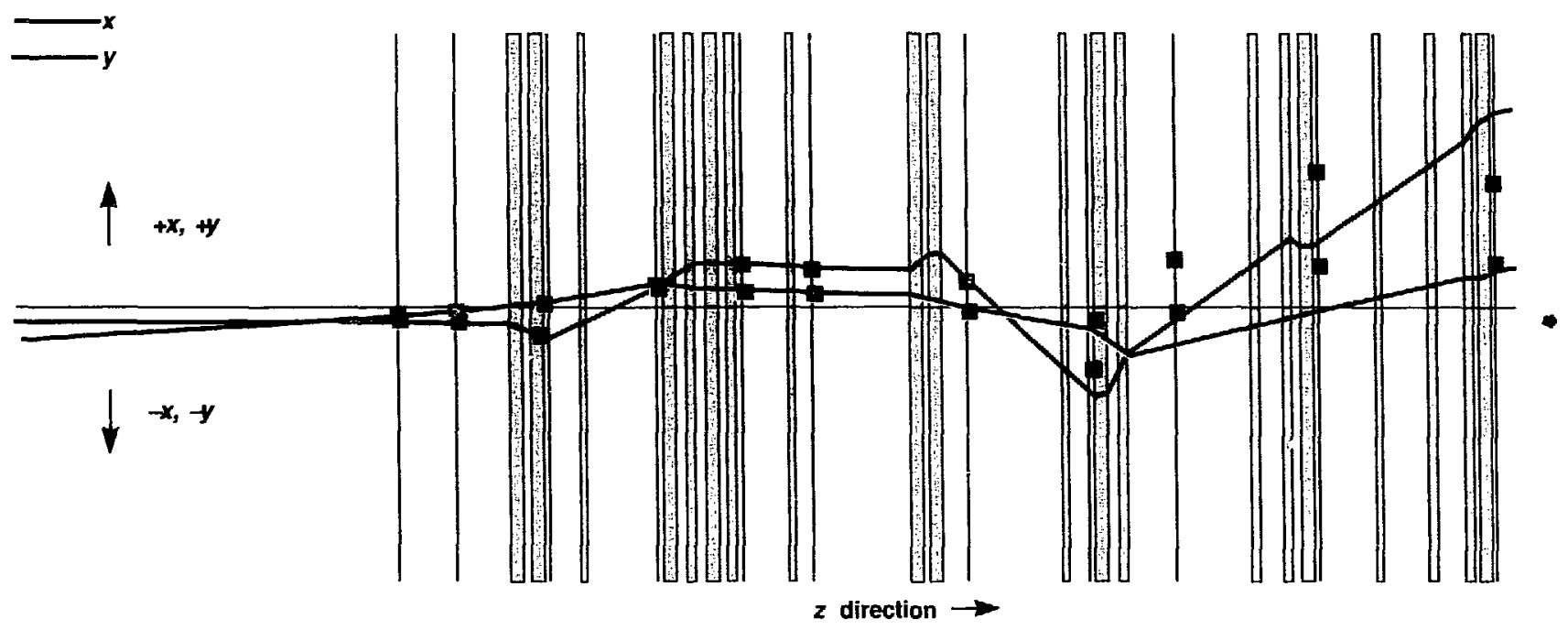

Figure I. Simulated section of the AT $\mathrm{A}$ beamline showing agreerient between the model prediction and the measured positions over the first seven heam-position monitors. The bean in both the $x$ and $y$ directions is plotted as a function of pesition along the beamline iz direction). Tall rectangles represent various heanline components; vertical lines represent beam-position monitors: syuares represent the bean-position ineasurements: the (near-horizontall colored lines show the modeled heam path. 


\section{Architecture Studies with SISAL}

Principal Investigator: J. T. I'eo
$\mathrm{T}$ he Laboratory has an ongoing program to design and implement SISAL (S.reams and Iteration in a Single Assignment Language), a high-level, applicative language for parallel processors. As part of this work. we must understand how different hardware components. such as the Cray-X/MP vector processors. affect the performance of SISAL programs on multiprocessors. The speed of a parallel program depends on the multiprocessor"s hardware comporents. the topology of the interconnection network. and the algorithms used to partition and schedule an application's concurrent computation units onto the processor's resources.

We are evaluating multiprocessor systems for a mode of parallel processing known as dataflow computing. Dataflow differs from conventional parallel processing in that synchronization and communication between concurrent computation units is the sole responsibility of the runtime system. The user does not explicitly encode synchronization and communication primitives in his programs: instead,

\section{We are evaluating the performance of multiprocessor} computer systems for dataflow computing by simulating the execution of programs written in SISAL on such machines. Our goal is to identify the architectural features that abet or hinder the programs' execution. An important spinoff of this project is the development of heuristics to map the tasks of a parallel process onto the resources of a multiprocessor computer system.

the compiler realizes the code's implicit dependencies and irserts calls to the appropriate system routines.

Our goal is to develop a dataflow simulator that will take as input a dataflow program and a description of a multiprocessor system. Once a program is mapped, the simulator will logically execute the program and output performance statistics. As part of this work. we are developing heuristics to partition and map dataflow programs to the resources of each system we consider. We are concentrating our initial efforts on systems for which we are developing SISAL compilers and runtime systems.

In FY88 we developed a profile utility and enhanced the SISAL debugger and interpreter (DI) to output execution traces of interpreted SISAL programs. The profiler generates a parallelism profile. which assumes an infinite number of processors. no communication delays, and unit instruction cost (all instructions take one unit of time): it observes all data and logical dependencies. We began upgrading the profiler to simulate execution on a shared-memory architecture with a tinite number of processors. nonzero communication delays. and variable instruction costs.
We also completed an extensive study of the current SISAL runtime system. This work led to improving the memory-allocation algorithm and to rewriting certain parts of the runtime system to alleviate bottlenecks. It is important that we understand the characteristics of the current SISAL system, because we plan to establish the correctness of our simulator by comparing the performance it predicts for an application on a particular system with the application "s actual execution on that system.

We have three main tasks to complete in FY89:

- Reorganize the projecl's approach.

- Develop a flexible but comprehensive paradigm to describe parallel architectures.

- Develop mapping heuristics for our initial target machines.

While upgrading the protiler. we realized that DI is an example of the simulator we want to develop. Presently. DI simulates the execution of SISAL programs on a multiprocessor system with infinite resources and zero communication delays: thus we need only to enhance 
DI to simulate progeram exedutem for an inpur archicesure. Althusgh this is no trivial task. at least we do not have to rew rite the support routines for program excecution (input/output. memort management, and instruction scheduling and execution ). Morrover. DI works directly w ith our datatlow graphs. known as IFI graphs. removing the need for execution trace files that can he very large for even simple programs. We hate decided on at table format to describe multiprocessor compuler systems. Al the very least. the lathle will include the mumber of processors. their type, the amount and layout of memory. instruction costs. network topology. and the communication delays between resources. We plan to consider cach memory as a separate resource. thus calsting all memory accesses as communication delays between a processor element and a memory resource. Finally. we will develop mapping heuristics for shatredmemory multiprocessor systems with hoth vector and scalar processors and with and without cache (high-speed local memories).

\section{Refierences}

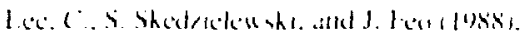

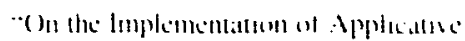
L.allogla!gen in Shared-Mlemory MI:MII)

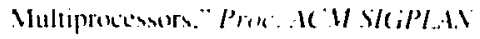
Simpename an Parallel Prostamming

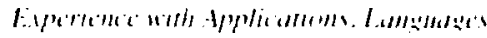

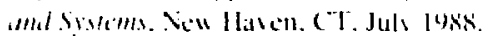

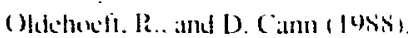

-Applicanise Patrallelism-Ponential and

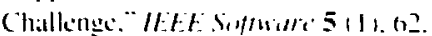

Sarkatr. V. 1 1457), Parmm,

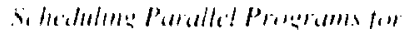

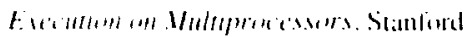
Inicersi!n Stanlord, CA. Report TR CSI. TR-k7-3is.

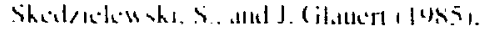

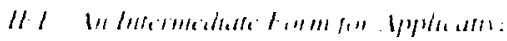

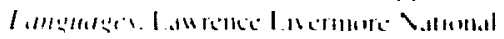
Lahoratury. Mantual \$1-1761.

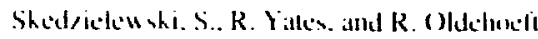
(19\$7). 1)1: An Interative 1) huserer

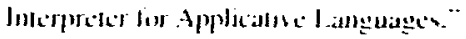

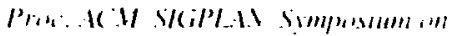

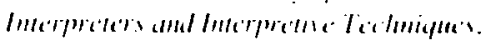

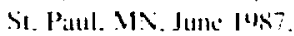




\section{Parallel Pseudorandom Number Generation}

\author{
Principal lnsertigator: M. Murst
}

$\mathrm{P}$

arallel random number

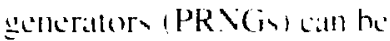

vienced at algurithm lor gemerating man! mutualls independem streams of pecudorandem mumbers. To gentrale sach stcams. whe mat split the xeyutence of a vingle ritndom number generaltor R $R$ (i) or unc at unicue generattor for eatcti stream. We hate completely dexcribed the statistical hehavior of PRNGis formed by splitting the seyuence from a congruential $R N G$. With a viriant of the well-known spectral lest, We lesled such generallors in use on the Craty-X/MP and found their hehavior acceptable. Wie also calculated bounds on their hehatvior and found that they will not provide thou ands of generally reliable streams. The'se theoretical inadequacies led us lo consider uniqute generattors for salch stream.

The most promising idea was to use a different multiplier for each stream. Using work done by: G. Fishman of the University of North Carolina. we projected that millions of individually acceptable multipliers exı t. We developed necessary. but not sulficient. conditions on the interrelationships between multipliers. Combinatorial

We developed nays to reiably generate up to several hundred streams of pseudorandom numbers, with definitive quantitative measures for schemes that split sequences from congruential random number generators. We also creaied a battery of empirical tests for any parallel random number generator.

anals sis of the interrelatiomship sugesos thatl thousands al mutuall! acceptable streams might he found.

We also studiced Wil!sol comblacting empirical less tor PRVCin. Full! gemeral PR VGis for as fell as a dogen streams must he acceptahle in hundreds of dimemsions: this makes exhatustive esting difticult. We comstrucled tasts lo comrelalte all streams al various latgs. Since these tests study pairwise dependencies. they alre necessiary but far from sufficient. We provided a preliminary hattery of tests (Durst. go8al for PRNGis that our Cray-X/MP implementations pass falthough sonke carlier schemes do not). A side benetit of this work is an improved minimal battery of tests for sandard RNGs: these tests uncovered defects in a published RNG. We also devised techniques for the ad hwe improvement of PRNGs for ditficult applications and for comparison purposes when a PRNG is suspect (Durst. 198Xh).

Our FY89 plans include at detinitive discrepancy calculation for splitting schemes for generalized feedback-shitt registers. Whose vatsly longer period and superior randommess make them more attractive for computations involving thousands of streams. In additionl. it maly he possible (o) adapt discrepancy calculatims at the scheme involving differcm multiplicers for cach stream fcurremel these calculationts are omi at ailathlc as an inpracticall! larọs discretc summition). Further cmpirical work should alses be dome as tind hes splits for coneruentials and of deternine when the theoretical failings of congruential spliting xhenemes atually impinge on calculations. Finally. we intend at implement a functional PRNG for the parallel language SISAL. which should make parallel simulations and Monte Carlo calculations in that language more natural. This could produce a lesi bed in SISAL for both. which would in turn point oul the most important remaining difficulties lor PR NGs.

\footnotetext{
References

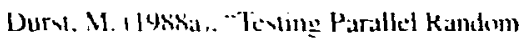
Number Ciemeraters." Cimputer Si inme

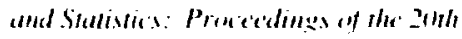
Sirmprasum. Amerkan Stalistical Asukcialion. Alexandria, VA in pressl.

Durst. . M. 1198s'b). "Imprewing Parallel Kandem Number Gelleralors." /

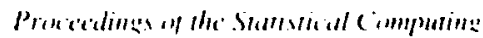
Sadien. American Statiotical Amoration.

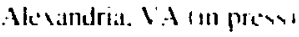




\section{Earth Sciences}

1.. Sichwarts.

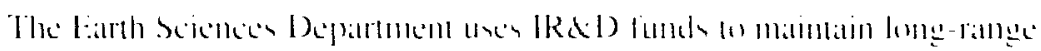

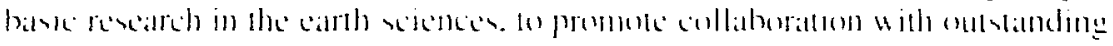

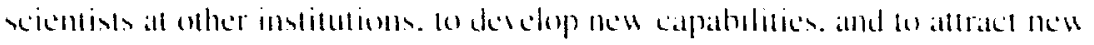
stati members. The Department provides support in the areas al geochemistry.

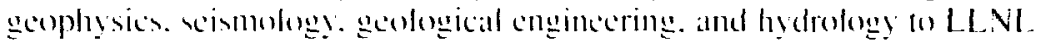
programs in Nuckar Tes Containment. Tratly Veritication. Nuckan Wask Nanagencent. and Fomil Fncrgy.

During FY8R. we used IR\&D funds Io estabish laboratories with unique capabilitices for the study and accurate charateterisation of earth materials. We completed the installation of at thermal image fumate in our ergedtat-gerouth

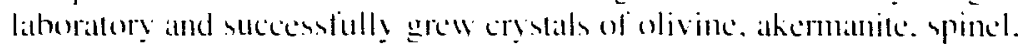
magnetike. rute. and nickel axide. The at ablathility of high-quality single cry uals of olie ine is copecially important for studies of the electrical conductie ity. diffusion. and deformation propertien of the carth supper mantle In allother effort. we are developing a barge-volume. high-pressure lakeilits for which we hatre designed a split-cone apparatus capathle of reaching pressures an high ats 250 hbar and temperatures up to $20000 \mathrm{C}$. When completed. this fatcility will provide a capathility unigue in the western L.S. extending the experimentally accessible "depth" to pressures believed to exist in the canth" lower matnle depths grealter than $60(0) \mathrm{km}$ ).

We also improved the computational and measurement lechniques thatl are required to develop and test models of geological processess with realistic complexity. The fluid tlow and transport modeling effert continued on at number of related fronts. We enhanced a hydrothermal thow code that enables us to study partially salurated flow in a fractured rock mass subjected to an episodic infiltration event. We are also developing codes to predict changes in fluid composition and mineral zonation as a thuid flow shrough and reacts with a porous mediat. In the areat of appeous geochemistry. We demonstrated the feasibility of a new method of determining the hydrogen ion activity in highionic-strengh solutions. We have also developed optical chemical sensors for an optical-fiber system to mealsure the properties and composition of thuids in hot. corrosive wells.

To develop and test competing hypotheses on crust-mantle interactioms. are combining seismological and geochemical techniques in a unique leclonic region of northern California. We collected a suite of crustal xenoliths and deployed a porlable broadband scisnograph at the Clear Lake volcanic tield. Initial analysis indicales that the senoliths record two phatses of thermal events. while seismic evidence indicates that the San Andreats Fatult is decoupled in this region all mid- 10 lower crustal levels.

We also co-sponsored efforts in hiotechnology and in modeling the equation of state of earth materials. Together with the Energy Program. we sponsored a study of thermophilic microorganisms in geothermal thuids that will eventually allow us to determine which types of thene organisms maty be usctul for the subsurlate processing of mineral. organic or geothermal wastes at cemperattures fatal ho ordinary bickeriat. In addition. He used a small gramt.

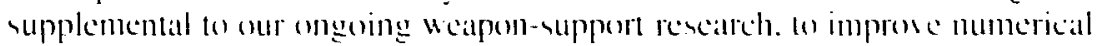
simulations of underground nucleatr explosions by incerporating a more the shate and accurate cepuation-ofl-state mokl into DYNA2D.

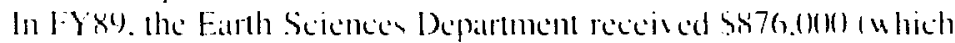

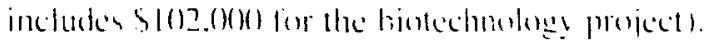




\section{Single Crystal Synthesis in a Thermal Image Furnace}

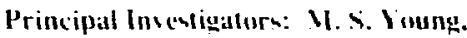
F. I. Riersun. and A. (;. I)uba

$\mathrm{T}$ he hulk of the information (an which we currenlly hase our understanding of the me: hitnisms governing creep. dilfusion. and electrical conductivity has been provided by meatsurements mate on natural single crostals, which include a large number of components and are ralrely of high quality. The thermal image fumace purchased with funding from the Basic Enero! Sciences Program and delivered an our erystal-growth laboratory in October 1987. makes it possible for us to invertigatle the sunthesis of many mineral phasess relevant to problems in geochemistry and geophysics.

The thermal image furnace is diagrammed in Figure 1. Two halogen lamps. each placed at one of the focial points of a gold-coated ellipsoidal mirror. provide the heat source for the thermal image furnace. The mirror focuses radiative heal on a small spot, thus generating the high temperature required for melting oxide minerals. A feed rod is made of well-mixed. stoichiometric amounts of chenicals that constitute the desired composition of the crystal. This feed rod is compateled under hydrumbatic presure and intered 501010100 ( $C$ belos the melting point of alde :s!stal
Many geochemical and geophysical expatments require wellcharacterized, high-quality single crystais for measuring phemonena ranging from diffusion and electrical conductivity to seismic attenuation and plastic deformation. Recognizing this need, we have established a crystal-growth laboratory in the Earth Sciences Department. In the past year, we have successfully used a thermal image furnace for growing crystals of olivine, akermanite, spinei, magnetite, ruile, and nickel oxide. compound. Cristal growth is intiatled br melting a smill xection of the feed rod and hringing the mollen ance in contact with at sed crstal. Becaluse the feed rod and the crystalgrow ing assembly are enclosed in at yuart/ lube. hoth the ersulat-grow h atmonphere and the avidation valle of the grow ing crystal can be controlled by regulating the thou -ihrough gas

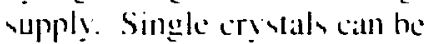
ohtatined h! catrefull! matintaining

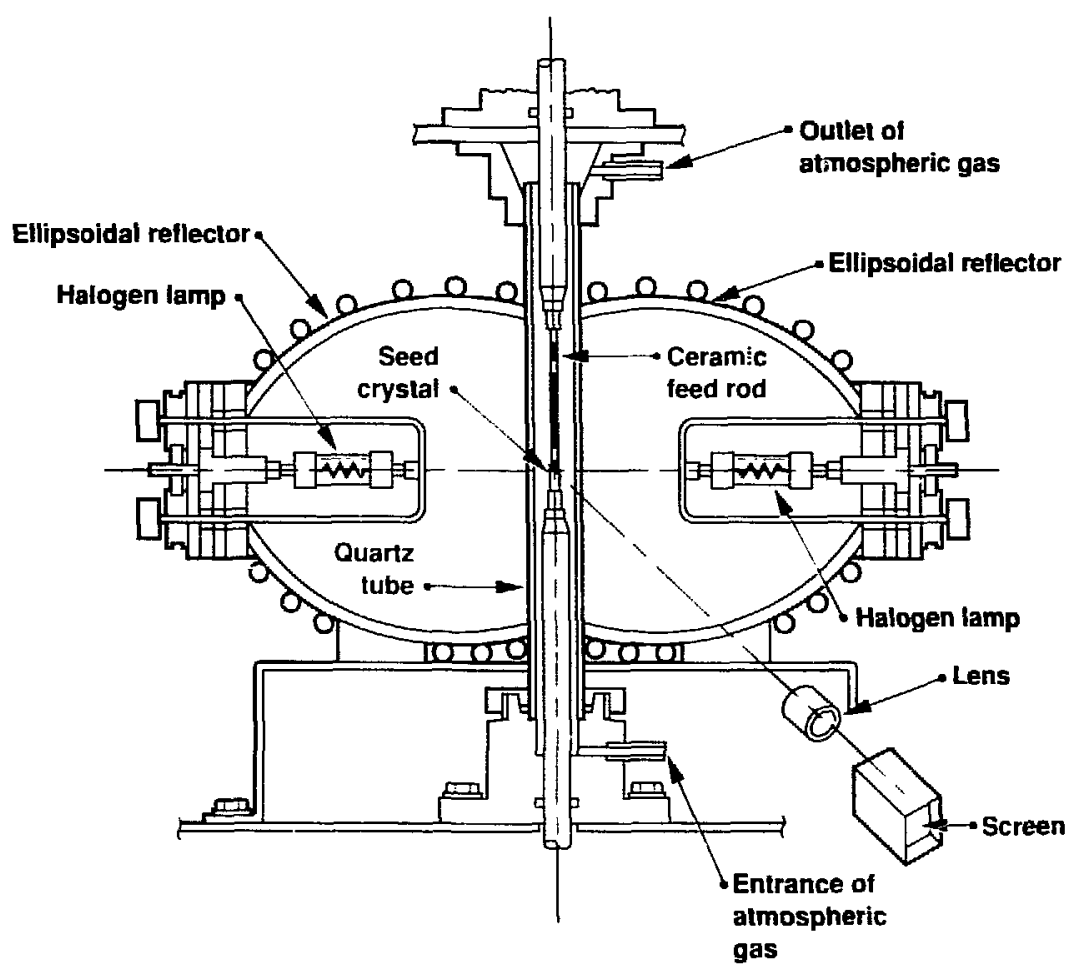

Figure 1. Schematic diagram of a thermal image furnace with Iwo ellipundal reflecturs. 


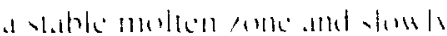

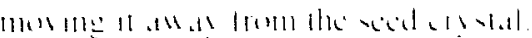

The themal imase turnate

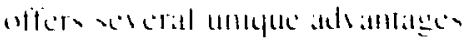

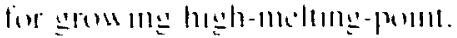

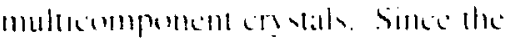

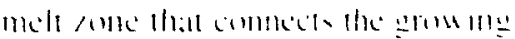
ansal and the leced rod a held an

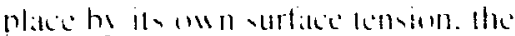

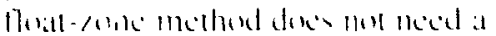

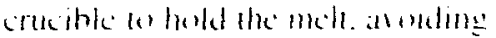

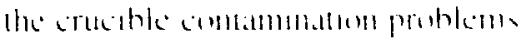

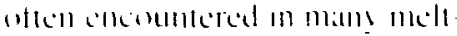
grom ih mothes. The heallm! al

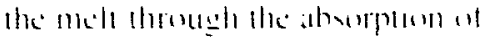

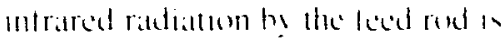

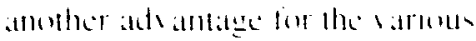
made w sicntints, ats mont at thene andes are clectric and matgmetic insulathrs.

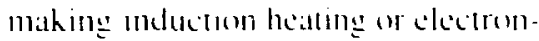
heam heating impratical. B! properly selecting the liyud-sone composition. which can he ditferent from the componition al the lecel rod. incongrucnt meltung compound can alve he sgrow h h! the thatl-rome methend.

The themal imatge lurmate is

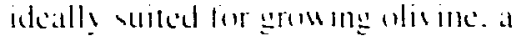

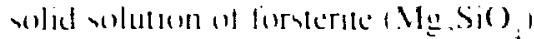

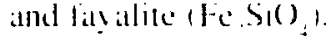

Linderianding the electrical conductisily. diffusion. and deformation propertices ol wisine help us determine conditions in the carth i upper mantle. of w hich olis ine is the major mineralogical constituent. Although geverphysical measurements on natural olivines are ahundant, interpretation whe results is aften complicaled hy the presence of minor constitucms stlch as cobitit. mangances and niched. The limuled

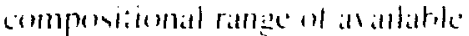

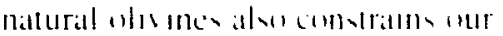
abllas lakel molek hethas for hased an hem delect

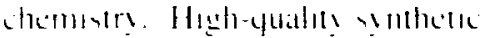
nlsine crotal at well-defored

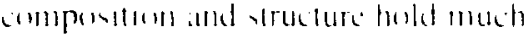

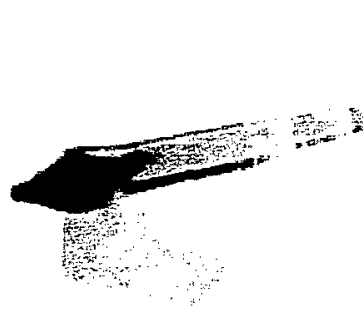

Figure? Ilisinc single cristal grow II utl a forsterite seed I right). In the average. this cr! ilal is $S \mathrm{~mm}$ in diameter and 50 $\mathrm{mm}$ in lenuth.

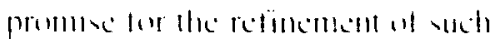
madels.

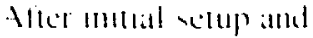

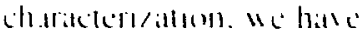

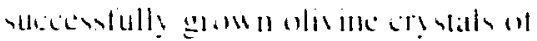
mormedialle composition. Alypical

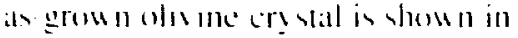
figure 2. The tramsparent lighlo-

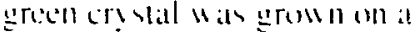

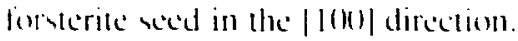

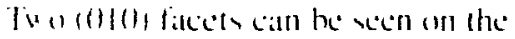

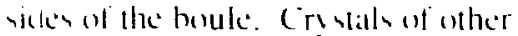
are contallom call he grom in by

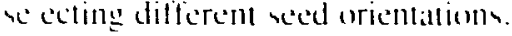
()hersallion under the uplical

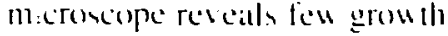
miperfections such as gas bubbles and inclusions. The ene laherallor! grom n olisine crystals hate a densit! is imperfections af $101^{+}-10^{2} / \mathrm{cm}^{2}$. all order of magnitude lower than that of nielural olivine

This gear. we hase successlull!

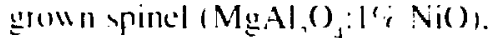
rutile (TiO):(1.5r; $\left.\mathrm{Cr},()_{1}\right)$. and fi rsterite ( $\mathrm{Mg}$.Si( $)_{4}$ ) in the themal

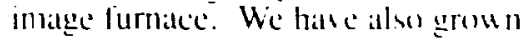
the follom ing scientificall

significant croslals:

- Magnetite ifo () t. Rakek

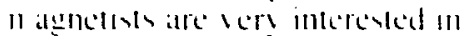

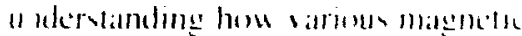

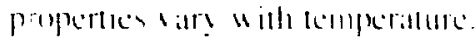
Matenctic stabilits depende crataills

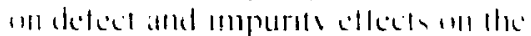

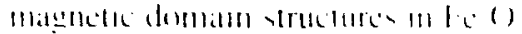

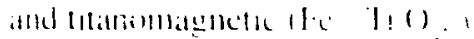

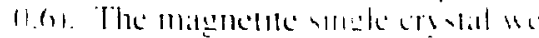

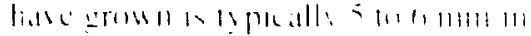

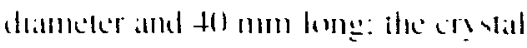

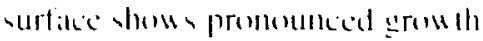
lacts.

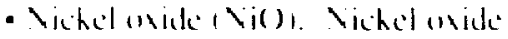

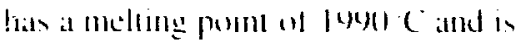
usuall! difficult warom by the melt methed hecaluse of its high realdis il! with nohle metal crucibles. We ublatiled a ringle crs tal of $\mathrm{NiO}$ in the thermal imate furtatc using a

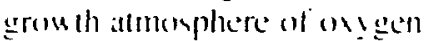
$120(1 \mathrm{~cm} / \mathrm{min})$ and argon

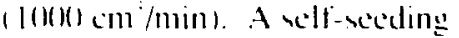
lechnicyuc is used lo ohtain the single ersial by necking down a polscrsstalline seed and cromding out the unlawarable slow-grom th oricntaltions.

- Akermanite and geinlenile Mclilite crsstals (solid solutioms of akernanile and gehlenites are needed for studies of oxyegen diffusion. Data from such studies are reyuired fir constrainung models that altempt to explain the correlated comatrattions in

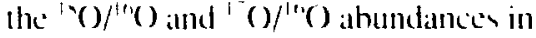
lle anholrous mincrals found in high-emperature anclusioms in meteorites. We hatse hat moderate sacess in grou inte an alkemlanilc cristal. although precipitates of a calcium-ride phatse hatse complicatled

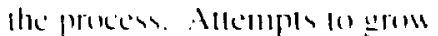

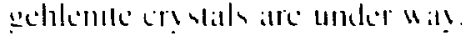


Large-Volume, HighPressure Apparatus for Geophysical Research

Principal Investigaturs: F. J. Ruerun and 1.. 1.. Dihle!
We have completed the design of a large-volume, split-cone' apparatus capable of reaching pressures as high as 250 kbar and temperatures up to $2000{ }^{\circ} \mathrm{C}$. By increasing the upper pressure limit of high-pressure, high-temperature experiments, this apparatus can extend the depth to which we can model the composition, structure, and evolution of the earth.
$\mathrm{E}$ iperimeme at moderatel! high

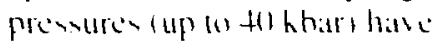
prosided an abundance of cyuilibrium and hinetic dalat that hase been uxed lo detine the composation. mineraloges. and structure of the sarth : lower crust ald upper mantle. Our concepin of magmal genesis and the evolution of the upper matntle and lomer crust are largely constrained by these data. Such experiments rely on yeenchit: and reconery al highcemperature and presure rum products lor subseyuent andalyis. Oer the past two decandes. a number of institutions. predominatuty in Jalpan. have succestully increatsed the applicable pressure range. extending the experimentill! alcessible depth to pressures approprialle to the carth is low mintle (depthe greater for $(\mathrm{hm})$. The (a)

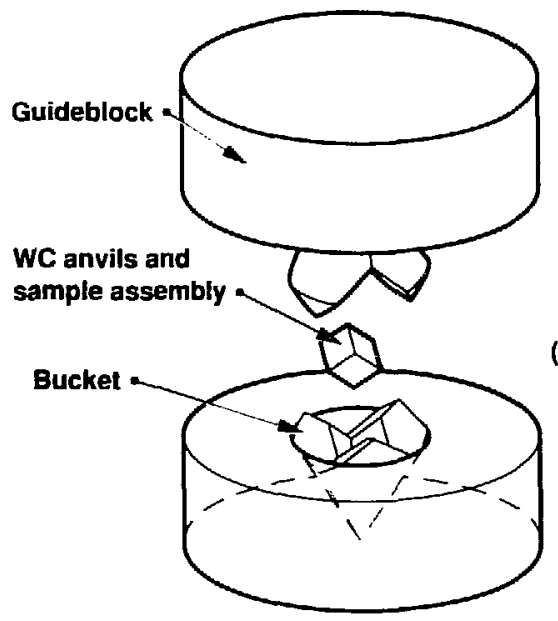

(b)
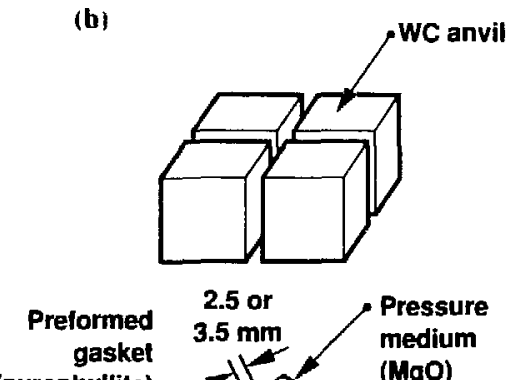

(pyrophyllite)
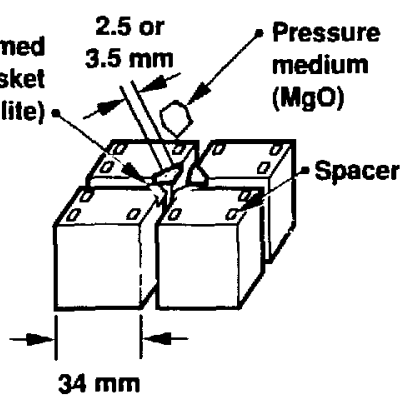

Figure I. (a) Diagram of the I.J.XI. split-cone multi-an il sliding s! utem, showing the guideblocks, buckets, and WI anvil sample assembly: (h) schematic illustration of the pressure assembly.

apparatur uxed in these experimlons are hnoun gencrically an multi-almil viding ungems IMASSI. Which comsis of al cancadding prensure davembly wi veel and lungsen carbide i W( ) ansi!s driven by al liage uniaxial press.

In FY87. He received funding (1) investigate the feasibilin! of constructing a MASS that would be compatible $w$ ith an? existing $12111-10 \mathrm{n}$ uniatial press all L.LNL while still permitling access to the press by wher apparatus. Having established that addapting our existing equipment was feasible. We recived funding lo design and fabricate the sylem in FYxs.

The MASS devign is batsed on at split-conce configuration in whi:h six conical steel anvils or buckets are confined in stecl guideblechs consisting of two interference-fit rings. This assembly fonms the tirst stage of the pressure system (Figure lat). The intersection of the upper and lower huchets forms al cubical volume containing the econd stage. knom an the pressure asembly (Figure Ib). comsinging of cight WC anvils with triangular truncations at calch corner. When placed logether. the asemhl! of the anvils has an octahedral wolume at its center that accommondate the 
prenture medtum and furnate simple ancombly the tarmate atmple anembly compunent are ly picall! matnulatuled from certmic matertals thatl ane chemicall! and stuctually sable all hish presure alld lempratures. The presule medium

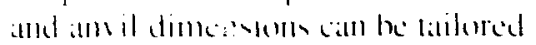
for the deredred applicatton and worhme prenure. The muncilted

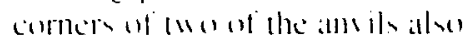
proske the electrical combets ler the

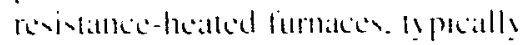
made of La(re) or maphite.

We completed the derign and drattung of platm for the MAss in December lest. We also bisiced the hegh-prenare bathoratom at the State

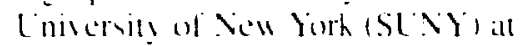
Ston! Brout of insestigatle the

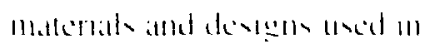
lathrallm: Hall tumate smple arembly. Anumber af lasal mathene hap bid an the L.I.VI.

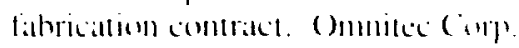
"as chusen lo tabricatle the suideblexhs. Nccuralle Matehine Engincerilly the conteal ans ih. and Kennamelat. Inc... the Wo' anvils: Ihe ceratmic malcrials reyuired fior lamale part were procurted from at mumber of Japiance ceramic manulaturer.

The syem will he arembled

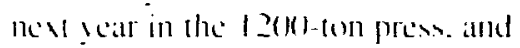
"se will hegin lo experiment with variow furnalce/sample ansemblies and the design of lumber pouersupply and lemperattire-control ynems. Becaluse the pressure transmission in the MASS depends

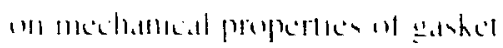

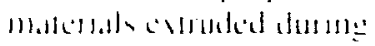

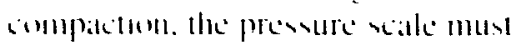
he chahlowed compiricall! for each aremhly desiens. Al rowm

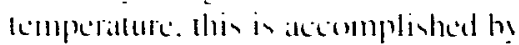
calihrating the untarial pers force atsaims plare tramsitions in sarious mitials. At higher lemperatures.

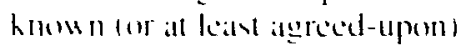
phase transitions in vilicalles can he ured. The callibrallion procedure is expected a tathe at keas hall the lincial ! call to accomplish. Me will also make periodic siste on laboralories atl SL Ni-Stom! Brouk and the I niversily al Albertit in Edmonton. Canada. la become more fimiliar with ststem operattions. 


\section{Modeling Fluid Flow and Particle Transport in Porous Media}

\author{
Principal Investigators: 1. 1. Buscheck. \\ R. B. Kinapp. J. J. Nitau, and \\ A. F. H. lompson
}

$\mathrm{T}$ he Laboraltory s research efforts in nuclear waste isolation. enhanced hydrocarbon recovery. geothermal energy. and groundwaler contamination involve the how of thuids and gatses and the transport of reactive chemicals in a variety of complex subsurtice environments. including fractured, heterogeneous porous media. Many of the relevint physicial processes are interdependent and not yet adequately understood. requiring significant advances in our conceptual and numerical models.

We are working 10 identify. modify. and develop codes capable of predicling changes in fluid composition and mineral zonation as a fluid flows through and reacts with a porous media. The reactions of

\section{We are tackling the problems involved in modeling the} hydrothermal flow and transport of reactive chemicals in porous media. This year, we developed a theory describing infiltration in partially saturated, fractured porous media. We also implemented several reactive-transport codes and began the development of a particle-based simulator for reactivetransport problems in porous media.

interest are it ieversible dissolution and precipitation. equilibrium precipitation. adsorption. ion and isotope exchange, and radioalctive decay: the transport processes of interest include advection. diffusion. and dispersion. This year, we modified a one-dimensional reactivetransport code MCCTM that has proved to be useful for simplified systems. We are continuing to refine the LLNL-developed EQ6 code for calculating water-rock interactions and to develop a general. finiteelement flow and transport code as well as a particle-based simulator for modeling reactive transport in porous media.

LLNL enhancements to the TOUGH code (Preuss. 1985). together with the development of preand postprocessors. facilitated several modeling studies in FY88. including an investigation of infiltration in partially saturated, fractured porous media. The system was modeled as a semi-infinite set of parallel vertical fractures. We found that the movement of the infiltration front $\mathrm{i}$ is governed by the interaction of gravity-dominated tlow in the fractures and by capillary imbibitiondominated flow in the matrix. Figure I shows the liquid saturation distribution around a $50-\mu \mathrm{m}$ fracture two days into the infiltration event. We conducted a parameter sensitivity study to identify fundamental relationships among various fracture and matrix propertics. In particular.

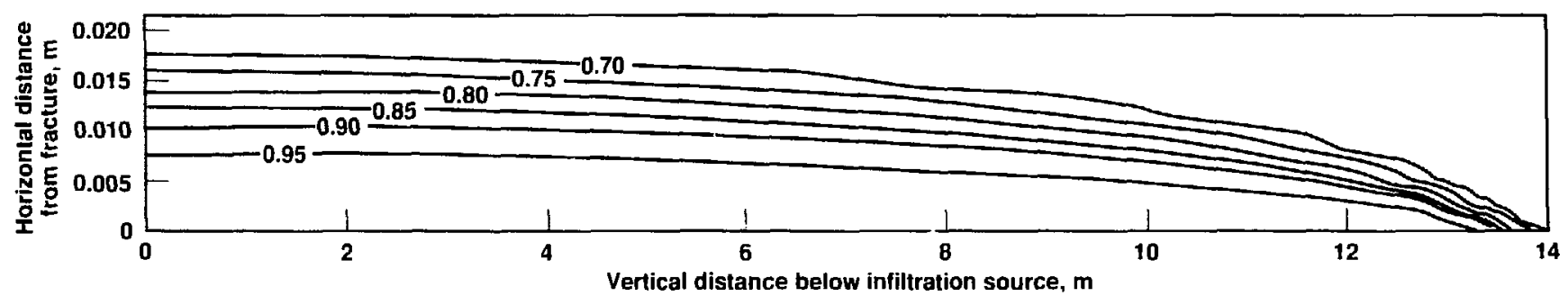

Figure 1. Liquid saturation distribution around a $50-\mu \mathrm{m}$ fracture two days into the infiltration event. Contour values represent liquid saturation: initial saturation was 0.65 . (To distinguish the contours, the distances on the $y$ axis are exaggerated by a factor of $1+3$ relative to the $x$ axis. 1 
"ce found that lor noninterlering fractures. the depth wo which the infiltrating fluid penetrates the fracture varies as the one-half power of time $\left(t^{1:-}\right)$ for sufficiently large times.

Starting with the clatsis of problems addressed in the modeling study. We derived astimptotic expansions for a range of tracture inclinattions. fracture spacings. and boundary conditions at the fracture entrance. A numerical solution to the integro-differential equation wals also derived for all cases. Depending on the boundary conditions. the movement of the infiltration front can be shown to experience three to five distine flow regines characterized by physically interpretable time scales.

We initiated work on several reactive-transport codes during FY88. We implemented the onedimensional code MCCTM (Lichtner. 1985) on LLNL computers and modified it to handle more general reactions and to be more computationally efficient in treating reaction fronts. LLNL's EQ6 code has been extensively used in modeling the reaction path of spatially static water-rock interactions. This year. we developed a version of this code (MPEQ6) to simulate one-dimensional. highPeclet-number reactive transport in a Lagrangian reference frame. Modifications include the incorporation of stationary-state theory. Reaction fronts that develop in natural systems move at a slow rate relative to the transport and reaction rates. Steady-state concentration profiles develop upstream from a reaction fromt. and precipitation and dissolution rates can be linearly extrapolated for the duration of the stationary state (typically $10^{+}$years). Thus, we can model these systems with a time step of comparable magnitude. greatly alceelerating our computations.

We are also developing al particle-based simulator for general problems of reactive transport in porous media. This simulator is an extension of an earlier particletracking solute transport code used to study the dispersion of contaminamt plumes in a spatially heterogeneous flow tield. Our extended model represents the malss of one or more aqueous chemical components as a large collection of particles, in much the same way as is done in particlebased plasma-dynamics simulators (Tompson and Dougherty. 1988: Tompson et al.. 1987). Particles are moved in space swer discrete time increments by advective, diffusive. and dispersive forces. Particles can also be selectively removed or added after each time step 10 accommodits the loss or gain of component mass due to chemical reactions. Particlebased transport models can be exiremely efficient in large threedimensional problems. particularly those involving multiple components. Such models are well suited to parallel computer architectures. allowing for even further increases in computational efficiency.

In FY89, we will continue to develop our general, finite-element flow and transport code. We plan specifically to configure this code for problems in nuclear wasle isolation and groundwalter contamination. In addition. we will continue our analysis of infültraltion in partially siturated. fractured porous media by addressing more complex fracture geometries and boundary conditions. We also plan to apply MPEQ6 and TOUGH to hypothetical nuclearwaste repository environments. We will continue our work on a geochemical reaction module for the particle-based simulator. and we will begin to develop a specialized reactive-transport simulator for fractured porous media.

\section{References}

Buschech. T. A.. and J. J. Vildo 1487 ,

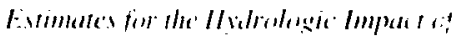
Drilling Hater on Conc Sample's Tahe'll

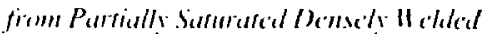
Tuff. Lawrence Livenmor: National Lahoratory. Report l/CID-21 24)4.

Lichtmer. P. C. 119851 . "Comtinuum Mokdel for Simultaneous Chemical Reactions and Mats Transport in Hydrothermitl Systems." Geochim. Cosmorhim. dita 49.779-801.

Preuss. K. (1485). TOlCiH Liser'x (indele. Law rence Berkeley Lahoralory. Berheley. C.A. Report L.BL-20)7(1).

Tompum. A.F. B.. E. (i. Vomworis, and L. W. Gelhar (1987). Numerneal Simulation of Sollue Tramspert in Remdem/s

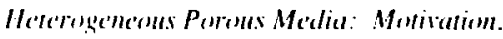

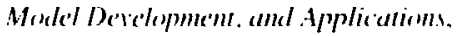
Law rence Livennore Nattional L Laboratory. Repor lICID-21 287.

Tumpsum. A. F. B.. and D. E. Dengherl! (1988). "On the Lise of Particle Traching Methods of Solute Transpon in Porous Media.. in Computational Metherls in H'arer Resmurces. M. Celia e't al.. Eds. (Elsevier. New York. NY). 


\section{Measuring $\mathrm{pH}$ in Concentrated Electrolytes}

Principal Investigators: K. (i. Knauss. J. Bennett. T. J. Woler. . J. Harrar, and

K. J. Jackson

$\mathrm{N}$ o method currenty exists for directly measuring $\mathrm{pH}$ in brines. Although $\mathrm{pH}$ maly be estimated indirectly by titration. direct measurement using National Bureatu of Standards (NBS) conventional or modified procedures is hindered by both theoretical and experimental limitations. If established. a method for direct measurement would henefit energy programs. programs in nuclear waste isolation. and programs in chemistry and materials science that investigate the corrosion of materials in brines.

Our objective wats to evaluate a proposed operational definition of measured $\mathrm{pH}$ based on high-ionicstrength standards. We used rwo pH
We have demonstrated the feasibility of a new in-situ method for determining the hydrogen ion activity in high-ionicstrength solutions. The results suggest that our proposed operational definition of the measured $\mathrm{pH}$ based on highionic-strength standard solutions may be applicable in a manner roughly analogous to the IUPAC's recommended definition of $\mathrm{pH}$ in dilute solutions. scales: the NBS scate, intended for dilute solutions. and a so-called "rational" scale. which assumes that the hydrogen activity coeflicient is 1 and which is more suitable for work in concentrated solutions. We measured the potential difference at $25^{\circ} \mathrm{C}$ between an $\mathrm{H}^{+}$ion-specific electrode (ISE) and both a CI ISE and a $\mathrm{Br}$ ISE in a series of aqueous solutions designed to investigate:

- Nernstian behavior (using Nernst's Law for calculating potential) over a wide range of ionic strength.

- Potential glass electrode/cation interference from $\mathrm{Na}^{+}$and $\mathrm{K}^{+}$.

- Response $10 \mathrm{H}^{+}$at both low $(\mathrm{pH} 2)$ and high $(\mathrm{pH} \mathrm{12)} \mathrm{rational} \mathrm{pH}$. - Interchangeability of the $\mathrm{HCl}$ and
Table 1. Caiculated composition of standard solutions.

$\begin{array}{llcl}\text { Electrolyte } & \begin{array}{l}\text { Molal } \\ \text { concentration }\end{array} & \text { pH } & \begin{array}{l}\text { Adjusted by } \\ \text { calculation to fix pH }\end{array} \\ \mathbf{N a C} & 0.01-4.0 & 2 & \mathrm{HCl} \\ \mathbf{K C l} & 0.01-3.0 & 2 & \mathrm{HCl} \\ \mathbf{K B r} & 0.01-3.0 & 2 & \mathrm{HCl} \\ \mathbf{N a C l} & 0.01-4.0 & 12 & \mathrm{NaOH} \\ \mathbf{K C l} & 0.01-3.0 & 12 & \mathrm{KOH} \\ \mathbf{K B r} & 0.01-2.0 & 12 & \mathrm{KOH}\end{array}$

$\mathrm{HBr}$ couples as a basis for the proposed method.

We used the Pitzer's equations option in the EQ3NR geochemical modeling code (Woler: 1983) to calculate the composition of 84 standard solutions used in six series of experiments. Table I identities the compositional range and $\mathrm{pH}$ spanned by the calculated standard solutions.

In addition to measuring the potential between the $\mathrm{HCl}$ and $\mathrm{HBr}$ couples. we measured the $\mathrm{NBS} \mathrm{pH}$ in all solutions. Our results demonstrate that our proposed ISE method, which is free of liquid-junction problems. works very well. whereas the conventional NBS method fails in all cases above ionic strength of approximatcly $(0.7$. The response of the ISE couples is essentially Nernstian in all cases. and the goodness of tit is 0.999 or better. The electrode couples respond linearly to $\mathrm{H}^{+}$at both high and low $\mathrm{pH}$ activity over an extreme range in stoichiometric ionic strength.

\footnotetext{
Keference

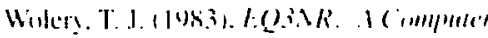

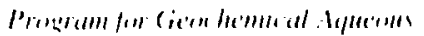

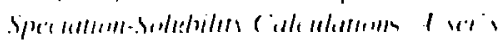

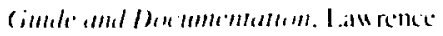

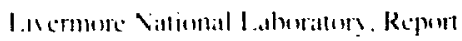

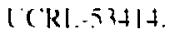




\section{In-Situ Downhole Measurements}

Principal Investigaturs: S. Ml. Angel. H. M. Buettner, and P. W. Kasameyer

To understand the in-situ conditions in the earth's crust, we must be able to determine the properties of fluids from deep boreholes without changing their chemical state. We are developing candidate optical chemical sensors (optrodes) for an optical-fiber system to measure fluid properties and composition in hot, corrosive wells.

demonsirated several candidale $\mathrm{pH}$ and Eh optrode materials based on an inert polymer electrolyte (Nalion). Although the polymer is stable only to about 25()$^{\circ} \mathrm{C}$, it immobilizes many $\mathrm{pH}$ - and Eh-sensitive fluorescent and highly colored dopants. The $\mathrm{pH}$ optrode demonstrates a reversible response over a $\mathrm{pH}$ range of 1.51010 and has been shown to be stable up to $180^{\circ} \mathrm{C}$. Measurements can be made either hy absorption or fluorescence.

We checked the $\mathrm{pH}$ responses of the doped polymer films by immersing the films in a variely of buffered solutions for at least 15 minutes and then measuring the absorption spectra. We determined stability hy heating the films in $180^{\circ} \mathrm{C}$ water for 24 hours. The

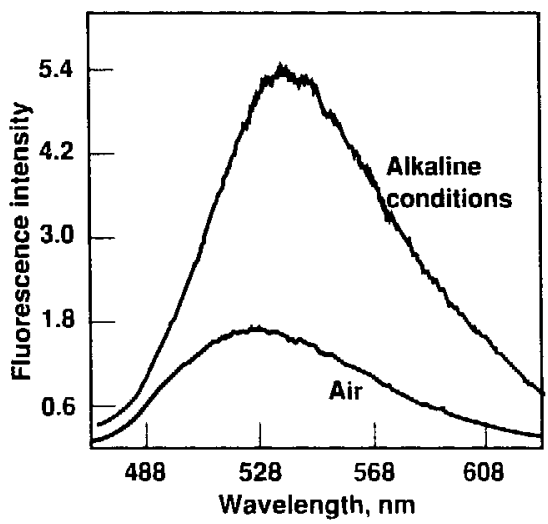

Figure I. Fluorescence response of a Vafion-based, high-temperature pH optrode in air and under alkaline conditions lexposed to $\mathrm{NH}_{4}(\mathrm{H}$ rapor). thuorescence response was mealsured at room lemperalure using a short optical fiber. Figure 1 shows the fluorescence intensity of a Nafionbased $\mathrm{pH}$ optrode upon exposure to $\mathrm{NH}_{4} \mathrm{OH}$ vapor compared to the tluorescence response in air. These pH optrodes are also sensitive to Eh changes in solution. A number of stable dopults show reversible Eh response in the Nation films at positive potentials.

Betore this measurement approach can be applied in the field. specific optrode designs must be carrefully calibrated in a number of solutions to deternine whether they are sensitive to more than one property. In addition, our proposed cable termination and protection methods must be tested with a prototype measurement system that can be taken to the field. The system will also have to be operaled in wells where adverse conditions exist to demonstrate that optical-fiber systems can indeed provide useful iit-sittl measurements al depth.

\section{References}

Angel. S. M. (1487). “Development of Fiher-Optics Sensors for Temperalure Measurement and Chemical Analysis in (ieonhermal Wells." Tramnaritum.

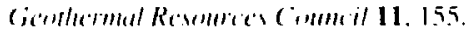

Anecl. S. M.. D. (i. Garvis. S. K. Shama. and A. Sehiones, "Irichl Applications al" Fiber-(Opuic Semors: 1. Templerature Meaburements in a Cieothermal Well."

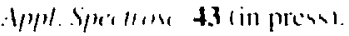




\section{Seismological and Geochemical Studies in Northern California}

\author{
Principal Investigators: (i. Zandt and \\ W. E. Glassley
}

$\mathrm{T}$ he relative motions of three tectonic plates al the Mendocino Triple Junction in northern Califomia (at the juncture of the San Andreas Fault, the Mendocino Fracture Zone. and the Gorda Subduction Zone; see Figure 1 ) have created an unusual zone of interaction between the crust and upper mantle. As il geometric consequence of the relative plate motions in this region, the Califomia coastal area southeast of the Triple Junction is progressively exposed to hot, upwelling mantle. This upwelling. together with its interaction with the overlying continental crust. is ultimately responsible for several Coast Range volcanic fields. for the PlioPleistocene uplift of the Coast Range. and for ongoing seismicity. crustal deformation, and the evolution of

We are combining geochemical and seismological methods to study a unique tectonic regime in northern California where crust and upper mantle interactions are currently generating an active volcanic field with an associated geothermal area. Knowledge about the way heat, fluids, and magma are transported through the continental crust has important implications for both basic and applied science.

ore bodies and geothermill liclds in coatstal northern Calitornia.

We are using seismological and geochemical techniques in this unique tectonic setting to develop and test competing hypotheses on crust-mantle interactions and crustal accretion. We have completed reconnaissance field work at the Clear Lake volcanic field, where we collected a suite of crustal xenoliths and deployed a portable broadband seismograph. Field evidence indicates that the xenoliths are from different eruptive phases. implying that different segments of the crust were sampled. The xenoliths appear to form two distinctive suites, one from a lower crustal suite of gneisses and schists and one from a more matic suite that may be related to earlier phases of magmatic

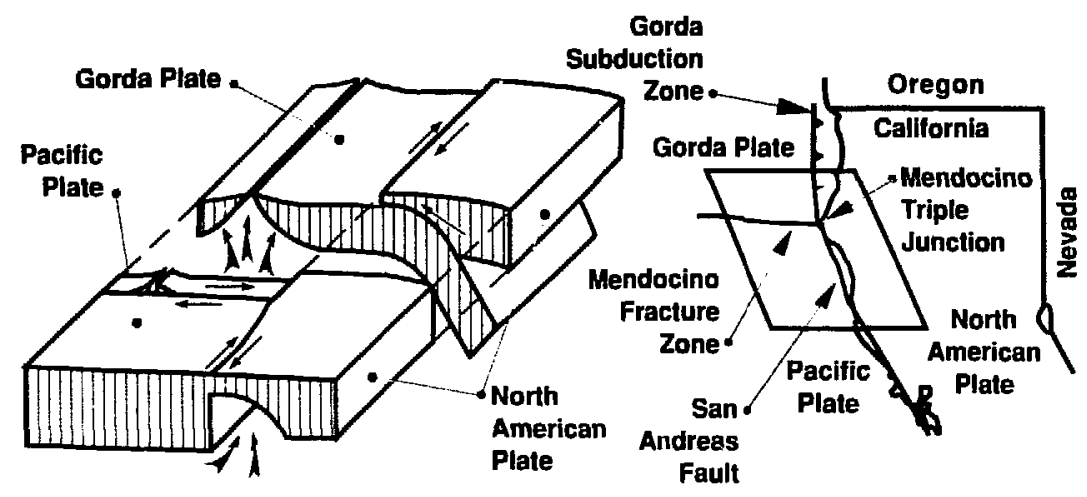

Figure 1. Tectonic plate interactions near Mendocino Triple Junction in northern California. Thin arrows indicate relative plate motions: thick arrows indicate upwelling of "warm" mantle. intrusions. Preliminary results from several gneissic xenoliths indicate that these rocks experienced a complex recrystallization history that is related. at least in part. to decompression. By reaction textures. we recorded recrystallization events in the samples all $18-3.5 \mathrm{~km}$ (lower crust) and at $12-1.5 \mathrm{~km}$ (mid-crustal depths).

To reconstruct the geometry and evolution of the San Andreas Fault zone (Furlong at al.. 1988). we mapped crustal and upper mantle heterogeneity by combining teleseismic imaging techniques with thermal-mechanical modeling studies. The results indicate that the surface trace of the fault is offset from a deeper plate boundary parallel to the surface trace but approximately $50 \mathrm{~km}$ to the northeast. The deeper boundary appears to form the southwestern boundary of a zone of "warm" mantle and to control the location of young volcanism at Clear Lake. Teleseismic earthquakes recorded at our broadband station at Clear Lake have anomalously large amplitudes on the horizontal components, similar to telescisms recorded in Long Valley Caldera. supporting the idea that the observed complexity may be due to magmatic structures associated with the Clear Lake magma chamber.

\section{Reference}

Furlong. K. P. W. D. Hugen. and (i. Zande

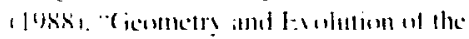

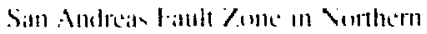

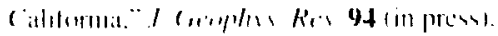




\section{Incorporating Equation-of-State Models in DYNA2D}

\author{
Principal Investigator: 1.. 1. Gilenn
}

$\mathrm{V}$ alid equations of statc (EOS) for rocks of athitrars comsistenc! are recpuired for numerical simulitions of underesound nuclear explowions. Last year. We incorporaled an EOS model into the DY NA2D code that hats srealler tlexibility and accuraty than the Butkovict roch gas model used in the TENSOR colle (which assumes that all rocks are combinations exclusively of silicatte. catrbonate. Water. and air). The Butkovich pressure-densily gals tables thal are generaled are also very sparse, so that large and potentially inaccurate interpolations and extrapolations are required to obtain pressure and energy datia. Furthermore. the absence of energy considerations in the Butkorich gas tables is thermodynamically inconsistent.

The DYNA2D model hals no restriclions on rock composition. however. and it yields a pressuredensity-energy table that is thermodynamically consistent and dense enough to allow reliahle interpolations. In developing an EOS table for an arbitrary rock composition. we first generalte pressure and energy isotherms using the HQEOS code. These isotherms are then combined to obtain a pressure-densily-energy table. the required form of the EOS for DYNA2D. No more than two daty are unually required tor this procen.

Wi alw improsed the TEXSOR mixture model " ithin DYX. Historically. the TEXSOR corke addresed the aporization on

\section{We improved our capability to numerically simulate}

\section{underground nuclear explosions by incorporating a more} flexible and accurate equation-of-state (EOS) model into the DYNA2D code. These improved simulations are essential for ensuring complete containment of underground nuclear tests. momporous rechs by mixing the Hugoniot with redeane addiaball tahles (which spanned only the gats stalles of the materiall and used the ration of peak pressure 10 vaporizallion pressure as a parameler to interpolitle linearly belween the Husenion and the gais phase. In our addaptation of the TENSOR mudel. we replaced the releatse adiatals with the HQEOS tables.

The effect of mixing the Hugonion with the HQEOS hats been evaluated. Figure I hows SiO, vaporization response as pressuretime histories and energy-densily paths, using HQEOS lables allone and using the Hugoniot mixed with the HQEOS tables. Each plot shows two identical pressurization-release curves, indicating that mixing the
Hugnniof with the HQEOS tables does nol aller the $S i()$, vaporization response oblaimed hy using the HQEOS tablen alone. Wilh a thresphatse EOS now quickly avalilable for rochs of arbitrary composition, it is no longer necessary to mix the Hugonion with a gats lable in simulating the vaporization of nonporous rocks, as was previously done in TENSOR. The same level of accuracy is provided in less computer time:

Reforence

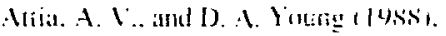

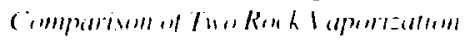

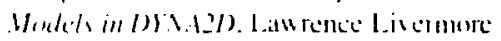

Valliomal Lathorators. Preprint 1 ckl.-

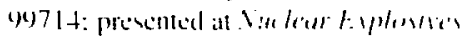

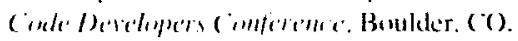

()elober $11-14$.
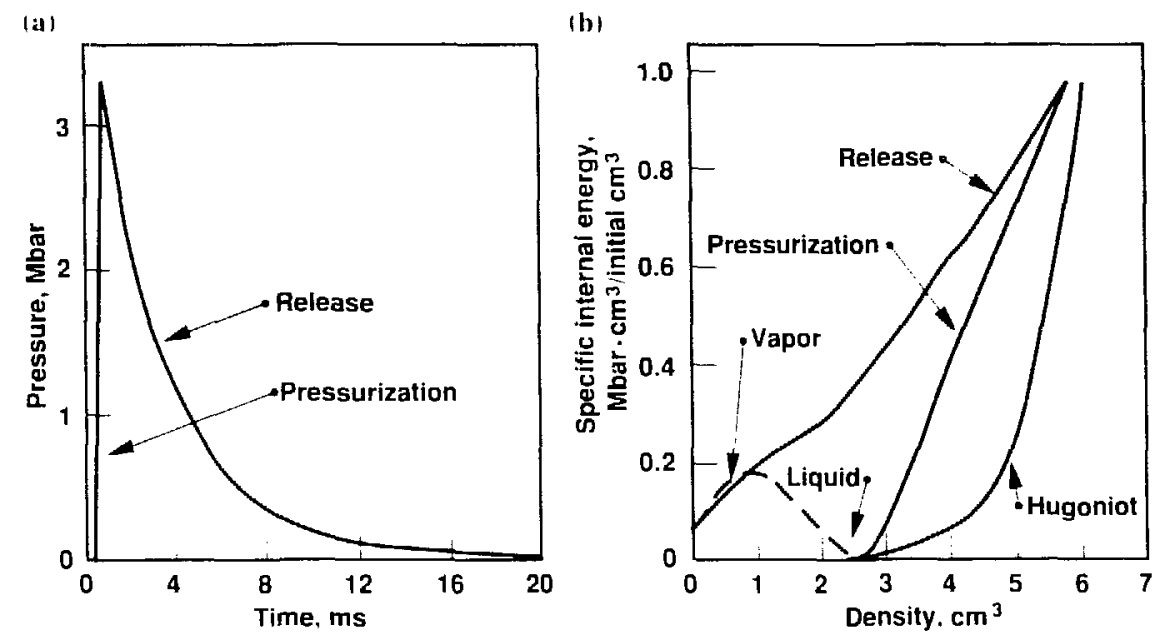

Figure 1. SiO, saporization response, shown as (al pressure-time histories and (b) energs-densit! paths. Pressurigation-release curve in each plot represents two identical curves. calculations using HQSE(OS alone and using both the Hugonion and H(2)ES. 


\section{Engineering}

F. A. Lafranchi
An important mission of the Engineering Department is to identify and develop the emerging technologies that will he needed to meet the future requirements of LLNL programs. Results of the research projects funded by the IR\&D Program in FY8\& will tind immediate application in the Laboratory"s weapons. lalser, heam research. and precision engineering programs. In addition, since principal investigators often collaborate with scientists at universities. industrial technology centers, and other laboratories. these IR\&D projects markedly increase and enhance the spectrum of engineering resources available to LLNL.

The engineering projects lunded in FY88 address the need to understand the behavior of materials. In one project. we investigated the breakdown of surfaces subjected to electric and electromagnetic fields and sought to understand the basic physical properties of materials that make them susceptible to surface breakdown. In FY88, we began the development of an experimentally validated model of such surfaces with the study of solid-plasma transitions and bounded plasmas. Our goal is to develop a validated calculational model that can be used to predict surface behavior under large transient fields. This understanding, coupled with a validated model. will have a significant effect on all pulsed-power and high-power-microwave research.

In another project, we studied the ductile grinding of brittle materials. concentrating on the material removal process. The goal of this research is to be able to fabricate components with high precision and excellent surface finish but without subsurface defects. This project requires the integration of theory and experiment as we work to develop a numerical model of the material properties that are dependent on chemical composition and material temperature. This model will help us to understand the transition between ductile and brittle grinding of a material. We have tested the hypothesis that ductile grinding can occur in the region between the yield and fracture envelopes of the material in question. So far, we have only collected preliminary datal and further analysis is required. Once we are satisfied with the validity of our theory, we will need to develop a grinding capability to determine if our theory can be achieved experimentally. Success in this project will have a major impact on the Laboratory"s weapons and laser research programs.

The Engineering Department received $\$ 498,000$ in IR\&D funds in FY88. 


\section{Surface Breakdown Induced by Large Transient Fields}

Principal Inventigators: R. Ziolkumsh. s. Kau, I. Friedman. and F. Mlarse:

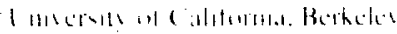

We are de'eloping experime ntally validated, realistic modeds of the behavior of surfaces when they are subjected to large transient electivic, magnetic, or electromagnetic fields. These models are needed because breakdow'n under such fields is one of the main limiters of pulsed-power and high-powe; microwave systems.
$P$ mbed-pomertand high-pow micromate sources are uned in several importanl Lahoralors proserams, and a mumber al new microwates laser. acceleralor. and simulator concepts are heing investigated. A severe obsale lo realising the full ponential of these concepts is the problem of breakdown of the componem surfaces. The avaliable intormation on lle behavior of surfices ander larese tratlsichl clectric. matancic. and/or electromatencelic field is empiricalls hased and anl mimimall! understool. and existing moxlsh at surfice breakdow nare crude and batsed on gross dy namical etlect. A thorough insestigation of fickd emission and vacuum breakdown and dielectric/insulator breakdown would greatly increasio the available database. Several Laboratory and national programs have a need. hoth current and long-term. for the information that would be gained.

The goal of this project is 10 investigate, hoth theoretically (through analysis and computations) and experimentally: the breakdown ol surfaces induced by large transicul electrical. mitgnetic. and/or electromagnedic fields. The end product of this work will be at nunerical model of surfice breahdown with predictive catpabilities and the experimental clata lo conlirmiti.
In fisti, ac vadied ulid. plasmat phatse ramsitions allat hermekel platmas using sceral approathes. There included nom-1.7t: a monlocal thermotynamic eyuilibrium). NL(io) (momlincatr geomedrical eptices, atmel aldathced PIC (particle-in-cell) calleulations, an well ats houmeled plasma moxkling and muliscalc methods. ()ur ohjective was lo exlemel current methods and molels lo more realivic st sems than has presiousls heell posible.

Prowers was manke in several arcats. We implemented a 1 arialion of the Hunter-keller No (io) alpproath 1 Hunler and keller. 1983) lo dencrihe the interaction of intense microm alse ficlds with nonlinear media. We also coinstructed a model of the response ol a compatel loroiclal plasma to an intense microwave pulse. The plasmat model hals a quadralic nomlinearity thatl is characteristic of many other bounded plasma systems. Combining this model with the NLGO approach. we have hegun fo sludy the heating of eompact lorroblat platsmas (Morse and Kinlhom shi. (exs).

Alse for houmded plasmals. We dercloped at new implicit methol fin

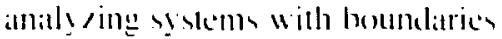
(Parker : 11. 1987). A simple particle injection/absomplim moxict "1s included that is comsisent with the implicil patticke allatles. An implicil molide

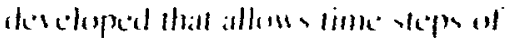

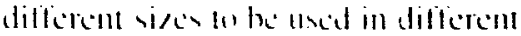
patrleat the plasma ifricdman ed al.

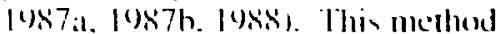
makes me calculation comsiderathly more eflicicoll. Quicscent portiom at the plasma can be trealled wilh at coarser lince resolution and turhulent pontions wilh a tiner resolution. allow ing compulational effort 10 ho yemi nnly where it is neceled. Work is under wals lo merge lle houmbel implicit and mullixcale implicil methods.

Progeress is alse being made in the development at mulliscalc methods that tars the spatlat gerid as well ats the lime sep sise. Although we have demonstrated the polemial effectiveness of the mullisiale implicil PlC melhol. "Le hate also ickentified a number of difticultic:s will the origian! algaribum. In particular, the particle mosider hat a number of unexpected ensilivitic:

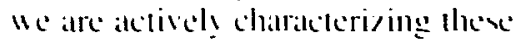
in order to alleviate or sliminate them.

In Frise. He will clancly couple our theoretical work 1 ith experimental effents. Specillually. wc will foxes on the breathelown at diclectric surfaces induced hy latege tramsichl vollages and micrumate

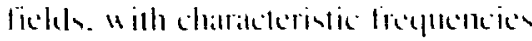


ranging from yuavi-sillic an micromats. Analyticial and numerical technicutes similar lo those needed for this work hale all _ aus becell dencloped for sidseous media

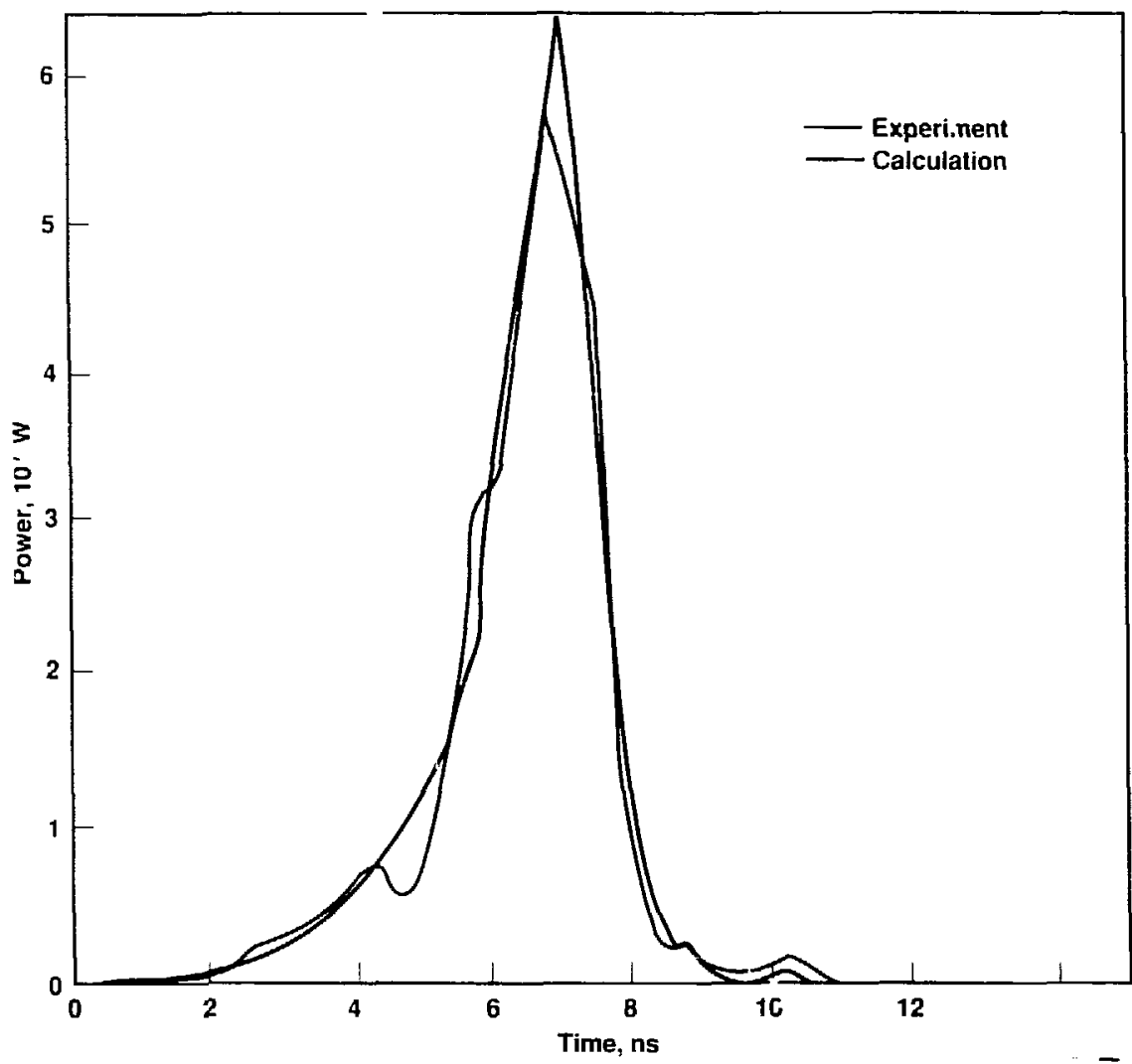

Figure 1. Breakdown of air $(300$ Torr) in a rectangular waveguide $13.34 \times 4 \times 7.1$ $\mathrm{cm}$ ) induced by a high-power microwave pulse (75 $\mathrm{MW}, 15 \mathrm{~ns}, 2.85$ ( $\mathrm{FHz}$ ). The results generated by a self-consistent, two-dimensional model based on Maxwell's equations and a fluid model of the resulting electron plasma agree very well with the experingental results. Similar modeling techniques and codes will be used in next year's studies of the initiation and evolution of breakdown on surfaces.
II ill he deviguced to provide the reyuisile itypuls isteds as rate coefficients) Io lest lle models under development. As sur modeling aipabilits develups. $11 c^{2}$ will moc (1) proseressively nore complex environments within the basic conliguralions. This combined theoretical and experimental prosaram will allow a sistemattic evaluation of lac factors that lead Io surface brealidomn.

\section{References}

Fricdman. A. S. I. Kats. C. K. Lindall. and

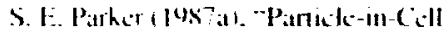

Plasma Simsulation with a 1 idk kamee of

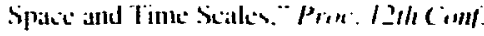
all Vimmerical Simulation al Plasma isan

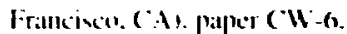

Friculnam. A. S. I. Kas. S. F Parher. and c. K. Birdatl a lesthe. "Prespects ter Multi-Siale Particile-in-Cell Simulation of

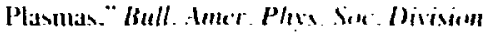

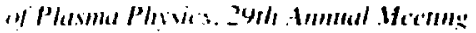
1San Dieg̣). (C).

Fricdman. A.. S. I. Ray. C. K. Birdnall. and

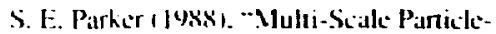
in-Cill Plasma Simulalion: Timestep Control and Some Tents." Hatrats of

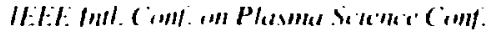
ISeatlle. NAI. P. 114

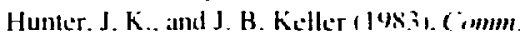
Pure t/pl Malh 36. 547-564

Morse. E. C.. and R. W. Ziolkowshi I I4Xsi. "Tramsiont Mictowate Healting of Compact Torovial Plasmas," Fusion Tirh It 13 . $1.325-1333$.

Parker, S. L.. C. K. Birdsall. A. Friedman, and S. L. Ràn. 11487 , "Direct Implicil Simulation of a Bounded Plasmo Sistem."

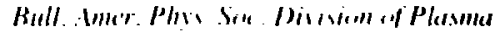

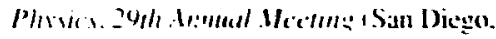
(A) 


\section{Ductile Grinding of Brittle Materials}

\author{
Principal Investigalur: K. I.. Hatedel \\ (a-Insewtigators: P. Das is and J. Framse*
}

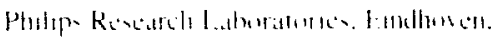
The vilherlands

$\mathrm{O}$ ur ohjectives are to undervand theorericalls the grindinge of britle malterials and ar develop at grinding process that remosw hritle material in a ductile fashion. In pursuil of these goals. we mus acyuire the capability lo perform ductile grinding for modestly sized glass and ceramic workpieces. Our efforts in FY8s have focused on developing a mechanical model for the transition from brittle to ductile material removal in precision grinding and on devising the machinery and lechniques 10 grind brittle materials.

Previous successful altempts 10 grind various britule materials in a ductile manner. both at low and high grinding speeds. indicate that mechanical properties of the malcrial. rather than chemical or thernal effects. predominantly determine the transition between ductile and brittle material removal. Thus. to improve our precision-grinding capabilities. we must develop a mechanical model (in which mechanical properties may be temperature- or chemistrydependent) for the transition from brittle to ductile behavior. Most needed is a criterion to distinguish the stress states in the matcrial that result in ductile behavior from those that result in critch initiation (britle behavior).

By reviewing the deformation and fracture patterris in glas under sharp and blunt indenters. We were

We are investigating grinding as a material removal process so that we will be able to cost-effectively fabricate workpieces made from brittle materials. Our effort involves both numerical simulation of the process and grinding experiments as we attempt to determine whether material removal occurs by crack propagation into the material or by plastic flow of the material.

able to develup such at criterion (Franse and Blatedel. I988). Shamp indenter cattse significant plastic deformation. whereas blunt indenters catlose monty elatstic deformation up to the point where cratch initiation begins. Our criterion incorporates al region in stress space within which no plastic deformattion occurs and outside of which plastic llow takes plate: the ron Mises criterion (Dicler. 1986) was chosen as an appropriate condition for platstic thow in normal glass materials. Our criterion also includes at region within which cracking oceurs and outside of which cracks initiate and propagate. Figure 1 diagrams the yield and fraclure regioms in principal sress space. We hypothesise that declile material removal ean occur between the umbrellat-shaped fracture houndary and the cylindrical yiclel houndiary.

We lested this hypothesis using analytical clastic solutions for the stress distribution under various indenters. both blunt and sharp. and found that our criterion correctly predicts the trends observed in indentation tests. The next siep will be to perform linite-elementmodeling stress analyses for particular indenters and Io corroborate experimentally the criterion for a specific sed of brittle

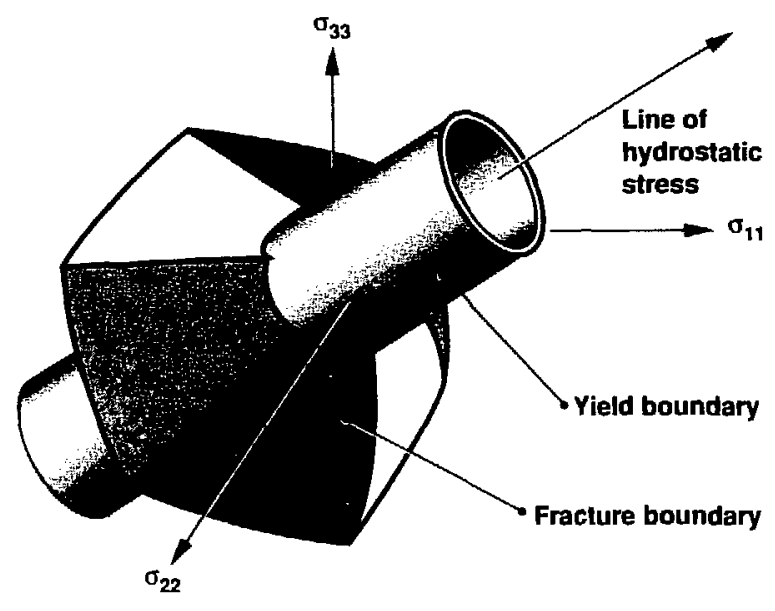

Figure 1. The three-dimensional fracture and the yield criteria in principal stress space. 


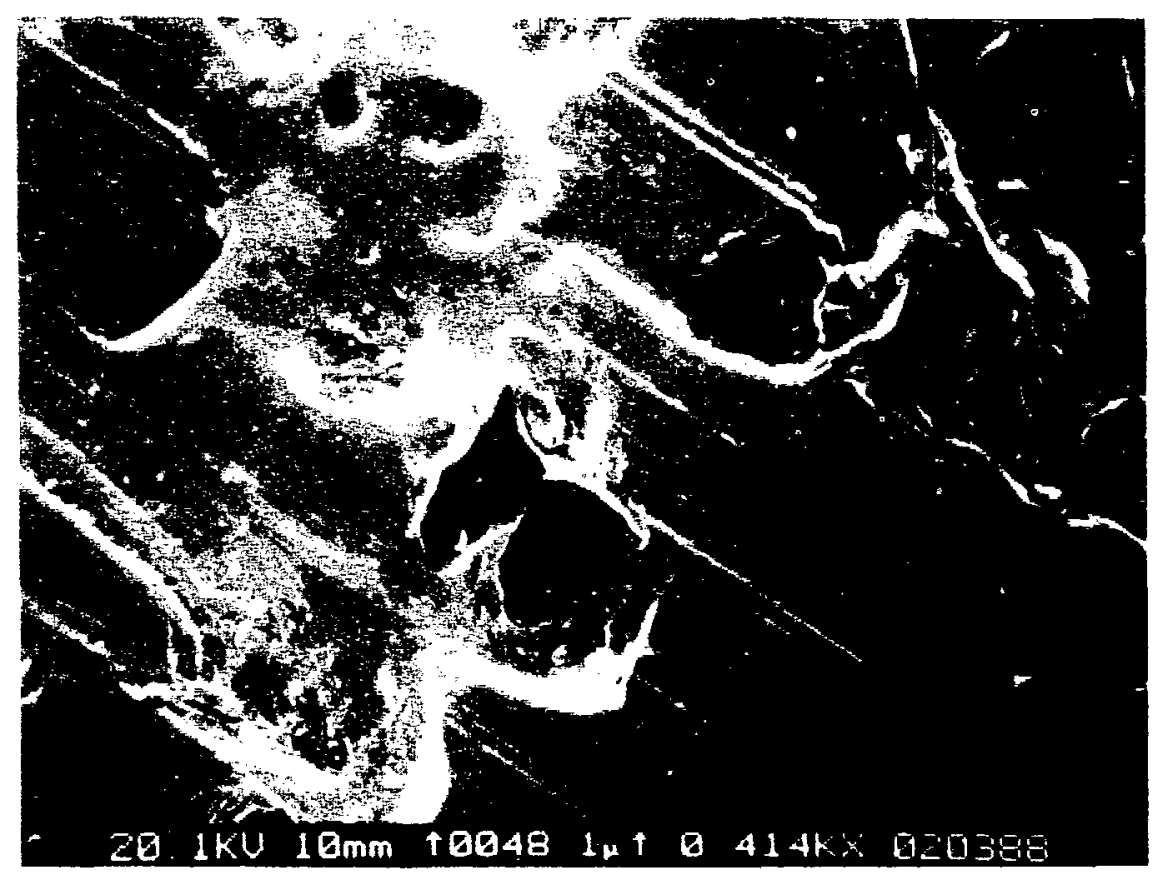

(t) side sien

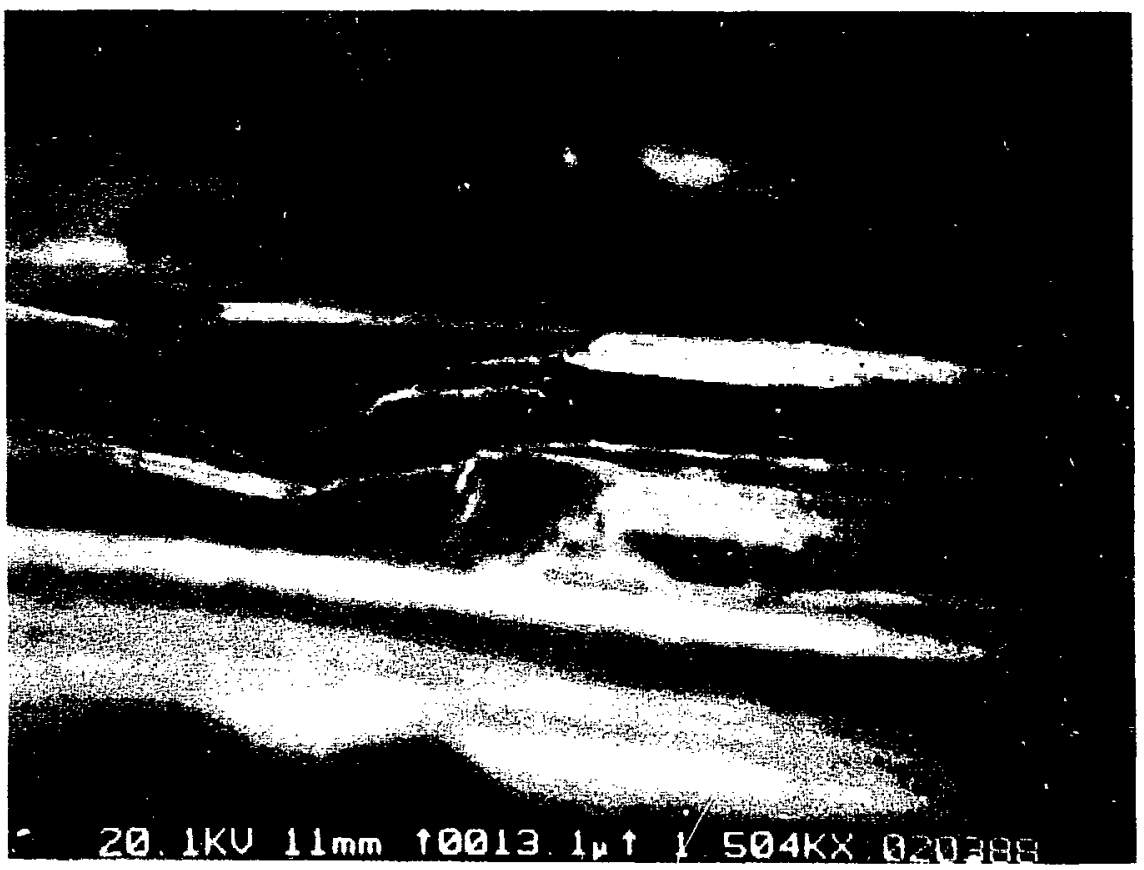

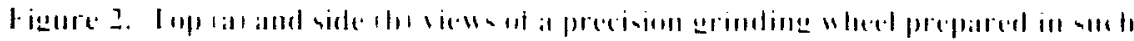

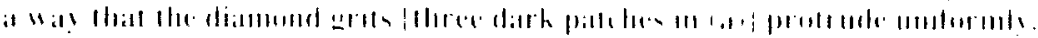

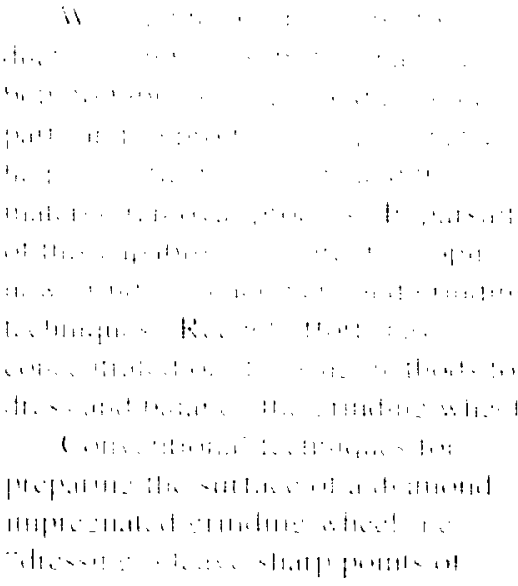

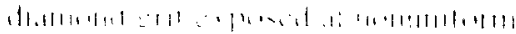

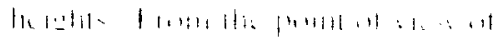

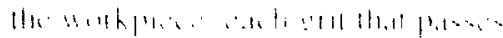

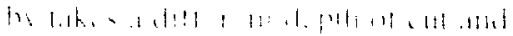

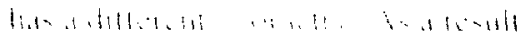

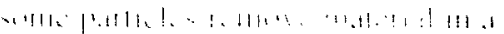

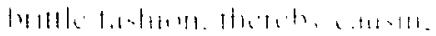

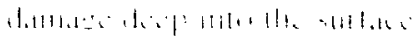

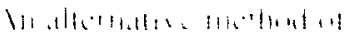

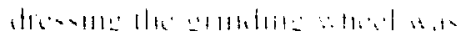

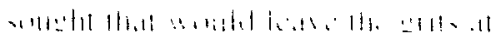

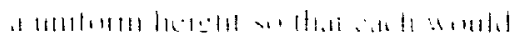

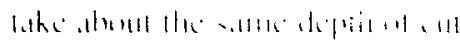

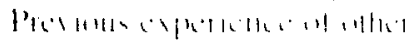

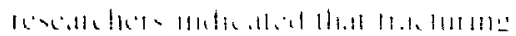

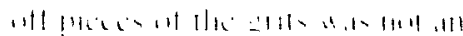

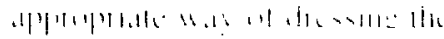

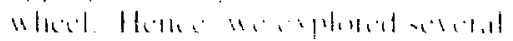

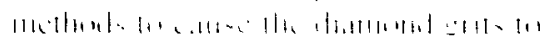

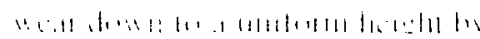

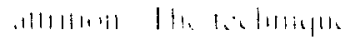

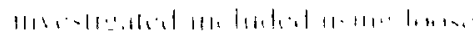
.

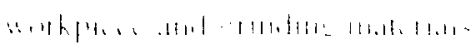

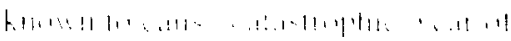

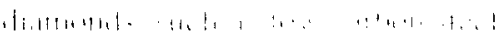

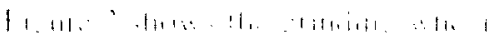

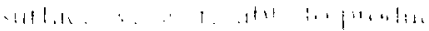

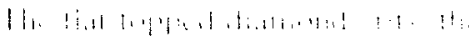

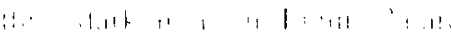




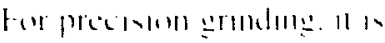

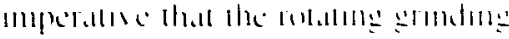

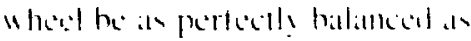

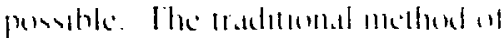

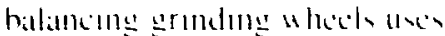
acolermencers of the vallor and therehs delcrman

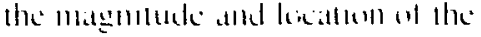
imbalatice: the methed a suatole 11 the statu is somentall compliamly monuted on the mathme. Homeder.

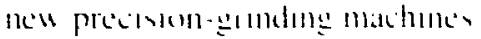
are much more riged and thus the

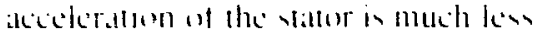

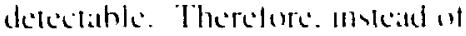
accoleromeler.

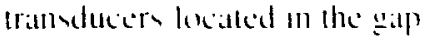

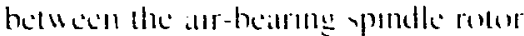

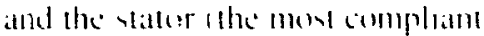

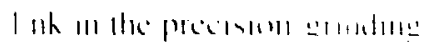

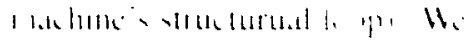

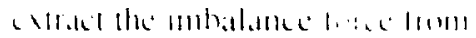

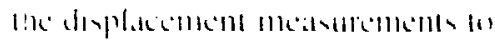

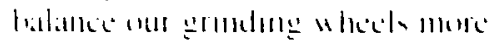

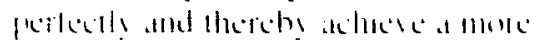

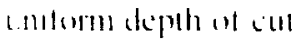

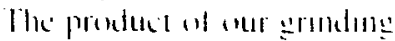

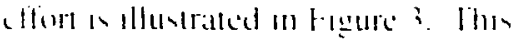

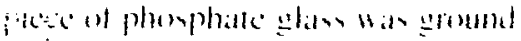

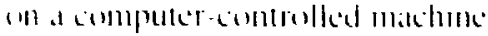

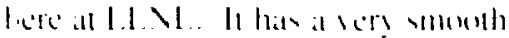

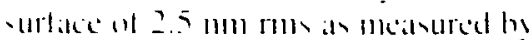

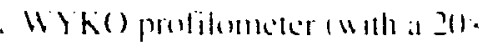

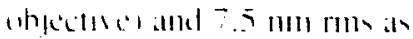

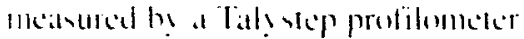

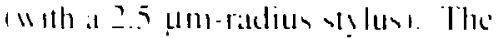
- urlace fmoth. howerer. on mo the

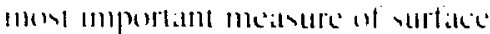

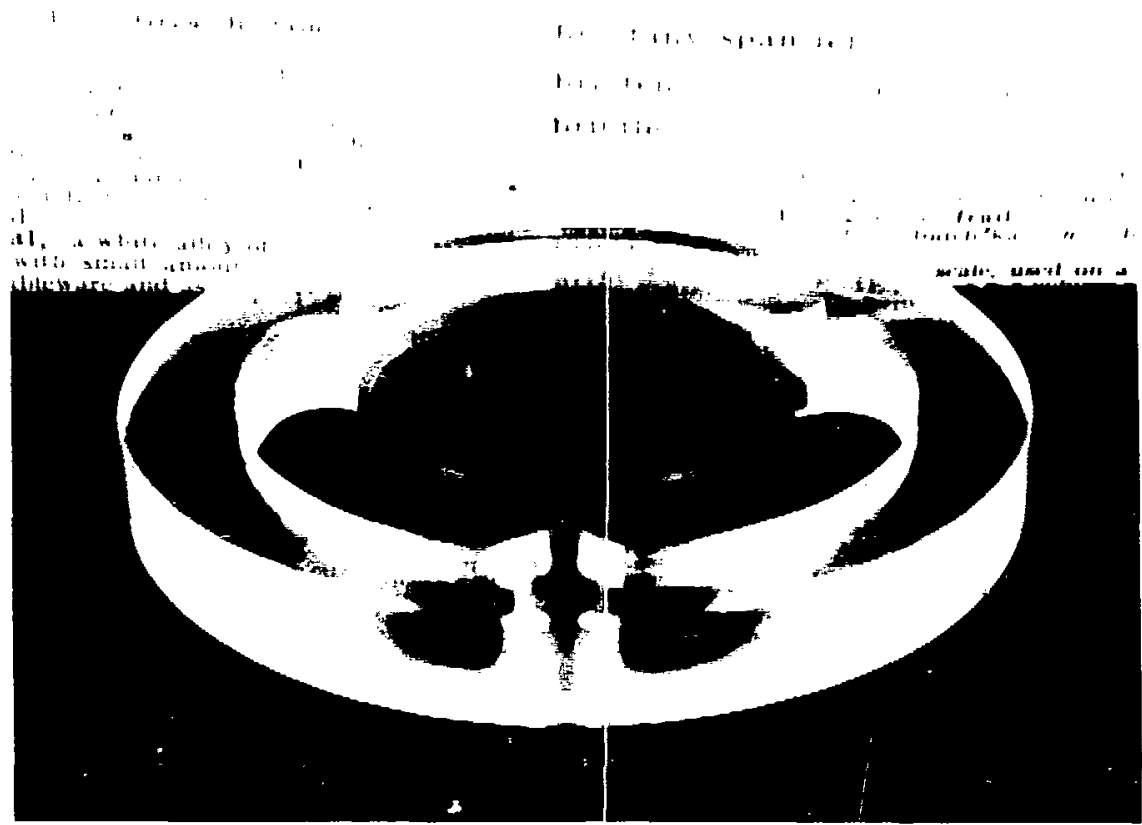

Figure 3. This 5-cm-diam phosphate-glass romponent was fabricaled using our new ductile-grinding lechniques. Its has a lers smonth surface, Ineasuring hetween 2.5 and $7.5 \mathrm{~nm} \mathrm{rms}$. depending on "he t! pe of profilometer used.

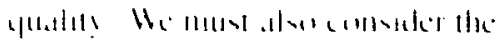

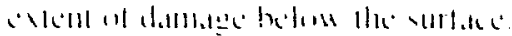

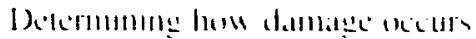

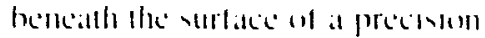

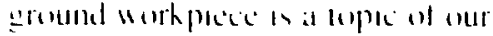

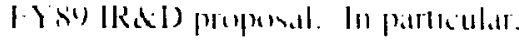
mev valt.

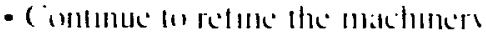

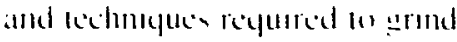
brible malterals in a duelale lashom. wath further emplatus an preparms

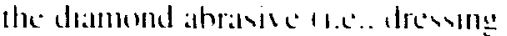
the grinding whesls

- Fialualle the surfake ground hy the mathiners and une lhe léthmyus

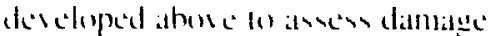
bemeals the surlate resulmestrom the grondeng procos.

- Validalle the mallerial tablure criterion developed in Flas ehroughy andentation lents.

- Evend the madeling from inala threc dimconsoms. progressing from simulatime the indentation of a vallic diamond grit into the surtate of a workpiece lo modeling a diamond grit sliding across the workpicie surface. The addition of tiding " ill give us a more realistic model of the aclual process of erinding.

\section{Keferences}

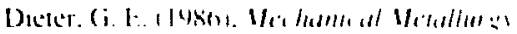

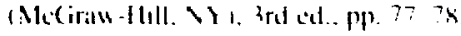

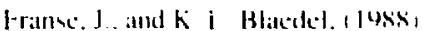

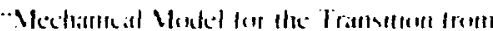

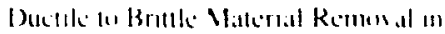

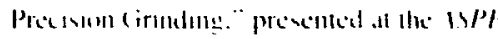

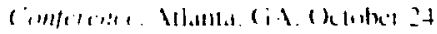




\section{Membership in the VCSL Precision Engineering Center}

Irincipal Insertigiturs: 1. F. Stuwers and f.. K. VIC lure

$\mathrm{H}$

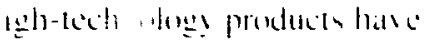

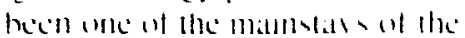
L S. batance of tritde. hull lattely there has heen a drop oll demand lor the

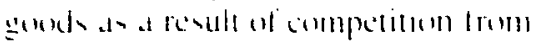

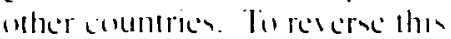
vemp. Amerkan compantic mus concentrate an developing men products. hemsing produciois! and improw inge minulacturing processes.

The Lathoratory is addelowing the need with its Precision Enginecring Program. To ategment our effors we hase hecome members of the vesl Precivon Engmecring Center. a multidivciplintary rexcarch and grildualle program established to prow de the new lechmolugher reded b! Americat high-lechmolug! mstitutions. An members. "le halle accers to and ane st the result of therr rescarch projects. man! (1) "hich parallel our precision engineering efforts at LLNL. In FYss, the Preciobun Engineering Center supported 11 major projects Idetails atre contamed in the center loss annuall report:

- Diamond lurnings of amorphous polymers. The cutting chatracteristics of polycarthomilte. Pleviglas, and poly slyrene ale heing interligilled. The surfiace culling upeed greatl! influences the temperature at the culting tool up and. correvpendlingly. the deformathen of the polymer.

- Ductile-regime lurmmen of slacon and germlanium. Acritical chup

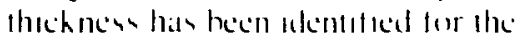

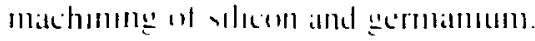

As members of the Precision Engineering Center at North Carolina State ('niversity (NCSL', Raleigh), we have access to the results of their iesearch projects, many of which are similar or related to Laboratory efforts in precision engineering.

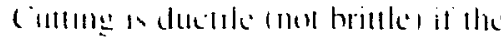
thp bichmess a mambanded belam this cratical thachnem.

- Revidual vtress m mathined surlikes. A mulcro-Raman

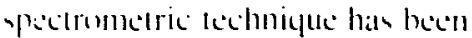
develuped on measure directls the

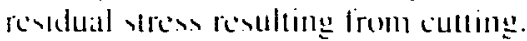
- Modeling dic nedal cutling procés. A traclure-mechanice model wheing incorporalted into a cighternode. iscparametric. singularits clement do permit simulation of the singularit! at the tip at a cutting toul during mokeling of the metal cuttitig process.

- Ds namice of simengle-porina diamomal cutting. The cutting foul lorecs associaled w ilh diamond turning are heing meatsured to aid in the deselopment of a numerical model for the servo control syitem of diamond-lurning machines.

- Machining of asvmmetric optical vartaces. A high-ypeced exro comeroller is being developed for a grinding machinc that will he uscel is fabricalte asymmetrically vhaped oplical surtaces. The controller uses capacitance galuges 10 s'llse coutler position and pic/aclectric erşalsto accurallely change the position of the cutler relatise lo the sample heing machincel

- Ciencric combroller for chamomel lurmmen madimes. Ageneric mathime-foul combroller is hems

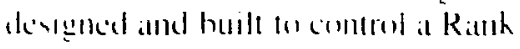

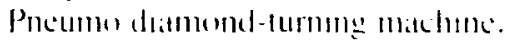

recomls acyuired hy the Precismm Finguluering ( inter.

- Muliproserse yped comtrol. A reall-tims.

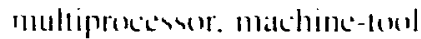
controller las beon devinged and is nearing completum. This commoller

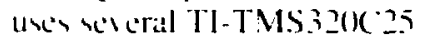
processore to combrol multiple ates of a matchine foul al high speed. - liccured-ion-healm micromachining. An ulirahigh-sacuum subssitem for a focused-jon-heam micromichining vslem is ander construction.

- Elaslic émi is continuing on a rolary polishing lechnologs: first developed in Japian. that offiers greall promise for pollishing arbil rary comlours $w$ ith nanomeler accurac!.

- Designn of a xanning lunncling microscope. A seimning lumneling microscope 1 STM i will a larger. $4 \times 4-\mu m$ scanning range has hean designed and comserueled. The STM is coupled lo al microcompuler-hased datal-icyuivition yolem for image processinge of the dastal. 


\section{Nuclear Chemistry}

II. I. I.tich

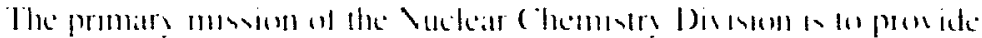

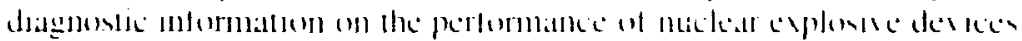
through the une at radiochemical and isolupic kednigues. We combine

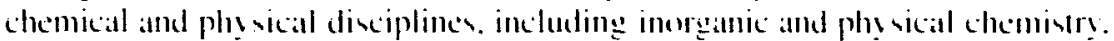

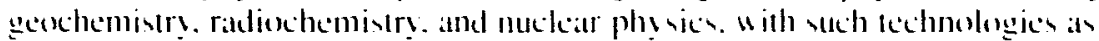

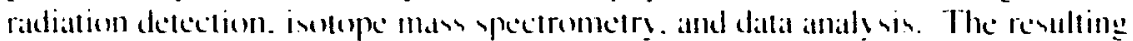

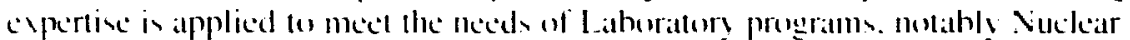

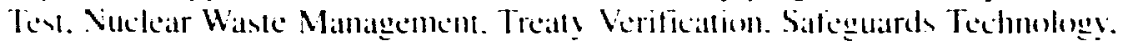

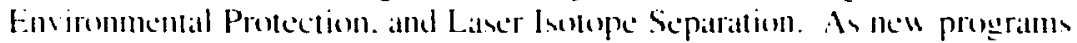

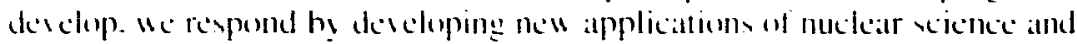
lcchmolog:.

Through IRdD-spomsured fundamental research in metear science and

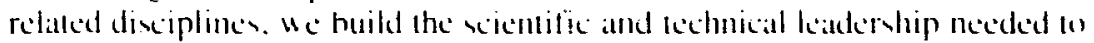

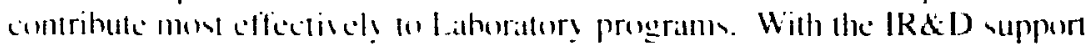
receiced an FYsts. We completed threc projecte and hegan the experinental-

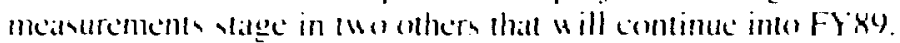

One of the completed projeces was a three-patre exploration of new lechnigues for measuring isolope ratios. One part involved the development of general isotope-ratio measurement capabilities he inductively coupled plasma mass spectronetry (ICP-MSt: this ins entigation is nearly complete. and further developments for specilic applications will be supported by Laboratory programs. We also completed the development of techniques for in situ oxygen isotopic allalyses hy secondary ion mass spectrometry (SIMS). In the accelerator mats spectrometry (AMS) part of this project. we used the accelerator at the Eniversity of Rochester to develop and test procedures for making AMS measurements of " $\mathrm{Cl}$ and ${ }^{\text {"No. }}$. These experiments have helped to spark widespread interest in AMS at the Lahoratory and have comtributed to the establistment of a new Center for Accelerator Mass Spectrometry at LLNL.

Our IR\&D-sponsored commochemistry research was also concluded in FYXX. We completed our determination of the is Re half-life. Our studies of titanium isotopic anomalies in meteorites hate led to some interesting conclusions and speculations about chemical and physical processes in the early solar system.

In the ultrasensitive laser spectroscopy project. we completed a lwo-year evaluation of photothermal spectroscopy lechniques for measuring alctinide solution speciation. We achieved comparable sensitivities at the submicromolar level for three different photothermal techniques. The technique for a given application may therefore he chosen on the basis of less critical technical criteria.

Also this year. we completed the assembly of a major experiment 10 meatsure the mass of the electron antineutring. This experiment uses a gaseous atomic tritium source to eliminate all know ns ystematic problems assoxiatled with the wolid-stale inlerattions of the tritium beta-decaly process. In FY89. we will finish kesting and calihraling the high-resolution magnetic spectrometer and will hegin measuring Iritium.

During FYXX. We alsocompleted the instrumentation for a steds of the thermodyramic propertien of the actinide elements. We developed and leved

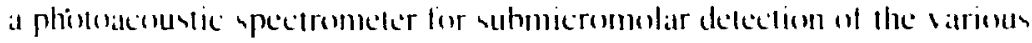
"sidation states of uranium. meptunium. plutomium. and americium. We also constructed at ariahle-temperature calurimeter for meisuring atctinide complexation enthalpes. Thermodynamic investgatione treing the capahilites will begen nexl tear.

In Fy funth. 


\section{New Techniques for Measuring Isotopic Ratios}

\author{
Principal Inventigaturs: (i. P. Kuss. III. \\ and R. ( . Finkei \\ (o-Inestigaturs: I). I.. Phinnes. K. I). \\ Mckeegan. I. M. Hazan, and H. W. I affee
}

$\mathrm{T}$ he objectises of this project were lo explome wals in increalse the comsitis it! of ICP-MS for bolin mulicelement and isolopic anslysis. to develep ion source and dedection sistems for AMS using LL.NLS tandem Van de Girallt acelerator. and to develop SIMS methods for measuring axygen isotope rallow in solich.

As a result of changes made 1 , the instrument. our ICP-MS is now roughly ten times more sensitive than standard commereial instruments. For many elements in solution. the limit of detection is now in the range of one part per trillion (pptr). L singe

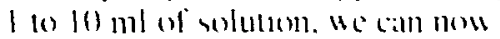
determine the concentrattions of twathird of the elements in the periodic table if they are present in concentrations of 1 ppm to 1 pptr. The enhanced sensilivity of our instrument also reduces the anount of sample required for analysis. For example. we are now using ICP-MS to meatsure the isotopic composition of uranium in emvironmental monitoring samples as small ats $f$ ng. This lask was formerly done by thermal ionization mass spectrometri (TIMS). Although TIMS vill has

By the end of this year, we will have demonstrated the isotopic analysis capabilities of two new techniques for high-sensitivity measurements of isotopic ratios in very small samples: inductively coupled plasma mass spectrometry (ICP-MS), and secondary ion mass spectrometry (SIMS). Design and constriction of a third technique, accelerator mass spctrometry (AMS), is continuing.

beller reditivity thatn ICP-MS for this particular element. ICP-MS andlysis is much fister and requires whatamlially less sample preparation. Wie are exploring new sample inled vycoms thall will allow as to make isolopic analyses on al variely of elements using less than I ng of simple.

Until this year, our SIMS instrument could not be tuned atcourately and reproducibly enough at the high-matss-resolving poucer

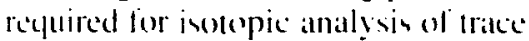
elements. With a specially designed. deal-microchionnel plate now in operation. the detector gatin on the SiMS instrument hats been increased by a lacelor of lo(0). We have completed preparations for oxygen isctspe measurements with SIMS at natural levels of ${ }^{17} \mathrm{O}(0.04 \%)$ and ${ }^{18} \mathrm{O}$ $(11.2 \%)$. These preparations included improving the tuning in the primary column for the cesium-sputtering source. writing extensive data acepuisition and reduction soltware. and collecting. curating. and preparing samples of oxygen isotope stilndards.

We hate designed the ditta colkection instrumentattion for 1.L NI A MS and have begun contrutum of the multiplatle gatsinmiatton delestor that we will uxe lar inchepe delection. We plan lan leser the delectur and gats control system by the end of less. In the interim. we have continted of use the AMS at the University of Rochester, New York. for pilol studies in I wo areas: - We have exlended our previous work on "I I I groundwaler from the Nevada Test Site lo include " $\mathrm{Cl}$. which we have now mearured in samples taken near the sites of the Cambric and Cheshire events.

- We have hegun analyzing " $\mathrm{Cl}$ in samples of huilding materials from Hiroshima to determine the neutron dose alssocialed with the Hiroshima attomic homb. The major uncertainty in the dosimeary for Hiroshima and Nagiasaki survivors is the neutron dose. Therelore, we plan to use " $\mathrm{Cl}$ that $u$ as produced by neutron activation in huilding materials io redetermine the neutron doses at Hiroshima and Nagasaki. Because of the low concentrations present. AMS is the only suitable detection technique for determining this isotope. We have measured " $\mathrm{Cl}$ in one rouf tile from Hiroshima and we will extend this work to a suite of simples collected in Hiroshima and Naglalsiki.

No IRED funding is requested for FYSy. Further development of 
the ICP-NS and SIMS lechniquen for specitic applications will be supported by Laborattory programs. Continued development of AMS techniques is planmed ats a new Direclor: Initiative, with specific aspects also included in a new Nucleatr Chemistry proposil.

\section{References}

Bazan. J. M.. (i. F. Hunt. and Ci. P. Russ

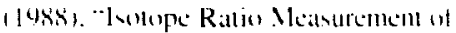

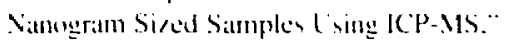

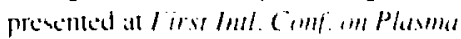

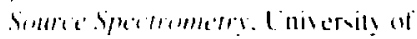
Durham. England isopemher luski: alon

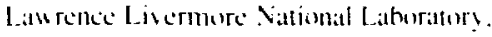
Preprint (CRL-4sysul tathetract).

Derhuk. E. C. Eddy. J. M. Bazan. and G. P. Ruw Ilyksi. "Trake Element Analysis an Milligrann Sised Ciedongical Samples." presented all Firv hol Cislf am Plasma Sentere Spectrometry. Lnisersity of Durham. England i Seplember fugsi: afso Law rence Livermore Natiomal Laboratory. Preprint (CRL-4845) (abstract).

Phinney. D. 1 488 ). "Lithitum Ahundanken in Vatural Diamorals: An Exploratury IonMicroprone Study.: Lomar and Plamerary. Si inter XIX. $4 \geq 7$.

Rum. G. P. (1988), "Istotope Ratio Measuremente L'ing ICP-MS."

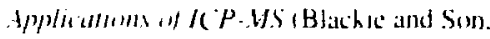
L.de. Cilangem. Sconlande. 


\section{Cosmochemistry Research}

Principal Investigators: S. Niemeyer and

M. l indner

(o-Ins estigators: J. U. Bazan. I). A. Leich. and (i. P. Russ. III

$\mathrm{T}$ he goal of this project has been to use meastured ariations in isotopic abundances to aldvance our understanding of early solar system and geochemical processes. The is- Re- ${ }^{-}$Os parent-daughter pair provides a radiometric clock that records the time scale of galactic nucleosynthesis prior to isolation of our solar system and promises to provide a valuable dating scheme for the formation of metallic and sulfide phases in solar sistem bodies. Isolopic anomalies in meteorites yield clues to stellar nucleosynthetic processes and provide a means of tracing the early history of the solar system. Titanium isotopic anomalies in meteorites have proven to be especially important for constraining models of the evolution of the dust in the early solar nebula.

This year. we completed isotopic analyses of osmium samples isolated from five independent rhenium sources. The osmium samples had been chemically isolated from each of the rhenium sources in approximately six-month intervals over a period of four years.

Measurement of the growth rate of

"Os relative to osmium isotope spikes led to direct measurement of the half-life in each of the live

We completed our determination of the half-life of ${ }^{187}$ Re by measuring the growth rate of ${ }^{187} O$ s in five rhenium sources over a period of four years. Studies of titanium isotopic anomalies in meteorites have also been completed, with the emphasis this year on interpreting isotopic data in terms of models of early solar system processes.

sources. The 42-billion-year halt-life wats determined with a precision of $\pm 3 \%$ (95\% contidence level) (Lindner. 1988).

We also completed our studies of titanium isotopes. We have published two papers that, together. represent the final and complete report on our investigations of tilunium isotopes in the carbonaceous chondrites, a primitive class of meteorite. The first paper (Niemeyer. 1988 a) reports our results on titanium isolopic anomalies in chondrules (a type of inclusion in stony meteorites): the second paper (Niemeyer. 1988b) deals with the distribution of titinium isotopic anomalies in carbonaceous chondrites. The highlights of this work include:

- A clear demonstration that the finegrained matrix in these primative meteorites also carries small excesses of ${ }^{5 \prime \prime} \mathrm{Ti}$.

- The development of a model in which maltrix and chondrule precursor assemblages are closely related to one another, whereas the genesis of ref ractory-rich inclusions involves additional processing in which the "Ti-rich carrier is enriched relative to normal titanium.

- A suggestion that FUN inclusions (where many elements are isotopically ancmalous) represent "unapshots" of a partial melting epirinde.
- The recognition of an s-process (slow-neutron-calpture) component in titanium in the mineral hibonite.

\section{References:}

Niemeyer. S. 198xat). "Titanium hotopic Anomalies in Chondrules from Carhonaceous Clundriles," Gendim. caxmushim. Art 52. 3019.

Niemeyer. S. (1 488h ). Asmopic Diversing in Nebular Dust: The Distrihuthem of Ti

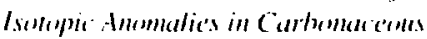
Chuhdrifes. Lawrence Lisermore National Laboratory. Preprin UCRL-98659: 10 be published in Cie'shim. Cosmorhim. Arta.

Lindner. M.. D. A. Leich. G. P. Russ. J. M. Baszan. and R. J. Borge (1988). Dirct t De'termination of the Llalf-Life of "* Re. Liwrence Livermore National Laboratury. Preprint LCRL-44537: submitled to Gordhim. Cosmonthim. Acta. 


\section{Ultrasensitive Laser Spectroscopy}

\author{
Principal Investigator: R. J. Silva \\ Co-lnvestigator: R. E. Russo
}

\section{We have developed and tested ultrasensitive photothermal deflection spectroscopy (PDS) and thermal lensing spectroscopy (TLS) for use in measuring optical absorption spectra in aqueous rare-earth and actinide solutions.}

excitation and probe beams are colinear). A narrow bandpatss filter is used to block the excitation laser and to transmit the probe beam to the

(a) PAS

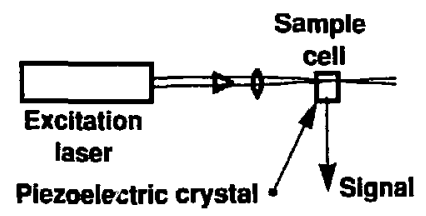

(b) PDL.

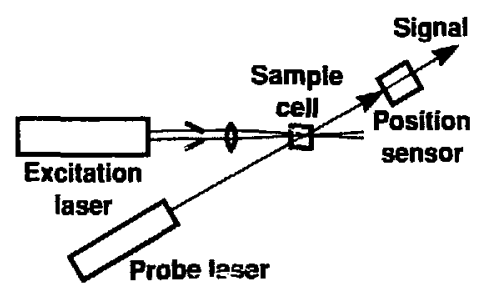

(c) TLS

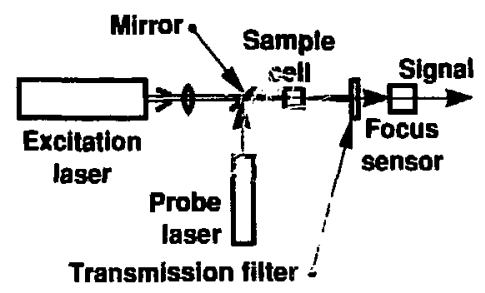

Figure 1. Experimental setups for (a) photoacoustic spectroscopy (PAS), (h) photothermal deflection spectroscopy (PIS), and ( $c$ ) thermal lensing spectroscopy (TLS). PDS and TIS exhilsit nearly the same sensitivity, which is about five times higher than that of unI PAS system. detector. However. a small amount of excitation beam leaks through the filter and reaches the detector. and this small background distorts the $\mathrm{Nd}^{3+}$ spectra at low solution concentrations. The preliminary TLS data suggest a sensitivity equivalen to thill of PDS.

Both PDS and TLS are about five times more sensitive than PAS. However. PDS and TLS require precise alignment of the excitation and probe beams and thus are more difficult to set up and operate. In addition, for best results. PDS and LTS require a tightly focused excitation beam. Because of this tight focus, beam intensities of $>0.75 \mathrm{~mJ} /$ pulse cause ablation of the sample cell's windows. A nore diffuse beam can be used for PAS. and intensities of $3 \mathrm{~mJ} /$ pulse have been used in our PAS measurements.

In practice, the three systems exhibit about the same detection limits-lhat is, about $1 \times 10^{\text {" }}$ absorbance unit for signal $/$ noise $=3$. PAS is easier to set up and operate but requires sample volumes of $1 \mathrm{ml}$ or greater. PDS and TLS can operate with much smaller sample volumes if necessary (c.g.. ().1 $\mathrm{ml}$ or perhaps less). Thus. PAS appears to be the method of choice unless only very small sample volumes are available.

\section{Reference}

Spear. J. D.. R. F. Rumo, and R. 1. Silsa (1988). "Differemlial Phomblemal Detlectum Spectroncops 1 amy a Sillgele

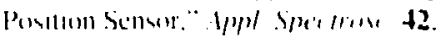
11113. intluenced by the beam of the excitation laser itself (in TLS. the 


\section{Measuring the Beta- Decay End Point of Atomic Tritium}

\author{
Principal Investigaturs: II. Stufth. \\ D. Decoman, and .I. Fingelage
}

$\mathrm{T}$ he mass of the neutrino is an important parameler in man! areas of physics. For example. a mass of even a fell clectron volts would have a profound effect on cosmology because of the vast number of neutrinos in the universe: the discovery of suct: a mass would support modern thereses of particle physics and set valt:- in some of the parantelers.

The mass of the electron antineutrino, in theory. can be determined by careful measurement of the hela deciay of Iritium. A noneero neutrino mass alters the shape of the electron spectrum neadr the end-point energy of the hetadecaly process. Rescarchers in Mascon (Boris a d al. 1985) reported the results of such a tritium heladecay measurement and claimed evidence for an electron antineutrino mass between 18 and $45 \mathrm{eV}$. The range comes from uncertaintics in the final-state distribution of their source material. In contrast, groups in Switzerland (Frischi et al. . 1986) and Tokyo (Kawilkamı et al. 1987) found no evidence for a neutrinu mass with upper limits of 18 and $27 \mathrm{eV}$.

respectively. These experiments uncel sources with the tritium embedded in a solid. a technique that introduces numersus systematic errors.

Our experiment has heen designed to eliminate these sy stematic errors. Electrom from tritium alloms that decill in our

We plan to determine the electron antineutrino mass with a precision of a few electron volts by measuring the shape of the tritium beta-decay spectrum near the end point. Our measurements will be sensitive to an electron antineutrino mass greater than $5 \mathrm{eV}$. We have completed the assembly of the gaseous atomic tritium source and the high-resolution magnetic spectrometer, and we have begun to test the experimental system.

ervegenic. gitseous. altomic tritium sourcti are guided into a large. toroidal. mignetic-lickd spectrometer by a system of tive solenoidal superconducting magnets. Only electrons emitted from the gatseous altomic tritium will successifully pass through the high-resolution spectro.meter and be detected.

During FY88. we completed the hardware for our experiment. This was often al very complicated undertaking becatuse most of the components involved some combination of high-vacuum surfaces. nonmagnetic materials. parlsoperating at cryogenic t'mperatures. and high voltage.

We completed the gas-handling sysem that introduces tritium into the gaserous tritium source and assembled the source. Figure 1 shous the flow of tritium and hetatdecily electrons lhrough the source assembly. Although not show'n in this simplilied diagram. the source tube is encased in a liquid-nitrogenconled radiation shield. which is further enclosed in a larger tube that is hept all high valcuum by its own pumping wesem. This multitube surcec a sembly is positioned inside the bore of live superconducting magnes. Also not shown is the reclion of the source lube that is lined uith charcoal that can be conled on cryogenic temperattures. The absorption of tritium onto the cold chatroal further inhibits tritium $5 \mathrm{a}$. form contering our ypectromeder tial $k$.
We run the source ansembly. including its support table. at $5 \mathrm{kV}$ : therefore all the power for the source equipment must be obtitined through isclation transformers. We use optical-lïher lines for computer control of the source parameters. The source was lested at a $3(1-k \mathrm{~V}$ potential and found to be stable.

The magnetic spectrometer (Figure 2) is housed in a large (3).(10)1) 1) vecum tank labricated from nommagnetic stainless steel. Using l wo lurbopumps and Iwo cryopumps, we achieved a vacuum of less than $5 \times 10$ "Torr.

The spectrometer focuses the electrons onto a cylindrical silicon detector that is segmented into 16 independent ring elements. Each element hals its own amplitier system. Because the silicen detector has good energy resolution. we can distinguish between good events and background from radionative decays and secondary cosmic-ray interactions. To avoid thermal stress, the spectrometer will be operated at at comstant licld and current selling. We "will obtain the energy spectrum of the electrons emilled in the source by applying a varriable eleceric potential that alcelerates the electroms to the energy that corresponds to the spectrometer s fictd sellin!.

We produce the toroidal manenetic field in the spectrometer with a 72 lexp stetem that has a lotal resistatnce of aboul 11.5 (2 and insolves more 
than 7010 comnections. This lom resistance is necessally becillase calch loop must carry 50 A. The outer portions of these loops are (1.5-in.diam aluminum rods: for the imner part. we use l-in.-wicle, 11.0155 -in. thich copper bands. We incorporalted ways to ensure that the copper baluds inside the loops ate straight: this is crucial to the resolution of the spectromeler becallse the electrons pass close w these hands as they are focused. To make them straight. we stretched each 12-1t band section 1.5 in. with 3000 to of force. The bands are held stralight in the spectrometer hy stainless-stecl springs. each of which applies a 60 -lb force.

Among our concerns were compensating for the earth"s magnetic field. minimizing the effect of the electric field produced by the conductors, ensuring a stable temperature. and determining the spectrometer's resolution function. The masnetic spectrometer cannot focus the electrons properly unless we cancel the earth "s matgnetic field. To reduce the fictd to less than $5 \mathrm{mG}$. we surrounded the timk with at shicld consisting of 30 coils containing approximately $20.0(0)$ fi of wire and energized with 17 computercontrolled power supplies.

We also considered the problem of the electric field produced by the conductors. Because the voltage is dropping along the current patl of the spectrometer. this electric field varies with position. To minimize the deflection of the electrons by these electric fields. we strung shield wires at ground potential 0.25 in. on either side of the inner conductors.

Similarly. we positioned a grounded wire mesh between the outer conductors and the electron paths.

We took several measures that should help keep the temperature of

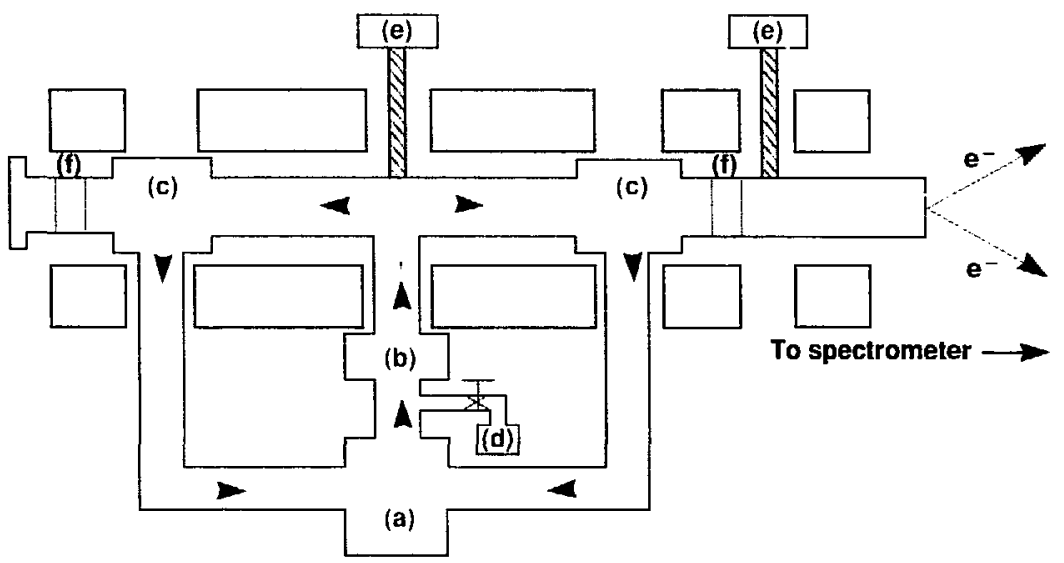

Figure 1. Cross-sectional view of the gaseous tritium source assembly. Tritium flows out of the liquid-nitrogen-couled cleanup trap (a) and is made atomic in the radiofrequency dissociator (b). 'The source gas circulates through a 16.4-fit-long. 1.25-in.-diameter aluminum source tube until being pumped out by turbomolecular pumps, four at each point (c). These pumps decrease the tritium gas pressure from about $10^{-3}$ Torr at the center of the source tube to $10^{-7}$ Torr at its two ends. Tritium gas can be added to the system from a gas bottle (d). The source tube is kept at cryogenic temperatures as low as $10 \mathrm{~K}$ by having it in contact with the cold heads of a closed-loop refirigeration uilit (e). Electrons from beta decay in the source tube are guided to the spectrometer by the magnetic field of the superconducting magnets (shaded areas). A potential of $5 \mathrm{kV}$ across the acceleration gaps (f) "tags" the electrons from the source with this extra energy for a total of about $23 \mathrm{keV}$; electrons from tritium that has leaked into the tank have no more than $18.6 \mathrm{keV}$. The tritium exhausted from the turbopumps is sent back through the trap (a) and reinjected into the source tube.

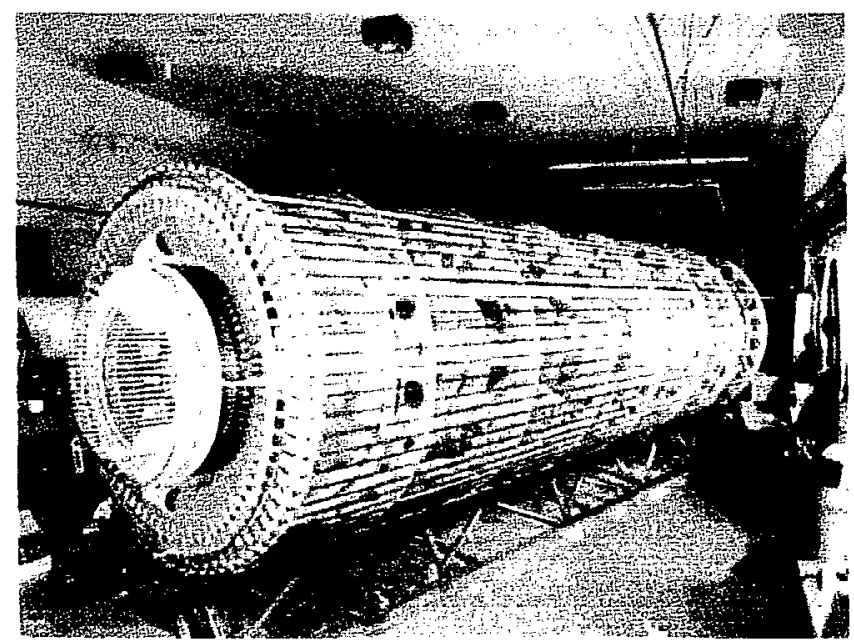

Figure 2. The 26-fit-long toroidalfield electron spectrometer that will be used to measure the tritium beta-decay spectrum near the end point. The large rings that support the 72 current lowps are $6.5 \mathrm{ft}$ in diameter. 
the spectrometer stable to better than $1 \circ \mathrm{C}$ :

- We monitor the temperature of the conductors and the space frame using temperature-sensitive integratted circuits.

- We chemically blachened the conductors so that they can better radiate alwaly the $1.2 \mathrm{~kW}$ of healt generated by the current they carry.

- We installed copper lines for cooling water on the space frame to stabilize the temperature inside the vacuum vessel.

We also built in several computer-controlled diagnostic and correction clements that help us achicve the necessary energy resolution. For example. 128 electrostatic deflector plates allow us to tune the spectrometer in 16 different sections. We can isolate the effects of each set of deflector plates by positioning a movable cup over the detector. The cup contains a slit that allows only a narrow range of electron trajectories to impinge on the detector. Similarly a movable slit installed at the first focus of the spectrometer allows us to study the resolution of the spectrometer as at function of the trajectories accepted from the source. Because the stepping motors for both the detector diagnostic cup and the movable slit are computer-controlled. we can do a very thorough optimization.

An important apsect of our measurement is knowledge of the system 's resolution function. The finite resolution of the spectrometer. as well as any energy loss in the source. will smear the shape of the belitdecay spectrum. Therefore. the resolution function must be unfolded from the data in order to extratet the vilue of the neutrino mass. We will meisure our resolution function by using the isomeric decay of the 17.r-keV conversion electron line of "Kr. This isomer, which has a halllife $\left(t_{12}\right.$, of 1.8 hours. is produced hy the decily of ${ }^{\circ 2} \mathrm{Rh}\left(t_{12}=86\right.$ days $)$. Becialuse the isomer is a gass. it mimics exactly the hehavior of the tritium in our source. and it gives us a monochromatic line that enables us to measure and tune the resolution of our system. In addition. we can measure the ${ }^{\mathrm{K}} \mathrm{Kr}$ line with idmixtures of hydrogen. deuterium. or tritium gas at various pressures (the nominal operating pressure is about $10^{3}$ Torr in the source tube) to measure the energy loss in the source gas.

To ensure that this complicated set of hardware is operating correctly. we developed a sophisticated. computerized, data acquisition and control system for our experiment. The system uses a dedicated VAX $11 / 750$ computer and a commercially available branch driver to interface the computer to several computer-automated measurement and control (CAMAC) crates. To monitor and regulate more than 500 parameters. we developed software that can communicate with a wide range of devices. including digital volmeters, output registers. valves. pumps. temperature sensors. magnetometers, stepping motors. and high-voltage power supplies. This system has been most useful during the developmental phatse of the spectrometer: we expect to use it extensively to optimize the resolution of the spectrometer and to monitor the stability of the system in the final experiments.

In early FY89. we will continue to test and optimize the electron spectrometer by using an electron gun positioned at the entrance of the tank. Litter. we will test the entire system using ${ }^{\mathrm{k}} \mathrm{Kr}$ in the gaseous source. After these tests are complete, we will hegin our first tritium meitsurements.

So far, we have found nothing that could keep our experiment from reaching the goal of being sensitive (1) a neutrino mass of $5 \mathrm{eV}$.

\section{References}

Boris. S., A. Collutin. L. Laptin. V'. Luhimos. V. Nagorizin. E. Nowikm. V. Nosik. V. Solowhenko. I. Tigonirove and E. Tretjakon (198.5). "The Neulrino Mass from the Tritium Beta Spectrum in Valince." Plls. Lc'tl. B 159. 217.

Fritschi, M.. E. Holsschuh. W. Kundig. J. W. Petcrsen. R. E. Pixley. and H. Slussi (1986). "An Upper Limil for the Mass of the Electron Anti-Neutrino from Tritium Beta Decaty," Phas. Letl. B 173, 485.

Kawakimi. H., K. Nisimura. T. Ohshima. S. Shibata. Y. Shoji. I. Sugai. K. Ukati. T. Yasudat. N. Morikatua. N. Nogama. T. Nagaluchi. F. Nailo. T. Suruki. H.

Takelani. M. Inahashi, K. Hisatake, M. Finjoka. Y. Fukushima, T. Matsuda, and T. Tanguchi (1987). "An Cpper Limit for the Mass of the Electron Anti-Neutrino from the INS Experiment." Pha. L.'tt. B 187 148. 


\section{Measuring the Thermodynamic Properties of Actinide Elements}

\author{
Principal Insestigators: P. A. Haisden \\ and R. J. Silva
}

( o-Investigaturs: P. M. Cirant, K. A.

Turres, and (C. F. A. Palmer

$\mathrm{N}$ ew lechnologies and instrumentation are essential to the development and application of improved methods for chemically: isolating atctinides from nuclear waste or nuclear lest debris, for detecting and charaterising actinides al trace levels in the environment. and for predicting their chemical behavior in natural systems. We are investigating the chemical properties of actinide species in ayueous solutions by medsuring their fre: energies of formation and their reaction enthalpies and entropies as a function of temperature. ionic strength. and oxidation/reduction conditions in solution. This information can be used to understand and predict the chemical behavior of these elements under a variety of conditions.

Most available thermodynamic data on actinides cone from measurements made at or near room temperature. To obtain data for predicting the effect of temperature on actinide behavior. we are preparing to measure reaction enthalpies and entropies as at function of temperature. For the $x^{2}$ measurements. we have designed and constructed a variable-temperature titration calorimeter (Figure 1). This new calorimeter is similar to our
We have developed two instruments for measuring the thermodynamic properties of actinide elements in aqueous solution: a variable-temperature calorimeter for gathering data at temperatures up to $125^{\circ} \mathrm{C}$, and a laser-based photoacoustic spectrometer for investigating solution species at submicromolar concentrations.

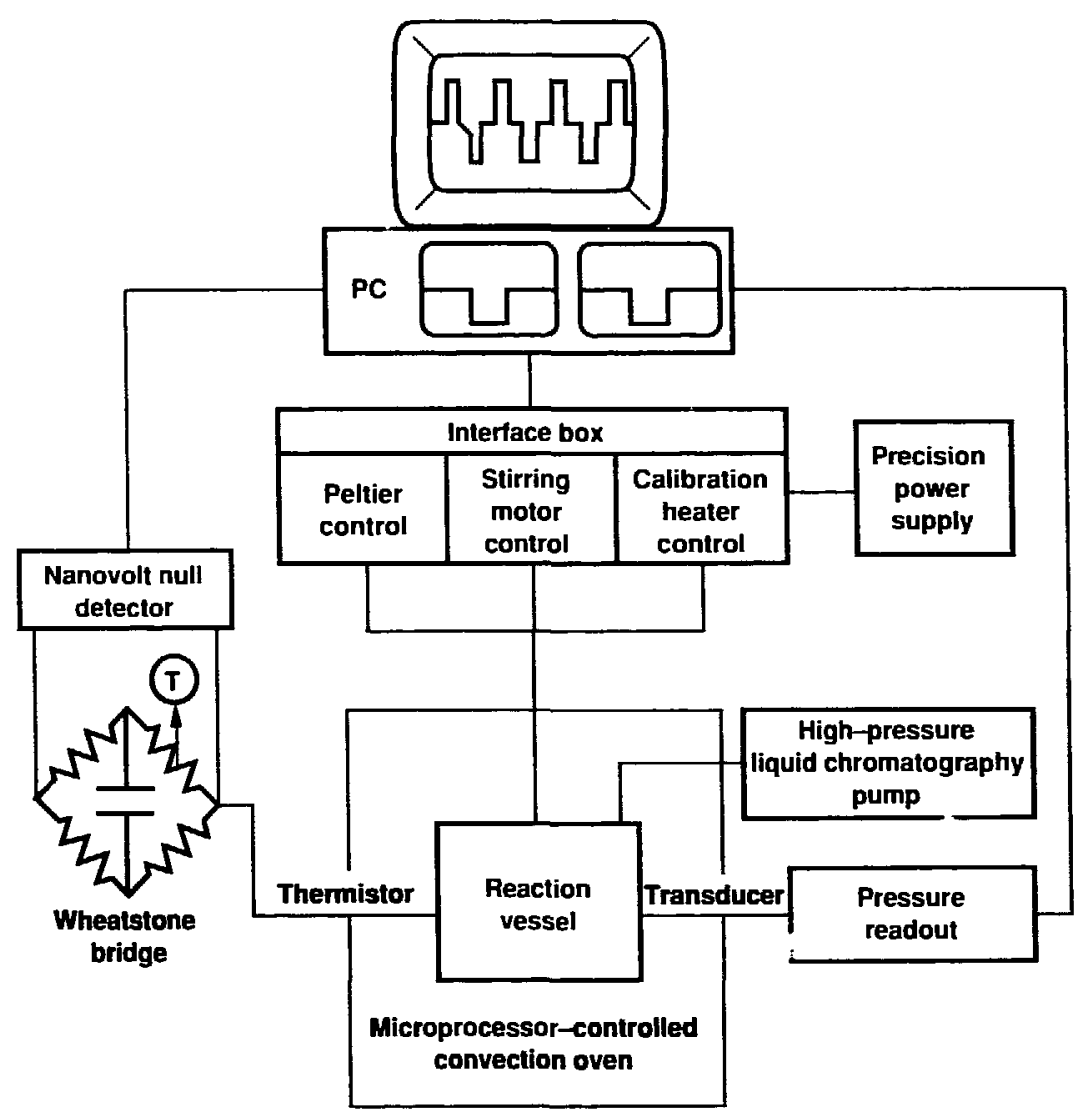

Figure 1. The variable-temperature calorimeter and associated equipment. The system is controlled by an IBM PC. which giv es us an on-line graphics display of the experiment in process. 
high-sellsitivit 25 ( caltrimeter (Bitisden et al. . 1487). excent that a microprocessor-controlled convection oven rather than at water bath is uscel to maintain the working-point temperature of the vessel. Also. to prevent sample loss due to avaporation that accompanies working with alyueous solutions: at high temperature, wa have incorporated the capability of pressurizing the calorim:-2ir"s reation vessel. This instrument is being tested and calibrated. and we expect to begin measurements in the next few months.

Since millimolar concentrations of the actinides are needed to provide measurable temperature changes upon reaction with most complexing agents $\left(\Delta T>100 \mu^{\circ} \mathrm{C}\right.$ per incremental addition of complexing agent), our initial studies will focus on the solution thermodynamics of reactions with uranium and thorium.

We are also interested in obtaining information about the behavior of actinides in near-neutral solutions. such as in natural water systems. However, under these conditions. hydrolysis severely limits the solubility of these elements and thus concentrations in the submicromolar range are typical. Since this concentration regine is inatessible by conventional optical methods, we have developed a laserbitsed photoatcoustic spectroneter (PAS) system. This gives us a sensitive means of meatsuring frec energies of formation and thus of detemining the speciation of aqueous atinide complexes at ultralow concentrations.

Initial lesting of our lasior-based PAS has been completed. A dataacyuisition program running on an IBM PC steps the monochrometer through the desired wavelength range and collects the raw data by linearly averaging a predetermined number of analog-to-digital conversions per laser pulse for the reyuired number of laser pulses per wavelength. With this progran, we can acquire data simultaneously from the sample and from a reference cell and photodiode. The photodiode signal is used to correct the absorption spectra for the pulse-10-pulse variations in the intensity of the laser beam.

We found that precise repositioning of the cell between measurements is crucial for

Table 1. Sensitivity limits for the detection of actinide ions by PAS.

\begin{tabular}{|c|c|c|c|}
\hline Ion & $\begin{array}{c}\text { Excitation } \\
\text { wavelength, nm }\end{array}$ & $\begin{array}{c}\text { Molar } \\
\text { absorptivity, 1/mol cm }\end{array}$ & Sensitivity, ppb \\
\hline$A \mathrm{~m}^{3+}$ & 503 & 380 & 3 \\
\hline $\mathbf{P} \mathbf{u}^{3+}$ & 600 & 38 & 30 \\
\hline $\mathbf{P} \mathbf{u}^{4+}$ & 470 & 55 & 20 \\
\hline $\mathrm{PuO}_{2}^{+}$ & 568 & 19 & 60 \\
\hline $\mathrm{PuO}_{2}{ }^{2+}$ & 830 & 550 & 2 \\
\hline $\mathbf{N p}^{4+}$ & 723 & 127 & 9 \\
\hline $\mathrm{NpO}_{2}^{+}$ & 980 & 395 & 3 \\
\hline $\mathrm{NpO}_{2}{ }^{2+}$ & 1223 & 45 & 30 \\
\hline $\mathbf{U}^{4+}$ & 520 & 58 & 20 \\
\hline $\mathrm{UO}_{2}{ }^{2+}$ & 415 & 8 & 150 \\
\hline
\end{tabular}

minimising the errors in replicalte sampling and in the ont-linc back grround subtraction of the sample $s$ refierence spectra. Therefore, we developied a cell holder in which we have rigidly bonded the yuartz cuvette. the yuartz coupling rod. and the piezorelectric transducer. The holder can be casily removed from the spectronieter. retilled. and then accurately replaced.

L sing our new cell holder, we are delemining the sensitivity of the system and the operaling parameters of the laser for the detection of submicromolar yuantitics of $\mathrm{L}^{t+h+}$.

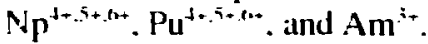

Photoacoustic spectra of $\mathrm{Am}^{i+}$. $\mathrm{Pu}^{4+}$. $\mathrm{Nd}^{3+}$, and $\mathrm{Pr}^{3+}$ have been obtained as a function of concentration in the micromolar range. and absorbances were found to be linear with concentration. A practical minimum absorbance limit $($ signal $/$ noise $=10$ ) of $5 \times 10^{-6}$ absorbance units was determined: this value is about 1000 times lower than whal can be achieved with conventional transmission spectrometers. Using this lower limit, we estimated the concentration sensitivities for the other actinide ions from their known nolar absorptivities (see Table l).

To obtain information about the speciation of aqueous actinide complexes from their photoacoustic spectra. we are developing analysis codes for extracting the free energies of formation for multiple species from the absorption spectra and from the known analytical concentrations of the actinide ions and the complexing agents.

\section{Reference \\ Baisden. P. A.. P. M. Grant. and W. F. Kinard 119871. "Development of a High-Sensitisit! Compuker Controlled Titration Calorimeter." Res. Sia. Instrum. 58. 1437.}




\section{Physics}

B. Tarter
The Physics Department s IR\&D work emphasies innowative research that could have a signilicant impact on LLNL senergy and defense programs. Wo also support disciplinary efforts that either provide substantial new long-lerm capabilities or have the polential to produce major xcientitic results.

Our projects reflect three methods for seeding new programs: (1) the creation and development of new capabilities. (2) the exploitation of technological advances for application lo other lields, and (3) a critical evaluation of the implications of major discoveries in the general physics community. Much of our work is interdisciplinary and multidepartmental in character. Our FY88 projects included collaborations with magnetic fusion. earth sciences, lasers, nuclear chemistry, and biomedical sciences. and nexi year's new proposals also include participation by chemistry and materials science and enginecring.

Nearly half of our projects reached their final stage under FY 88 IR\&D sponsorship. Our multiyear effort to develop a comprehensive magnetic-fusion modeling code was limited by changes in the direction of the research program. but the BASIS code system we developed is finding signilicant applications in many other Laboratory computer projects. The experiment aimed al producing insulator-to-metal transitions in a diamond anvil cell sel a new record with the 2-Mbar transitions observed in xenon, the highest pressure attained in noble gasses. Fabrication of our new two-slage. light-gas gun is complete. and it is nearly operational. The high-pressure cell designed for benchmark measurements of the muon-catalysis fusion rate is nearly ready for use in accelerator experiments in Switzerland. The quark earch project should soon yield the world"s best upper limit on the number of free quarks in ordinary matter. Our accelerator mass spectrometry work identified such an extraordinary array of possible applications in archeology. biomedical and environmental science. and applied physics that it has expanded to a separately funded program.

Among our continuing research efforts is support of design studies of a laboratory $x$-ray laser. During the past year, we made significant progress on lasing at shorter wavelengths, and it was also shown that holography experiments are best carried out just short of the "water window." A cryogenic source that is the crucial element in our neutrino mass experiment is nearly complete. and we expect to be taking data in the coming year. Our gamma-ray laser work identified a number of nuclear shape isomars that are potential candidates for laser storage states. We have also made significant advances in understanding the mechanisms that could trigger the lasing action.

Our program to explore the physics of materials with short-pulse. highintensity lasers saw both theoretical and experimental successes. In particular. we carried out a sequence of detailed multiphoton ionization measurements on xenon and modeled the results very accurately. The short-pulse experiments successfully demonstrated the technique of creating warm plasma under essentially hydrostatic conditions for material properties measurements.

Finally, our global-scale climate modeling efforts continue to provide important scientific developments. A highlight this year was the initial coupling of oceanic circulation models to the atmospheric circulation codes.

The Physics Department reccived \$2.01(0.(1)(0) in IR\&D funds in FY 88 . 


\section{Magnetic Fusion Modeling}

Principal Ins estigator: A. Friedman
We have investigated the computational modeling needs of the Laboratory's Magnetic Fusion Energy tokamak research program, examined computer codes used by other laboratories, and adapted critical codes to our needs.
$\mathrm{T}$ his project wats a joint eflort of the Physics Department and the Matgnetic Fusion Energ! ( MFE) Program to develop al comprehensile numericial modeling ciapability lor near-term tokamak experiments and advanced reactor-scale sustems. Our intent is 10 build on past efforts. hoth at LLNL and elsewhere. These include BASIS. an advanced generalpurpose. code-development system and scientific computing environment. and MERTH. at tandemmirror simulation code built by us using the BASIS system and incorporating plysics relevant to the tokamak configuration. as well as at wide variety of computer condes developed elsewhere.

Our initial work wals aimed all understanding the current state of the ant in tokamak modeling. We acyuired the tokimak transport code ONETWO. developed al General Atomics in San Diego. This code has been used extensively to model the DIII-D tokamak and its predecessiors at General Atomics. It can be used in either a predictive (sinulation) mode or an interpretive (analysis) mode. in which transport properties are inferred from experimental dati.

If a tokamak machine is to sustain a stable equilibrium. a large plasma current must thow around the torus. In present-day machines, this current (and most of the plasma heating) is provided by induction drive: the plasma acts as the secondary of a transformer. The process is inherently pulsed. a major limitation as the primlary current cannol he ramped up indelinitels. Any steady-stale lohitmiah reacloir thus will require altemative heating and current-drise mechamisms: at maljor thrus of our research progeram is lo apply intense microware radiation to these ends.

LLNL researchers visited the Kurchator Institule in the Soviet Enion. where the T-I) lokamah employs intense clectron-eyclotron healing (ECH). We have run the ONETWO code using data ilcyuired during this visit. To match the experimentill observations. we had Io improve the transport models in the code. We then used the enhanced ONETWO model to predict the rimge of behavior of the Lahoratory"s fortheoming Microwave Tokamak Experiment. In this experiment. we will use a modified version of the Laboratory's free-electron laser to provide pulsed ECH power for heating and current-drive experiments.

In designing and analyzing tokamaks with a noncircular cross section. we must understand the plasma shape that arises from a given combination of external-coil currents and plasma parameters. To this end. we are using the magnelohydrodynamic equilibrium codes GAEQ and EFIT from General Alomics and the NEQ code from the Oik Ridge National Laboratory. We have constructed equilibria for LLNL: conceptual reatctor designs TIBER-Il and ITER: the xe hate heen uned for stahilit! and ral!-lralcing sudies here and at the Princelon Plasmal Phosics Laburatury.

We hate leatned for whe the Princeton TSC coder. at timedependent magnelohy drodynamic program that embodies a wide variely of lohamiath phesics. The corde models an entire tohamak discharece on al resistive time scalle. We have employed it to determinc a ramp-up seyuence for external coil currents in an ITER :tart-up scenario. When the processes goveming transporn are hetter understood. the TSC code will provide a strong simulation framework.

The involvenent of the Physics Department in this project has ended: ongoing efforts by MFE Program personnel are building on what has been accomplished during the IR\&D phase of the project.

\section{References:}

Dahoin. P. F.. Z. (E. Munteler. and P. A.

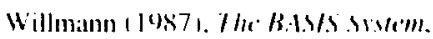

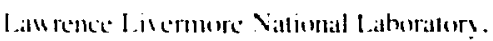

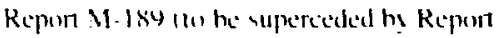
N. 3251 .

Friedmant. A. M. R. Renumb and W. 11.

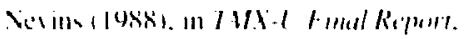

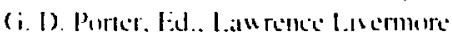

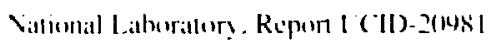

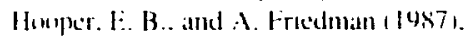

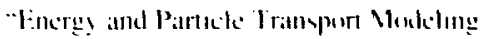

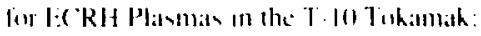

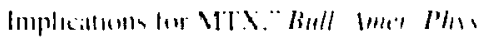
S.4 32. 15i: 


\section{Insulator-to-Metal Transition in Xenon}

Principal Invertigaturs: H. Kums. R. Reichlin. 1. h. Mc Mahan. and

i. Martin
$\mathrm{C}$ alculatum- of electron hand sructure indicite that in whlad venon the hand gap between the empl 5/-lihe conducturn band and the full 5 p-like calence hand in decreaving wh increasing densils and that a tramstlen to the metallic sate would aceur when the se band cross at sufticiently high pressure. predicted 10 he in the ratnese of 1.3110 20(1 GPa. Structural sudien of venom using s-ras lechniques hase hown that renon freeser in at factedentered cubic ifectsucture. Recentls. Jepheral e't al. 11987, reported phane tranvition in xenon at $1+$ GPa from fee in an intermediale. clone-pached phase and al 75 GPat an a hexagonal close-pached hepl sructure that remaned vable 10137 GiPal.

In our suds. venon samples were loaded in the diamond anvil cell h! condensing gas on the tip of the diamond anvils and remotely closing the cell to trap the liquid cobserved visually in the sample chamber. Once a sample was sealed in a cell. it was warmed to room temperature. Absorption and reflection spectra were measured at Livermore. and energy-dispersive $x$-ray diffraction techniques were used lo collec: i-ra! data at the Cornell High Energe? Sinchroirun Source iCHESSi Diffractum data were ued tw whtaton the lattice comstant it venon on 172 CiPa: presurew were delomined from the equation at viate of the rhenum gasket.

Oplical athorptum med-urements, made al prosurs up

\section{The equation of state and optical absorption of condensed} xenon have been measured in a diamond anvil cell up to 172 GPa. At 150 GPa, we observed sudden changes in the absorption spectra of xenon that we attribute to the onset of metallization. Xenon is the first inert gas solid to be metallized.

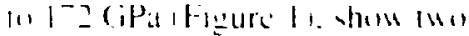
impurtant fattures. Firnt. athose

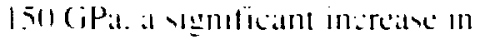

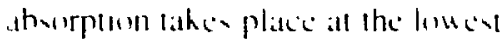

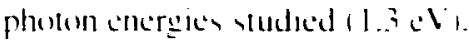
Second. near lisu GiPa. a new presure-insensitice atororption peak appears at 2.10 el and increases in promenence with increasing presure Altheugh the structuac remains hep. the sudden appearance of this peat wer a narron pressure range vegegess tha onset of a transition whose origin was m! stifying until uc calculated the electron hand structure.

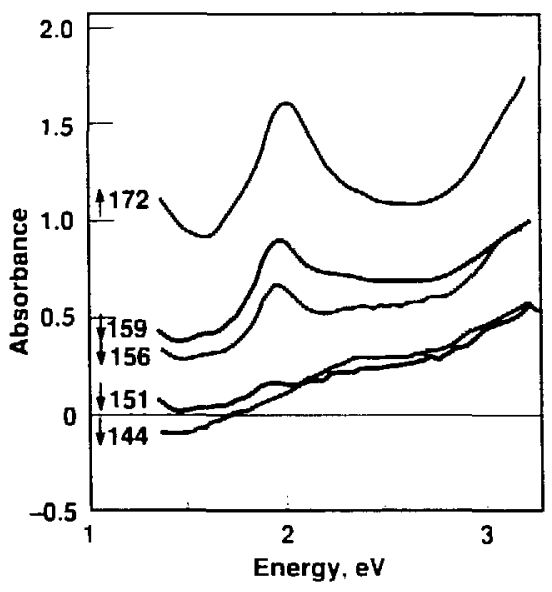

Figure I. Absorbance of solid senon plotted against energ! at indicated pressures (arrows. in (;Pa). Vote the increased absorption above 151 ( ; Pa at lower photon energies and the new. pressure-insensitice absorption peak around 1506 (iPa at 2.1$) \mathrm{el}$.
In hep. unlihe las. sementhe wop

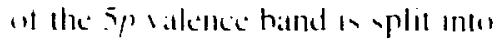
wa subhands. xeparalled by ahoul 2.l. He identily the atherption peak with this 2-c.' ytitting. Melalligalden accurs iat the indirect Eap wher the bustom of the conduction hand mose helow the Fermi vurface. This drops the Fermi level helom the top of the balence hand. providing empts tates in the valence hand that we helieve are responsible for the z-el aburption peath. He made hand srueture calculations all sereral densities lo verify the pressure independence of this transition. An inspection of the hand structure fails to shom any other transition that can lead to a relativel! pressure-insemsitise 2-el' atherption and can aloo account for the ahrupt appearance of this fealure.

The metallic character of the sate is further supported by infrared retlectivily measurements we collected at the vemon-diamond intertace at $16(1 \mathrm{GPa}$. Thus the 2-eV upical transition provides at unique vignature for the insulator-to-metal transition in hep xemon.

\footnotetext{
Kefferences

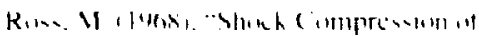

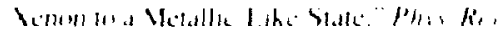
171 . -

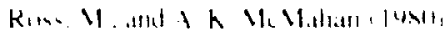

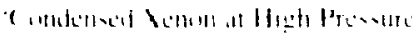

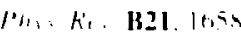

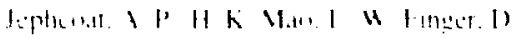

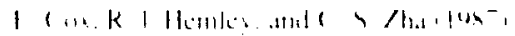

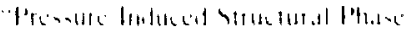

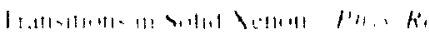

$1,+54:+1,-11$
} 


\section{Advanced High- Velocity Two-Stage Light-Gas Gun}

Principal Insestigator: II. J. Vellis

$\mathrm{T}$ he tia-siage light-gat gun ifigure lo in ased an study the propertices of materials at high shoch pressures and temperaltures. Io derclup shoch diagnostics for use at the ver ada Test Sile. and to "ythesile new materials. The wide a ariel! of applications for the gun has crealed a high demand for gun lime by various Liborattory researchers and $\mathrm{L} C$ collahorators. To meet this demand. we needed al second (wostage gun. To minimis eyuipment and operating costs. We designed a gun one-thircl the sise of the original one. Which is $19 \mathrm{~m}$ long. Becialuse of advances in diagnostic resolution. many of the experiments performed with the original gun can also he performed with the smaller one.

Higher projectile velocities are also needed to achieve higher pressures and temperalures of relevance to Laboratory programs and to induce interesting physics phenomena. Computer calculations have shown that the waly to achieve higher velocities is to use the original full-scalle two-stage gun with a smaller-diameter lighter projectile. a shorter launch tuhe, and a reduced gas loalling.
We are developing an advanced two-stage light-gas gun facility to increase the number of high-pressure shock-wave experiments and to achieve higher launch velocities, shock pressures, and shock temperatures in those experiments. The older two-stage gun will be modified to increase its launch velocity, thereby producing higher shock pressures and shock temperatures. ()ur future plans are 10 mose the new onc-rhird-scalle gun 10 al rom adjacent lo the full-scale gun and to procure hardware for the high- celocity lersion of the original gun. Funding for this work will be prowided by Weapons Supporting Reneirch in FYS9.

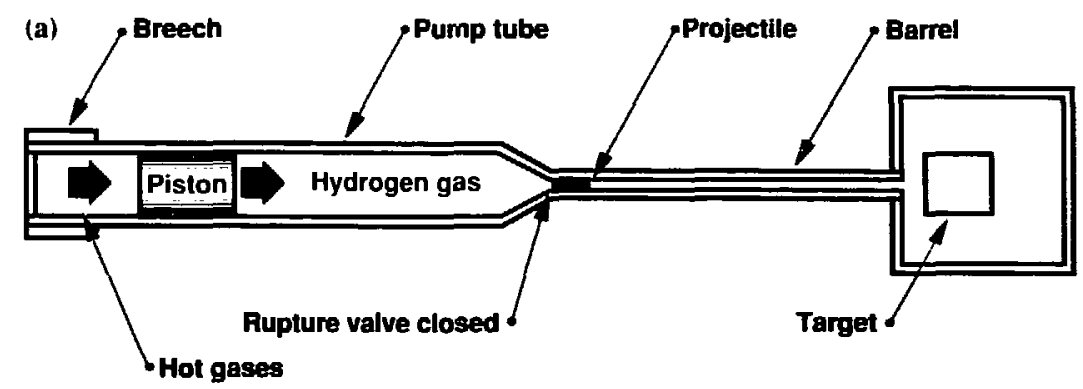

(b)

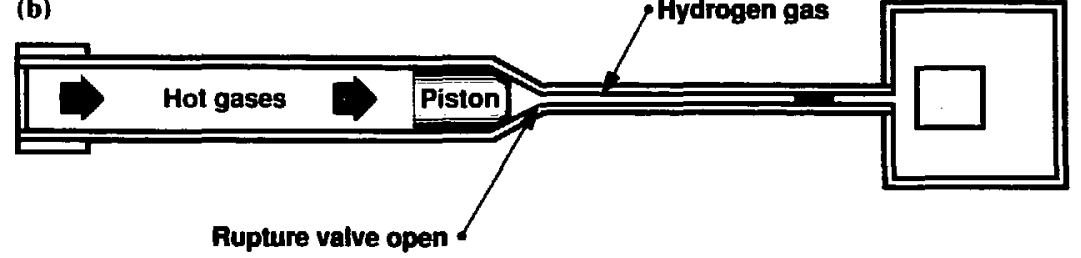

Figure 1. Diagram of the two-stage light-gas gun. (a) The hot burning gases from gunpowder in the breech drive a heavy piston that compresses hydrogen gas in the pump tube. The high-pressure hydrogen gas breaks open the rupture valve and accelerates the projectile down the barrei. (b) Al the end of the barrei. the projectile has reached its highest velocity and impacts the target. 


\section{Muon-Catalyzed Fusion}

Principal Investigators: B. J. Alder and $W$. Durham
I I hats been known for 30 lealrs that at negatice moun ( $\mu$ i will induce a spontaneous fusion reatction in a cold (room-temperalture) molecule of desuterium-tritium (DT) according to the reaction:

$\mathrm{DT} \mu \rightarrow \alpha+\mathrm{n}+\mu+17.6 \mathrm{MeV}$.

In this realction. the muon acts as an agent that brings the deuterium and tritium nuclei close enough together so that fusion occurs by quantum-mechanical tunneling. In principle. such a reaction could be used for large-scale production of usable energy. However. early erroneous calculations of muon capture cross sections discouraged further research. When. more than a decade ago. Soviet scientists found the mechanism that produces a larger cross section. interest revived in this alternative fusion technology.

Our muon-calalysis research has been directed at determining how many fusion reactions could be

Our work on muon-catalyzed fusion has focused on the design and assembly of a high-pressure cell in which to carry out key experiments at a Swiss accelerator. Our cell has successfully reached the maximum temperature and pressure required and is being tested for hydrogen permeability and the number of times it can be recycled. After safety tests, it will be shipped to Switzerland. Theoretical understanding of the stripping processes, which could lead to a scheme for enhanced catalysis, is progressing well.

cittaly ked by at single muon. Specifically. we are preparing an experiment in the high-pressure. high-temperature range where (controversial) extrapolation suggests at high fusion rate. We are also exploring theoretically the muon stripping rate to see whether there are ways to enhance the predicted catalysis efficiency. (The muon stripping rate is the probability of a muon captured by an alpha particle being freed to calalyze more fusion reactions. which in turn means lowering the crucial sticking parameter.)

Both our experimental and our theoretical programs have made good progress and will conclude by the end of FY89. The experimental apparatus has held pressure at 200 MPa and temperature at $200(0) \mathrm{K}$. and is now in the final assembly stage (Figure 1). We have incorporated the pressure-producing part of the apparatus (a simple liquid(o-gals expansion device) and all electronic diagnostic controls. The chicf remaining issues are how many timen the pressure and lemperalture conditions can he recyeled and the permeability of the nutal container to hydrogen. We are still experimenting with the vessel liners and their surrounding ceramic (currently TZM) to find the best materials for them. We are testing ceramic's from two commercial sources and vessel liners made of rhenium and a tungstenrhenium alley. We are also exploring the possibility of fabricating such a container on sitc.

We are currently in the final stages of testing the experimental apparatus. Using an inert gas. He have reached maximum design temperature and presibure. Preliminary indications from hydrogen testing show encouragingly low levels of hydrogen permeation throughout the liner. The tests with hydrogen should be completed in FY84. The apparatus will he shipped 10 Switzerland after the safety test has been satisfiactorily completed in the presence of hoth Los Alamos and Suins experts. 


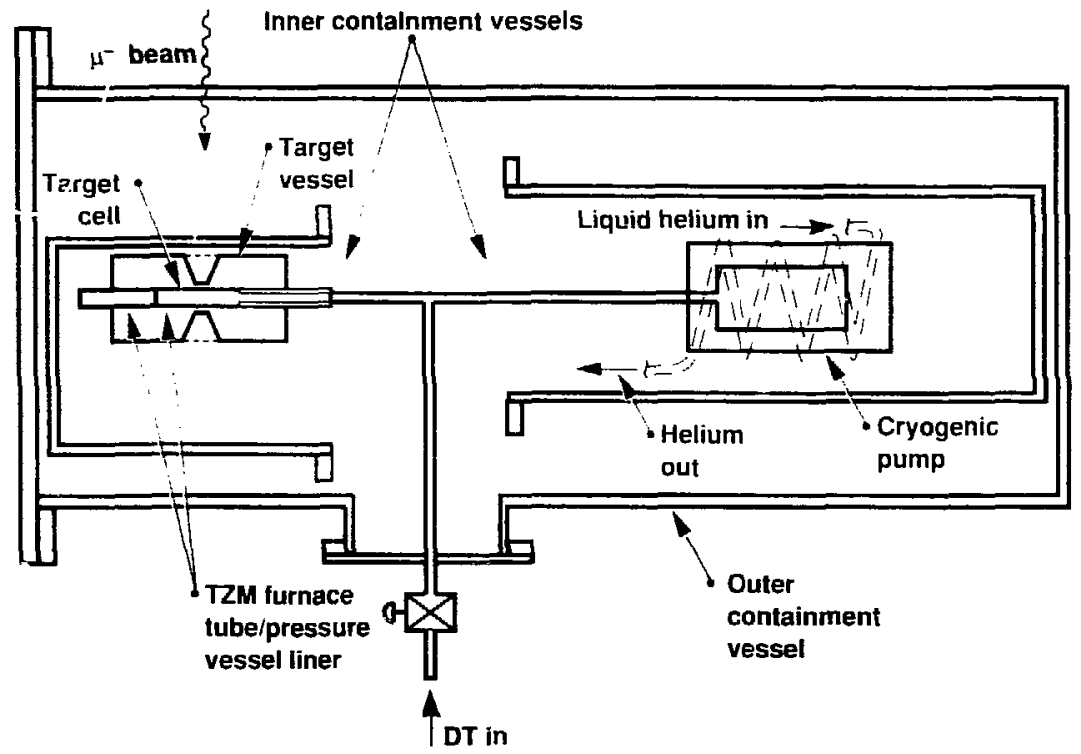

Figure 1. Schematic cross section of the experimental apparatus. The target cell. containing about $2 \mathrm{~cm}^{3}$ of DT gas at high pressure and temperature, sits within alt inner containment vessel. The cryogenic pump that injects the DW gas into the target cell sits in another vessel. it beam of negative muons $\left(\mu^{-}\right)$enters from the outside. causing DT fusion in the larget cell. ()ur theretical calculatmm

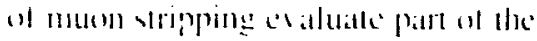
sripping process. We are in the precess of cheching out the computer program fior calculating the rematining part. When compleded in a fell month. these calculations should predict the nes sripping ate can expect in the experiments. We will conclude our theoretical effort wh thatculatim of the Stank mixing facler. lhe Auger decaly ratles. the nuclear fusion ratles for enciled balles. and a multiphoton process that could lead to conhatnced lusion in excoled saltes fou ing to comsiderabls lew viching . 


\section{Quark Search}

Principal Investigator: 1 . Hendricks

\begin{abstract}
During the past year, we significantly improved nearly every major feature of our experimental system: the drop generator, the rotating-disk chopper system, the dataacquisition system, the pressure controis on the gas system. and the overall electronic timing of the system. With this qualitatively improved experiment, we can now obtain an upper limit on the number of free quarks per gram in diffusion pump oil.
\end{abstract}

ystem. The resulting particle trajectories depend on the ratio of cad!l particle"s net charge to its mass. the intensity of the electric field, and the time a particle spends in the field. The deflecting field is produced by creating an electric potential between two vertical. carefully aligned. parallel plates. Since the particles are generaled with a uniform mass and velocity. the trajectory of an individual particle between the plates then depends only on its net electric charge.

During the past year. we completed the assembly of a neu. very stable droplet generator (Figure 1 ) and a rolating-disk chopper system, and mounted them atop our 5-m drop tower. The droplet generator. operated with a $10-\mu \mathrm{m}$ diameter orifice. has produced droplets of diffusion pump oil continuously for more than 48 hours without any apparent change in their characteristics or direction of travel. The rotating-disk chopper renoves the required number of droplets from a stream of $25-\mu \mathrm{m}$-diameter drops.

Drops are generated sequentially. about three drop dianceters apart. from a cylindrical liquid jet at a high ratle tup to lo(). (o) do drops per second). To atroid interactions between the dreps via induced dipole fields. the drops must be separated by ahout $6(1)$ drop diameters. This is accomplished by removing 19 out of every 20 drops in the stream using the chopper (a rotating slotted disk): the rotor freyuency is synchronized with the drop-generation frequency. This attenuated stream of droplets is then passed through the electric-field deflection system where eacin particle s trajectory is observed and its net electric charge is determined.

After bench-testing the chopper. we mounted it on the drop tower and tested it again for proper operation. As in the hench test, drops generated at rates up to 100.000 per second were directed to the appropriate spot on the rolating disk. The chopper successfully removed 19 of every 20 drops. allowing the 20 th drop to continue undevialed along its trajectory. producing an attenuated stream of $5(0)(0)$ drops per second. The drop stream and individual drops were observed optically above the chopper disk. and the altenuated stream and individual drops were observed below the chopper disk. Drop streams, both chopped and unchopped. have heen observed at the botlom of the lower luring the alignment process.

We have also implemented at much-improved data-acyuisition 
Figure 1. The 5-m drop tower used in our yuark detection experiments. Simall particles cor droplets lalling between the charged plates are detlected by an amount that depends on their net electric charge. Sensitiv e delectors and a data-analy sis is stem can determine the charge on a particle to within $5 \%$ of the charge on an electron.
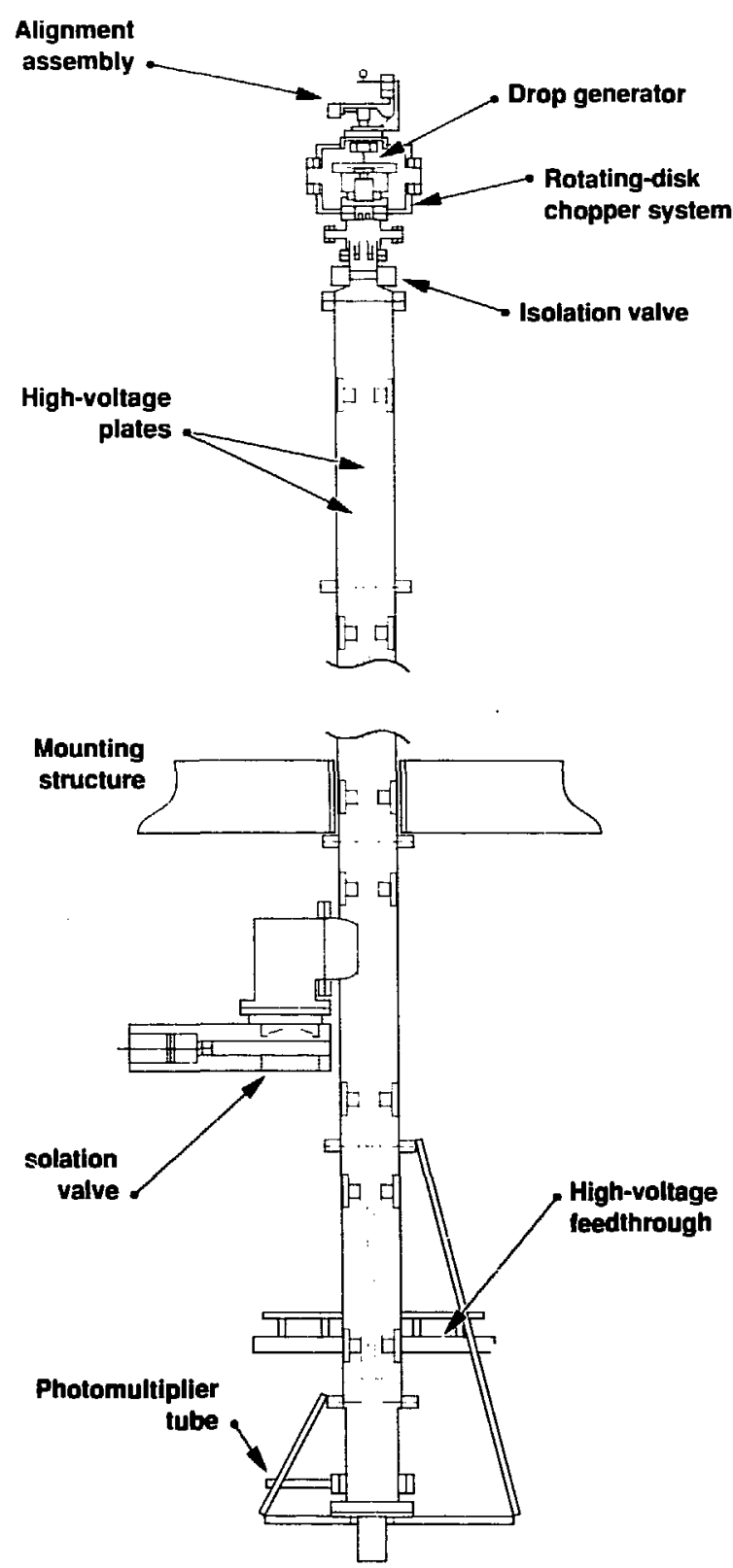

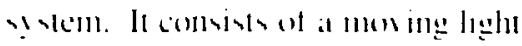
source with a betler-focured (RT (callhode-rats-lube) spent that has a shorter decaly time (now about 16 ms) than the carlier one. a beller photomultiplier tube. and vastly improved compuler harduare. soltu are. datti storiges. and output systems. The data-acyuisition system and the improved photomultiplier are curremly being ksad logether on the drep lower.

In iddition. "le hate improved the regulation of the gats system used to pressurize the droplet liquid to provide control of the pressure to athoul one part per million at a pressure of a few pounds per square inch to more than 200 psi (1.4 MPa). This ensures that the initial vertical velocity will be virtually constant from drop to drop.

The function generaltors used to drive the drop generator. the slrobes. the chopper motor. and the CRT sweep are all locked to a stable oscillator that has both a long- and a short-time frequency stability of about one parn in $10^{10}$. This is an improvement over previous systems of about five orders of magnitude.

With all these improvements and changes. accomplished during the past year, we now have an operational experiment. Next year. we plan to do our first quark search on drops of diffusion pump oil and to publish the results. Simultaneously. we will develop a proposial for outside funding to produce and simiple a varicty of difterent candidate yuark materials. 


\section{Biomedical and Environmental Applications of Accelerator Mass Spectrometry}

Principal Investigators: J. Davis and I. Proctor

Co-Investigators: C. Poppe. B. (iledhill. and E. Yelson*

* Simun Fraser I niverull. Vankeus cr. Brimbh Columbial, Canadia.

$\mathrm{A}$ ccelerator mass spectrometry (AMS) was developed to improve the sensitivity for counting small quantities of long-lived isotopes (e.g. ${ }^{111} \mathrm{Be} .{ }^{1+} \mathrm{C} .{ }^{3+} \mathrm{Cl}$ ). primarily for archeological and geoscience applications. We are investigating new uses of the ulirasensitive AMS technique in biomedical and environmental research and in other energy-related Laboratory programs. Many of the isotopes for which AMS has been developed are also commonly used as tags in biomedical and environmental research. In addition to the search for new scientific applications. we are pursuing the technological advances necessary to increase greatly the throughput of AMS measurements, thus making the economics of the technique more attractive.

iVith the IR\&D support available in FY88, we have accomplished the following:

- Convened at LLNL iwo workshops that have identified more than 20) experiments with potential for either dramatic scientific results or major clinical importance. Most important
We are extending the use of accelerator mass spectrometry (AMS) to new areas in biomedical and environmental research. The gain of six to nine orders of sensitivity that AMS offers for detecting isotopic tags will make possible great reductions in dose in present clinical and research procedures and will allow the development of new ones. New applications for other Laboratory programs have been identified as well. among these are adduct tagging experiments using ${ }^{14} \mathrm{C}$ and body calcium investigations using both ${ }^{+1} \mathrm{Ca}$ and ${ }^{+5} \mathrm{Ca}$ (the latter to be done with staff from UC San Francisco).
- Participalted in a workshop with collathorators al Simon Fraser University that set the design for the ion sources and accelerators required for the next generation of AMS

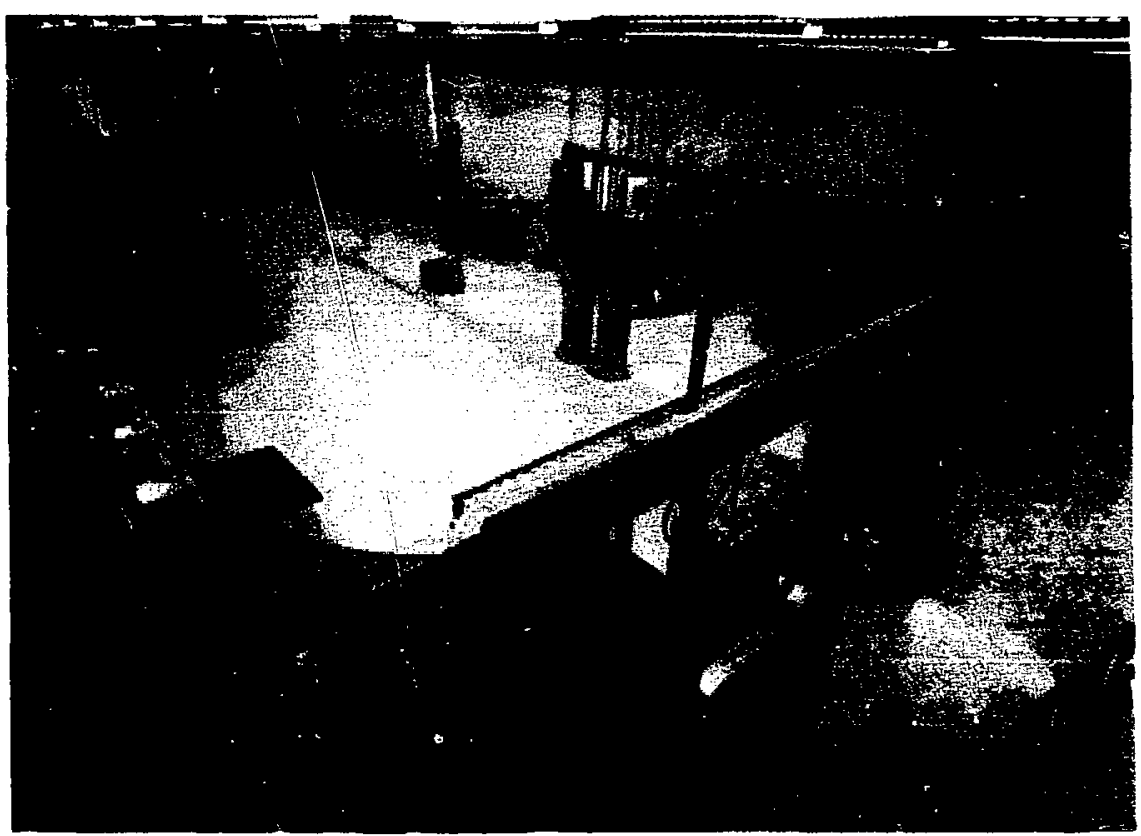

Figure 1. Beamline and magnet of the UC-LLNL accelerator mass spectrometer; the accelerator vessel is at the upper left. 
faccilitien. An a result of this mesting"Ho acyuired a tandem accelerator 10 donate to a future dedicated AMS licilit!

- Completed the initial beamcallibration runs of the IC-LLNL AMS in the Laboratory is neu tandem alceleraltor laborator! (Figure 1 ).

- Supported the fabrication and programming of the electronics for the initial detector sytem on the IC-LLNL spectrometer. This system will be used for the inilial measurements w ith light isolopes.

- Supported the construction of equipment for preparing graphite simples by the Ens irommental Sciences Division.

In FY89. We will bring the spectromeder into routine operattion for light isotopes li.c.. atomic mass $<+(1)$. perform the experiments that usc ${ }^{1 \pm} \mathrm{C}$ als a tage. and develop al detector system lo make measurements with calcium isotopes. The beam diagnostics and computer sistenss required for automated operation of the tandem accelerattor will be developed and tested. New applicattions of AMS in acquiring field data for climatology research will be assessed. Finally. we will explore the possibility of developing an AMS diagnostic for laser-driven inertial-continement fusion experiments.

\section{Reference}

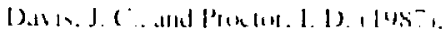
"Muludiaciplenary I andent Aesclerather

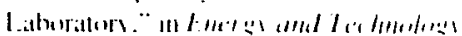

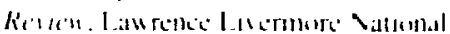

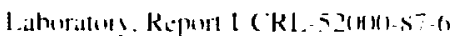
Pp. $1+211$ 


\section{Laboratory X-Ray Lasers}

Principal Investigaturs: M. I). Rosen (u-Insestigators: M. \$. Mason. D. ( . Fder. and R. A. London

$\mathrm{T}$ he Laboratory produced the first successful demonstration of lasing at x-ray wavelengths in FYst using the Novette laser. Since that time. our work has focused on understanding the data to improve new designs for more coherent lasing at shorter wavelengths, with a view toward hiological applications. Our specific FY88 goals were to understand the previous nickel-like $x$-ray laser $(X R L$ ) results and the 10(1)-ps recombination XRL results. to design neodymium-like schemes, and to assess photopumped schemes.

In FY87. we designed targets that achieved gain att 7 and $5 \mathrm{~nm}$ with nickel-like $d_{1} l-4 p$ systems. Two major mysteries - our failure to achieve predicted $J=2$ gain (in europium and ytterbium) and the low $J=0$ gain observed (in ytterbium) have been largely solved this year. Analysis of a density profile from KMS Fusion. Inc. (Ann Arbor. MI) led us to change our hydrodynamics model to produce cooler, denser foils. The ensuing kinetics do a far better job now of explaining the large nickel-like database. This will enable us to design the tungsten experiment $(4.3 \mathrm{~nm})$ with more conlidence. We are also serving as an international

We are providing the theoretical leadership for a joint effort to develop the physics and technology of laboratory $x$-ray lasers, with special emphasis on biological applications. This work is sponsored by the Physics Department and involves Lasers, Defense Systems, Biomedical Sciences, and Electronics Engineering. Analysis of experimental results continues in preparation for attempts at lasing in the 4.5-nm regime needed to image biological structures.

clearing house for the analysis of nickel-like data from lasers and tokamaks.

In collaboration with the

Massachusetts Institute of

Technology and Lockheed

Corporation. we have designed neodymium-like $(5 f-5 d)$ schemes that may be suited to shortwavelength. table-top lasers $16.5 \mathrm{~nm}$ with uranium ): alternatively, with a large laser system. these neodymiumlike schemes may serve as a test bed for saturation and laser-architecture studies.

We are preparing for hydrogenlike aluminum (3.9-nm) recombination experiments in the spring of 1989. when a required 20-ps oscillator comes on line on the Nova laser. We have been analyzing 100 -ps data on aluminum from Nova and from the laser at Limeil. France. and on lluorine and magnesium from experiments conducted in the U.K. and Japan. Although some of the data agree with predictions. some do not: we are collaborating with modelers in the U.K. to study the problems. The situation is similar with regard to lithium-like schemes. In addition. since the Nova laser has more energy at $1.06 \mu \mathrm{m}$. we have designed al hydrogen-like aluminum scheme driven by hot electrons at that wavelength.
Our planning and design of : neon-like series at Limeil has yielded a rich harvest of optimizalion and Z-scaling datia (Figure 1). We have begun to assess (in collaboration with J. Nilsen) the possibilities of enhancing gain with photopumped systems, particularly photoresonances that can enhance neon-like or nickel-like gain. We have also done hydrodynamic modeling of a hot-electron-boosted neon-like silver experiment carried out by a joint team from the Naval Research Laboratory and the University of Rochester Laboratory for Lidser Energetics.

In FY89, we will seek to understand the physies behind our new ad hoc cooler hydrodynamics model for the nickel-like scheme. More data on density from KMS and on density and temperature from the National Research Center. Ottawa. will be available soon. Refined designs for lungsten will be carried out. as well as special pulse-shaped designs that enhance gain and shorten the XRL pulse.

In the recombination schemes. we hope to resolve some of the I()()-ps discrepancies. either with diflerent hydrodynamies models or with better atomic datat liles from the 
Laboraturs - high-Iomperature

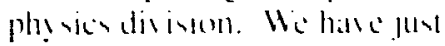
recied undul 20-p inem-XKL) aluminum data from the l'.K. and frum - Auntralia that w ill he comprared

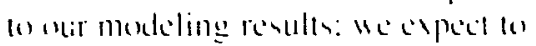
recice more 20 -p data irom k.l1s and the Nuclear Regulatur!

Comminion I NRC'

When the l.meit neon-like dat: are digitised. thes will be analy as will VRC ditti an kemperatture and demsity. More phoson-driven echemes will be ansereded. particularl! inner-shell phousoniers. This approach san proside the ihilit! in drivers thor enample. une af a compact lorust and will also insolse us in the grom ing worldwite effors in ularashort pulwes. Together with a

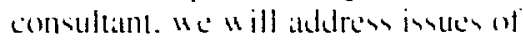

cohereme and pomsible aplantation

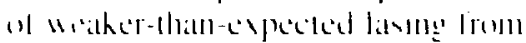

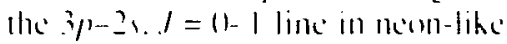

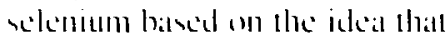
superflumencence reduces the upperkel population betore amplified ypontancesus cmimerom has at chance t1) accur.

\section{Refierences}

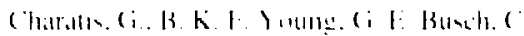

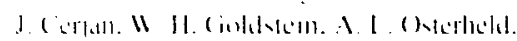

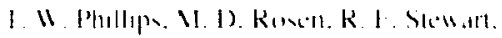

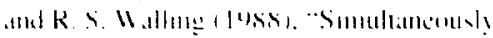

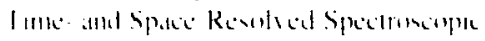

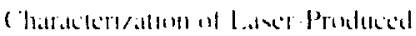

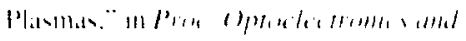

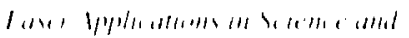

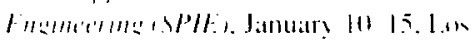

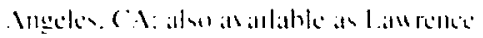

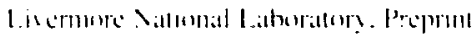
ickl.-9sing
Figure 1. Fample of $Z$-scaling and optimization data obtained at Limeil. France. The plots show how the $i_{0}=16.41-\mathrm{nm}$ line intensity of a strontium target tan element not previously studied at LL.NL i varies with target length for two incident irradiances. The gain coefficient $k$ is derived.

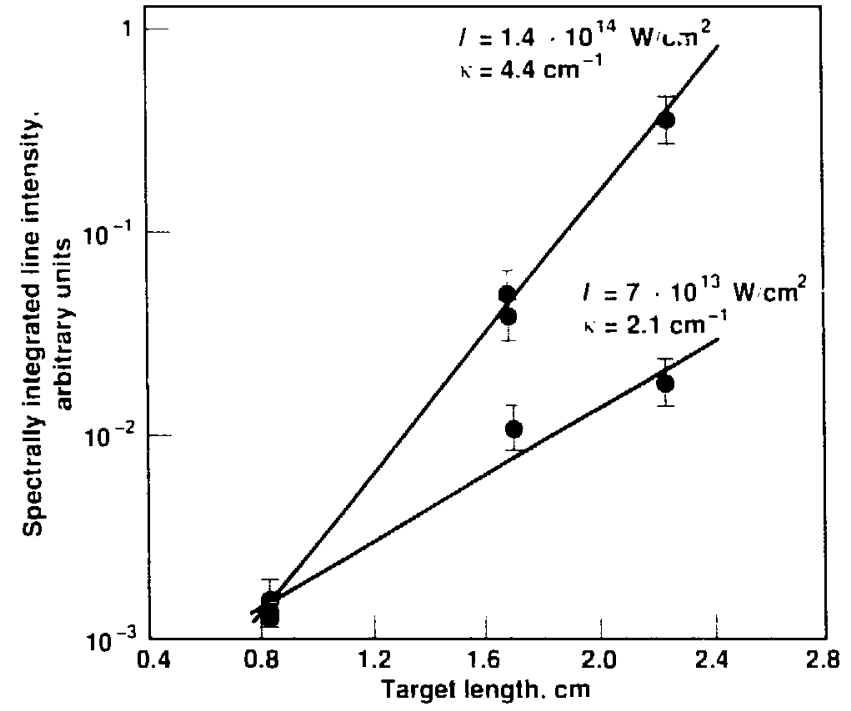

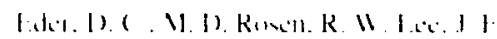

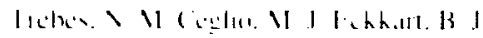

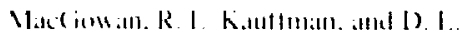

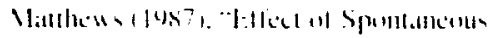

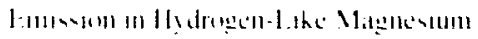

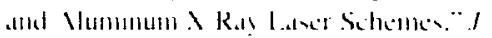

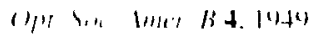

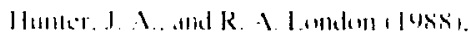

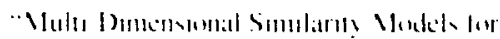

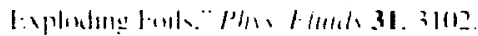

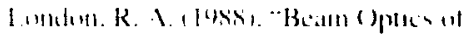

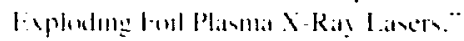

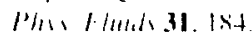

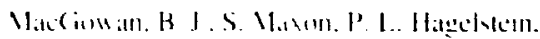

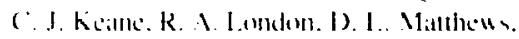
11. 1). Kunch. J. H. Sinlicld. and I). A.

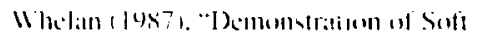

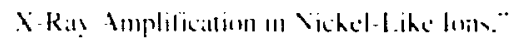
M kit len 59.2157.

Matun. S.. R. Matd iuman, R. L.ondent. J. Sinficht. M. Kunch. M. (holl. and P.

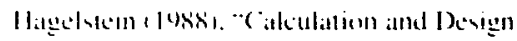

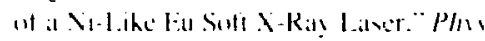
Rov 137.2227.

Rus.n. 11. D.. P. L.. Hagekkin. and R. A.

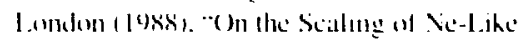
Scheme for XRL, w Shors Wa aclengeth." Pla H/mh 31.606.

Ruen. M. D.. R. A. L.mudon. P. 1. Hagelvein. M. S Manm. D. C. Fier. B. 1. Whitlen. M. H. (herl. J. K. Nash. J. H. Scotichl. A I. His, R. Minner. I) A. Whelin. R. F. Sl:Watt. T. W. Philliph. H. E. Dalhed. B. J. Matciman. J. F. Treher, C. I. Ke:ante and

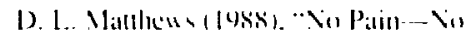
(iain: The Complex Arl of Solt A-Ral l.ance Talrget Devign and Anals ais." ( iullf.

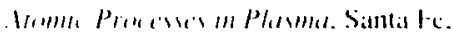

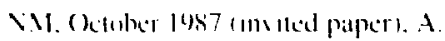
Hatuer and $\mathrm{A}$. Merk Lik M American

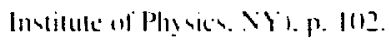

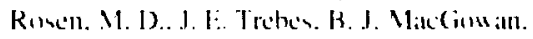

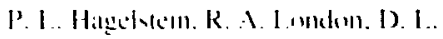
Milllews. I) (; Vhen. 1. M. Phillıp. 1)

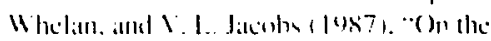

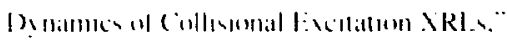

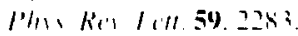




\section{Neutrino Mass Experiment Using a Frozen Tritium Source}

\author{
Principal Inventigators: (1. Fackler \\ and V. Vugge
}

A tinding : hat the clectron neatrine hat a tinite mam would hals $e^{2}$ ignificant corsecyuences for both elementary-particle phy sice and astrophts ics. Since the neutrino is ane of the clementary building blocks of all matler. its properties alld the forces that govern its interations are of greal interent. Furthermore. since more neutrinos " were crealed in the Big Bang than ant other elementar! particle. elen a ver! small neutrino mass-on the order of a few electron volt- - would be sutficient exent. to halt the expansion of the uniserace. The physical imporance of the neutrino mass is evidenced by the fact that morr than a dozen groups throughout the world are attempting to measure it.

Our goal is to determine the mass of the electron neutrino to within a few electron volss. Our experimental approach is to measure the shape of the beta-decay spectrum of tritium near the maximum betil energy. The measured energy distribution is sensitive to the mass of the neutrino that accompanies hetal decas. The unc of a frosen. pure tritium source. a fealure unique to our experiment. allow calculation of molecular final state and solidt-state effect for an

We are attempting to determine the mass of the electron neutrino with a precision of a few electron volts by measuring the tritium beta-decay energy spectrum near the maximum beta energy. Unique features of our experiment are an extremely high-resolution electrostatic spectrometer and a frozen tritium source. Last year, we demonstrated success/ul operation of the spectrometer. This year's work focused on designing and fabricating the cryogenic tritium source and on upgrading the specirometer.

alcuralt of heller than 11.5 el: A pure wurce alwe permils bers high datal rates. These features. logether with the high resolution of our spectrometer. should enable u- 10 determine the neutrino mass to within a few electron volts. the best accuracy currently obtainable.

Progress this year has centered on completing the cryogenic source and on improving the spectrometer. In addition. we have worked on a new low-noise detector system and on a new dala-logging and acyuistion wistem. Spectrometer upgrades to ready it for the source are also being completed.

The ultrahigh-vacuum. cryogenic. high-voltage, and mechanical tolerance requirements associated with freezing tritiun and installing the source in the apparalus posed difficult engineering challenges. To meet these. "re: - Developed a source substrate with a smosthness of helter than $1 \mathrm{~nm}$.

- Designed a liquid helium feedthrough that is nonmagnetic and electrically imsulating.

- Desienced low-eas-leakine and thermal seals betueen the $2-K$ source substrate and the tritium deposition chamber.

- Developed a specially shaped tritium deposition chamber wo obtain a Iritium source of uniform thichnes
The partialls asembled vource is shown in Figure lat. The 2-m-lon! source arm enters the tritium deposition chamber's heat shichl at the keft. The shorter arm at the right hold the deposition chamber. which mates with the source during tritium deposition. After tritium is frosen on the substri : $\therefore$ the source is passed through a vacuum valve into the spectrometer vacuum vencel.

Figure $\mathrm{Ib}$ is a clo:er vien of the source entering the heat shicld: the extremely smooth source substrate is clearly visible. Development and assembly of the source and component testing are hoth nearing: completion.

We have developed a né detector that counts low -energ! electrons. Its imponant feature is that it discriminates against most backgrounds. Final bachground rates wil, he less than one count per 21 seconds. With the ponsihilit! of achieving one count per 4010 seconds. This lou halckgeround rate $w$ ill provide a statistical remsitisits on needrino mass of hetler than $+\mathrm{el}$. We exped the delector to be completed shorils affer source imstillation.

We hate at 40 nearls completed derelopment of a new datatacyuisition ?h 
Figure I. |al Suurce assembly during construction. The 2-m-long sourece arm is shown entering the depesit in chamber"s threearmed heat shield (right). The shorter arm, at right. contains the tritium deposition chamber itself. which mates with the source during tritium deposition. (b) C'loser view of the source entering the heat shield.
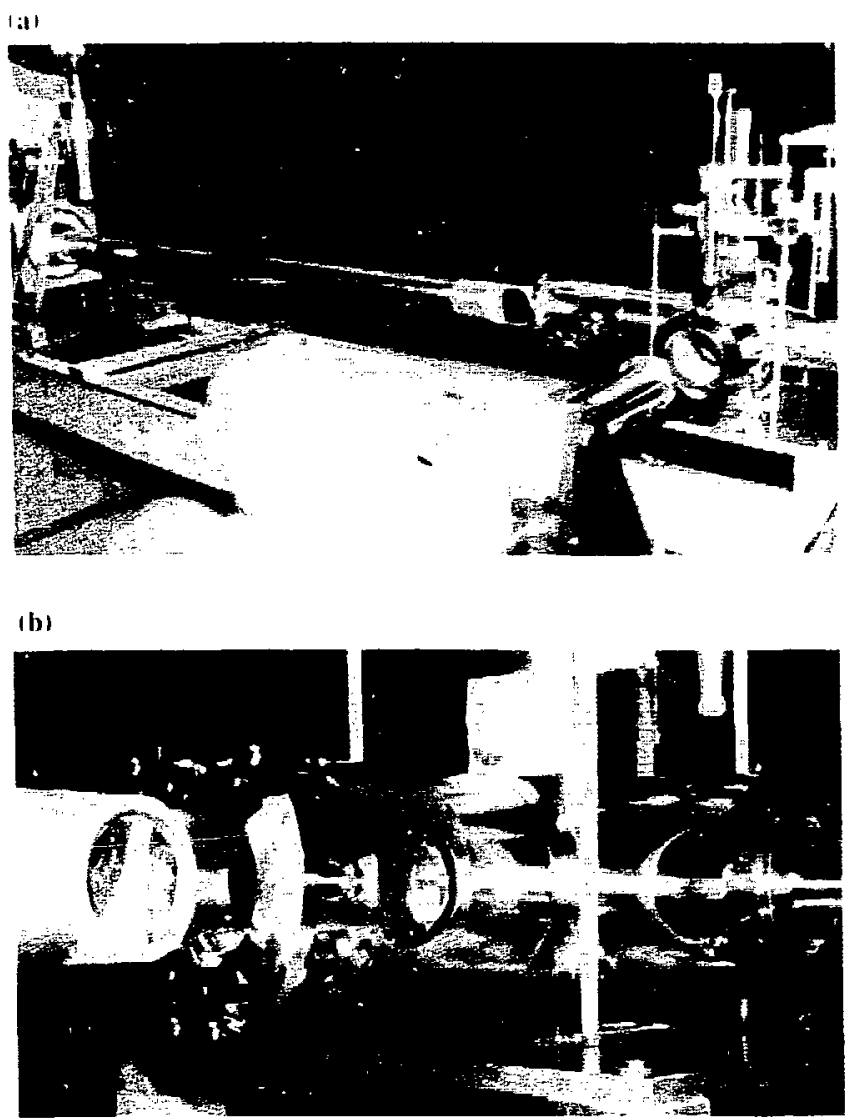

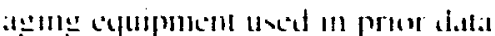
laking. The mow $\because$ sim 1 all he sublantialls fiscer. merre reliatle. inct more thesible.

Our eyperimental apparatus has heen improved and uperated in several wals an accommendate the crsogenic surec and to ented back "around problems found in carlicer datia. Moditied complonemes include the spectrometer. the collimbater. atrd the reflectur. The yectrometer hat hecoll modilied la increatse ils acceptatlos mat resolution. The collimatlo has heon aldusced lo produce an experimcinal resolution al 3.1. He hale designed a new rellectur with higher aceptance that eliminates batchenumd discomered n the early phasc of this work.

()ur spectromcler. which contalins at number of significant improvemems. Nill som he malled with the newly fabricated. crnogenic tritium source. All work this sear has

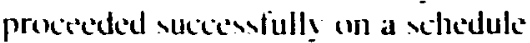
that will permit us to comduct experiments wilh frozen lritium in Fy'89. This should make us the tirst group amom! the competing Russian. Japancse. Cienman. Su iss. and I ..S. groups able to deted neutrino masses of less than 15 eV. We plan to probe for masses down $10.5 \mathrm{CV}$ in FY90. 


\section{Nuclear Shape Isomers as Candidates for a Gamma-Ray Laser}

Principal Investigator: M. Weiss he overall goal of this project is to explore the possibility of making a gammat-ray laser based on nuclear storage stattes. Last vear. we identified shape isomers ats the most promising nuclei. This vear. our main objective was to complete static Hartree-Fock calculations of osmium and mercury nuclei to delineate those species with secondary minima in their potential energy surfaces and to identify those most likely to yield experimentally verifiable shape isoriters. A second aim was to begin work on incorporating nuclear dynamics into these static calculations. A third goal was to complete our semiclassical calculations of laser-induced nuclear transitions and to hegin to look lor quantum-mechanical corrections.

Toward our main objective, we have completed three-dimensional potential-energy maps for 12 evennumbered osmium isotopes with the Skyrme III nuclear potential and for 16 mercury isotopes with both the Skyrme III and the more modern SKM* ${ }^{*}$ potential (Weiss, 1988). From these we have selected mercury-194 (Figure 1) as the most accessible for experimental verification. and several experiments are being designed.

Toward the second goal. we have begun configuration-mixing nuclear Hartree-Fock calculations that will
We have used the most modern techniques of nuclear theory to predict a new class of nuclear isomers efficacious for the design of a gamma-ray laser. We have identified several species for experimental verification. Advances in many-body theory, in progress, will refine these predictions by adding nuclear dynamics and will permit calculation of branching ratios and lifetimes. provide dynamic corrections to our slatic results. The algebra hats been completed. and computer codes are being tested.

Toward the third goal. we have formulated a solvahle quantummechanical model that yields an analytic solution to the Schrödinger equation for an atomic electron in an intense laser field. We have derived expressions for the nuclear transition rates from coupling to the atomic electron. Numerical evaluation of the analytic formulas is in progress for comparison with our semiclassical calculition (Berger. 1987) of the nuclear transition rate and inversion density.

For future work, our primary objective is to test and implement the

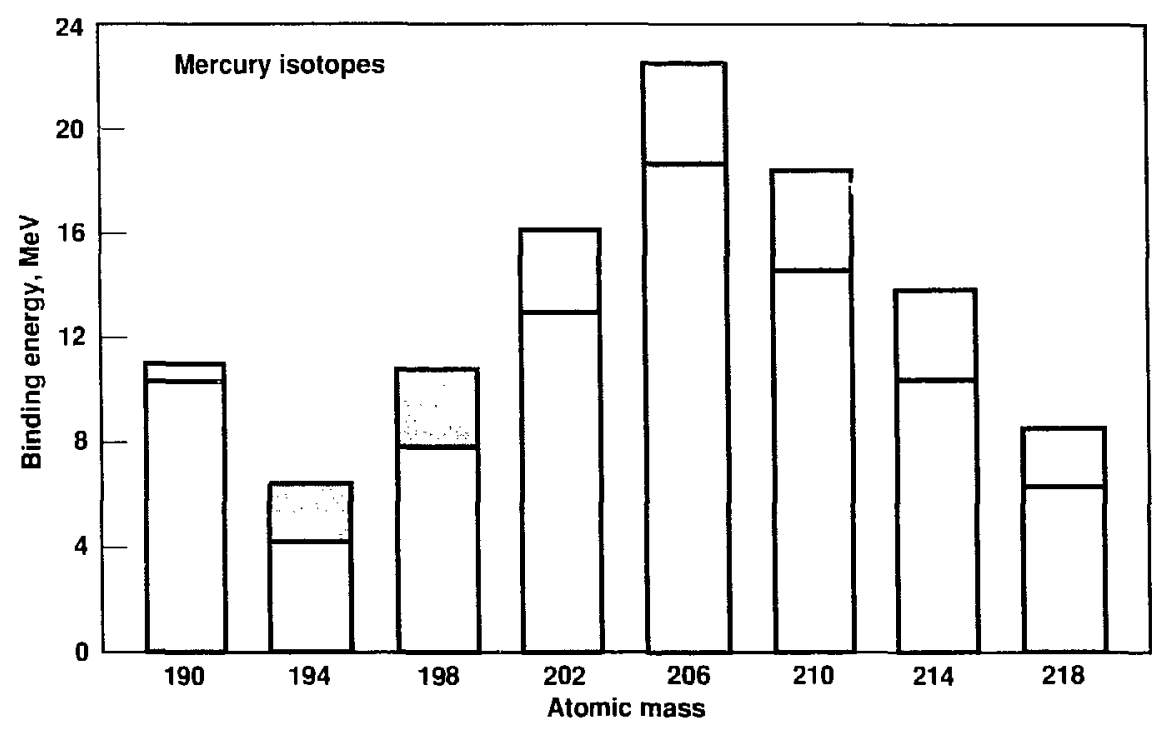

Figure 1. Excitation energy (dark gray) and well depth (light gray) predicted for shape isomers in mercury isolopes. Mercury-194 provides the best ratio of excitation energy to well depth and has neighboring stable nuclei that can also be used as targets. 
contiguration-mixing nuckear Hartres-Fock theory: to appl! it to dynamic corrections lo our static predictions. and 10 extract lifetimes and branching ratios. We hope also to be able to test the physies on actinide nuclei for which fissioning shape isomers hate been measured. On the basis of these results, we inay look into other regions of the periodic table for nuclei that may have more inleresting properties as laser storage states. In addition. We will finish and evaluate our solvable model of laseratomic electron-nucleus interaction and "ill compare it with our semiclatssical calculation.

A spin-olf of this work that is latr less demanding technically is the possibility of generating multi-keV per atom explosives by triggering an isomer to decay. It will do so by emilting a cascade of gamma rayss. and. if the ground state is stable. there will be no radioactivity. Speculations along these lines using the lar-less-efficient spin isomers have been reported in Soviel journals (Arulyunyam, 1987: Avramenko. 1986). We will carry out some preliminary estimates along these lines in the coming year.

\section{References}

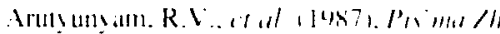

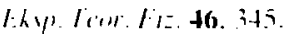

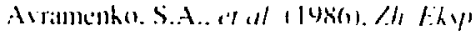
lour.tiz.91. 953

Berger. J. F. D). (ingens. and M. S. Wiem (1957). Lam rence Lisermore Nattonal Lahoratery. Preprint L'CRI_4, iU: also

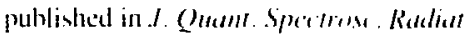
Trumser (December losks.

Weiss, M. S. l Jexk, "Shape Inemers as Candidaters lon the Gammat-Ra! Laser

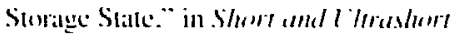

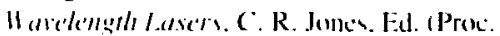
SPIE: 8751. 


\section{The Femtosecond Laser Project}

Principal Investigators: Y. Landen. R. M. More, D. C. Stcarns. and I.. M. Campheil

\footnotetext{
D
} uring the past year. we completed the construction of at short-pulse laser that produces pulses with a 0.33-ps pulse width and exhibits excellent energy reproducibility. We characterized the laser output using pinhole-focus, autocorrelation. and spectral-analysis techniques, and verified that a transform-limited pulse is indeed produced (Figure I). When focused to a several-times diffraction limited spot. this laser will be capable of producing intensities in excess of $10^{14} \mathrm{~W} / \mathrm{cm}^{2}$.

We also investigated the interaction of a high-intensity, picosecond laser probe beam with a preformed plasma. The plasma is produced first by focusing a pump picosecond laser beam onto a solid, planar target of gold, silicon, or carbon. X-ray yield is produced by a second probe beam. We monitored $x$-ray yield as a function of the intensity, polarization, and angle of incidence of the probe beam and of the relative time delay between pump and probe beams.

The measured $x$-ray yields, plotted as a function of beam polarization and angle of incidence. are chracteristically produced by a
The very short pulse of a subpicosecond laser allow's us to heat solid targets to plasma temperatures $(1-50 \mathrm{eV})$ before hydrodynamic expansion occurs, producing a thin layer of target material at solid-state density and plasma temperature. Studies of matter under these unique conditions will help resolve fundamental questions about atomic processes, previously inaccessible to direct experiment, that occur at high densities in stellar interiors, laser fusion targets, and nuclear weapon experiments. combination of inverse

bremsstrahlung and resonaince absorption processes. Figure 2 shows resonance absorption for a gold target with a pulse delay time of $10 \mathrm{ps}$ and a laser wavelength of $583 \mathrm{~nm}$ : a theoretical fit to these data yields a critical density scalelength of $75 \mathrm{~nm}$.

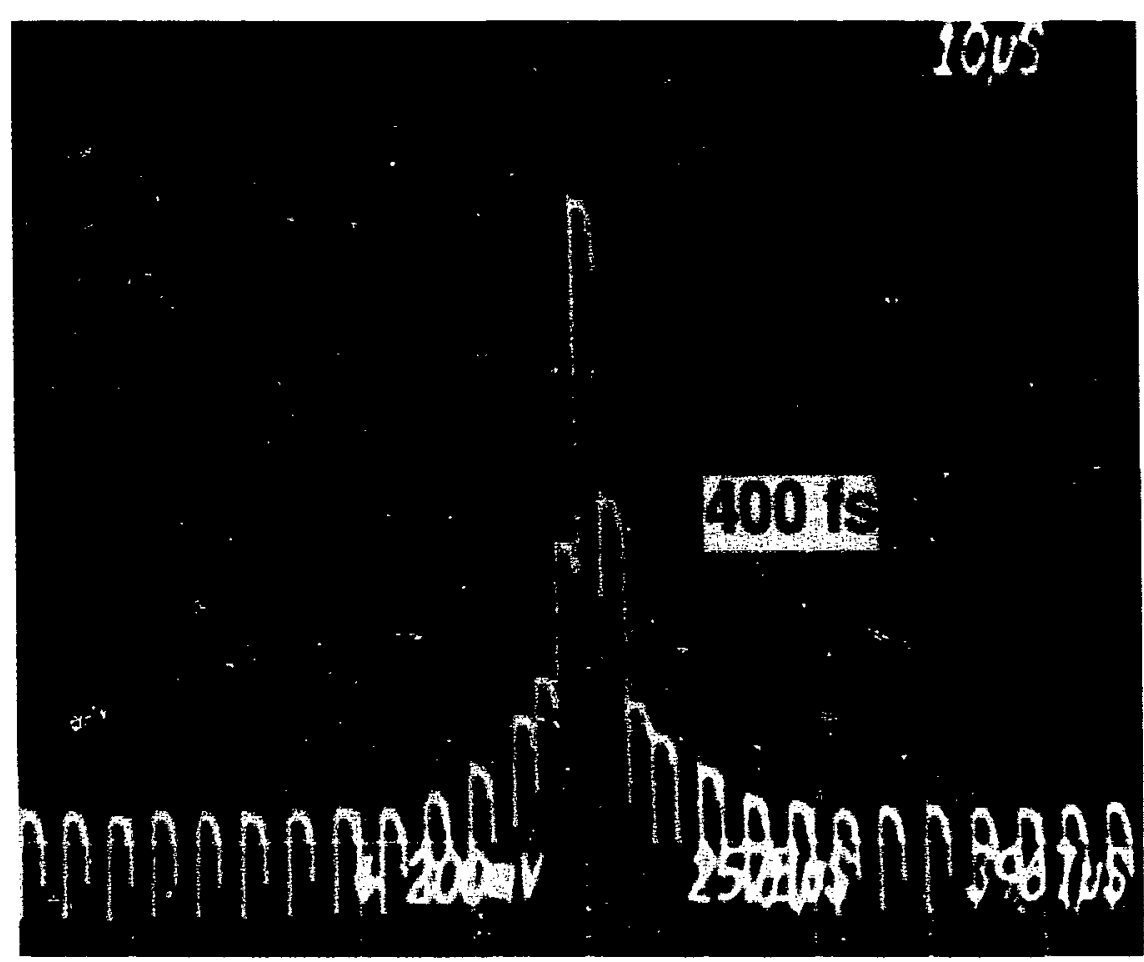

Figure 1. Autocorrelation curve of an amplified 583-nm laser beam showing a 400-fs (full width at half maximum) pulse. 


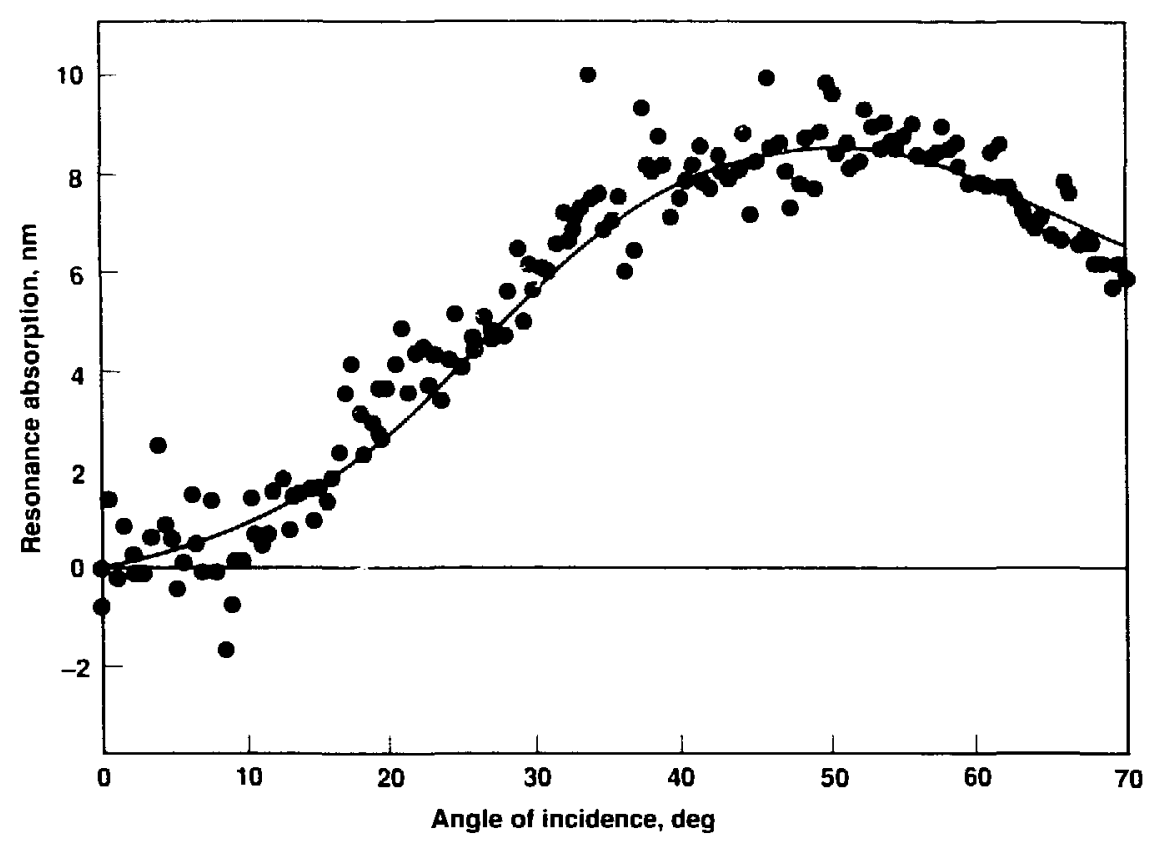

Figure 2. Measured resonance absorption vs angle of incidence of the laser probe beam. We used a gold target, a laser wavelength of $583 \mathrm{~nm}$, a pump beam intensity of $10^{13} \mathrm{~W} / \mathrm{cm}^{2}$, a probe beam intensity of $10^{14} \mathrm{~W} / \mathrm{cm}^{2}$, and a 10 -ps delay between pulses. The solid curve is a fit to theory that assumes a linear density gradient, yielding a critical density scalelength of $75 \pm 10 \mathrm{~nm}$.
Bi mciasurme sälelemenh for

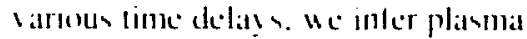
hlou-off selocilien on al plecosecond time scale. The shortes atalelength measured to datle is $2010 \mathrm{~mm}$ ant represcents an improsement in spattial resolution at altmons luo orders oll magnilude over more consentional interferometric lechniquers.

Our theoretical worh centered on inferpretation of aluminum reflectivity data taten by our collaborators at A.T.\&.T. Bell Laboratories. The exe experiments show al minimum reflectivits of $3.5 \%$ (p-polarization). which closely mirrors the theoretical minimum electrical conductivity occurring at target lemperatures of $10-20 \mathrm{eV}$.

Next year. we plan 10 retine the two-pulse experiments to provide a direct measure of the larget's surface expansion velocity for various materials in the preheat temperature range $(1-50 \mathrm{eV})$. We will also consider a second method of measuring expansion velocity based on Doppler shilt of the incident laser radiation: measurements by this method have been performed al Bell Laboratories, and we will analyze those data. In addition, we will make a number of improvements to the SPRINT computer code used to calculate short-pulse laser-larget interaction. In particular. we will extend the code to treat interband transitions in more complicated metallic target materials and to allow for a limited degree of hydrodynamic expansion during the laser pulse. 


\section{Multiphoton Interaction of Intense Lasers with Atoms}

Principal Insecitigaturs: 1. Sanke. J. \. Bardeles. I. I anden, and MI. I). Perr!

I

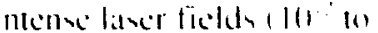

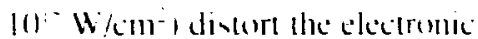
structure of atcoms and ionise them when electrom abuorh man! photoms The ofjecries of aur experimental and theoretical research is 10 demonstratce clearls the role of intermediate exciled stater in multiphoton ionization. We used our time-dependent Hartree-Foch. splitoperaltor, and yuantum-defect coder to simulate dalta from experiments performed at LLNL. Bell Laboratories (Murray Hill. NJ). and Saclay (France). This work has dispelled nus:h but not all of the controversy regarding the ionization process and the associaled production of high-order harmonics. Figure I shows that our model calculations are in very good agreement with experimental results. Our work, both experimental and theoretical. has been extensively published.

We plan a second year of experiments, designed primarily to explore the effects of electron correlation. An improved electron spectrometer will be built to enable us to take full advantage of the current lasers and to ensure a continued flow of new data while more powerful lasers are being designed and constructed.

In our theoretical efforts for next year. we will continue to perform calculations: on multiphoton ionization and harmonic generation to complement current experiments.
Our laser facility, designed to carry out a variety of physics experiments, is now in full operation. We are investigating the process of multiphoton ionization and the properties of materials in the warm (few-electron-volt) solid-density phase. We are also assessing the physical phenomena that may be accessible with future, more powerful lasers.
We will apply the imeight geanded the veatr w computer simulations of the interation of cers intence labers

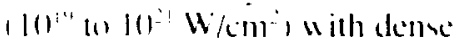

gilsere and wolids: his will help us lo identity tuture applications of shortpulse. high-iniensity latsers. Initially: we "

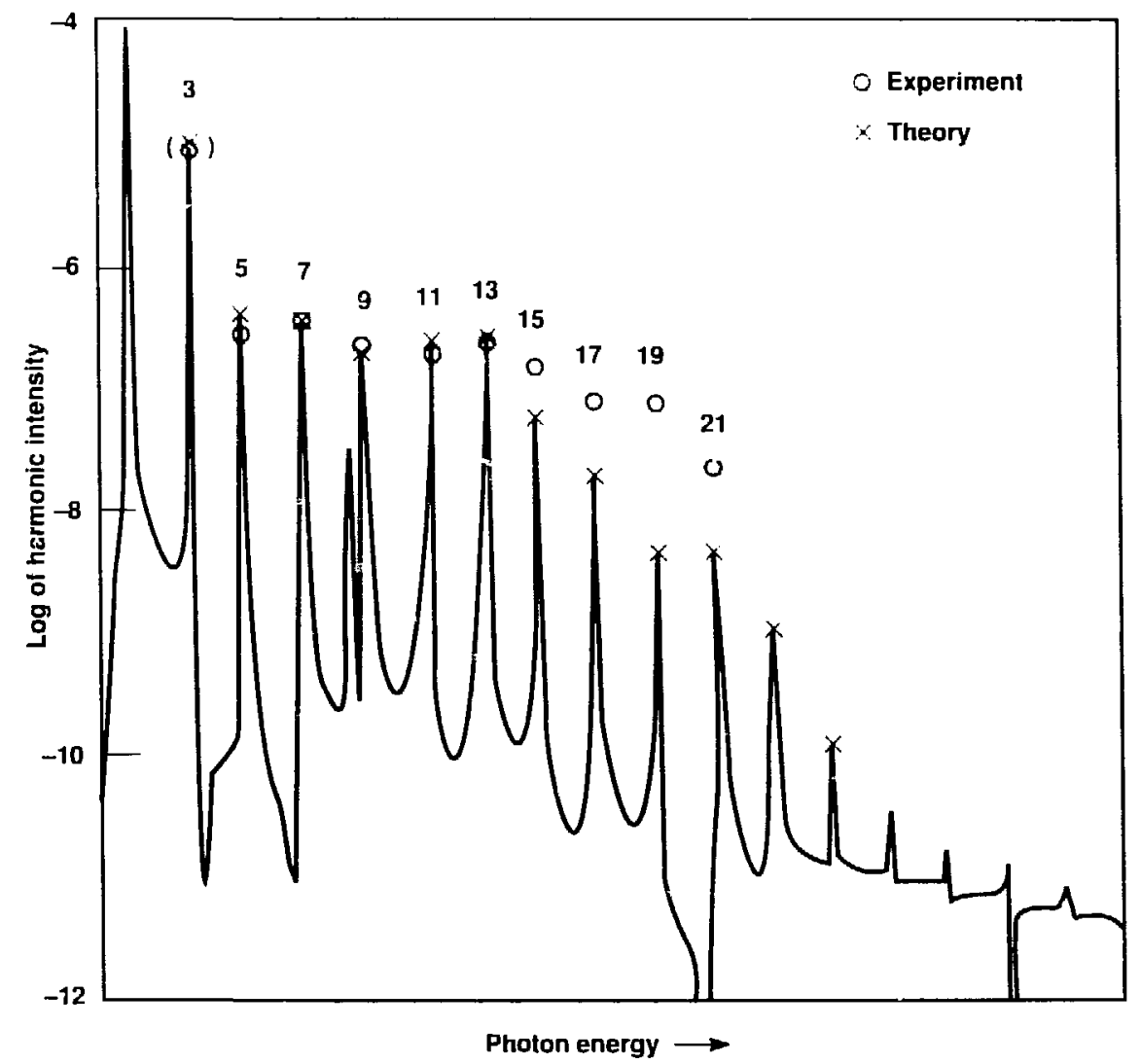

Figure 1. Predicted $(x)$ and measured $(0)$ harmonic intensities demonstrate intermediate states in xenon gas excited by $1.06-\mu \mathrm{m}$ laser light. The numbers above the lines identify the harmonies of the laser frequency. Computer results are scaled to agree with the measured seventh harmonic intensity. 


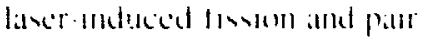

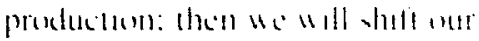

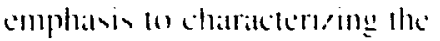
production on colds. sromgly lomed plasmas sutable for recombinatlon everme-ultratioled laners. This latler suds will be perlowmed in conjunchon w ith an allal! sis ol vinilar electron-heam-plimped lasers intialled at the requen of the lose Janon Study Ciroup.

\section{Refierences}

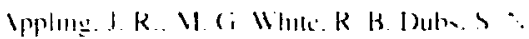

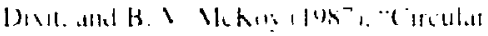

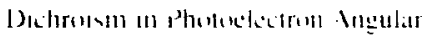

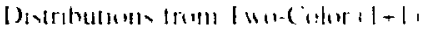

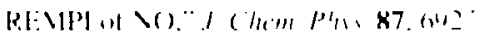

Cirgan. ( .. and R. kimlotl +1487 . " VanPenurhatace Treatmeth of Pantise

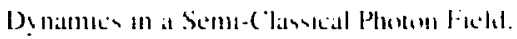
$I P M B 20 .+4 I$

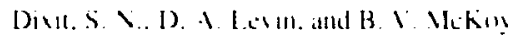
1/4Sis. "Revonant Enhanced M/uluphortun!

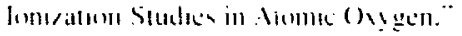
$P / 1, R+137+2311$.

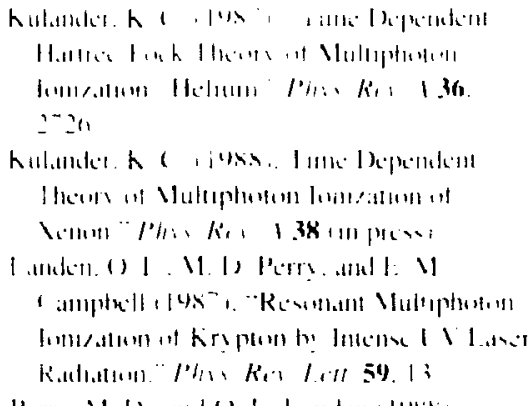

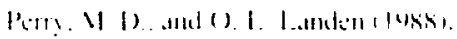

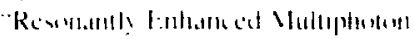

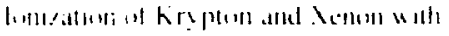

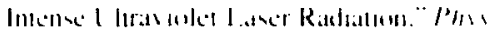
kit 138 in plan

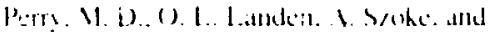

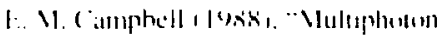

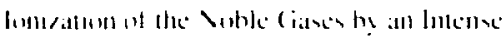

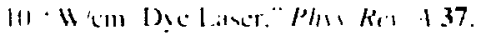
$74:$

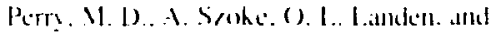

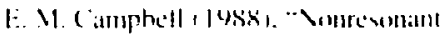

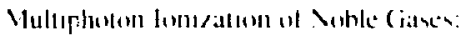
Theors and fepersmemt." PMW Re't Leth. 60. 1 .

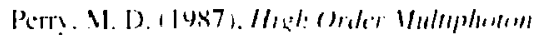

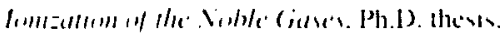
I moversity of Caltfornat. Berhetey.

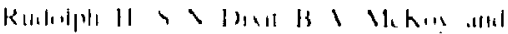

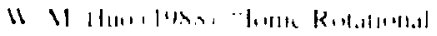

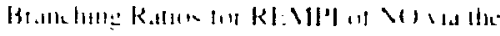

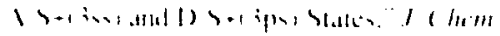

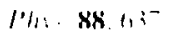

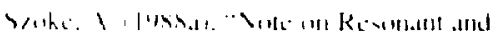

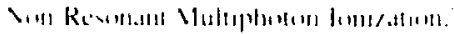
$1 / M, B \geq 1.125$

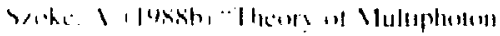

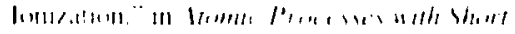

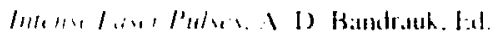

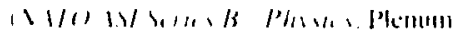
Pren, Dal I

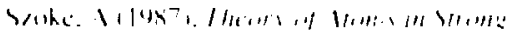

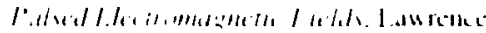

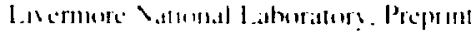
I ( RI - 45? 24

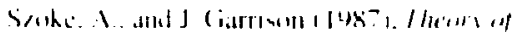

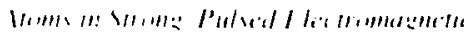

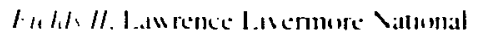

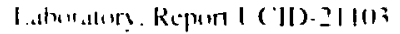




\section{Modeling Trace Gases and Atmospheric Chemistry}

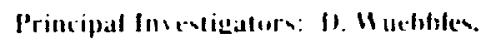
l. Ponter. and VI. Vace rachen
Our atmospheric models have played key roles in national and international analyses of the possible effects of trace gases on atmospheric ozone. We are now extending them to address the impact of trace gases on climate and on global atmospheric chemistry in the troposphere and stratosphere.
$\mathrm{D}$

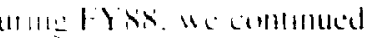

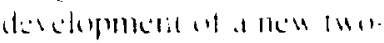
dimenumbal I andally ateraged

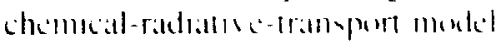
of the ghat tripherphere and

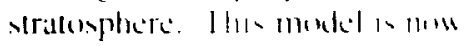
uperatturial and a heing unde in study the polestlos mintate of chlorofluorocartam . md other trate gases on chemistry and climatc. There a a presing need for vuch reseurch. D. ASt is even nom sponsoring weveral conceptual designs for high-tly ing. hypersmic transport aircraft. although vtudies done in the 1970s. before sophisticalled models were avaliable. found a hen sensitivity of stratospheric ozone $\left(0_{i}\right)$ to nitrogen axide $\mathrm{NO}$, emissions from possithe future flertis of high-flying anreratt.

Comprehensive studies of tratcegas effech w ill require further development of our model. We must include additional leedbalck of atmospheric chemical and radiative processes with advective and eddy transport processes. and eventually climatic feedback processes and interactions with the oceans and the biosphere. To make the model more representative. we must find ways to treat the effects of wave interaction. on eddy transport and to handle chemistry-wave interations. We also need to make the model more efficient computationally to permit gratler revolution and longere

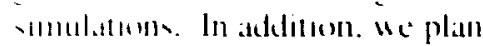

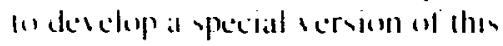

mo-dimeneional model hior detailed

vadien ol global troperpheric

themiver: we will insentigale the

porsibilit! of coupling this model

with a lwo-dimensional ocean model

for vudies of alir-sea chemical

interations.

We are also working to der clop

a global. three-dimensional

tropospheric transport.

transformation. and deposition model for imsestigating subcontinental. hemispheric, and global-scale perturhations of the realctive chemistry of the troposphere. Such a model is needed to study the international impacts of various energy policies and complicalted climate-chemistry interactions. Within the past year. several atlemipts to simulate the tropospheric distribution of several long-lived species (whose chemistry can essentially be ignored) have been published. both by our group and hy others.

We are developing a tropospheric reactive-chemistry model. using the Lagrangian approach embodied in our GRANTOUR model, that should accurately portray the gradients and spatial heterogencity present in the tropospheric distributions of reatctive species whose sources are primatrily continental. With this model. we will initially treat species that react promarily whth the hydron! ( ) radicat: $\mathrm{VO})\left(\mathrm{CH}_{4} \cdot(\mathrm{C})\right.$. and

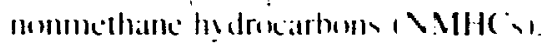
The vraighteruard cheminery of

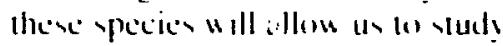
their eycles as we develup and relince the model. The ney vep will he w"

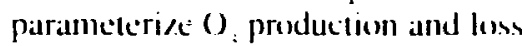
for the concentration of these species. The concentration of $\mathrm{OH}$ will also hecome a parameterised function of the concentrations of the wher species. During FY89. We expecl to complete our studies of the NO and

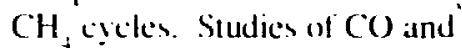
VMHC s. as well as the development of a parameterised chemistry model for $\mathrm{O}_{\text {, and }}(\mathrm{OH}$ will be carried out in FYo().

\section{References}

Kimmsm. D. H. Johmenn. alrul D. Wuetorles

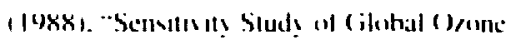
wo N( ) Enussions trom Aircratt." Pron

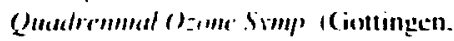
Federal Republic nf (iemmany)

Walton. J.. J. Penner. and S. Hameed I laksi.

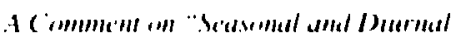

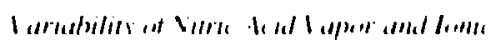

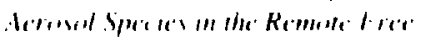

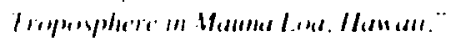

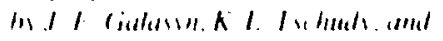

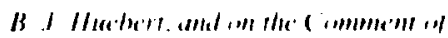

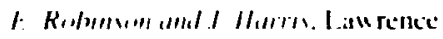

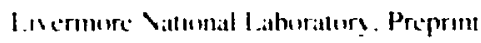

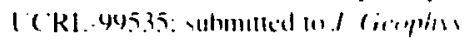
Ris 


\section{Global-Scale Climate-Chemistry Modeling}

Principal lnsesligalurs: 1 . I ise

I). Wuebbles. J. Penner. and M. Macl racken
$\mathrm{O}$ ver the past seleral !ears. interest hats increased in the potential global-scale effects of human activities. Emissions of carbon dioxide. methane. nitrous oxide. carbon monoxide. reaklive hydrocarbons. and other species pose the potential for significant chemical and climatic change. In addition. potential effects of global-scale nuclear war include significant chemical and climatic interactions among atmosphere. ocean. and land domains. Only models. carefully tested against observations. can address these issues.

Recent evidence of global climatic warming due to industrial activities (the greenhouse effeco) has stimulated attempts at realistic oceanatmosphere modeling. Accordingly.

To meet DOE programmatic requirements for addressing potential global-scale environmental perturbations arising from energy and national-security activities, we are developing three-dimensional interactive models of the climate and chemistry of the coupled atmosphere-ocean-land surface system in both prognostic (predictive) and diagnostic modes. The models will eventually cover scales from regional to global and domains from the deep ocean to the stratosphere. As interim steps toward this five-year objective, we are developing, testing, and applying a suite of models incorporating various dimensions, domains, and physical-chemical processes.

last year we fireused our global climate modeling (GCM) efforts (nI dssessing the effects of oceanic heat transport on present-day climate and on simulating possibic climatic changes. Results from the tirst of these efforts support our hypothesis that changes in oceanic heal transpon can be counteracted by compensating changes in atmospheric heat transport (Covey. 1988). In the second effort. we examined the sensilivity of climate to changes in ocean surface temperalure and atmospheric aerosols. We postulated massive dust loading following impact of an asteroid or comet with the earth at the time of the Cretaceous-Tertiary boundary and at other times in the distant past. Surface temperature reductions resulting from blockage of sunlight by dust resemble but are more severe thitn. "nuclear winter" (Figure 1 ).
We plan to extend our almospheric $G \mathrm{CM}$ studies 10 model sersions that include the cicle of the seadsons and more realistic trealment of Iurbulence and surface processes. We also propose to test an intermediale-stage atmosphere-ocean model in which the almosphere is represented by our GCM but the ocean is represented by a simple model of the upper mixed layer only. The foregoing steps. in addition to being necessary preconditions for developing a complete coupled ocean-atmosp.tere model. will continue to produce useful results concerning ol mate processes and sensitivity.

\section{Reference}

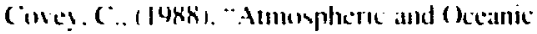
Heat Transport: Simulatim crous

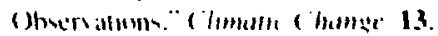
1+4. 154. 


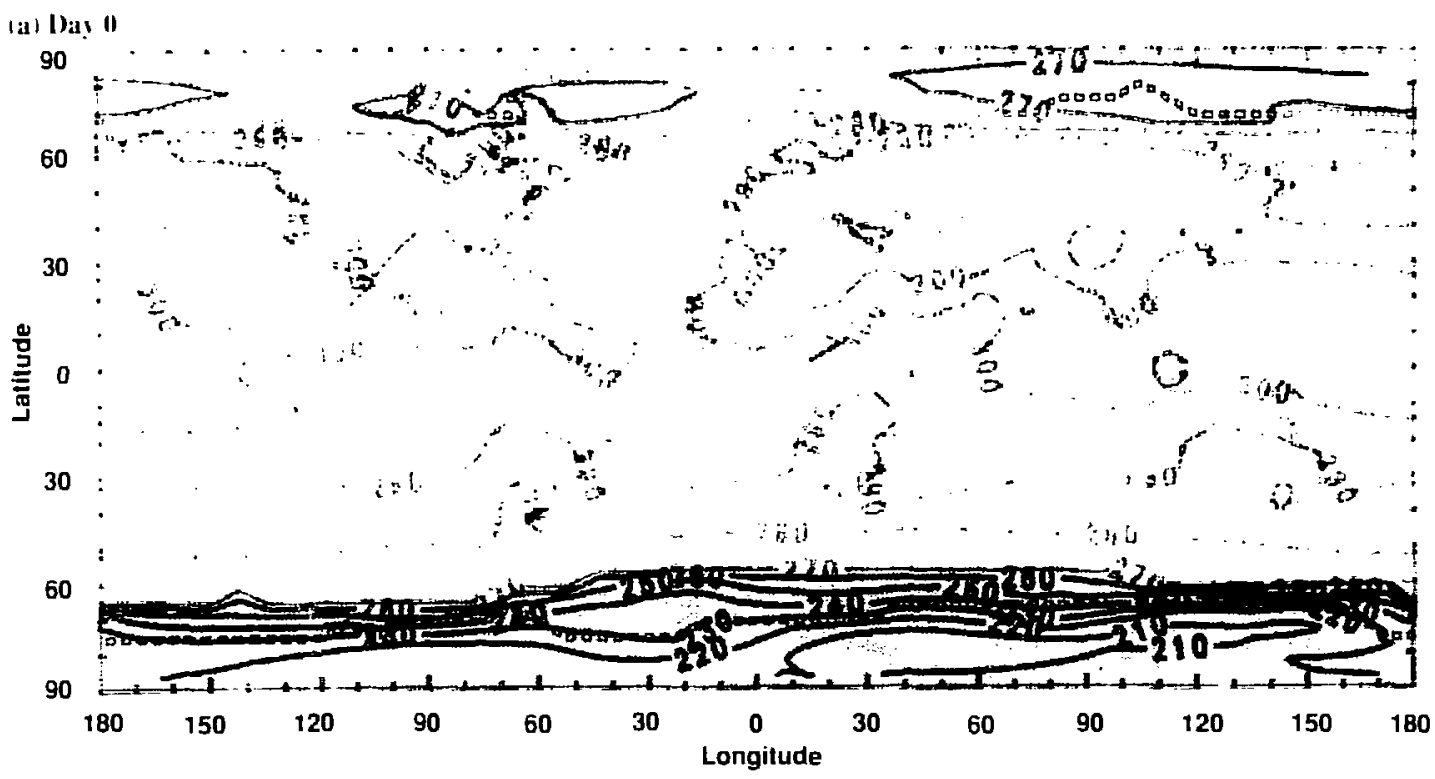

(b) 1)ays 10-20

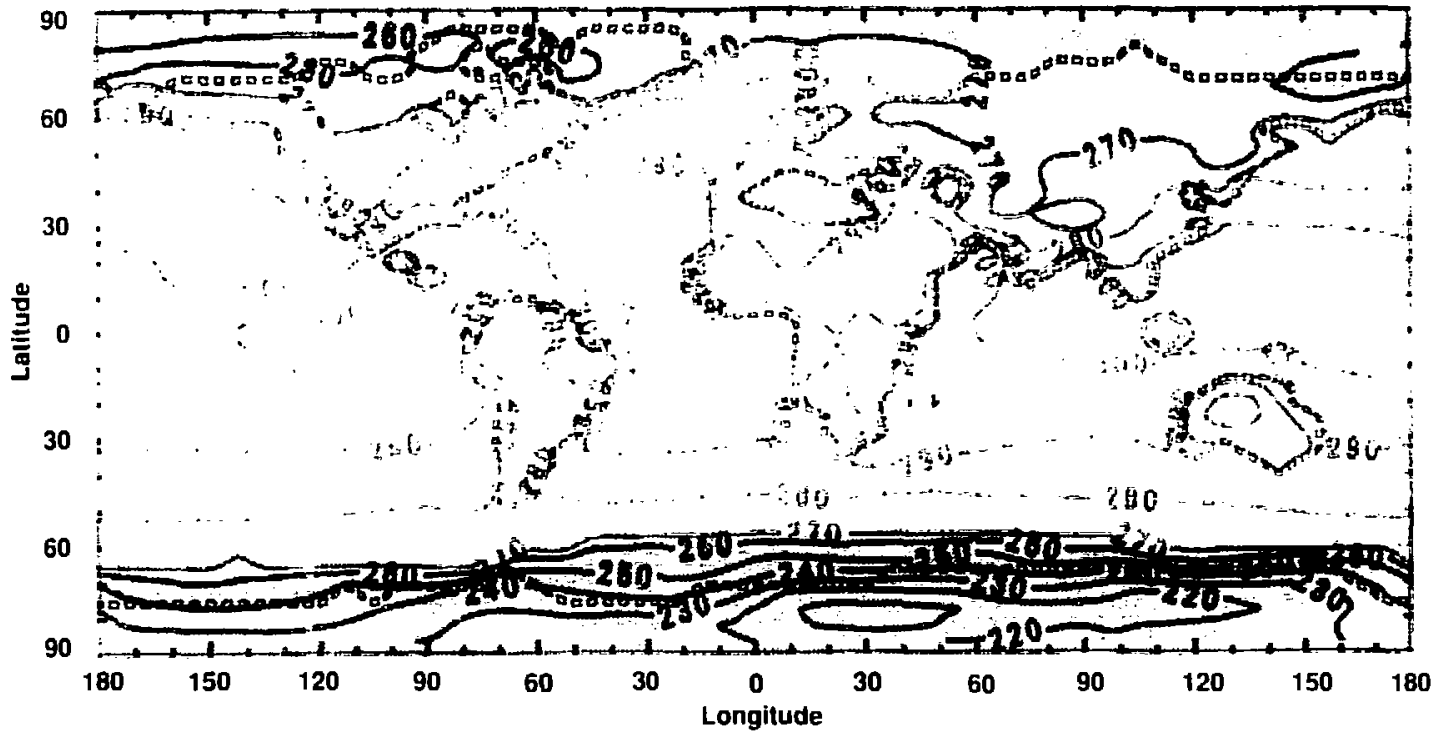

Figure 1. Isotherms show temperature response (in kelvins) of our global climatc model to stratospheric dust aerosols generated by hypothetical impact with earth of a large asteroid or comet at the end of the Cretaceous era, about 70 million years ago. Extensive terrestrial and marine extinctions at that time included the disappearance of the dinosaurs. The amount of dust assumed saturates absorption of both visible and infrared radiation: virtually all sunlight is absorbed at the top of the model's atmosphere. and the dust acts as a blackbody in the infrared. Surface temperature reductions are qualitatively similar to, but more extreme than. those obtained in "nuclear winter" simulations: the global average of land surface temperature drops by about $15 \mathrm{~K}$ between Day 0 , in mid-July (a), and Days 10-20 (b). nearly reaching the freezing point. Cooling is concentrated in the eastern (downwind portions of the large Eurasian continent, however, with temperatures generally above freezing (>27) $\mathbf{K}$ ) elsewhere. 


\section{Director's Initiatives}

(i. L. Struble
The Directurs Iniliatives are a select group of larger projects ehonen by the LLNL Director for their lechnical merit and their potential to develop into large. independent. multivear programs. Proposals are submilted by the appropriale Associale Director, who agrees lo field a leam ol expert scientists and engineers and to manage the project. The proposals alle carrefully reviewed by the IR\&D Review Commitlee and by inviled specialists from inside and outside LLNL. Their recommendations are submitted to the Director for his approval. A lypical Director's Initiative is funded for no more than three years at $\$(1.5$ to $\$ 1.5$ million per year. Ealch project is reviewed by the IR\&D Review Committee all least lwice a year. In FY $8 x$. 14 Dircclor's Initiatives were supported. for a total of $\$ 6.5$ million.

The Director:s Initiatives for biotechnology addressed three lopies with broad impact: the ecological effects of low temperature and fow light that are projected to lollow nuclear war. the application of monoclonal antibodies as immunochemical sensors lor monitoring environmental pollutants. and the use of recombinan DNA techniques to address environmental. energy production. and resource recovery issues. IR \&D funds are also being used to track the national energy supply and demand: this helps us anticipate future energy trends and adjust Laboratory research elforts accordingly.

Beam research seientists are đeveloping retaivistic klystrons as a power source for hiogradient joceleraters. Such klystrons could be used for large. linear electron-pōsitron colliders, compału accelerators, and free-electron laser sources. Two relativistrk

Laboratory expertis thers is beifo extended in three Initiatives. In the first. new processes are being developed for growing the large. optically homogeneous crystals required for high-power lasers. Problems in optical homogeneity plague existing crystal-growth methods, and new process development is crucial to the future of solid-state lasers. The removal of waste heat is a serious problem in diode-array lasers: a second project is adapting silicon microchannel coolers, originally invented for wafer-scale integrated circuits. to cool laser diode arrays. In the third project, researchers are developing the technology to create three-dimensional. high-resolution x-ray holograms of biological structures in vitro. a long-sought goal of both $x$-ray-laser and biological research. The IR\&D also sponsors a project to develop nonstandard high-resolution imaging techniques to overcome the atmospheric distortions that currently limit ground-based observations of objects in space.

One of the Laboratory's long-standing missions is the development of low-cost fusion energy. The goal of the Compact Torus project is to demonstrate the proof of principle of accelerating and focusing plasma rings magnetically confined by the fields of a compact lorus. If successful. this work will provide the basis for an accelerator that could serve as an efficient. low-cost. inertial fusion driver, as a fast-opening switch. as an injector for magnetic fusion machines, and as an $x$-ray generator for simulating nuclear weapon effects.

Finally. the Director's Initiatives are supporting two projects to develop the tools and techniques needed to design. manulacture. and test the complex digital processors of the $199(\mathrm{l})$ and the 21 st century. These will be very highly integrated, with electronic assemblies containing millions of components on a single 10- to $15-\mathrm{cm}$-diameter silicon wafer. The goal of one project is to develop the computer-aided design tools for optimizing the layout of these complex circuits; the goal of the other is to devise the new fabrication techniques that will be needed. 


\section{Biological and Ecological Effects of Nuclear War}

Principal lnvestigators: .l. K. Kercher and 1.. K. Anspaugh

$\mathrm{O}$ ur goal is to determine the biological and ecological effects that would be caused by a period of reduced light and temperature that has been projected to follow a nucleal exchange. We first convened a work shop to develop an agenda for such reseilrch (Kercher and Mooney, 1985). The work shop recommended an approach that distinguished between agricultural systems and natural, unnanaged ecosystems. It also recommended research at the

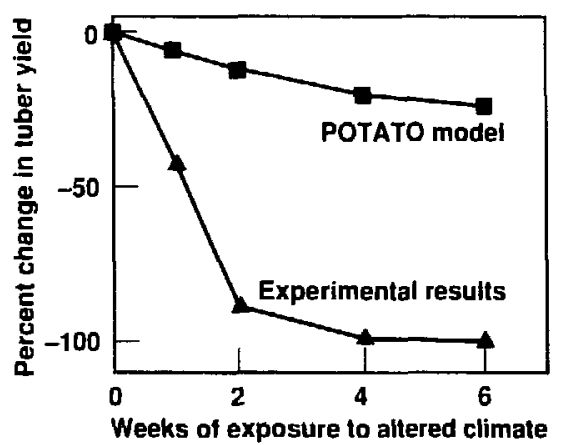

Figure 1. Comparison of calculations on tuber yield from the POTATO) model versus experimental data on potatoes from the University of Wisconsin Biotron. The large disagreement at extended exposures 10 altered climate conditions is due to the inability of the POTATO model to simulate the mortality of tops of potato plants observed during recovery from altered climate.

We are developing our capability to assess the effects of climate change caused by nuclear war on both agricultural and natt:ral ecosystems. We found that in two of the three tested crops, existing crop models do not predict the results of experimental treatments of lowered light and temperature. In addition, our regional model of forest recovery indicates that reforestation of dominant species occurs in a regular pattern, whereas reforestation of subordinate species is irregular and stochastic.

organism. community. and regiona! levels of resolution for both agricultural and natural ecosystems. The report from the workshop stressed that the physiological responses of interest would arlse from a climate regim z outside our current research experience, and new phenomena might well be observed.

We are implementing these recommendations by carrying out two types of studies. The first includes coordinated experimental and modeling studies on individual crops to provide the capability for an agricultural assessment. The second includes modeling studies on natural systems at the regional scale to assess the recovery potential of unmanaged systems. We identified integrated modeling and experimental studies at the plant level as necessary precursors for crop assessments (Detling et al., 1988). We studied the three crops-wheat. potatoes. and soybeans- hat rank first, third. and eighth. respectively, in global production. In natural systems. we are continuing our modeling of forest recovery at the regional scale. The unique computational capabilities att LLNL lend themselves to research in this area: regional studies constitute a new field in ecology. and exploratory work should yield large returns.

In FY88. we compared the output of existing models for wheat. potatoes. and soybeans to the experimental response to reduced light and temperature obtained in prior years (Cowles el al. 1988). As described below. we found that existing models for wheat and potatoes do not exhibit the phenomena actually observed in experiments. In soybeans, on the other hand. an existing model does yield an adequate description of experimental responses (Kercher et al.. 1988a).

In research funded by LLNL and conducted at the University of Wisconsin Biotron (Rose et al.. 1986 and 1987), potatoes. wheat, and loblolly pine were exposed to a $99 \%$ light reduction and a $15^{\circ} \mathrm{C}$ temperature reduction for $1,2,4$, and 6 weeks (soybeans were exposed for 1 and 2 weeks only). Potato yield was reduced by $42,89.99$. and $99 \%$ for the 1-, 2-. 4-, and 6-week treatments, respectively. No potato plant tops survived the 4- and 6-week treatments, and most plant tops for the 2-week treatment died as well. In contrast, the POTATO model of Ng and Loomis ( 1984 ) predicts yield reductions of only $10,23.48$. and $72 \%$. respectively. In this nodel. reduced yiclds result from reduced top growth during the treatment period and natural leaf senescence resulting in reduced levels of net 
production recosen lor tuher grom dh Figure 1 (ompares ihe PoTta) model for tuber yield with the Wisconsin data. The model did nes predict the plant-top mortalit! observed in experiments.

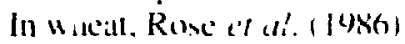
found that ! ield w its reduced ower the same fout ireatment periods by (1. 71 . 86, and $81 \%$. whereas the CERES wheat model (Otler and Ritchic. 1985). predicted a yicld change of $+24,+3,-26$. and $-38 \%$. respectively. Although a dramatic decrease in tiller and spike production occurred between the I - and 2-week experimental treatments. the model predieted no such reduction. The yield loss computed for long treatments can be attributed to reduced top growih and natural senescence in the model simulations.

Experimental yield reductions for soybeans were not significant for the 1- and 2-week treatments (Rose "t al.. 1986). The SOYGRO model (Jones et al.. 1987) predicted a yield reduction of 4 and $8 \%$. respectively: the GLYCIM model (Acock a' al.. 1983 ) predicted no yield change for both treatments. Rose at al. (1987) have suggested that compensatory growth occurs in pine and soybeans after the treatment period. but no such grow ii occurs in wheat and potatoes.

The conditions we have studied lie outside the range of experimental experience on which most crop models are based. We conclude that existing models do not simulate the phenomena that occur in wheat and potatoes under such unusual conditions.

II: have continued to develop our regional-scale model of forest recovery. VISTA (Kercher 't al.. $1988 b)$, which is constructed as a grid of community models spread over a landscape. At each grid square. the community model SILVA

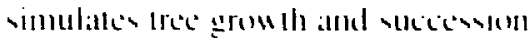

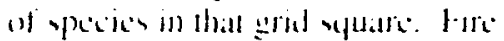
and seeds call ypreatd from one grid syuare o another. During Fyss. Me compleked moditications in V'ISTA Io allou emprirical functions of eced spreatd. afnd we irrstalled seced spread functions exarated from the ecological literature. We also performed preliminary lests of model performance and examined the reforestation responsic of a mixedconifer forest to at massive dislurbance. Our simulations indicate that reforestation is regular and deterministic for the dominant species and irregular and stochastic for subordinate species.

Figure 2 shows a simulation of reforestation from seeds of a mixedconifer forest deposited in one corner of a $2(\%)$ by $2(0)-\mathrm{m}$ area. Figure 2 a shows the ponderosa pine balsal areal 50 years after seed deposition, just before maturation and seed production. The term "basal area" refers to the lotal cross-sectional area of a species in the stand: the basal areal in the figure is in square meters per hectare. Figure $2 \mathrm{~b}$ shows the hasal area 100 years after seed deposition from mature trees. A monotonic decrease in seed dispersal from the source results in larger values of basal area near the source. At 200 years, availablc seed no longer limits basal area growth. Other species of the mixed-coniler type persisted near the original corner but were not as successful as pine in dispersing throughout the area.

We plan to study the biological assuntions embedded in the crop models that produce the discrepancies between predictions and observation. We will examine the possible modifications of the models" treatments of aging. Wilting. and phenology (timing of life slages) that might improve predictions for conditions of reduced light and temperature. We also plan to

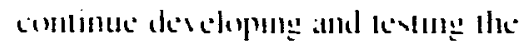

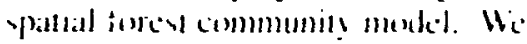
expect to improve the subnoudel concerning waler relations for increased accuraty for Califomial copolong. lo include otler Californiat coniters, and (1) mathe combariome of model results to selected data from Calitornat toress.
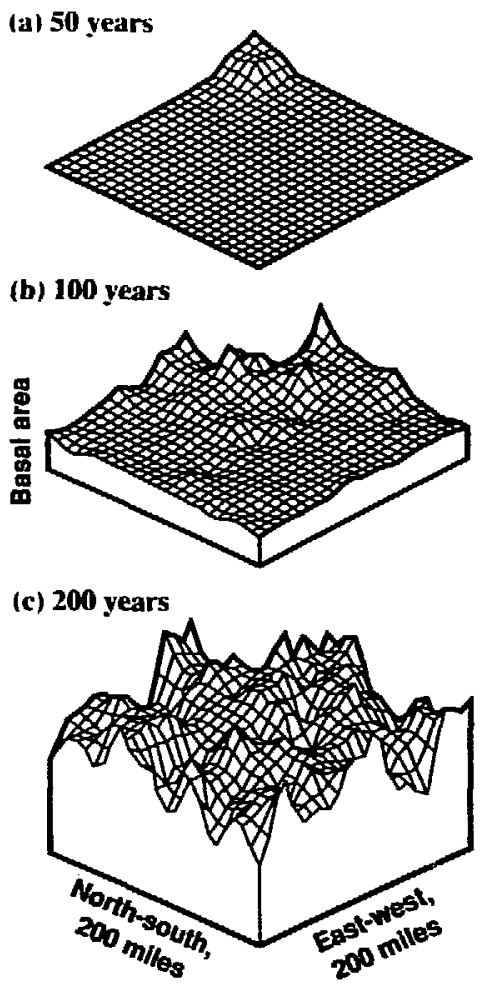

Figure 2. Simulation of reforestation at three times following a massive disturbance. (a) Basal area of ponderosa pine $\mathbf{5 0}$ years after deposition of a mix of seeds of the mixed-conifer forest type in one corner of a 200- by 200-mile area. The onset of maturity occurred approximately $\$ 6$ to 4 y years after seed deposition. (b) Basal area of ponderosa pine 100 years after deposition. (c) Basal area of ponderosa pine $\mathbf{2 0 0}$ years after deposition. 


\section{Referentes}

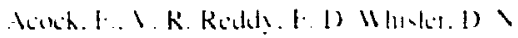

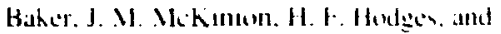

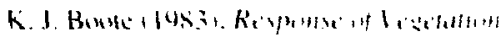

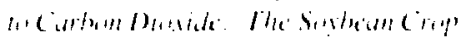

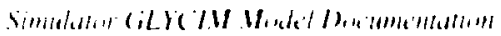
IMS: Department of Agromom!. Mlmimppe Agriculture and Fircelr! Experimental Statum. Mimimippi State Cniberil! Mminippi State. MS.

Comk. S.. 1. R. Kercher and P. 3. Tate

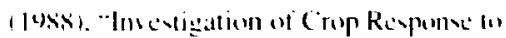
Climitc Aheration Induced hy Nackar Exchange," Bull Fon. Sin Amer. 69 lahuract, in prew.

Detling. J. K. J. R. kercher. W. .I. Pont. S. II. Comles. and M. A. Harnell a lesisi. Priorities for Mheding Biological Precerses in Clintate Alered hs Nuclear War, in Pro. Horhs/mp on Ecolnesical Elfe't all Vialear Her. Technoluge! Applicalion Center Report \&s-2. Liniversity at Ven Mevico, Alhuyberyus. VM.

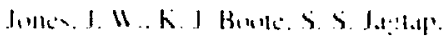

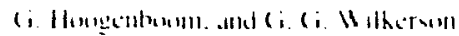

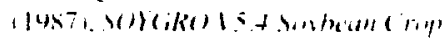

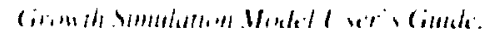
Aericulural fengin:ersuge Department and

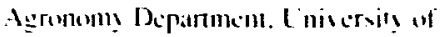
Florida. Ciandesille. FL. and IBS. SAT

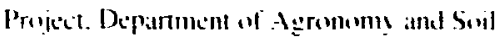
Sicnea. Lnisersit! of Hawaii. Honolulu. Hl: Florida Agriculuaral Esperimental Statlion. Joumal Xir. Nith

Kercher. J. R. S. C.M L. P. Talt: and L. K

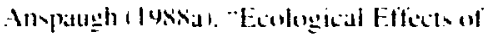
Climate Changers Caused h! Nuclear Watr."

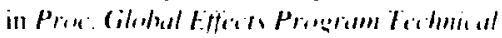
We'tim: dDetiense Nuclear Agenes. II ashingtun. D.C.I.

Kirsher. J R. S. M. Lmochicd. and D. Fleddermlan $11488 \mathrm{~h}, \cdot$ Mlodeting Dy namic of Spatial Helerogencit! in is Mixed-Conifer Landscape." Bull. Fow. Sore. Amer. 69 (ahowriti, in press).

kiercher. J. K. and H. A. Mouney. Eds. 145.5,

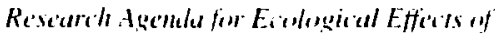
Vilc lear ll imer. Law rence Livermore Sational Lahoratory. Keporn LCRL-5358

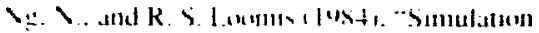

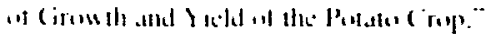

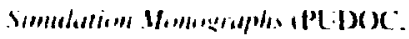
Mageningen. The Xetherlands.

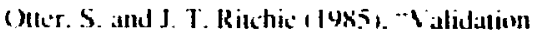
"the ctRES Whe: Mlendet in Diverse Environments." in 11 heal amal cirsurth Madelin: W. Dal and K. K. Athin. Eds. i $A T O$ Adranced Silencie Invilutes Series $A$ : Lile Sciencis. Plenum Press. VY. Vill sh. pp. 3117-3111.

Rome. E., J. Palta. B. M/.Comn. T. Tihhitts. and .11. Vinulli ( I9א61. "Prentuctis ils ol Ninter Whealt and Penatedes during a Vuclear llialer Sienario." A:momem! Abatrats American Societs of Agronomı . p. 14.

Reme. E.. P. Palta. B. McCoun. T. Tihhills. and M. Vinotli $1487 \%$, Promluctis its o1 Lohlolly. Pines and Soygheans L!nder a Nitclear Winter Seenario." Plame Plicsial. 8.3. 71 . 


\section{Monoclonal Antibody Research and Instrumentation}

\author{
Principal Investigator: 11. Ianderlaan
}

\section{We are building two biosensors that combine the specificity of antigen-antibody reactions with microelectronic sensors using our antibodies to dioxin and pesticides. One sensor is based on changing the vibrational frequency of a piezoelectric silicone membrane; the other is hased on an optical-fiber fluorescence detector.}

\begin{abstract}
chemical "alstes. We halle shomn that immunochemical metheds are comparathle in vensilivity 11 lechniques ot comsentional analstical chemiars lior envirommental monitoring while offering considerahls lasler vample andilsus. Thin sear. "le hale heen integrating our antihodies imo fwo new rensin!
\end{abstract}

assaly sy sems for detecting environmental pollutants. In past gears. we hate developed at het of monoclonal antihodies fo dioxin and various pesticides. Methods hate atso heen retined for extrateting these pollutants from food. wil. and devices. The destees differ from combentional antegen-antihod! immunochemical absats in that the! proiske an electronic nutput. are suibable for microliabrication. and catl polentiall! wfier moline immunochemical delection.

In collaboration with the Selluell and Actuator Center all I C Berketes! "le have designed and tabricaled surtace-alcoustic-uale

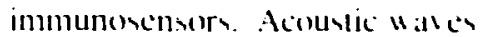
propalgate in picselectric ersyals and are influenced hy changes in the cristal surface. The delector vhoun in Figure 1 consises of at silicon water coatced on one side "with silicon nitricle and with /inc wide a peranelectric materials. The silicun is elched allat complesels. kaaring a rectangular well abuul 1 cm in areal. where the immumohemical redelion occurs. The remannm! metmbranc at silicon milride and sinc aside is induced to ascillate h! lanuchme: a wate from one interdigitated aluminum tranuducer. The wate propagalles acrom the mesmbran : and is detected with the secomel antennas. Becature the warelementh of the ancillatum is longere hath the thechases at the membralle. Walle

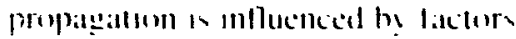
wh boll vertace al the membrime IIth the deber. We Lath meatsure hill - H alle part per mollow the lome

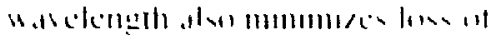

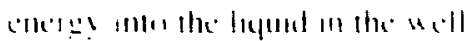

Figure 1. Surface-acoustic-wave immunosensor. I silicon wafer is coaled with a layer of cilicon nitride and a piezelectric layer of ainc oxide. Vext, a well aisut $1 \mathrm{~mm}$ wide is chemically etched in the silicon. leaving a thin membrane. Ifter an aluminum oscillating amplifier circuit is printed on the bottom of the anembranc. a wave launched from one antenna is received b! the other. When antibod! and frec antigen are added to the " ell. the amount of antibods bound to the membirane causes a shift in frequenc! In the acoustic wase. We can enhance antibod! delection bs increasing antibods mass through eonjugation (1) colloidal goidd. 


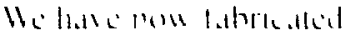

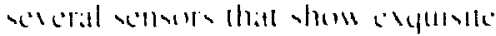

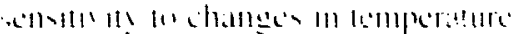
premare. flual demsil. thual

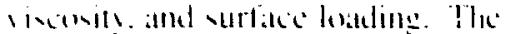

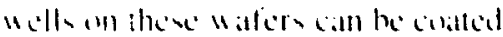
wh antestl. and the antitinl in whlionl $\therefore$.

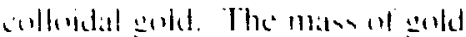

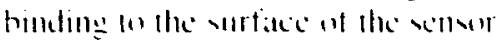
hould prodece at reatils deketahle

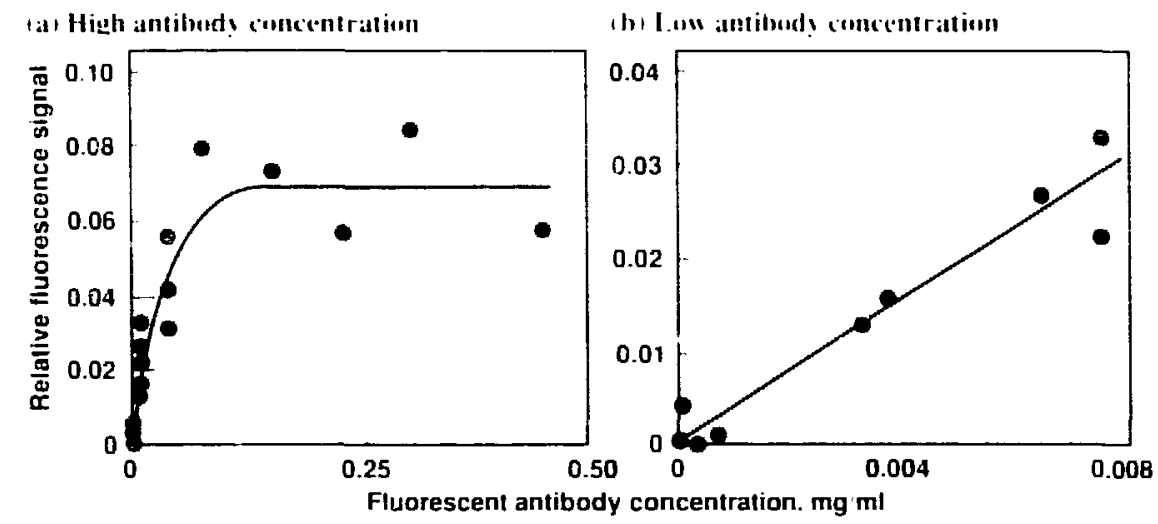

Figure 2. Flumescence signals recorded by un optical-fiber probe. Filores were coated with albumin-phenow bensoic acid and incubaled with the PY - I

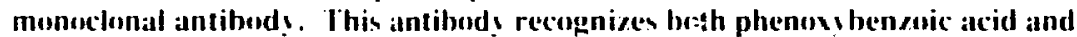
permethrin. a widel! used insecticide. The PY - I antibod! was conjugated to nuorescein to proside a fluorescence lag for detection. ial Fluorescence saturales in antibody solutions $>11.1 \mathrm{mg}$ ml. F.yuilibrium fluoresence was reached 10 min after placing the fiber in wolution. (b) At low concentrations of antibudy. nuorescence is proportional to antibods concentration.

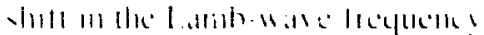

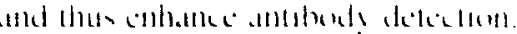

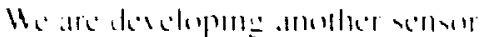

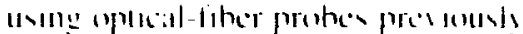

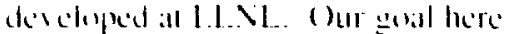
has heon to fahriatle immomosemers

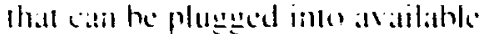
upical hardmate fir measurements of ens iromental pollution. In this work. alllecen is colled on all oplical

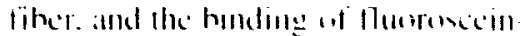

(h) I.un antiluds concentration

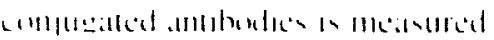
แ1

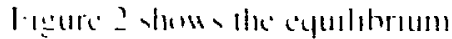

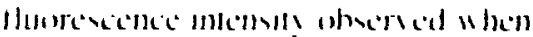
alligentorbaled fiher are incubatled in s)lutions of 1 arious concentrations al

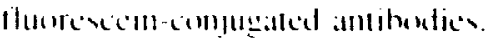

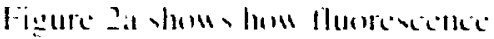

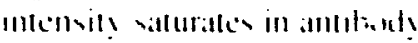

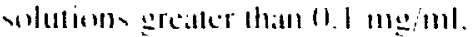

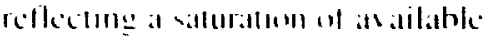

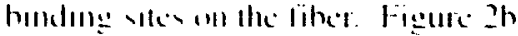

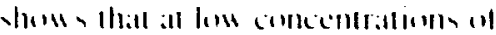

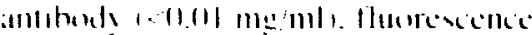

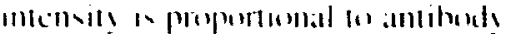

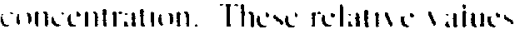

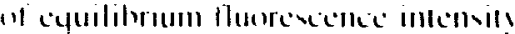

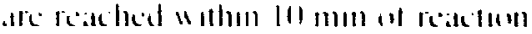

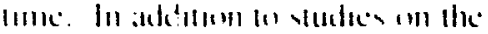
cyuilihrium flunrencellec intemsti!. (p)tall-tiber immumbas a call he uscal la melependenth measure the

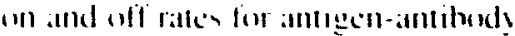
hinding.

\section{References}

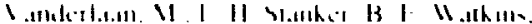

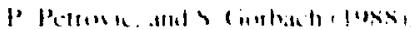

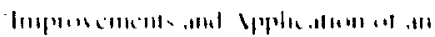
ImImแm,

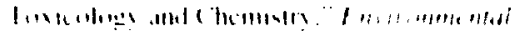

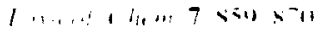

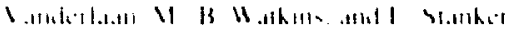

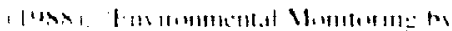

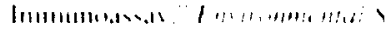
fitm, 22. 24 ב4 


\section{Microbial Genetic Engineering Biotechnology}

Principal Insestigator: F. liarcial (io-lnvestigator: 1. I. Fri
$\mathrm{U}$ जIIE: the lathneque wi recimbinant DAt, ue plan be enhance hincomseremens carred

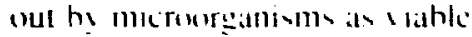
altermate for the reclambation of revercen and the detovilication on encre! - related waskes. Simle of the pomshilite tor the biolectomeloge:

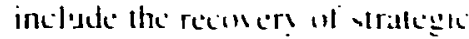
metal- trem the anh. the remorial of prorlle valfur Irom coral. and the

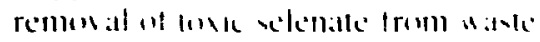
naller.

blut anmentmial chemleal on

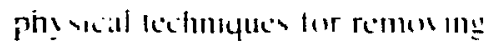
waske preducls and for recosering metals invelue lechnologien that are

We are continuing to develop technologies for the genetic engineering of bacterial species with metal-detoxification and resource-recovery properties. Our effort is focused on two microorganisms: Thiobacillus ferrooxidans will be used as a biological agent for removing pyritic sulfur from high-sulfur coal and for recovering valuable metals from fly ash, and Clostridium pasteurianum will be used in a bioreductive process that may be useful in the detoxification of oxyanions from agricultural and mining drainage waters. We have also started a collaborative project to study the properties and potential applications of new'ly discovered, extremely thermophilic bacteria found in geothermal fluids.

encrey-inlenvide. derrimental to the somiremment. and expensis: Mlicrohial aldisitien that can he substituted for the more cons contumal technique hase distincl advamtages in that thes are smple. emsirommentally safe, and meypenvise. Allhough naturai actillice carriced out hy

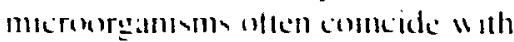
rhome ate-lo itlen that are desirable in leman of hiolectomolegencal

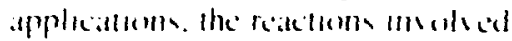
are. for the mow parn. ven. low in

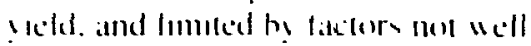
understend. To inderess some of the'e shorleominges. "se are develupmeg genctic engeinetring:

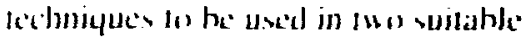
balclertal yecies. Deselopment of thexe lechnique should allow for the elucidation and naanipulation ot pathwas in the bacleria of interen that are cruscial to melal delovilicatton and recoucr.

We hase made mponatia atd ances the ? ear m develuping:

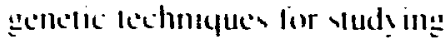

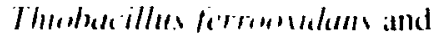

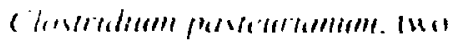
hackeral specke that e hithit uncese reductisc and ondalate propertics. respecties ly. low ards metals. In the area col metal reduction. we hatse

\section{Table 1. Removal of selenate iuns from solution by genetically engineered $E$. coli.}

\section{Original} concentration.

ppm 0 25

50

100

\section{E. coli with pSelr2}

Concentra
ppm
15.3
31.11

319

Percent

removal
E. coli with pUC18

\begin{tabular}{cc}
\hline $\begin{array}{c}\text { Concentration, } \\
\text { Ppm }\end{array}$ & $\begin{array}{c}\text { Percent } \\
\text { removal }\end{array}$ \\
0 & - \\
18.1 & 27 \\
34.3 & 31 \\
80.11 & 20
\end{tabular}

E. coli with pSelr3

$\begin{array}{cc}\begin{array}{c}\text { Concentration, } \\ \text { Ppm }\end{array} & \begin{array}{c}\text { Percent } \\ \text { removal }\end{array} \\ 11 & \\ 18.3 & 27 \\ 34.2 & 31 \\ 42.0 & 8\end{array}$

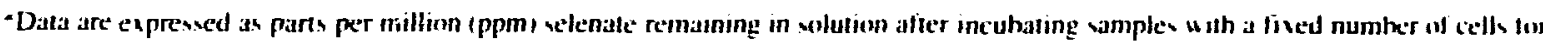

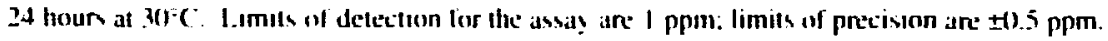




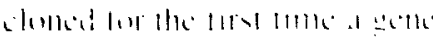

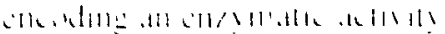

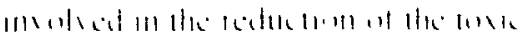

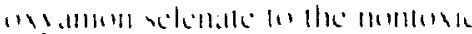

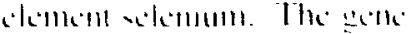

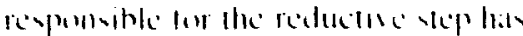

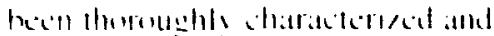

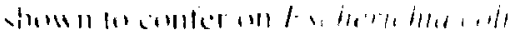

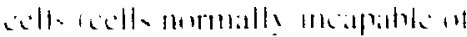

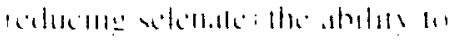

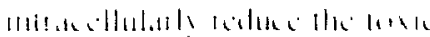

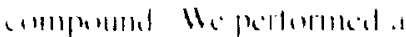

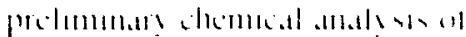

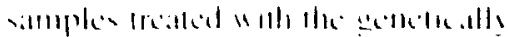

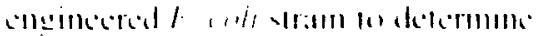

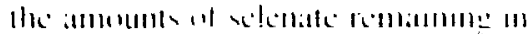

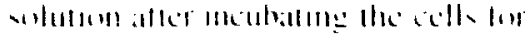

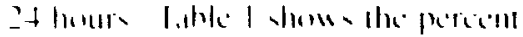

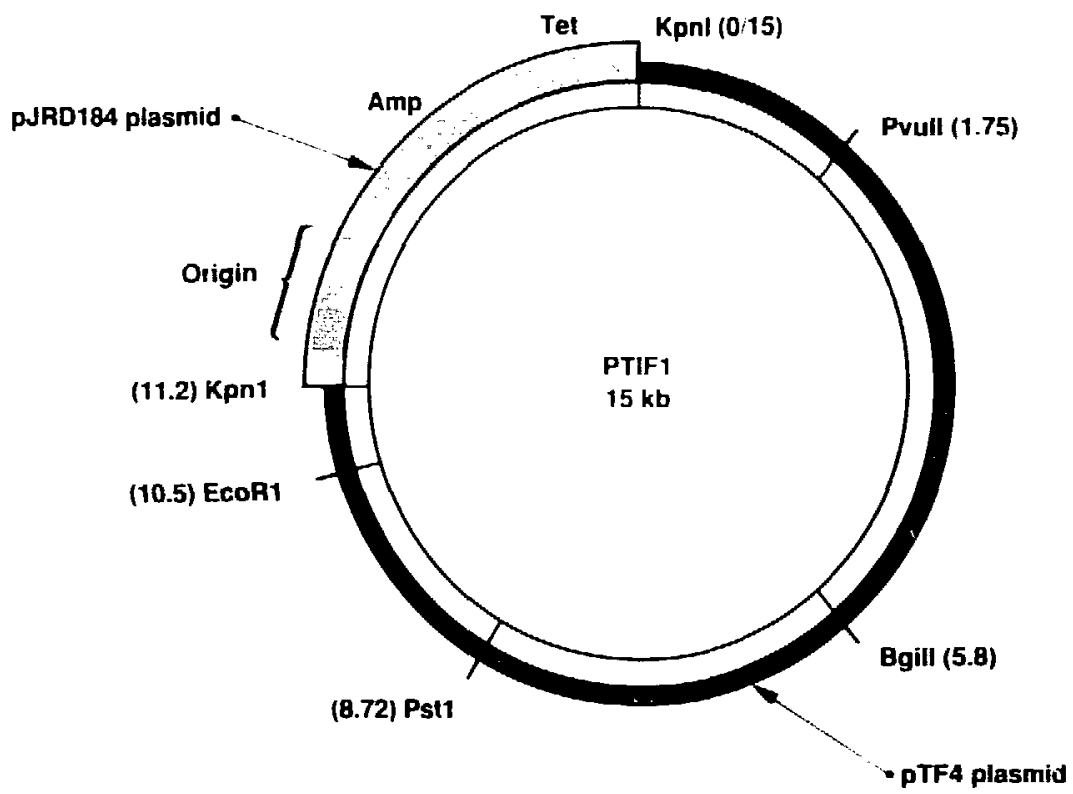

Figure I. Thiobacillus ferrmeridams-licherichia coli hsbrid plasmid. I his h! brid plasmid was constructed hy ligating I) V 1 segments from an $E$. colf plasmid ip.JRI)I84l and a newly diseovered plasmid lirom $T$. ferrooridans ip Tr+l. Pasnid p.JKDI\&4 contributes genetic information that allows replication of this hyhrid plasmid in $E$. coli cells and genes for ampicillin and tetrat' for selection and maintenance of the plasmid. Masmid pitft contributes appropriate genetic information for replication and maintenance of the hybrid plasmid when resident in Thiobacillus host cells. The term kl refers to the viec of the plasmid in kilobases or I0MO) bases (such hases are the building hlocks of W 1 . vumbers in parentheses are the dislance in bases from an arbitrary heginning to a gis en point in the plasmid. Designations such as Kpnl and l'oull refer lo sifes in the plasmid al which specific I) M.1-cutting en/s mes eath act. The origin at repication is the part of the plasmid insolsce in making new copies at the time of ceell dis ision. Ihe lostal sise of his hslorid plasmid is I5 hb.

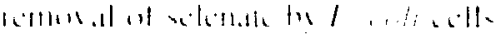

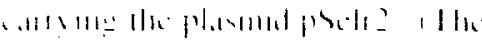

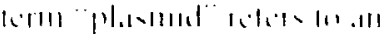

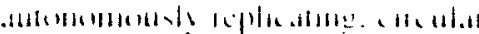

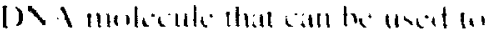

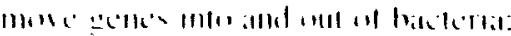

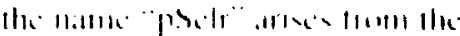

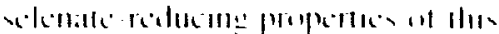

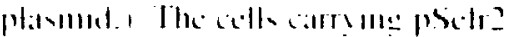

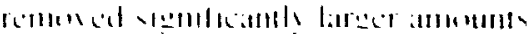

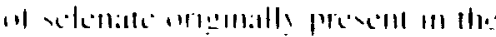

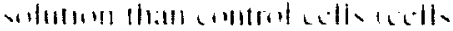

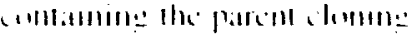

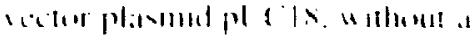

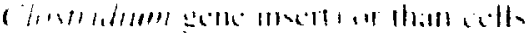
whl ble plasmol pselt: in wheh

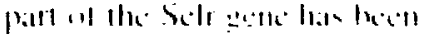

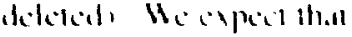

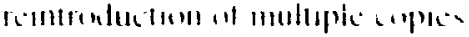

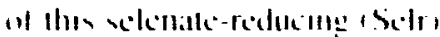

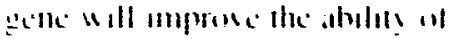

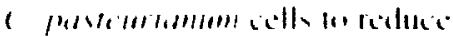
sekenalle. Wi are correml!

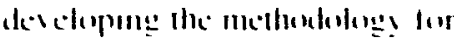

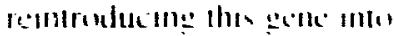

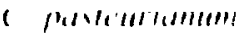

The useful prophenterat

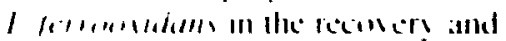

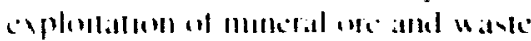
defondicallum alepend an the

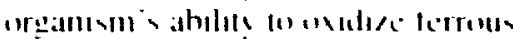

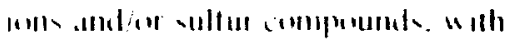

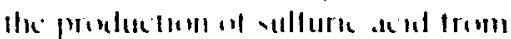

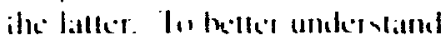
the a werall xheme an the sulfut

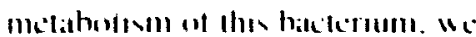

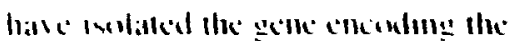

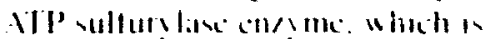
lle lird soreme in the sultu

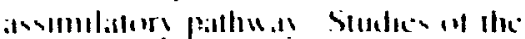

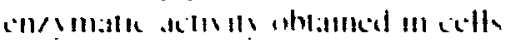

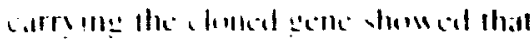

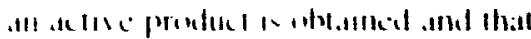

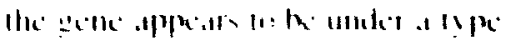

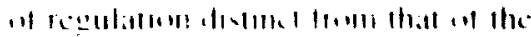
1 , hl himl

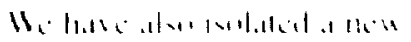

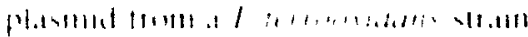




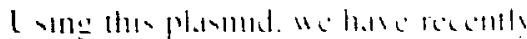

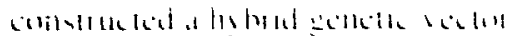

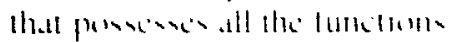

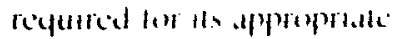

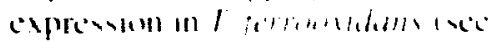

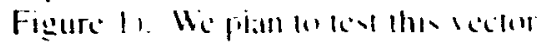

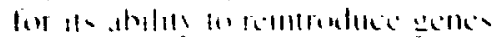

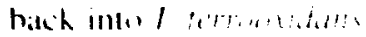

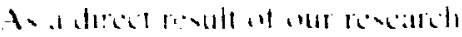
under the pregraml. we hate: wablished a lowe perent

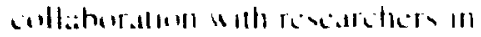
the I atheratem V Farth sicences

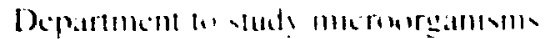
living under everme lemperallures and presures He hate analsad

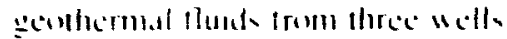

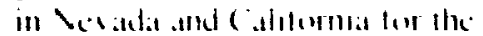

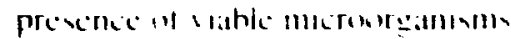
Batckeria w ith murphoseluge that are charackorelte of estreme thermophiles theat lewers hate been abereded repeitledly hy phasecontrat mormedps in eash ot the "alter simple" ablamed thu tar. ()ur prelimmary studere indeatled thall some of the "rogeams the latborators at temperalure as high an 105 ( $)$ Ho hasc recently cultured in large number ance clawill

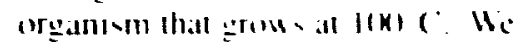

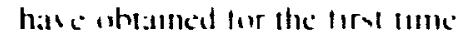

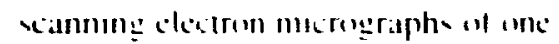

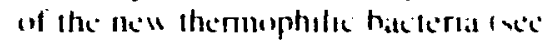
Figure 2. Eventually we hope to identify themmitalic hacteria from which we can develop biolechnologies fir uas in subvarlace procesong of mineral. organtc. and geothembal " asken. Vincl. healresistant biscatalyw and bicpolymers obtanced frem such

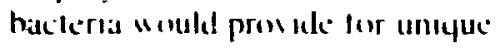
ene?mattc reacilems at hegh lemiperature and the prenlucterisi on unparalleled huseleoriatathls: he:al restiant plasles

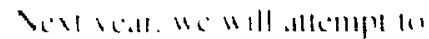
.

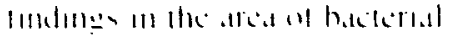

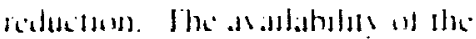

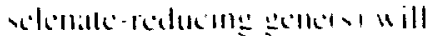

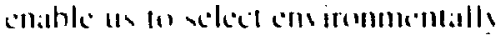
meturing halderia from celemum-

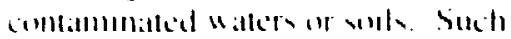

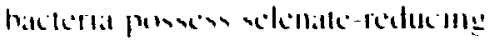

\section{'at I ivihle-light micrograph}

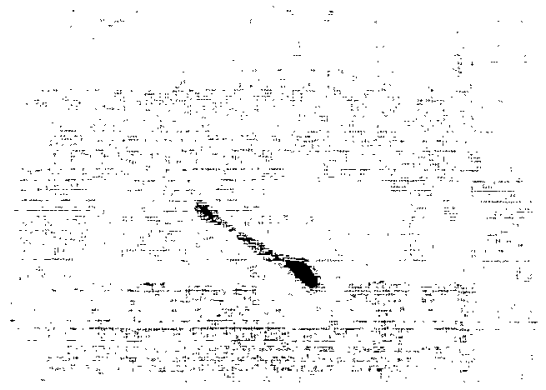

(b) F.lectron micrograph

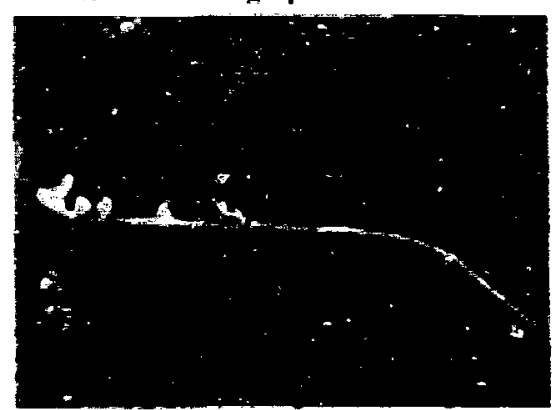

Figure 2. tal Visible-light micrograph $\mathbf{1 3 5}(\mathrm{W}) \times \mathbf{x})$ of a recently isolaled thermophilic bacterium. The cell is approximately $3 \mu \mathrm{m}$ in length. with an enlarged structure at one of its ends. (b) Electron micrograph of the same bacterium as that show $n$ in (a). The magnification is sy+40x. We obtained this organism by culturing fuid samples from the Steamboat Hill lieothermal plant near Reno. Jev ada. The incubation lemperature "as IIMI 1 .

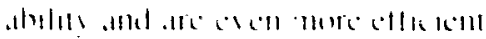

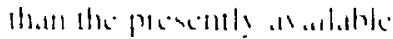

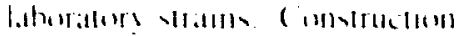

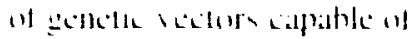
morolucing mew genctic malcrial into

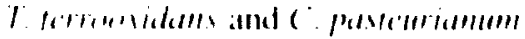
will he a hewh primals. He will use the resently diecencered plasmides

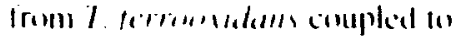
alproprialc antihiotic and metalrevetant gence for the comstruction of

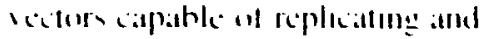

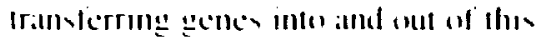

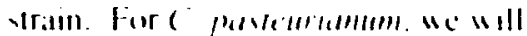
develop at simbat shuttle bector hs adaptime a planmid from a relatled bacleriumi

In the areat of D) A uptathe amd tramsler. We will combmuc inur work (II) protuplast generation and regencration eslablished fur ('Pastemtammoll. We will uxe the new Is deseloped method al electropuralion. which makes une at

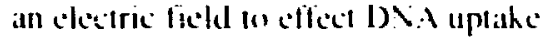
h! hatcterial cills

\section{Reforences}

M.I I W I Hamma K I Inher, I

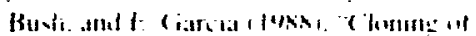

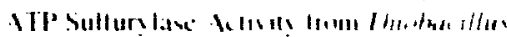

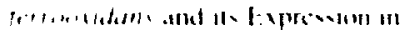

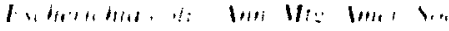

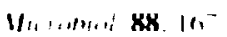

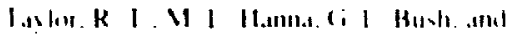

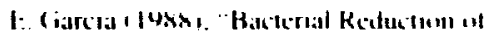

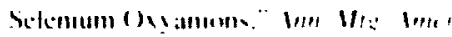

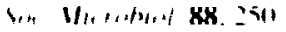




\section{Methane-Conversion Enzymes}

\author{
Principal Investigalors: K. I. Iạlur and \\ II. II. Irotege \\ I n-Insestigaturs: \$. S. Park and \\ V. I.. I arman
}

I

I

microurganisms san eflicicontl

and solectivels utitise methanc gals

1CH, as the sulc semece of carthem lor enere!: and cellular grmoll. The first reaction in this medabolic pathe ats is the comsersim at methatle on methanol. cattaly 2 d h! the methalle munum!genate consmes:

$$
\begin{aligned}
& \mathrm{CH}_{+}+\mathrm{O}+\mathrm{NADH}+\mathrm{H}^{\circ} \\
& \stackrel{\mathrm{S}}{\longrightarrow} \mathrm{CHOH}+\mathrm{HO}+\mathrm{OAD} .
\end{aligned}
$$

A thorough understanding of this hickatalyic sysem ma! lead to the development of a process that uses sahilized protein components for the comsersion of methanc lo methanol and perhaps even to the devign of new lower-temperature. nomensmatic chemical caltals sts that mimls the ens mattic atetion thatl acurs in the initial hioconsersion wi meihane.

We are attempting to develop technologies that convert methane to a useful liquid fuel by duplicating the characteristics of the reaction catalyzed by methane monooxygenases, naturally occurring bacterial enzymes that transform methane into methanol.

()ur rexalath is heime conducted in three stiges: 11 grom ing actect organisms thatl comtain methate

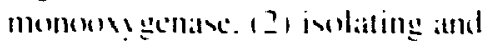
puritying the ative ens yme protein. amal 13 ickentiting the detive callatic sice and elucidalting the medhanism of the ans ymallic coaliom. In FYxx. We coméntrated our efforts on the tirst phasestudying the growth af the organisms.

We are studying IWo !ypes at

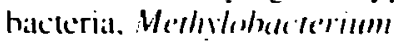
"'salmophilum (CRL-26) and

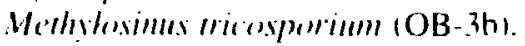
We cultured these organisms in scrile nutrient media using methane gals as the substratc. We transterred the growing organism lo agar nutrient culture platess and stored them under methanc gas, allowing the grouth of individual hatclerial colonics. Individual eolonies were then culiured and plated io produce single-clone subcultures of the histeria. These suheultures have heell frosen and will serre as seed cultures fir future čperiments.

Preliminar! hinctic studices are under wa! lu deteminc the gromth curves of these Imo oreanisms in order lo maximise haclerial growth ratce in the presence of methance and (1) manimize intracellular ensyme proluction. In Fr84. We will comtinue to examine the influence of cell-culture paramelers on the intracellular levels and sahility of the methane monowxyenase enzyme. This work will lead directly to largescale production of the hacleria tusing a fermentation reactor) and subseyuently lo isolation of the enzime protesn from broken cell estracts for nonaqueous-solvent catalytic sludies and for experiments directed all descriting the propertics af the metal-binding active site within the hiocalalyst. 


\section{Culturing Strains of extreme thermophilic bacteria have been identified Thermophilic Microorganisms from Geothermal Fluids in and isolated from geothermal fluids taken from several locations in western Nevada. We are attempting to develop the techniques and apparatus needed to culture these bacteria in the laboratory.}

Principal Investigators: .I. Tang. F. Siarcia.

and .1. J. Siwerne!

I

n Fist. ac uned dired

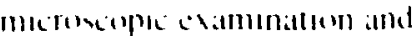
ranmong clectron microscop! lo

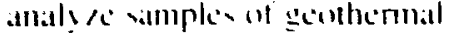
thuse for the prenence of a lathle microorgeanisans. Anumber of interesting coll morpholugion werc identiticed that are comsisent wh the charactersicic of extremc thermopniles. the backeriat that thrive in conditions of extreme healt and pressure.

This vearr. with funding irom both the Energy Program and Earth Sciences. "le halce investigalled several techniques lor determining the optimal media and conditions for culturing the themophilic backeriat

(a)

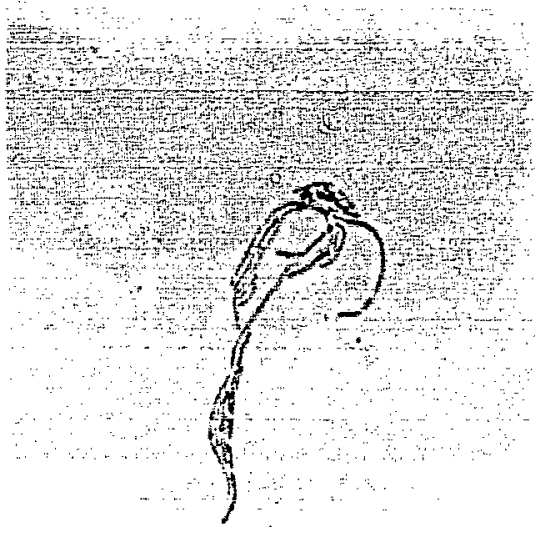

Irom onr samples. Susces in

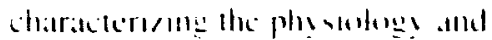

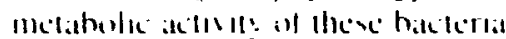
noruld open un pomsibilitien lor

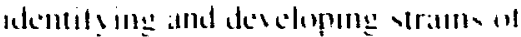
thermophiles that can be uned for

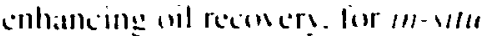
proceseng of minerat. orsalnic, or gecothernal waste's at lemperatures talal lo ordinars bacteria. and for oiher biolechnological alpplicatlom, that exploit the thermal stabitities of the prolexin catalysts lemesmens present in these bateteria. It is likels that this work can also improse our understanding of how microorganisms mal contritute w underground metal corrosion and the

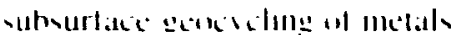

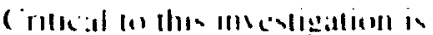
the ahilts lowhtall the athersed orgamsum in pure lorm. Tathe chal. Me havi develend d vectalised whld media and hate recomls ewhated pure cultures of threc lipers thermophile hackeriat lakell from samples obtained from a discharese pond al a geothermal foud-processings plant in Neradd. The lemperature of the fluid in the pond is 93 C. All three isolates are gram-negative (pensessing a charackerivlic lype of cell wall. rod-shaped bacterial. and all three are faccultative anderobes capable of growing in the presence or absence of oxygen). However. |b $\mathbf{b}$

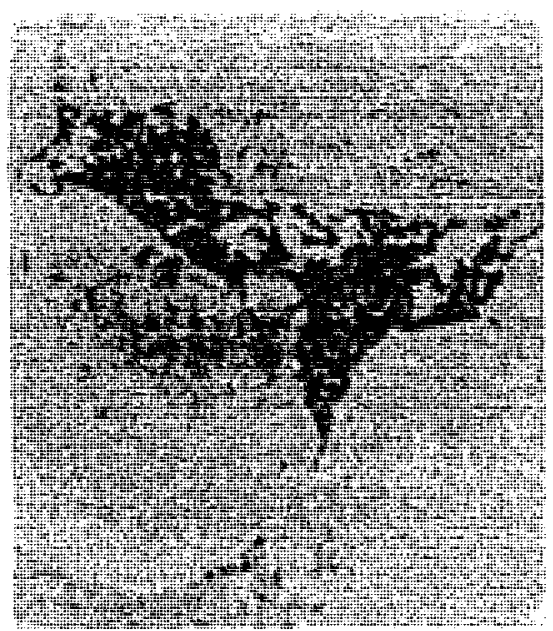

(c)

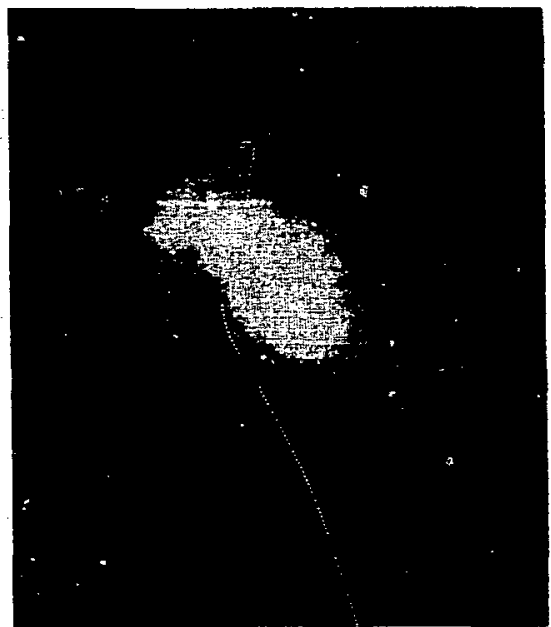

Figure 1. Phase-contrast micrographs (2500) $\times$ ) showing the morphologies of the three isolated thermophiles: (a) filamentous rods that can form chains up to $214 \mathrm{~m}$ long. $(b)$ short rods occurring in pairs, and (c) rods that have specialized endospore structures. 


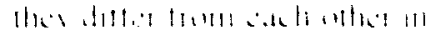

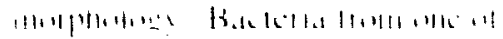

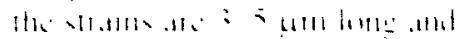

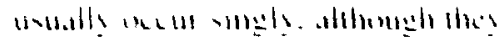

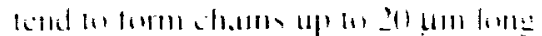

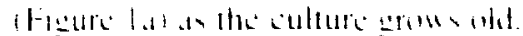

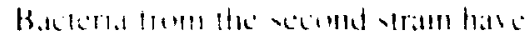

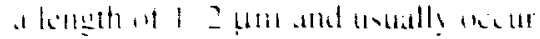

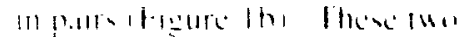

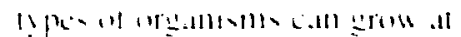

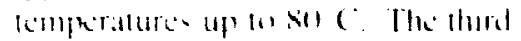

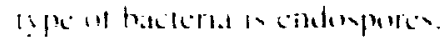

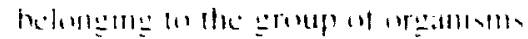

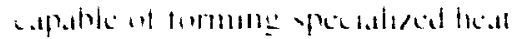

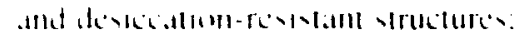

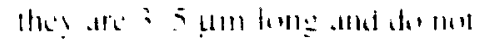

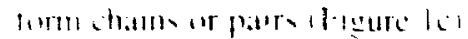

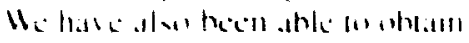

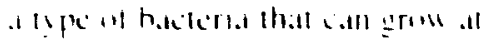
flk| (' in lequal medium. The rad hat a sematramparem sheath that surranuds the cell. Mi are currentl atcollpung fo further charackerse the rrẹlitsill.

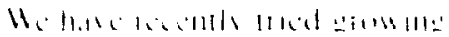

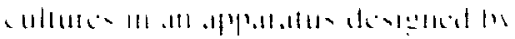

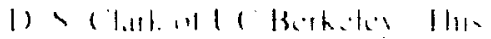

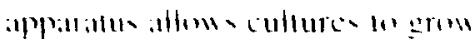

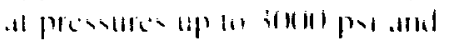
lemperalluses atume 1111$) c^{\circ}$.

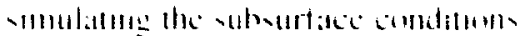
at wheth the themepholes mat he

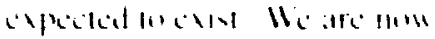

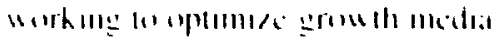

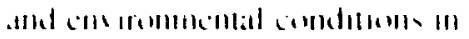

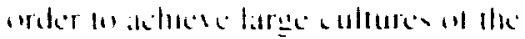
haterlat It: late alurecombl

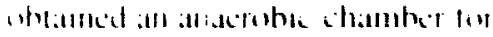

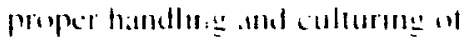

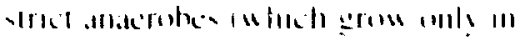

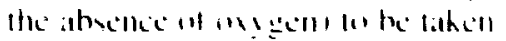

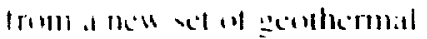

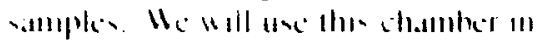

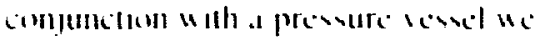
halle hegun lo huld al I.I . VI. hased in ( lath v devgen that will enahle us w lemperatures abolic $\mid(H)$ ( and

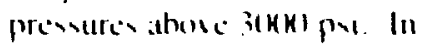
proparallont tor the chemeal and

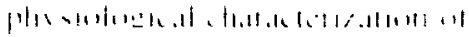

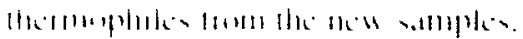

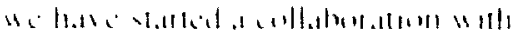

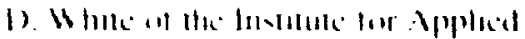

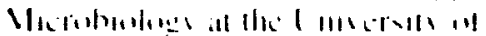

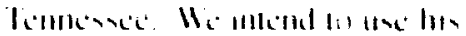

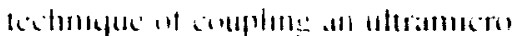

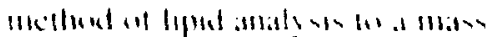
yeclameler for veteteme the

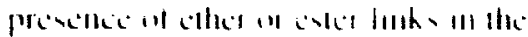

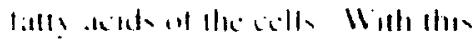

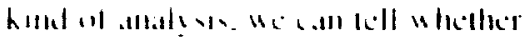

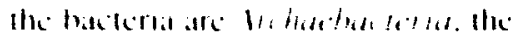

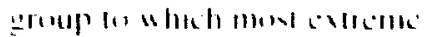
thermothles helests:

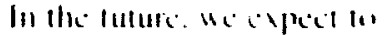

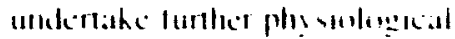

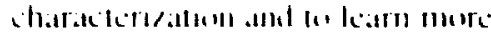

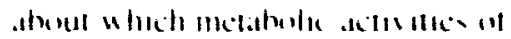

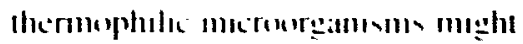

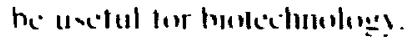




\section{I s. Fonergy supply and Demand}

Principal Insestigallor: 1. Basy
We have analyzed the C'.S. energy situation for 1987 as part of our mission to identify critical research needs. Improving the efficiency of processes that convert fossil fuels to useful energy poses important technical challenges, especially to the transportation industry. predects comprised $1 f^{\prime}$; of total $1 . S$ impors on durable and mondurathle

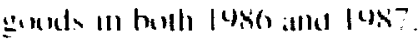

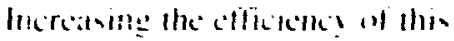

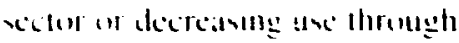
collerersation. wh hoth. mould reducio nus dependence an oil empert.

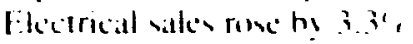

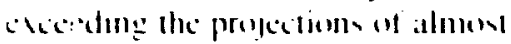
all forcionlers. Avatesult of the rapid growth of the electrical energe! vector. increasing amounts of the nattion s large coul resources are heing ured to generate electrical enere!s. This promines to exitcerbate the convironmental problems ansociated with the use of coal.

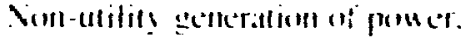
some of which in sold to the utilitios hy concencralurs. contribuled athoul ti, of ile whole. The amount of clectritil senerated by independent

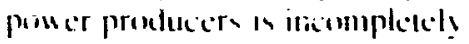

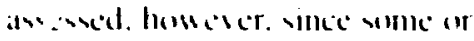

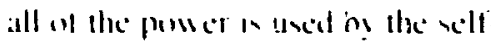
gencrater themade and is nol repurted. Regulaters changes under discussion. anticipated regional shorliages of clectricits. and the inathilits of mams utilities io tinamec large base-load plants promixe to encourage the grow th of nom-utility power generation in the new deciatle.
Figure I. Finergy now diagram showing al net primary resource consumption in the $1 . S$. in 1987 of 76 quads II quad equals $10^{15}$ Btu).

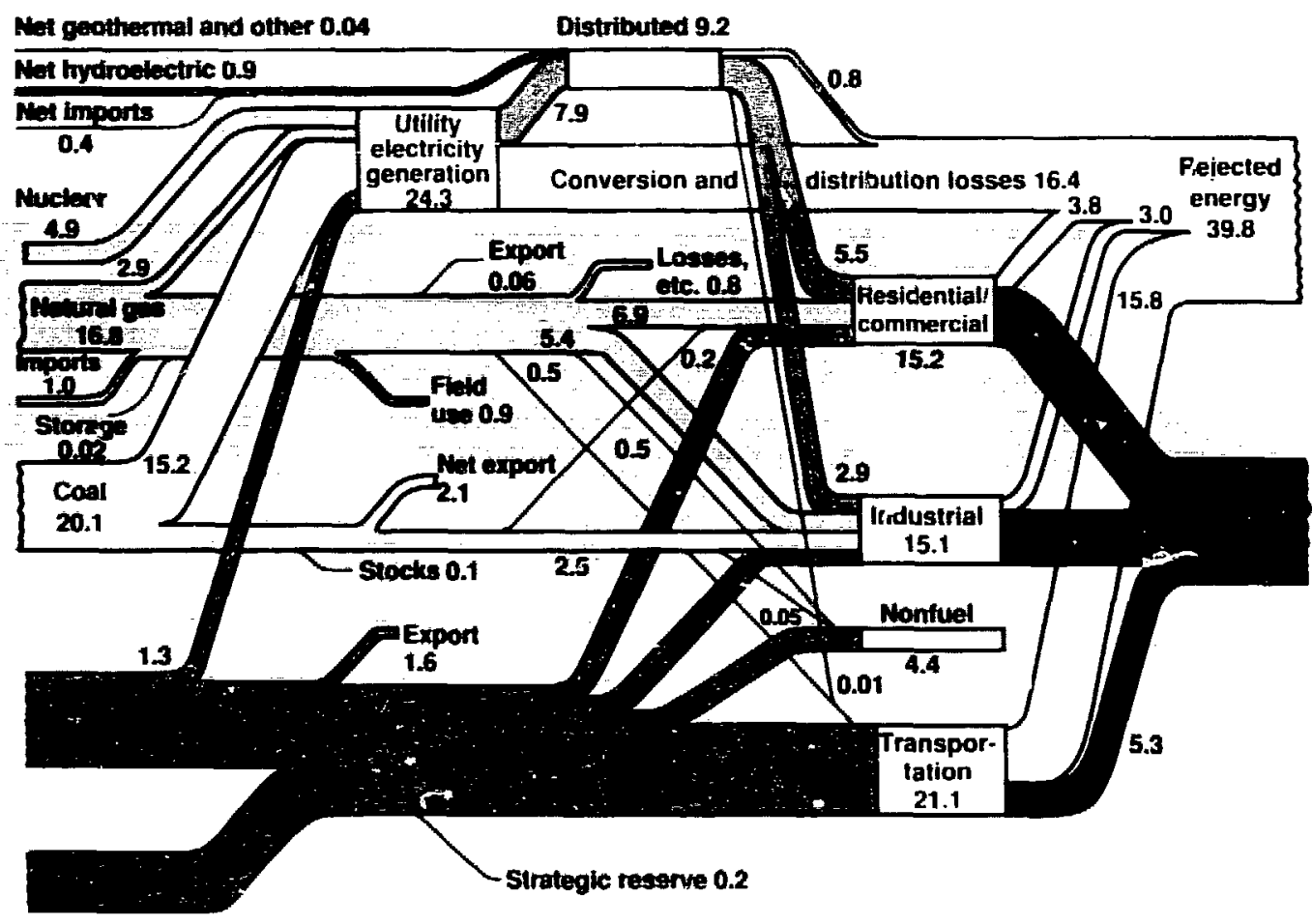




\section{Relativistic Klystron Research for High-Gradient Accelerators}

Principal Investigators: S. S. Yu and (i. 1. Weitenskim*

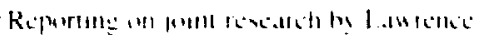

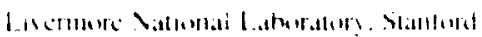

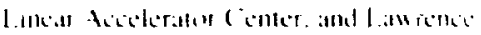
Herhele! l.ther.ther?

$\mathrm{L}$ arge linear clectron-pomitron colliders. compact atcelerallom. and liciceclectron laser sureces require a new generation af highgradient accelerators. For example. conceptual designs of linear electron colliders for research at the fronticer of particle physics call for center-ofimatss energies of $\mathrm{I}$ to $2 \mathrm{TeV}$ and luminositien of $10^{: *} 1010^{* 4} \mathrm{~cm} \div$ ! Accelerating gradients of 1.50 - $2(k) \mathrm{MV} / \mathrm{m}$ are desired to minimise atcieleralor length. and frequencies of $11-17 \mathrm{GHz}$ are desired to keep peah-power requirements and heam loading reasonably small. The peak pow er necensary to drive at traveling-uave structure in this freytency range with the desired gradient is $-1 \mathrm{GW} / \mathrm{m}$. with a pulse length of $50-1(0) \mathrm{ns}$.

Putsed electron heams of such high peak power can be oblained using the lechnologies of magnetic pulse compression and induction acceleration (Reginato and Birx. 1988). Beam pulses of I-kA current and $5(1-I(K)$-ns duration are routinely accelerated lo several MeV at LLNI. These teams contain several gigalualts of peak power.

The first demonstration of radiofrequenc! irfi pouser extraction from such a beam sielded more than

We are developing relativistic klystrons as a pou'er source for high-gradient accelerator applications that include large linear electron-positron colliders, compact accelerators, and freeelectron laser sources. Our near-term goal is a high-power (500-MW), short-wavelength (2.6-cm) relativistic klystron. We have attained $200 \mathrm{MW}$ peak power at $/ \mathrm{I} .4 \mathrm{GHz}$ from a relativistic $k$ !ystron and $140-M V / m$ longitudinal gradient in a short, 11.4-GHz accelerator section.

I cill at 35 (iH/. using a tres electron later 10 rechom hi er al.. IMS. A. M. Sender and S. S. Yu. following at suggestion hy W. K. H. Panofiky. propused a more dired method to extritt energy by bunching a relarivistic beam and passing it though extraction cavities. Sessiler and Yu suggested that if only pan of the beam energy were extracted, the beant could he reacceleraled and energy again extratcted. The concept of repeated reacceleration and extraction was called a ". lativistic klystron Iwoheam accelerator" " Sessier and Yu. 1487;. Relativistic klysirons can be imagined that span the range from a $1-G W$ device powering $1 \mathrm{~m}$ of accelerator. to a $1(1-G W$ device powering $10 \mathrm{~m}$. to a 1 wo-bean device extending several kilometers.

These ideas led to collaboration between the Stanford Linear Accelerator Center. Lawrence Berkeley Laboratory, and LLNL. Io study how to combine the klystron concept with induction accelerator and magnetic pulse-compression technologe! (Allen at al. I988). The tirst experiments have been done all the Acceleriltor Research Center I.ARCI at LLNI. Using as a geun tor injector) an induction alccelerator designed lo produce 1-hA currents with 1.2-MeV kinctic encrey for up 11 75 ns. Three kl! strems hatce been tested with this injector:

- SL.i. a multicirvity klystron with a conventional gun. designed to uperate al $8.6 \mathrm{GH} /$.

-SHARK. a ubbharmonic-drive relativistic klystron will relatively low gain.

- SL4. a high-gain relalivistic klysiron designed for a high-power pulsed beam.

Below. we summarize the design of these klystrons, our FY8s esperiments wilh them. and our future plans.

Klsstron Sicaling. In a Klystron. the hean is velocily modulated by an ri drive cavity and allowed to drifi until velocity modulation bunches the beam. The buncined beam is then passed through another cavity that maly be used lo extract rf power. In practice. such a two-cavily klystron has low gain: most klystrons have several intermediale "idler" cavities. The first cavily hunches the beam. The hunched heam drives the second cavity to an rf vollage an order of magnitude greater than the lirst. which in tum bunche"s the beam more srongly. This prexess continuces until the final idler cas it! of the hlystron's lincar-gain region. 


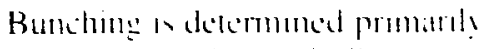
b! the whlage on the lmal atler

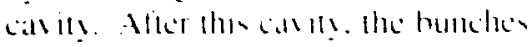
are allomed lo drote until the ri curremt is all at masimum. Al this point. the heam is passed through Imo more cats itles: a highly detumed penulsimate car in! that weeps villunhuncted clectrom into the bunch. and an outpul catsts that extracts eneres by decelerating the heim. The outpul cal its could be replated by a cerien of call itre or by a tratcling-uate iructure.

An important parameler in khs ston sialing is the heatm plasma wavelength. Velocil modulation bunches alde heam. Howeder. ypacechatroce repulatom imoditied hy the driti tubet caluses the bean to debunch. In the linear region. this process produces oncillations. The distancen helween castites in a klsstron are choven lo be approximalely one-yuarter of at plasma uavelength for optimal bunching. For a long relativistic beam of current / and radius $a$ in a narros lute of radius $h$, the plasma Watcelength on axis is

$i_{n}=i_{11} \sqrt{\frac{17 h A}{l} \frac{(\beta \gamma)^{\prime}}{1+2 \ln (b / a)}}$.

where $\beta=1 \%$ and $\gamma=1 / 11-\beta^{2}, 2$. Increasing the beam energy ameliorates longitudinal space-charge effects but increases the bunching distance. Increasing the frequency reduces the bunching distance.

Our choice of a 2.6-c'm ri wavelenglh makes possible a multicavity klystron that can efficiently bunch a I-MV. I-h.t bean and extracl poucer from it in al total distance of $1 \mathrm{~m}$. For more eneregetc heams. hending matencts can be uxed ic create differences in path lengthe lem partacken difleremt energen.

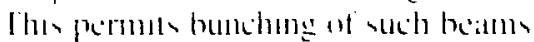
con though their colecit! w mearl! melependent of entergy.

Antuler important patrameter in hlystron scitling is the malgnetic field necestaly to focus the beam. For a yace-charge-dominated beam of untorm croms rections the solenoid

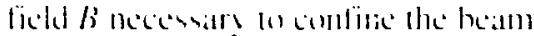
currem / la radius a

$$
\begin{aligned}
B & =\frac{2 m_{\mathrm{c}} \cdot 2}{\mathrm{c}^{\prime} \mathrm{l}} \sqrt{\frac{2 I}{17 \mathrm{kA} \frac{1}{\beta y}}} \\
& =\frac{3 .+\mathrm{kCi}}{a} .
\end{aligned}
$$

(a)

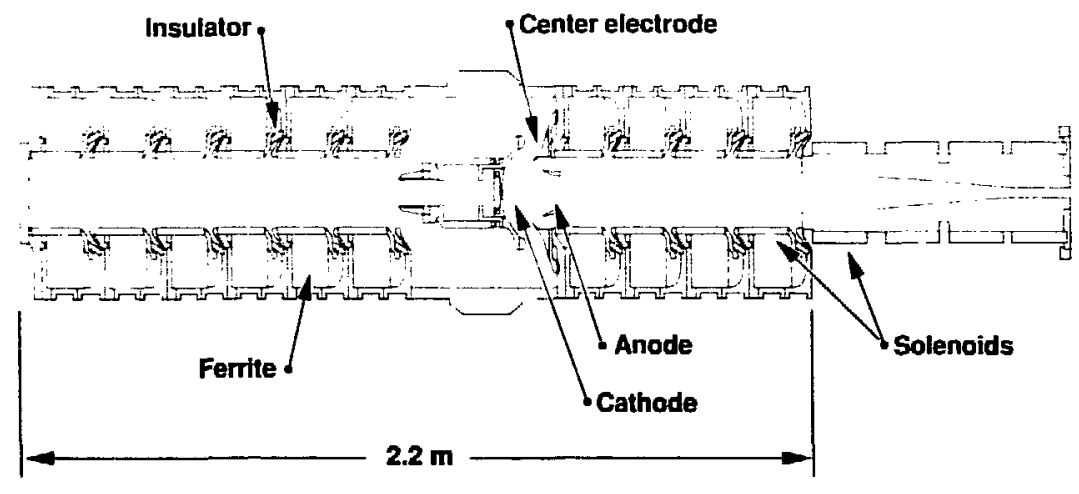

(b)

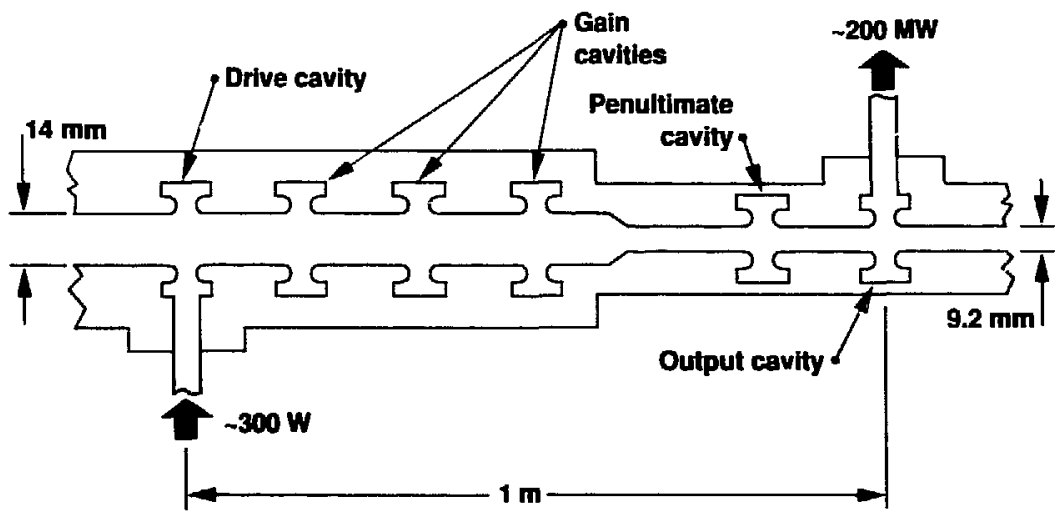

Figure 1. Schematic of (a) the SNOWTRON injector and (b) the Sl.4 klystron experiment. 


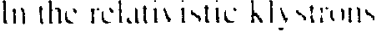
decused here. buth y amd / alle

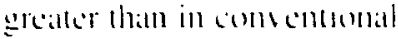
hlystrons, Al shorea wallelenghts. higher magnetic fichls are necoled lo focus the heam since the radius a the drili tube scales with wavelength. An estimate of the reyuired fichl must include lhe cifects of heam hunching. Ihe peat current in the bunched heam typically is about four times the initial de curremt. Thus the matgnetic ficld reyuired is typically twice that calculated for focusing a de heam.

Frist Fiperiments. Most of our experimentall studies Were pertormed using the SNOWTRON injector at the ARC lacility. SNOWTRON is a linear indaction injector composed of ten $1.50-k V$ induction cells driven by pulsed magnesics (Reginato and Birx. I988). For klystron experiments. il triode-electrode configuration wats uned with a cathoke of 1 2.5-c'm diameler and $35-c m$ spherical radius. The inner thameter of the andede driti lube wats $8.8 \mathrm{~cm}$. The callhode was placed $3.5 \mathrm{~cm}$ from the downstream end of the injector (sece Figure l). Accelerating voltages up to $1.2 \mathrm{MV}$. heall currents up to $1 .+$ k.A. and pulse widths up to 75 ns have been ohtained. The greatest stress on the injector is $200 \mathrm{kV} / \mathrm{cm}$ on the catthode shroud at poik voltage. The DPC computer code. which was used to design SNOWTRON, predicts peak currents of 2.3 kA at 1.2 MV (Boyd. 1487 . However, the operating pressure of the injector led to cathode contamination. which precluded uniform space-charge-limited emission.

The distance from callode to klystron was 4 m for the SL.3 test and $1.6 \mathrm{~m}$ for the SHARK and SL 4 tests.
Table 1. Parameters of relativistic klystrons tested.

\begin{tabular}{|c|c|c|c|c|}
\hline & & SL3 & . & SLA \\
\hline Output frequency, GHz & & 8.57 & 11.4 & 11.4 \\
\hline Drive frequency, GHz & & 8.57 & 5.7 & 11.4 \\
\hline \multicolumn{5}{|l|}{ Output power, MW } \\
\hline Peak (maximum) & & 75 & 82 & 200 \\
\hline Wide pulse (maximum) & & 75 & 47 & 68 \\
\hline Design gain, dB & & 54 & 20 & 65 \\
\hline \multicolumn{5}{|l|}{ Efinciency, \% } \\
\hline Design & & 60 & 20 & 40 \\
\hline Operation (maximum) & & 55 & 25 & 50 \\
\hline \multicolumn{5}{|l|}{ Beam voltage, $\mathbf{k V}$} \\
\hline Design & & 330 & 1200 & 1200 \\
\hline Operation & & 1000 & 1200 & 1000 \\
\hline \multicolumn{5}{|l|}{ Beam current, $A$} \\
\hline Design & & 300 & 1000 & 1000 \\
\hline Operation (maximum) & & 350 & 750 & 750 \\
\hline Number of cavities & & 5 & 2 & 6 \\
\hline Total length, cm & & 31 & 25 & 98 \\
\hline Drift tube diameter, mn & $=$ & 11 & $19-9.2$ & $14-9.2$ \\
\hline \multicolumn{5}{|l|}{ Beam-off loaded $\boldsymbol{Q}$} \\
\hline Input cavit: & & 250 & 725 & 280 \\
\hline Idler cavities & & 4000 & - & 120 \\
\hline Penultimate cavity & & 4000 & - & 3800 \\
\hline Output cavity & & 44 & 40 & 20 \\
\hline
\end{tabular}

Jubl dom nstream from dice injector is a in-con taper. where the heam pip: natrom e from an 8.8- 10 at 1.9-cml diameder. The pipe natrous furber to 9.2 mm in the SHAKK and SLt klystrons (sce Figure 1). Ninc 2.5-kG solenoid coils powered by live separale power supplies focus the beam between the cathode and the klystron. Three independently controlled. 5-kG solenoids focus the beam in the relativistic klystron. Four sets of dipole magnets for horizontal and vertical steering are used to correct for beamline misalignments. Additional klystron parimeters are listed in Table 1.

Beam transport calculalions made with the ST code have been used to estimate the required strengths of the focusing fields for It)( $\%$ current transmission through the klystron (Boyd. 1987). The result of one such calculation is shown in Figure 2.

SL3 is a conventional high-gain klystron designed 10 operate al $8.6 \mathrm{GHz}$ with a conventional gun or injector. With this gun replaced by an induction accelerator. it served as an expedient finst demonstration of a relativistic klystron. It was driven by a I-kW, X-band, traveling-wave tube (TWT) amplifier.

SHARK is a two-cavity. subharmonic-drive relativistic klystron. The input cavity is driven by a 5-MW. 5.7-GHz rl klystron thal modulates the beam velocity. After drifting, the beam :urrent has large Fourier components at 5.7. 11.4. and 17.2 GHz. Resomant cavilies tuned to the higher hatrmonics can be used to extract power and measure hreakdown fickls at the higher frequencies. The 11.t-GiHs cutput calvity is posilioned atter a $25-\mathrm{cm}$ drift pipe for optimal bunching at that harmonic: With only two highte $Q$ resomatnt structures in this klystron. problems with heam breakup 
instatbilitien are minimised.

Howerer. the gain of a twa-cis it! lube is low. Therefore. w athiele a beam-lo-rf power converson comparable of that in multicatit! tubes. a comventional kly stron is used to drise SHARK. The rf ficld in the input and output cavities are comparable for $2 \mathrm{MW}$ of drise and 50) MW of output beciase of the different $Q$.

SHARK "ar designed an al ter bed for calvill designs. It allows us to study a wide range of heam parameters and minimizes difficulties with beam propagation. The drift pipe and output carit! are cals! 10 replace. making it possible of use SHARK Io study different output cavities al several trequencies.

$\mathrm{SL}+$ is a six-cavity relativistic klystron that operales at $11 .+\mathrm{GH}$. and was designed specifically for the 50-ns. pulsed SNOWTRON heam. Therefore. unlike most klystrons. it was designed without an integral gun assembly. To make the of filling time of the SLt cavities much shorter than the $5($-11s beam pulses. three of the gain cavities are coupled by irises and waveguides to absorptive ceramic wedges. This results in loaded $Q s$ of 120 and filling limes of 2 to $3 \mathrm{~ns}$ for these cavities.

To reduce the difficulty of maintaining a well-focused electron beam over a $1-m$ drift length. we tapered the SL4 drift tube. Its 14-mm diameter in the first four cavities tapers to $9.2 \mathrm{~mm}$ just upstream of the penultimate cavity. Tapering permits the use of solenoid magnets with axial fields of $2.7 \mathrm{kG}$ for most of the klystron s length. A 5-kG solenoid surrounds the penultimate and output cavities.

The design gain $(65 \mathrm{~dB})$ and efficiency $1+0 \%$, for SLA were obtained $w$ ith the MASK computer code (Eppley. 1988). MASK simulation optimies the Sl t design paramelers alld predected the

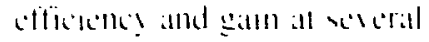
different beam correms and woltates

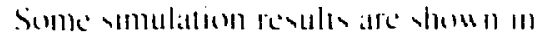
Figure? The sitturatton it drac power in approximatlely $2(10) \mathrm{H}$. which is supplied by a l-h H. X-hand TWT ampliticr.

Becille of the hish peath clectric fickds in the SLt penultimate and outpul callities. good valcuum is necessary to prevent calvit! breakdoun. A 5 ono-liker/s ervepump ealcuates the h! $\mathrm{stren}$ collector section. and lus s-liter/ - alcuum ion pumps evaluate the output "adeguide. In this contiguration. "areguide and collector pressures can he maintained at $11^{\text {" Torr. }}$

To complement the SLt experiment. a 26-cm-long. 11.t-CiH/ accelerator structure operatting in the $2 \pi / 3$ traveling-wave mode was huilt. This constant-impedance structure consists of 30 cells and has $r / Q=$ $14.2 \mathrm{~kW} / \mathrm{m}$. The attenuation parimeter is $(1.136 \mathrm{~Np}$. The group velocity is 0.031 l - giving a filling time of $28.4 \mathrm{~ns}$. The iris diameler was chosen to be $7.5 \mathrm{~mm}$.

Parameters were calculated by the SLPERFISH code and contimed by cold-iest measurements. Coupler dimensions were approximalled by extrapolation from S-band data and finalized by cold test. The accelerator was fabricated from machined "cups" that were stacked and brazed. A special tool permits each cavity to be tuned up or down in frequency to obtain the correct phase advance per cell.

Experimemal Results. Our design goil of $10 \% \%$ beam transmission through the klystrons hals not been achieved experimentally. exen after focusing adjustments sere made. The maximum current transported through SHARK in 7501 A. only 6.5'; of the currem entering the hly srom. Lploseri tramsmiarion has beell

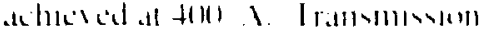

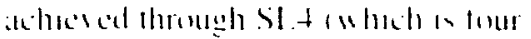

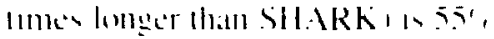

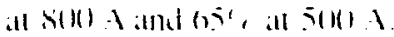

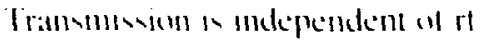
drice for Stt.ARK. For Sl t. a vlight

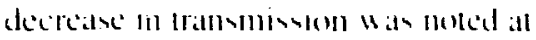
hegh rt orupul levels. (There was no dom toveam current monther in the

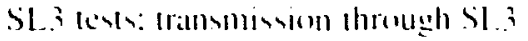
"lan not mearured.1

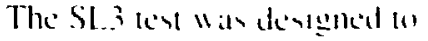
demomstrate of the effects of putting! at comentional kly seron tube stripped of its geun in a high-poucer pulined beatr. So unusual or unexpected phememesna were obersed. No

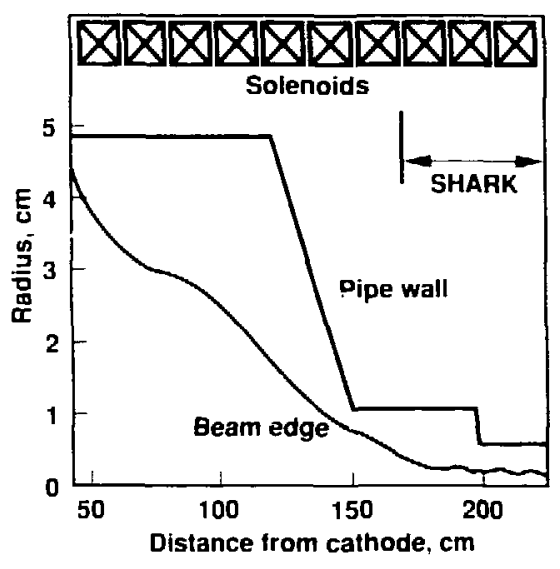

Figure 2. Heam size calculated through SHARK.

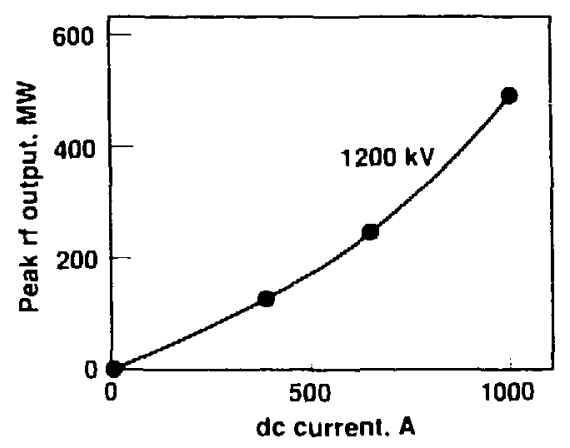

Figure 3. IIASK simulations of Sl.t outpul power. 

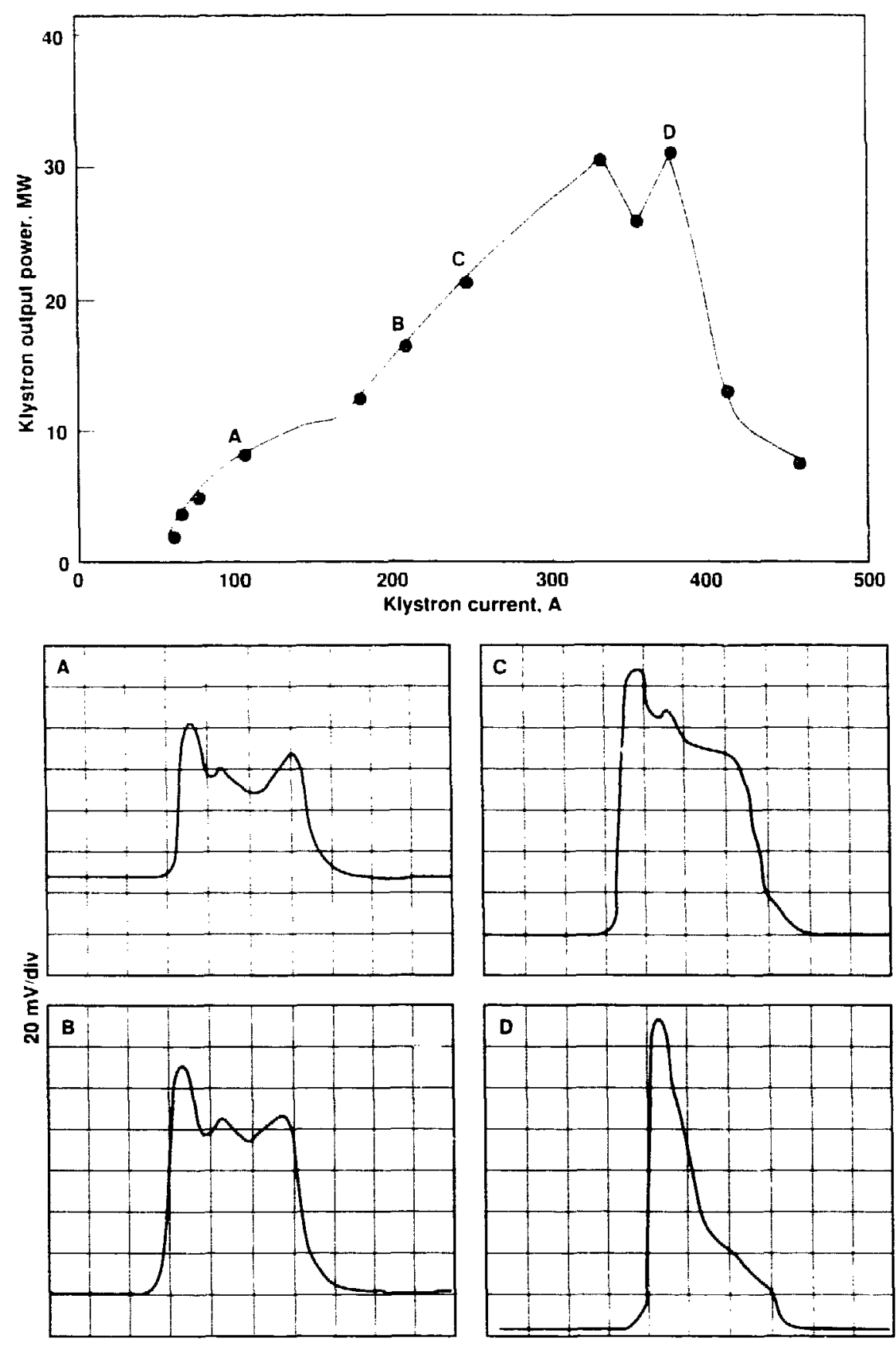

20 nsidiv

Figure 4. Radiofrequency pulse shortening whserved in SHARK tests. Beam voltage is $950 \mathrm{kV}$ : drive power is $-1.4 .11 \mathrm{H}$.

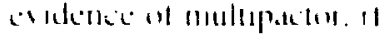

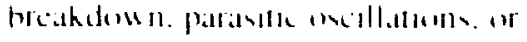

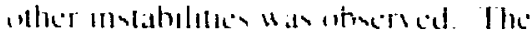

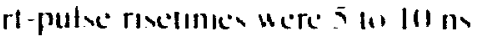
The se putes reproblecel the thape at the beall corrent pulser yuile well

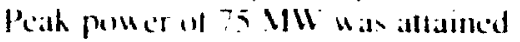
with an S(H)-hl. - Iill-A heam. ()utput pumer agreed wall with the predictions of the MISK vimulation inde.

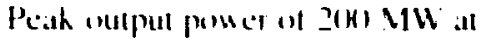
I1.t (iH/ Wa allained wath the SI

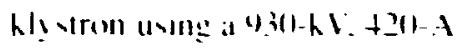
healll. SL $t$ has mot !et operaled at is 114k1-A deveng current. Hawerer. ancement is escillent between output puwer medsured at lower currents and MASK preduchoms (Figure i) for operation al these currems. The $2(x)-\mathrm{MW}$ peak power delivered b! SLA wo the $11.4-\mathrm{GH}$, accelerator corresponds los at longiludinal accelerating gradient of $140 \mathrm{MV} / \mathrm{m}$. Early indications are that there is appriciahle dark current in the acceleraltor when the accelerating gradient soxceeds y) $\mathrm{MV} / \mathrm{m}$.

In our lests of holh SHARK and SL.t. We observed that as the heam current through the klystrom is increalsed up an a cenain level 1 25() A . lle wiput-power pulses remain relatively that. However. when the heam current is increased heyond this level. the trailing edges of the output-power pulses diminish in amplitude. while the leading edgers continue an grow. This hehasior in SHARK tests is illustrated in Figure 4 .

()ur ahilit! (u mbain that outputpuner pulser is affected hy tealm current. ri-drace lesel. and focusing magnedic-ticld strmgth. The pratical mpertance of these observallom is thatl ach thuugh z(I) $11 \mathrm{~W}$ of to power was prodiced with Sil.t. the maxmum. reasmably llat ri pulec athered was anl! 


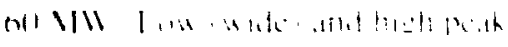
fwom fo!

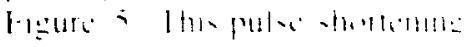
phem

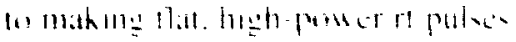

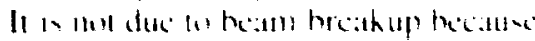

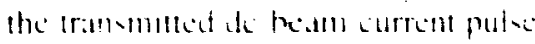

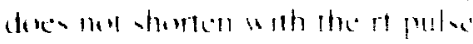

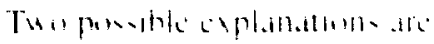

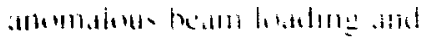

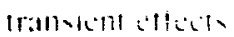

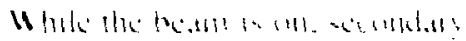

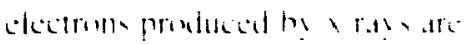
combled from the he

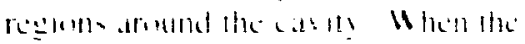

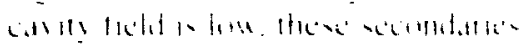

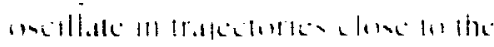

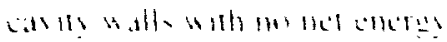

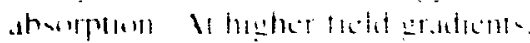
thex elcetrme hatc longer path

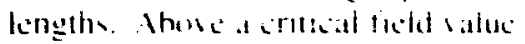

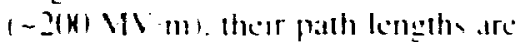

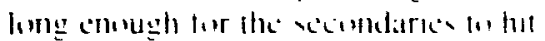
the "ppomite mose come and depent

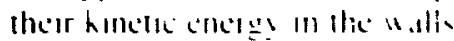

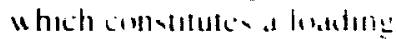
phemomement. The secometar! cicetrom in the athemalitur heatm

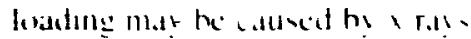
from the beams. Hetlece the turn an and int wilh the heam Prelimmars

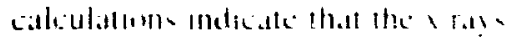
probluced ars comsinemi wh the

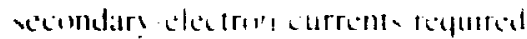
(c) account tor the sedelumal loddme(5-1) $\$ 1$.

We reconly mslalled a new druc callu for SHARK whth an tron rim! that shunt the matnctle fictel trom the drise calll!. creatlo! a magnetic hoste near the casts isters. Tha expermentally increased the amsel

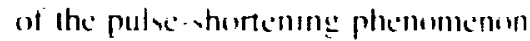

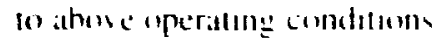
Howerer. the wape at the magneds ficld mereaded the rathal thatted in the

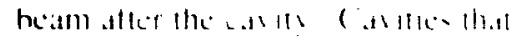
"plerate in

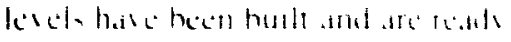
tim $10,1+1)$ :

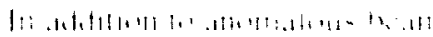

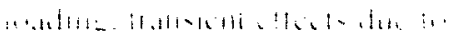

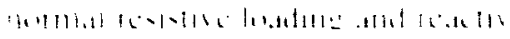

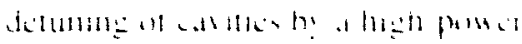

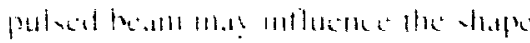

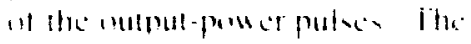

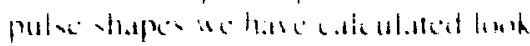

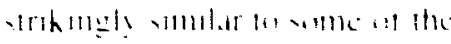

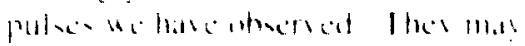

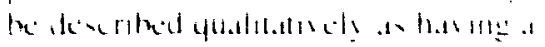

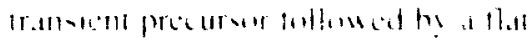

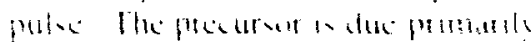

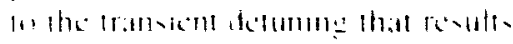

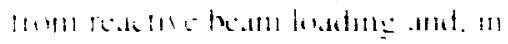

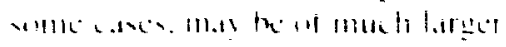

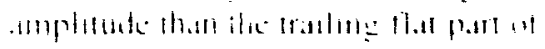

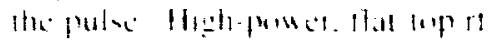

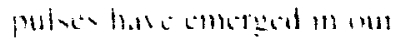

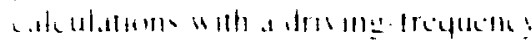
handw ath narrower thati and vilfed

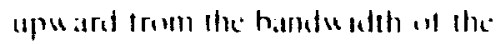

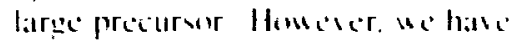
mall !el ahersed the rectangular pulace trom S1.4 atl an! treyuenc! presumathly becatuce all ancmatus heam landilly.

Gher evpermicutal protblem concuntered were hreathelems in the stl IRK and mulupatoming an the

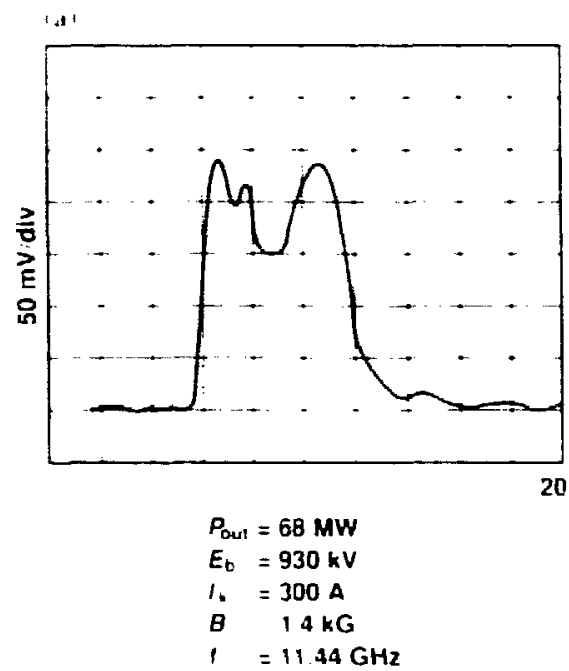

$20 \mathrm{~ns}$ div

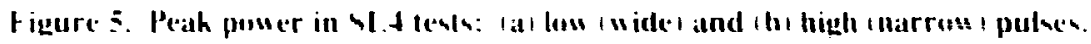
Pulse shortening at high peat power is the mont serious problem encounle red in uur relalis istic klystron experiments.
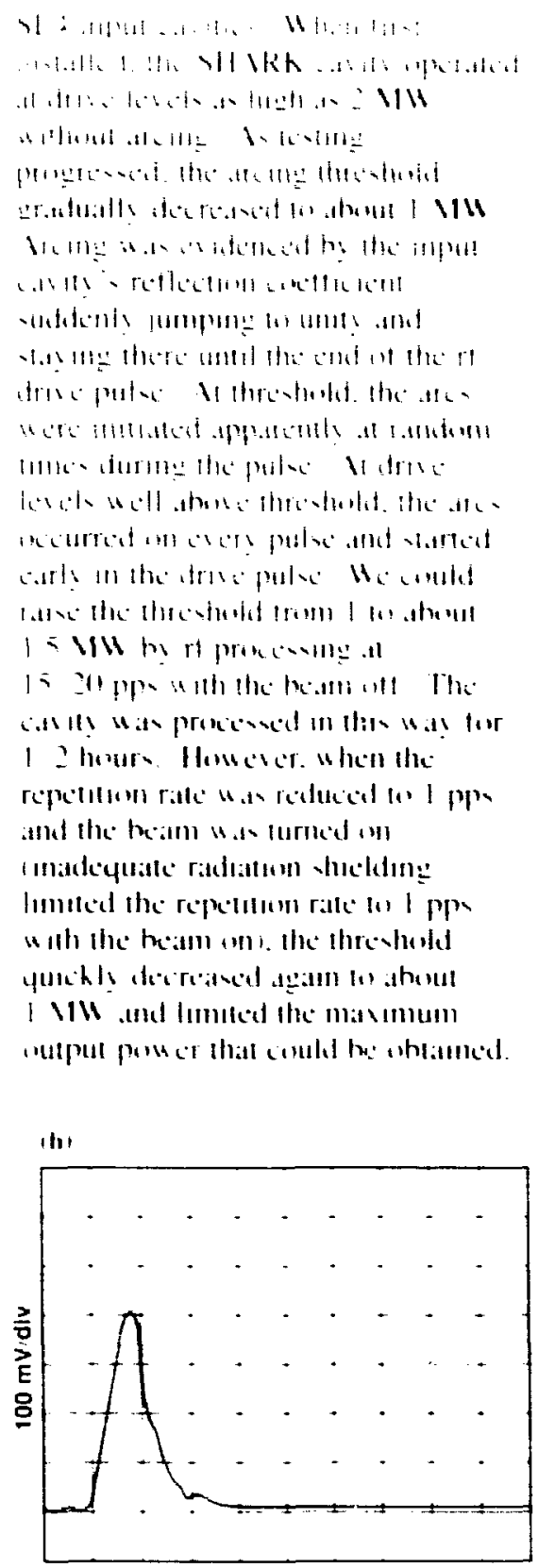
"utpul puse of that could the whatuled.

$$
\begin{aligned}
& P_{\text {out }}=202 \mathrm{MW} \\
& E_{\mathrm{b}}=930 \mathrm{kV} \\
& I_{W}=420 \mathrm{~A} \\
& B=1.4 \mathrm{kG} \\
& t=11.45 \mathrm{GHz}
\end{aligned}
$$




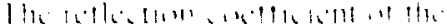

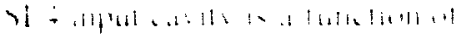

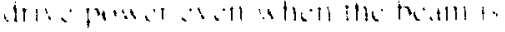

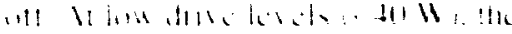

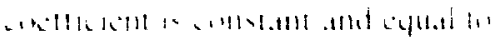

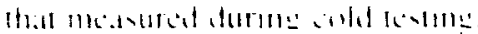

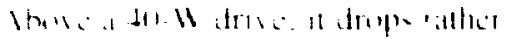

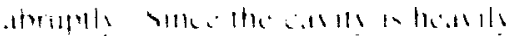

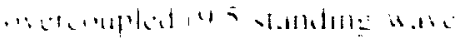

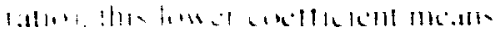
that s.

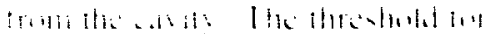

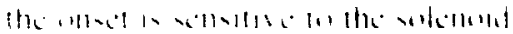

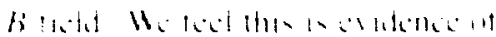

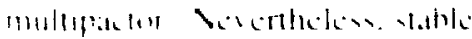

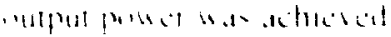

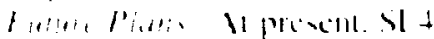

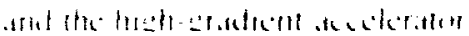

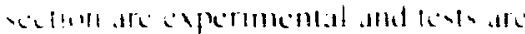
communge. Fotumber underedand

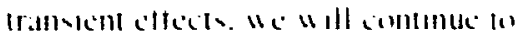
measure inpul cat ils heam loadin!

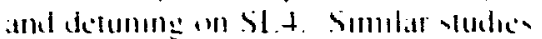
will he malded on the hegh-ladd SHARK IIPUl sats when remblalled. He hope wh suls correlutw

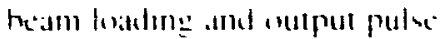

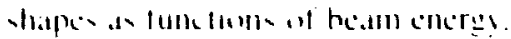

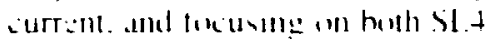
and SHARK. SIudew hen-

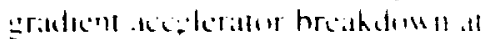

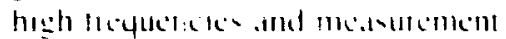

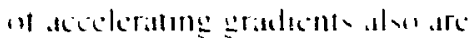
anticipalice.

To reduce anomalous beam hading in SHARK. WL plan w" appls lechniqué that hase reduced multipactorng in ankei if $\because$ stcms The'se mefude collimaltan: the heam apenure upatream af the hlistroll. If comditumng at higher repetulan rates wh thelter shelding. and steflung the moses at the drite callits an redese reimdart-clectron commonn.

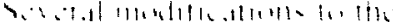

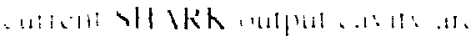

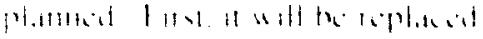

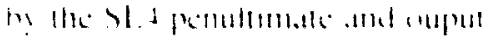

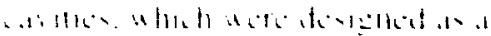

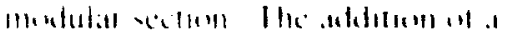

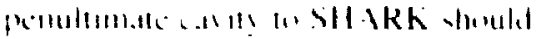

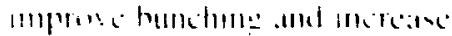

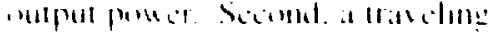

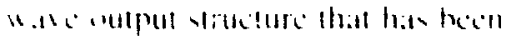

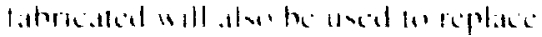

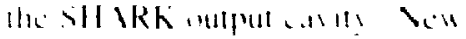

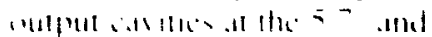

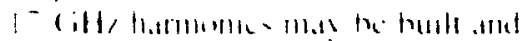

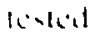

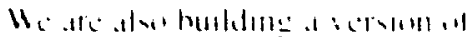

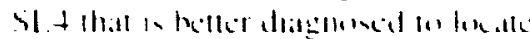
the cistl! in which the andel of the

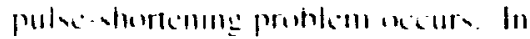

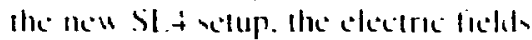
II all af the gan call Ite w wll ho mimilured.

1he woukd like waperate the relatluslu hls hegher thatl what a pusible walng

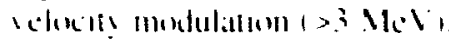
1 chopper athome fir curremt mofulatim al these hegher encreas has heon worked and and is hellly prepared for kentalle. The aheme

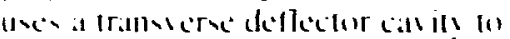

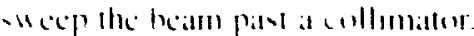
Alece the collomaters the chepped

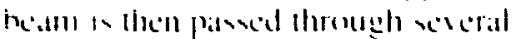

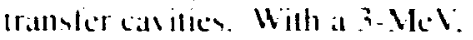

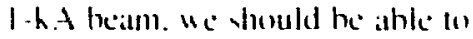
produce near I Gill uf rf pumer all 11. \& (iH, Tareduce the keflection "ycm v sembltist! melectron-heam contr! angle. coller!! atnd cmittance. the istem is full! continced within an antal magnelle ficld wilh a quarter.

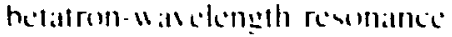
heluedn the drace anth and the

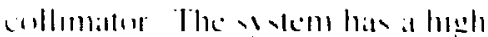

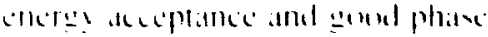

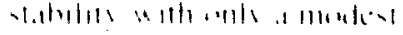

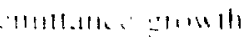

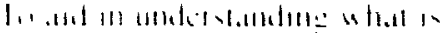

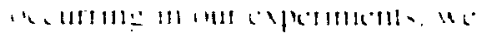

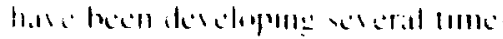

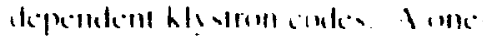

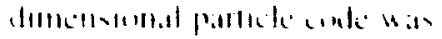

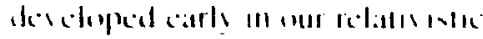
hls thom progeram and has heen aned

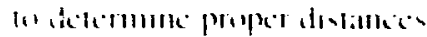

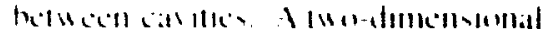

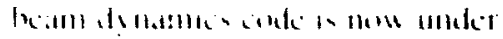

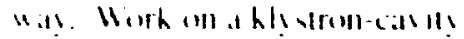

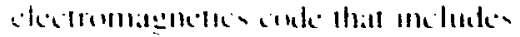

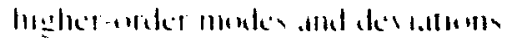
frum a

\section{Keferences}

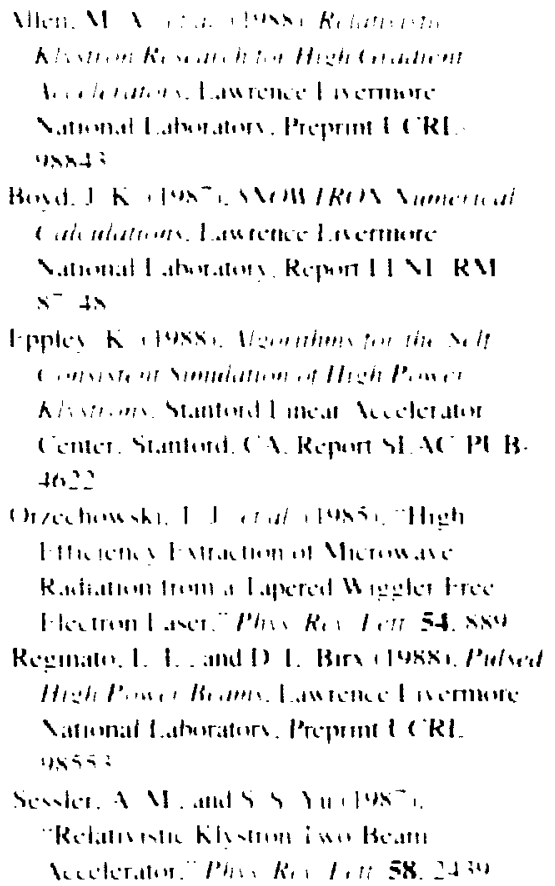

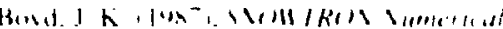

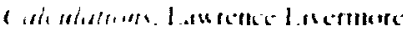

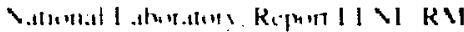
is

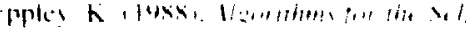

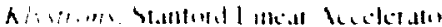

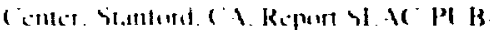
to:

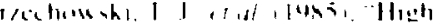

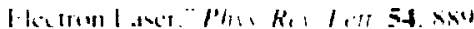

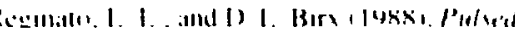

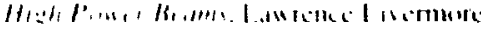

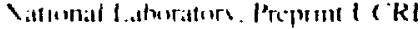

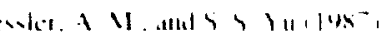

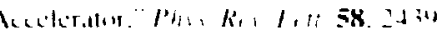




\section{Id ianced lechnologies for Growing $l$ arge ()ptical Crystals}

Principal lanestigators: .1. F. 1 inper and

l. .l. Mlertun

W c.

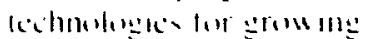
opleatl crsate in the torm of larec

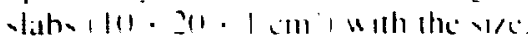

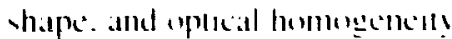
requated her hish-power lasers. Currents. the law orate properten of homon baser mallerials cammot he lulls exploitcd hesause of hambalioms in scale-up and oprical homogenest! encountered with esmome cry salgrow th eachnolugkes.

We atc atlathing this problem on exeral tromls. Wie hatc destenced and hate had hutt a clasical Brideman fumace lor grow ing sath-shaped crsals. We are grom mn neadymum-diped !ltrium-

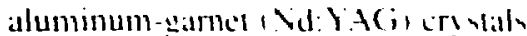
in at gradiem-freck furmate thatl or similar encugh to the new furmacio

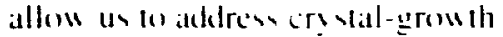
problems commmon la hoth furnaces. We are alos improving the analstical technicuess used to address eritical diagnostic. control. chemistrs. and materials issues and lo derelon heller themal diagmontice and more stable fumace-hosting units. We expect that we will he able subseyuents to appls the eyuipment and ecchnicues developed in this projezel to other important laser crosals. sach as gadohinium-scandium-aluminum garnee i (iS.AC i) and hthum-calcum aluminum-thumrade + I $\mathrm{s}(\mathrm{Al}$.

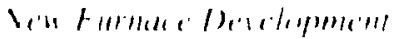

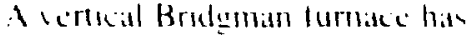

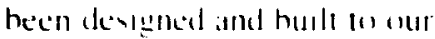

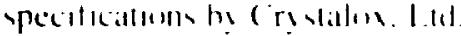
England: it will he delacered in

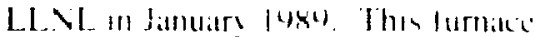

We are developing a modified Bridgman process for growing large, optically homogeneons crystals for high-power laser applications. To test this crystat growth process, we have developed a new, inductively heated furnace and have modeled the temperature distribution within it. We have grow'n Nd:Y.1G; crystals in an existing furnace of a related design lo resolve critical diagnostic, control, and materials issues.

"IIl cllathle w. w shaped crestals af hegh oplecal yualits. With 11. "se 1 ill lev atamed larmace control programs. defferem healthe conflegratloms. and mes furnate and irs sat-grow th driglnomllien

In the clasvidid d?ridyman crs sal-grow th process. an ampouk contaning a polsers stallime liced matcriat anith the laser-alctic

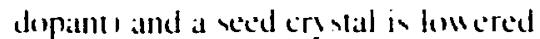
through a two-sone furnate (o) progersicels melt the lecol material and grom the crsyal ase Figure lal. The lup ane is held al a temperalure ahowe the melting point of the malerial. and the bottom ance s held at a liser lemperature. An insulatled 1"aliahallic", ane belucen the

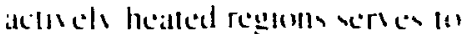
llatlen the melt/sry sal interlate. The lemperature gradient at the intertace is determined by the lemperature difierence hesween the upper "hol" ane and the lower "eold" / $/$ nes.

In classical Bridgman srowth af many malerials. the laser-active dopant in the melt huilds up at the melters stal interface becaluse it is aclectivels rejected bs the arowing crastal. Is concentration mereases monotoncalls along the length on the crs stal. and the mhomogencill catl

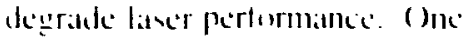

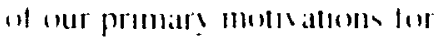
desheping a modified Brolgman

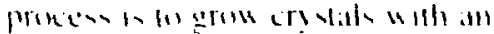

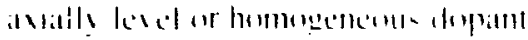
onlecturallont

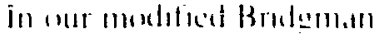

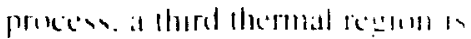

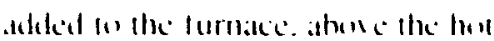
ank. which is eobler than the

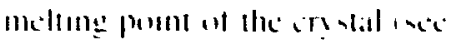

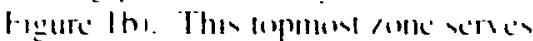
as a pretheater and permols the $-1 / 2$ al

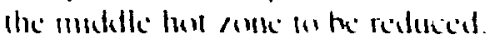
This relativels smatl hol ame produces anli a small regem al melt In the amporile: ahere the mell ance is the pulvers sallime leed slath and helow 11 in the newls grown ils sal. Viewed from the ampuale s trame at reterence, this small melt fonce moses from one end whe thter: "we call this Iariation of classteal Bridgntan crstal grow th the "moneng medt

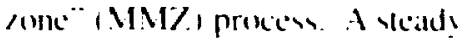
salle is reathed in the MMY process in which the ralle al which mallerial is adeded on the medt at the upper materlace cyual the ratc at which is « "fro/en" into the new/ !rown

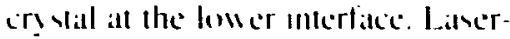
atcite depants in the polyers stalline lecel will therefore he unitomils distrabuted axialls. In addition. the small meli volume sabilises thuid flow. therebs producing a crustal "ith a high degrec at aptical homongentils.

A process robated for clameal Bridgman ers sal grumb a called

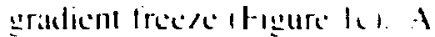

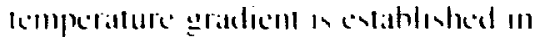

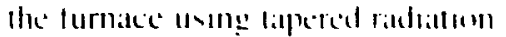

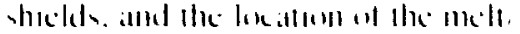

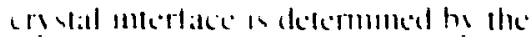
pustum in the nothme pom an the furtates In the gratelem treese

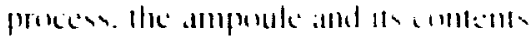

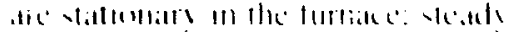




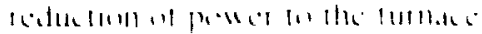

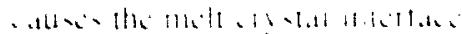

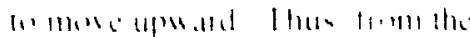

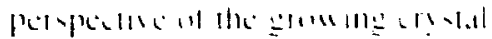

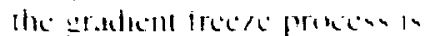

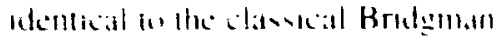

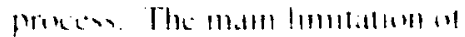

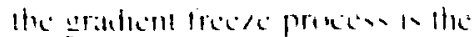

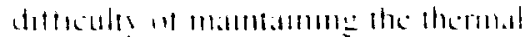

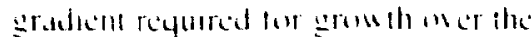

full kengeh of the ampente Important

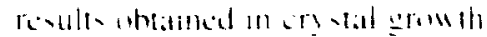

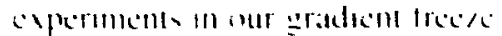

turiate the deconhed hater ofl ho atlisle.

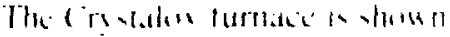
whemalteally an Figure ? It will he

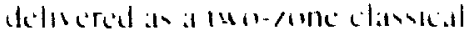

Brol:man tumaci. and we will wי 1 as such lo grom larege crs stat vlath lo cer atdianced comtanl progeratils.

fumace cinflignations. and (bagenowe prior for additum at the

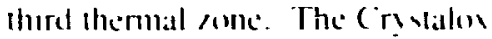

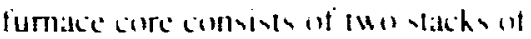
graphile slinders osuseptors that

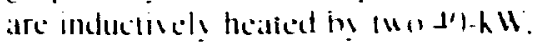
25.kH/ pumer supplies (1) prow ide a

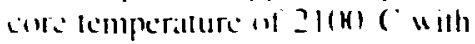
exceptomal pumer vabilat 111.11:3; The "Traphle eylomder are called
-16.

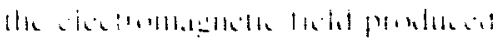

m the :

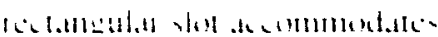

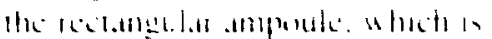

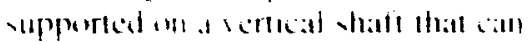

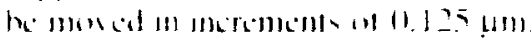

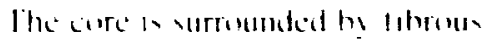

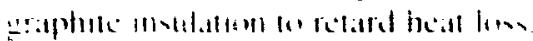

The lemperature of the lambate

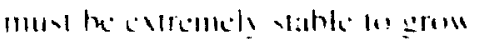

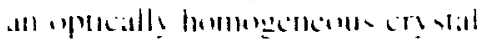
Betore we combl yecils the requared lemperalure vahilin for ilse

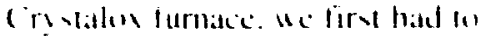
stats moleratand the relatom

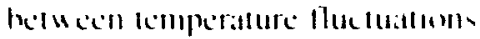
in the meth /ome durme crs sal

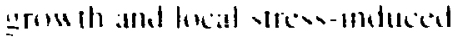
hirefringence fat hes Indicatur al the kegrec of uplical homogeneis! In the resulting crs sal. Ahrupt changes in lemperature at the melters tal merf ac during arom th will aller the ratce af incorporation al dopant inlo the ers sal structure. catusing the

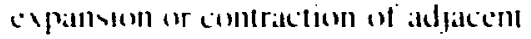
laters and thus meroducing shear aresse, in the :revial. Since thene later comtan ant me concentrations

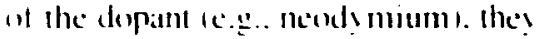

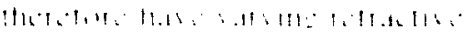

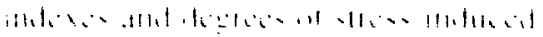

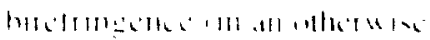

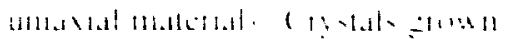

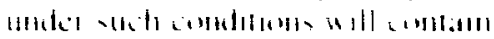

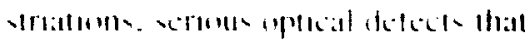

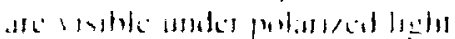

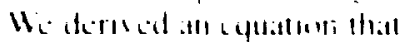

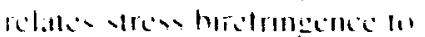

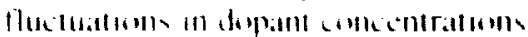

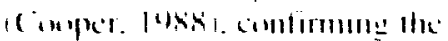

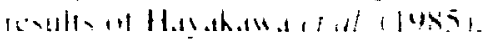

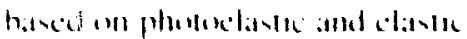

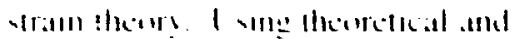
ampurical tha rmolsmamm datat.

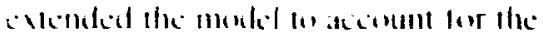
dependence al depant comecontmalum

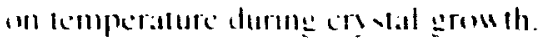

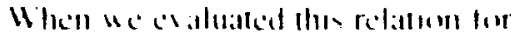
Vil: YAt we lound that a low athelule hirefrmesnce of $3 \mathrm{~nm} / \mathrm{cm}$ demanded a bahlith hand af 11.1 ( al the grow th lemperature ol ly5a ( \& (imper. It)ist.

Mi modeled the mafuetum healimg and heall irambler of the (irstalos funtace through the sraphite insulation and suscieptor slach fo detemme late sathilits ot inc power suppls meeded to restrict

\section{(a) Classical Bridgman}

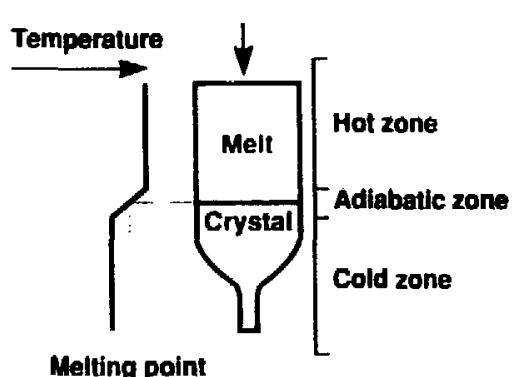

(b) Modiried Bridgman

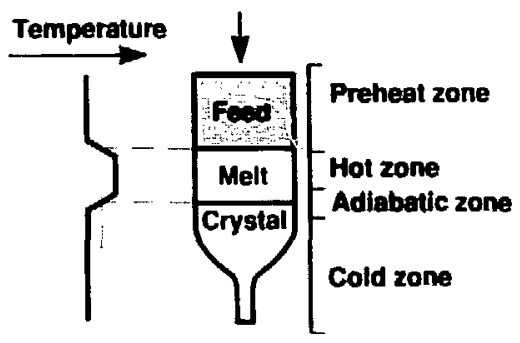

Melting point (c) Gradient freeze

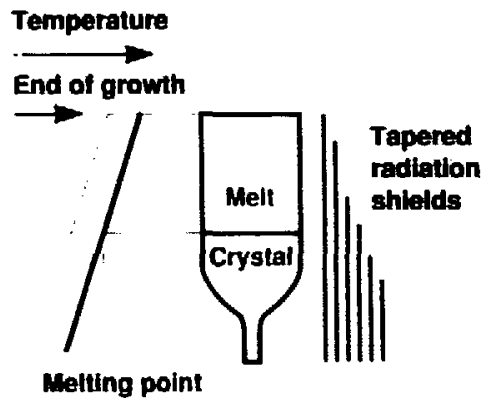

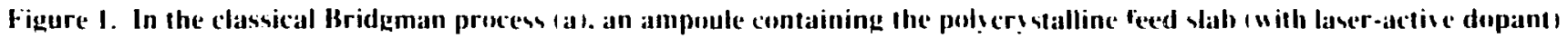
and a seed crsstal is lowered through a two-sune furnace: an upper hot anne is separaled ' rom al lower cold ane hy an adiabatic region that flattens the melt erystal interface. In our modificalion of the classica Bridgman process (b). a preheat asne is added abowe the bot ane: this allows a reduction in the sise of the melt ane and th solume of medt. presducing conditions in which opticall! homogenewus crystals can be grown. The gradient freege configuration te) is closely related fo

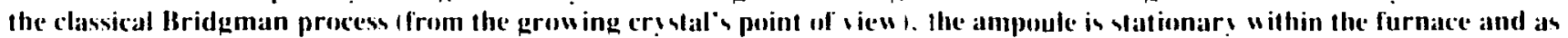
power is progressivel! reduced to the furnace. the ery stal grows as the melt eryatal interface mos cos upward. 


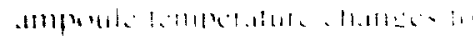

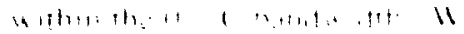

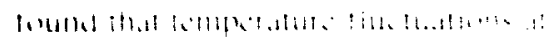
the - 1 and

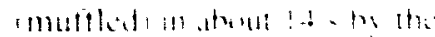

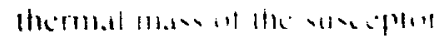

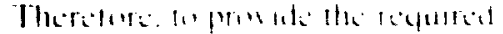

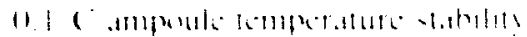

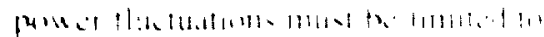

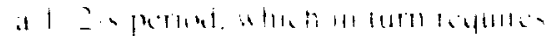

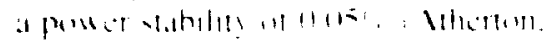

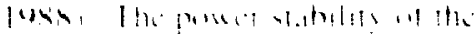

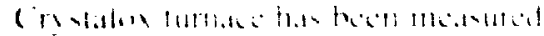
li) he 111 il

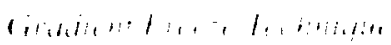

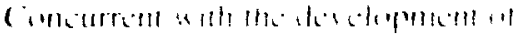

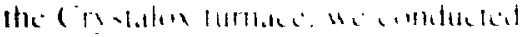

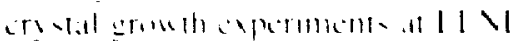

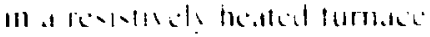

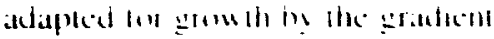

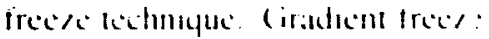

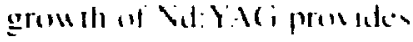
insaluate informallan fur the

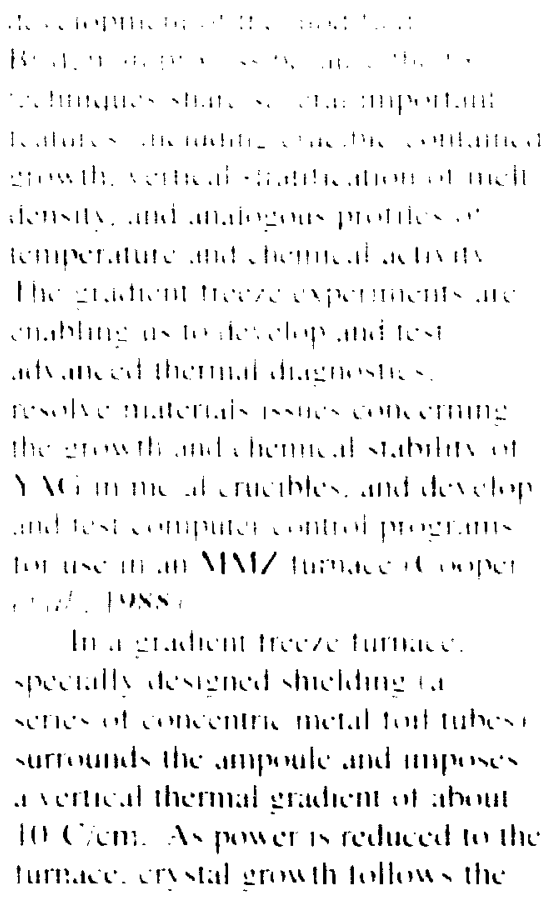

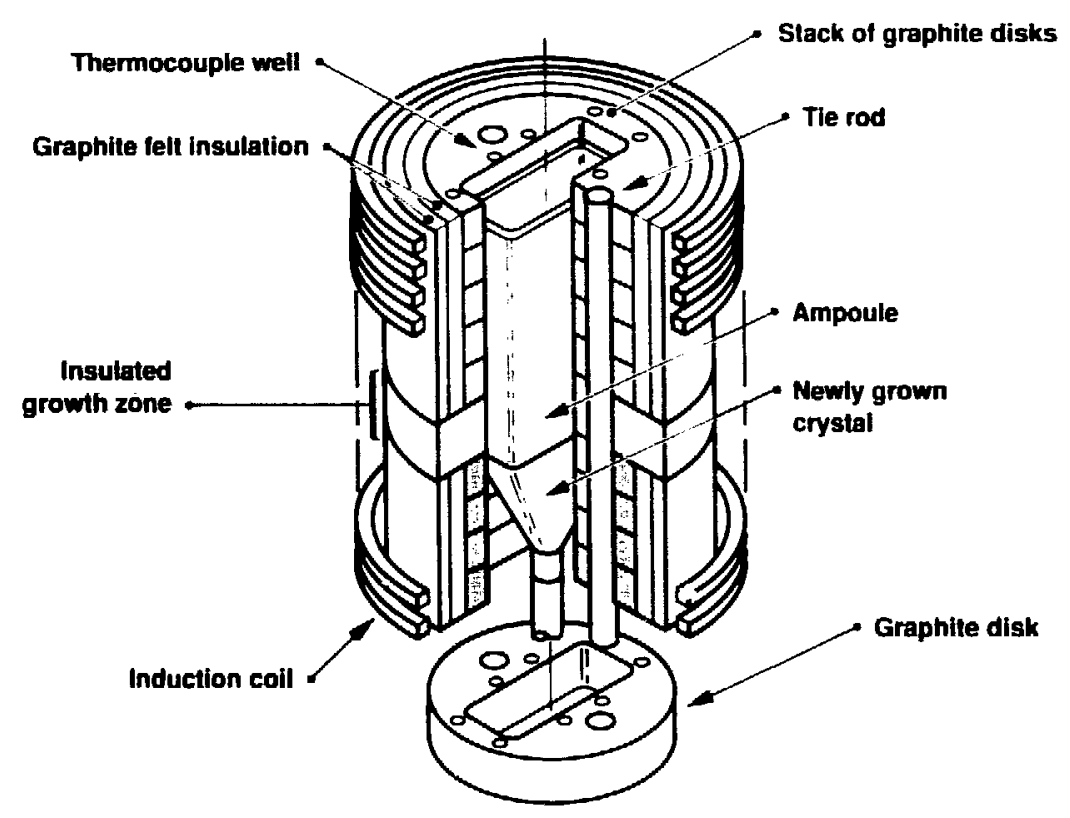

Figure 2. The ( rostalon furnate consints of two stacks of graphite disth isuseeptorst that inductis els cosuple lo the masnetic field af two independentl! controlled generator conls, surrounded h! fihrous graphite insulation. I he Iwn stack of disk are weparated by insulation fo flallen the melt eretal inferlace. I rectangular ampoule is sow ly lowered through the asial slot in the graphite diath li grow the cristal.

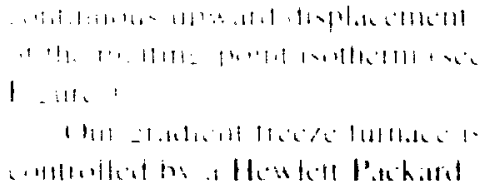

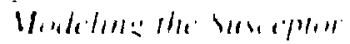

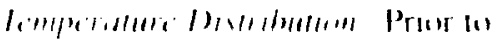

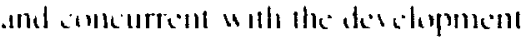

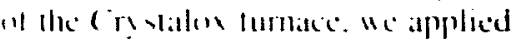

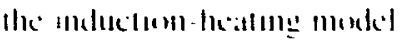

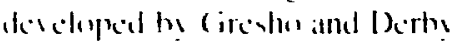

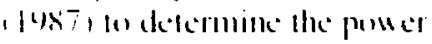

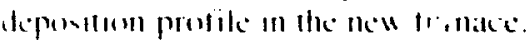

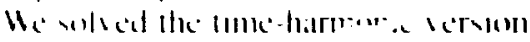

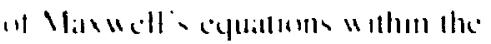

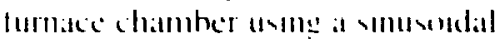

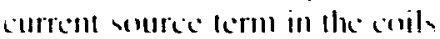
Ihat surround the surcepler and

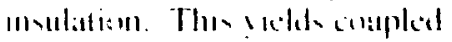

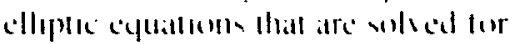

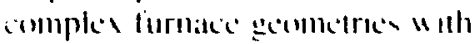
1. II) AP. a limice-dement thual

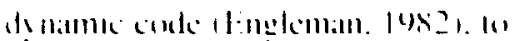

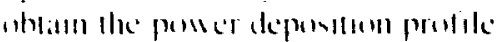

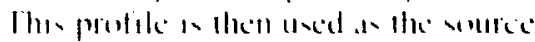

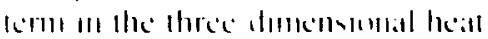

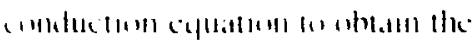

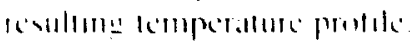

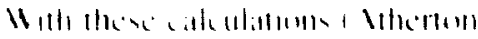

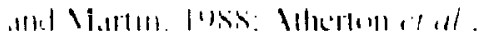

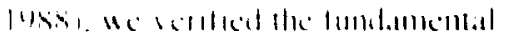

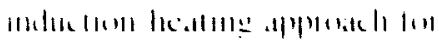

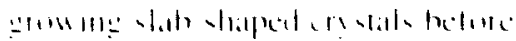

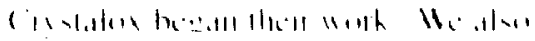




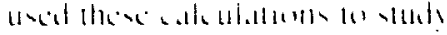

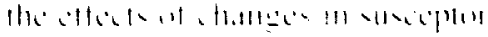

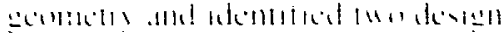

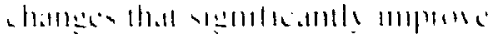

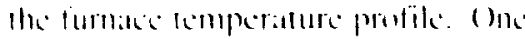
chathes

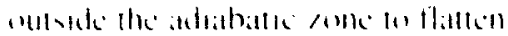

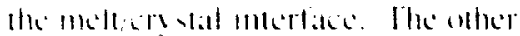
แats

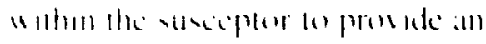

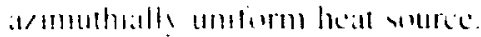

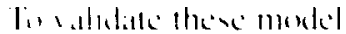

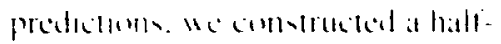

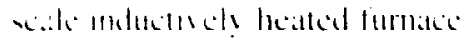
here.t1 I. Y . In this turmates the

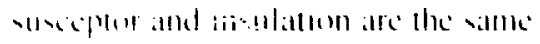

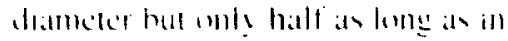

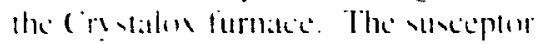

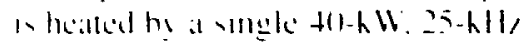

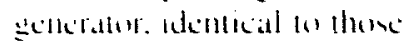

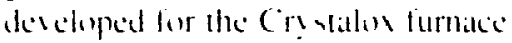
hut with related poucr-stabilits reyurements. The mitial results trom tists an the furnate suppon our model atculations, and turther kas are uncler wall.

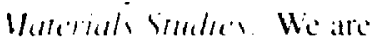

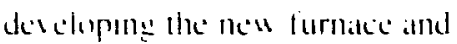
cresal grow th process usitlg

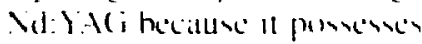
grow hroblems ly picil of thone

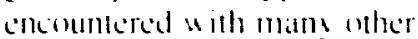
laner matlerials. During process deselopment. It is cratcialls important 16) destinguish process-induced

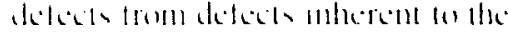

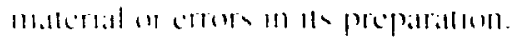

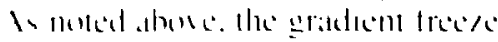

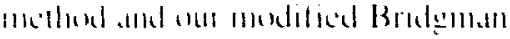

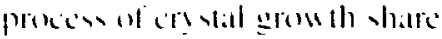

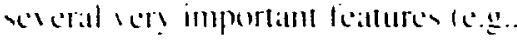
stucible-contatimed grom h, sertical sratification of mell demsit! and analogen protiles at kemperature and chemical actis il / that atfect the inclusions. stiattons. and depant demsit! of the resthing crybial. We

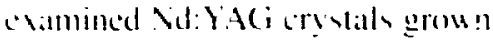
ba gradion frece to karn hou hest

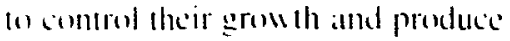
uplicall! homogerencencery stals.

A fill. rare inclusions of $\mathrm{Al} O$ and $\mathrm{y}_{:} \mathrm{Al}\left(\mathrm{O}_{21}\right.$. resulting from croms in the componition of the starting matcrials, were idemilled by samming electron microscopy and microprohe analysis. More common inclusions of metallic tungsten $1-1$ ftm diameler. -4 particles/mmin croms section) were found in Nd: YAG grom in lidded hut unscaled tungsen crucibles. These particles evidents resule from the dissociative eaporation of alumina from the melt $\mathrm{Al}(\mathrm{O} \rightarrow \mathrm{AlO}+\mathrm{O}, \mathrm{f}$ followed h! the reduction al dissolved angsten ajdes by the Al(). No inclusions were lound with Vid: YAC samples eroun in seilled molyhdenum crucibles iprocured from researchers in the People Repuhtic of ('hinat. Thus. carstul chovec of erucihle maltertal and/or strict relaudation al catporatiom should climinale inclusions.

We also examined the acumence of strialioms in Nd: Y AG. As discussed athoue, strialions are periondic variations of optical properties f such as hirefringence or atosoptivity) along the direction of cryal growth. In Nd: SAG. periodic sress-induced hirelingence reflects local changes in the neodymium concentration of the crssial. and the concentration of neodymium ahsorhed is at strong function of growth temperature. We constructed a circularly polarised light polarimeter to measure the layered strain fields in samples of $\mathrm{Nd}$ : YAG. Initial results show huctuations in hiretringence of about $2(1)-3(1) \mathrm{nm} /$ cm. which is in good agreement with our model predictions for the measured temperature bandwidth of $\sim \mathrm{C}$ in our ummuffled fumace. In the Crystalox furnace, the use of high-thermal-mass materials for furnace internal components logether with the improved power stability will provide the required (). $\mathrm{C}$ temperature stability and thus limit birefringence to the target level of $3 \mathrm{~nm} / \mathrm{km}$.

\section{Table 1. Diagnostic techniques used to measure temperature distributions and fluctuations in crystal-growth furnaces operating above $2000^{\circ} \mathrm{C}$.}

\begin{tabular}{|c|c|c|c|c|}
\hline Diagnostic & Precision & Resolution & Accuracy & Description \\
\hline $\begin{array}{l}\text { Optical-fiber } \\
\text { thermometry (OFT) }\end{array}$ & $0.2^{\circ} \mathrm{C}$ & $10+{ }^{50} \mathrm{C}$ & - & $\begin{array}{l}\text { Fast-response pyrometric technique: can delect very small fluctuations } \\
\left(10^{\circ} \mathrm{C} \text { at } 10(0)^{\circ} \mathrm{C}\right) \text { : particularly useful for distinguishing between } \\
\text { hydrodynamic instabilities in the melt and changes in fumace power. }\end{array}$ \\
\hline $\begin{array}{l}\text { W/W-0.26 Re } \\
\text { thermocouples }\end{array}$ & $\mathrm{H1OC}$ & $0.1 \%$ & $101 \mathrm{C}$ & $\begin{array}{l}\text { Used to measure furnace temperature distribution: also heing used to } \\
\text { guide development of furnace hardware to provide high thermal } \\
\text { gradients }\left(10-210^{\circ} \mathrm{C} \text { ) required for crystal growth. }\right.\end{array}$ \\
\hline
\end{tabular}

\begin{tabular}{|c|c|c|c|c|c|}
\hline Rhodium & & - \\
\hline
\end{tabular}


In addition. We measured the distribution of the neodymium dopant in the YAG erystal using $x$-ray thuorescence and absorption spectroscopy. We found a nearly uniform axial (vertical) distribution of neodymium, despite the low segregation coefficient of neodymium in YAG. These results are contrary to the predictions of two transport models, one assuming a well-mixed fluid and the other assuming a stagnant tluid (see Figure 31 and may have important implications for our modified Bridgman process. When we examined the radial distribution of dopant in YAG. we found that it was essentially uniform except for a very high concentration of neodymium (roughly $30 \times$ enhancement) in a $50-\mu \mathrm{m}$-thick layer adjacent to the crucible wall. where the interface between crystal and melt curves sharply downwards to form a crevice. Such a crevice is predicted from heattransfer analyse.;. given the differing thermal conductivities of melt. crystal, and metal. but we had not anticipated such a large concentration of neodymium at the wall. We conclude that the axial uniformity of dopant concentration results from a balance of the rate of rejection of neodymium from the growing interface. the flow of neodymiumrich melt into the crevice, and its spontaneous precipitation in the crevice. This effect has not been reported for growth of large cylinders of $\mathrm{Nd}$ :YAG by gradient freeze: the smaller surface-to-volume ratio for these larger crystals would reduce the impact of the relatively small layer of neodymium-enhanced polycrystal at the edge of the crystal on the overall crystal mass balance. However. in the growth of crystal slabs by the Bridgman process. the surface-tovolume ratio is similar to our smallscale cylindrical experiments in gradient freeze. Thus, we expect to see a similar behavior for the growth of $\mathrm{Nd}: Y A G$ in the Crystalox furnace: if this is indeed the case. we may be able to produce axially homogeneous $\mathrm{Nd}$ :YAG without adding the third thermal zone to form a MMZ furnace.

Flature Plans. In FY89, we will concentrate on growing slabs of $\mathrm{Nd}$ :YAG in the Crystalox fumace in

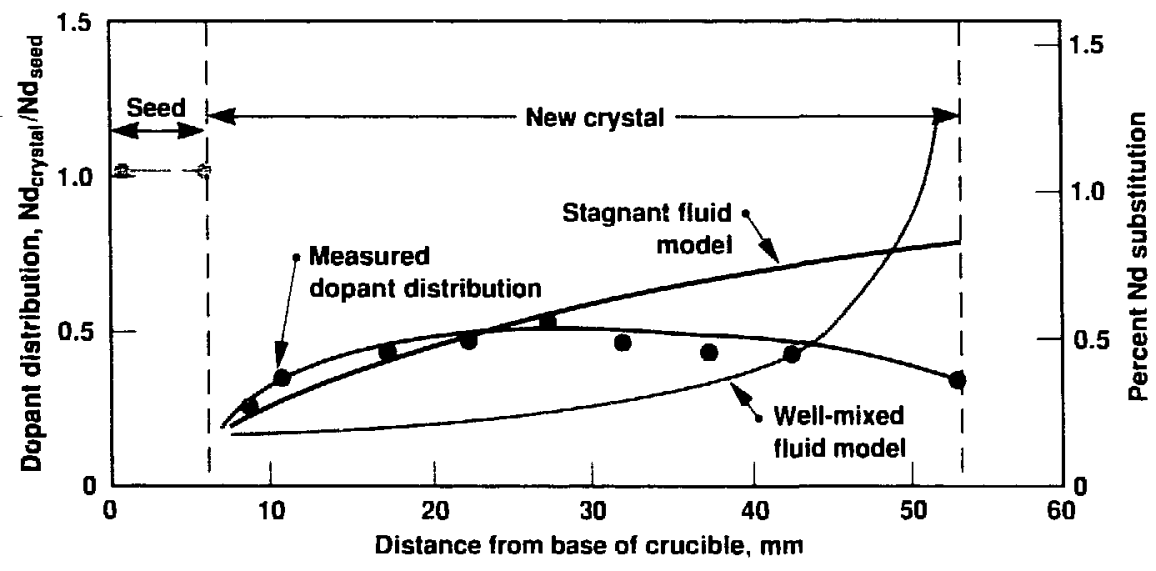

Figure 3. Axial distribution of neodymiu $n$ in a YAG crystal grown in a gradient freeze furnace. The dopant distribution measured in this crystal was found to be nearly uniform. contrary to predictions by mass-transport models based on the limiting cases of well-mixed and stagnant fluids. This uniform composition evidently results from a combination of balanced rejection of neodymium from the axial interface and enhanced precipitation at the crucible $w$ all. This discovery may provide a way to achieve uniform doping levels in slab-shaped crystals using the classical Bridgman process. both the classicial and the modified Bridgman configenration. We will also refine our models of temperature distribution and stability to fully understand their effects on ery'stal grow'th and on dopant distribution. We will continue to develop appropriate crucible materials and furnace controls and diagnostics. and we will explore the extrnsion of the technology thus developed to other materials.

\section{References}

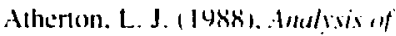
Tempcranure Fluctuations in a Graphine' Susceptor. Lawrence Livermore National Laboralory. Technical Memorandum LRD8X-1)25 (February 23).

Atherton, L. J.. and R. W. Martin ( (4SX). Medeling Indurfiom Hearing and i-D Ho'at Tramsler lier Gronth of Re'clangular Cristals Lsing FID.AP. Lawrence Livemore Nalional Laboratory. Preprint UCRL-99629.

Atherton. L. J.. R. W. Martin. D. H. Roberts. and J. F. Cooper (1988). Indiation /learing for Bridgman Cowstal Cromall: Model Predictions and Experimental Results. Lawrence Livermore National Laboratory. Preprint UCRL-98875.

Comper. J. F. (1988). T/k Dependence of Srress Birefingenes an Temperature Fluctuations at Ihe Crisfal Mell Interfine', Lawrence Livermore National Laboratory. Technical Memorandum OMG-88-19 (April 5 ).

Cooper. J. F.. H. Lugg. M. Shinn. D. Roherts. and L. J. Atherton (1988). Growith of Yrmium Aluminum Garmet by Gradic'n Fre'ce Te' hnigut. Lawrence Livermore National Laboralory. Preprint UCRL98877.

Engleman, M. S. (1982). “FIDAP-A Fluid Dýnamics Analysis Package." Adh. ting. Soffuare 4. 16.3.

Greshos. P. M.. and J. J. Derby 119871. Sollatisn of alle Time-Harmonis Semi-

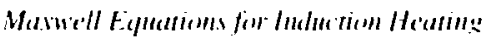
( ving $F /$ ) AP. Lawrence Livemore Vational Laboratory. Preprint liCRl. 97322 .

Hayakawa. H. M. Emino. H. Mori. and Y. Fuji (1985). "Ohervatlion of Sirnatlum in Vol: YA with Circularl! Polaried

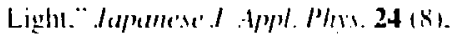
1.-(1) 14 . 


\section{Diode Array Development}

Principal Investigat ur: R. W. Siolars Cu-Investigators: 1). C . Mundinger. R. I. Beach. W. F. Krupke, ana W. J. Benelı

$\mathrm{F}$ or high-allerage-power semiconductor lasers, wasle he:at removal is the primary limiting factor. This in turn affects both later lifetime and laser system com. Lifetime and efficiency decrealse rapidly ats the operating lemperature rises above $+1(1-50)^{\circ} \mathrm{C}$. and the cost per watl of average power scales inversely with the device duty fitctor. The heilt-sink technology currently used to package diode arralys typically allows a device duty facior of only $1 \%$ or less. severely limiting the use of these arrays in many potentiai applications.

Our objective is to adapt silicon microchannel coolers (Mundinger "t al. 1988) to cool laser diode arralys. with the primary emphasis on developing incoherent pump sources for solid-state lasers. Microchannel coolers were originally invented for cooling wafer-scale integrated circuits and have proven to be very effective at removing large amounts of waste heat with only a small temperature rise. Using microchannel coolers for laser diode arrays should easily give a factor-often improvement in average power over present diode packages and even larger improvements in lifetime. The packages. once developed. should allow pulsed and continuous-wave (cw) pumping of high-average-power solid-state lasers and will find ready application wherever low-cost. highpulse-repetition lasers are required.

Our activitie:, have been both analytical and experimental. We

\section{We are adapting the techology of silicon microchannel} coolers to that of high-power semiconductor laser arrays. When integrated, these tw'o technologies will make it possible for semiconductor lasers to operate at average powers in
excess of $1 \mathrm{~kW} / \mathrm{cm}^{2}$ for very long lifetimes. hate deseleped a model thall describes the heal flow hetween the active region of the semicenductor laser and the conlant. and have projected the pertormantec for a range of conler archilectures and channel dimensions. We developed hondin? procedures for achicving reliable. lou-thermal resistivity honds. We also develuned a simple and reliahle coolant monifold that provides high thow rales with a minimum of pump power. In addition. we fabriciated and tested several integraled assemblies that demonstrate the essential features of this cooling approach using a one-dimensional diode array. The measured performance of these assemblies is in good agreement with our projections.

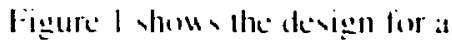
compict. high-puser arrall of dondo

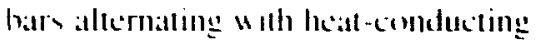
fins lo lorm a lwo-dinlensional viach arteh-and vach-archilecture). This derign use the readil! all ailathle. high-power. edge-emilling diode hars

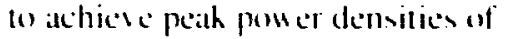
kiloualle per syuare centimeler. It also users commerciall! available ynthetic type-za diamonds as chip carriers. These carricers have high thermal conductivity and thus reduce the thermal impedance hetueen the silicon microchannel plate to a value that is small compared to the overall thermal impedance of the diode package: This rack-and-stack approach could readily be realized lasing jumction and the surface of the

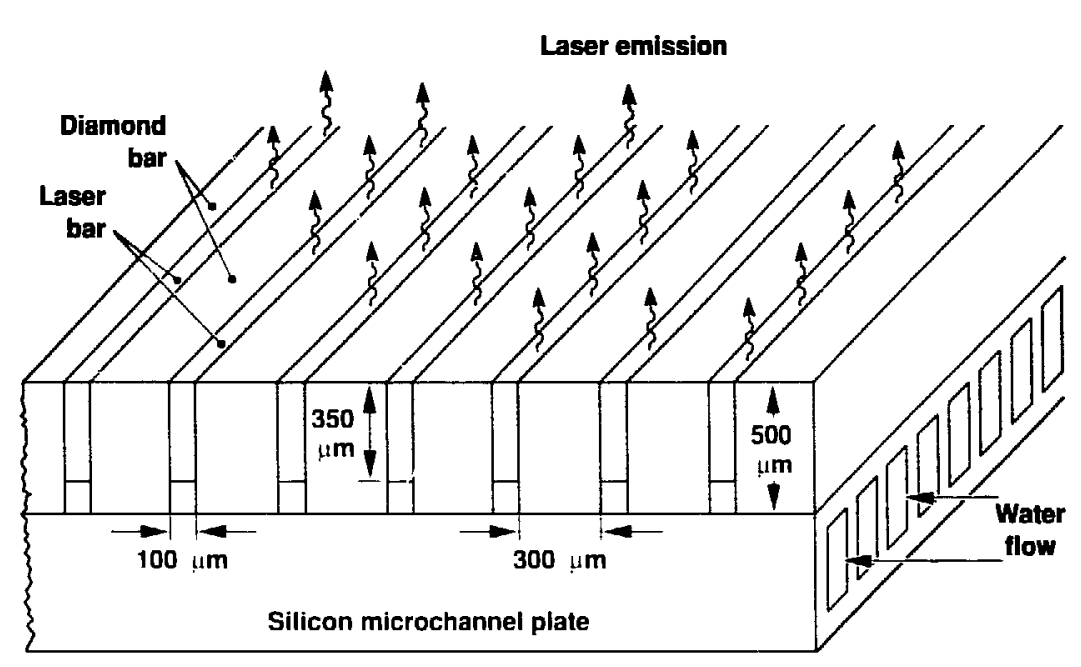

Figure 1. Design of a compact. high-average-power. laser-diode array. In this rack-and-stack architecture. diode bars alternate with heat-conductirs: fins to form a two-dimensional stack. 


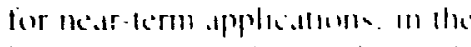

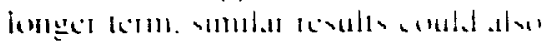

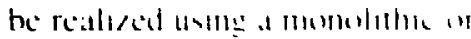

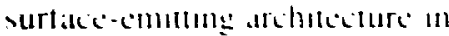
juncuon-dumn comligurallath

The low thermat mopedatice ot the ex merochamel structure

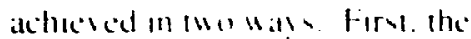

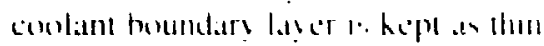
as poushle white sull mantrammule a

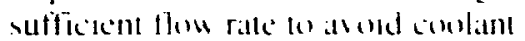

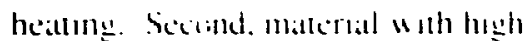

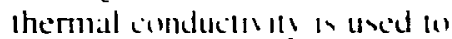
maxime the elfectac area of the coolant houndars later. The How through the channcis is lamumar. which gu心 hetter couling performatnce for reasomabic pump power than turbulent thow. Figure? is a photograph of the microghamel structure.

Figure i show the fatbricalled assembly. consistang of a silicon heal exchanger. a diamond-chip carrier. a copper n-side contact. and a .3-mmthick taser diode har. For this test. the microchannels were "salwn" in the silicon using a diamond waler salu. After the channels were cut. the silicon " $a$ lier was allached $t o$ a borosilicate glass back-plate manifold by anodic honding. The glass was etched with grooves to provide for water inlet and outlet in the microchannels. This composite wafer was then cut into four individual coolers. each with an area of $4 \mathrm{~cm}^{2}$. Two electrically separate contact pads were created on the upper surface of the cooler by depositing a 5-mm layer of nickel. Silicon with high electrical resistivity (>30 $\mathrm{W} / \mathrm{cm}$ ) was used to ensure good electrical isolation between the two pads. The 3-mm-thick diode har was a gain-guided device with lik)-mmwide emitting facests localted on 150-nom centers. Typical opical output for these devices is $5 \mathrm{~W}$ per 3-num bar or $250 \mathrm{~m} W$ per licel al three to four times the threshold current. Threshold current uas
16.

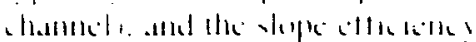
u.t? $(1)-112$,

I-1gure + plos the lemperaturs is andmhls as a functlun al thermal puwer under :u eperallon. The

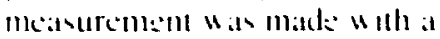

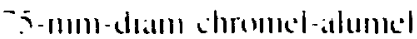
thermoxisuple momiled an ath $1.1 \%$

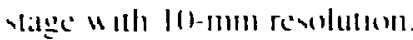
lemperature wa measured an the

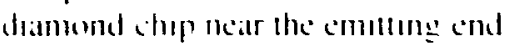
at the diude atrat. B! sweepmen the thermukeruple function acrome the varlides. "se determmed that line duce bar ascembls was unilumu in lemperallure lo within our measuring accuralc! of $\pm 1 C^{\circ}$

From lhese data. w ith a healt-

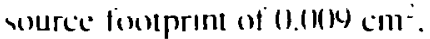
we inler a thermal resistivity ot $0.14 \mathrm{C} / \mathrm{cm}^{-} / \mathrm{W}$ between the diodediamond bar interfice and the now ing coolant. For comparison. detalited calculations batsed on the formalism presented by Tuckerman (1984) predici a value of (1).09 $\mathrm{C} / \mathrm{cm}^{-} / \mathrm{W}$ for a close-packed. wo-dimensional array. In our single-

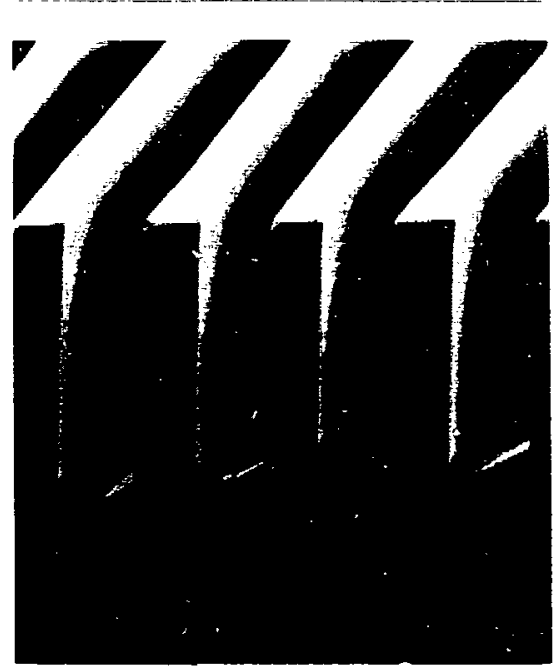

Figure 2. Typical silicon microchannel structure.

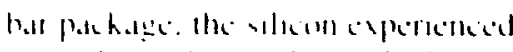

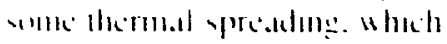

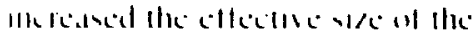

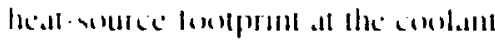
hemolars later the degereal cepected ypeadlung

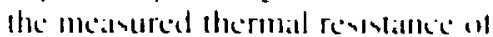

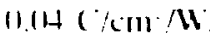

Recomls. "e tahricalled dinde pachalges with ?-mm-diam apertures that can uperate all higher at eratece puscr. I nder is eperation the? achiced an oplical power of 1 b. and under yualsi-cu uperallum thes reitched a peak power af $1+\mathrm{H}$. Hi hate also developed a silicon-etethed manitold ssem thall will allow us to achicse vers short channel length. $1-5(1) \mathrm{mm}$ ). consuring low thermal resistivily and very uniform couling. Thene devices were recently measured lo have a thermal resislivity of $11.0113 \mathrm{C} / \mathrm{cm}^{2} / \mathrm{W}$

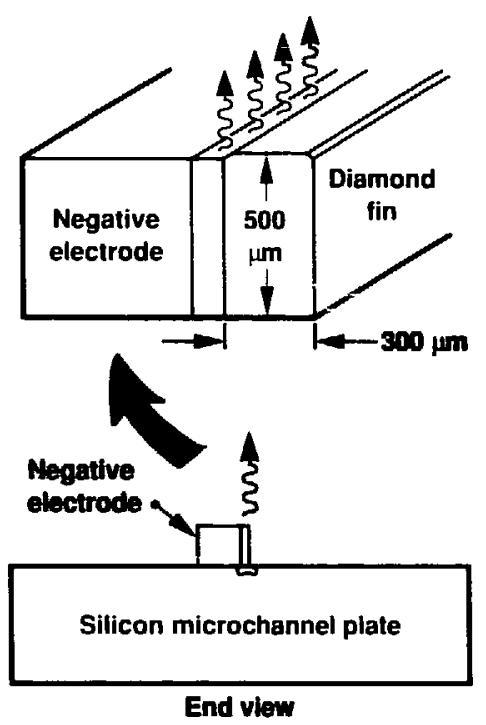

Figure 3. Diagram of the integrated laser-diode/microchannel cooler assembly used io demonstrate heat sink performance. 


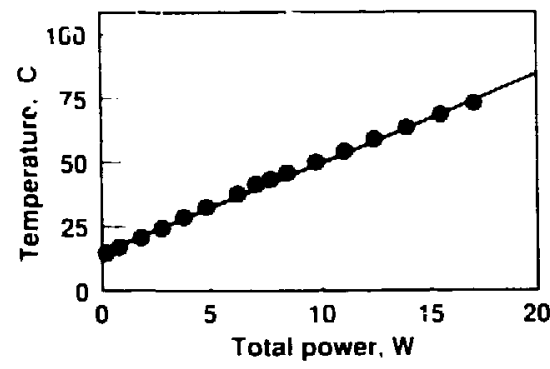

Figure 4. Temperature rise versus thermal power for one heat-sink diodebar assembly llike the diagram in rigure 31. This assembly was determined to be uniform in lemperature to within \pm 1 ( 1 the accuracy limit of our measurements). For this assembly. we inferred a thermal resistivity of $0.04 \mathrm{C} / \mathrm{cm}^{2} / \mathrm{W}$.

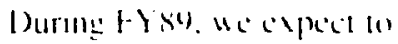
be athle la dememstralle bers hegh thermo-eptical pertormance " ilh doamond har/microchannel couler patchilge that deliser more thats 15-20 W (c) per céntimlerer of aperture. and with incle-dimemsional piathages that generale more than lo(1) $\mathrm{H} \% \mathrm{~cm}^{2}$ (c) We will cominue our evaluation of silicon-on-silicon honding methoks. and " we will innestigate 1 arious micro-splice fabrication concepts for efficienty transporting radiation from Iuso-dimensional diode arra!s (1) solid-state laner amplitiers.

\section{References}

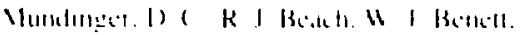

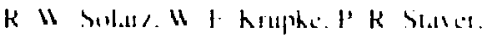
allal 1) B lathermant lesm

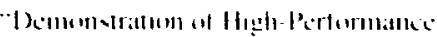

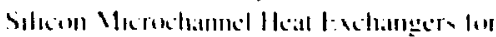

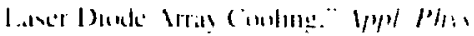
l.t 531121.111011 .

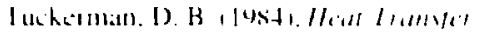

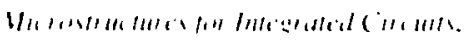
P'h.l) dimertatlon. Sianford l maserall. Sianfurd. ( $: 1$ 


\section{Derelopment of X-Rily I ater Holograph!}

Principal Investigaturs: I. Trehes and

I). Pinkel

Cin-Insestigaturs: I. Brase. 1;. C)ark.

I. liras. K. Lundon, 1). Matthells.

1). Pelers. M. Kosen.

P. I an Irodall, and T. Vorke!

$\mathrm{T}$ he development of y-rit lisers for high-resolution holographic imaging of hiolugical structures has long been a goval of laser researchers uorlduide. Although r-rat laver holography hals heen demonsiraled (Trebes e't al.. 1987). fundamental questions remiain aboul its pratclicality and its ultimalte limitations. We have heen investigating these issues both experimentally and theoreticall!. Specifically. ue are attempting (1) determine:

- The optimal x-ray wavelength. exposure. and exposure duration for coherent inlaging.

- The ultimat: three-dimensional spatial resolution.

- The effect of the target object's complexity on resolution.

- The effect of x-ray absorption by the object (and resultant damage) on resolution.

We have developed a simple model for $x$-ray scattering for biological materials in water based on Rayleigh-Gans scattering (London et al. 1989). With this model. we have determined the optimal wavelength fo: maximum scattering and minimum aborption. It appears that an s-raty laser with al walelength of $4.5 \mathrm{~nm}$. at coherent output energ!
High-brightness x-ray lasers offer the possibility of creating three-dimensional, high-resolution, x-ray holographic images of biological microstructures in vitro. This new imaging technology will be a major advance over current imaging capabilities, with the potential to provide structural information about cellular components that cannot be obtained by any other method. We are developing this imaging technology and are assessing its ultimate limits and utility. of $5(1)$ J. and a pula durallom of 50 prasuld be sulficicon for holegraphic imageing of biological malcrials ith a itl-nm spatlial resolution.

We have also been investigating the fundamental capabilities of $x$-ras holography using scaled visible-light allalog experiments (Pelers ef $a l$.. 1988). Familiar hologralphy deals w ith the three-dimensional representation of the (twodimensional) exterior surface of an object. Using an optical holography system. We can test our ability to

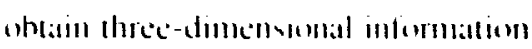
from holegratms. including leatures wt the incrior of comples ohjects. Clusters ot tratmsparent plastic upheres mathe vuitable kes abjects lis proliminary studies ( sce Figures 1-3): their side can be scaled so thall the ration of the sphere diameler to the optical walvelength is the same as that for the desired $x$-ray resolution to the x-ray wavelength. The truc thresdimensional configuration is obtained hy standard optical-microscopic sectioning. The holograms are reconstructed using numerical codes.

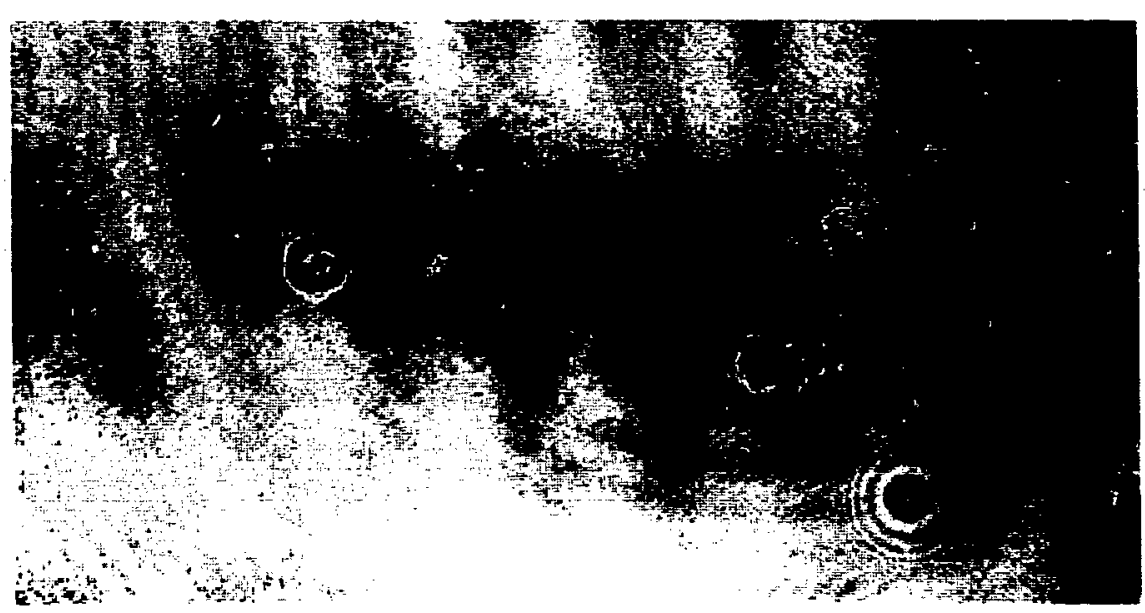

Figure 1. Photograph of two clusters of plastic spheres illuminated with laser light. The lens is placed so that a plane through the clusters is in focus. Spheres above and below the plane cause blurring. Some interference rings due to the coherence of the illumination light are visible. 


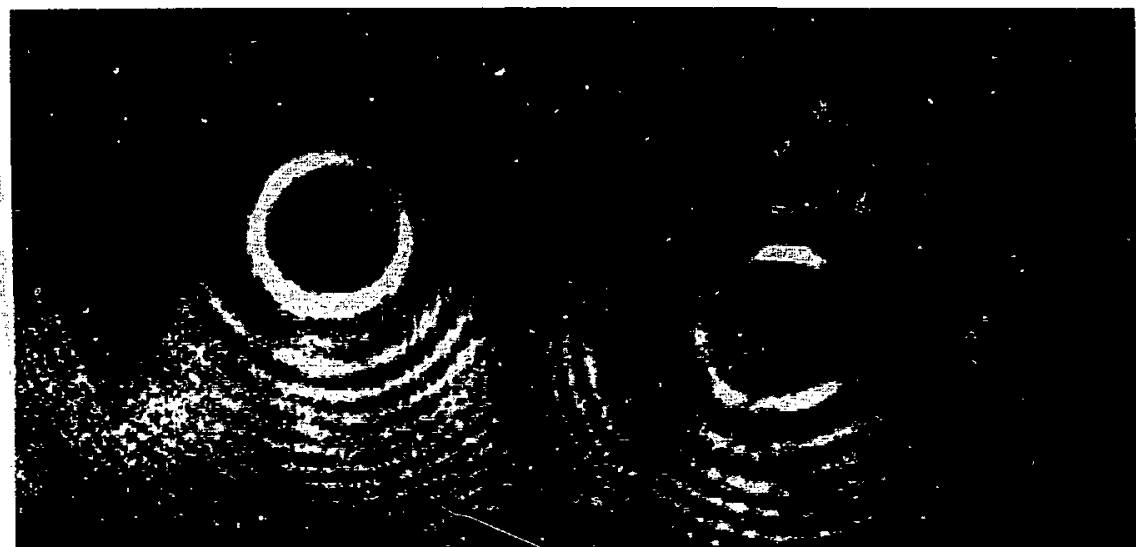

Figure 2. Hologram (in (iabor geometry) of the same clusters shown in Figure I using the same illumination source.

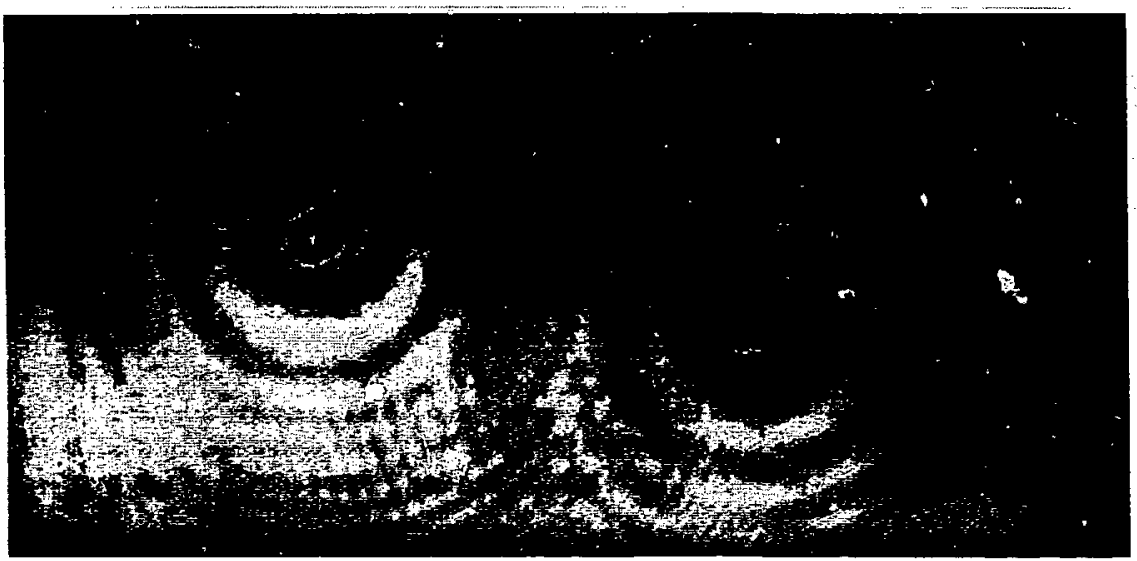

Figure 3. Digital reconstruction of the hologram shown in Figure 2. The depth of the plane of the reconstruction has been chosen to give the best correspondence to the image in Figure 1. Most of the features of the direct image are visible. The remaining interference rings are due primarily to the presence of the virtual image in the reconstruction. Improved reconstruction techniques and alternative holography geometries are being explored.

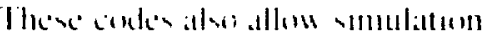

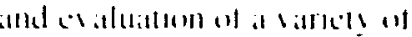
holugraply getometries. and will he

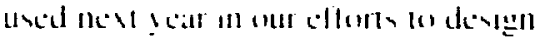
$x$-rat prout-ut-primciple holengraphy experiments lor lathorallory a-raty lasers producid with the Vorat laser.

\section{Relierences}

Tretuen, J.. S. Bromnt I Campledl.

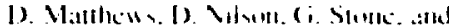

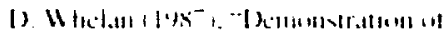

X-K.u Holugraph! w!ll an X-Kan Lascr. Stron: 23.3.517.

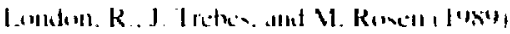

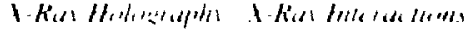

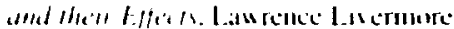

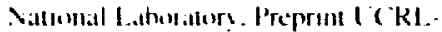
issist.

Peler, D. I Brane (i. Clarh. I Ciras D. Pinhel. J. Tretmes. P. Van Aradall. and r. Yurhes flyks, "A Cinmpariven at Holography and (Jplical Sectionine for

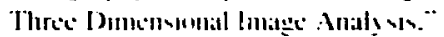

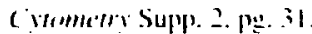




\section{High-Resolution Imaging}

\author{
Principal Investigalors: .J. I. Matis. \\ 1. A. Massie, and .1. P. Fitch
}

$\mathrm{T}$ he angular resolution of ohjecls in space for ground-based telescopes using comventional imiging techniques is limited by the distortions of the atmosphere. This effect is calusid hy the sallme phenomenat that caluse stars 10 twinkle and is the result of minule temperature lluctuations in the atmosphere. As a consequence. even the 5-m telescope al Mount Paluniar in southern California has an effective resolving power of a $101-\mathrm{cm}$ telescope. despite its enormous lightcollecting capability.

Obtaining diftraction-limited images would be of greal vilue in terms of national security and for the discipline of astronomy. The Soviet Union. for example. launches over 100 satellites per year and is alleged to have the capability of launching four antisatellite weapons in a single day. Forly percent of the more than 7000 objects in orbit belong to the Soviet Union. The Soviets have clearly demonstrated their launch capacity and national resolve to provide for a tremendous presence in space. The mandate of national security requires that the U.S. determine the precise nature of that presence. Our project seeks to provide a low-cost technology for ground-based identification and atssessment of objects in spice.

We are pursuing advances in monstandard imaging techmiques

for ground-based telescopes that will lead to angular resolutions limited solely by a telescope's ciameter. We have completed important experimental demonstrations this year and have generated concepts for economical telescopes with effective apertures of 20 to $100 \mathrm{~m}$.

Substamial xeientific henelits will arise from diffraction-limited imaging as well. For ceample. al telescope diameters of about $10 \mathrm{~m}$. features on the surtaces of supergiant stars can he resolved: at $1(10) \mathrm{ml}$. active galactic nuclei can he resolved. Concributions of high-resolution imaging lo date include mealsurement of the separt!! ions of double slitis. determination of the diameter of supernova 1987A in the Large Magellanic cloud, and resolution of the controversy concerning the existence of superluminous stars. Properly designed large arrays could resolve planets around local siilrs.

Our technical approach. called speckle interferometry. is derived from a family of so-cialled "nonstandard" imaging lechnicyues and is the optical analog of successful techniques used by radio ilstronomers. Astronomers have pioneered such techniques in imaging simple celestial objects. albeil with extremely long integration periods. The technological advances we seek would generate high-resolution images of the more complex sattellites from data obtained during short observation periods. Furthermore. given the desire for $1(1)-\mathrm{cm}$ resolution. telescopes with effective apenures greater than 1()$(1) \mathrm{m}$ will eventually he required. As at result. const reduction hecomes a major ohjective. Our near-lerm objectises are 10 pron ide a humdredfold increase in resolution wegether with at fentold reduction in cust.

We faced three separate but relatled technical prohlems. ciach of which is discussed in more detail belou:

- Signal-te-noise enhancement.

- Signal procissing: thai is. unsicrambling the signal of interest. - Large-effective-aperture. lon-cost celescope design.

Our initial analysis of the first problem revealed that the signal-tonoise ratio would be substantiatly improved if we malde our observations at the red end of the spectrum. This realization led us 10 consider using a charge-couplec device (CCD) imaging sensor. This concept is contrary to the previliting wisdon. which asserts that imaging should be perforned in the midvisible range with photoncounting sensors, primarily hecause the use of CCD sensors necessitites overcoming additive noise. We lelt that to gain alceeptance of CCD sensors and to validate imaging of complex. latint objects. ill experimental validation would he benclicial. However, observing an actual saltellite would be expensive. and defectors for optimial 


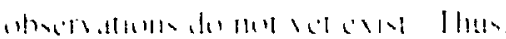

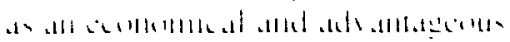

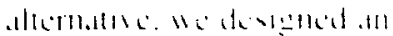

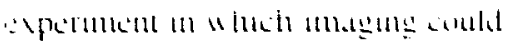

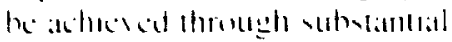

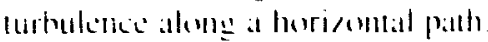
The lesel and nature al the

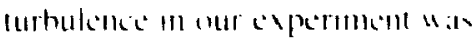

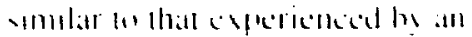

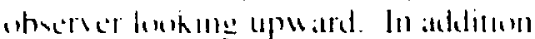

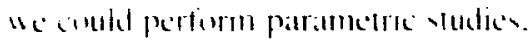

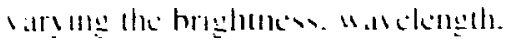
and wher tidsure

lin understand the problem pured

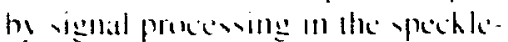

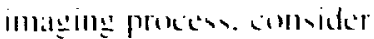

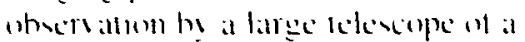

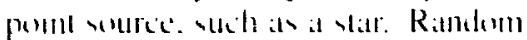
divfortam at the attmonplate. when aberagesd were seconds. create :! circular blur of light at the focal plates. A pertect kescinge al (liameter $/$ ) imalging an ohject through a vacumm would produce a spot of angular $"$ ielth $\dot{A}_{/} / l$ ). "hereals looking through the altmosphere producas a! spolt at angular width of $d / r_{18}$. where $r_{i t}$ is the coherence length of the discortion. I! picall! $I(1 \mathrm{~cm}$. B! usine a marrow hand filer to increatsc the coherenci length of light. and hy taking shom exposures lo frese the distortions. we lind that the imilge is actually compused of a ralldom analy of tint sposs. called speckles. of size $\lambda / D$. Intormation up to the diffraction limil of a telescope is present even though it is scrambled. The issue then becomes ane of how o unscramble that information. Unscrambling the information (i) ohain the inlage is the signalprocessing challenge.

The problent of recosering a diffiction-linaled image from a seyuence of speckle imlages is watlally treated at the sepatrate extimation at the matgrnitude atmol phase al the

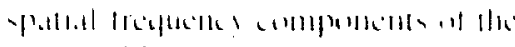

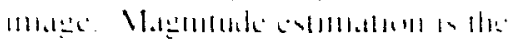

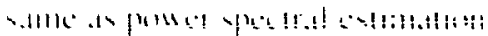

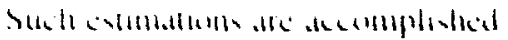

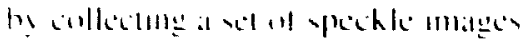

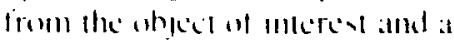

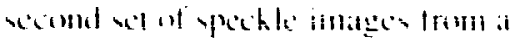

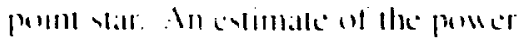
yectrum fir enh sel t:! data is calculated hy atseraging the puser plectrum from eith irame. The

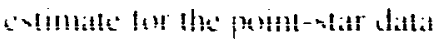

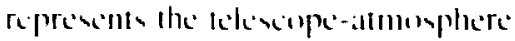
yvem. It the pumer yectrum vilmiatle from the ahject ypeckle seyterlec a dis deled hy the power spectrum estimatle from the point var. the elleck of the lelesedereatmompheres ss sem are corrected init io ihe dititatetion limit of the kisecupe, resulting in an estimalle at the ohject's power spectrum. This lechnique for estimatling the power spectrum (or Fourier miannitude) of ats ohjecl from two sets of speckle images is called Latheyrice: lechnique. Except fir certain upecial calses. however. an inlage canmel he ontained withoul know kedse of the Fouricer phatse.

Tun lechniques for recosering the Fourier phatse of the object from speckle mealsurements halle heen implemented. One lechnique. known as Feinup is spectral itcration. uses the matgnitude estimate from the Labeyrie algorithm together with finile support and positivity constraints of the spatial-domain object inage to estimate the phase. This technique is compuationally slow, stagnales. and ean lead an artifacts in the image. The second lechniyuc. known als hispectral estimatlons. is similar to the poucer spectral estimattom of I atheyrice

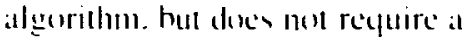
reterence puint uar for phasc

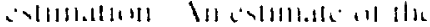

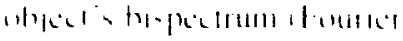

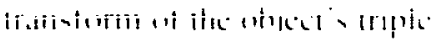

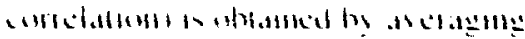

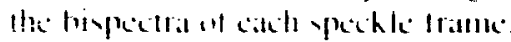

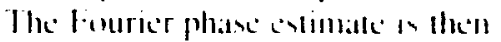

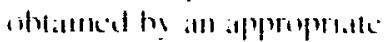

integrallont of phatse in the hepectral

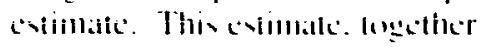

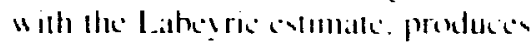
a fecomstrucled sulas:

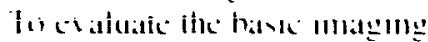

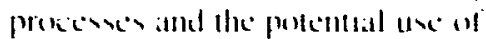

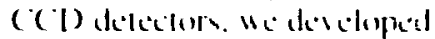
capabilitices for hoth numbercal and (vperimenail simulation. ()ur compuler-hancel allmomplotic

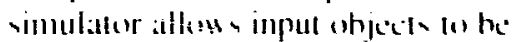
propatgalled through an inginlanatic atmosphere with arhitrars $r_{11}$ The whjects are received by a lelescopte "ilh a pupil function defined as the superposition of excral circular apertures with different sikes and arbitrary ohseurations. The simulator also includes noise sourcess resulting from Poisson photon statistias and nomideal photon delection. With respect lo our "lerrestrial" experiment. We ohtained sereral gigabyles of dalla in FYXs. We used a $1.5-11$ telescope lo imatese small targess over a distance of $1.2 \mathrm{~km}$. Becaluse we comtrol the lateget 4 i/c. shape. and brightness. He can demonstrate imaging oner a wide range of conditions.

Figure I bous images al a sallellite target ohtained from data laken during our experiment. This iesi imalge hats a large dýnamic range and comtaims al lull ramge of leature sires exalemding to oulside of the diffration limit of our celesconpc. lhis sel al datlat is representatlice al 


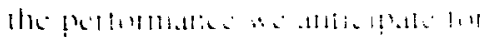

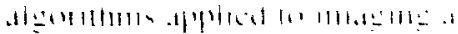

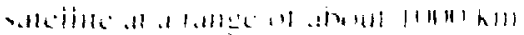

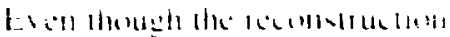

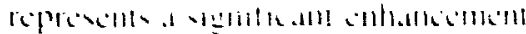

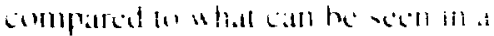

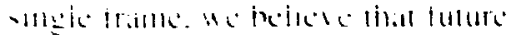

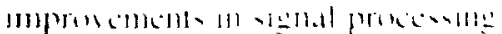

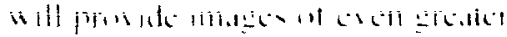
tidelus

( )

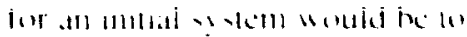
rewle 111 all al a rallec al loll hl km

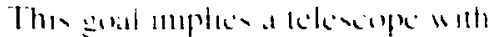

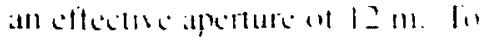

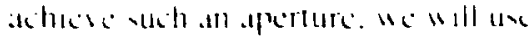

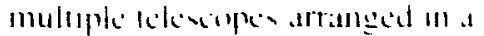
monrsdumblath pallerm w

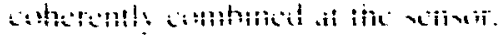
as shown in Fignte 2. The ypeckleimageng proces reyuires that patth be mitiched onls lo within the coherence lenghth of filtered light. nut in a fractum of at warclengeth. as in comsontomal imagng. Thus. the requircment for path-length matchn! in ncarly anc hundred times buser. With this comcept in mind. We cant now contemplatc the desen problems fir larges. low-comb leterenpers.

Cimsider that the keck teleneope. "hich w mow under somstructum. is planned locom S/101 million and lo

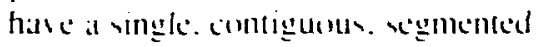
aperture of $10 \mathrm{~m}$. Telescope cost

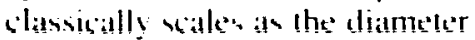
cubed. Thus. a $4(1)$-m)-diameser sstem should cost $\$ 1.5$ hillion. Ohviousls. We musl seck concepts for radical conl reduction.

Our rationalc for athicsing large effectise apertures al low coss is bated on aceral important concepts. First. the use ot an arras ot lelescopes specifically designed for speckle

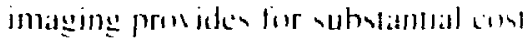

(a) ving̣le topuntirt

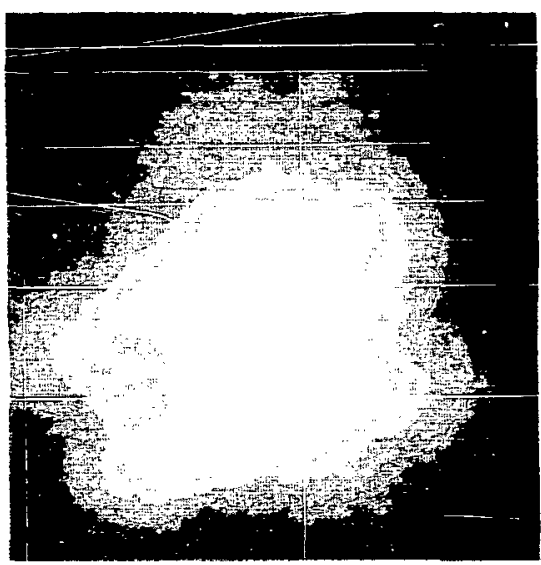

(c) Bispectrum

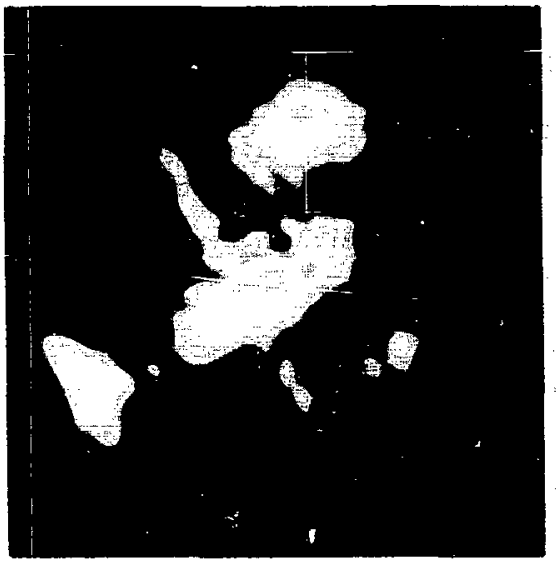

(b) loilfration linifod

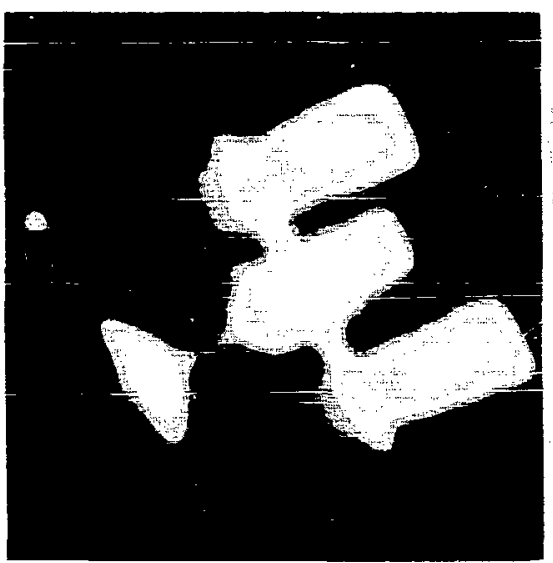

(d) Bispectrum plus Feinup

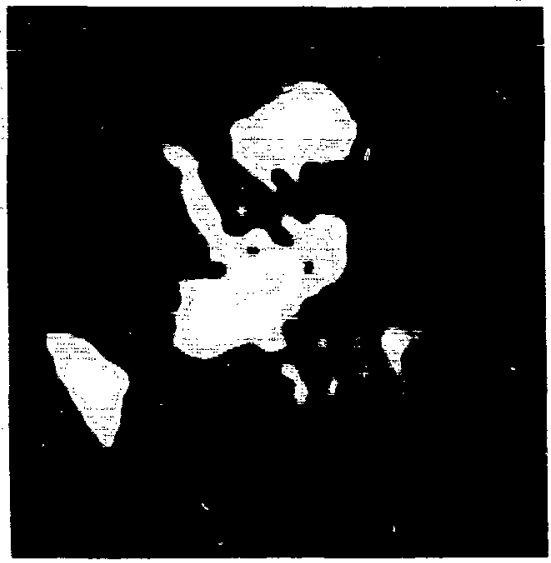

Figure 1. Fxperimental results from the terrestrial experiment. This experiment was conducted with a $(1.5-\mathrm{m}$ telescope. a wavelength of $0.7 \mathrm{~mm}$, an optical bandwidth of $+10 \mathrm{~nm}$. an image exposure time of $5 \mathrm{~ms}$ and a 3-cm-diameter satcellite target ifilm transparency ! at a range of about 1 . $2 \mathrm{~km}$. These datas ara representative of imaging a satellita at I000 km; 2014) spectite images were collected with $\mathrm{I} / \mathrm{r}_{11}=17$. (a) Single. short-exposure speckle image: (b) numerical calculation of the expected diffraction-linited image ano atmosphere, theoretical best case): (c) reconstructed inage using bispectral estimation; and (d) reconstructed image after constraint (supporl and positivit 1 inposition on the bispectral estimate using $\mathbf{5 0 0 0}$ ilerations of the Feinup algurithm. 


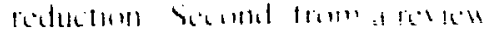

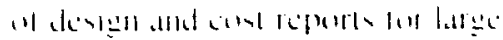

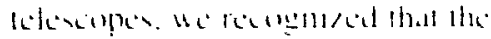

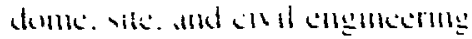

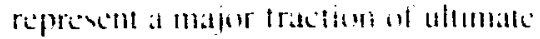
cont. Ava result. Me celected to comstrut a tekencope that would mo reyure a clameal dome hut would he

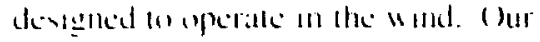
lekexple would hate an inexpensise.

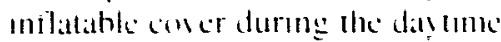

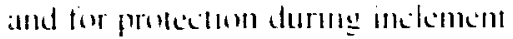

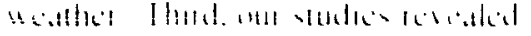

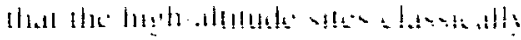

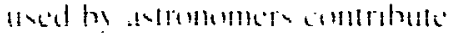

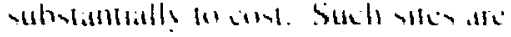

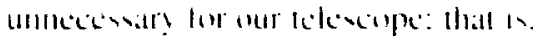
lle necd mol rise abose almopplicric

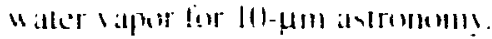
Inderd. "le hatse dentlled a she atome the morthem ( allitimnat colse that has superh "eceing" llarest,

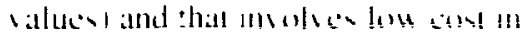

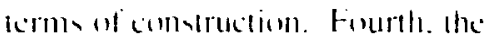

llakmand :

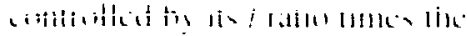

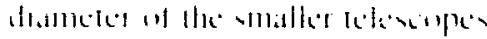

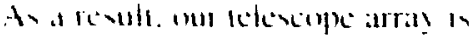

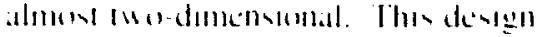

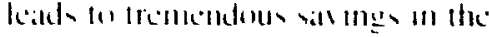
medratlical structure and readil!

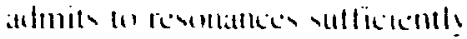
hegh for protected aperatlon willast at dimles.

The atevioge momet current!

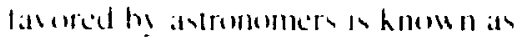
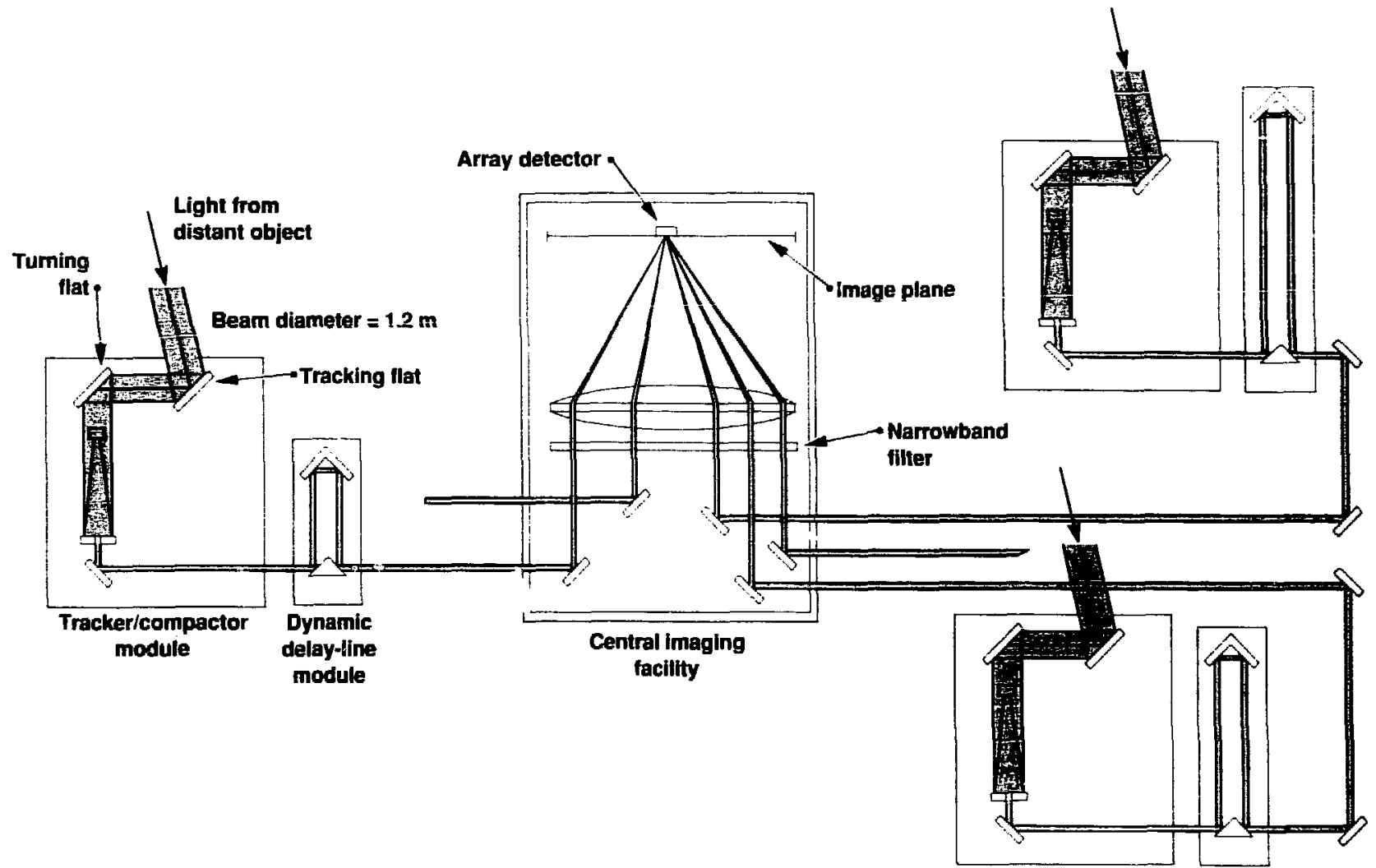

Figure 2. Opticai layout of the high-resolution-imaging telescope. Outputs are coherently combined in this arra!. Requir ements for path-length control are nominall! 100 times low er for a speckle interleronetry lelescope compared to those requirements for conventional imaging. 


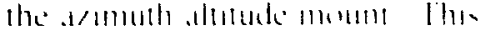

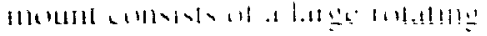

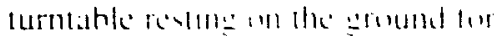

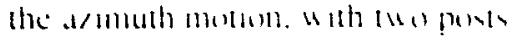

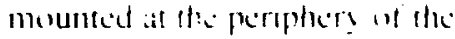
curmathe. Bearmes for the altitude motion are at the lap at the pous. The eleserpe w stpported hesucen

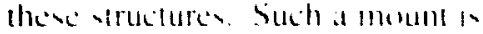
yunk barge: the unsupported yan wat

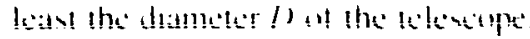

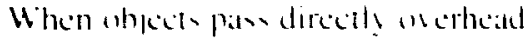
in this destgn. thes cammon he drated dec whe reyutement tor mfintc acceleration in the a/muth axs. and such a tatlure represents at major drawhach tior salcilice arack me

In mef comcent. an the other hand. the telescope is centrally supported on at hall or gembal. and the longey unsupported span is $L / 2$. Beciatuse the lowes structural resomance sales as the cute of the unsupparled length. the revinance is cignt limis higher. leading w) greater frecdom (1) operate in the wind. The mount is frec lo rolate in hoth angular directions. allow ing for all-alt tracking control. and cables are used as force actualors. Figure? show a 20-m. I 2-aperture embodiment of nur devign. In addition. we halcalso designed a $10-\mathrm{m}$ icrion wit the telescope. This ste would perhaps represent an oprimal compromise between utility and risk and is likely to become the demonstration system.

During FYRY. We will continue to assess system performance. We plan extensive use of the numerical simulator and will conduct additional terrestrial experiments. We will also construct a detailed desinn of the 10-m system. with the ohjective of ascertaining a cost estimale accurate to within ?t)?
(1) P'all vieb

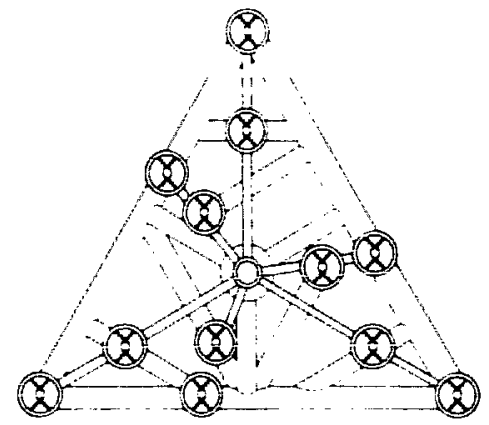

(b) Flevation sien

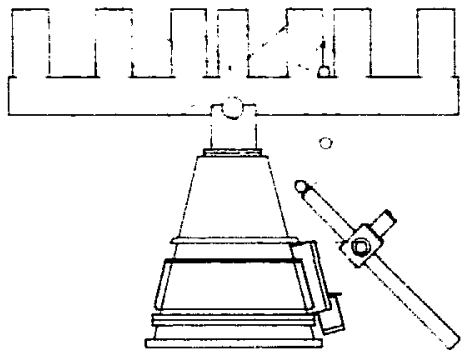

ic) Mndel

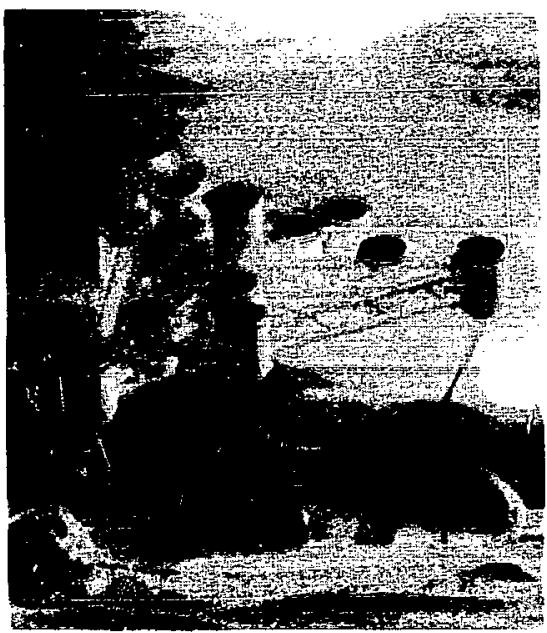

Figure 3. la | Plan view. Ihe clevatiun

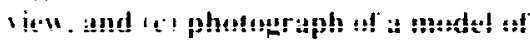
the high-resolution-imaning teleseope. ( )ur unigue design usew a mounting un a centrally localed ball. 1 1 2-element. nonredundant arra! is shown with 1.5-m telescopes for a total effective aperture of $20 \mathrm{ml}$. 


\section{( impact lorme lecelerator}

Principal Inventigaturs: 1, II. Harman and .I. H. Hatmmetr
The Compact Torus Accelerator project reached a major milestone this year: Ring-trajectory determinations from magnetic field measurements, accelerator inductance, and code calculations using the measured ring mass are in good agreement and strongly support the predicted acceleration process. Qualitative agreement was also obtained between the ring's measured and predicted internal structure and between ring-focusing experiments and predicted magnetic field increases and ring reflection in the cone. In addition, we have show'n that a compact torus accelerator could be an efficient soft-x-ray generator for simulating nuclear weapon effects. comfined he compalet-lorus matenctic ficlds. In 1487. Mce illecesstully accelcralled plasma rings in straight courial electrodes $1020 \mathrm{~kJ}$ kinetic encres $u$ ith a trajectors-minterred mass of 20 ) $\mu$ g (Hartman and Hanmer. 1987). The neasurements of ring acceleration made then. although incomplete. supported the predicted acceleration process bated on magnetohydromagnetic (MHD) theory and simulations of a constantmass ring. Measurements of the ring trajectory with probes. measured accelerator inductance. and calculations of ring trajectory using the $\mathrm{RAC}$ ring acceleration conde could be brought into agreement by titting the inferred ring mass.

In 1988, we improved our plasma-density diagnostics to measure total ring mass and the ring"s internal density distribution. We improved the sensitivity of our HeNe interterometer to $\sim 10$ "fringes and deployed a $\mathrm{CO}$, interlerometer to allow us to measure the ring s lineaveraged electron density. Additional monochrometer measurements of visible radiation at the breach of the accelerator enabled us lo determine that. under the conditions presented here, the alcelerated ring was composed of nearly all hydrogen ions

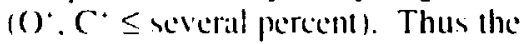
ring mass could be estimaled from the line-averaged alectron density.

\begin{abstract}
Figure 1. A compact torus undergoing acceleration $b !$ the $B_{11}$ field in the middle of our RACF apparatus. The initial magnetic field of the gun is estahlished by discharging the solenoid capacitor hank through solenoids localed outside the gun " salses admit roughl! $1 \mathrm{~atm} \mathrm{~cm}^{3}$ of gas. The gun's capacitor bank leeds the gun through a low-inductance arra! of couxial cables and collector plates. Discharge currents t? picall! have a 2-us risetione and a son-k. I peak current.
\end{abstract}




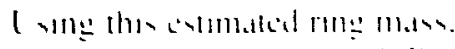

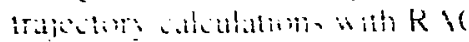

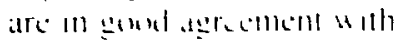
measurememln. mare anmplemels contimming the prodicted accictation

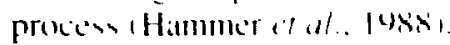

Ho initiated ring-fixusing experimeme in Fisis uning a $+-m$ straisht consial clectrode and Z- ind 3.x-m-lons concelectroles. These in is in proseres hate shem the expected hatic ring-retlection trajectors in a conce and threctivid compressmen in radusuand magnedic fickd. A majur mpromement if the HAM ma-dimensmal MHD code was completed. H.1.11 now uxes a nonrectangulat ment). which allows calculatlons of ring nomion in comical electrode regans. Preliminary results " ith this sode shom ring focusing ats expected. Simulation af actual R.ACE-dinension rings. Where $L_{\mathrm{rnm}} / L_{\text {innc }}=01 .+$. in in progeres.

We also studied the use of a compalct torus alceleraltor to generatle nense hursto of soli x ras for simulating nuclear watpon effeck. LASNEX calculations hatic heen applied to the shock heating and radiation of a focused. accelerated plasma ring. and numerical acceleration calculations hate hean used to evaluate the xaling of accelerators up to a $10(1)-\mathrm{MJ}$ simulator. Such a simulator appears uniquely able to simulate nuclear weapon effects on whole warheads or satellite systems.

The discussion below summarizes our FY88 work. As a context for this work. Figure I show's schematically a compact-torus plasma ring being accelerated in cur RACE experiment.

Magnetic field measurements made with probes arranged aviall! at the outer accelerator electrokd confirm that the ring structure is preserved during acceleration. As shown in Figure?. the ring evolse

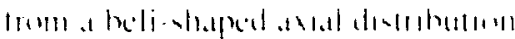

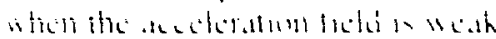

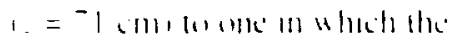

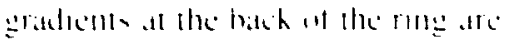

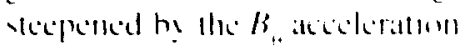

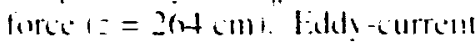
bartation mear the prothes are mas correstcel for and leitd lo the barlatum in vignal hoight.

Three independent determinatioms of ring trajectars ate comvinkent with our models. Figurs: compatres the ring trajectory mealured hy magnelle probes with the curremt sheath pusitum delermined from the atceleratur inductance and with a / dimensional R.AC calculation for a

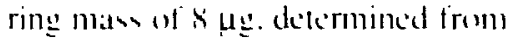
the Heve interferometer. The
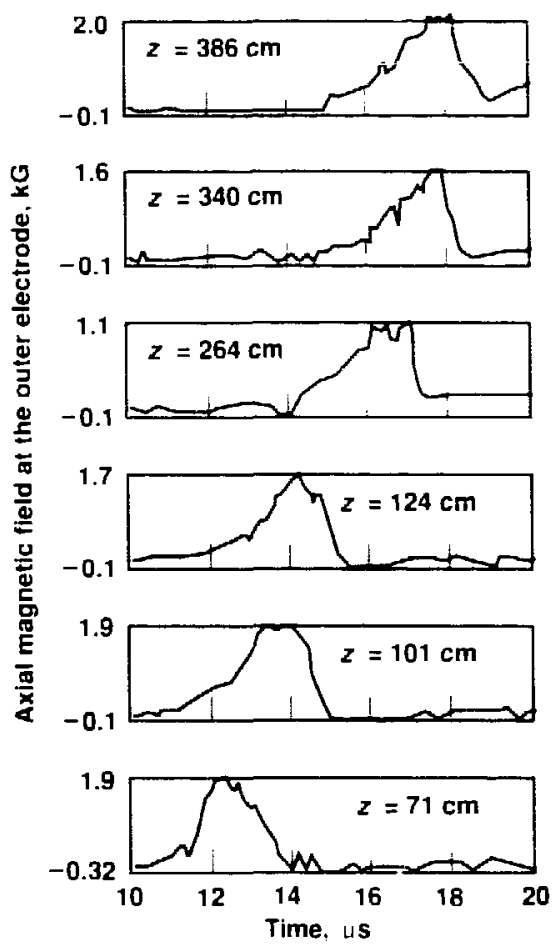

Figure 2. Time sequence of the axial magnetic field of an accelerated compact-torus plasma ring. The field is measured by magnetic probes located on the onter electrode and arrayed along :.

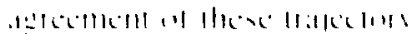

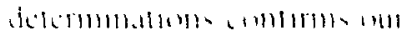

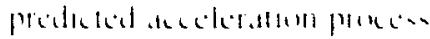

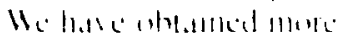

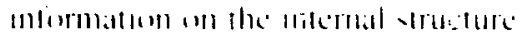
af the aceleralcel ring and lind it th,

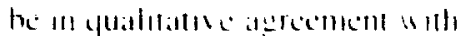
MHI) alkulation waing the H.11

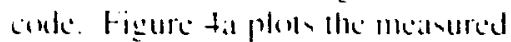
andal tick alome with the atecteratim! $B_{\text {n }}$ ricld al $z=124 \mathrm{~cm}$. The $k_{\text {, lichl }}$ distrihution vhem that the accoleratur current lloms all the back "If the ringe. indicathes that the ringe

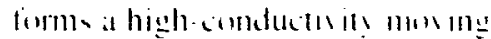
short. The secentimg at the aradient at the hitch of the rang and the ring shorting are in qualitatio agerement with MHD predictions of the accelerated ring s structure radjusced $B_{+1}$ curvel. The HAM ateulatome hate simeshat ditferent initial conditions than the experiment.

Figure the hows the lineat eraged clectron demsit! 11 and the $B$ fiedd at the ruter electrode: $=$ 12t cmol. For this case. the electron densits remained helow delectabilits for fl) us aller the ring sassages. indicating bery little plasma $1 n \leq$ $5 \times 10^{\prime}$ cm " following the ring ur evbled hy electrode interactions with the ring or accels rated ficid. The magnitudes of $B . B_{\mathrm{H}}$ and $"$, predicled by the HAM conde in Figure + are adjusted in werall magnitude and scale lemghth

The data in Figure thare also in qualisative atgreement with MHD) calculations. Two features of this agreement. comsintent with a barting aceleration tield. are the condene? al $B$ all the (nuter w all wo trail $n$ and for the 11 profile w also be shaped h! acelerattion. The trailings $B$ revulte

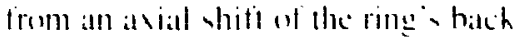
thas surfaces in reypune w the rathal

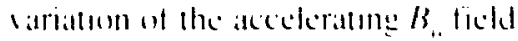

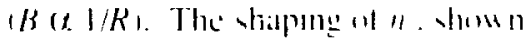


Figure 3.

comparinon uí measured and calculated ring trajectories. The circles indicate peak ring fields measured by probes at the outer electrode. and the bars indicate halfamplitude points. The accelerating current sheath closely coincider with the ring $B$.

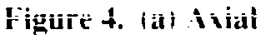
nlagnetic and accelerating $B$ fields measured at the outer electrode $1 z=124 \mathrm{~cm})$. The adjusted calculation was made with the HAll twodimensional MHI) code. (h) Axial magnetic field at the outer electrode and line-as eraged electron densit! measured at $z=124 \mathrm{~cm}$. The adjusted $B_{4}$ and densit; curves were also calculated with HAM.

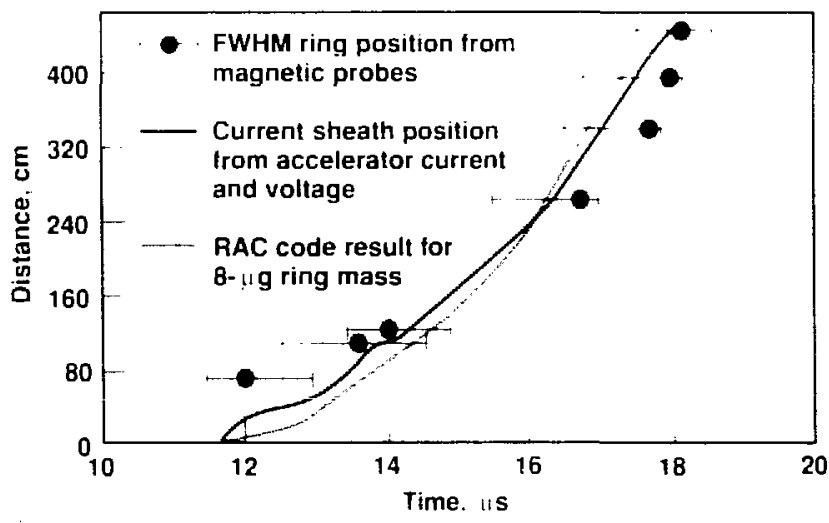

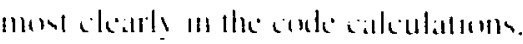
resule from the accelemalced plasmal tending lo" "s/ump" for the reall al

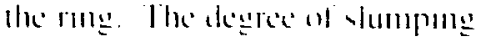
depends an plasmal lemperature. which can differ significailely helueen experiment and simmlation. The latler in houn for yualiatise comparisull.

He alucenduced preliminat sudics of rime focusing " ith 2- and

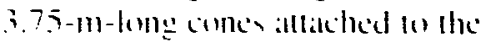
4-m statight accoleration section in

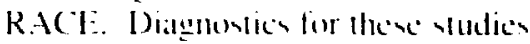
"ere limited to matemetic fictd probes arratyed along the come valuer clectrode.

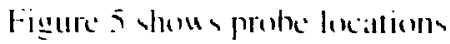
and the $B$ fich meatsured alome the I-m conc lor a ring whone axial peah-lictd point pencerates to ahout $z=486 \mathrm{cml}$ and whose head end radches (1) aherut $5(1) \mathrm{cm}$. The peak field lor this catse increatsed hy at factor of 2.6 . and the radius compression reatebed 2..35. No chear reflection aceurs.

( ) n sme shoss. the ring cleatry reflects from the conce fats expected from simple dy namics) and stops at the conc s entrance. where it decays

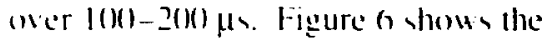
trajecturt of a ring that reflects from the 2-m conce al a radius compression ratios at . h. For this shot, the ring protile remianed identifiably eonstant so that the ring length (FWHMA) could he estimated alome the trajectors. As can he exen. this length decreases as the retlection point is approached.

Analvic entimalles and (wa)dimensional MHD calculations shom that if the ring is adiabatically fixused and $\beta$ remams low. Hhen

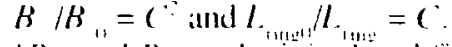
I $B_{1}$ and $B$ are the intual and final ffocused) anial magnedic tichls. I. and $l$. are the inilial and final ring 
lengths. and $($ in the ratcial compreseion ratio.f Datlat for thene III) rattion sersus ( for both the ?and $3.75-\mathrm{m}$ cones has: been oblaned for at limited numiser of shots in which the ring is clearly self-similar during focusing. We find that for both cones. $L_{\text {intel }} / L_{\text {lint }}=("$ while $B \cdot B_{\text {. }} \equiv$ C . clearl! devialling from adiabatic NHD compression. The source of this discrepanct is not set knoun. However. we mote that deviation from predicted fixcusing might be expected in this experimem for several reasums: $L_{1} / L_{\text {.n. }} \equiv 11.3$

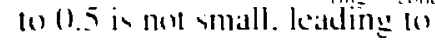
nonduliathatlicill: the ion $9 !$ ro radlius is comparaticle whe ring sic: and an! lows of ring maw or large slumping during focusing can push the ring beyond current-driven streaming instabilities. introducing large anomalous resistivity and rapid ringfield decas. These effects hould be reduced ladiabaticity should increase whell. in FYSy. a precompression conce is added at the beginning of the alcelerator. and the gun/acelerator bank energien are increatsed.

The axisymetric HAM code wats extensicely resiad in FY SR to allou generalized yuadrilateral zoning in a mixed Eulerian-

Lagranglan mesh. The code's previous version was extremely useful for analyzing the operation of the magnetized coaxial gun and the subseyuent formation of the compacttorus plasma rings. HAM calculations included the selfconsistent estahlishnent of the poloidal hield structure by solenoidal field coils. gas flow from the pulsegas valves into the interelectrode regen. dixcharge of the gun bank. recomnection of the polovidal field around the gun-produced plasmat (1) form isolatled plasma rings. and acceleration of the rings by the discharge of a second capacitor bank.

The corle's upgrade was motivated by the need for generalized sming to simulate the effects of arhitrary electrode shapes and heundary conditions. We are nou using the new code to analyze the compression of accelerated plasma rings in converging conical electrodes. These simulations will enhance our physical understanding
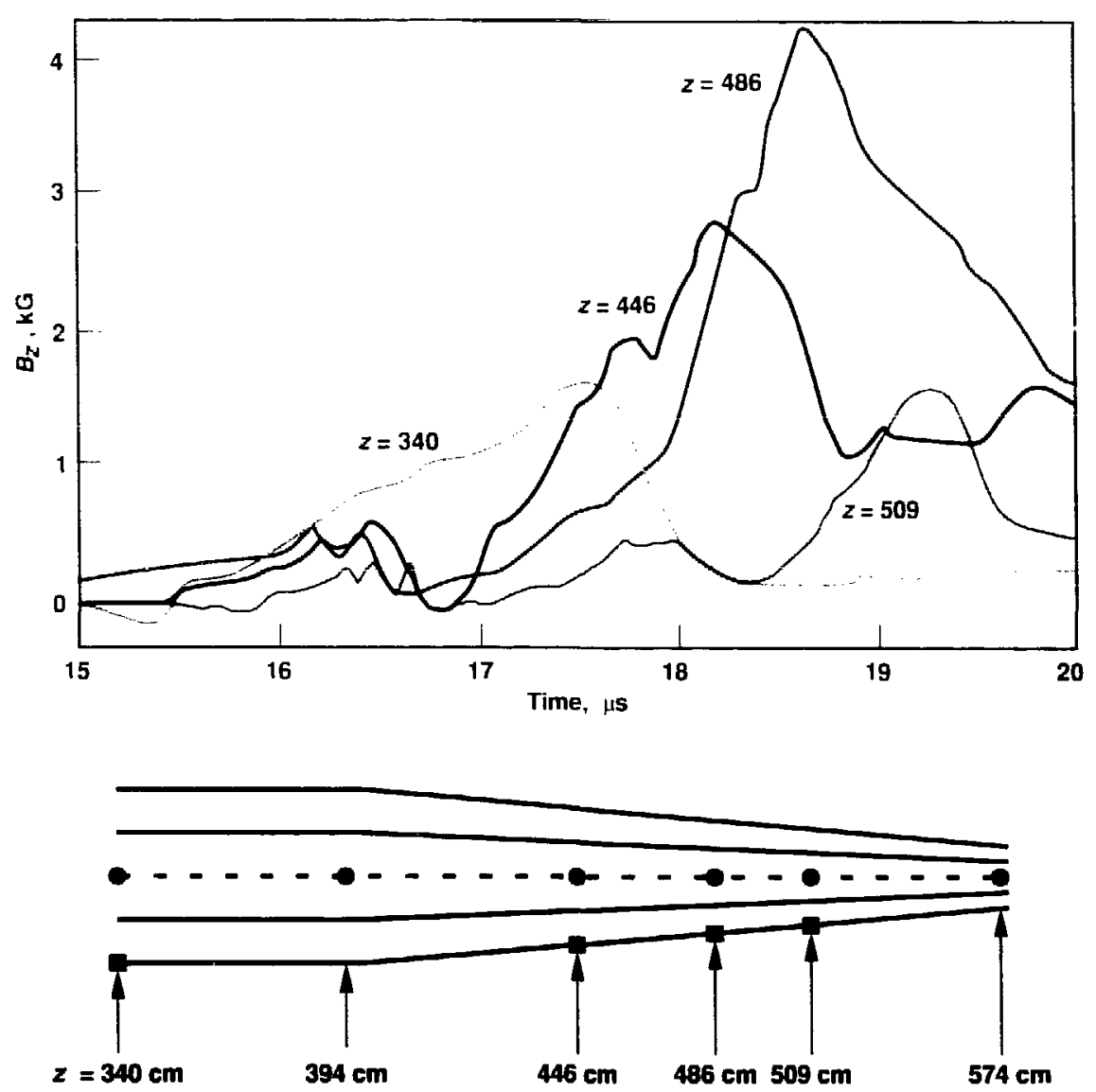

Figure 5. Measured $B$, field at the outer electrode for an accelerated ring entering the $2-m$ focusing cone. The ring stagnates at about $486 \mathrm{~cm}$, where the $B$ field has increased by a factor of about $\mathbf{2 . 6}$ and the ring radius has decreased by a factor of 2.35. Probe locations (black squares) are shown at the bottom. 
Figure 6.

Trajectory of an accelerated ring Ibased on measured $B$. field ) that rëflects in the 2-II cone at a radius compression ration of l.o. Ring length $\left(L_{\mathrm{K}}\right)$ decreases as the reflection point is approached.

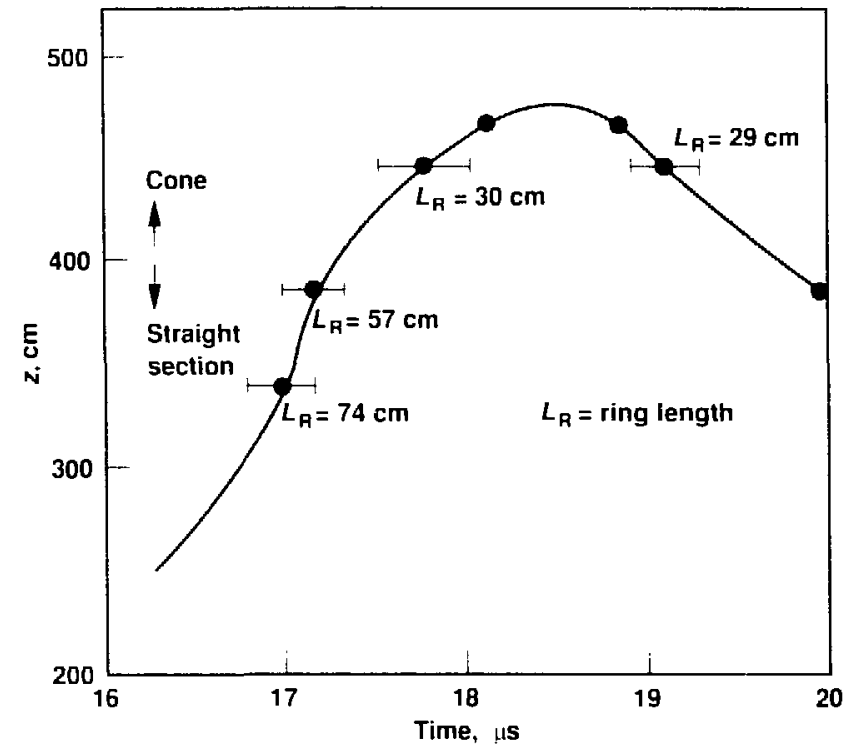

Figure 7.

Calculated radiation spectra for rings accelerated over a range of energies from $260 \mathrm{~kJ}$ (RACE) to $100 \mathrm{M}$, .) The efficiency of acceleration $U_{\text {hinctic }}^{\prime} / l_{\text {banh }}^{\prime}$ is 0.5 . and the ion species and ring mass are chosen to optimize the radiation output. With a I00-M.J accelerator bank, $22 \mathrm{MJ}$ is radiated.

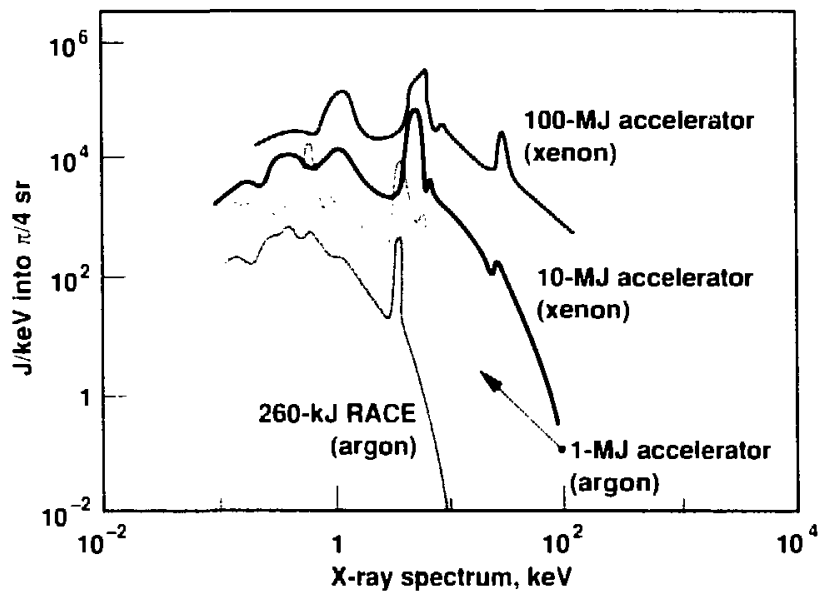

(1) ring hehas ior for various comb geometrien, intial velestices at the come culances. and intermal ring strictures.

During FYSR. We also coalualed the compact-torus accelerator ats a soti-x-ras encrator for simulating nuclear weapon elfech. The hasic process is fo acceleratce and fixus a high-atomic-number ion ring plasma. which then impacts a solid surtilce. arresting the ring s kinctic encros and sheck-heating the ions. If the locused plasmal densits is high enough. during the shock time i $T \equiv$ I MeV). the ions will collisionally heat the electrons. The hot electroms strip the ions to high-charge states. which then efficiently radiate $K$ - and $L$-shell excitation line spectral. along wih plasma bremsstrahlung ridiation. At focused ring speeds of $11.5-2 \times 10^{\prime \prime} \mathrm{cm} / \mathrm{s}$. Inpical of these a)ready athieved in RACE. the hinetic energy is in gigajoules per gram. Thus the electrons may be healled $00-10 \mathrm{keV}$ or radiale $10-30 \%$ of the ring s kinelic energy with a spectrum that peaks at $5-10 \mathrm{keV}$. To produce enough fotal radiated energy for testing whole weapon systems. we investigated scaling compact torus accelerators up to $10(1) \mathrm{MJ}$.

Figure 7 summarizes LASNEX calculations of the radiation produced by compact torus acceleralors with acceleralor bank energies from 
26() hJ I R.t(F) (1) I(1) M.J. For the

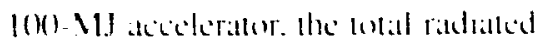

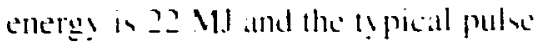

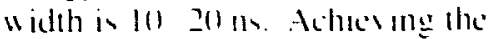
calculated radiation output shom in Figure 7 lor R.ACE with areon-ion rings will plate the experiment at the state-of-the-art ked for sofi-s-tals gencrators.

We used RAC We damine the scatling of compatet torus accelerators. RAC calculate ring trajecturs in straight and conical colatial electronder and includer electrode healing hy radiattion and eddy-current dissipattion. It also calculates ring decal and plasma propertic:s from radiation. ohmic heating. compression. and wher aneres thows. Figure $x$ show schematicalls the scale of atcceleraturs from RACE (260) $\mathrm{kJ})$ to $10(1) \mathrm{MJ}$. In each casse, the expected limits on acceleration and ring decal have not been exceded. We assume at precompression phase that couples the accelerator more efficients to the lou-voltage capacitor hanks and also shortems the overall acceleration length. Precompression increalses the peak field in the vraight atceleration region: for the 1(1-and 1(10)-11J caree shown. this field reached $3(1)$ kG

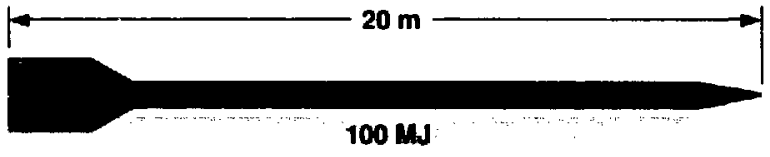

Figure 8. Scaling of compact lorus accelerators from 260 kJ ( RAC ( $\mathrm{k}$ ) (1) 100 M.J as solt-i-ray generators. All accelerators are assumed to use a precompression phase.
Cost as well as scalability is an important consideration for veryhigh-enerey alcelerators. We have designed and estimated the cost of the atcelerators capacitor banks the primart electrical costl using off-theshelf capacitors. Since the discharge time is long $(10 \mu \mathrm{s})$ and capacitor boltage is low $(<5(k) \mathrm{kV})$. energy storige is relatively inexpensive and economies of seale are significant. A I()()-MJ. 5()()-kV accelerator bank unuld cout ahout $\$ .55$ million. or $\$(1.35 / \mathrm{J}$.

\section{References:}

Hammer. J. H. C. W. Harman. J. I.

Eddleman. and H. S. Mclean I lossi.

Everimemal De'momstrathon of

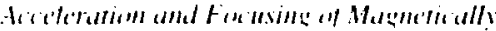
Canfined Plasma Rines. Lawrence Licermure Naltomal Laturalara. Preprinl ICRL.-4XYSX.

Hartman. ('. W.. and J. H. Hammer ( 4 S67). "The Compace Torus," Imsurminmal

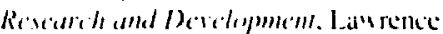
Liscrmore Nilliumal Lahuralurs. Repurt ICRL $-53684-87$. pp. 1012-1017. 


\section{Computer-Aided Design Tools for Very- Large-Scale Integration}

Principal Investigator: W.S. Scott

$\mathrm{D}$ uring FY 88 . we extended our previous work in developing tools to aid in the physical design (layout) of water-scale svstems. In addition to completing the semiautomated hint router, we developed and demonstrated a fully automated router capable of exploiting two. three. or more wiring layers, each with its own electrical and physical characteristics. such as are available in hybrid wafer-scale and semicustom gate-array laser pantography processes. We also developed the key elements of a higher-level logical design tool for digital systems resynthesis-the automatic conversion of existing designs to such new implementation technologies as mapping a discrete board-level TTL (transistor-transistor logic) design into a hybrid waferscale semicustom CMOS (complementary metal-oxide semiconductor) version.

Design and Fabrication of

Custom Integrated Circuits.

Increasingly, builders of highperformance electronic systems are discovering the advantages of designing their own integrated circuit (IC) chips to implement these systems. Several methodolngies have been developed for designing IC chips. ranging from semicustom approaches. in which the designer builds the chip from a collection of

The primary goal of the very-large-scale integration (VLSI) computer-aided design (CAD) portion of the Laboratory's efforts in supercomputer research and dc velopment is to create a vertically integrated CAD toolset to facilitate the design, manufacture, and testing of high-performance digital systems. We have placed particular emphasis on exploiting the manufacturing techniques developed by LLNL's laser pantography project, techniques that allow rapid fabrication of wafer-scale digital systems.

predesigned components, to fully custom approaches, in which the entire IC is designed from scratch. Three semicustom approaches-gate array, standard cell, and macrocelland the fully custom approach are described more thoroughly in the box on page 129.

Recent technological advances. such as those provided by laser pantography (McWilliams and Tuckerman. 1985), have enabled collections of individual ICs to be assembled into water-scale systems. As a result, much higher packing densities are attainable than with the conventional approach of placing each chip in its own plastic or ceramic package and using a printedcircuit board to interconnect them. Wafer-scale systems created by laser pantography have much in common with standard-cell or macrocell styles used to create individual ICs, but they use ICs interconnected on a silicon wafer substrate instead of fixed transistor patterns on an individual chip.

Semiantumated Himt Ronte's: In high-performance. custom IC designs, it is often necessary to route a few key signals along carefully chosen paths prior to the automatic routing of less performance-critical wires. To aid in this lask. we have developed the hint router. an interactive maze router. as part of the
Magic IC layout system (Arnold and Scott. 1988). The hint router is a tlexible tool intended for use whenever tight or unusual constraints do not permit fully automatic routing. It has already been used in the layout of an 80,000-transistor CMOS chip (the "smart substrate" that was developed by our group and reported last year) as well as for routing the control signals of a 100.0000 transistor. high-performance CMOS tloating-point chip being developed hy the UC Berkeley SPUR project.

Several new ideas for maze routing have been developed in the hint router. Hint layers permit the user 10 map out the general path of a route and pull the route in desired directions, while leaving details. such as obeying the layout width and spacing rules, to the router. Several additional routing heuristics were refined last year. Their use both improves the quality of routes in heavily congested designs and reduces the time it takes to complete those routes. The gross structure of the layout is now preprocessed to facilitate accurate cost-to-completion estimates during routing and hence to allow effective pruning of misdirected partial routes. A windowed search strallegy slowly shifts the focus of the router from the sart point loward the goal. permitting consideration of alternatives all all 
stage of routing without the penall! of exhaustive exponemtials blow up in highly congested regions. Finall!. the general make-routing algorithm has been exlended an allow an arbitrary number of source and destination points. effectively allowing it to he used atomatically to complete partially wired signal networks.

Mulsilaver Reruser. We have also implemented a fully automatic. gridless and channelless multilayer router as part of the Magic sistem. This router iddresses several new routing problems arising from somk of the expanded capabilities of laser pantography processes.s. particularly those of uafer-scaie complexities (wiring feature sizes of a few microneters but total problem sizes of $10 \mathrm{~cm}$ ) and multiple. electrically different routing layers (four or more on a single silicon printed-circuit board).

This router incorporates three key ideas. First. it represent nets as rectilinear Steiner trees with Hoating segments. Segments of these Steiner trees correspond to wire segments of a net. and the relationship among segments detines the topology of the net. A floating segment is bound to a routing layer but not to a specific

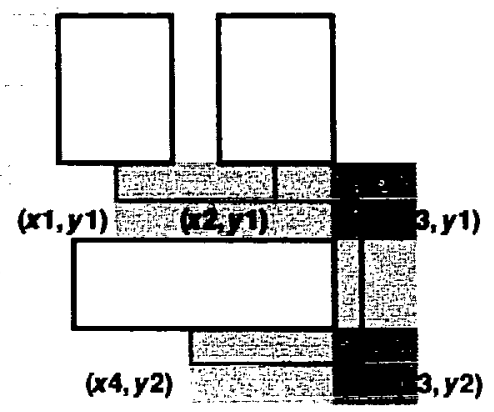

Figure 1. A rectilinear Steiner tree defining the course route of a threeterminal net. Shaded areas delineate ranges of floating segments.

\section{Semicustom and Fully Custom Design Methodologies}

Four common design methodologies constitute the range of choices for VLSI. Gate arrays (a) consist of rows of identical cells of transistors. The designer specifies which of a collection of standard metal interconnect patterns is to be placed atop each cell (thereby defining a given logical function) and how the terminals on each cell are to be connected. Gate arrays are the least expensive to fabricate since the underlying array of transistor cells can be mass-produced independently of the metal interconnect that is added later.

Standard-cell designs (b) also make use of standard logical functions, but they are not implemented atop an underlying array of identical transistor cells. Instead, the placement of cells within predefined rows or columns is under the control of the designer. Because the underlying transistor pattern can vary from cell to cell, standard-cell chips cannot be built atop prefabricated transistor arrays and are therefore more costly than gate arrays.

Designs using macrocells (c) offer still more flexibility than standard-cell designs. Macrocells are parameterizable, rectilinear blocks that are customized from a library of templates; they are connected either by abutment or by automatic routing.

In fully custom designs (d), there are no restrictions on the components; the designer is free to create new circuits and to lay them out in the best possible way. As a result, it is possible to achieve greater density with a fully custom design than with any of the other design styles.

(a) Gate array

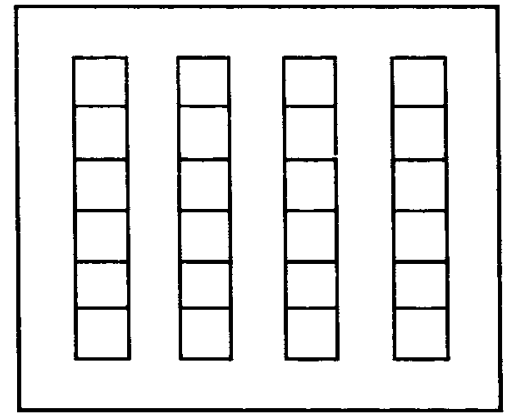

(c) Macrocell

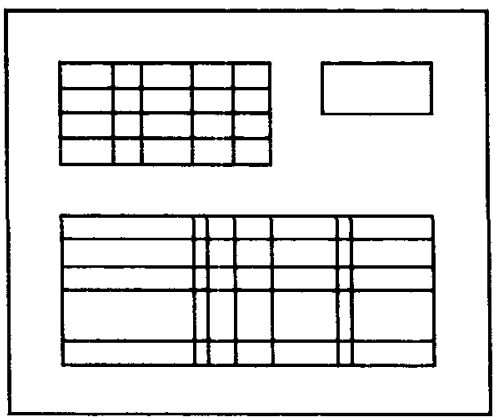

(b) Standard cell

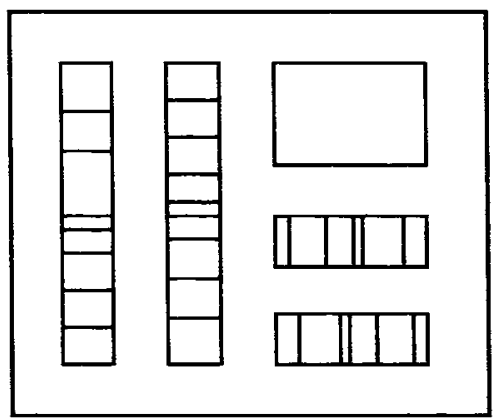

(d) Fully custom

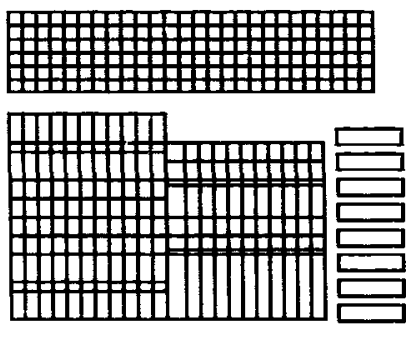




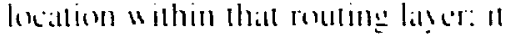
mat! lend wethon a range of balues.

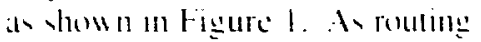
proserences lloalms scyments are hound to fiscd keations. B! preserving the thoating segment repiencentation throughout the routing procens it is eas! to allow nets to he partially ripped up. enabling the router lo explore alternatle routes ito "changec is mind") w ithout incurring the cond-game penalty of exponemial ruittime Iypicial al Iraditional rip-upand-retr! roulers.

Second, a routing seheduler applice at sel of routing strallegies lon a quedic of partially routed nets: each srates! attempts to further the routing of a net. Simple srallegics are applied lirst. followed by more complex strategies to resolve more difficult problems. The orchestration of strateggies is controlled by a finitestate machine. analogous to the controlling "expert" in the Wiater system. for example (Joobbani. 1986). hut without the exessive runtime overhead typical of such general-purpose expert systems. Routing strategies are typically simple. They involve generating course routes. laying wires in routing regions. make-routing through congested areas. and ripping up obstructing segments.

Third. a comer-stitched database (Ousterhout. 1984) represents obstacles and wiring as the routing progresses. Comer-stitching is a technique for representing twodimensional objects. It provides a representation for such spatial relationships as adjacency that results in fast. efficient algorithms for searching for. creating. and deleting objects. By using corner-stitching. the router can both work with wires of varying widths and asoid preevisting wiring.

()ur approach avoids several of the limitations charateristic of conventional routing methods:
- The router worh a on ance ale lad apposed lo a chanmell : 1 a lime. hut It docer mot necel to full! rouke a net hetere it atd ancess 10 , ther nets. N1 all! geiven time. a net maty be partially routed or partially sipped up. The router thus has the flexibility to change its mind ahout the routing of a net ats the routing problest is theshed out.

- Because new course roules can be gemerated dynamically to aroid congested areals. generating course router is a routing strategy. not at distinct routing phatse.

- Commections may be made anl where in a routing region. nor only al its poriphery. making it possible to route dense seato-of-gales or seat-olt-transistors designs als well as more conventional. channelized standard-cell or gale-atray designs.

We have successfully rouled several large wafer-scale designs in times comparable to those required for single-chip designs-roughly 30 minutes of Sun-3 CPU lime (Lunow. 1988.)

Digiral Sysiscms Re'symllessis. The rapid prototyping and waferscale integration capabilities offered by laser pantography technology mike it very attractive to have a tool to automatically convert existing designs into a form that can exploit that technology. The digital systems resynthesis effort aims to produce a conversion tool that will take (for example) an existing discrete-TTL design and reimplement it as (for example) semicustom CMOS circuits interconnected by a silicon printedcircuit board.

It is essential that we evaluate the tools we develop with realistic test cuscs. For this purpose. We have chosen a circuit design for a memory and input/output controller donc as part of the Advanced Processor Project (APP). Because it consists of matchine-readable shemation fion buth a discrete-TTL braddboard version and a pair of hand-designed

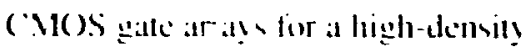
cersell. the circust prosides un with hoth a vartinge point and a handgeneralled end point lor comparison.

During the past year. we halle written a number of portions of the resynthesis system. The basic design for the digital sylems renymesis Iorl. called SECTAR ISeliCorrecting Timing and Resynthesis). is complete. This system is hased on nesworh modification in ensure confumbance or electrical design coistraints lliming. power. fantut. (li.). SECTAR i. made up of an incremental timing analyzer. a network extract-and-replace algorithm. and a simulated annealing optimizer that ures several networkmoditicalion techniques to transform a nes work inte one that meess its functional criteria. SECTAR is designed to inform the engineer of trouble spots in cases where the tool could not conform to specitied consiraints.

Input Io SECTAR is currenty in a simple design-specilication language, and the input interface has heen designed to easily accommodate the integration of other designspecitication languages (EDIF. VHDL). EDIF 2.(1).0 is scheduled to be used because of industry "s commitment to making it available for electrical design information transfer between tool sets. Valid Logic Systems will have an EDIF 2.0.0 reader and writer available late in 1988. which will allow SECTAR to operate on the APP kest case.

We have also implemented the SECTAR databaste. which is tailored for quick traversal by the timinganaly sis algorithm and for casy extraction and replacement of subnetworks. Wie halve developed the following network transformation algorithms for use in SECTAR. as illustrated in Figure ?:

- Primitise function vahstitution (a). Simple replacement of input 
(a)

\section{AND-2}

(Standard drive)

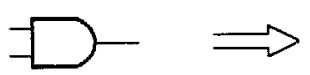

AND-2

(High drive)

\section{Propagation delays for 16 equivalent loads:}

Time $($ low $\rightarrow$ high $)=3.6$

Time $($ high $\rightarrow$ low $)=1.6$
Time $($ low $\rightarrow$ high $)=1.7$

Time (high $\rightarrow$ low) $=1.4$

$|c|$

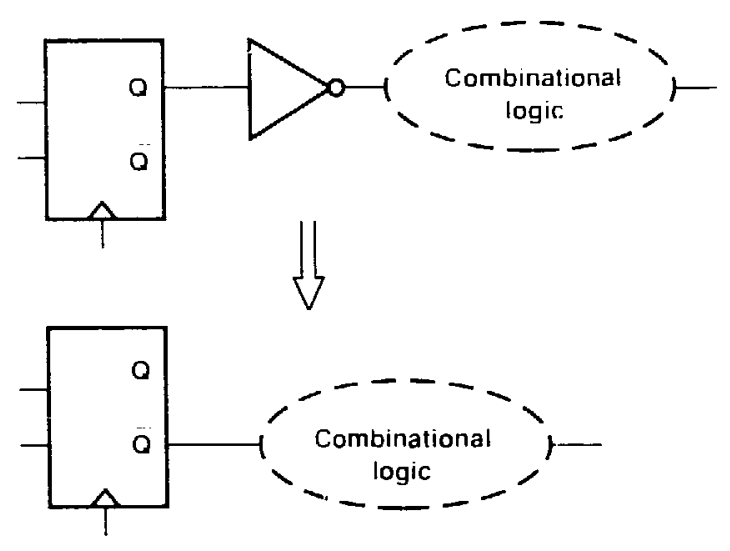

(e)

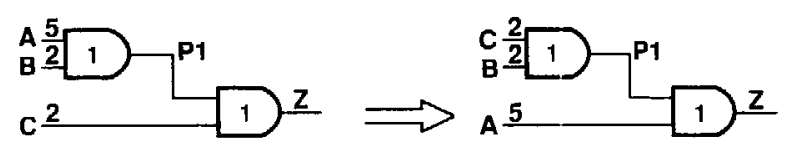

P1

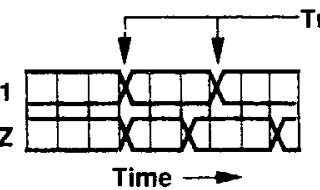

Time $=8$

Transitions $=\mathbf{5}$

(b)
Discrete gates

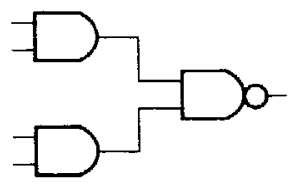

Gate count $=5$

Time $($ low $\rightarrow$ high $)=1.6$

Time (high $\rightarrow$ low) $=1.2$
Technology-specific gate 2 ANNOR

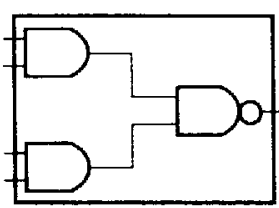

Gate count $=2$

Time $($ low $\rightarrow$ high $)=1.3$

Time $($ high $\rightarrow$ low $)=0.6$ (d)

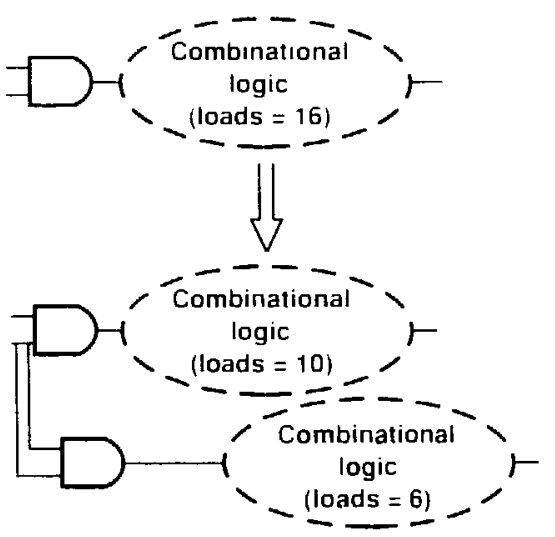

Fanout reduced to lower load on driver, resulting in improved propagation delay but increased gate cost

(f)

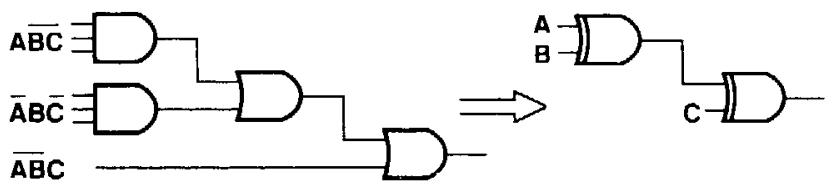

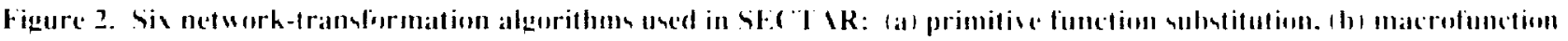

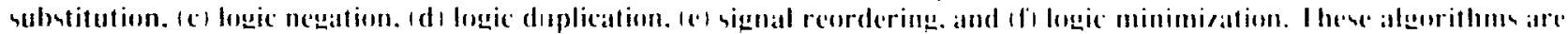
described in the lent. 
componems is: thome an the iallogl

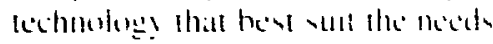
of the carcult. This transtommatlent automallicalls chomes, for example. whether to use high-power latud theretore high-specdl gates in approprialle siluations.

- Macrofunction substitution the Graph-malching kichniques map a

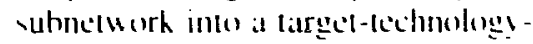
specitic componemt. These componems are usuall! kechmolug! -

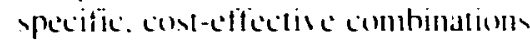
al galles.

- Lugic negation (c). A subnclusth is negalled to takc advantage of atn al ailiable complementary iutput of the driving subnetwork.

- Logic duplication (d). A subnetwork in the design is duplicaled to improve the timing in an area by fowering the affective loading lianout of a noxle in the network.

- Signal reordering (e). The logic in a combinational subnetuork is reordered so that late-occurring signals atre evaluated last. thus cutting down on the switching noise of the network.

- Logic minimizatlonn (t). A combinational subnewwork is minimised in order o reallize the

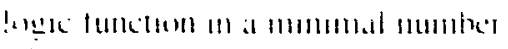
(1)

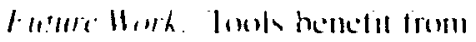

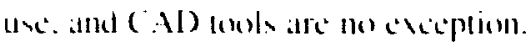
The semidummaled hint romer hats already he:n distributed as part al the Malgic IC layout sisem lo a number of vites. Where it hats heen used in the clesign of fully custem ICs. It will he part af a wide distributam at the Magic syem that is curremtly shediuled for the spring of !ysy.

Although the multilater rouler has shown its usefulness in routing a variets of circuits. more expericalce is lleceled in its operattion and performalnce helore it will he reall lor widespreald distribution. In the coming vear. we hope fo use it on several semicusiom and ualfer-scialc designs that span at range of labrication technofogies. New seal-of-galles and scat-of-transistors semicustom arrays also appear lergy uell suited to our new router. and we hope to demonstrate its usefulnesis to these sorts of designs as well.

Work on SECTAR is still in progress. Next year. we expect to hring up a lirst version of the complete system and apply it (1) retargeting the breadboard iersien at the APP circuit into a CMOS gate array. Alter this relargeting, it will

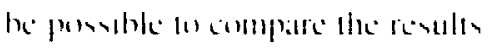

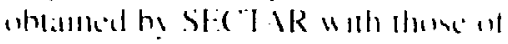
lhe matmat retargetume that has gus hecll completed. The experience gaimed from the real-morld circuit should provick us with all excellent nlcassure at the elledisemess al SECTAR ab all atumbatic comersion

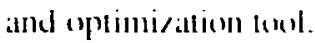

\section{References}

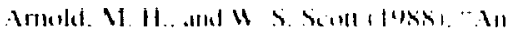

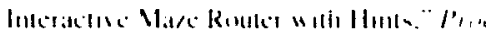

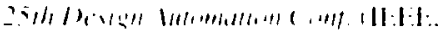

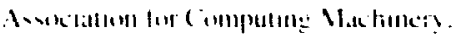

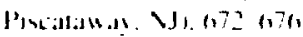

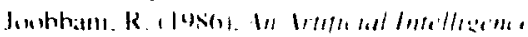
l/P". virucll. M1:.

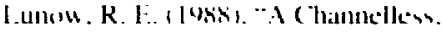
Multilayer Rouler." Pros soth Meven

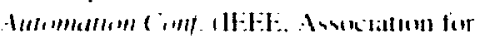

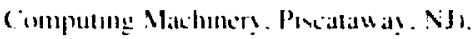
$607 \cdot 671$

MeWillians. B. M. and [). B. Tuchenalar 1 Guxis. "Water-Siale Integratmon" and -1.ancer Pallugeraphs!. "He're! amal

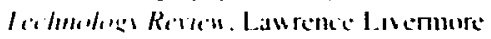

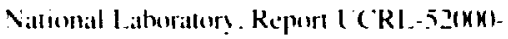
S.5.12. pages 1 ? 21

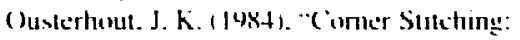
A Data Siructurmen Technsute for VISI

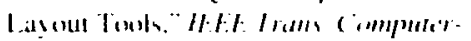
lated I) - ven. ( 11$)-3,1$, 


\section{Fabricating Ads anced Bipolar Transistors I sing Two New Technologies}

Principal Inımtigators: B. W. Mcllilliams and $h . H$. Ileiner Cu-Insestigaturs: P. li. lares: and $\bar{i}$. is. sigmmn*

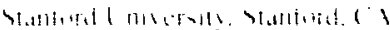

$\mathrm{T}$ he tabrkatlull al heghl!

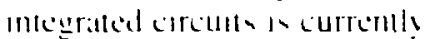
hampered by the formation of ultrashallow $<$ < $(1(1-\mathrm{n}) \mathrm{m})$ impurity doped regions and ha the electrical isolation of individual transintors. To reach the next step in the design and manufacture of intearated circuitsultralarge-scale integration ILLSI, and gigascale integratton (CiSl). w ith millions lo hillions of transivers per chip. respectively - me need a fabrication sequence that is as simple. precise. and defect-free as pomible.

to integration levels increare. the consentomal dopeng and isolation lechniques of ion implantation and trench isolation become Ioo complicated. and yields are markedly reduced. We are attempling to solve these doping and isolation problems by incorporating two neu techniques-gas immersion laser doping (GilLD) and silicon-oninsulator ISOI) epitaxial laver grow th-into the standard integratedcircuit fabrication process. Thene ino techniques bould enahle us to simplify shallou junction formation and tranvintur molitton. therebs reducing the comt and complestr of

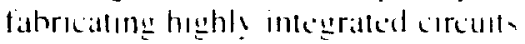
and expedtung the entruductom on

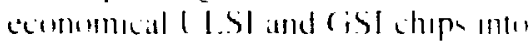
the marketplace.

We are developing a fabrication process for robust, highperformance, bipolar transistors that incorporates the technologies of gas immersion laser doping and silicon-oninsulator epitaxial layer growth. The use of these two new technologies will increase the switching speed and radiation hardness of the transistors without reducing their manufacturability or yield.

The (ill 1) proces will mithe pumble vignificant mprosemens in tramsistor performance. Gill. D can he used to form junctions of wers precixe depth $\pm 10 \mathrm{~nm}$ ). allowing the atctive base width of the derice la he reduced trom the $10101010150 \mathrm{~nm}$ pemsible with etirent processes to $<50 \mathrm{~nm}$. " ith no lows in yield and simpler processing. Since transistor suitching speed is proportional to the syuare of the hase width. the smaller hase widths produced hy GILD make porsible four- to ninefold increases in upecel. In addition. b! using GilLD in plate of ion implantition. more fitsorable impurity profiles are achieved. Standard Gaussian impurity profiles are replaced by box-like. abrupt junctions similar 10 those abtained with molecular-heam epitaxy. The abrupt junction reduces base punch-through effects in the devices and lowers basce resistance. which leads io improved device performance.

The use of Sol lechonglug! will produce tramiviom with performiance and radliation immenity much mprosed oner that of londat! i lasken

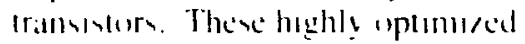

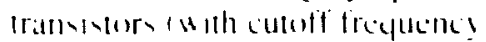
$1=21$ cille are approachung the max mum perturmathe punible whll current latbricallen lechmentes an a

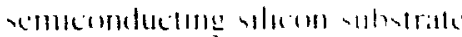

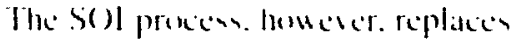
the semleondetim! substrate with an electrically insulating subsirate. therehs eliminating parasitic capacitance from the collector of the hipolar transister to the substrate. Since this parasitic capacitance represents one-yuarter to one-third of the total capacitance of the device. Ise of the SOI vubstrate will substantially increase transistor performanice. In addition. the insulating substrate is much more immune to ionizing radiation. which canl cause errors in circuit operation. Thus. by replacing silicon with an SOI substrate, both the transitors performance and its radiation immunity will be increased.

Our overall project goals are to 11 derekp CillD as an insertable process for current and future integralted-circuil fabricattum processes. 121 develop an SOl lechnoluge! suitable for fabricalong high-performance. hipolat tramsistors. and 131 design and implement a tathrication process for rebust. radiation-immune hipulat tratlessters for the custem integrated corcuts requered at $1.1 . \mathrm{N}$.

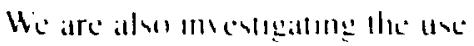

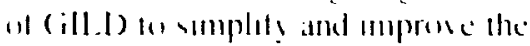
lathricattion and performante of the

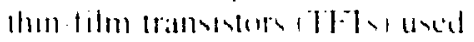




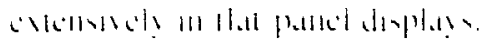

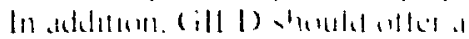

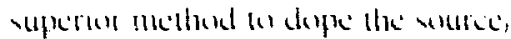

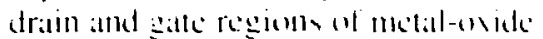

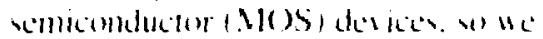
arc worhing an incorporalle (ill.t) into the labrication proces for Mos

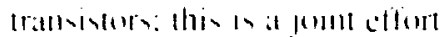

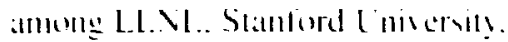
and the Sembonductur Research

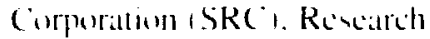
"Triangle. $\mathrm{VC}$.

In the (ill.D) proxes, a pulsed. ultravioled (3) uned to medt the arlates of the silicon substratc. Doping acure when impurits altoms in the gals phase P!rolise on the healted surface and diffuse into the molten silicon. The molten latyer regrows epilaxially. creating electrically alctivaled. damage-lire doped layers. Since diffusion occurs in the liquid phase. junction depth is limited by the penetrattion of the melt front into the vilicon. By eomerolling the number of pulses and the latser energy: one can producte ultrashallom and wery abrupt impurity profiles. In addition. since melt depth is a function of laser entergy and the impurity profiles are abrupt. junction depths can be placed ver accuralely $1 \pm 10 \mathrm{~nm}$. Furthermore. because the doping process oceurs in nanosecond time scales and the dopant is electrically atcive. high-temperature annealing is not required. This eliminates diffusion in the solid state.

Conseyuenty. placement of the enitter does not alfect the batse depth. With Gill.D i unlike dititusion processes). the relative junction depthe nats he varied independentls. and basce widths as narrou as 511 nill ar lew become pusible. Prosess reproducthllit! N emsured hy all alral!

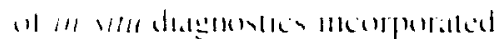

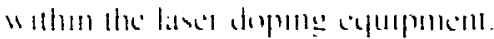

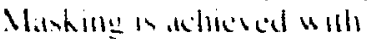
consemismal lithorapht: at thin aluminum ar mide film is applicel on

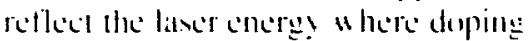
in $n$ on devired. This combination af perdictabilis. reproducibilits. and compatihility with current labricallom Precesen makes (illD an ideal

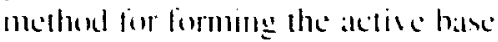
alld emiller regions in hipolat Hambisturs.

During FYsid. We concentrilled on the fabrication of hipulat and M()S transisturs using the (illo) prexcess. Signilicant progress Mals matde low atd the original galls. along with promising results in new. potentially high-leverage areas of alvanced hipolat transistor labricaltion. Notably uhis yearr. we precisely charatericed the GILD process. malde signiticant improvements in the GILD apparallus. and comstructed al

(a) Hefore laser melting

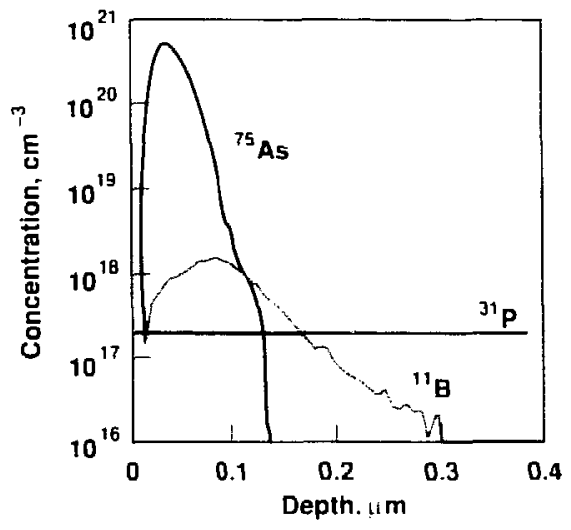

(b) After laser melting

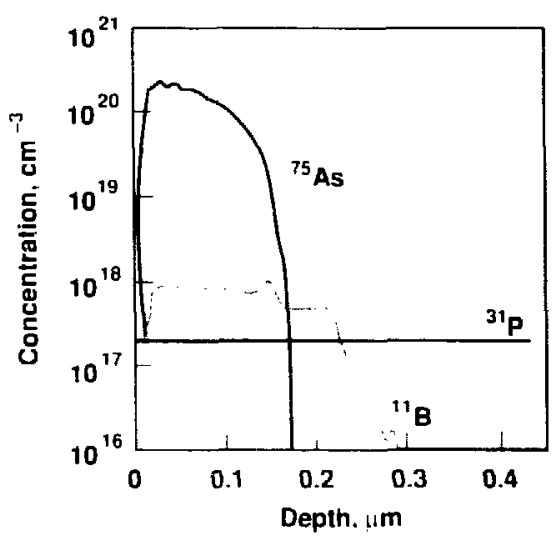

Figure 1. III.) ion-implantation profile before (a) and after (b) laser melting and ion redistribution. The base width is $<71$ nm. The ${ }^{75} \mathrm{As}$ and " $\mathrm{B}$ profiles were determined using secondary -ion mass sectroseop! wilh owgen bombardment: the "I" profile was determined b! spreading resistance profilometrs. 


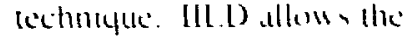
immediatle labreatlion of natrom - haine transmors usme colahlished highperformalne hipolar processes. IILD combines the exceptional junction depth control of GILD with the accuratce denc comtrol of ion

(a) Current 以 viltage

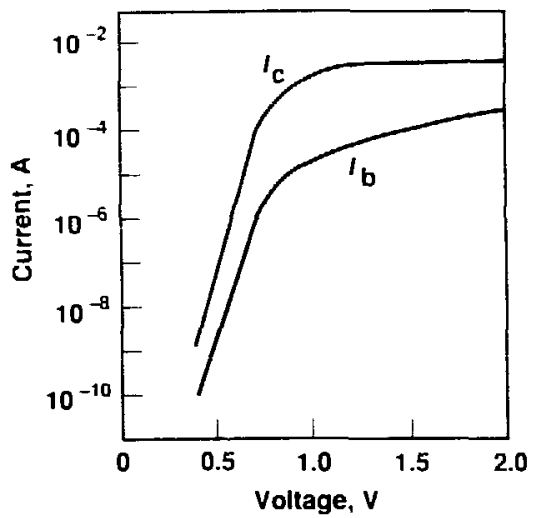

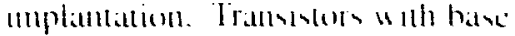
"1dtha 70 1m and maximum forward current gains of 10 (h) hate been labricated using IILD. Figure I shous the results of the laser melting and ion redistribution. and Figure ? shows the electrical charateteristics

\section{(b) Current gain vicurrent}

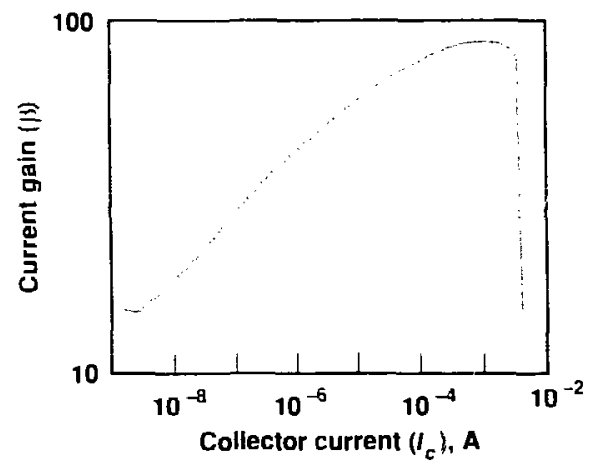

Figure 2. Electrical characteristics of an IIL.D transistor with a $100-\mathrm{nm}$ base width. (a) current $I$ vs voltage $V$, and (b) current gain $\beta$ vs collector current $I$..
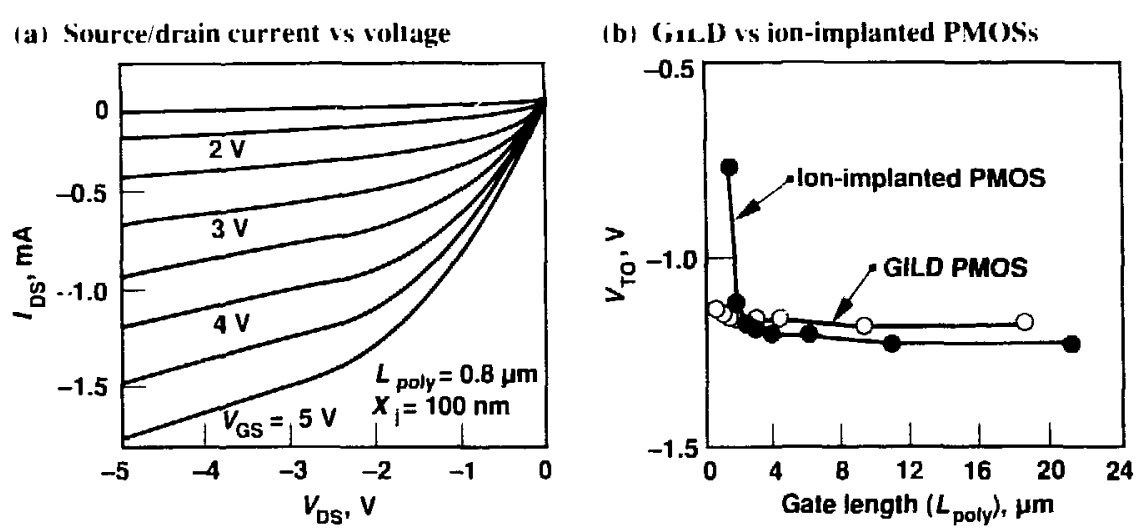

Figure 3. Electrical characteristics of typical PMOS transistors fabricated using GILD. (a) Source/drain current $I_{1 \mathrm{~B}}$ vs source/drain voltage $V_{\mathrm{DS}}$ as a function of gate/source voltage $V_{\text {Gis }}$ of a (FILD PMOS transistor. (b) Comparison of threshold voltage $V_{\text {ro }}$ is gate length $L_{\text {pul }}$ for a PMOS transistor fabricated using (ill.I) and one using ion implantation: thie (iILD device exhibits a maximum threshold shift of $2 \mathrm{mV}$.

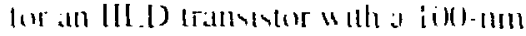
hanc whith. Although prohlemin with hase-ion-dosc control hate limited (ill) tramsistors to maximum current gains of 5 , recent efforts to control the halse-ion done have been stecessiful and the expect soon Io be able to prenduce GilLD hipolar aransistors with improsed formard current hehalvior.

( Mos Fabricanim. (ilLD has, been incorporated into the labrication process for a complementary metaloxide semiconductor i CMOS) device. Working at the LLNL GILD facility. T. W. Sigmon and P. G. Carey of Stanford University. under an SRC contract. produced submicron-size NMOS and PMOS transistors with excellent current/ voltage charateteristics. Figure 3 a plots source/drain current vis source/ drain voltage as a function of gate voltage for a typical PMOS transistor. Figure 3 b compares plots of threshold voltage vs gate length for an ion-implanted transistor. used as a control device, and for a GILD transistor. Unlike the ion-implanted Iransistor. the GILD device shows no threshold shift even at submicron gate lengths. These results indicate that GILD is indeed a superior method for fabricating the ultrashallow impurity regions required in submicron-size transistors.

Epitarial Laver Girouth. Highperformance bipolar transistors of the future are predicted to operate at switching speeds greater than 100 Git\%. These devices will undoubtedly incorporate epitaxial layers for enitler and bise structures. However. current methods of epitaxiall layer growth do not allou the labrication of high-cquality latyer while maintaining the eare of the 
platate shacons proceses. Hithout the

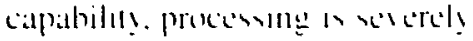
hampered by the necd for mesat inolation and other fow-denaits. lom- - icld processés for clectricall! isclating the tramsistors. We hate dereluped a (ill.l)-hased proces for fabricitling desce-yualis epilasial laters on patlerned substrates. This mo-step process ind olses lirst. depositing an almorphous sificon or germanium film and. then. using at later an melt through the film to the silicon substralle. The substrate atets at a wed crs stal from which the molen amorphous lager regrows as a single crsstal. Figure $t$ is a highresolution transmission electron micrograph of the silicon/Ge Si , intertace. The interface exhihis no defects. indicaling the high yualis! of the epitaxial laser. We have successtully grown very thin (24-mm;

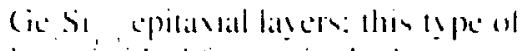
lasere is idcat lor une in the bate regem at heterofuncen hipolar trannisturs. Silleom langers for une as cmillere in both homo- and helerejunction deriers halse alsen heon labricalled.

In FY84. He will increatse the pace of our work a adapt the Gill.D and soll lechnologies in the fathrication process lor hipolat tramsistors. Wi plan to develop (ill.D eyuipment suitable for the fathrication of l'LSI circuits. We will also work lo incorporatc a highperformance GILD process on an SOI substrate. The performance level for the bipolat tramsistors fabricated with these new techniques is titrgeted for a cul-olf frequency $f$, $\geq 15$ GHz. GlLD and SOI processe? will also be incorporalled into various MOS echnologies. In particular. we
Figure 4. Highresolution. crosssectional. transmission electron micrograph of the $\mathrm{Si} / \mathrm{Cie}_{11 .} \mathrm{SPi}^{\mathrm{St.x2}}$ intertace. Vote that the interface (dashed line) is perfectly crystalline, exhibiting no dislocations or point defects.

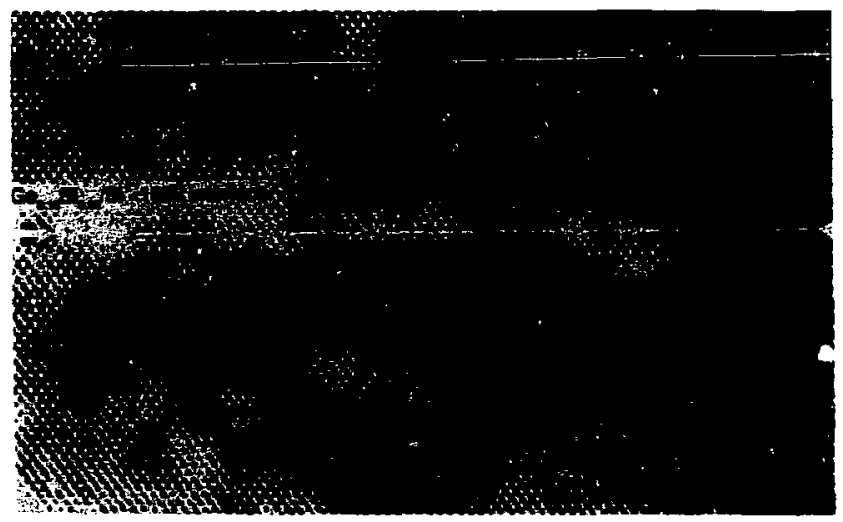

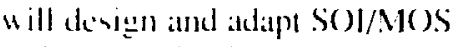

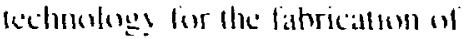
Mos tramsistors in active-matris liquid-ersstall displats. In addition. "le plan to explore the use of the (ill.D process to improse TFT labricalion by lowerilly the maxinum process lemperatures and hy increasing the amount of dopant that is electrically active in the source/ drain reggon. Lastly. We will investigate the advantages of $\mathrm{SO}$ and Gil.D for fahricating image semsors: by simplifying their fabrication process. "la should be able of increarse the performance and yeid il these delceturs.

\section{References}

Ahelsum. J. K. K. B. Kim. K. H. Wemer. and T. W. Sigmon ( I TSk I. "Epitavial (ic Si, /Si f l(1)1) Structures Produced bs Pulsed Laner Mixing of Exaporaled Ge on

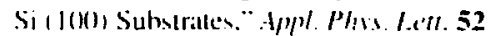
(3). $23011-232$.

Carcy. P. Ci. K. H. Weiner. and T. W. Sigmon 198851. - A Shallum -Jumcion

Submicromeder PMOS Procitss Mithoul High-Temperature Anmeals." Heletrom. Le'tt. $91111.542-54$.

Weiner. K. H.. B. M. McWillims. and T. W. Sigmon 1 14881. "Meatsurements of Melt Depth 1 imited Diflusion in (ias Immersion Latser Doped Silicon lising an Improved Laser System. Pron of Simp, an Laner Prosesses fin Miemelectromin Applicatioms. J. J. Ritsko. D. J. Ehrlich. and M. Kashiwagi. Ek. Vol. kK-10. pp. 53-61. Weiner. K. H.. and T. W. Sigmon (1988). "Emitter and Base Fabrication in Advanced Bipolar Tramsistors l sing Cias Immersion

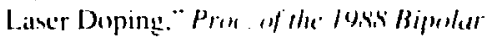

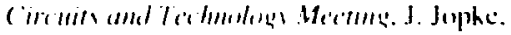
Ed. \{IEEE. pp. 37 . 40. 


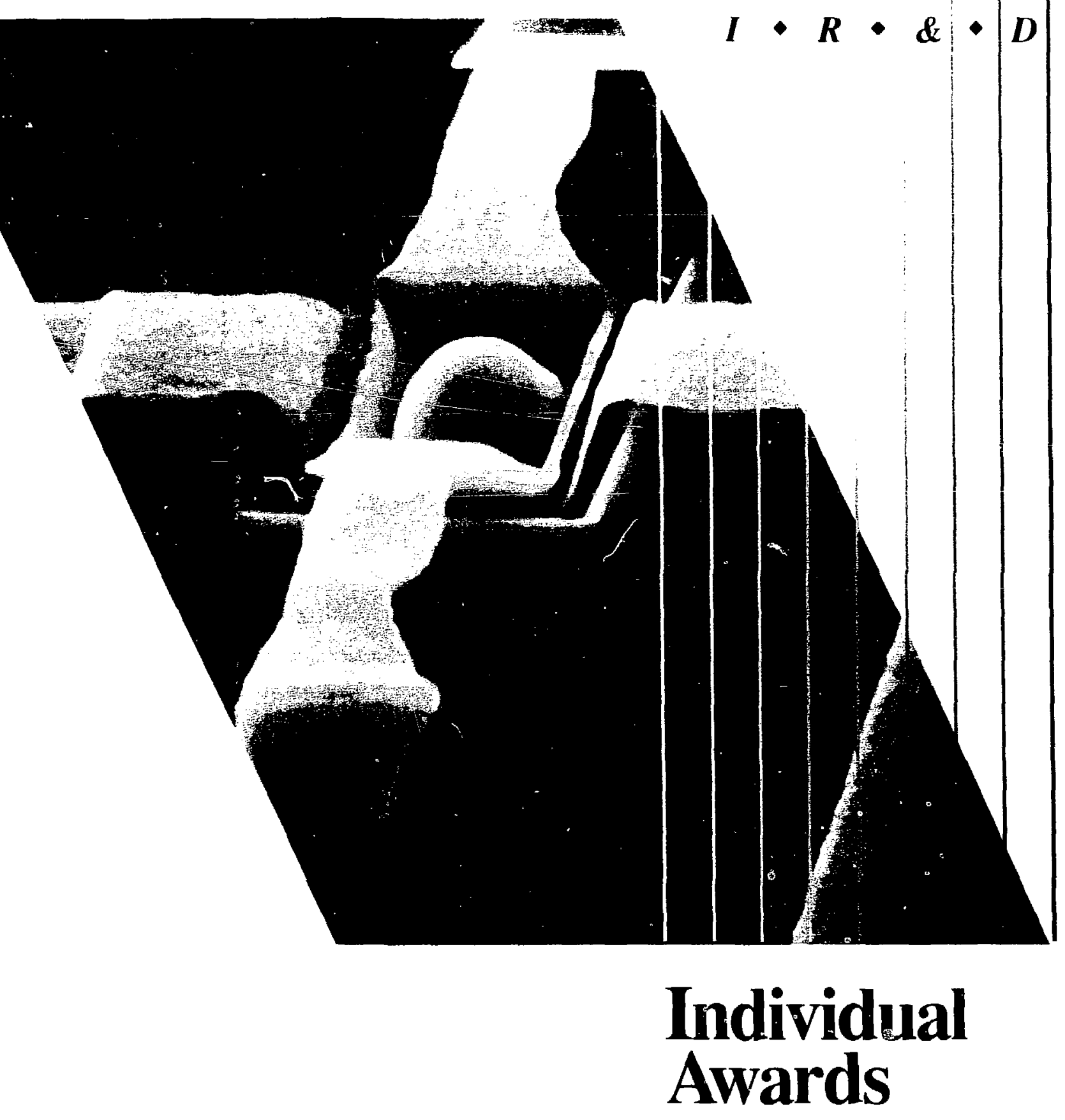

Lawrence Livermore National Laboratory 


\section{Individual Awards}

R. A. Ward
The IRED Individual Auards pron ide a meams by which nowel ideas cant be given seed funding outside of the usual programmatic channels via grants awarded on indiv idual LLNL inventigattors. The IR\&D Rexearch Commitlec focuses on highly leveratged projects that offer good potential of developing into self-sustaining programs. The concept of seed funding is extremely important in the committec $\mathrm{s}$ considerations of projects that w ill explore promising new directions for xience and lechnology in areas relevant to the Laboratory's mission. The selection criteriat for the FY 88 proposals consistent with Department of Energy guidelines) were:

- Scientitic or technical yualiț.

- Impact on the Lathoratory or the general scientitic community.

- Leverage for future funding.

The FY88 Research Committee consisted of 19 members appointed by and reporting to the Director: the members represent the wide spectrum of scientific disciplines pursued at the Laboratory. After all written propessals were

submilted. two committee members interviewed each principal investigator and then reported back to the full committee. The committee ranked each proposal in order of overall scientific excellence and pertinence to the Laboratory"s scientific mission. Propasals were then funded in decreasing order of ranking until the available funds were exhausted. The descriptions below highlight a few representative proposals that were chosen for funding.

One project proposed the design. fabrication. and testing of micropole undulators to be used as insertion devices in synchrotron storage rings. The Lorentz force exerted by the periodic magnetic field inside the undulator causes the electrons to describe periodic oscillations as they are forced to undulate in microscopically prepared, spatially varying magnetic fields. As a result. the electrons accelerate over small distances $(100) 101(0)(0) \mu \mathrm{m})$ and produce veryhigh-energy. extremely monochromatic electromagnetic radiation.

In the biomedical and environmental sciences, researchers proposed to perform accelerator-mass-spectrometry measurements of carbon isotope ratios $\left({ }^{1+} \mathrm{C}:{ }^{1:} \mathrm{C}:{ }^{12} \mathrm{C}\right)$ in bottom-feeding marine microorganisms. Once the technique is perfected. they plan to study the basic food web to determine how petrolcum and gas carbon are utilized by organisms in and around natural petroleum seeps on the ocean floor.

Researchers in engineering proposed to develop the modeling and technology necessary to design and analyze very small (micrometer-size) vacuum tubes. These devices would be fabricated on a small silicon water using semiconductor technology but would be tolerant of high temperatures. radiation. and high-voltage electrical transients.

Another project would determine the technical teasibility of using a cyclotron autoresonance maser (CARM) with an induction linear accelerator. The CARM is based on Doppler-shifted cyclotron resonance in a strong axial field guide, rather than on a wiggler, and gives much higher frequencies than the free-electron laser (in the range of $(0.5$ to $5 \mathrm{McV}$ ). This allows the possibility of more compact. lower power modules for generating millimeterwavelength radiation.

Several projects developed computer codes to model diverse physical processes. One project proposed to compile a theoretical understanding of high-temperature superconductors by applying methods and codes originally developed to study solid-stitle latser materials. The calculations would use the ah inirio molecular orbital cluster method for clusters of several hundred ions and would he correlated with experimentially observed changes in critical 
lemperature with ox!gen valcancies and with high-pressure. diamond-anvil cell measuiements being conducted at LLNL.

Another project proposed to build a prototype system for the simultaneous ohservation of up to 100 objects in an astronomical telescope. This automated system would use optical-fiber sensors. precisely positioned at the desired location on the telescope's focal plane: the light collected would be sent along the optical fibers to a spectrograph for analysis.

An all-time high of 151 proposals were submitted this year. requesiling $\$ 19.8$ million in funding. which included 220.3 hours of time on the Laboratory's supercomputers. For FY88. 26 Individual Awards were granted. for a total of $\$ 3.353$ million. with $\$ 112.0(1)$ for capital equipment. 


\section{Nuclear Magnetic Resonance Analysis and Molecular Modeling of Protamine}

\author{
Principal Insestigator: R. I.. Balhorn \\ Co-Ins estigators: R. Ward and N. Mas
}

\begin{abstract}
We are using nuclear magnetic resonance spectroscopy and innovative techniques in high-resolution computer graphics to study the structure of protamine. By identifying the normal DNA-protamine and interprotamine interactions present in fertile sperm, we will eventually be able to identify molecular defects responsible for certain types of human infertility.
\end{abstract}

$P$ rotamine is a small DNAbinding protein that packages DNA inside the nucleus of mammialian sperm. As each spermatid in the mammalian testis differentiates into a mature sperm. approximately $10^{\prime \prime}$ protamine molecules are synthesized and deposited into its DNA. replacing the majority of existing chromosomal proteins. Although the molecular structure of the resulting DNAprotamine complex is not yet known. the positively charged center of the protamine molecule is thought to bind in the minor groove of one turn of DNA (1) base pairs). completely neutralizing its negatively charged phosphodiester backbone (Balhorn. 1984). Soon after binding. hoth ends of the protamine molecule fold inward and form crosslinks that interlock each protamine to its neighbor around the DNA helix. This charge neutralization and the subsequent formation of crosslinks between adjacent. folded protamines result in the inactivation of the sperm's genes and the packing of its DNA in a maximally condensed state.

The purpose of our investigation is to model DNA-protamine and protanine-protamine interactions and the patchaging of DNA in mammalian sperm. Our work combines the expertise in molecular graphics that his been develuped in the LLNL Computation Department. the nuclear magnetic resonance (NMR) capabilities now available in the Chemistry and Materials Science Department. and knowledge af the molecular structure of sperm chromatin gained in the Biomedical Sciences Division.

The four goals of our project are 10:

- Model the binúing of protamine to DNA and the folding of terminal peptides using a computer system developed al UC San Francisco.

- Refine our modeling of the DNA hinding and folding interactions by using NMR.

- Produce a multistrand graphics model of the interactions of DNA and prolamine in sperm chromatin. (This type of model can be used to assess existing experimental evidence and to facilitate the design of future experiments.)

- Explore the feasibility of using an energy-minimization sofiware program to adjust centain molecular interactions (such as the hincling of the polyarginine segment lo DNA and protein folding).

We have completed the initial steps required to meet the goals involving molecular modeling. In particular. we halve constructed graphically a small segment of the protinnine molecule thit hinds to DNA. This segment, relerred to as an anchoring unit, contains four arginine residues (see Figure I).

We interactively manipulated the anchoring unit by computer, using an Evans and Sutherland Picture System and the UC San Francisco modeling program. MIDAS (Ferrin e't al..

1988). until the terminal amide groups were moved within $0.2 \mathrm{~nm}$ of the phosphates on five base pairs of DNA. Alternating arginines zigLagned across the minor groove of DNA. crosslinking the phosphodiester strands. We determined the free energy of this structure. and we adjusted the conformation of the polyarginine molecule to yield a minimum freeenergy value using the UC Sin Francisco program. BORN. run on a Cray computer. We then used the resulting minimized conformation as an initial step in a moleculardynamics simulation with the UC San Francisco program. NEWTON.

During both the minimization step and the molecular-dynamics simulation. DNA was held rigidly in the $B$ form, and only the protein was 


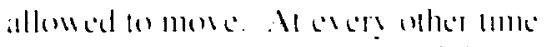
sep in our simulation. We macd the condinatson produce a somputeranimaled film of the d! namices that "sere lathing plates. For this purpose. "L develuped an ncw thadom-calsling program based on the lathoratory ATCMll.Ll. rendering proseram for moleculat motels. B! using only it small segrment of the DNA-protamume hinding sitc. "le " ere able to ensure that wach step in the modeling and computinge procen warked correctly helore we allempled to comstruct llic

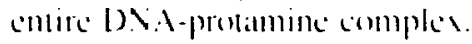

Hith respect on ont wath

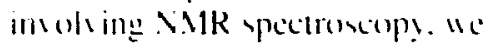
isolated and purilied prolamine liom hull sperm. moditied the essteines using methyl iodicle, and then obtatined protom NMR spectral for both the modilied and unmoditied proteins. In addition. we ohtained spectrat for calch of the component ambmo alche. Four of the is stathetic peptiden that comespond of specilic fratzlents al the protamine molecule were alvo symtesised and purificel. We have hegun lo assign the protoms in protamine by comparing NMR spestra of individual amino alcids with those of synthelic protamine fratements. Once all protons are assigned. WL will then conduct computer analyses to identity coupled (neighboring) (a)

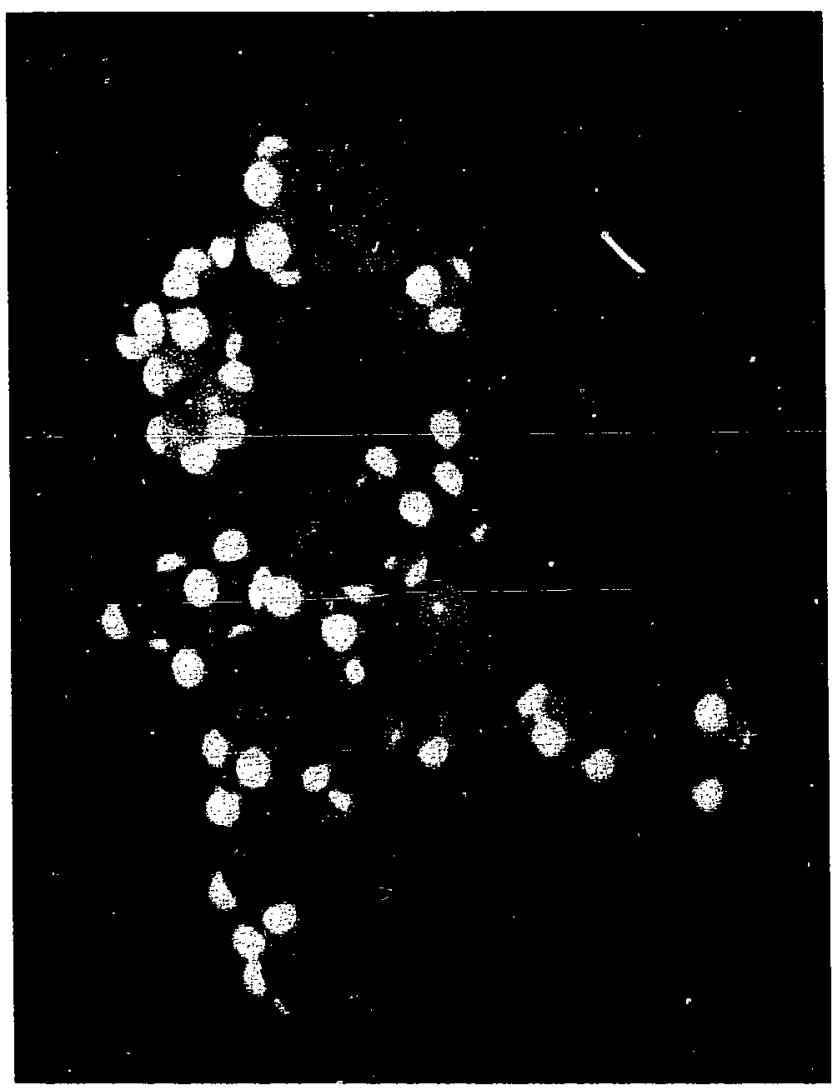

(b)

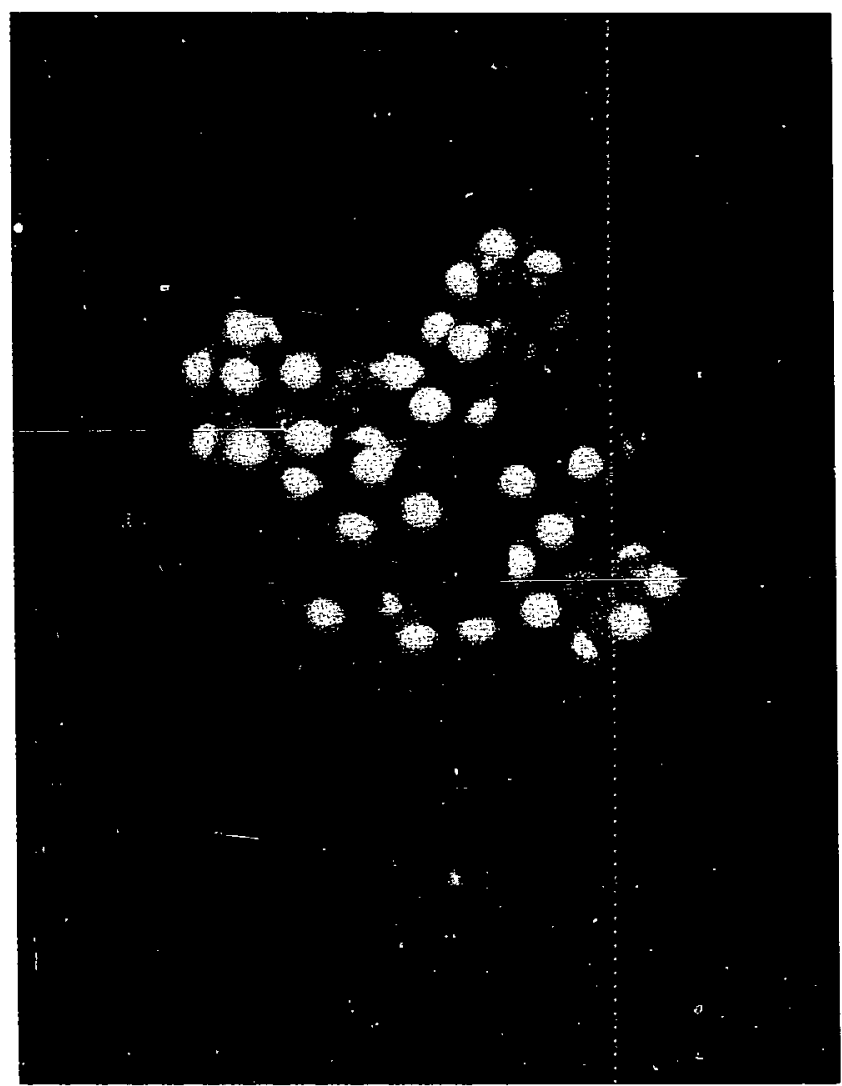

Figure 1. Computer-generated model of the interaction between a DNA-protamine binding unit (arg I $_{4}$ and a segment of DNA. (a) The arg-arg-arg-arg peptide (top) and the DNA segment (bottom) shown as separate inolecules. (b) Front view of the minor groove of DNA filled with the arg $_{4}$ peptide after rolating $90^{\circ}$ to the right the DNA-peptide complex sluown in (a). 
protons in the same amino acid and interacting protons in different amino acids. We halve prepired folded forms of the protamine molecule in vitro and are now separating and purifying these forms for subsequent NMR analysis. We have also prepared a covalently crosslinked protamine dimer in its two forms and are purifying them for analysis.

During FY89. we will concentrate on completing the identification of all unfolded protamine protons and on analyzing the spectrat of naturally folded forms of protamine and folded synthetic peptides. By exploiting the nuclear Overhauser effect (which permits the identification and localization of protons in amino acids that are well separated in the peptide chain. but within $0.4 \mathrm{~nm}$ of one another in the folded molecule) and by modifying specific cysteines with radioactive $\left({ }^{1} \mathrm{C}\right)$ reagents, we should be able to map the location of anino acid residues within the amino- and carboxy-terminal folded domains.

We will use two approaches to locate the region of the protamine molecule that binds to DNA. The tirst approach involves constructing a synthetic DNA-protamine complex and monitoring the immobilization of specific amino acids after the protein binds to DNA. This approach requires the preparation of a soluble form of the DNA-protamine complex in a suitable solvent because the complex is insoluble in water. If a sufficiently soluble complex cannot be prepared, our second approach will be to attempt to obtain solid- state NMR spectra. Should both approalches fail to provide information on the location of the DNA-binding region. then we will use methyl glyoxal to chemically modify arginine residues of protamine not bound to DNA in intact sperm. The location of unbound arginines can then be determined by combining NMR spectroscopy and protein-sequencing techniques.

\section{References}

Ballhorn. R. (1984), "A Model for the Structure of Chromatin in Mammalian Sperm." I. Coll Biol. 93. $298-305$.

Ferrin. T. E.. C. C. Huang. L. E. Jarvis. and R. Langridge (1488). “The MIDAS Display System." I. Mol. Graphic 6. 13-27. 


\section{Application of Accelerator Mass Spectrometry to Marine Ecology}

Principal Insestigator: K. K. Spies

Co-Investigator: J. Bauer
We are applying accelerator mass spectrometry to basic problems in marine science. Our ability to measure carbon-14 in microgram-size samples of carbon promises to advance our understanding of carbon cycling in the oceans.
$\mathrm{W}$ e are meatsuring the nattural abundance of ciarbon-14 $\left({ }^{1+} \mathrm{C}\right)$ in smiall samples of sealwaller. sediments, and marine organisms l! elucidalte aspects of the oceanic carbon cycle. One reason that ${ }^{4} \mathrm{C}$ is a useful tracer in the ocean derives from the falet that the carbon turnover time in oceans $(50)-10(0)$ years) represents a signiticant fraction of the ${ }^{i+} \mathrm{C}$ half-life $(5730$ years). Surface waters, where carbon is incorporated into the food web. are more nearly in equilibrium with the atmospheric source. New organic matter is, in general, significantly enriched in ${ }^{1+} \mathrm{C}$ relative to deep-water organic matter. In addition. along the west coast of the U.S.. persistent northwesterly winds in the spring and summer result in upwelling of deep. nutrientrich. but ${ }^{14} \mathrm{C}$-depleted. water (Robinson, 1981).

Conventional measurements of the abundance of ${ }^{1+} \mathrm{C}$ by decaly counting require several liters of seawater for the determination of inorganic carbon and $1 \mathrm{~g}$ of organic matter for organic carbon. Samples of marginal size often must be counted for several days to obtain an accurate determination. Thus. conventional techniques have limited the usefulness of using ${ }^{14} \mathrm{C}$ as a tracer The separation and direct counting of carbon isotopes by alcelerator mass spectrometry (AMS), on the other hand. allow us to use sample sires als small as 20 to $30 \mu \mathrm{g}$ and counting times of less than 1 hour. Early this year. we made the first measurements of ${ }^{14} \mathrm{C}$ content of dissolved inorganic carbon in sediment porewaters (samples obtained from the pores in sediment) using simples of 1 to $5 \mathrm{ml}$. the smallest seawater samples successfully analyzed for ${ }^{14} \mathrm{C}$ to date.

Although ${ }^{14} \mathrm{C}$ enters ocean surface waters mainly as $\mathrm{CO}$. a key to better understanding of the oceanic carbon cycle is the cycling times of various forms of organic carbon. Recent evidence suggests that dissolved organic carbon in the ocean is relatively old (with a mean age of about $6(10)$ years in the central North Pacific (Ocean) and that a large fraction of such carbon appears to be only slowly decomposed by microbes (Williams and Druffel. 1987). It is clear that the cycling time of various classes of compounds comprising dissolved organic carbon needs to be investigated; because of the sample sizes that are practical to collect. such measurements can only be done with AMS. Our plan was to separate from seawater some specific classses of such compounds and then to measure the ${ }^{12} \mathrm{C}$ content.
We lirst used AMS to answer longstanding yuestions about fossil carbon eycling iti the sediments of a shallow-water petroleum seep. In particular. we wished to know whether the higher population densities of some organisms in the sediments of the seep were due to the use of fossil carbon by the food web. Our previous investigations had strongly suggested this possibility. A dilution of modern carbon by fossil carbon in organisms from the sediments of the seep would constitute nearly irrefutable evidence of fossil carbon use.

Figure I shows the results of our radiocarbon analyses of total organic carbon in sediments, of dissolved inorganic carbon in porewater. of meiofauna (animals passing through a sieve with $0.5-\mathrm{mm}$ openings). and of macrofauna (animals retained on a sieve with $0.5-\mathrm{mm}$ openings). We obtained all samples from sediments of the Isla Vista petroleum seep located off the coast in the Santa Barbara Channel. The ${ }^{14} \mathrm{C}$ content of dissolved inorganic carbon in porewater shows a clear gradient due to the influence of lossil carbon. Station A. with the greatesl active seepage. also has porewater with the greatest depletion of modern carbon. Station B has less seepage and more modern carbon. Station $C$ has 
exientially no sepalge and the mow modern sarbon. The cepth proffilen in each cance are related to the intluemes of microbial metabolism. porewater pumping. diftusion into averlying seawater (which is nearly modern). and an upward tlux of fossil $\mathrm{CO}$. from the underlying. oil-hearing strata. Both meiofitunat and macrofiuna show a depletion of ${ }^{15} \mathrm{C}$ with increasing seepage. This

(a) Sediments

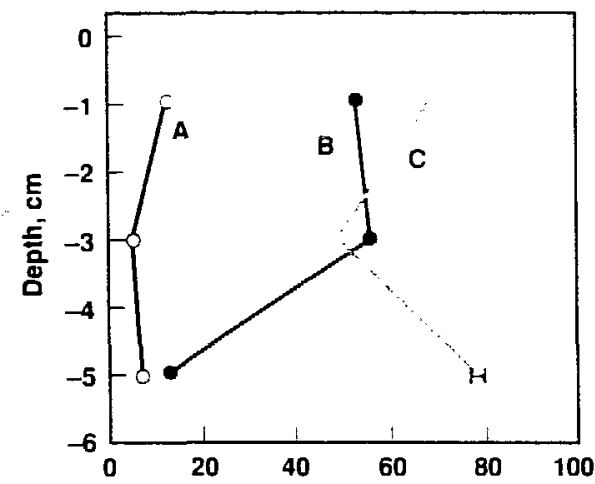

(c) Meiofauna

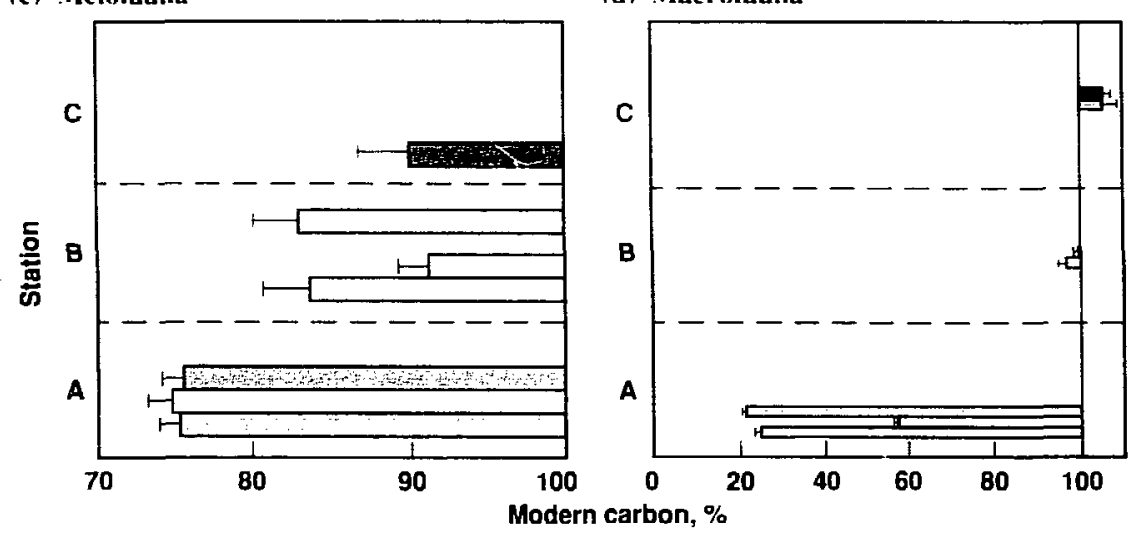

Figure 1. Natural abundances of ${ }^{1+} \mathrm{C}$, expressed as percent modern carbon, in (a) total organic carbon within sediments, (b) dissolved inorganic carbon within porewater, (c) four types of meiofauna, and (d) seven types of macrofauna.

Sediments are from three stations with varying degrees of seepage near the Isla Vista petroleum seep. Data such as these indicate a dependence of the food web on fossil carbon. relation indeath a dependenes of the fired web on liwsil carbon use in lala Vista redimlems.

Our future plans include a timeeries analysis fa series of tests over monthss of $\mathrm{C}$ content of dissolved inorganic carhon in stawaler. phytoplankion. suspended particulate matter. lotal organic carbon in sediment. and benthic thotlomdwelling) organisms from a coastal

\section{(b) Porewater}

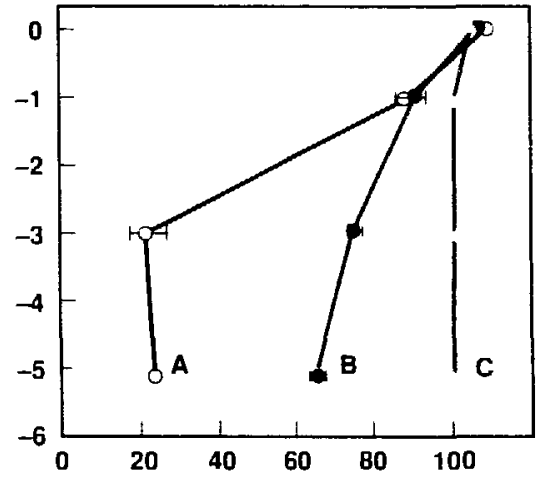

(d) Macrofauna focatlon in (alliformat that has bollh upw slling and non-upucolling veasons. Such dala will help us to establish how organic matler is used wer time on the California continental shelf and will serve as at reference for subsequent measurements of even more specific classes of organic matter. such ats haclerial lipids.

\section{References}

Rohinnoll. S. H. MGKl, "Nillural and M:allMade Radiocarbon as a Tracer for Cobalat Cpuclling Procisnce." Amer. Cirophas.

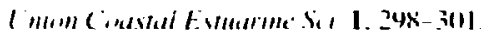
Williams. P. N.. and E M. Druffil 1 I4ST/.

"Radiourbon in Dienolved Oreanic Maller in the Central Vimblacitic Oceanl." Silmer 330. $246-2+8$. 


\section{Fluorescence Detection and Quantification of Gene Expression}

Principal Investigator: M. (;. Pallavicini

We have developed fluorescence techniques to detect and quantify gene expression in individual cells. This capability allows us to track messenger RNA from a nucleus to cytoplasm, where it is translated into specific proteins, and to follow the movement of translated protein back to the nucleus. Such methods are useful for investigating selective gene expression in proliferating and differentiating systems and for in situ analyses of intracellular macromolecular traffic.

system for developing techniques to measure and quantify gene expression.

We used flow cytometry and an immunotluorescence-based assay to quantify the amount of c-myc protein produced in cells that contained different levels of c-myc DNA sequences. We found that the level of production of c-myc protein was related to the number of c-myc sequences present in the chromosome. Although the c-myc protein is believed to play a role in regulating cell proliferation. our studies indicated that cell proliferation was independent of c-myc protein levels. We did, however, observe increased lethality in cells expressing c-myc protein at levels 20 to 40 times higher than normal. We also were able to follow the movement of the $\mathrm{c}$-myc protein from cytoplasm to its functional domain, the nucleus.

To detect c-myc gene transcription, we used fluorescence in situ hybridization. a technique based on the formation of hybrids between complementary sequences of nucleic acid. In this teclinique. nucleic acid probes are first labeled with biotin and hybrized (with complementary sequences present within the (ell) with biotinylated RNA probes. The resulting hybrids are detected using fluorescenated avidin. a protein with high affinity for biotin. We initially detected intracellular c-nyc mRNA following hybridization with the biotinylated c-myc DNA probe. Although we were initially successful with this approach. it proved to be too variable for routine biological applications. We subsequently hybridized c-myc mRNA with biotinylated RNA c-myc probes. which were produced and characterized at LLNL. We found that RNA-RNA hybridization allowed for reproducible and sensitive message detection: that is. we were able to detect mRNA derived from Iranscription of 50 genomic copies. We analyzed both nuclear mRNA and cytoplasmic c-myc mRNA using this procedure.

Our work is the first demonstration of detecting nuclear mRNA using fluorescence in situ hybridization. We have already used image analysis to quantify total cellular fluorescence. and we will apply that technique in the luture to separately analyze nuclear and cytoplasmic mRNA. We have 
also dereloped the capatollls simulatmeously latel colls for a

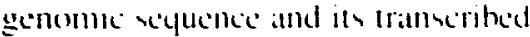
product. Thus. He mom catl medasure both the copl number and expression of selected gencs. This development

\section{(a) C-myc mkNA}

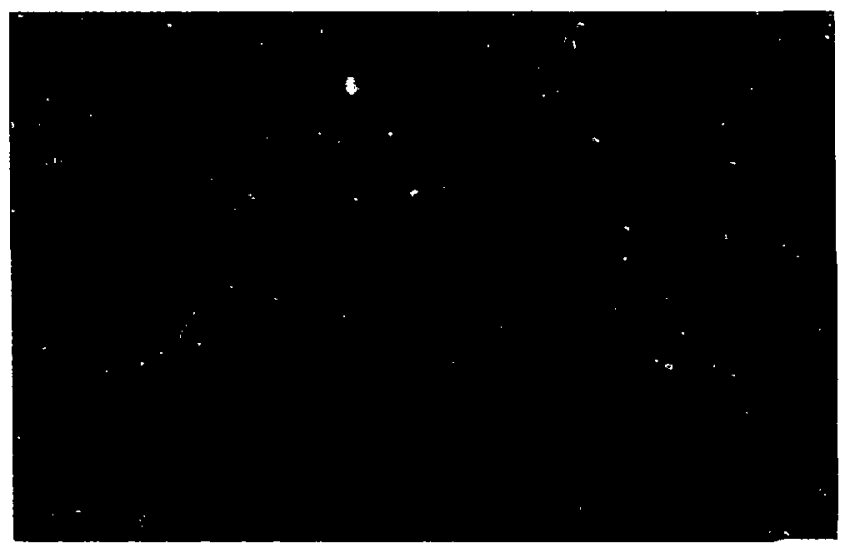

\section{(b) C-myc protein}

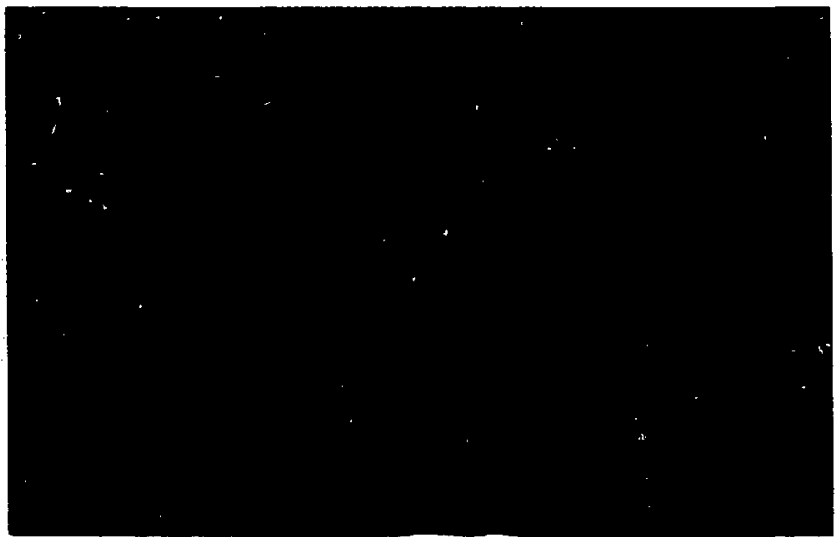

Figure 1. ('-mvc messenger RVi and protein in heated recombinant cells. (a) (c-msc messenger RN $\mathrm{A}$ is visualized as a bright, tight!! localized spot in the center of the nucleus. (h) $C^{\circ}$ myc protein is localized within the nucleus and appears as a relatively diffuse, yet distinct pattern. These cells were heated at $43^{\circ} \mathrm{C}$ for 20 minutes and then returned to $37^{\circ} \mathrm{C}$ for 4 hours to produce - -myc protein.

\section{Relierence}

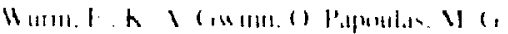

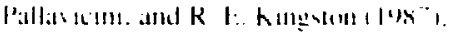

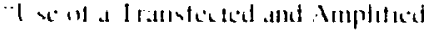

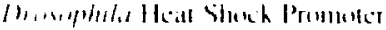

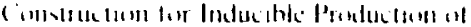

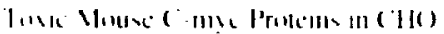

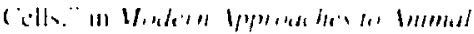

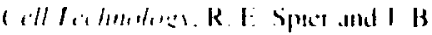

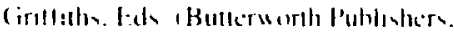
I lat. 1 ondurn. pe $2152+1$ 


\section{Scanning Tunneling Microscopy}

\author{
Principal Insentigator: W. I.. Hell \\ Co-Inewigallors: K. Balhurn. T. Bebbe. \\ II. I. vichhatu. 1. II ilunn. and \\ II. valmeron*

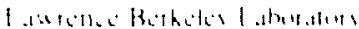

Buthes 1

$\mathrm{S}$

tude of the phoseal and

cicelrents struciure al surtades

on the vale of atom in of ectltal

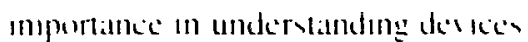

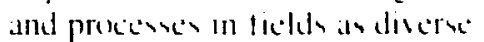
as remicomiluctor electromics. machining. polishing. surfice chemustr. and hiolowe! Intil recentl. mos surtice-semsitse lechniyus hate heen reviricted lo) ultrahigh vacuum ens ironments. The adient of the acammin! cunncling microseope (STM) now prosides us with the opportunity to stud! surface phencimonat. such as corrosion. Belling. electrochemical deposition ot metals, and callals vis on a variels of surtalces al normal operating pressus $\therefore$. Furblemore. STM can be used lo imatge varfacts of hiofogical molecules.

In list ycatr" report. We showed the main features af the microseope we have huilt. We replaced the piczoslectric tripod with a eylindrical tuhe for grealter speed and stability in manipulating the tunneling probe tip. In general. electric ficelds applited to the piesolectric erystal tuhe through exaporaled metallic contacts induce strain in the tube that moxer the tip. The luhe seanner prowides a maximum up range of 1 (1) $140 \mathrm{~mm}$ in all dircitions $w$ ith displacement controf at betles than $11011 \mathrm{~nm}$. We can acyurs squarc pactures $111 \mathrm{~nm}$ inl cach side in less than I min.
We have used onr air-operated scanning tunneling microscope and other new techniques to image bare DNA without the metallic coating commonly required in transmission electron microscopy. We can determine the DNA structure with a resolution of $\sim \mathrm{I} \mathrm{mm}$, revealing for the first time its distinct helical structure through direct imaging.
Tis heller mollerstand the

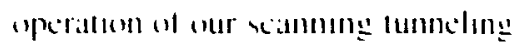
microncoupe. mateme anc alom at the end of an allumicially warp melallic neculc chene an the surtice af a corducling matcrial. For gap distanceso of $0.5 \mathrm{~nm}$. an applicel hias al sereral tems al millivales inducis current thow in the nanoampere range. Electrom flow atcrom the gatp hecause (1) the yuamum-mechamial tunncling cllect. The current It plealls decreates hs and arder al matymilude for elery $11.1 \mathrm{~mm}$ in gap ypacing.

Wi halse used threc uperating modes: comstant current. comstant height. and hoal-harrice height. In

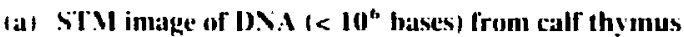

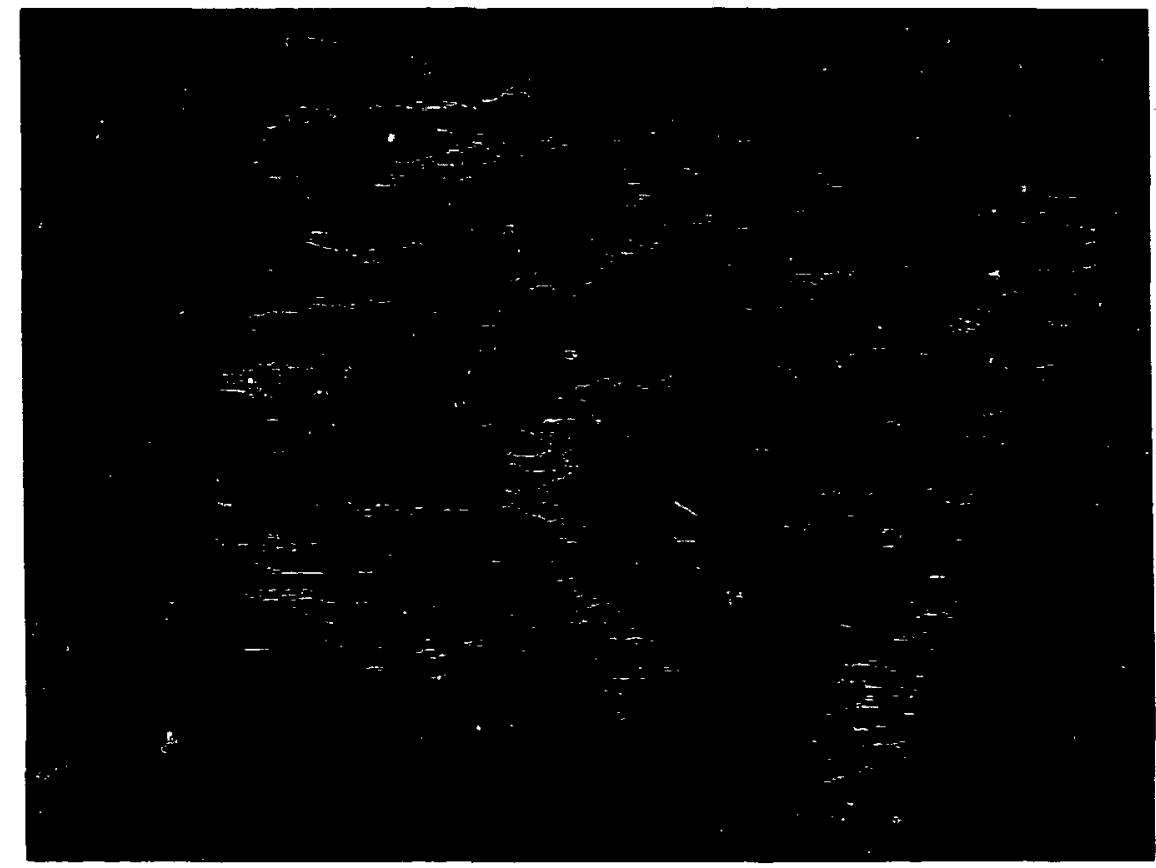

Figure 1. (a) STM image of ealf thymus obtained froun Worthington Biuchenical (imp. (Freehold, N.J). The highly polsmerized thymus was diswilsed onernight in aqueous I1)-mM K( I $14.5 \mathrm{mg} / \mathrm{mli}$. Nliquots of stex/k DNA solution were then diluted with II-m.M KCI to a working concentration of I mg/ml. We then esaporated one droplet in air an a freshly cleaved py rolytic graphite substrate, which provides al 


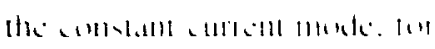
the vartate latedalls

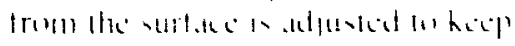

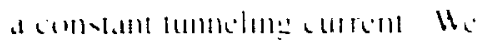

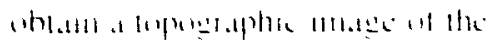

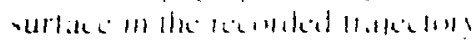
(1) Ihi ilp

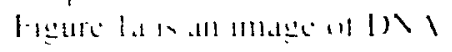

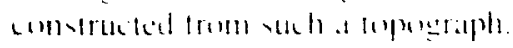

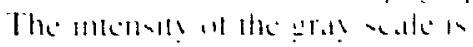

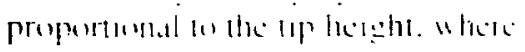

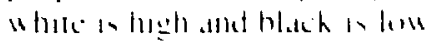

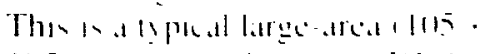

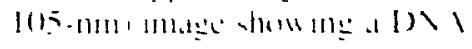
comples that mather mam!

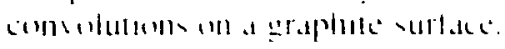

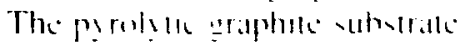

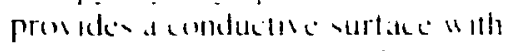

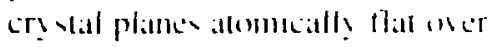
hundreds at namomilers. Buth

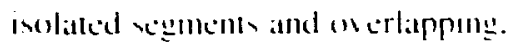

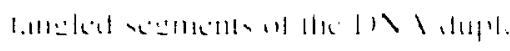
$.110,1121 \mathrm{hl}$

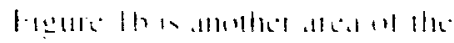

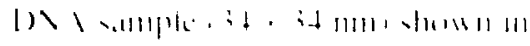

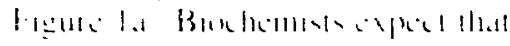

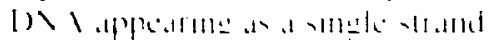

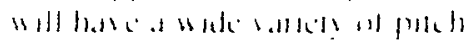

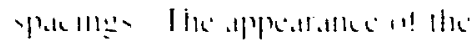

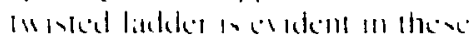

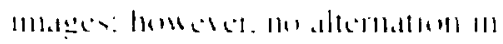

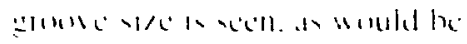

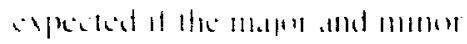

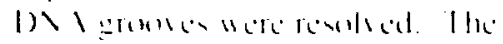

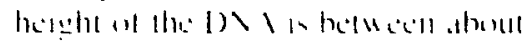

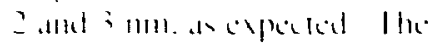

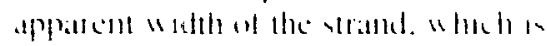

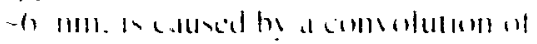
the atual O) 1 whith wh the up unlil

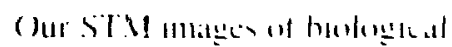
molecules hate a restulum lar

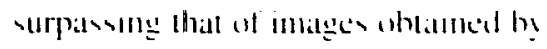

(b) STII image of spiraling. right-handed I) $\mathrm{A}$ from a alf thy mus

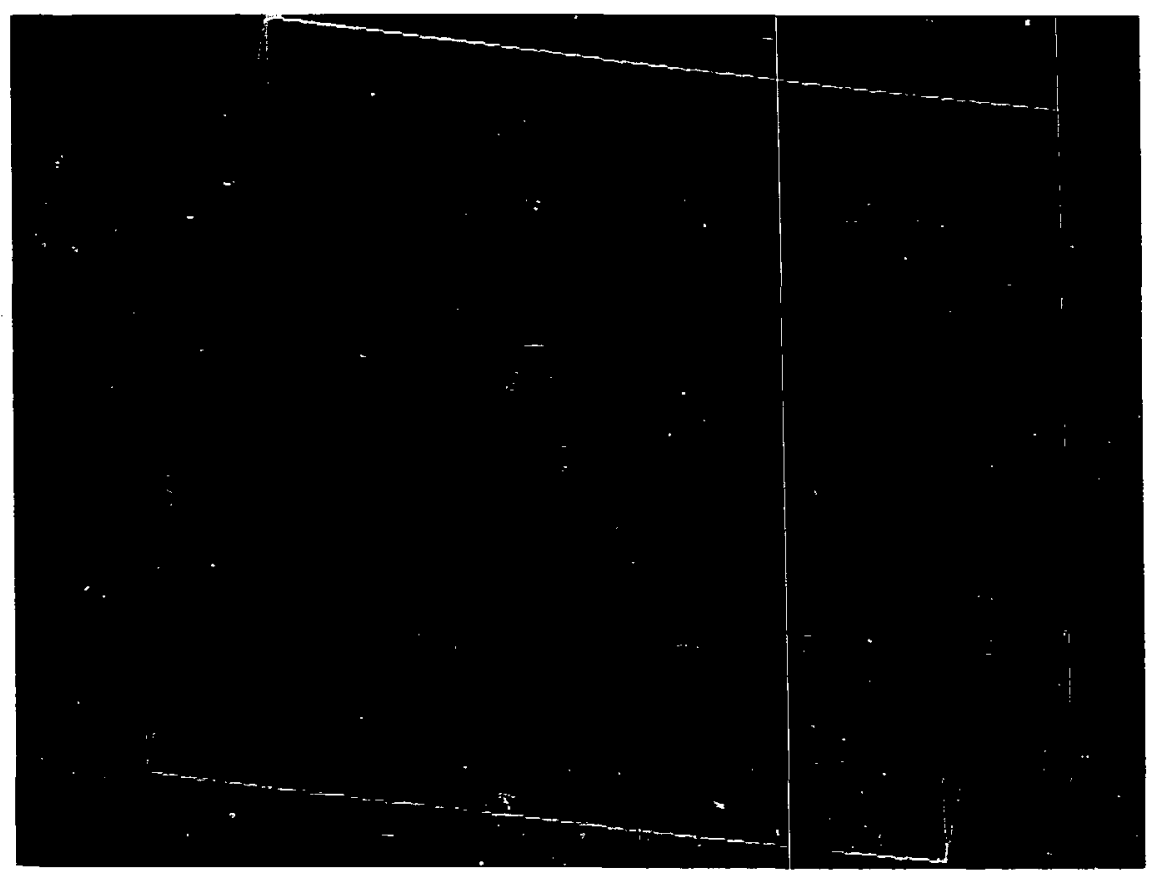

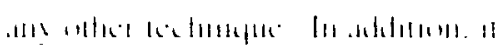

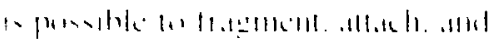

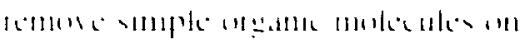

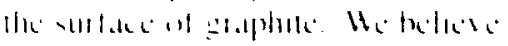

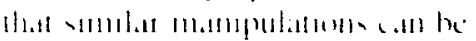

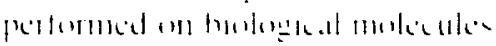

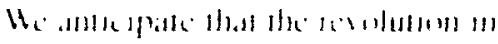

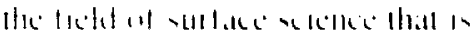

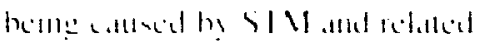

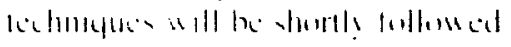

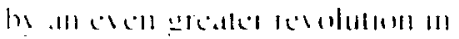

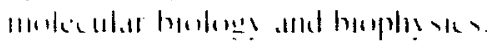

(c) INi hedix

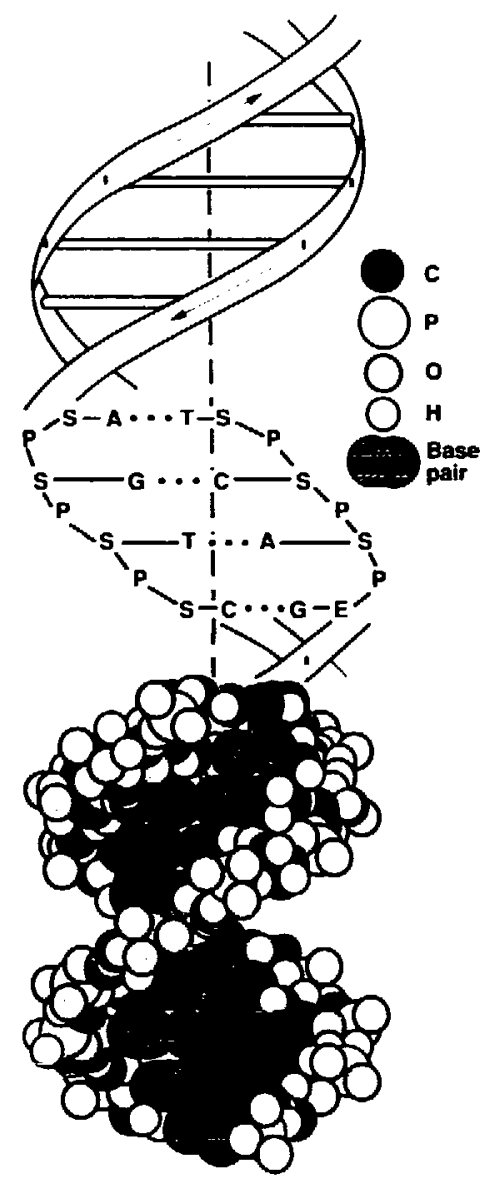

conductios surface with crystal planes atomically that over hundreds of nanometers. This lypical large-area image shou, a I) 1 comples that makes mans consolutions on the surface. Both isolated segments and on erlapping. tangled segment of the on duples are visible. This image is viewed from a perspective 45 abowe the plane and 20 cluckwise in the plane. the lnuther area of the DNA san ple taken within a few minutes of the image in lal. The spiraling. right-handed IDV I structere in clearly vinihle. (c) Schematic of the Ineliv af I) 1 for comparison. 


\section{Synthesis of Dense Energetic Materials Using Polymer Supports}

\author{
Principal Insestigatur: 1. R. Mitchell
}

$\mathrm{O}$ ur objective is to find nell "Ia! 10 unthesise high explosises that are more energetic than HMX (Com. 1988). Figure I bous the structure of this important explosibe. which has a densil! of 1.9() $\mathrm{g} / \mathrm{cm}$. Densily is important becaluse it is direclly related !o the ChapmanJouguel ( $C$ ) pressure $P_{1}$, the detonation propert! that principally determines the impulse delivered by an explosive:

$P_{1,}=\rho_{11} D^{-} /(K+11$

where $p_{1}$ is the initial density of the explosive. $D$ is the detonation velocity. and $K$ is the adiabatic expansion coefficient of the chemical reaction product gases at the $\mathrm{CJ}$ state. Because the detonation velocity and the adiabatic expansion coefficient both increase linearly with the initial density. $P_{1,}$ is proportional to the
We have developed synthetic methods that will enable us to prepare larger-ring homologs of $H M X$ and other new explosives related to HMX.

intial demsily squared. Therefore. 10 decolop more poucriul explosises. lle must identity energetic materials "with vers high densities ITarver. 14)74.

Vielsen (1973) predicled higher densities than that of $\mathrm{HMX}$ for the compound is larger-ring homologs. estimating a maximum of $2.09 \mathrm{~g} / \mathrm{cm}$ for the iwelve- 10 fourteen-member rings $(1 . n=6.7)$. Allempts bs researchers to prepare such compounds have been unsuccessful. thus indicaling the need for altemative synthetic strategies.

Our generial approach is illustrated in Figure 2. At the start of this investigation. we obtained only six - and eight-member rings (III or V. $\|=3.4$, when using either carboxamides (II. $\mathrm{R}=\mathrm{CH}_{3}$ ) or urethanes (IV. $\mathrm{R}^{\prime}=\mathrm{CH}_{3} \mathrm{O}$ ) in reaction b. Furthermore. although carboxamide derivatives (III) could

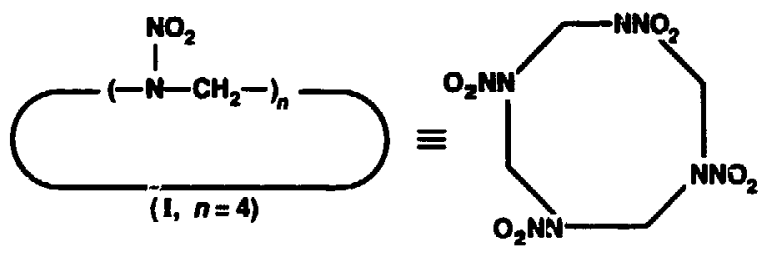

Figure 1. Two structural representations of $H M X(1, n=t)$, which is an important military explosive. The number of methylenenit ramino groups is represented b: $n$. HMX is a cyclic methylenenitramine with an eight-member ring and a density of $1.90 \mathrm{~g} / \mathrm{cm}^{\prime}$.

be nitroly aed a l. uredhance deris allses I Vifailed to ! icld I in reaterion c (Gilberl e'l al. . 1976).

The disconery of derivatives that would allow the formation of larger ring s'stems $(n>4)$ wats critical to the suceess of the project. We reinvestigated the use of urethanes with a focus on the more acid-labile derivatives. We found that we could use urethanes derived from $\| / \%$ butanol. which are normally employed as terr-butyloxycarhonyl (BOC) protecting groups in peptide synthesis (Barany and Merrifield. 1979). In Figure 2. $\mathrm{R}^{\prime}$ in such urethanes (IV) would be $\left(\mathrm{CH}_{i}\right) \mathrm{CO}$. Especially noteworthy are the mild reaction conditions required for nitrolysis of the BOC group.

In an analogous fashion, we prepared and investigated the use of polymeric urethanes derived from benzhydryl alcohol bonded to $1 \%$ cross-linked polystyrene. In thi: case. $\mathrm{R}^{\prime}$ in Figure 2 was $\left(\mathrm{C}_{11} \mathrm{H}_{\xi}\right), \mathrm{CHO}$. The polymer derivatives were designed to have chemical reactivity similar to the BOC group and possibly acl as templates that would lavor the formation of larger ring systems (Mitchell and Merrifield. 198.5).

Low-molecular-weight j!nd polymeric urethanes reacted as show'n in Figure 3. The formation of ten-and twelve-member cyelic 


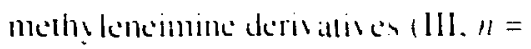
5. 6) wats demometrated by chemical ionization mass spectronctry in reaction mixtures also containing the known six - and cight-nember ring compounds (III. $n=3 .+1$. Nol surprisingly, the trimer $V l$. in contrast to the monomer ll. promoled the production of lareser cectic products (III. $n=5.6$ ).

In conclusion, we have developed a synthesis for precursors that will enabic us to prepare largerring homologs of HMX. In addition. we discosered a mild nitrolysis realction that should improve our ability to ynthesise new explosives.

\section{References}

Barans. (i.. and R. B. Merriticld (1474). "Solid-Phise Peptide Syntesis." in Th'

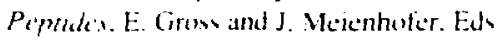

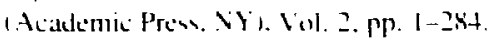

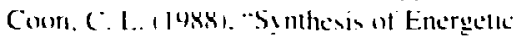

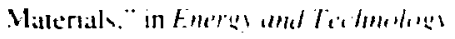
Revew. Law rence L Wermore Vattomal

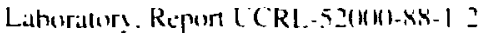
I anuary Februar! IUKR।

Gilimen. F. F.. J. R. Lectatcorw. and 11. Warman 1 14761. "The Preparation of RDX from 1.3.5-Triats lhe sahy dro-s-triartmes."

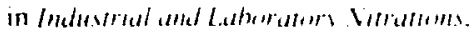
L. F. Alhright and C. Hamsom. Eds. ACS Symponium Serser 22. American Chemical Sockly. Washinglun. D.C.1. pp. 327-3411. Mitchell. A. R.. and R. B. Merritield (1485). "Peptide Cyclizalions on Polystyrene Supports: A Study of Intrasite and Intersite Reactions." in Pepride'x. Srrme furres und Fumriom. C. M. Deher. V. J. Hruby. and K. D. Kopple. Eds. (Pierce. Rochlord. IL). pp. $289-292$.

Nielsen. A. T. (1973). (allalutwm of

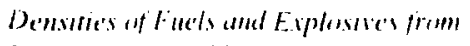
Molar lollume Addirive Inoreme'ms. Nas al Weapons Center. China Lake. CA. VWC Technical Puhlicaltion Vio. 545?

Tarser. (. M.114741, “Densil! Eulmallem,

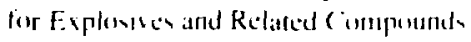
ling the (iroup Addurw! Approath."

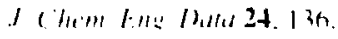

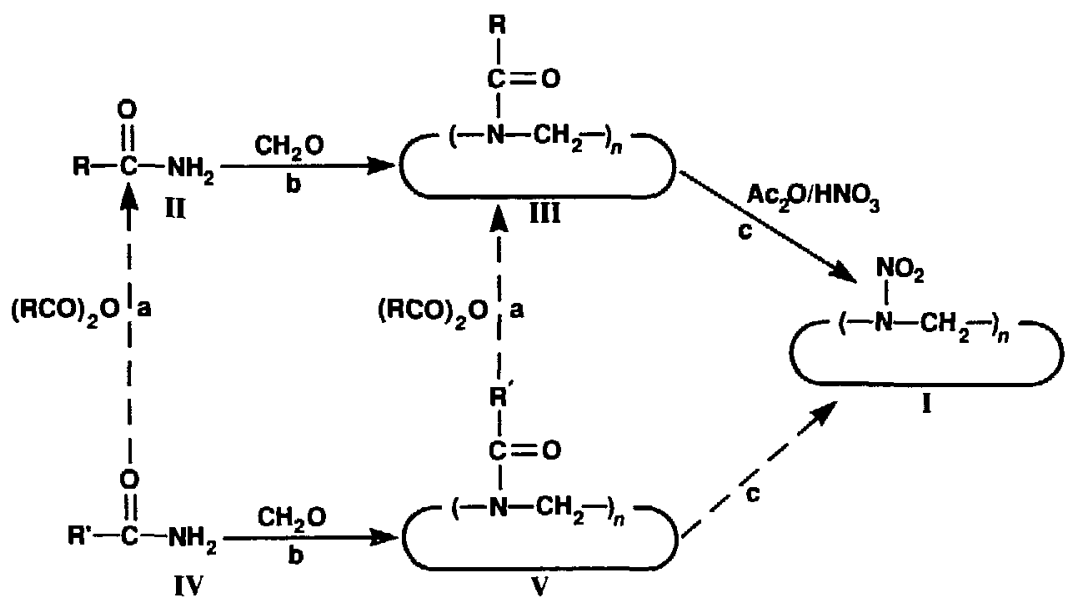

Figure 2. General approaches to the synthesis of cyclic methylenenitramines (I). Carboxamides (II. $R=$ alkyl) or urethanes (IV, $R^{\prime}=$ alkoxy) are used. Irethanes can be converted to carboxamides (reaction a). Ring formation (reaction $b$ ) followed by nitrolysis (reaction c) yields $I$. Dashed arrows denote reactions unknown at the start of the investigation.

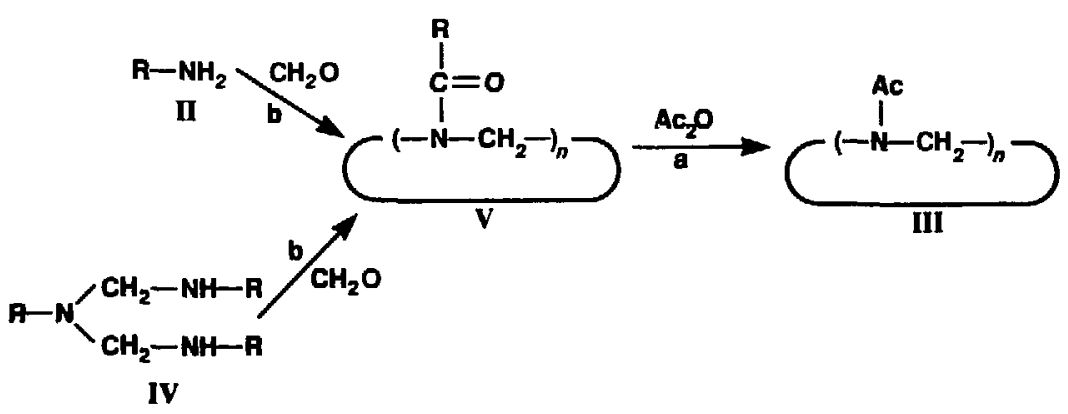

Figure 3. Formation of acetylated cyclic methyleneimines (III) from monomer (II) and trimer (VI) urethanes via ring formation (reaction b) and acetolysis (reaction a). $\mathbf{R}$ is tert-butyloxycarbonyl or $1 \%$ cross-linked polystyrene incorporating henzhydryloxycarbonyl groups. 


\section{Multilaver Gratings for $\Delta \boldsymbol{n}=\mathbf{0}$ Spectroscopy}

Principal Inse tigaturs: T. W. Barbece, Ir.. and 1). D. Dietrich Cu-Insestiguturs: I. Hivler and R. Marrus* ( II)
We have developed ways to fabricate and characterize normalincidence, multilayer focusing gratings for moderate- 10 highresolution spectroscopy in the wavelength range of 5-50 $\mathrm{nm}$. We will use these gratings to study the emission spectra of foilexcited heavy-ion beams from accelerators, particularly the $I s_{12} 2 p_{12} 3 P_{11} \rightarrow I s_{12} 2 s_{12} 3 S_{1}$ transition in helium-like ions.
$\mathrm{O}$ ur werall objectice in 1 ) apply normal-incidence multilayer diftratction gratings, which allou moderate- to high-resolution spectroscopy in the spectral wavelength range of $5-50 \mathrm{~nm}$. 60 the study of heavy-ion beams. Simple. 17att. multilayer coatings alre manmade depth-periodic structures that have been experimentally shoun to hive nombal-incidence retlectivities in excess of 30 ) $\%$ over the spectral range of 10-25 nom (sec Figure /al). These reflectivities atre (wo to three orders of magnitude larger than those attainable with Iraditional singlelaver eoatings. Code calculations of multilityer reflectivities for 5-10-nm atrd 25-5()-nm light predict similar performance. Although these measurements are for that multilayers (Trail e' al.. 1988). we have oblained similar relleclivilies for multilaver structures synthesized onto sphericial (a)

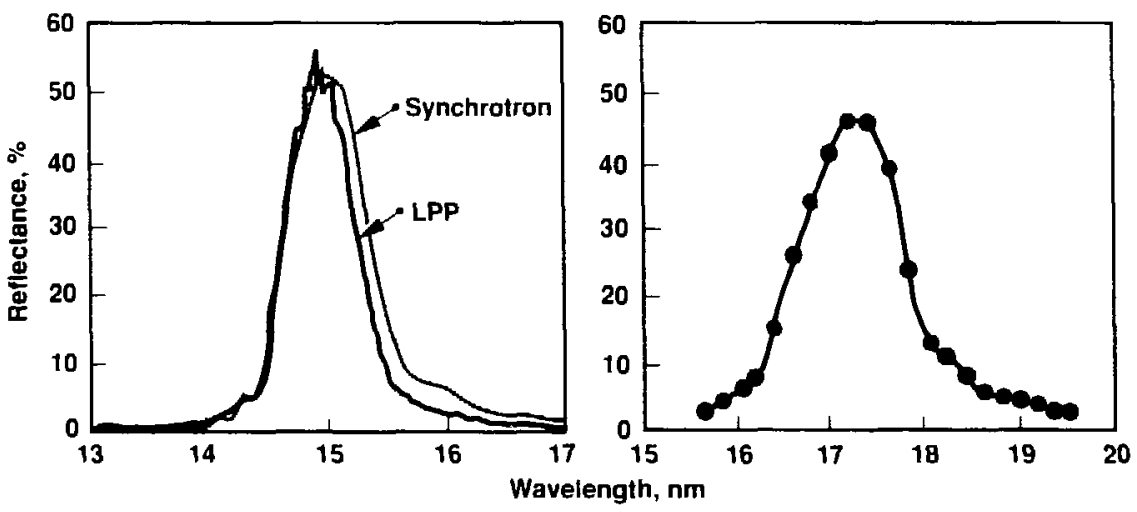

Figure 1. Measured reflectivity of (a) a llat molybdenum-silicon multilayer (7.8-nm period) at normal incidence. using both synchrotron radiation and light generated by laser-produced plasma ( $L(P P)$ and (b) a molybdenum-silicon multilayer $19.31-\mathrm{nm}$ period) deposited onto a concave. 1-m-radius, superpolished substrate, measured at 15 off normal incidence. The measured reflectivity $148 \%$, in $(\mathrm{h})$ compares well with our calculation $154 \%)$. substrates with ratdii from $0.5-4.0 \mathrm{~m}$ (sec Figure $\mid \mathrm{h}$ ).

Diffratction grattings. used as substrates for multilayer deposition in our study. are in-plane microstructures that have been used as spectroseopic elements for over eight decades. Convolution of the diffractive properties of these a wo periodic structures (the grating and the multilayer result in specific design criteria for multilayer diffraction gratings.

During FY8X. the lirst year of our two-year study. We acyuired a McPherson 225 valcuum spectrometer and lested it with a standard 12(0)-line/mm. 1-m-radius, iridiumcoaled blazed grating. We also fabricalted two multilayer gratings. Both a 120() -line $/ \mathrm{mm}$. 1-m-radius holographic graling and a $12(1)$-line $/ \mathrm{mm}$, blazed replica grating were coated with a molyhdenum/ silicon multilaver designed to reflect $15.5-\mathrm{nm}$ light al normal incidence. The holographic grating operated in second pecudoblase order and the hlazed grating in third order at this wavelength. Chatracterizalion of these gratings is still incomplete heciluse of interference from stromg tirst-order dispersed lines excited in the plasmal source used. (irating 
resolutuen is determined from these

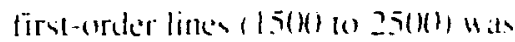
as expected.

In tpril 1988. We ran a preliminary experiment at the G.ANIL adecerator complex in Caen. France, on measure the energy of the $1,2,2,2 P_{1} \rightarrow 1,2,2, \ldots, S_{1}$ transition in helium-like xenom. In this experiment. a hean of helium-

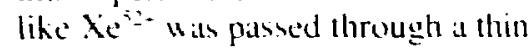
carbon foil placed in front of at normil-incidence spectromeler (xec Figure 21. We observed a weak spectral line at the expected energy $183 .+$ eV 1 . However, since this wals at parasitic experiment. We did nor have line of reprodace our results or explicitly verify the line's spectral order.

This iransition in xenon is analogous to the Lamb-shift $2 x_{12} \rightarrow$ 2p a transition in hydrogenic ions. It occurs all $15.4 \mathrm{~nm}$ (Drake. 1988 ). with quantum electrodynamic (QED) corrections accounting for $8{ }^{6}$ it (6.5 eV) of the total 83.4-eV Iransition energy: Our goal is 10 measure the wavelength of this transition $t 0 \pm 0.15 \mathrm{~nm}$. which requires knowing the angle belween the ion beam and the spectrometer fo only I mrad. The resulting measurement of the Lamb shift will then have a $0.4 \%(0.03-\mathrm{eV})$ uncertainty level. Current Lambshift measurements are at the $10 \%$ uncertainty level and exist only for much lower $Z$ [ 18 for $n=2$ (Gould and Marrus. 198.3) and 36 for $n=1$ (Tavernier $e^{\prime \prime}$ al.. 1985)). At $0.4 \%$ uncertainty, we would be sensitive to additional QED effects (estimated al 0.168 eV i due to the extra electron.

We are currently completing a facility at LLNL to unambiguously measure the absolute reflectivity of

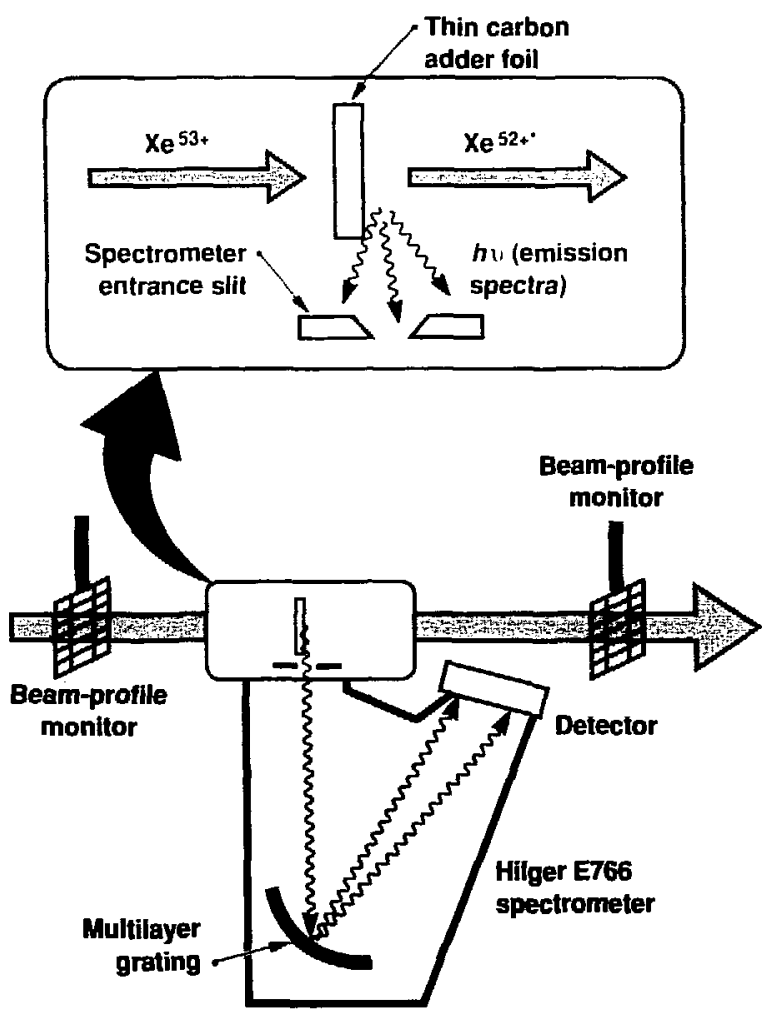

Figure 2.

Schematic of our experiment at the (iANIL. accelerator, showing the normal-incidence spectrometer. adder foil. and ion beam. these gratings in any spectral order. We are also setting up a normalincidence spectrometer in Cave $\mathrm{H}$ at the Lawrence Berkeley Laboratory SuperHILAC. We have requested beamtime on the Michigan State University (MSU) cyclotron. a new accelerator that promises to duplicate the performance of the GANIL one. We expect to perform experiments on xenon at MSU after our initial SuperHILAC experiments on iron. We also expect to run experiments using a heliuni-like uranium beam at the new SIS/ESR accelerator facility in Darmstadt. West Germany. when it hecomes available in late 1989.

\section{Reterences}

Dratke. G. W. F. 119881. "Theoretical Encreices for the $\|=1$ and 2 Stales of the Helium Isoclectronic Seyuence up $10 \angle=1$ (10)." Call. I. Phrs. 66. 586 .

Gould. H., and R. Marrus 14831 . "Lamb Shiti and the Lifetime of the $2 S_{1}$, State of Hydrogenlike Argon $1 Z=18$. Phy. Rev. A 28. 2001 .

Tavernier, M.. J. P. Briand, P. Indelicillo. D. Liesen. and P. Richard (1485). "Measurement of the (1S) L.amb Shifi of Mydrogenlike Kryptun," I. MMa, $B 18$. 1.327 .

Trail. J. A.. R. L.. Byer. and T. W. Barbec. Jr. | |4KX|. "Mealsurememt of Solt X-Ra! Muliblaser Mirror Rellectance at Normal Incidence I sme t.aser Produced Plasmas." lphl $1 \%$ l.ch. 52. 26y 


\section{Monte Carlo Atomic Kinetics Calculations}

Principal Investigators: J. R. Nlbritton, B. (i. Wilson, and T. Thomson

$\mathrm{T}$ he absorption and emission of radiatlion by attomic electrons are imporlant in the calculation of energy transport in platsrolats. Direct evaluation of these contrihutiens is difficult because of the multiplicity of atomic configurations that must be accounted for. The Monte Carlo method is a new alternative 10 exhaustive search schemes and 10 schemes involving a limited or preselected ensemble of atoms (Albritton. 1986). Its principal virtue is its well-known ability to realize solutions, efticiently and without bias. to multivariate problems that are difficult to formulate and solve rigorously.

The Monte Carlo method uses direct numerical simulation of the transitions of an atom in its ambient plasma and radiation field. Starting with a definite initial configuration given by the occupation of all the

We are working on a computer program that employs a Monte Carlo approach to determining the ionization and excitation distribution of the dominant atomic configurations in localthermodynamic-equilibrium (LTE) and non-LTE plasmas.

atom 's quantum levels) and the rates for transitions to all accessible configurations. the code casts random numbers to determine the lifetime of the configuration and 10 choose at transition lo a new configuration. Diagnostic information is recorded. and the "test" atom is advanced to the new contiguration. The test atom randomly but rapidly "walks" from the initial configuration to sample those configurations that are the most probable-those in which it is likely 10 spend the nosit time.

We are now implementing the transition processes of radiative and collisional excitation and deexcitation. ionization and recombination, and Auger and resonant-capture transitions. The large amount of microphysical intormation required, such as the energy levels and matrix elements, is being provided by a relativistic. selfconsistent field midel (Liberman and Albritton. 1984).

\author{
Reterences \\ Albritton. J. R. 1 I4k6). Mlonte Cariu \\ Calculation of Nim-LTE Line Radiation."

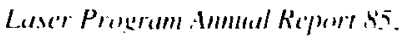 \\ Law rence Liscrmore Nalliomal L aborators. \\ Report LCRL-50)21-85. pp. 2-53. 2-54. \\ Libernaan. D. A.. and J. K. Albritton (14St). \\ -Rapid Calculation of Properties of Plasmal \\ Atoms and lone. "Laver Programe thmad

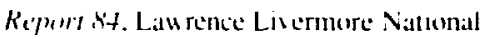

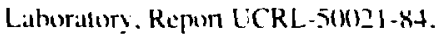 \\ Гр. $3-66-3-68$.
}




\section{Micropole L indulator Insertion Devices}

\author{
Principal Investigator: 1. Toor \\ Co-Insestigaturs: P. ( sonka,* J. Hunter. \\ R. Hornady. K. Tatchın, $\div$ D. Whelan,** \\ and (i. Westenskm

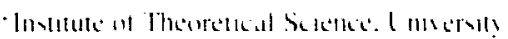 \\ 110 (3)

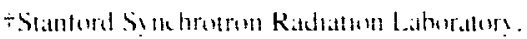

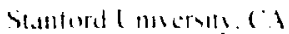 \\ - Hughes Alrcratic cimpams. \\ l.in thecter. 0
}

A recently as lats geatr. the feasibility of scaling undulator insertion devices to submillimeler periods was highly conts iversial and believed by many to be ateipossible. Nevertheless. the theor: $:$ in $^{1}$ benefits of such devices mere a $. \cdots:$ : $\ldots$. Installed on high-energy electron storage rings. such insertion devices would produce monochromatic $x$-raly beams with significantly higher brightness than currently attainable in the laboralory by any other means. We have investigated theoretically the scaling limits for micropole undulator (MPUs) and believe that $100-\mu \mathrm{m}$ period devices with $10^{4}$ periods are achievable. Such devices would provide a new class of highbrightness. monochromatic $x$-ray sources.

Our research this year has focused on the development of two prototype designs for MPUs using two different technologies to address the issues in huilding spatially coherent structures with 1()$^{\perp}$ periods. In the first design. the periodic

We have developed tw'o prototype micropole undulator insertion devices to demonstrate a new class of highbrightness $x$-ray sources. In experiments conducted on the LLNL 150-MeV linear accelerator, we demonstrated the firstever production of photons from submillimeter-period undulators. Installation of either of these devices on the Bates linear accelerator at the Massachusetts Institute of Technology would produce tens of milliwatts of monoenergetic soft $x$ rays, thus providing an $x$-ray source that is competitive with bending magnets installed on high-energy electron storage rings.

magnetic structure is mathined in a single. monolithic block of material: the MPL' is biased with an external magnetic field and cooled with liquid nitrogen. W'e used the LLNL

150-MeV linear accelerator (linac) of measure the intensity and angular distribution of 66-e $\mathrm{V}$ photons radiated by $75-\mathrm{MeV}$ electrons passing through a 7(16- $\mu \mathrm{m}$-period undulator 35 periods long. These experiments were the first to produce pholons from submillimeter-period undulators. The advantage of this type of MPU is that ion-milling of anisotropic materials such as $\mathrm{NdFe}(\mathrm{B})$ or $\mathrm{SmCo}_{-}$can produce very-short-period $(-50)-\mu m)$ devices with lithographic accuracy. thereby simplifying the technical challenge to fabricate MPUs with $10^{4}$ periods. The major disadvantage is the bulk associated with the bias magnets and the active cooling that is required to dissipute the electrical energy needed to produce the hias field.

The second decign is a laminar MPL: for which each "pole" piece is a stack of thin magnetized waters with alternating magnetic polarity. A protolype of this design was assembled from $\mathrm{NdFe}(\mathrm{B})$ wafers with 54 periods of $986 \mu \mathrm{m}$ (i.e.. a total of 216 magnets). In a second series of experiments using the LLNL linac. we generated 7()$-\mathrm{e} V$ photons and charatcterized the radiated photon intensity as a function of photon energy and angle (Figure 1). The advantage of this laminar design is that it does not require a bias field with the attendant cooling apparatus: thus it can be remotely positioned and scanned in valcuum using manipulators with micrometer accuracy. Disadvantages of this design are associated with the handling and characterizing of a large number of separate fragile components whose internal magnetic forces approach the inherent strength of the materials.

The measured performance of both MPU prototypes was in agreement with our theoretical predictions. With both types of MPL's. we found that the frequency. 
intensity. and angular distribution of the photon output were limited by the electron-bean characteristics (e.g. energy. current. emissivity) of the accelerator and by the resolution of our diagnostics.
During this work. We discowered that the field strength of $\mathrm{NdFe}(\mathrm{B})$ decreatses with decreasing thickness below $-1 \mathrm{~mm}$ as a result of surlace effects due either to oxides or to machining. Therefore, $\mathrm{SnCO}_{;}$

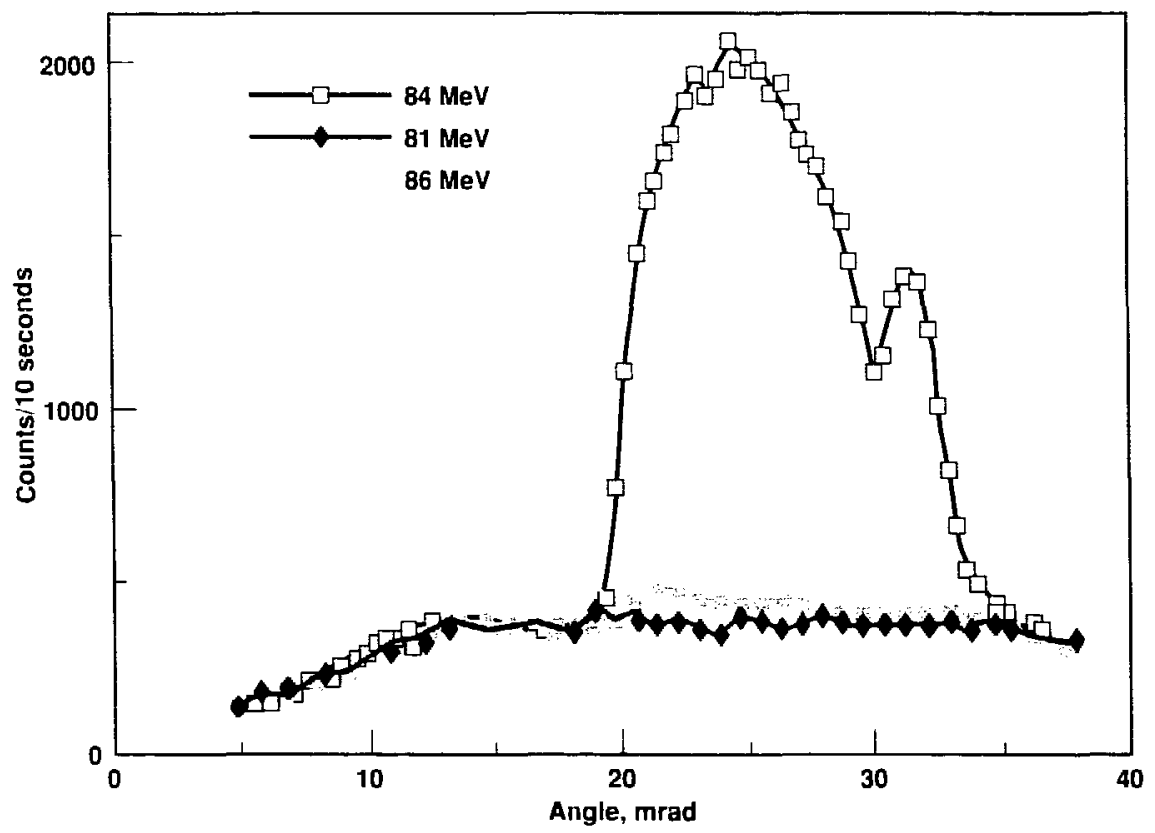

Figure 1. Angular distribution of radiated photons for the $\mathrm{NdFe}(B) 986-\mu \mathrm{m}$ laminar MPL at three electron energies. These data show that a $\pm 3 \%$ change in electron energy moves the radiated photons out of the diagnostic's bandpass, thereby eliminating the possibility that the detected photon origin is due to some other process (bremsstrahlung, or channeling radiation).

(which was demonstrated not to exhibit this property) was used to fabricalte two additional laminar prototypes: a $494-\mu \mathrm{m}$. 120-period MPU. and a 253- $\mu \mathrm{m}$. 248-period MPU, both of which are ready for testing. Theoretical field-strength uniformity and phase criteria coupled with the measured values of field and thickness for each wafer currently limit the number of periods attainable with $25(0-\mu \mathrm{m} \mathrm{SmCo}$ wafers to about 1000 . or four times that of our largest prototype MPU.

The LLNL linac does not have low enough emittance to allow us to adequately test the performance scaling of the 250- $\mu \mathrm{m}$ MPUs. Thus. we must either $u_{4}$ grade the LLNL linac (which is being considered by the Physics Department) or travel to the Bates linac at the Massachusetts Institute of Technology or the Race Track Microtron accelerator at the National Bureau of Standards (which is currently under construction).

Installed on the Bates linac. either of our two prototype MPUs would radiate narrowband, $\sim 10-$ 25-keV $x$ rays at the tens-of-milliwat level. This would provide a highbrightness $x$-ray source facility Ispectral brilliance greater than $10^{14}$ photons/(s-mm $\mathrm{mr} \cdot 1 \%$ bandwidth) I that is competitive with the bending magnets installed on high-energy electron storage rings. 


\section{Pressure Effects in High-Temperature Superconductors}

\author{
Principal Investigator: B. Bonner \\ (o)-Investigators: M. Young, R. Reichlin. \\ F. Ryerson, and $1 ;$. Smith
}

$\mathrm{P}$ ressure-enhanced superconductivity appears to he at general property of high-temperature superconducting (HTSC) materials. This pressure effect. believed to result from an underlying change in structure or in the mechinism that mediates pair formation. has yet to be explained by theory. We are investigating this eflect by comparing experimental observations with theoretical simulations in which the ionic spacings are reduced to model the pressure effect.

We used the diamond-anvil cell to study the optical properties of single crystals of $\mathrm{Y}-\mathrm{Ba}-\mathrm{Cu}-\mathrm{O}$ (supplied by J. Z. Liu. Argonne National Laboratory) at high pressure. When pressure is increased to $22 \mathrm{GPa}$. there is a $3(0)(1 \%$ rise in near-intrared normal-state reflectivity, indicating increased oscillator strength (Figure 1). This suggests that the density or mobility of the free charge carriers increases with pressure. implying more metallic behavior that must be treated theoretically.

Reflectivity data in the midinfrared show a weak spectral feature near $0.4 \mathrm{eV}$ that we attribute to an exciton or to a $\mathrm{Cu}-\mathrm{O}$ charge-transfer excitation that shifts only slightly with pressure to 20 GPa. Additional mid-infrared meilsurements of diffuse
We are probing the nature of high-temperature superconductivity in cuprate oxide ( $\mathrm{Cu}-\mathrm{O})$ materials. By comparing the pressure dependence of the s"perconducting transition to that for related optical and vibrational properties, we should be able to identify aspects of the electronic or phonon structure that are critical to superconductivity. reflectance at atmospheric pressure have clearly demonstraled that such data are useful indicators of annealing history and oxygen content for the Y-Ba-Cu-O system.

Also this year, we applied highpressure synthesis techniques to La-Cu-O (the parent HTSC system), which is not ordinarily a superconductor. By annealing this material in oxygen overpressures of $20-300 \mathrm{MPa}$. we produced a superconductor at $T_{\mathrm{s}}=18 \mathrm{~K}$. Extensive characterization efforts are under way to identify the structural changes associated with this effect.
Nexl year. We will exend our optical meisturements to observations of Raman balckscattering. beginning with normal-state meatsurements for yttrium compounds to $25 \mathrm{GPa}$. Pressure shifts of the vibrational frequencies for oxygen will be compared lo predictions from ab intrin cluster simulations. We will use $x$-ray diffraction to measure changes in cell dimensions with increasing pressure for yttrium- and lanthanum-based superconductors to see if changes in the $\mathrm{Cu}-\mathrm{O}$ plane separation can explain the observed pressure effect.

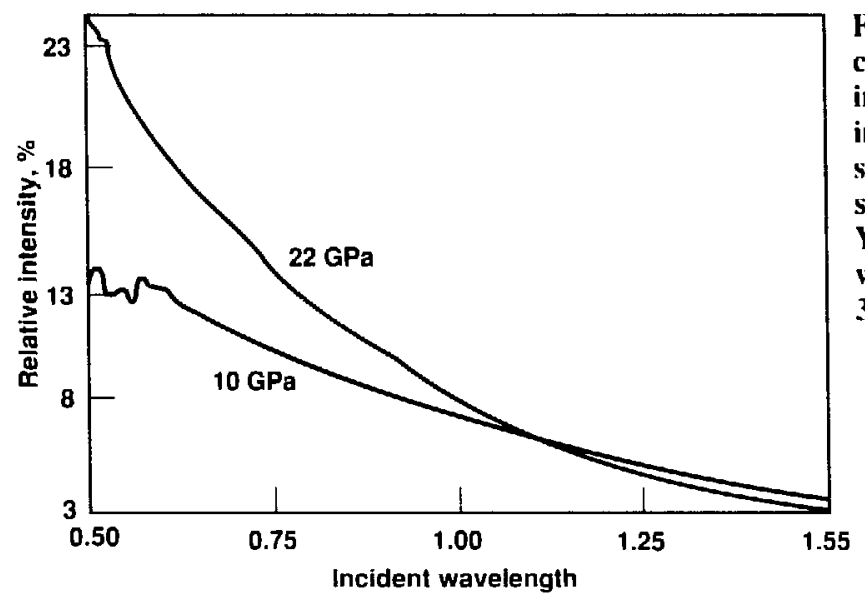

Figure 1. Pressure causes large increases in nearinfrared normalstate reflectivity for superconducting Y-Ba-Cu-(O. Data were collected at $300 \mathrm{~K}$. 


\section{I'sing Geochemical Modeling to Investigate the} Paleoecology of Closed Basin Lakes in the East African Rift During the Plio-Pleistocene

Principal Investigator: k. J. Jackson

W e proposed to use trends in the composition of witler samples collected from closed basin lakes in the East African Rift Valley (Figure 1). logether with observed differences anong the mineral phases precipitated from these lakes, to gain insight into changes in lake water chemistry that occurred during the Plio-Pleistocene. By illustrating

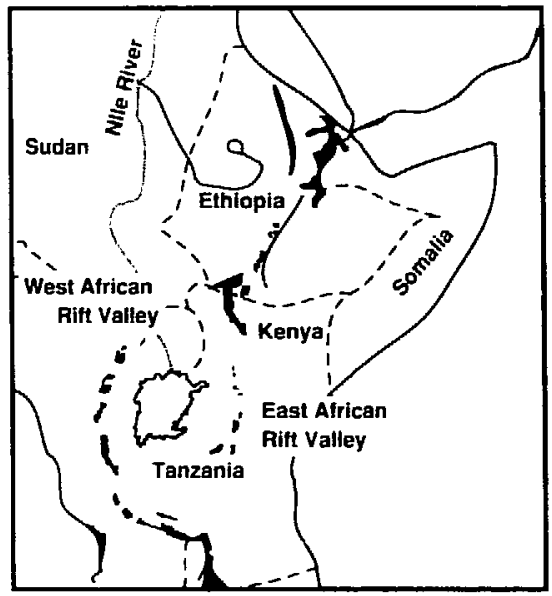

Figure 1. Map showing the location of the East African Rift Valley, the area in which many important earlyhominid remains have been found.

Modern geochemical modeling codes have been advanced to the point that we can evaluate quantitatively the chemical interactions between mineral phases present in sediment samples and the solutions from which they precipitated. Our project was to collect water and sediment samples from the closed-basin lakes in the East African Rift Valley and to use the EQ3/6 code to ascertain the kinds of geologic and climatic events that might have produced the observed mineral phases. The lake water chemistry in the East African Rift Valley is of special interest because this is the area in which many of the most important discoveries of early-hominid remains have been made.

the systematic dependence of chenically precipitated mineral phases on the compositional variations in water chemistry in the modern lakes. we hoped to be able to model how the mineral assemblages present in sedimentary rocks formed during the Pliocene and Pleistocene provide a record of the changes in water chemistry that occurred during those epochs.

Past compositional changes in lake water chemistry in this region are of special interest because of the impact they would have had on the paleoecology of the East African Rift Valley - the area in which many of the most important early-hominid remains have been found. Changes in the chemistry of lake waters in the geologically recent past have apparently been responsible for environmental fluctuations in which a number of lacustrine lakedwelling) species have alternately flourished and died off. Molluse's and fish that might have been important sources of food for early hominids are anong these species.

By coupling recent advances in theoretical geochemistry with corresponding advances in of geochemical modeling codes like EQ3/6. it is now possible to evaluate quantitatively the chemical equilibria between the mineral phases present in lake sediments and the aqueous solutions from which they precipitated. The identity and relative proportions of the various minerals found in Plio-Pleistocene lake sediments would have served as the input constraints for the geochemical modeling codes. From the code calculations. We hoped to be able to ascertain the kinds of geologic and climalic events that might have provided for the observed changes in mineral assemblages al. $d$ variations in lake water chemistry:

In order to carry out this project. a research permit from the government of Kenya was needed. However. no permit was granted in time. and therefore the proposed project coul:I nor be done in FYss. 


\section{Atmospheric Compensation Algorithms for Imaging}

\author{
Principal Investigator: J. P. Fitch \\ Co-Investigators: T. W. Lawrence and \\ I). M. Gioodman
}

We are developing algorithms for imaging astronomical objects and man-made satellites to the diffi sction limit imposed by a collecting telescope instead of that imposed by the atmosphere. Our work will benefit the scientific and defense communities by reducing or eliminating resolution-limiting effects of atmospheric turbulence.
$\mathrm{T}$ he world's largest telescopes, such as the 5-m Hale telescope on Palomar Mountain in southem California. have a theoretical diffraction-limited resolution of about $0.1 \mu$ rad. In practice. however. these instruments are limited by the turbulent atmosphere to a $5 .(0-\mu$ rad resolution. the diffraction limit of at 10-cm telescope. The limitation is suffered by all ground-based telescopes and severely hampers our ability to image distant objects. Recent advances in short-exposure imaging technology and computer postprocessing algorithms could provide a method for imaging astronomical objects and man-made satellites to the diffraction limit imposed by the telescope instead of that imposed by the atmosphere. In addition to the immediate impact on existing telescopes. sparse optical arrays hundreds of meters in diameter could be constructed to image higheraltitude earth-orbiting satellites. The new atmospheric-compensated arrays could potentially revolutionize astronomy.

Our approach is based on a class of nonstandard imaging techniques that have been applied successfully by radio astronomers. The turbulence-induced effects of the atmosphere on the object image can be frozen if the image-exposure time is reduced below the correlation time of refractive index fluctuations 11 io $10 \mathrm{~ms}$. depending on wind velocity. Short-exposure images captured this way are a random superposition of diffraction-limited images of the object. Each short-exposure interference pattern. called a speckle image. is analogous to the speckle seen with coherent laser light.

Procedures for extracting object information from a sequence of speckle images are collectively referred to as speckle interferometry. These techniques have been successfully applied by the astronomical community to image star clusters; however. no algorithms have been demonstrated for imaging extended objects through the atmosphere.

We met the following major objectives this year:

- To conduct a scaled, horizontalpath imaging experiment and to investigate image reconstruction of known objects under realistic atmospheric conditions and illumination levels.

- To conduct a comprehensive numerical simulation of the speckle imaging process and to extend this simulation. backed by experimental validation, to a complete range of imaging scenarios.

- To implement state-of-the-art image reconstruction algorithms used in the astronomical community and to investigate ways to statistically optinize the reconstruction process.
The summer months on Mit. Diablo in northern California altorded excellent access to a range of horizontal path lengths from about 1 to $3.5 \mathrm{~km}$. We used a $0.5-\mathrm{m}$ telescope designed by our group. a low-noise. $512 \times 512$ charge-coupled device (CCD) amay controlled by a MicroVax data-acquisition system. and a white-light illumination target board. Data from an unresolved point reference on the target indicated turbulence levels in the range $D / r_{11}=$ 15 to 25 for a $1.2-\mathrm{km}$ path. where $D / r_{0}$ is the ratio of the telescope diameter to the coherence scale length in the atmosphere. This ratio characterizes the amount of degradation introduced by the fluctuations. such that a value of 15 means that the resolution of the telescope is degraded by a factor of 15 by the atmosphere.

We obtained data with illumination levels simulating signals expected for objects between low earth orbit $(300 \mathrm{~km})$ and high earth orbit $(1000 \mathrm{~km})$. We also obtained data with various bandwidths and exposure times. Analysis of the data is now under way. and we are planning to continue the experiment later next spring to extend the range of imaging conditions.

A complete simulation of the speckle imaging process is now operational. The computer-based atmospheric simulator allows input 
objects to be propagatled through an isoplanatic atmosphere with arhitrary values of $r_{11}$. Ohjects are received by a telescope with a pupil function defined as the superposition of circular apertures varying in size and with arbitrary obscurations. In idition. the simulator includes noise sources resulting from Poissom photon stattistics (arising from the randomness associatled with the quantum nature of light) and nonideal photon detection. The speckle images-wos simulated of a point reference (nd objects used in the experiment compare quite well with experimental datat. In iddition. at reconstructed image from neveral simulated specthe latmes alon compatres well with experimental results, thus addressing the goval of detailed validation. Our future plams for the simulator include a survey of a variety of satellite imaging conditions.

We hatve implemented stateof -the-ant algorithms lor image reconstruction to process both experimental and simulated speckle images. The algorithms are:

- The Labeyric technique for Fourier magnitude estimation.

\section{(a) Recorded image}

(b) Processed image

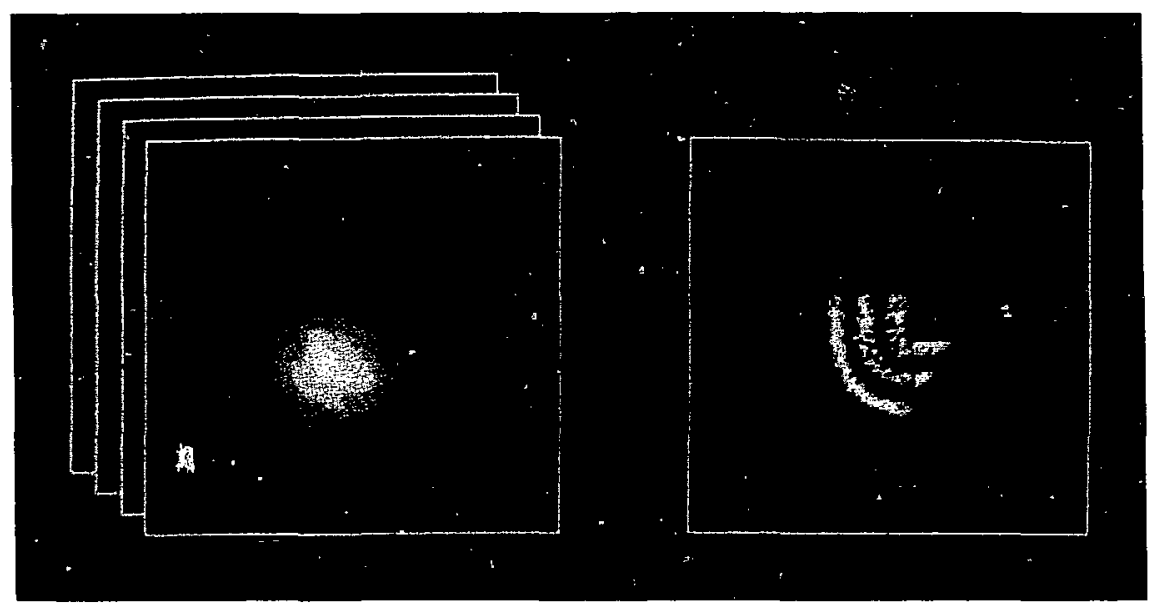

Figure 1. Reconstruction of a test target using speckle interferometry. (a) One of a set of $\mathbf{4 0 0}$ speckle images recorded by our CCD camera mounted on the $0.5-\mathrm{m}$ telescope. The telescope was located at Curry Point in the foothills of Mt. Diablo. The target, a 3-cm cutout of the Laboratory logo illuminated with a high-intensity light bulb, was located on a hill $1.2 \mathrm{~km}$ away. The image, captured with a 5-ns exposure time, shows the degrading effects of the atmosphere. (b) The result of processing the $\mathbf{4 0 0}$ speckle images using the three algorithms described in the text. Comparison with (a) underscores the power of our technique in reconstructing diffraction-limited detail about an object.
- A bispectral criple comelations lechmyut lor fonmes phase cotimbation.

- The Gerchberg-Saxlon-Ficmup fouricr-iteration lechnique for nomlinciar imporition of ohject comstralints.

We hase appliced a combinalion of these lechnicues and a neu algorithm dexeloped at 1.1.NL. L recomstruct exemded objects a ilh holl binary and gras-scale intemsity feallures all illumination lesels of low sarth-orbit sallellites. These are the first reconsiruetions of extended objects degraded by almospleric lurhulence using specike imaging. This work constitules a first-order demonstration that speckle imatging of salellites is indeed feasihle.

Figure I is an exalmple of one of the many ohjects we recoustructed from experimental datat.

Because none of the techniques listed above is optimal in a slatistical sense, we are now allempling io produce an optimization-batsed algorithm for image reconstruction that direcaly imposes positivity and support consiraints on the image. That is. the final image must be positive in value everywhere and occupy a finite region ol space. In addition to statistical appeal, our development of an optimal algorithm is motivaled by preliminary indications that the techniques we have used 10 date do not effectively reconstruct objects with an increased dynamic range of intensity features. Our comtinuing analysis will address this problem in more detail. extending reconstruction performance to include objects illuminated all high earth orbil and eventually al $40.000 \mathrm{~km}$. 


\section{Thermally and lon- Assisted Etching of Tungsten and Molvbdenum}

\author{
Principal Inbestigatur: D. F. Viller \\ (a-Imentigators: W. J. Siekhaus and \\ U. Baloweht

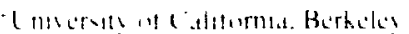

$\mathrm{R}$ drackirs motals arc increasingls unced at intercinnections and gates in neicroclectronic devices and integrated circuits. One reason for their grow ing use is that metals. such as tungsten and molybdenum. have high temperature stahility w ith high conductivit! and amenability to dryetch patterning. Multilayer and superlattice microstructures containing these metals are proving to be vitul components of extremely efficient and novel $x$-ray optics. However. fundamental etching studies of these metals. including those using molecular chlorine. have not previously been done.

Modulated molecular-beam mass spectrometry allows us to determine the elementary steps of the overall heterogeneous etching (or deposition) reaction. The steps include adsorption of a reactant with or without dissociation. surface reaction of adsorbed species. surface or bulk diffusion of intermediate species. and desorption (or deposition) of products. Moreover. modulatedbeam experiments can yield quantitative rate constants for the elementary steps in addition to a mechanistic interpretation of the reaction itself. Our previous investigations with modulated molecular heams determined specific
We are investigating the kinetics of etching tungsten and molybdenum by chlorine alone and with simultaneous argonion bombardment. The reactions are directly related to plasma and ion-beam etching processes needed to form patterned tungsten and molydenum films for future microelectronics and $x$-ray optical microstructures. mechanisms for hydrogen and chlorine reatctions with gillium arsende and silicon. respectivel! (Balorch e' al.. 1986: Olander (t) al. 1987).

Our immediate objectives were to determine the:

- Etching rates of tungsien and molybdenum with temperature. reactant fiux (beam intensity). and reactant degree of dissociation.

- Principal reaction products.

- Kinetics and mechanismis of the werall etching reaction with and without simultaneous ion bombardment.

The goals during the second phase of our research included measuring the effect of oxygen additions, which is a common industrial practice in fluorine-based plasma processing. We also wished to investigate the silicides of tungsten and molybdenum.

In seqential sets of experiments. we achieved the first two objectives listed above for both tungsten and molybdenum. With extensive calculations based on the experimental data. we found satisfactory kinetic models for the thermally assisted etching of both metals without ion assist. The results for tungsten etching by atomic and molecular chlorine are described in detail elsewhere (Bulooch 't al.. 1988a1. Our more recent assessment of data on the molyhdenum reaction with chlorine show ed man! similaritices Io the tungsiten datta: however. we observed a markedly increased influence of adsorbed reactant diffusion in the overall reaction seyuence over the temperature range of $9(1)$ to 1250$) \mathrm{K}$. Our molybdenum experiments included measurements of the chlorine reaction with a modulated argon-ion beam using multixcaling 10 improve data collection compared on techniques for our earlier tungsten work. We have summarized our findings on the kinetics of molybdenum elching by atomic and molecular chlorine (Balooch at al.. $1988 \mathrm{~b})$. and we are now preparing for publication a detailed description of chlorine-molybdenum reaction kinetics.

To summarize our work. we studied etching reactions of tungsten and molybdenum with atomic and molecular chlorine. both with and without simultaneous $4-k V$ argon-ion bombardment. Surface temperatures ranged from 300 to $1500 \mathrm{~K}$ without ion assist. while the simultaneous argon-ion beam was modulated during steady chlorine inpingement with surface temperatures held at $3010 \mathrm{~K}$. Beam intensities lor molecular chlorine were $5 \times 10^{1 *} 10$ $3 \times 10^{1-}$ molecules/ $/ \mathrm{m}^{2} \cdot \mathrm{s}$ : the atomic 
chlorime hedll cllunced fromll a

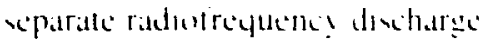
chamber.

The main reaction products up w $10(0) \mathrm{K}$ "were WCl, and MoCl. respectivels. For tungeven and molyhdenum surtidies holler thatl lomk atomuc chlorinc was the dominant speckes. Dissociation of

(a) Ion heam oft

(b) lon beam un

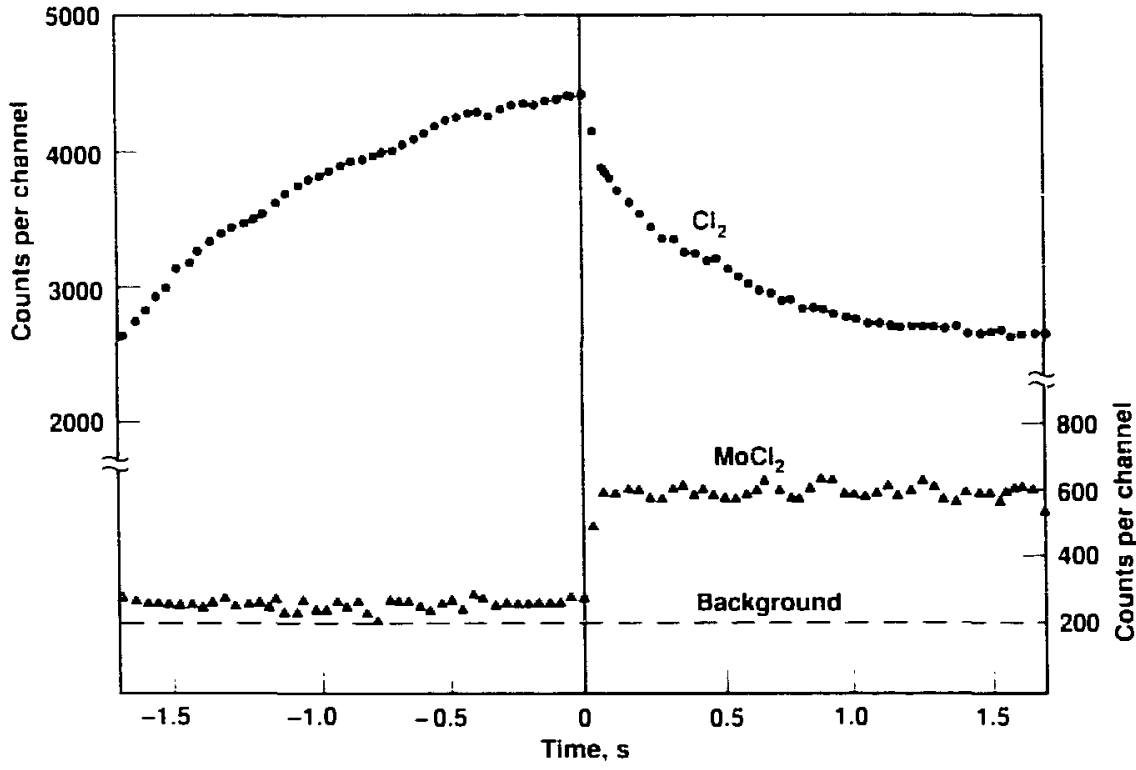

Figure I. Reflected (i.e., unreacted) chlorine (color) and molybdenum dichloride (black) intensities (a) without and (b) with argon-ion assist at room temperature. In this experiment. the argon-ion beam intensity was $10^{14}$ ions $/ \mathrm{cm}^{2} \cdot \mathrm{s}$ using $4.4-\mathrm{kV}$ argon-ion bombardment, and the surface temperature was $300 \mathrm{~K}$. After background subtraction, these data show that simultaneous ion bombardment produces a $10 x$ enhancement of molybdenum etching by chlorine.

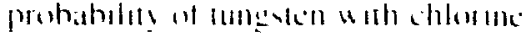
hut wo hats nol vel ohtalmed at retathle yuamlatlic compartsom. For molyhienum on the wher hand. We ohserved an increasc in elching by unc arker of mignifude. as shown in Figure 1

thes goal for fulure rescatch is 10 acquire experimental data on product velacil! distrihutioms. Such data will cmable us in invevellatc mechanisms responsible for the signiticant ionheaml cohancemlent uf chlorinc

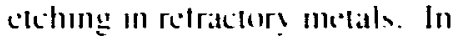
anticipation of stuch experimlents. "le hale designed and purchased a new reation chamber and mass spe:troscopic apparatus that will allow us to whain time-of-ifight mcasurersents on celching producls.

\section{References}

Balomh. MI. D. R. (Mander. and B: I

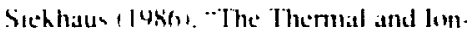

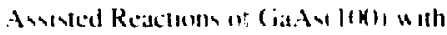

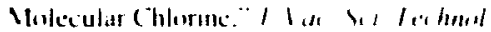
B4. 744

Balukin. Mi.. D. S. imini. U. k. Mander, and il J. Sichhaus ilexkit. "The Kinetic of Tungusen Elching by Alomm and Mrolecular

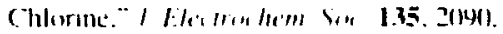

Baburh. V.. D R. ()landes. U J Sichhaus.

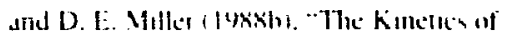
Molybdenum Elcheng hy Alome and

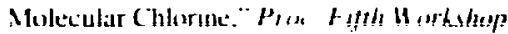

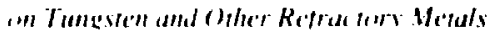

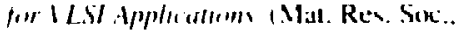
Pilloburgh. PA)

(Mander. D. R.. M. Baleuch. J. Ahrefath. and W. J. Sickham 1 1987,. "Montulated Mollecular-Beam Siudien of the Surtate

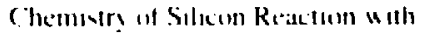

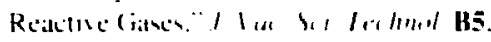
IHIH. 


\section{Miniature lacuum Tubes for Harsh Environments}

Principal Insestigators: II. I. ()rvis. 1 . I.

Ilel inaghs. I). R. ( iarlu, and J. H. tee

$\mathrm{M}$ mature ad aum tubes are $\checkmark$ alcuum-suiching and poucr control desces analogous lo cxistmg vacuum euhes. What makes them unique b! toda! is siandards is that thes are micronicter-sice desices. they are comstructed on it semiconduclur wafer using fabrication techniyues specific for integrated circuits. and thes emplos field emission rather than themionic emission to generate charge cartiers. Compared to existing semiconductors, minialure vacuum ubes should operaic lasies and be much meire lolerant of high temperatures and radiation. Such characteristics make them strong candidates for use in power and control applications in nuclear and high-lemperalture environnents 10.9. in weapon systens, nuclear reactors. fusion reactors. and sitellites).

A millimeter-size thermionic vacuum tube developed at Los Alamos National Laboratory has now been subjected to $10^{-}$neutrons $/ \mathrm{cm}^{2}$ and $2.5 \times 10^{*}$ rad $(\mathrm{Si})$ with no degradation. These levels are IOKK) to 10.000 times larger than the levels that destroy silicon devices. We expect our device to have a similar tolerance to radiation and heat.

In semiconductor devices. the velocit! of an electron is ahout $100^{-} \mathrm{cm} / \mathrm{s}$. Electrons saturale hecause they are moving through a solid. and collisions with atoms in that solid resirict the velocit!. Because the

\section{We are establishing the modeling and technology necessary to build and analyze miniature, integrated vacuum tubes for use in electronic devices operating in hazardous environments.}

celocits in saturated. increasing the applied whtage will not upeed up the derke. In a sileum deriec. on the other hand. charge-carrier transport recurs in a licuum. where the clectron relocill saturates at the peed of lightol $13 \times 10^{101}(\mathrm{~cm} / \mathrm{n})$. which is considerabls faster that the velocity in silicon. While the velocity of an electron is important in delermining a device's speed. the device s capacitance is also important and must be kept low for high-speed operation. A device's capacitance can be controlled by design considerations rather than by considerations of electron physics. as is the case for electron velocity. With these considerations in mind. we expect that miniature vacuum tubes can operate 10 (1) I(K) times faster than conventional silicon devices.

During FY8X. we designed and built two variations of a proof-ofprinciple device to integrate the necessary fabrication methods and to determine the operating characteristics. Our first vacuum tube is an encapsulated. fieldemission vacuum triode: our second is a field-emission vacuum diode with an anode-to-cathode spalcing of $2 \mu \mathrm{m}$.

The vacuum triode consists of a silicon wafer on which is etched a ny ramid-shaped silicon tield emiller. The field emuller is huried in phosphorus-doped silicon dioside glass. (On lop of the glass is a laver of poly silicon with a hole formung the grid. I okatting thin grid later accurated required that we develop new alignment methods to emsure that the hole was precisely centered wer the field emilter. The structure w then buried once aguain in glass and another laver of polysilicon to form the anode. At this slep of fahrication. we have a structure that is filled with glass rather than a vacuum. We then etch away the glass from under the anode and grid. leaving a miniature vacuum tube (see Figure 1). The use of the glass sacriticial layer to

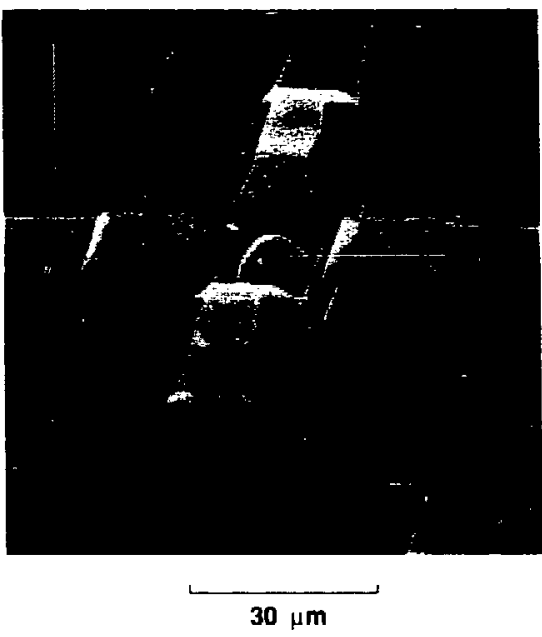

Figurc 1. Encapsulated field-emission vacuum triode. Such devices should prove to be faster than conventional semiconductors and more lolerant of high temperatures and radiation. The novel fabrication procedures are described in the tent. 


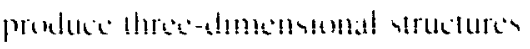

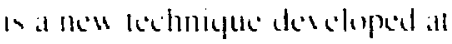
LC Berkeles. Becaluse the kedhmigue is new and themetore not well chatriderised. "we mus delermine defomition and elch ralles experimlentall!

()ur acomid derice is bated on the valcum triole: homerer it omits the gritd and the second layer al glass 10 produce a vateum dionle. $W_{i}$ developed the diode so that we could hegin lesting ficld emitter before we completed fabrication of the valeum iricile. He recenty perturmed a labricallun run of satium diader and

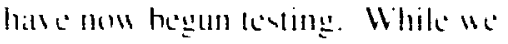
hat measured curreme in our diodes that coruld the des lo licld emissiom. ue have noll yel werifical that fact.

()ur mokting effort is focused (m) examining ficld enhancement neat the tip of the ficld emitter and on simulatting device operation. The medeling has been productive in that WE were able lo idemity secreral problems helore a device was atclually labricalted. We will simulatc device operation to verify the existence of ficld emission and to predict device outpul charaleteristics. Such modeling efforts will also give

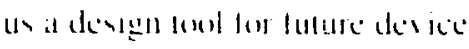
chancincering

We halve prexented more detatiled ersions of rur work in lun papers all the First Inlermaliomal Valcumm Micruelectronice Conlerincis in Williansburg. VA. Ven !catr. Wt will continuc lo develop the design of miniature vacuum tuhes and attempt o demomstrate both thermal and radiation hardesess. At the completion of our project. WL expect (1) have the capability to design and fabricalle miniature valcumm switching and comtrol devices and to predict their operational characleristics. 


\section{Development of an Induction Linac Cyclotron} Autoresonance Maser

\author{
Principal Investigatur: M. Caplan \\ Co-Investigators: J. K. Boyd. A. Salop.* \\ R. R. Stone. and $C$. Thorington $\div$ \\ - iso Crechnde Dr. Palu Alu. (C) 94:36.

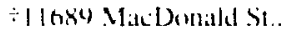 \\ culser cils. (A) y)zil).
}

$\mathrm{T}$ he only operational eyclotron autoresonance maser ( $C A R M$ ) is in the Soviet Lnion (Botvinnik ct al.. 1982). where output powers of $10 \mathrm{MW}$ all $125 \mathrm{GHz}$. with $3($ )-ns. 0.5-MeV heam pulses at $1 \mathrm{kA}$ have been achieved. Efficiency was only $2 \%$. however. due to poor beam quality and lack of magnetic tapering. We believe that greal improvements in performance cain be made by using the high-brightness beams and tapering techniques that proved so successful in the LLNL microwave free-electron laser (FEL). With improved effiency. the CARM could become an alternative microwave source for heating fusion plasmas. During FY88. our efforts were directed toward developing new computational techniques for analyzing the beamline and interaction circuit of a CARM and a conceptual design for a CARM amplitier. We also conducted a performance-cost analysis for the proposed CARM as compared to the FEL.

To improye our ability to analy/e the CARM beamline. we developed and brought on line a variable-mesh electron-gun devign program ICRMGi $N$ ibased on tarlicr

We are investigating the design of a CARM (cyclotron autoresonance maser) amplifier that can generate gigawatt peak power levels at millimeter wavelengths by using an induction linear accelerator injector as the beam source. This device may supplement or provide an alternative to the microwave free-electron laser for heating fusion plasmas.

versions with no self-magnetic field (Caplan and Thorington. 1981). With CRMGLIN. we cin analyze beam dynamics, including self-consistent radial and axial space-charge forces. within the large variation of scale lengths occurring as the beam is compressed from a 12.7-cm calhode at $1+\mathrm{G}$ to a $(0.5-\mathrm{cm}$ diameter it $22.8 \mathrm{kG}$.

We also developed a quasi-threedimensional beam-dynamics code (WIGCRM) from an earlier version with no self-magnetic fields (Nezilson (') al. 1985). WIGCRM uses fiastFourier transforms to solve Poisson?s equation al every axial position. This code is useful for modeling nonsymmetric transverse spacecharge forces in the beam as it corkscrews from the helical wiggler to the interaction region: it can also be used to model the emiltance growth in the drift region. In addition. we developed a threedimensional CARM interaction code (CARMRP). based on earlier gyrotron TWT codes (Sulop and

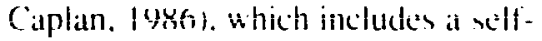
tapering algorithm adapted from a lecholique used in FEL cosles for monitoring a trapped resonant particle.
Another objective for FYsk was to develop a conceptual design for a CARM amplifier based on typical beamlines that now exist or will exist at LLNL's Accelerator Research Center (ARC). The design is also compatible with an existing superconducting magnet at the Massalchusetts institute of Technology. We developed a first set of blueprint drawings showing all internal dimensions of a beam-pipe transmission system. circuit. and beam dump. We also deternined the positions and settings that will be required for the 34 magnets $t o$ focus the beam into the high-ficld region without wall interception. Figure $l$ is a schematic drawing of the CARM amplifier. indicating key design parameters: Table I gives the amplifier's predicted performance.

In conducting a performance-cost trade-olf study for the proposed CARM as compared to the FEL at $280 \mathrm{CiHz}$. we found that for a total average power above $5 \mathrm{MW}$. a number of CARMs operating at $2 \mathrm{MeV}$ and $2 \mathrm{kA}$ would be more expensive than a single lll-MeV FEL. However. below $5 \mathrm{MW}$. (ARM become relatively much lew expemsice becalluse uigegler 
constraints prevent the FEL. Irom operating at lower voltages for lower power. CARMs could also become competitive at higher power labove $5 \mathrm{MW}$ / it they could operale at higher current. However. we do not know at present whether CARMs could maintain high efficiency in the presence of the increalsed beam emittance resulting from increased space charge.

This project will continue into FY89. Our main objective next year will be to design a proof-ol-principle experiment. which could be performed in the ARC. That experiment will most likely test a CARM oscillator using Bragg resonators. The CARM circuit and accompanying drift sections will be fabricated and cold-tested. We will also continue work on designing magnet coil configurations that minimize beam emittance.
Refierentes

Bum munik, 1.. H.. V. 1. Bramman, 1. B Volkor, (i. (i. Denmon. B. D. Kall chugn.

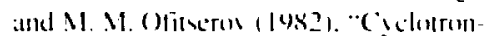
Autoresomance Masce with a Warclengeth of

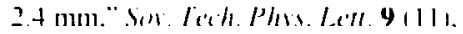
into-517.

Caplan. M.. and (C. Thormengon (145)1. "Impresed Compuler Midelling al Magnetic Injection Guns lor Giyrotrons." ImI. I Elemmin. $511+1 .+15 .+26$.

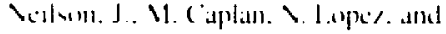
k. Ickla 1 /

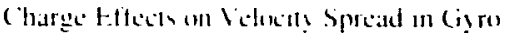

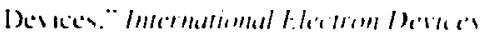

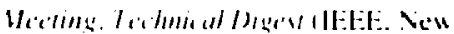
Yiorh. VYi. 184-187.

Salop. A.. and M. Caplan I lexhi. "Siltcomsisemt Ficld Large Signat Analsom of

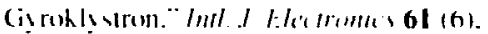
$10015-102+$.

\section{Table 1. Predicted performance for the 280-GHz CARM amplifier.}

Parameter

Peak output power, GW

Average power, $\mathrm{MW}$

Tapered efíciency, \%

Gain, dB

Transverse velocity spread, \%

Axial velocity spread, \%

\section{Predicted value}

2

2

50

60

5-10

$0.2-0.4$

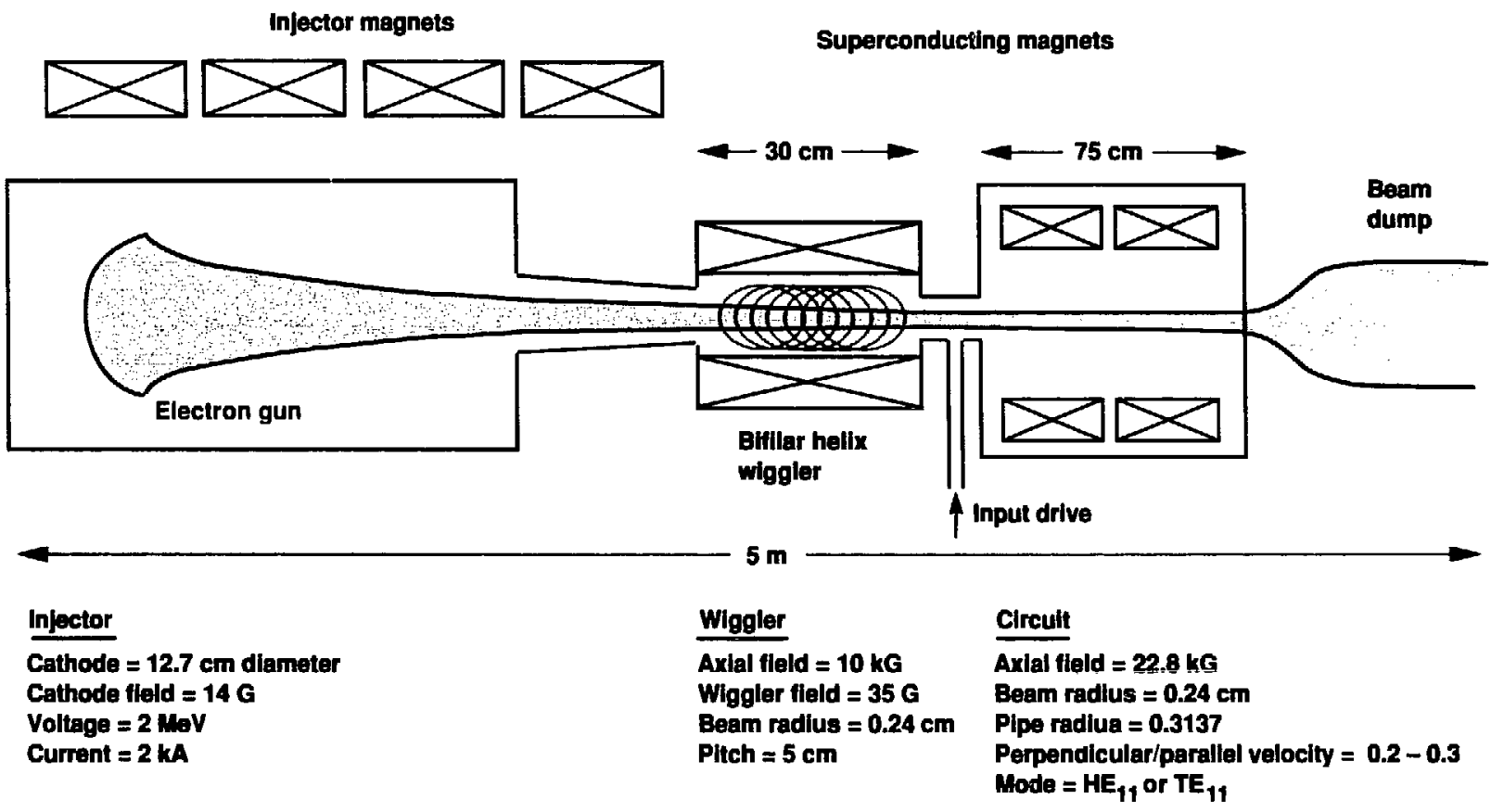

Figure 1. Schematic diagram of a $28($ - 1 ;Hz CAKM amplifier. Key design parameters are listed below the corresponding section of the amplifier. 


\section{Generation of High Electrical Potentials in Plasma for Application to the Mirrortron}

\author{
Principal Investigator: R. F. Post \\ (o-Investigators: S. Douglass.* \\ T. Weisgraber $\div$ and S. Fallabella \\ - Lniverste af (alifiorma. Dands. \\ $\div($ nucrom of Culifomia. Sian Diegon.
}

$T$ he Mirrortron concept is based on our substantial understanding of the mirror confinement of plasmas gained from years of research al LLNL and other laboratories. Mirror theory predicts that if a mirrorconfined plasma containing multi$\mathrm{MeV}$ electrons and low-temperature ions is subjected to a rapidly rising and spatially localized. pulsed magnetic field (a pulsed, local mirror). then a local region of high (megavolt) positive potential will be generated. Repetition of this process down a linear array of mirror cells synchronized with the passage of a bunched ion beam would result in a kind of plasma linac (linear accelerator). What distinguishes the Mirrortron from conventional ion linacs is the much higher acceleration gradients that we should be able to achieve. In addition, the Mirrortron is distinct from other accelerator ideas that are based on plasma spacecharge fields because of the precise spatial control and focusing character of the electric fields that should be achievable. Such control arises because the spatial distribution of accelerating electric fields is determined by the spatial distribution of the pulsed mirror tield. the

\author{
We have assembled experimental apparatus and performed \\ theoretical analyses in preparation for a proof of principle \\ of the Mirrortron, a new concept for a high-energy ion \\ accelerator.
}

characteristics of which should be precisely controllable from outside the plasma.

Because the plasma density required to produce megavolt potentials in a plasma is relatively low. several methods for creating the hoi electron plasma needed in the Mirrortron are available. Previous methods include cyclotron-resonant microwave heating and slow magnetic compression. The most demanding technological requirement of the Mirrortron is, therefore. generation of the fast-pulse mirrors. Fortunately, major advances have occurred in this area associated with the development of high-power switching techniques for use in induction linacs (such as the Advanced Test Accelerator) and for other purposes.

The objective of our experiment during Phase $I$ is to generate and characterize a low-density. hotelectron plasma created in a $150-\mathrm{cm}$ long cylindrical resonator located within a de magnetic field of the mirror type. We will use continuouswave microwave power at two frequencies. 2.4 and $4.0 \mathrm{GHz}$, to excite electric-field modes in the caivity resonator and to create and heat the plasma to temperatures on the order of $250 \mathrm{keV}$. During
Phase II. we will apply a pulsed mirror field ( -3()$-n s$ risetime) to the plasma and measure the transient potential using a probing electron beam shot down the central axis of the plasma.

We have assembled and conducted preliminary tests on all necessary equipment for Phase $I$. including the diagnostic apparatus needed to measure plasma characteristics. We have completed the design, fabrication. and testing of a prototype pulser for implementation of Phase II. Our pulser uses Blumlein transmission lines and is fabricated from copper foil and Mylar film; the switching action is performed by mechanical penetration of a sharp metallic point through a replaceable element. This pulser more than met our required specifications, exhibiting pulse risetimes on the order of 2 ns. We have also made progress in terms of theory. We have developed a computer code that traces the trajectory (position and velocity) of an electron or ion beam down the magnetic axis through the spacecharge field. This code is useful for both the diagnostic portion of Phase Il and for predictions of acceleration in the Mirrortron. 


\section{Microcalorimeters for X-Ray Spectroscopy}

\author{
P'rincipal Insestigatur: F.. Silver \\ Co-Insestigators: S. Labov, F. Coulding.* ${ }^{*}$ \\ Y. Madden.* I. I. andis,* J. Beeman.* \\ E. Haller.* and .J. Rutledge \\ "Lamrence Berheles Ladoraturs. \\ Berkeles. ( il

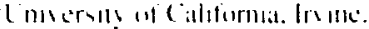

$\mathrm{C}$ ryogenic calorimeters offer high resolving power and sensilivity. Detection of dark matter in the universe and high-resolution stellar $x$-ray spectroscopy are notable examples of their application. We began an experimental effort two years ago to develop resistive microcalorimeters for studying the $x$-ray emission from laboratory and astrophysical plasmas.

In principle. an $x$-rity calorimeter may be any material that exhibits a perceptible temperature increase after it absorbs a single photon. For the temperalure rise to be mealsurably large. the material must possess a small heal capacity. This can be achieved below $1.0 \mathrm{~K}$ in crystals with small dimensions. since the volume heal capacity of an ideal crystal drops with the third power of temperature.

Using well-developed infrared bolometric techniques as the foundation for our work. we have consiructed prototype calorimeter/ spectrometer refrigeration systems to operate al 1.4 and $0.3 \mathrm{~K}$. We have fisbricated and studied the properties of hoth monolithic and composite calorimeters.

In monolithic devicess at single material functions as both x-ray athourber and thermometer. To datle. we have fabricalled and lested watere

We are developing new $x$-ray spectrometers that lake advantage of the small heat capacity of their materials at cryogenic temperature to measure the temperature rise associated with the absorption of a single $x$-ray photon. When operated between 0.1 and $0.3 \mathrm{~K}$, these microcalorimeters will offer the broad bandwidth capability of photoelectric detectors, nearly $100 \%$ efficiency between I and $10 \mathrm{keV}$, and the high resolving power of Bragg-crystal $x$-ray spectrometers.

of single-crystal gemanium, which have been doped via neutron-induced transmutation. The dopant level defines a well-characterized variation hetween the sample resistance and temperalure.

An $x$-ray spectrum obtained with a $0.1 \times 0.1 \times 0.01-\mathrm{cm}$ monolithic germanium sample is shown in Figure lat. The calorimeter was cooled to $0.3 \mathrm{~K}$ and irradiated by a radicactive source of americium-241. which produces neptunium $L x$ rays. and fluorescent copper $x$ rays from the backing in the source container. The source also contains some iron-55. The 32()$-\mathrm{eV}$ resolution is within $20 \%$ of that predicted for this device and these operating conditions. Further improvements in resolution will require a reduction in heat capacity. achieved by changing either the materials or the size of the device or by lowering the device temperature.

A spectrum obtained with a much smaller germaniun sample (0).(1)25 $\times 0.011 \times 0.01 \mathrm{~cm})$ is shown in Figure $1 \mathrm{~h}$. This spectrum shows the manganese $K \alpha$ and $K \beta$ emission lines nealr $6 \mathrm{keV}$. which are produced by a source of iron-5.5. The resolution of $80 \mathrm{eV}$ is $40 \%$ hetler than the best resolution achievable with a lithiumdrifted silicon detector (Sitver al al. 198xil.
We are also developing composite microualorimeters. in which the $x$-ray absorber and thermometer are two distinct materials. In our composite design. a thın-fïm germanium-gold alloy thermometer is evaporated onto a sapphire substrate. The excellent thermal contatc between the evaporated thin film and the sapphire should make the thermalization time of this device $5(1)-10()$ times faster than conventional composite calorimeters used for infrared astronomy. Furthermore. the heat capacity of this device is dominated by the sapphire absorber rather than by the thermistor as in conventional composite designs. We have successfully measured the heat capacity and the time response of a composite calorimeter at $1.0 \mathrm{~K}$. Our measured heat capacity agrees with previous measurements of sapphire to within $10 \%$.

We have also worked on adiabatic demagnetization refrigerators for use in the laboratory and eventually in space. $A$ temperature of <0.155 K has been atchieved, and the hold time at $0.1 \mathrm{~K}$ is more thatn 12 hours. To athieve a resolving power of $1(0)(0)$ at an operating temperature of (1.1 K requires a lemperallure slahility of 
Is ph. He hate hegun wark an developing a mictuprocesser-hased servo-control ysem that will adgust the supercomducting matenet current. and thereby the emperalure, of the calorineter to the desired precision. A low-resolution probotype of this comtroller hats hecon lested. and al stabilit! of \pm 2()$\mu \mathrm{K}$ has already heen achieved. We are contident that the new control ysem will provide the required lemperature stability.

Finall! we have yarted an investigation of an inmovatice concept that takes ad anladge of the lemperature dependence of the dielectric constant in ferroclectric materials. A diclectric calorimeter operated with a charge-sensitive preamplifier would have many potential advantages over traditional

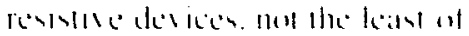
which is the reductorn of Johusen morse. This usuld make the energ! resolution tor phoson-coumting spectrencens limited only to the phomon noise. This would also increase the semsitivity orer a hroader frequeney range than is possible with resistive devices. opening the $w$ at for development of delectors that can handle higher count rates.

We hatve fabricalced a diclectriccilorinker promit-at-principle device from strontium-litanale glass ceramic and have operated it all $1.4 \mathrm{~K}$ (Siller et al. 1984). We obtatined at pulse response from the calorimeter h! irradiating it with at short hurst of infrared radiation. This responste demonstrattes that calorimetry with dielectrics is indeed possible. We

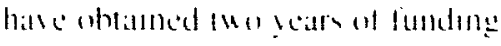
from the Xitumal Acromalulles atld Space Admmistration, Imonates Rescalrch Pregram lo comtinus: development of this device.

\section{References}

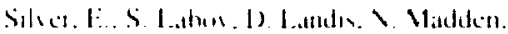

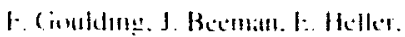

1. Rutledgec, (i. Bermwton. and I'. Imunte

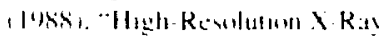

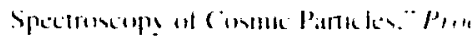

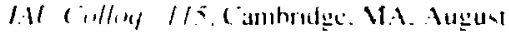
2ב 25 וn prom

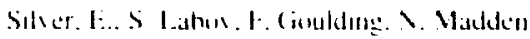

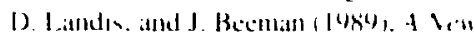

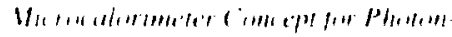

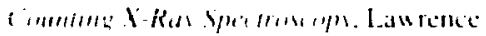
l.s combre Vallomal l.atheratury. Preprom f ('RT.-20Y4h: al'ctepted for publication in bel Imarum Mrdh (a)

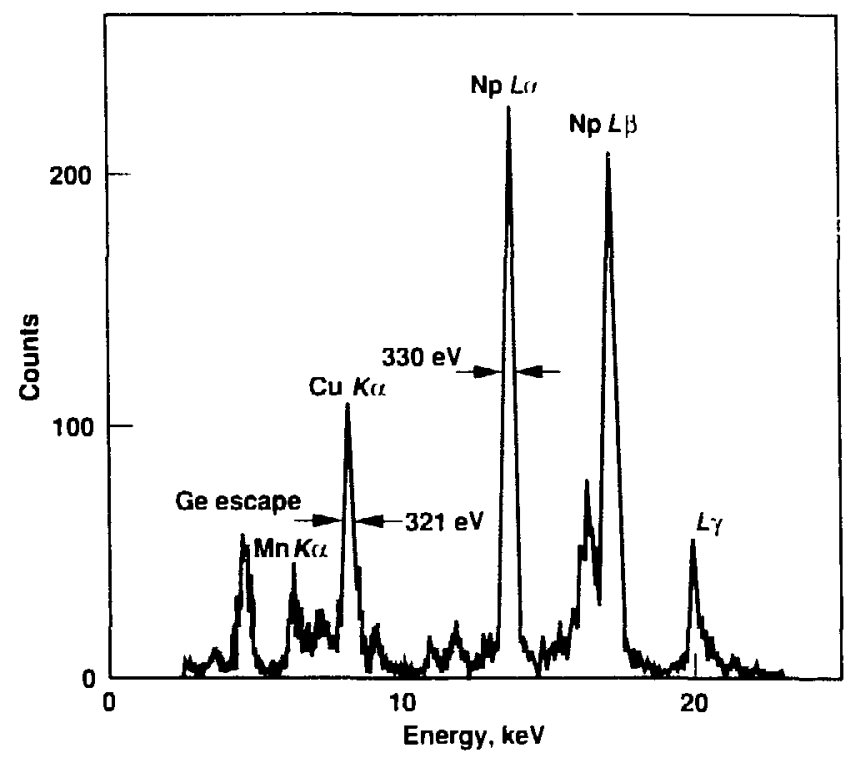

(b)

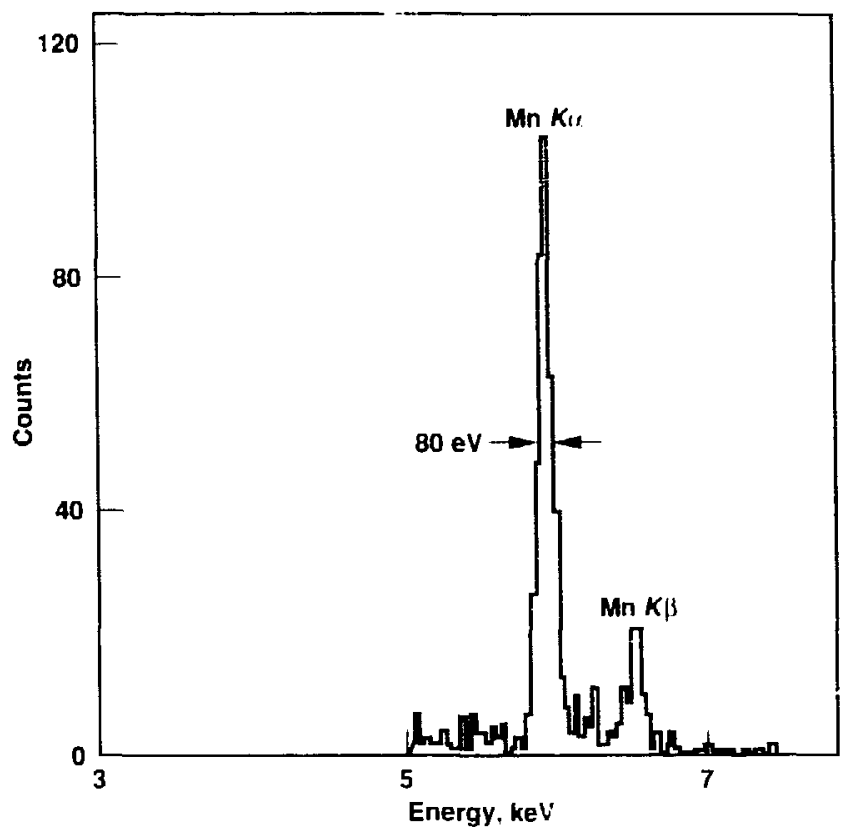

Figure 1. X-ray spectra measured with two monolithic germanium microcalorimeters at $0.3 \mathrm{~K}$. (a) The larger des ice (crystal dimensions are $0.1 \times 0.1 \times 0.01 \mathrm{~cm})$; the resolution of this device is within $20 \%$ of that predicted for these operating conditions. (b) The smaller device (crystal dimensions are $1.0125 \times(0.01 \times 0.01 \mathrm{~cm})$ : the resolution of this device is $40 \%$ better than that achievable with a lithium-drifted silicon detector. 


\section{Chaos in Amplified Spontaneous Emission}

\author{
Principal Investigator: J. C. Garrison \\ (io-Investigators: H. Nathel and \\ R. Y. Chiao*

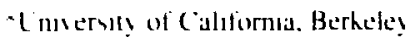

\begin{abstract}
A
\end{abstract} mplified spontaneous emission (ASE) is the basis for x-ray laser action and occurs naturally in other laser media. Dyes are convenient for ASE experiments. and they are particularly useful for the study of chaos, i.c.. the apparently randon changes in the polarization or intensity of ASE radiation. Chaotic behavior in ASE is interesting in itself and has practical implications for laser physics.

Dye molecules are polar in that they have definite orientations in space: therefore. the response of a medium depends on the polarization of ASE light. To include this effect. we have augmented our previous theory (Garrison ef al.. 1988) with a generalized Debye model in which collisions cause the molecularorientation unit vector to diffuse on the unit sphere at a rate inferred from experiments on induced molecular polarization (Nathel. 1986). For our dyes, the orientational diffusion rate is comparable to the stimulated emission rate and to the inverse of the light transit time across an experimental sample. Under these circumstances, chaotic behavior can be expected in the polarization of the ASE field.

As a first step. we are working on the relatively simple problem of an

\section{We have developed a vector theory of electromagnetic polarization dynamics in media consisting of polar molecules. Numerical simulations to locate the parameter range in which polarization chaos can occur are under way. Our experimental searches will use streak-camera polarimetry that has been demonstrated in the laboratory.}

external signal injected into a dye medium in which an inverted molecular population has been produced by laser pumping. We wrote a numerical simulation program tor this case and are now searching for parameter values leading to chaos.

We set up a streak camera with 100-ps resolution for time-resolved polarimetry, and we obtained a master dye oscillator for use in future injection experiments. Figure 1 shows a schematic of our initial ASE experiment. Pump radiation was linearly polarized either transversely (perpendicular to the propagation axis of the ASE beam) or longitudinally (parallel to the ASF. axis). In preliminary experiments.

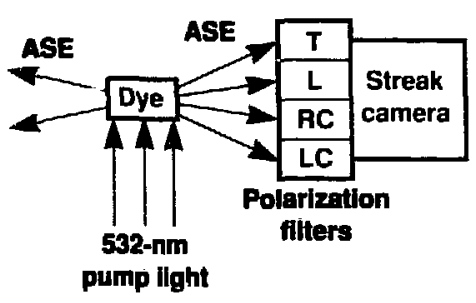

Figure 1. Experimental setup for timeresolved polarimetry. The polarization filters transmit transverse (T). longitudinal (L), right circular (RC). and left circular (LC) polarizations. we found that transverse pump polarization produced ASE linearly polarized in the same direction. However, for longitudinal pump polarization. there was no preferred ASE polarization direction. and the ASE was unpolarized within the time resolution of the streak camera. This result suggests a form of chaos in which the polarization of the ASE beam wanders rapidly over the Poincaré sphere. This effect might show up as rapid intensity switchings between the fields of the streak camera image. corresponding to different states of polarization. Another possibility would be intemittency. i.s.. periods of fixed polarization interrupted by interludes of rapid wandering. Neither switching nor intermittency were seen for the limited range of parameters in this experiment. We will next apply our technique in injection seeding experiments with the master dye oscillator.

\section{References}

Garrison, J. C.. H. Nuthel, and R. Y. Chian (I988). "Quantum Theory of Amplified Spontaneous Emission: Scaling Pruperties." I. (Ipt. Si4. Amor. B5. 1528.

Nathel. H. (1')86). Da'velopment amd Application of a lligh-Pondered Brostly

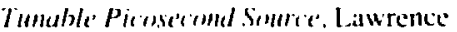
Berkeley Lahorators. Berkeley. CA. Report 211446 


\title{
Algorithms for the Lamb Shift in High- $Z$ Hydrogen- and Helium-Like Ions
}

\author{
Principal Investigator: Y. I. Sn!derman
}

$\mathrm{T}$ he experimental meatsurement of the Limb shift in atomic hydrogen (the - 10 "-eV' splitting of the $2 s_{1}$ and $2 r$, levels that are degenerate in relativistic yuantum mechanics) stimulated the development of quantum electrodynamics (QED). For hydrogen-like uranium. on which experiments will he done in the near future. the Lamb shift is expected to be $\sim 100 \mathrm{eV}$. Since $Z \alpha$ the nuclear charge times and fine-structure constant) for uranium is no longer the small parameter for perturbative expansion that it is for hydrogen. new calculational methods are required. Because of the magnitude of QED radiative corrections to the inner shells of high- $Z$ atons, they are no longer small corrections but are necessary for an accurate understanding of the atomic structure of highly stripped ions.

Our objectives were twofold: to explore ways to simplify the calculation of the electron radiative self-energy in high- $Z$ hydrogen-like ions, and to begin to understand how to incorporate this self-energy into multielectron atomic structure by studying it in helium-like ions.

For the hydrogen-like selfenergy. we reformulated the
We have reformulated the calculation of the electron radiative self-energy in high-Z hydrogen-like ions. We also developed a quantum electrodynamics approximation scheme that systematically incorporates radiative corrections into the structure of high-Z helium-like ions. calculation in two waty and obtained renormalised algorithms appropriate for computer implementition. In our first algorithm. the best features of the two existing methods for calculating $K$-shell self-energy were synthesized. (Only one of these methods could obtain the $L$-shell result.) However, this algorithm still shares with the previous methods the numerical difficulty of obtaining the answer as a small difference of two large numbers. It requires two raddial integrations. a partial wave summation, and a photon-frequency integration. In our second algorithm. the subtraction is eliminated at the expense of two additional radial integrations. These new algorithms may be able to calculate $M$-shell self-energy.

Since the self-energy calculation is most sensitive to distances of the order of the electron Compton wavelength $(\mathrm{lc}=h / \mathrm{mc})$ from the nucleus. penetration by additional bound electrons within this distance (the Bohr radius is $\lambda / Z \alpha$ ) screens the nuclear charge and thus modifies the hydrogenic result. For helium-like ions. this screening. as well as the energy levels in general. cin be calculated by QED perturbation theory in the background nuclear Coulomb field. We have derived renormalized formulas appropriate for computer implementation for all Feynman grapho of order $\alpha^{2}:$ these formulas account for electron correlations and screening corrections to the Lamb shift. In principle. their evaluation will give the energy levels of helium-like uranium $10 \sim(1) .1$ eV $\left.(1 \text { parl in } 10)^{\mathrm{n}}\right)$ il detalled nuclear-structure corrections can be shown to be small enough. The helium-like system offers a conceptually clean foundation on which to build an accurate understanding of high- $Z$ ions with few electrons.

\section{Referencess}

Brown. G. E.. J. S. Langer. and (i. W: Schatefer (1959). "Lamb Shift of a Tighly Bound Electron." Pror. Ron. Sort. Limdorn. Sit. A 251. 105.

Mohr. P. J. 114741, "Self-Energy Ridialive Corrections in Hydrugen-Lihe Systems." Ann. Phys. (N.Y., 88. 20.

Mohr. P. J. (1082), "Self-Energy of the " = ? Slates in a Sirong Coulumb Field." Plins. Rer. A 26. 23.38.

Mohr. P. J. (14X.i). “Quantum Elecirodynamics of High- $/$ Feu Elecoron Aloms." Pho Rer +32. 1444

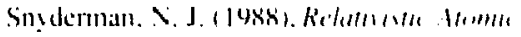

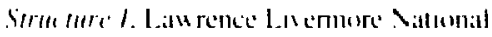
L.aburatury. Repert t ( 11$)-21577$.

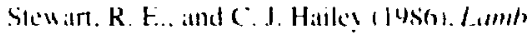

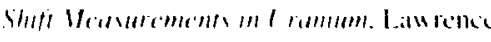

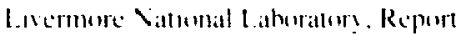

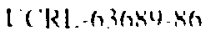




\section{Density Fluctuations in the Big Bang and the Dark Matter Problem}

Principal Investigators: (i. Fuller. (C. Neecti. and (i. J, Mathews

$\mathrm{A}$ central yuestion in modern astrophesices is the dark matler problem: if the universe is closed las mont astrophysicists believer. then up to yey of the malss of the universe is in unseen "dark" matter. It has been thought that this matter cannot be ordinary baryons (e.g.. neutrons. protons. and other heary nuclear particless because. if it were. the process of primordial nucleosynthesis in a standard. homogeneous. Big Bang would seriously underproduce deuterium.

We are investigating (Aleisck ct al. 1987: Fuller e't al.. I488) an alternative 10 the standard Big Bang model. Our $₫$ nas focused on (1) the produciun of density 17uctuations in the primordial yuarkhadron transition. (2) the subsequent evolution of these fluctuations. including their effects on primordiai nucleosynthesis. and (3) a reconciliation between the abundances of the light elements predicted in a universe closed by baryons and their observed abundances in the galaxy.

When the universe is at a temperature greater than $T \approx$ I() $\mathrm{MeV}$. it consises of a plasmat of uncortined yuarks. gluoms. and mher

We have investigated the production of density fluctuations in the early universe from a phase transition between unconfined quark-gluon plasma and a gas of bound hadrons. Our calculations show that the universe may be closed by ordinary baryons, a result that differs from the standard model of the Big Bang which requires massive neutrinos or other exotic, weakly interacting particles for closure.

light partictes ( $T$ is the phase coexistence temperature). Present theoretical andyses point to a weak first-order phase transition from the unconfined plasma to a confined gas of hadrons (protons. neutrons, pions. hyperons. etc.). Since the solubility of the baryon number is higher in the quark phatse than in the hadron phase. the small net baryon number in the universe tends to be concentrated in lumps that correspond to the shrinking bubbles of yuark-gluon plasma. We have done detailed baryon-number transport calculations for this epoch to ascertain the spalial distributions and shapes of the tluetuations lefi over after the yuarkgluon bubbles have shrunk away and the entire universe has been converled to bound hadrons.

As the universe expands and cools after the yuark-hadron transition. the lluctuations lend 10 be preserved until the temperature falls below the weak-interaction decoupling temperature $T_{n \mathrm{~L}}=1 \mathrm{MeV}$. Subsequently. the neutrons begin to diffuse out of the fluctuations. so that hy the whe the temperature has fallen low enough for nucleosymthesis (o) begin ( $T_{\text {nu }}=0.1 \mathrm{MeV}$ ). the universe consists of dense proton-rich regions and tenuous neutron-rich regions.
Our efforts to model the process of nucleosynthesis are complicated by the fact that as neutrons are used up in nuclear reatctions in the highdensity regions. neutrons diffuse back in from the low-densily are: Furthermore, this neutron-diffusion time seale is comparable to the nucleosynthesis time scale. We lind that for an appreciable range of the parameteis ihat characterize the fluctuati is, our models viald D. ' $\mathrm{He}$. and ${ }^{\mathrm{H}} \mathrm{He}$ abundances that are in agreement with observations, even if the universe is closed by baryons. However. "Li seems to be overproduced relative to the standard Big Bang by a factor of sil.

The Li overproduction is potentially a problem for this model. We plan to study the $\mathrm{Li}$ abundance evolution in the galaxy to see whether current observations could be compatible with a high primordial Li abundance.

\section{Referel res}

Alcreh. (. R.. (i. M. Fullor. and (i. J.

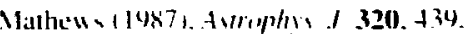
Fuller. G. M.. (i. J. Mathews. and C. R.

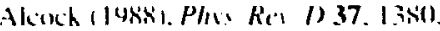




\section{Multiphoton Ionization of Atoms in Strong Fields}

Principal Investigators: M. D. Perry.

A. Szöke. and (). L. Landen

$\mathrm{T}$ he goal of our research is to understand the response of an atom to an applied field with al strength comparable to that of the atomic Coulomb tield. Such an applied field is too strong to be considered a weak perturbation on the atomic svistem. Our work in FY88 continues earlier studies on the multiphoton ionization of atoms subjected to strong laser fields.

Multiphoton ionization of an atom by an intense laser field is the process by which the atom is ionized by absorbing two or more photons from the laser field, each single photon having an energy that is insufficient to ionize. The process may be purely nonresonant or it may be enhanced by an intermediate resonance. At low laser intensities $\left(<10^{12} \mathrm{~W} / \mathrm{cm}^{2}\right)$, both nonresonant and resonantly enhanced multiphoton ionization are well described by perturbation theory. As the strength of the applied field increases, several phenomena emerge that cannot be explained within the framework of lowest-order perturbation theory. Examples include the well-known phenomenon of tunneling ionization and the more recently observed above-threshold ionization, defined as that occurring when an atom absorbs more photons than the minimum required for ionization.

Our initial work on nonresonant multiphoton ionization (Perry et al. 1988b) shows that the tunneling ionization theory of Keldysh. Faisal. and Reiss predicts reasonably

\section{We are investigating the role of bound-state resonances in the multiphoton and above-threshold ionization of atoms in strong laser fields.}

accurate values of the ionization probability of neutral atoms at a given laser intensity. We extended this theory to account for distortion of the outgoing electron by the Coulomb field of the residual ion and found remarkable agreement between the theoretical and experimental results with no adjustable parameters (Perry et al.. 1988c).

Exploiting the tunability of our short-pulse. dye-latser system. we investigated the influence of intermediate resonances on the multiphoton ionization probability (Landen e't al.. 1987). We observed significant resonant enhancement in the multiphoton ionization of krypton near the $4 c l^{\prime}$ and $5 d$ manifolds at intensities approaching $10^{14} \mathrm{~W} / \mathrm{cm}^{2}$ (Figure 1). Using a two-level-pluscontinuum model of the krypton atom. we were able to deduce the three-photon excitation rate to members of the $4 d^{\prime}$ and $5 d$ manifolds. We were also able to determine the photoionization cross sections and ac Stark shifts of these states (Landen et al.. 1987; Perry and Landen, 1988).

In FY88, we began measuring the energy distribution of the electrons emitted during multiphoron ionization in addition to the ion charge states produced. This work extended our ability to make quantitative measurements of atomic parameters because the energy with which the photoelectron is detected is a direct measurement of the laser intensity at which it is produced (Perry el al., 1988a). This phenomenon is a result of the
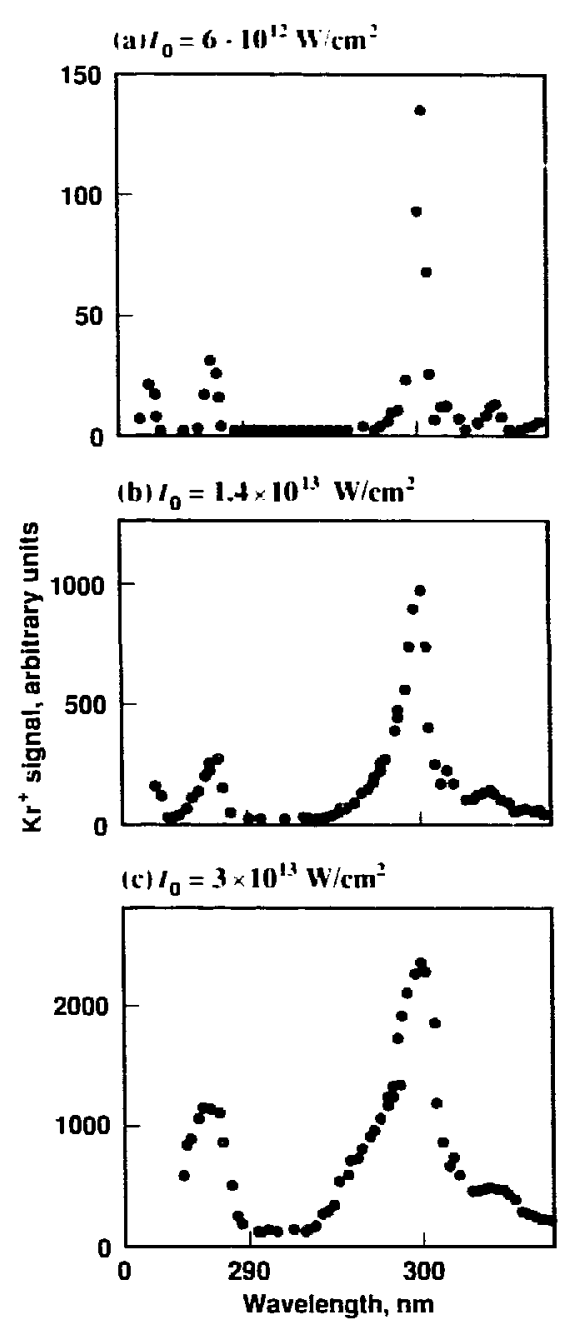

Figure 1. Relative yield of singly charged krypton ions as a function of laser wavelength at various peak intensities. Vertical lines mark the fieid-îree positions of dipole-allowed. three-photon resonances in neutral krypton. 
(a) Resonance positions

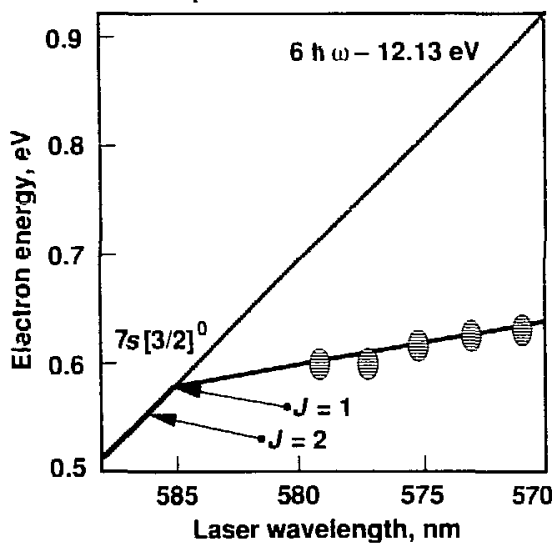

(b) Observed spectrum

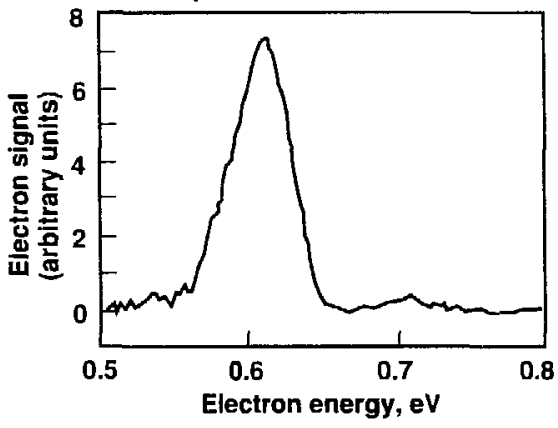

Figure 2. (a) The observed position of the resonances originating in the $7 s[3 ;<]^{0}$ levels of xenon. The nearly horizontal line corresponds to an ac Stark shift equal to that of a free electron. The Stark shift is in good agreement with the observed shift of the resonance position. (b) One of the observed spectra. ponderomolive polential present at the laser focus, which alters the ionization potential of the alom according to

$I P(I) \sim I P(0)+U_{p}(I)$,

where $I P(0)$ is the ionization potential of the atom in the absence of the field and $U_{\mathrm{p}}(I)=9.33 \times 10^{-14}$ $I\left(\mathrm{~W} / \mathrm{cm}^{2}\right) \lambda^{2}(\mu \mathrm{m})$ is the intensitydependent ponderomotive potential in electron volts (Szöke, 1985).

The shift in the ionization potential of the atom from its fieldfree value can be observed only by using lasers that have a pulse width significantly shorter than the time required for the eleciton to leave the laser focus. For the vast majority of experiments, the pulse width would have to be in the picosecond or subpicosecond range. The shifts were easily observable with our short-pulse, dye-laser system. By tuning the frequency of the laser near-allowed five- and six-photon resonances, we obtained a direct measurement of the shifts of the intermediate levels as a function of laser intensity (Szöke et al., 1988). Figure 2 shows the results of our measurements.

This area of research continues to expand as experimental capabilities improve and higher laser intensities become available. One recent, important advance was the nonperturbative production of extremely high harmonics of the incident laser light with surprisingly high conversion efficiency. By using a tunable laser to generate such harmonics in pulsed gas jets, one might obtain an efficient, compact source of tunable extreme-ultraviolet radiation with a source brightness equal to that of a synchrotron. A study of this phenomenon and further investigation of resonantly enhanced multiphoton ionization using exiremely high-resolution photoelectron spectroscopy constitute our work in this field for the next year.

\section{References}

Landen, O. L.. M. D. Perry, and E. M. Canipbell (1987), Phys. Ret. Lett., 59. 2558.

Perry, M. D.. and O. L. Landen (1988), Phys. Re'v. A, 38, 2815.

Perry, M. D., O. L. Landen, and A. Szöke (1988a), Lawrence Livermore National Laboralory. Report UCRL-98960.

Perry. M. D., O. L. Landen. A. Szöke. and E. M. Campbe'l (1988b), Phys. Ra' A, A, 37, 747.

Perry, M. D., A. Szöke, O. L. Landen, and E. M. Caripbetl (1988c), Phys. Rev. Letl., 60. 1270.

Szöke, A. (1985). J. Physs. B. 18. L427.

Szöke, A., O. L. Landen. and M. D. Perry (1988). Lawrence Livermore Nationai Laboratory. Preprint UCRL-99422. 


\section{Atomic Physics Studies at the LBL ECRIS}

\author{
Principal Investigator: P. (). Egan \\ Co-Investigators: S. Chantrenne and \\ M. H. Prior* \\ *Lawrence Berheley Lahoratory. \\ Berticley. CA.
}

$\mathrm{E}$ lectron-impact excitation of multiply charged ions is an important process in many of the high-temperature plasmas studied at LLNL, such as those in laser and astrophysics work. However, there are virtually no experimental data on excitation cross sections for ions more than singly or doubly ionized. This lack forces us to rely on theoretical calc'slations for cross sections. For instance, the inclusion of complex. indirect processes (recombination-excitationautoionization) for a simple system such as lithium-like oxygen $\left(\mathrm{O}^{5+}\right)$ is predicted to change the cross sections for dipole forbidden processes by a factor of four near threshold. yel this effect has never been verified experimentally.

We have built a low-energy, atomic physics beamline at the Lawrence Berkeley Laboratory (LBL) ECRIS so that we can measure electron-impact excitations in multicharged ions (see Figure 1).

The cross sections will be measurcd with a merged-beam, electronenergy-loss spectrometer (EELS) that we have also built as part of this project.

The ECRIS is a relatively new development in ion-source technology that produces high currents $(1-10 \mu \mathrm{A})$ of highly stripped ions. The source itself is essentially a magnetic mirror plasma that is heated

We are measuring cross sections for electron-impact excitation in multiply charged ions with an electron-energy-loss spectrometer. The spectrometer, along with a connecting atomic physics beamline, has been built at the Lawrence Berkeley Laboratory electron cyclotron resonance ion source (ECRIS).

solely by microwaves at the electron cyclotron resonance frequency. Originally developed as an injector for nuclear physics experiments at the cyclotron, ECRIS has become a useful tool for atomic physics with our addition of a low-energy (10-keV) beamline that runs parasitically on the cyclotron.

With EELS (Figure 2), we can measure the electrons that lose energy after excitation and hence determine the cross sections not only for optically allowed but also for optically forbidden transitions. EELS uses trochoidal analyzers (crossed electric and magnetic fields) to merge an electron beam with the ion beam from ECRIS and then to demerge the electrons and analyze their energy. The long merged-beam interaction region and the use of a position-sensitive detector increase the sensitivity of EELS over more conventional techniques used for singly ionized systems. Also, EELS detects all electrons that interact, rather than just a small fraction of fluorescent photons, increasing the counting efficiency and broadening the number of excitations that can be observed by allowing us to look at states that do not have a dipoleallowed transition back to the ground state.

EELS was installed at ECRIS in the spring of 1988; it can be seen in the foreground of Figure 1. Initial beam tests with multiply charged ions have shown that the currents and beam-spot sizes are as expected; for example, we can produce several microamperes of $\mathrm{O}^{5+}$ in a $2-\mathrm{mm}$ diam, 20-cm-long interaction region. The ion beam has been successfully merged in this region with a $100-\mathrm{cV}$ electron beam.

The major challenge that faces the project now is to separate the signal of energy-loss electrons, which is expected to be about several hundred counts per second, from extraneous background counts in the detector that arise from other processes producing low-energy electrons. For example, even in the spectrometer's ultrahigh vacuum $\left(\sim 4 \times 10^{-8} \mathrm{~Pa}\right)$, the electron and ion beams interact with the background gas to ionize it, giving a low-energy electron signal that can mask the true signal. Or, a poorly tuned ion beam can scrape on an aperture, again producing unwanted low-energy electrons.

Our present experimental effort at LBL is directed toward finding the beam operating conditions that minimize such background effects. In addition, we are studying other ways to improve the experiment's signal-to-noise ratio. One approach is to redesign the trochoidal analyzers to avoid beam aberrations and add more pumping capacity to reduce the residual-gas problem. 


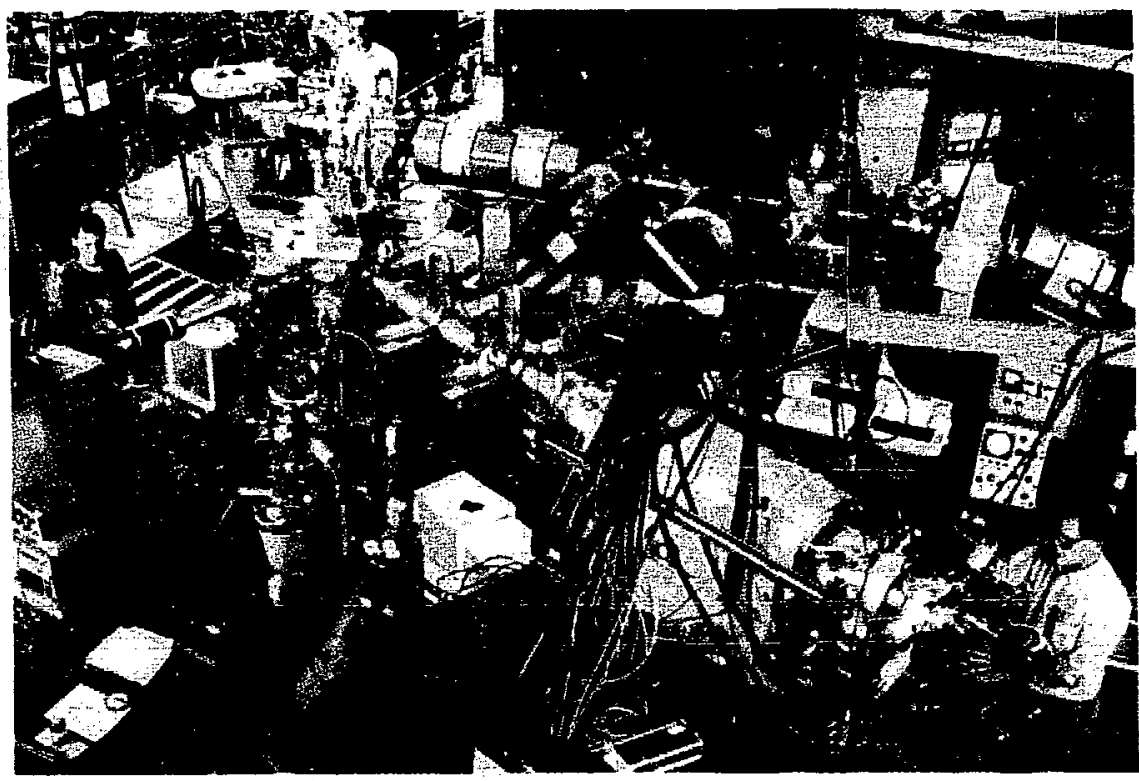

Figure 1. Atomic physics area at ECRIS. The source is in the upper left corner of the photograph; the atomic physics beamline and EELS are in the for eground.

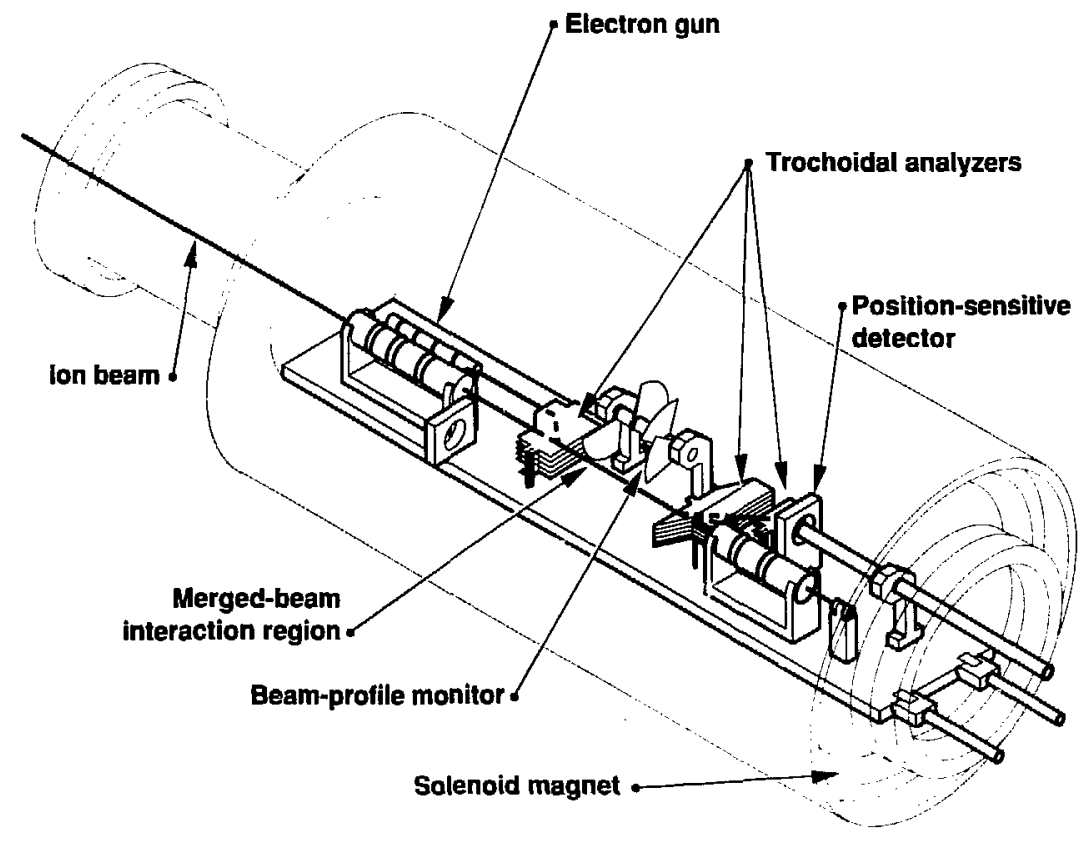

Figure 2. Electron-energy-loss spectrometer (FELS). An electron beam from the eleciron gun merges with an ion beam from ECRIS at the first trochoidal analyzer. A second analyzer extracts the electrons, and the position-sensitive detector measures those electrons that have lost energy by exciting ions in the merged-beam interaction region.
An importam corollar! a the experiment is lo model the cratel

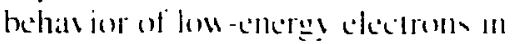
complex electric and magnetic ficlds. We have developed a net of computer codes that allows us to solve the problem of merging the ino heams without imparting unwanted transverse energy to the electron heam. These codes are also used to model the expected low-energ! electron trajectories in the analyzer plates and the resulting signal on the detector.

Our initial plans were to measure the cross section for $n=2 \rightarrow n=3$ excitation in lithium-like oxygen and then to continue to explore the lithium-like sequence at higher $Z$. Since these cross sections are rather small, typically $10^{-1 x} \mathrm{~cm}^{2}$. it will be difficult to study the systematics or parameters of the experiment with the present background-noise level. Instead, we now intend to concentrate on the $D n=0$ transitions in the $\mathrm{O}^{5+}$ system. where the cross sections are closer to $10^{-16} \mathrm{~cm}^{2}$; this will improve the signal-to-noise ratio and allow us to better understand the systematics.

\section{Reference}

Clark. D. J.. (') al. (1989). "The Atomic Physics Facility at the LBL ECR Source." Nuct. Instrum. Math. (in pressi). 


\section{X-Ray Spectroscopy of Highly Ionized Atoms}

Principal Investigators: D. Dietrich and J. Silver* Co-Investigators: 1. Simionovici. W. Hallett." J. M. I.aming.* and S. I,ea*

- Clarendon latorators. Mforall masersls. En:aland.

B I hombarding a monatomic gas with a very highly charged. fastion beam. one can produce slou. electronically excited. highly charged ions in sufficient quantities to allow very precise $x$-ray spectroscopy. We take advantage of the directed nature of these recoil ions to obtain spectra of hydrogen-like and helium-like argnn ions with very high resolution.

Such ions are produced in collisions with impact parameters of the order of the "radius" of the Is electron orbit. The angular deviation from scattering perpendicular to the incident ion beam is very small: for example, in an $\mathrm{Ar}^{1 \mathrm{tot}}$ recoil-ion source produced by bombarding argon gas with 2-GeV U ${ }^{71+}$ ions, it is a mere I mrad. This produces Doppler shifts of only $0.1 \mathrm{ppm}$, some three orders of magnitude smaller than with perpendicular viewing, so that the Doppler widths are characteristic of the temperature of the gas from which the ions were formed.

Several experiments using this technique were performed at Oxford's 10-MV tandem accelerator (Laming and Silver, 1987) and recently at the Lawrence Berkeley Laboratory's SuperHILAC. A stripped beam of gold or xenon at 8.6-MeV/amu was directed into a I-m-long argon-gas target maintained at 1 Torr. A slit at the end of the target formed the entrance to a Johann $x$-ray spectrometer. The spectrum was normalized to the charge collected from the ion beam.

We used axial observation of a recoil-ion source to produce $x$-ray spectra of highly charged ions with the best resolution achieved to date.

Figure I shous two a-ral spectra taken with different entrance-slit widths (and theretore different resolutionsi for the $1 x^{\prime} \cdot S_{11}-1 \times 2 p$ : $P$ transitions in helium-like argon. The spectrum taken at a low resolution of $\sim 20(0)$ (a) has the characteristic appearance seen in earlier work. By reducing the width of the entrance slit. we obtained higher resolution. The best resolution achieved was $\sim 5000$ for the $1 s^{1} S_{11}-1 s_{2} P^{1} P_{1}$ transition of helium-like $\mathrm{Ar}^{1 \mathrm{th}^{1}}$ (b). which exceeds that obtained by Deslattes et al. (1984), the bestresolved published spectrum of this ion. Unfortunately. the statistical quality of our spectra is not as good: as resolution improves, our spectra break into a number of lines which we believe are satellites to heliumlike transitions arising from ions of lower charge. One reason for this could be the different excitation of the spectra. In Deslatles at al .. vers highly charged uranium ions were used to generate the recoil ions. We were unable to use the SuperHILAC " intense uranium beam. which would have given a higher yield of helium-like argon and a lower yield of satellites.

We conclude, therefore. that our new technique gives the besi resolution achieved to date in the $x$-ray spectroscopy of highly charged ions. However, further work with incident beams of uranium ions is required if we are to properly compare this technique with other work or to apply it to accurate measurement in the ions studied.

\section{References}

Deslattes. R. D.. H. F. Beyer. and F. Folkmann (1984). J. Phyx. B17. L689. Laming. J. M. and J. D. Silver (1987). Phys. Lefr. A 123. 395. (a) 500- $\mu \mathrm{m}$ slit

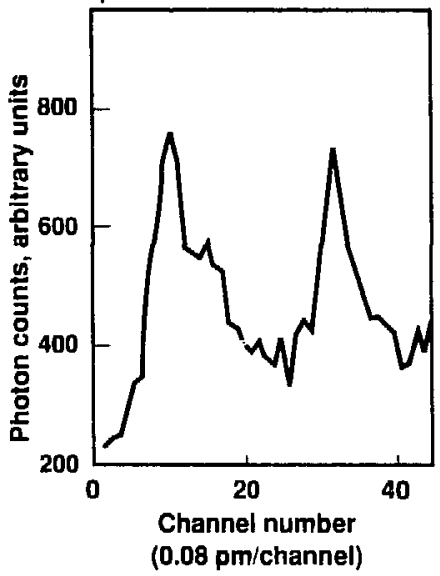

(b) 200- $\mu \mathrm{m}$ slit

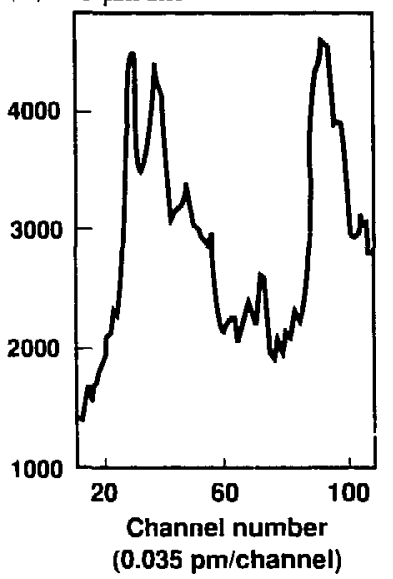

Figure 1. Two $x$-ray spectra for $1 s^{21} S_{0}-1 s 2 p^{1-3} P$ transitions in helium-like argon. (a) A 500- $\mu \mathrm{m}$ entrance slit yields a resolution of 2000. (b) A 200- $\mu \mathrm{m}$ entrance slit produces a resolution of 5000 ; note the increased detail in peak features. 


\section{Multiple-( )bject Spectrograph for Astronomical Observations}

Principal Investigator: ( . J. Hailey ('u-Investigators: .J. I'. Brodie," and

R. F. Stewart

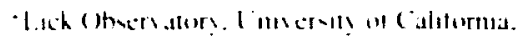

Samis Crus
An instrument is being developed for use on the 120-in. telescope at Lick Observatory that will permit simultaneous acquisition and observation of up to 100 object spectra over a 1-deg field of view. The resulting increase in telescope efficiency will allow us to conduct research that would otherwise be impossible using conventional instruments. simultaneously. telescope efficienty sould be draniatically increased.

We are building a multiple-object specirograph (MOS) to observe separately many individual objects in the telescope ' 1 -deg tield of view.

Up to IOH oplical fibers can be individually positioned to collect light from objects if interest. The input end of each tiber is placed at the focal plane of the telescope: the output end mates with the input slit of a spectrograph. which is coupled to an image intensifier.

The quality of the spectrographic results depends greally on the
Figure 1.

Diagram of the apparatus for positioning and holding the optical-fiber ends (a). Up to 100 fibers can be pusitioned and focused to collect spectra. Lateral sliders ( $x$ motion) hold a cross slide (y motion) between them. A robot gripper ( $z$ motion) lifts and emplaces the fiber "button" (b) on the focal plate of the MOS. A magnet in the base of the button holds it securely on the focal plate. (a) Positioning and holding apparatus

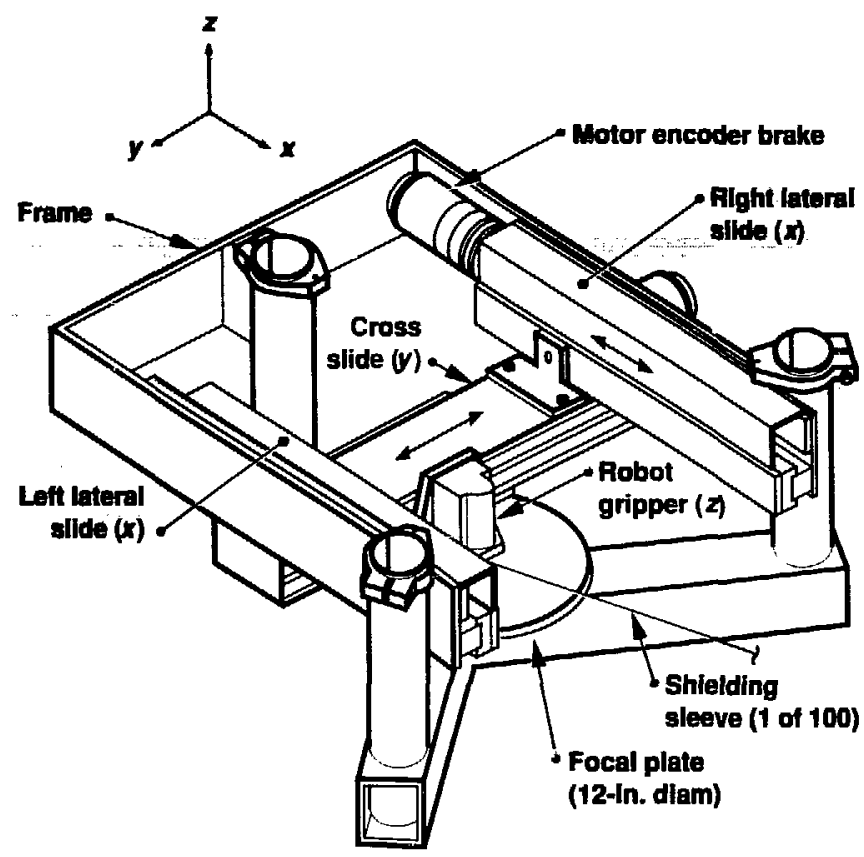

(b) Fiber-end "button"

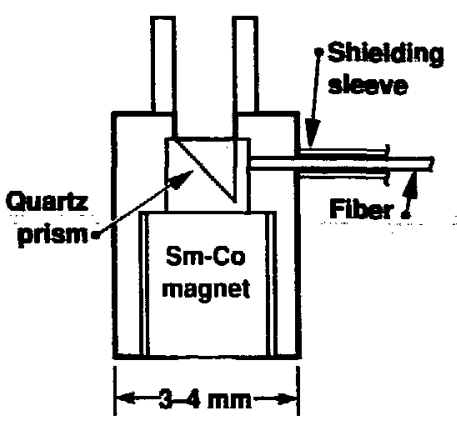


precingen with uhich the fiber end cian te pornted at the object whe observed. Each liber end mus be positioned with an adcurat! of greater than $111 \mu \mathrm{m}$ in order (o) properly collect the light of the object of interest. We have huilt a positioning and holding wistem that is accurate wo better than $10 \mu \mathrm{m}$ in any orientation. This apparalus (Figure lal uses a robot gripper for three-dimensional positioning of the liber ends: each fïber end is mounted in a "button" (Figure lb).
The leght collected hy ciath upteal tiber w delected h! a upecorograph. which is coupled w an image intemsifier. We have huilt and conducted preliminary kests on a large-area optical image intensitier with good yuantum efficiency. The large-format detector is essential for simultaneously recording the spectra of many objects in real time.

Additional research has heen done to develop lechniques for accuratcl! positioning and mounting the prisin and film in the "button." This is essential to ensure maximum efficiency in the coupling of light to
Whe spectregraph. It reyutros ase at sophesticalled. meratede laver allenment and micromampulatwn techniques.

Finally. we have carefully studied the effects of atmompheric dispersion on our ability of pertorm precision spectroscopy. and have developed the necessary lechniquee to compensate for this ceffect.

With the fabricaltent of our spectrograph/camera nearing completion. we expect to hegin cvaluating the MOS at Lich Ohservaluery in carly FYKu. 


\section{Theoretical Studies of High-Temperature Superconductors}

Principal Inwertigature: Y. II inter and

II. Kush

$\mathrm{T}$

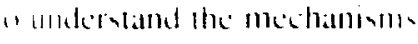

repromshle lan heg-lemperatus

superconductio ils. W: must he ahle

la calculate alcouralels the clectromic

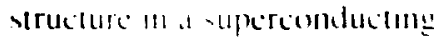

material. ancluduse the effect.

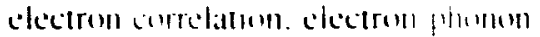

interacterls. and eteetron-spin

coupling. The gath of this research is to delermine the clectrenic structure

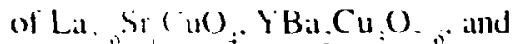
refaled compounds using advanced

We are using advanced calculational methods to determine the electronic structure of $\mathrm{La}_{2-1}, \mathrm{Sr} \mathrm{C}_{3} \mathrm{CuO}, \mathrm{YBa}_{2} \mathrm{C}_{3} \mathrm{O}_{7-j}$, and related new superconductors and thereby gain a better understanding of the mechanisms responsible for superconductivity in these materials. The theoretical models developed in this study will also help us to predict new superconducting materials.

Hesertical methods and compuler cinder

Specifically. He are using ant a: imirin, Hantree-Fock (HF) cluster approalch thall calculatles the exchange interactions. instead of approximating them at is dome in the more conventional electron-band-theory calculatlons. By including contiguration interaction ( $\mathrm{Cl}$ ). we can incorporate the electron-correlation and spin-coupling effects that are
Figure I. The unit cell struclure for YBa, $\left(u_{3}()_{\text {. }}\right.$. The three $(u$ vites in the unit cell ICu. $\mathrm{Cu}_{0}$, and $\mathrm{C} \mathrm{u}_{-}$) are shown in color.

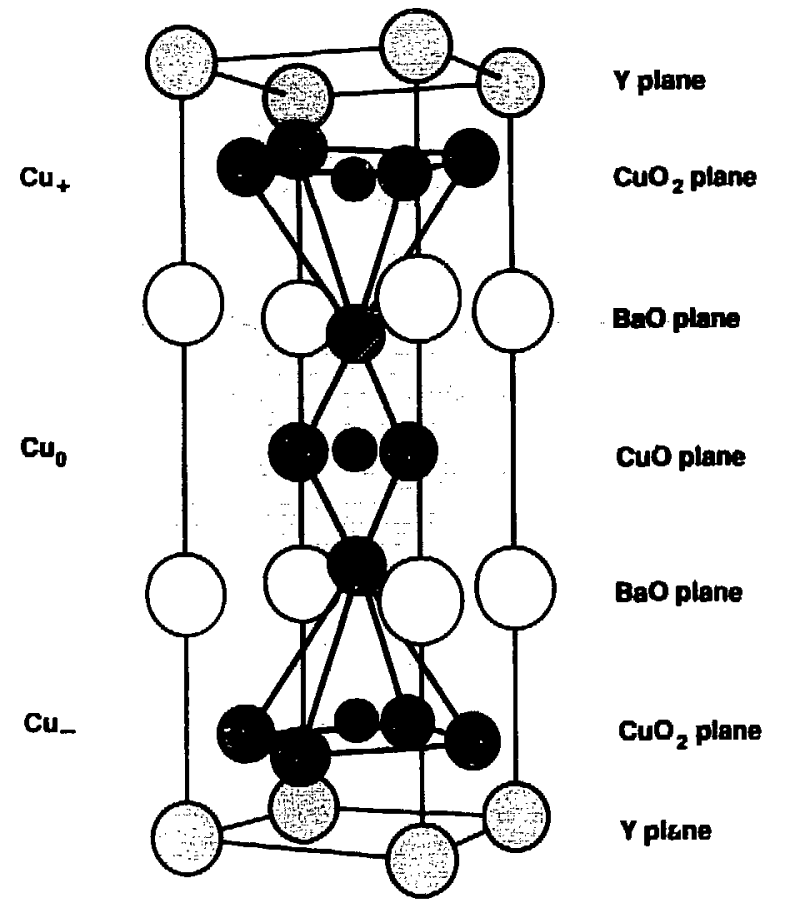

imponant in high-temperature superconducting materials.

We hegan hy sludsing YBa (u) () one of the more promising high-lemperature superconduclors: its orthorhombic unil cell structure is shown in Figure 1. Assigning formal charges to the ions and imposing charge neutrality requires that of the three $\mathrm{Cu}$ ions in the unit celf $\mathrm{Cu}_{\text {. }} \mathrm{Cu}$. and Cu ). one must be trivalent and the remaining Iwo nust he divalent. This can be described by a Cl warefunction $\Psi$ of the form

$$
\begin{aligned}
& \Psi=c_{11} \mid \mathrm{Cu}_{*}{ }^{\circ} \mathrm{Cu}_{11}{ }^{i} \mathrm{Cu}{ }^{2+}> \\
& +\because \mid \mathrm{Cu}^{\circ}{ }^{\circ} \mathrm{Cu}_{11}{ }^{++} \mathrm{Cu}{ }^{\circ}> \\
& +\cdot \mid \mathrm{Cu}^{2+} \mathrm{Cu}_{11}^{2-} \mathrm{Cu}{ }^{i+}>\text {. } \\
& \Psi=c_{11} \Psi_{11}+c_{2} \Psi_{2}+\boldsymbol{\Psi} \text {. }
\end{aligned}
$$

where $c_{n}$ and $c_{1}$ are mixing coelficients that determine the amount of trivalent character at each $\mathrm{Cu}$ site. The four $\mathrm{O}^{2}$ ions surrounding each $\mathrm{Cu}$ site are not shown explicitly above but are included in the calculations.

The $\Psi$, components of the ground-state wavefunction represent charge-Iransfer configurations where an electron has moved from one of the $\mathrm{CuO}$, planes to the $\mathrm{CuO}$ chain. leaving behind a mobile hole, which gives rise 10 the intrinsic metallic hehavior observed in $\mathrm{YBa}_{3} \mathrm{Cu}_{i} \mathrm{O}_{7}$. This is in sharp contrast to the results oblained from band theory. which 
predict that verrige bonding and antibonding interatetom, hetweon $\mathrm{Cu}^{2 *}$ and (): orbitals give rese lo the metallic nature of the $(\mathrm{cu})$, planes.

The value of the mixing coefficients, are related to the carrier density. Charge transter within the (it), plance is also included hut dow not lead to tharge carriers.

The (uo) chain exidertly erse as a reservoir of hole for the $\mathrm{Cu}(\mathrm{O})$. planes. This helpe explain the observed nensitivity of the superconducting transition temperature of $\mathrm{YBa}_{2} \mathrm{C} \mathrm{C}_{\xi}(\mathrm{O}$, , whe integrity of the $\mathrm{CuO}^{-}$chains. The role of the CuO chains is similar to that of the $\mathrm{Sr}^{2+}$ ions in doped $\mathrm{Lil}_{2} \mathrm{Sr}_{3} \mathrm{CuO}$, and the $\mathrm{BiO}$ and $\mathrm{TlO}$ planes in the $\mathrm{Bi}-\mathrm{C} \mathrm{a} / \mathrm{Sr}-\mathrm{Cu}-\mathrm{O}$ and $\mathrm{T}-\mathrm{Ca} / \mathrm{Ba}-\mathrm{Cu}-\mathrm{O}$ superconductors.

To obtain a yualitative understanding of the nature of the $\mathrm{CuO}$ bonds when $\mathrm{Cu}$ has a $2+$ or $3+$ valence. we made $\mathrm{HF}$ molecularorbital calculations on the linear cluster O-Cu-O-Cu-O-Cu-O. We found that a net charge on the cluster of 2-. appropriate for the $\mathrm{CuO}$, planes of $\mathrm{La}_{2} \mathrm{CuO}_{4}$ or $\mathrm{YBa}_{7} \mathrm{Cu}_{7} \mathrm{O}_{7}$. corresponds to a formal valence of $\mathrm{O}^{2-}$ and $\mathrm{Cu}^{2+}$. Also, a net charge of $1+$ corresponds to oxidation of the $\mathrm{Cu}$ ions to the $3+$ valence. which is consistent with the $\mathrm{CuO}$ chains in $\mathrm{YBa}_{2} \mathrm{Cu}_{3} \mathrm{O}_{-}$. The $3 d .4 s$, and $4 p$ orbitals on the $\mathrm{Cu}$ ions and the filled $2 p$ orbitals on the $\mathrm{O}$ ions participate in the formation of bonds and/or charge transfer: thus. calculated charges can differ significantly from these formal charges.

Initially, each $\mathrm{Cu}^{2+}$ ion has eight closed-shell electrons and one open- shell clectron wh the contiguration id"ti"t/". In terms of the atomic orbetals. Ihe kead an the follow ing configeurations:

(a) $\left.d^{\prime \prime}+i^{\prime \prime}+p^{\prime \prime}-2\right)^{\prime \prime}$

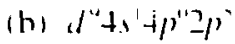

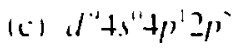

(d) (d" $+s^{\prime \prime}+p^{\prime \prime 2}-p^{\prime}$

The HF watefunction in dominated by contiguration (al). With contributions from (b) and (c) that allow the (): ions an slabilize their lilled $2 p$ shell by hybridizing with the enpty +1 and $+p$ orbizals. A population analysis of the HF wavefunction shows that the three singly occupied levels in the cluster comespond to $\mathrm{Cu} 3 \mathrm{~d} /$ orbitals. The holes are not constrained to the $\mathrm{Cu}^{3+} 3 d$ orbitals but can transter to the $\mathrm{O}^{-2} 2 p$ orbitals by mixing with contiguration (d). There is littie evidence of this in the high-spincoupled planar or linear clusters due to the unfavorable exchange interaction between $\mathrm{O}^{1}\left(2 p^{5}\right)$ and its second near-neighbor $\mathrm{Cu}^{2+}\left(3 d^{4}\right)$. The singly occupied $3 d$ orbitals on $\mathrm{Cu}^{2+}$ can be coupled antiferromagnetically to give the ground-state electronic structure observed for the $\mathrm{CuO}$, planes in $\mathrm{La}_{2} \mathrm{CuO}_{4}$ and $\mathrm{YBa}_{2} \mathrm{Cu}_{3} \mathrm{O}_{4}$. In this case, the open-shell electrons are singlet-coupled. and the contribution from configuration (d) increases. This has been verilied by calculating the nuclear quadrupole resonance lines for the $\mathrm{Cu}$ sites and comparing to experiment.

By removing three open-shell electrons from the cluster. we investigated the bonding in $\mathrm{O}-\mathrm{Cu}\left(3 d^{*}\right)-\mathrm{O}-\mathrm{Cu}\left(3 d^{*}\right)-\mathrm{O}-\mathrm{Cu}\left(3 d^{N}\right)-\mathrm{O}$ chains. In this case, the $\mathrm{O}^{2}$ ions $d$ ) strongly hybridize with ihe empty $3 d$ orbitals on the $\mathrm{Cu}^{3+}$. The totat gross populatloms indicalle that -11.65 electrons are transferred wo the ("u". with the matorit! going into the 3 , orbital. In contrasis. only -1 . I electroms are tramsterred to the ( $u^{-}$

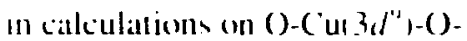
(iil a)

Another. more realistic calculation was ciurried out that included all the valence electrons in the unit cell cluster (see Figure I) plus those from the near-neighbor ions in surrounding cells. By including the valence electrums from adjacent ions. we were able to impose the correct boundary conditions on the ions that are only parially in the cell. The population analysis of the HF wavefunction predicts the following atomic charges:

$Y$ planes: $Y$ '"'.

$\mathrm{CuO}$, planes: $\mathrm{Cu}^{1+10} \mathrm{O}_{1}^{1 \mathrm{Ne}+} \mathrm{O}_{!^{1 \text { the }}}$

BaO planes: $\mathrm{Ba}^{1+17+} \mathrm{O}^{1+5}$

CuO chains: $\mathrm{Cu}^{14+} \mathrm{O}^{1+1}$

The $\mathrm{Cu}-\mathrm{O}$ bonding is indicative of $\mathrm{Cu} 3 d^{*}$ in the chains and of $\mathrm{Cu} 3 d^{4}$ in the planes.

We are now using these cluster wavefunctions to ralculate the nuclear quadrupole and nuclear magnetic resonani:e spectra of ${ }^{6.3 .6 .5} \mathrm{Cu}$ and ${ }^{17} \mathrm{O}$. as well a ; vibrational frequencies, posi ron anihilation cress sections. and Mossbauer spectra. These wavefunctions will also serve as a starting point for the $\mathrm{Cl}$ calculation of the real-space pairing energies of the mobile holes in the $\mathrm{CuO}$, planes. 


\section{Laser Cooling of Positronium}

\author{
Principat Investigator: K.-P. Ziock \\ Co-Investigators: $($. D. Dermer,
}

F. P. I.iang, K. Howell, K. H. Jones,* and

li. Magnotta

- Willam, Colleges. Willamblom M. MA.

$\mathrm{P}$ ositronium (PS) is the hydrogen like hound state of an electron positron pair. The study of $P_{s}$ is complicated by the small amount available. its short litelime $1+2 \mathrm{n}$. for the fongest-lived ground statc). and its high thermal velocity $\left(-10^{\circ} \mathrm{cm} / \mathrm{s}\right)$. Our goal is to take room-temperalure $P$ s produced at the LLNL electron linear accelerator (linac) and use laser cooling to lower its temperature $10 \sim 1 \mathrm{~K}$.

Precise measurements of the fundamental properties of Ps are currently limited by its high thermal velocity. Ps cooled to near absolute zero would help solve this problem. It has also been suggested that a new state of matter-a low-density BoseEinstein condensate--might form from the gas phase of cold Ps. Stimulated annihilation gamma radiation could be produced using such a condensate (Liang and Dermer. 1988).

The ground state of Ps consists of a short-lived (I25-ps) singlet and a longer-lived (142-ns) triplet spin state. We perform cooling on the $I^{2} s-2^{3} p$ transition of Ps due to the longer lifelime of the triplet state. This involves irradiating half the Doppler profile of the cooling

We apply the technique of laser cooling to positronium produced at the LLNL linac. Cooling improves the accuracy of fundamental measurements on positronium; it is also necessary for the creation of a gas-phase Bose-Einstein condensate - a new state of matter that may allow the stimulated production of annihilation gamma radiation.

Iramition with broadband lascr light cuned lo frequescices betow the resonance freyuence. For optimum cooling. the laser mus producte highintensity. broadband. ultraviolet light 1-0.7 $\mathrm{nm}$ FWHM. 24.3 $\mathrm{nm}$ ) with a duration of approximately one triplet lifetinte and with a sharp cut-off at the high-frequency edge.

This vear, we veritied that we could create a light pulse with the required frequency and intensity protiles: we also veritied that no unexpected losses occur from the Ps cooling transition. We used the frequency-doubled output of an excimer-pumped dye laser. modified to give the desired bandwidtn. Laser light is passed in front of a heated copper target that is being exposed to the linac's low-energy positron beam. Thermal Ps boils off the heated copper surface. The interaction region. where the laser beam passes through the resulting $P s$ gas. is monitored with a collimated gamnaray detector to measure the annihilation radiation ïrom the Ps.

The laser light affects the Ps annihilation rate in two ways. First. excitation to states with longer annihilation lifetimes decreases the overall Ps annihilation rate. Second. the weak - 2(K)-G magnetic lield used to licus the positron bean causes a vight mixing of the singlet and triplet spin states of exciled-state Ps hut leaves the ground state unaffected. Any $P$, in the singlet excited state decars lo the singlet ground state. from which it annihilates in $125 \mathrm{ps}$ : this increases the observed Ps annihilation rate. We use the change in annihilation rate resulting from these two effects to monitor the degree of optical saturation of the $1, s-2 p$ transition.

Both laver-on and laser-off annihilation time profiles are recorded. The laser-off protile provides the background spectrum: the difference between the laser-on and laser-off profiles shows the effect of the laser. The increase in annihilation rate due to the laser and the magnetic field is clearly visible in the spectra in Figure 1. Examination of the effects of laser intensity. polarization. and magnetic field strength on such time profiles reveals that we have indeed attained sufticient laser intensity in a bandwidth required for cooling. This work also represents the first time that any $1 s-2 p$ transition in Ps has been optically salturated

We also developed a method for determining the degree of cooling achieved. This measurement is 
performed by exciling the cold P, out of the If stalle into higher-ly illy

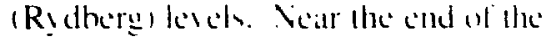
cooling pulse. We expose the Pa 10 narrou - bandw idth red light that is tuned to interate only with the cooted atoms. The ecouled Ps exciled hy the red light is delected. using licid ionization. and a comparison of the amount of Prexcited with and without the cooling laser pula provides a medsure of the number of couled Pr alloms.

In a preliminars ces of this technique. "ue achieved excitation of Ps w the $n=1.3-1.5$ excited viltes. The stitem was simultancenusly

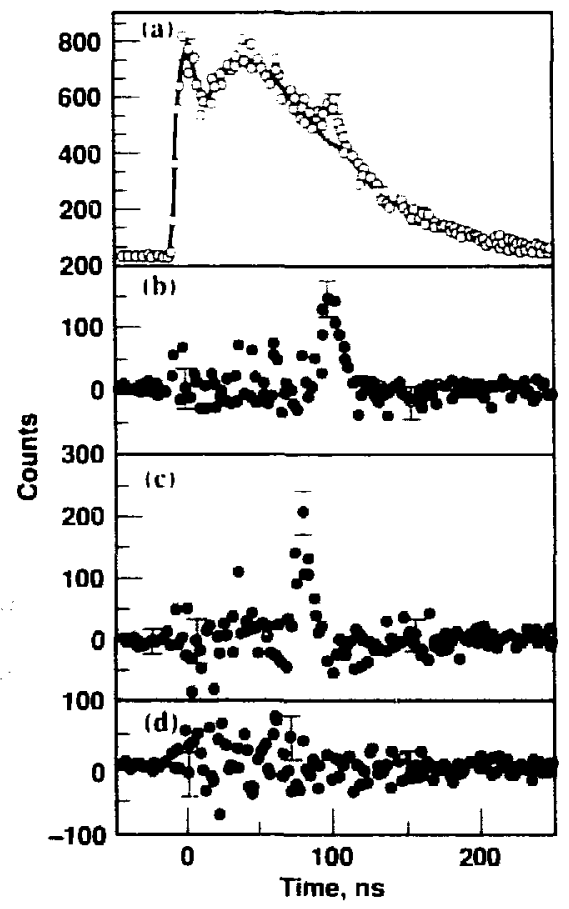

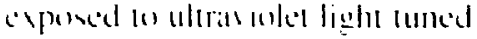
whe l i-2: tramsition and an red lygh trom a recond dee laves. The variation of the annihilation rasts as a function of red-laser freyuenc! Was used to verify excitation to tice Rydberge levels. A charalcteristic signiature of the ammihilation time protike $u$ as ohserved when the red light wals turled (o a $2 p-n l$ ) resonanec. This represents the lirst time that any excited state of $P$ s wher than the $n=2$ level has heen ubserved.

All of our work (o) date has heen done with a I(1)-ns-pulse laser. For cooling to occur. the excited state

Figure 1. Typical Ps annihilation time profiles. In (a), the solid black curve is the laser-off profile: the open circles give the laser-on profile (laser pulsed at $90 \mathrm{~ns}$, with a 200-(i magnetic field ). Represenative I $\sigma$ crror bars are shown for two points in the laser-on spectrum; errors for the laser-oft spectrum are less than the width of the line. (b) Difference spectrum obtained by subtracting the laser-off spectrum from the laser-on spectrum in (a). (c) Difference spectrum as in (b) but with the laser pulsed $20 \mathrm{~ns}$ earlier. (d) Difference spectrum as in (c) but with the laser detuned $\mathbf{I ~} \mathbf{n m}$ to the red of the $1^{3} s-2^{3} p$ transition: the laser peaks approximately where the representative $1 \sigma$ error bar is given at $70 \mathrm{~ns}$. mus decaly yontameousls ahout 50 times. Thus the 3.2-ms decill lifetime of the Prexcited state recpuires a latser-pulse duration of approximately $1.50 \mathrm{~ns}$. In the coming year. we will install a llew latser with the required longer pulse duration. We will then perform experiments Io cool Ps. lirst in one and then in three dimensions.

\section{References}

Dermer. ('. D). K. H. Huwell. K. M. Jumes

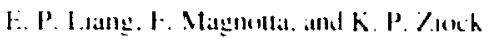

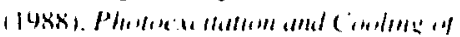

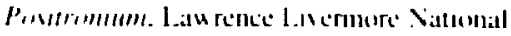
L.ahbrallory. Prepromt l:('Rl-4877.5.

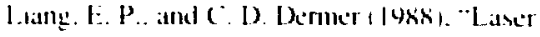

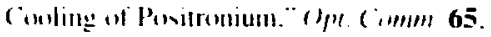
+19 .

Vinch. K. P.. C. D. Dermer. R. H. How ell. F. Magnolta and K. M. Jolke (I98X).

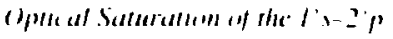
frumsillm in Ponirommm. Lawrence Livemore National Laboralory. Preprint [CRL- I (K)|GI]. 


\section{University of California Institutes}

C. E. Max
Several University of California (LC) advisory committees have recently reterated the importance of increased scientific collaboration anong staif nembers at the national laboratories and scientists at UC campuses. The latest contract between the Department of Energy and UC re-emphasizes the importance of such collaboration. This type of interaction has advantages for Laboratory staff members, who gain professional enrichment, closer contacts with the academic community, and expertise in fields that are underrepresented at the national laboratories. Likewise, such collaboration has advantages for UC researchers. who obtain access to unique Laboratory facilities and expertise, particularly in applied fields. In recent years, several joint UC-LLNL Institutes and Programs have been establishıd with the goal of enhancing campus-Laboratory collaboration in areas of overlapping interests and expertise.

The four current UC-LLNL joint Institutes, which are at various stages of maturity, are:

- The LLNL branch of the Institute of Geophysics and Planetary Physics, approved by the Regents in 1982 as the fifth branch of a University-wide Multicampus Research Unit.

- The Institute for Scientific Computing Research, a new projeci undertaken jointly by the LLNL Computation Department and participants from UC Berkeley.

- The Plasma Physjes Research Institute, a new project in collaboration with the College of Engineering, UC Davis.

- The Program for Analytical Cytology,approved by the Regents in 1982 as a joint program of LANL and UC San Francisco.

All of these joint programs are currently functioning at LLNL, sponsoring collaborative research, postdoctoral and student researchers, workshops, and seminars. At present, the first and last collaborative projects listed above receive funds from the system-wide administration of $\mathrm{UC}$, as well as from other campuses, LLNL, and national funding sources. The system-wide funding is used to sponsor small awards to UC researchers for collaborative projects with LLNL. 


\section{Institute of Geophysics and Planetary Physics}

C. E. Max
The LLNL branch of the lastitute of Geophysics and Planetary Physics (IGPP) was established by the UC Regents in 1982. Its purpose is to make LLNL's unique facilities and expertise in geosciences and astrophysics available to outside researchers, primarily those associated with UC. The program also broadens the scientific horizon of LLNL researchers by encouraging collaborative and interdisciplinary work with University scientists. At present, the IGPP at LLNL has three research centers:

- The Center for Geosciences, headed by G. Zandt.

- The Astrophysics Research Center. headed by C. Alcock.

- The Center for High-Pressure Sciences, headed by W. Nellis.

The IGPP also has administrative responsibility for the new UC Accelerator Mass Snectrometry Program at LLNL.

The IR\&D Program provides funding for IGPP administrative and secretarial costs at LLNL and provides one-half the salaries of the three Center heads. The LLNL Physics and Earth Sciences Departments contribute scientific and technical personnel to the IGPP.

At the core of the IGPP branch at LLNL is a group of research grants open to scientists from all UC campuses. These peer-reviewed grants (jointly funded by the UC Regents and by the IR\&D Program) have been awarded annually since FY83. Typical grants range from $\$ 5,000$ to $\$ 20,000$ and are used for research in seismology, geochemistry, cosmochemistry, high-pressure physics, and astrophysics. In recent years, we have received about twice as many qualified proposals as we can support (see Figure I).

The grants heip support visiting graduate and postgraduate researchers, experimental facilities for visiting researchers, and supercomputer time. The opportunity for University faculty and students to use LLNL's supercomputers has been a prominent component of the program.

Several advanced facilities are available to researchers visiting the IGPP at LLNL. The Center for Geosciences has a variety of digital, broadband
Figure 1. IGPP

funding from

LLNL since FY84

and cost of

supercomputer

time awarded

to campus

researchers as

part of the

collaborative

projects.

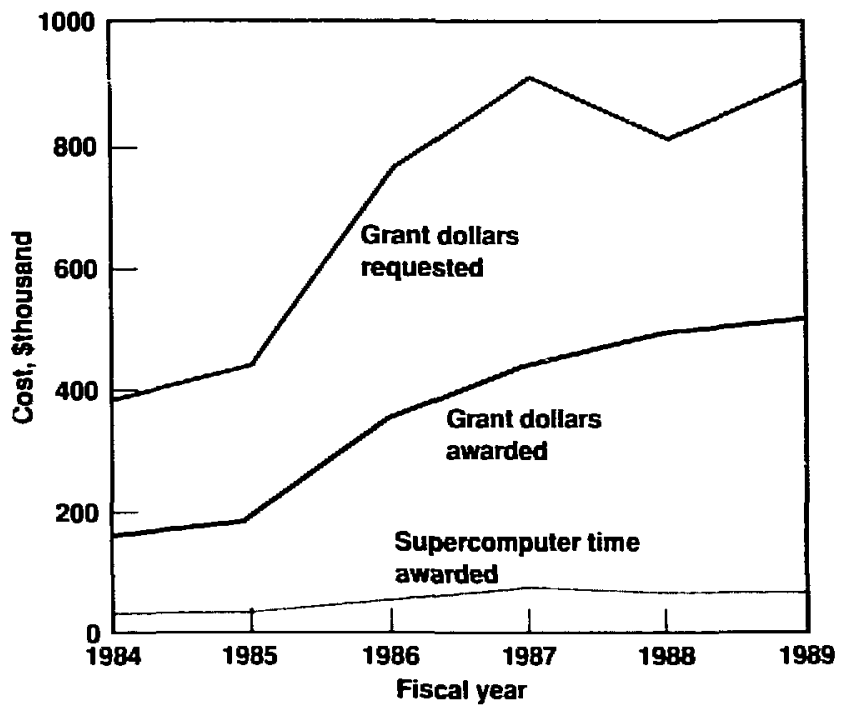


seismographic eivipment. The Astrophysics Research Center maintains a state-of-the-art image-processing facility for analyzing and displaying astronomical data. The Center for High-Pressure Sciences has two light-gas, guns. several diamond-anvil-ceil laboratories, a piston-cylinder appar:tus. and facilities for synthesizing and characterizing specimens at high temperatures and pressures.

For data analysis, powerful LLNL-developed geophysical software can be run on a network oi Sun workstations. Researchers also have access to the Cray supercomputers of the National Magnetic Fusion Energy Computer Center. The Crays can be accessed through a local node in one of the IGPPLLNL buildings and are at present used most extensively by the Astrophysics Research Center.

In addition to providing grants for campus researchers. the IGPP strives to provide an intellectual focal point for UC-LLNL interaclions. To further this goal, the IGPP runs a weekly seminar series. helps host University visitors for periods ranging from a few days to a full sabbatical year. and sponsors conferences and workshops.

The high scientific productivity for IGPP-sponsored collaborations is evidenced by the volume of publications that have resulted from IGPP research at LLNL (Figure 2). In all, about 135 IGPP papers have been published since 1983.

In FY88, the Labcratory`s IGPP received $\$ 1,454.000$ in IR\&D operating funds plus $\$ 57,000$ for capital equipment.

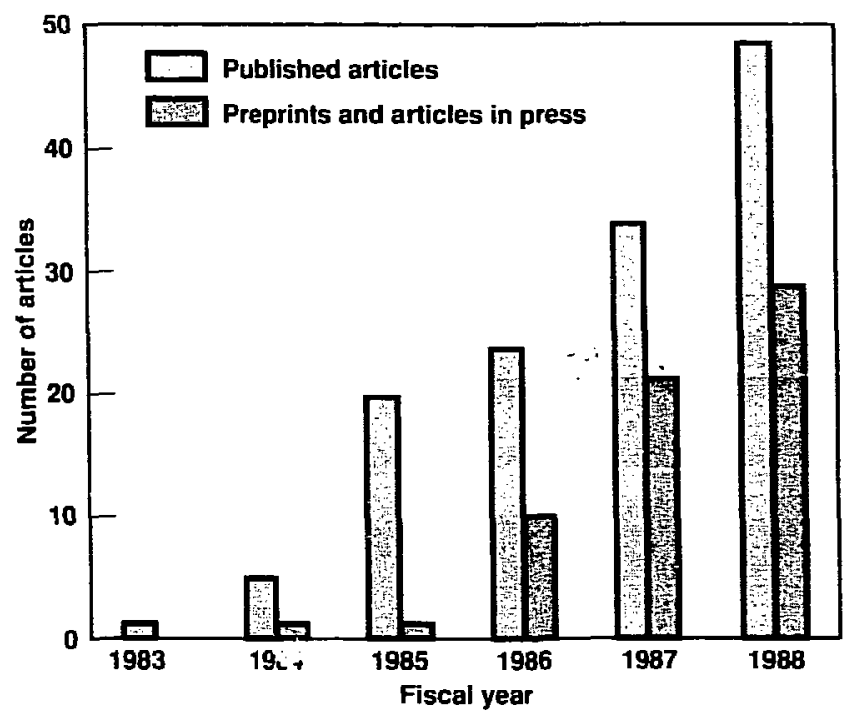

Figure 2. History of IGPP publications (refereed journal articles and published conference proceedings) 
Analysis of the Mt. Lewis Earthquake and Prior Activity (1980-1986) Using Digital Seismic Data

Principal Investigator: K. C. McNally* Co-Investigators: G. Zandt and $G$. Nelson*

* University of California. Santa Cruz.

$\mathrm{T}^{1}$ he coda. or temporal decay in seismic energy arriving after the main ray-arrival, is a measure of the attenuation of the medium through which seismic waves from an earthquake propagate. This measure is quantified by the coda quality factor $Q_{c}$. which is a function of frequency and is related to inverse attenuation. Several previous studies have indicated that temporal variations in coda $Q$ precede and accompany the occurrence of large earthquakes. The March 31, 1986. Mt. Lewis earthquake (magnitude 5.7 ) in Fremont, California. presented us with an opportunity to study this phenomenon with an extensive data set obtained by the Lawrence Livermore Seismic Network (LLSN).

We determined coda $Q$ for earthquakes that occurred from 1980 through 1987 within $10 \mathrm{~km}$ of the Mt. Lewis main shock. The coda $Q$ was determined at three stations located within $10 \mathrm{~km}$ of the main shock using the Sato (1977) singlescattering formulation. We observed that coda $Q$ increases with lapse time and that three distinct decay slopes are commonly obtained in the lapre-

Changes in the coda quality factor may precede the occurrence of large earthquakes. We determined the coda quality factor and studied its dependence on lapse time and distance for earthquakes within $10 \mathrm{~km}$ of the $1986 \mathrm{Mt}$. Lewis main shock to search for precursory temporal changes associated with this moderate-magnitude event.

time range of 2-20 $\mathrm{s}$ and greater. Within the confines of the singlescattering model, we have modeled this increase as being due to:

- Increasing intrinsic $Q$ in the upper mantle.

- Scattering into surface waves in the uppermost crust.

- Increased scattering strength in the uppermost crust.

The lapse-time range of 5-12 s excludes both the complicated early coda and possible upper-mantle scattering. We find that coda $Q$ has a local minimum in the standard error when computed over the lapse-time range of 5-12 s. Our finding may signify that different parameters apply to scattering outside this lapsetime window. In this range, the average coda $Q$ measured at station $\mathrm{CDV}$ at $6 \mathrm{~Hz}$ was 135: however. the value exhibits significant variation. with both temporal and spatial dependence.

Coda $Q$ also exhibits a dependence on distance from the main shock and time before and after the main shock. We found that. for events within $5 \mathrm{~km}$ of the main shock. attenuation $(1 / Q)$ at $6 \mathrm{H} /$ was $63 \%$ higher $1 Q=10(1) 15$ months before the main shock occurred. began to decrease nine months before the main shock, and reached a low $\left(Q_{\mathrm{c}}=160\right)$ six months after the main shock. Coda $Q$ also exhibits a dependence on the distance of the source epicenter from the main shock epicenter. Attenuation was highest for sources closest to the main shock $\left(Q_{c}=114\right)$, decreased to a minimum at a distance of $6-8 \mathrm{~km}$ from the main shock $\left(Q_{\dot{c}}=167\right)$, then increased to a distance of $14 \mathrm{~km}$ $\left(Q_{c}=125\right)$, beyond which we have no dala. The aftershock had a radius of $5 \mathrm{~km}$. which is slightly smaller than the radius of the area with smallest attenuation.

Our results imply that temporal changes in coda $Q$ may be associated with the occurrence of moderatemagnitude earthquakes. However. the distance dependence that is also present complicates the usefulness of this measure as a tool for earthquake prediction.

\footnotetext{
Reference

Sato. H. 19771. "Energy Propagation Including Scattering Eflects: Single Ivotrupic Scattering Approvmation." I PhM tewh 25. 27
} 


\section{Mapping Changes of Crustal Heterogeneities}

Principal Investigator: R. S. Wu* Co-Investigators: (;. Zandt and G. Nelsen*

* Luiversity of California. Santa Cruz.

$\mathrm{T}$ he temporal changes of coda $Q$ $(Q)$ and coda duration of foreshocks and aftershocks associated with a major earthquake are the subject of many reports from around the world. Most observations, however, are based on one or two stations. and the results are often contradictory. The Lawrence Livermore Seismic Network (LLSN) provides an excellent opportunity to study temporal variations in coda duration. postulated to be an earthquake precursor. because of the dense distribution of stations and events around the main shock zone of the

We have used the Lawrence Livermore Seismic Network to determine changes in the coda duration as a function of distance and time before and after the magnitude-5.7 Mt. Lewis earthquake.

March 31. 1986, Mt. Lewis earthquake (magnitude 5.7) located near Fremont, California.

We grouped the 25 stations of the LLSN into three rings based on their distances from the epicenter of the Mt. Lewis earthquake:

- Ring 0 extends from 0 to $15 \mathrm{~km}$. - Ring i extends from 15 to $25 \mathrm{~km}$. - Ring 2 extends from 25 to $38 \mathrm{~km}$.

We used earthquakes occurring from the beginning of 1980 to April, 1987, with depths $\geq 5 \mathrm{~km}$ and epicentral distances $<10 \mathrm{~km}$ from the main shock to study temporal changes in coda duration. We used as the reference background the USGS magnitude that was derived from the average $\log T_{\mathrm{c}}$ (the logarithmic coda duration) over stations in a broad area. We then plotted the difference between the average $\log T_{\text {c }}$ for each ring and the background $\log T_{\text {c }}$ versus time to study temporal changes of the scattering coefficient of crustal heterogeneities sampled by coda waves recorded by stations in different rings. We found an increase of average $T_{c}$ starting about 2 years before the main shock. After the main shock, the average $T$ decreased gradually. The anomaly of $T$ was more pronounced for rings 0 and $I$ than for ring 2. 


\section{Teleseismic-Converted Waves in the Long Valley Caldera}

Principall Investigator: W. Pruthero. Jr.* ( o-Investigators: (i. Zandt and L.. Steck*

I neterily of California. Santa Barbara.

$\mathrm{T}$ eleseismic $P$ (compressional) waves impinging on a velocity discontinuity, such as the interface between solid and semimolten rock. generate converted $S$ ( shear) waves. Such converted $P$-to-S waves provide direct evidence on the location and velocity contrast of the causative interface. We recorded teleseismic $P$ waves in an active volcanic area to search for converted waves and to assess the utility of converted waves in the identification of magma bodies.

\section{We are using teleseismic P-to-S-converted seismic waves to determine locations and configurations of magma bodies beneath the Long Valley Caldera.}

Datia for our study were recorded on a combined Lawrence Livermore Nattional Laboratory/UC Santa Barbara seismic array located on the northwest shoulder of the resurgent dome of the Long Valley Caldera in eastern California. Using arrayanalysis techniques. we have shown that the large. delayed arrivals seen on horizontal components are converted shear waves. These phases originate from beneath the western moat. a region identified by other researchers as possibly containing magma bodies. We also found then dired $P$ waves are perlurbed from expected great-circle back-azimuths. most likely by the same siructure as that generating the shear waves. We are now determining station corrections to remove the effect of near-surface velocity variations on our array-analysis techniques. Such corrections will allow more accurate estimates of the locations of converting interfaces. 
Crustal Fault Zone Study with the Lawrence Livermore Seismic Network

\author{
Principal Investigator: .I. Vidale* \\ Co-Investigators: (G. Zandt, (;. Nelson.* \\ and D. Garcia-Gonzales*
}

L nivernits of California. Santa Crus.

$\mathrm{T}^{\mathrm{s}}$

he zone of malerial up to a

few kilometers wide around

major strike-slip faults has been hypothesized to have compressional and shear velocities that are lower than those of the surrounding material by $10-40 \%$. The waves that travel in the fault zone or lowvelocity channel can provide important diagnostic observations of the lault zone.

We examined the waveguide effects from earthquake-generated seismic waves traveling along a fault zone with data from the Lawrence Livermore Seismic Network located

We are studying earthquake-generated seismic waves in crustal fault zones to search for waveguide effects that may provide valuable diagnostic measures of fault properties.

in the east San Francisco Bay area. SH waveforms (horizontally polarized shear waves) for paths that follow the fault trace are quite similar to waveforms for paths that cut across the fault zone. These observations suggest a much narrower or less anomalous fault zone than has been proposed for the Calaveras fault in other locations and for the San Andreas fault near Bear Valley.

We have developed a novel scheme to compute travel time to determine whether there are indications of a low-velocity fault zone in the travel times to the stations near the Calaveras fault. The travel times are consistent with $10 \%$ lowervelocity material in the fault zone than on either side. Surprisingly, however. the results are not mathematically unique.

Nevertheless. the scheme for traveltime analysis has proven to be quite useful. We are currently using the scheme for windowing finitedifference calculations. Kirchhof $1^{\circ}$ migration. and tests of the resolution of tomographic inversions. 


\section{Seismic Attenuation from Earthquake and Explosion Sources}

\author{
Principal Investigator: S. Hough* \\ Co-Investigators: J. Anderson ${ }^{\dagger}$ and \\ H. Patton

\footnotetext{
"Invitute of (ieophysics and Planetary

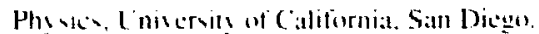

tScripp Imsllution of (lecameraphy.

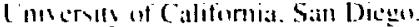

$\mathrm{W}$ a are studying the attenuation of regional seismic waves at frequencies between 1 and $15 \mathrm{~Hz}$ and alt epicentral distances from 20 to $250 \mathrm{~km}$ in western Nevalda.

Following the method of Hough ct al. (1988), we parameterize the asymotote of the high-freyuency acceleration spectrum by a twoparameter model. We interpret the model parameters in terms of a simplitied two-laver model for seismic-wave attenuation $Q$ and relate the observed model parameters Io $Q$ and $Q$. the frequencyindependent and the frequencydependent components of the coda quality factor $Q$. respectively. We obtain total $Q\left(Q_{1}\right)$ by $l / Q_{1}=1 / Q_{1}+$ $1 / Q_{u}$. In the top $5 \mathrm{~km}$ of the crust. we obtained a $Q$, of $\sim 67$. We have no resoiution of $Q_{\mathrm{d}}$ in the near-surface layers.

Comparing our results to those from previously published $Q$ studies in the Basin and Range region, we find that our estimate of $Q_{1}$ in the shallow crust is consistent with shear-wave $Q$ at close distances. as determined by Patton and Taylor (1984) and Chavez and Priestley (1985). For depths greatter than $5 \mathrm{~km}$. we obtain $Q$, that increases from $-1.5(1$ at $1 \mathrm{~Hz}$. $10 \sim 6(1)$ at $15 \mathrm{~Hz}$. This estimate of $Q_{1}$ is consistent with coda $Q$ reported by Singh and Hermann (1983) and with $Q$ determined from the $L$ phase ishear

\section{We are investigating the attenuation of regional seismic waves and comparing the high-frequency content of explosions with that of earthquakes in western Nevada.}

Waves propagalling in the crustal layers) reported hy Chavez and Priestly (1986) (see Figure 1). This result suggests that both coda $Q$ and $Q$ determined from $L$ are insensitive to near-surlace contributions to altenuation.

In addition to our results on attenuation. we compared the highfrequency content of explosions with that of earthquakes. Our results from $S$ waves are similar to results for $P_{\text {a }}$ waves (compressional waves

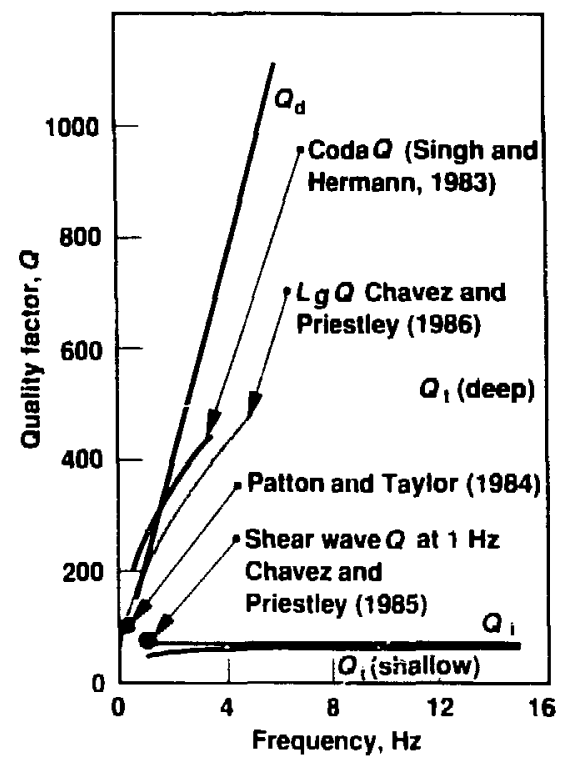

Figure 1. Summary of variation of quality factor $Q$ in the Basin and Range. See text for a more detailed interpretation of these data. propagating in the crustal lavers) by Chacl (1988). who found that the $P$. wave spectra from explosions are depleted in high-frequency energy with respect to earthyuake spectra. Taylor et al. (1988) compared spectral energy at $\mathrm{I}-2 \mathrm{~Hz}$ with energy at $6-8 \mathrm{~Hz}$ for earthquakes and explosions. These researchers found relative depletion of the higher frequencies for explosion sources. especially for $L$, waves. This result is also consistent with those in the present study. The combined results indicate that spectral differences between explosion and earthquake sources ohserved al regional distances may be an important discriminant in the seismic verification of compliance with nuclear test-ban treaties.

\section{References}

Chael. E. P. (1988). Go'ophlys Re's. Le'tl. 15. 6.5

Chavez. D. E.. and K. F. Priestley (1485). Bull Serism. Sor Amer 74, 1583

Chavez. D. E.. and K. F. Priestley (1486). Giriphre fer Le'H 13.55i

Hough. S. E.. J. (i. Andersom. J. Brune. F. Vernon, III. J. Bereger. J. Fetcher. L. Hatar. T. Hank and I. Baker I Y 488 I. Bull serem ser temen 78.672

Pattun. H. J., and S. R. Tils lor a lykt1.

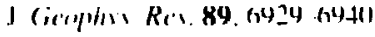

Singh. S.. and R. B. Hermann (1483).

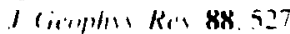

Taslor. S. K.. \. W. Shermath. and II D.

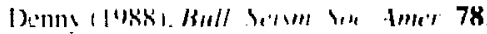
156 


\section{Crustal Genesis and Recycling in Northwestern Mexico}

Principal Investigator: K. Cameron* Co-Investigators: $S$. Viemeyer and (i. Nimz*

" Inicorit! of Califorma. Santa Crur.

$\mathrm{T}$

he largest Cenozoic rhyolite

province in the world occurs in westem Mexico. If these silicic volcanic rocks originated hy fractional crystallization of mantlederived basaltic magmas, then their extrusion marked a major Cenozoic crust-forming event. Alternatively: the rhyolires may largely represent melting and recycling of preexisting continental crust.

Our analyses have established that the mid-Cenozoic rhyolites overlap in strontium and neodymium

We are studying silicic volcanic rocks in northwestern Mexico to determine the mechanisms responsible for their origin.

isotopic compositions with coeval basialtic rocks. The basaltic rocks. in tum. have strontium. neodynium. and lead isotopic ration similar to those of mantle pyroxeniles. demonstrating that crustal assimilation is not required io explain their isotopic compositions. About two-thirds of the granulite-facies xenoliths we have analyzed from Mexico appear to be Precambrian basement. and they have neodymium and/or strontium isolopic ratios that differ greatly from those in Cenozoic volcanic rocks. The remaining xenoliths, mostly cumulate mafic granulites. are isotopically indistinguishable from the Cenosic volcanic rocks. These mafic granulites may he the first recognized samples of several-kiloneter-lhick. cumulate-dominaled. mid-Cenozoic crust that formed during the fractionation of the basalt-10-rhyolite series. 


\section{Geologic Application of Discrete-Particle Models for Earth Materials}

Principal Investigator: R. Shreve* Co-Investigators: $O$. Walton and

T. Drake*

"Lniversis uf Catifumia. Lan Angedes.

$\mathrm{F}$ low of granular material is important in a variety of scientific and engineering studies. Examples from the earth sciences include avalanches, pyroclastic flows, and impact cratering. Examples of some engineering applications are the industrial transport of coal and other particulates, fluidized-bed technologies. and proposed designs for inertially confined fusion reactors.

Experimental studies of the flow of granular material in progress at UC Los Angeles and the discreteparticle computer models developed by the Granular Solids Flow Project at LLNL are providing a unique opportunity for mutually beneficial collaboralive research. Our physical experiments provide a means of calibrating. validating. and refining the computer models. which can then be used to simulate flows that are experimerially impractical.
We are combining the results of physical experiments with those of discrete-particle computer models to simulate mechanisms of flow in granular material for applications in which experiments would be impractical.
We have completed our experiments comparing collisiondominated grain llow performed al UC Los Angeles and discrete-particle computer simulations performed al LLNL. We direcled mosi of our recent work toward the sensitivity analyses of computer simulations to how parameters, such as friction coefficients between llow particles and tlow and boundary particles. number density of particles per unit length of a channel. and spacing of parallel walls that confine particles to essentially two dimensions.

At LLNL. we are currently transferring the computer code to Sun workstations. Many of the graphics capabilities readily available on the Cray will be implemented on those workstations. We are also exploring new ways of visualizing the experimental results obtained at UC Los Angeles and LLNL.

At UC Los Angeles. we are conducting physical experiments using geologic materials to determine several parameters for the simulations. including the coefficients of friction and restitution. Our previous computer experiments and available theory indicate that flows of geologic materials should not be sensitive to choices of these parameters. Thus. we should be able to proceed rapidly to our proposed simulations of the development of eolian (wind-bome) slipface deposits. After we understand the uniform-grain-size eolian system as a first. relatively simple geologic application. we envision using the model to investigate a variety of problems in sedimentologic surting. The lengthy process of validating and calibrating our computer simulations should eam exciting scientilic dividends. 


\section{Isotopic Analysis of Microscopic Domains in Garnet Porphyroblasts from Sri Lanka}

Principal Investigator: J. Reynolds* Co-Investigators: W. Cilassley and J. J. Irwin*

- Lmererily at Califomia. Berheles.

$\mathrm{T}$ he purpose of our project is to establish the pressuretemperature-time history of highgrade metamorphic rocks from $\mathrm{Sri}$ anka. To do so. we are integrating etrologic studies conducted at .LNL with microanalysis of argon iotopes at LC Berkeley. We slected from a large collection of amples of high-grade metamorphic
Our results on electron microprobe analysis of garnets from Sri Lanka suggest that more than one episode of metamorphism affected these specimens. rocks obtained from Sri Lanka a few specimens of garnet and feldspar that best illustiate variations in temperature and pressure of formation of different parts of single crystals. Electron microprobe study of the garnets indicates that the rims of some crystals contain more iron and less calcium than the cores of the same crystals. These data indicate that the rims of some crystals formed at a considerably lower pressure than the cores. This finding implies that more than one episode of metamorphism may have affected these rocks. The pronounced compositional variations observed in these garnets. combined with their large grain size, make the specimens ideal for laser-microprobe argonisotope analysis. 


\section{Trace-Element and Isotope Geochemistry of Cretaceous/Tertiary Boundary Sediments}

\author{
Principal Investigator: S. Margolis* \\ (o-Insestigaturs: (i. P. Kuss. III, and \\ F.. Dirhne*
}

( III e have analyzed trace elements and stable isotopes in a seric:s of sedimetnt simplen crossing the Cretaceous/Tertiary ( $K / T$ ) boundary and obtained from critical sections at Zumaya and Sopelano. Spain. Our aim is to distinguish extraterrestrial versus volcanic or aluthigenic concentration of the platinum group and other elements in $\mathrm{K} / \mathrm{T}$ boundary transitional sediments. These sediments have been shown to contain evidence for the stepwise extinction of several groups of marine invertebrates atssociated with negative oxygen and carbon isotope excursions occurring during the lass million years of the Cretaceous period. The isotope excursions have been interpreted to indicalte major changes in ocean thermal regime. circulation. and ecosystems that may be related to multiple "events" during the Late Cretaceous.

Our results to date on the petrographic and geochemical analyses of the Litte Cretaceous and

We have developed a new approach for identifying the sedimentary minerals responsible for trace-element concentrations associated with the end of the Cretaceous period. This should enable us to resolve the controversy surrounding the volcanic-versus-impact origin of anomalous geochemical concentrations.

Early Paleovene sediments indicalte that diagenesis has alfecled the tratceslement geochemistry and stableisotope compositions at Zumaya. The degree of diagenetic alteration is correlated with lithology. The bestpreserved samples are sofi marls with high clay contents and limestones that have undergone early. permeability-reducing marine cementation. More porous sandstones and bedding-place veins show the greatest alleration and depleted stable-isotope values.

Plattinum and nickel grains perhaps represent the first direct evidence of siderophile-rich minerals at the $\mathrm{K} / \mathrm{T}$ boundary. The presence of spinels and nickel-rich particles as inclusions in aluminosilicate spherules from Zumaya suggests an original. nondiagenetic origin for the spherules. The chemistry and morphology of the platinum grains. spinels. spherules, and nickel-rich grains most closely match chondritic lireball or ablation dehris. This linding suggests that a substantial portion of any proposed $k / T$ holide(s) may have burned up in the earth s atmosphere. A volcanic origin for the houndary particles is incompattible $w$ ith the chemistry of the Zumaya particles. Chalcophile elenents appear to have an authigenic origin and may be derived from seawater or an carly diagenetic enrichment.

Our research represents a new approach in trying to directly identify the sedimentary mineral components that are responsible for trate-element concentrations associated with the $\mathrm{K} / \mathrm{T}$ boundary. These techniques are currently being used on several other we!l-preserved marine and terrestrial $\mathrm{K} / \mathrm{T}$ sections. Such applications maly provide valuable information that could resolve the controversy surrounding the possibility of multiple $\mathrm{K} / \mathrm{T}$ houndary events. the volcanic-versus-impact origin for anomialous geochemical concentrations. and the relation of these facturs ou hiotic extinctions. 


\section{Nondestructive Gamma-Ray Analysis of Uranium-Series Nuclides in Volcanic Rocks}

Principal Investigator: J. D. Macdougall* Co-Investigators: R. Finkel and $K$. Rubin*

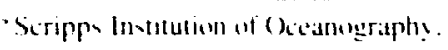
I mersals of Cahtornta. San Diegu.

$\mathrm{T}$

he aim of our work has

been $t 0$ assess the feasibility of nondestructive measurements using the $\mathrm{Ge}(\mathrm{Li})$ detectors belonging to the LLNL Nuclear Chemistry Division to analyze uranium-series nuclides in young volcanic rocks. Earlier work indicated that. for samples having uranium concentrations in the partsper-million range. this method would be most useful for measurement of

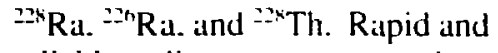
reliable radium measurement is important in our studies. With its approximately I $h(1)$-year half-life.

We are investigating the use of nondestructive techniques to analyze uranium-series nuclides in an effort to understand the extent and time scale of chemical fractionation in volcanic processes.

- Ra is ideally suited to the investigation of processes occurring in magma chambers of young volcanoes because it has the same time scale as the processes of interest. Moreover, radium is a chemical analog of barium. an important trace element in geochemical modeling: ${ }^{22 x} \mathrm{Ra}$ is especially useful for very young volcante rocks. The ${ }^{2 x} \mathrm{Ra} /{ }^{20} \mathrm{Th}$ diseyuilibrium could provide svidence of recent fractionation acompanying or immediately preceding volcanic eruption.
Over the past year. we have successfully completed nondestructive measurements of 2"Ra using Ge(Li) detectors. Our measured activities generally agree with those we determined using the destructive radon-emanation technique at the Scripps Institution of Oceanography. Such measurements help constrain the extent and time scale of chemical fracionation in volcanic processes. We plan to extend our work to samples with lower activity levels. 


\section{Stable Isotope Ratios of Reactive Metals in Seawater \\ We are obtaining precise measurements of lead isotope ratios as a means for tracing the origin and flux of contaminant leads in the biosphere.}

Principal Investigator: A. R. Flegal* Co-Investigator: $S$. Niemeyer

*University of Califomia. Santa Cruz.

$\mathrm{O}$ ur objectives were to improve the analytical capabilities al LLNL for accurate measurements of stable lead isolopic compositions in small ( $1-n g$ ) lead samples. In addition, we sought to use those measurements to study the biochemical cycle of lead in the marine environment. We require precise meas'irements of lead isotopic compositions because most concentrations of lead in seawater are $<5 \times 10^{-12} \mathrm{~mol} / \mathrm{kg}$, and isotopic ratios must be accurate to at least four significant figures for environmen al research. Measurements of the isotopic composition of lead are extremely useful because they provide a fingerprint of its origins and may be used to trace the flux of contaminant leads in the biosphere.

We have developed ultraclean techniques for measurements using thermal-ionization mass spectrometry of stable lead isotopic compositions in water samples. The lead concentrations in the samples are one part per $10^{12}$. We are using these geochemical fingerprints to identify sources of contaminant leads in the Great Lakes, the Antarctic, and the
North Pacific (see Figure 1). Fluxes of industrial lead currently account for more than $95 \%$ of the total lead fluxes to those three systems. We are also investigating the applicability of our measurements as tracers of associated contamination. including that arising from acid rain.

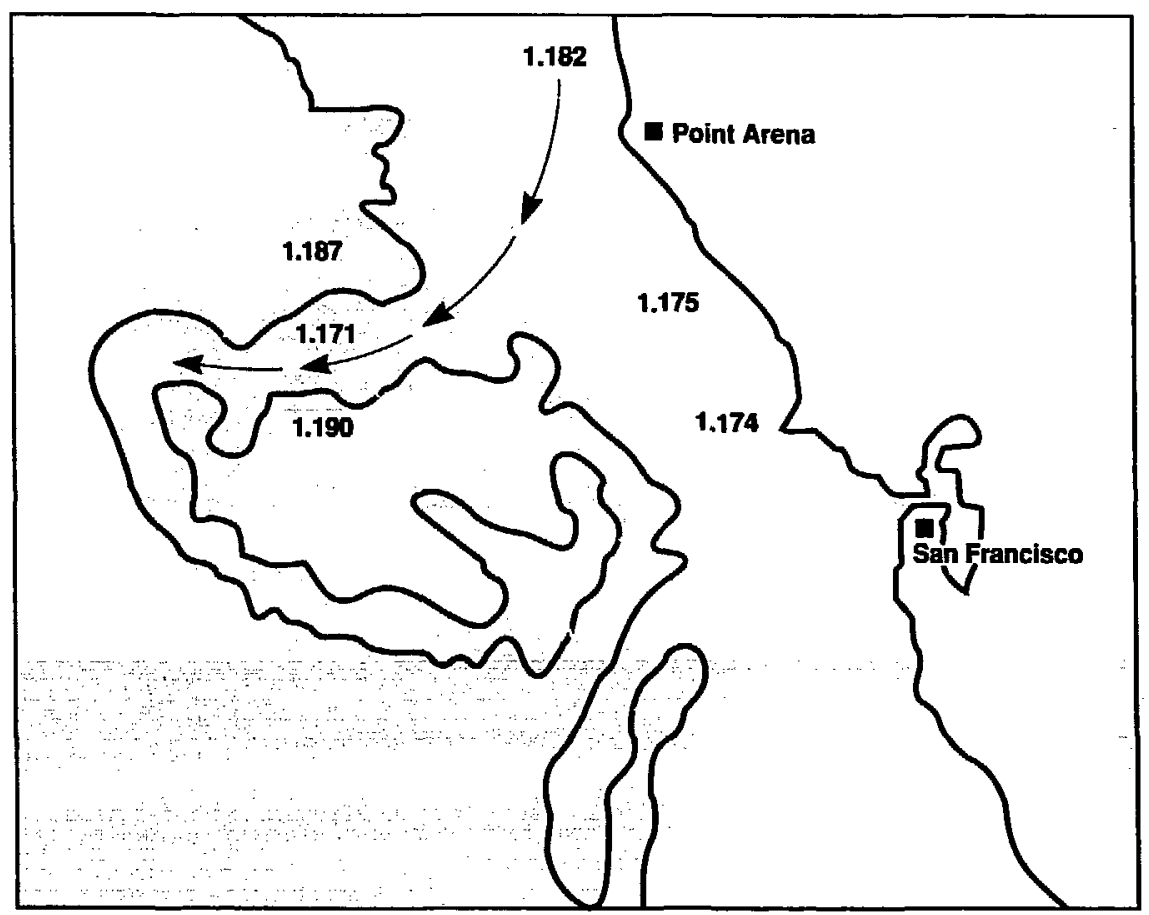

Figure 1. Ratios of ${ }^{206} \mathrm{~Pb}$ to ${ }^{207} \mathrm{~Pb}$ from surface waters in an upwelling filament (colored arrows) off the coast of central California. The filament outline is derived from satellite imagery of the thermal boundary. 
Multiwavelength Study of the

Continuum in Active Galactic Nuclei

\author{
Principal Investigator: M. Malkan*
} Co-Investigator: D. Band

* Liniversity of Culitornia. Los Angeles.

$\mathrm{H}$ ow trillions of solar luminosities are released within a light day of the center of an active galactic nucleus (AGN) has not yet been determined. In the standard theoretical scenario, material accretes through an accretion disk onto a massive black hole, which powers a surrounding source of $x$ rays and gamma rays. Our goal was to combine a model for the accretiondisk spectrum with a model for a nonthermal source surrounding the black hole to explain the radiation continuum. We fit observed spectra to derive the basic quantities that characterize the source. such as mass of the black hole and radius of the nonthermal source. With these quantities, we can investigate the physics of the central engine.

We modeled the continua, from infrared through gamma rays, of an AGN by combining the accretion disk of Malkan and Sun with the nonthermal source model of Band (1987). The accretion-disk model adds relativistic effects to the emission from an optically thick,
We are attempting to explain the radiation continuum, from infrared through gamma rays, of active galactic nuclei by combining a model for the accretion-disk spectrum with a model for a nonthermal source surrounding a black hole. geometrically thın accretion disk. In the nonthermal source model. relativistic electrons radiate the infrared continuum by synchrotron emission and the $\mathrm{x}$-ray spectrum by inverse Compton scattering of ultraviolet photons from the accretion disk. The electron distribution consists of a flat $\left(\gamma^{-2.4}\right)$. low-energy component and a steeper $\left(\gamma^{-3.4}\right)$, highenergy component, where $\gamma=E / m c^{2}$ is the electron Lorentz factor.

We found that the typical AGN in ou. iample has a black hole of mass $\sim 4 \times 10^{8} \mathrm{M}_{\odot}$ at its center (where $\mathrm{M}_{\odot}$ is the solar mass), a total thermal and nonthermal luminosity of about onehalf the Eddington luminosity, and an accretion rate of $\sim 0.4 \mathrm{M}$ per year. The high accretion rate indicates that the approximation of a thin accretion disk is only marginally acceptable. Because the AGN lifetime is short, $\sim 10^{9}$ years, the activity in a given galactic nucleus is short-lived compared to the age of the universe. The nonthermal suurce has a radius of $\sim 2 \times 10^{15} \mathrm{~cm}$, a relativistic electron density of $-5 \times 10^{6} \mathrm{~cm}^{-3}$, and a magnetic field of $\sim 200 \mathrm{G}$. Consequently, the photon and magnetic fields are in rough equipartition, while the relativistic electron energy density is smaller by a factor of $10^{3}$. In an inhomogeneous source, the electron density could be greater. The luminosities of the nonthermal infrared. ultraviolet accretion disk and the nonthermal $\mathrm{x}$-ray to gamma-ray continua are comparable. Our combined model of an accretion disk and a nonthermal source reproduces quite well the observed spectra of the ten AGN we have studied so far.

\section{References}

Band, D. L. (1987). “On Nonthermal Models for Active Galactic Nuclei." Astrophss. I. 321, 80 .

Band, D. L., and M. A. Malkan (198x). Symhesis of Accretion Disk and Nonthermal Sontce Models for Active Galactic Nuclei. Lawrence Livermore National Laboratory. Preprint UCRL97451. 


\section{Modeling Supernova Spectra}

Principal Investigator: S. Wousley* Co-Investigators: T. Axelrod, P. Pinto,* and D. Hartmann*

*Lniversity of Califomia. Santa Cruz.

$\mathrm{T}$ he term "supernova" refers to the giant explosions of aging. massive stars. The most spectacular event in the history of the study of supernovas occurred in February 1987. This event was the supernova in our neighboring galaxy, the Large Magellanic Cloud (LMC), and is known to astrophysicists as SN 1987A.

We traveled to Christchurch, New Zealand, in April 1987 to observe SN 1987A in the infrared using the NASA Kuiper Airborne Observatory. We obtained highquality spectra during the April flights that covered the region from 3-11 $\mu \mathrm{m}$ at energy resolutions of $3000 \mathrm{~km} / \mathrm{s}$. In addition, we observed the argon $6.9-\mu \mathrm{m}$ and nickel $6.6-\mu \mathrm{m}$ lines at high resolution $(300 \mathrm{~km} / \mathrm{s})$.

We are modeling the energy budget, spectra, and other features of the February 1987 supernova in the Large Magellanic Cloud after obtaining high-resolution images of that Type II event.

The resulting profiles showed both asymmetric tails to the red end of the spectrum and an overall red shift of the profiles in excess of the $\mathrm{LMC}$ recession velocity. We have explained the red line shifts and asymmetries observed in the infrared as the effect of radiative transfer through an expanding cloud of electrons. Model profiles fit to the data yielded an electron column depth at 400 days, which agrees with predictions of models for radioactivedecay ionization.

We have also continued our work on modeling the energy budget and emergent spectra of ejecta from SN 1987A. We have produced synthetic spectra from self-consistent models of the ejecta, which include all elements and ionization stages observed in SN 1987A and in other supernovas. These models agree reasonably well with infrared observations, especially of lowionization infrared lines of nickel. argon, and cobalt. We are beginining our work on optically thick line calculations for earlier-time spectra of SN 1987A; however, few results are yet available. Finally, we are now working with researchers at the Cerro Tololo Inter-American Observatory in Chile in an effor to match recent optical observations because the optical spectrum of SN 1987A increasingly resembles the Type Ib supernova spectra that Chilean researchers investigated previously. 


\section{Neutron-Rich Nucleosynthesis}

\author{
Principal Investigator: S. Wousley* \\ Co-Investigators: (i. Mathews and \\ D. Hartmann*
}

Lniversity of Calitomea. Santa Cru/.

$\mathrm{O}$ ne of the principal problems in nucleosynthesis continues to be the origin of $r$-process nuclei. which are nuclei that are more massive than iron and have neutron-to-proton ratios that are higher than average. The $r$ process is a proposed mechanism for making such nuclei by rapidly growing seeds of iron in an environment that is rich in neutrons. General trends and requirements are known. but despite enormous efforts invested during the last 30 years. a specific site that renders the requisite neutron flux. temperature. and time scale is still lacking. We have combined the special expertise at LLNL and UC Santa Cruz in this area to carry out two studies relevant to the $r$ process: nucleosynthesis of neutron-rich matter in nuclear statistical equilibrium (NSE), and neutrinoinduced neutron spallation.

Abundances in NSE are sensitive to uncertainties in the partition functions at finite temperature, nuclear-force parameterization, Coulomb shifts in strongly coupled plasmas, freeze-out corrections, nuclear binding energies, and other effects. We have studied the sensitivity to nuclear binding properties because they enter the

\section{We are examining the nucleosynthesis of neutron-rich matter and the interaction of neutrinos with various shells of heavy elements ejected during a Type II supernova explosion.}

calculations exponentially in the nuclear Saha equation. The binding energies of experinientally inaccessible nuclei atre detenmined by an extrapolation scheme that relies on a nuclear mass law. Errors associated with this method increase with distance from the valley of $\beta$ stability. which reters to those isolopes (defined by atomic mass and atomic number) that do not decay by emission of an electron or positron or the capture of a positron. We calculated neutron-rich equilibrium mass fractions. Final abundances were calculated atter $\beta$ decay to the stable isotopes. Concentrating on the abundances of those isotopes that exhibit strong meteoritic isotopicabundance anomalies, we conclude that neutron-rich equilibrium abundances are uncertain by a factor of about two. Our earlier conclusions (Hartmann et al.. 1988) werc that nucleosynthesis of ${ }^{48} \mathrm{Ca},{ }^{51} \mathrm{Ti},{ }^{34} \mathrm{Cr}$, and ${ }^{6} \mathrm{Ni}$ occurs within neutron-rich zones that have achieved NSE. These conclusions have been confirmed by recent high-precision measurements of meteoritic isotopic anomalies (Birck and Lugmair, 1988).

We also studied the interaction of neutrinos with the various shells of heavy elements ejected in a Type II supernova. such as SN 1987.4. Here. inclastic neutral-curtent neutrino scatlering on nuclei in or near their ground state can lead (o) the excitation of particle-unbound states that decay by neutron or proton emission. For specific calibration. we adopted initial radii and densities for a 2()$-\mathrm{M}$. star. This choice of mass is a representative value for supernovas responsible for producing the solar abundance set and has the additional advantage of affording direct comparison with abundances that might ultimately be measured in SN 1987A. We found that the resulting abundance yields are extremely sensitive to the radius of the interaction zone. Our preliminary results indicate that the neutrinoinduced $r$ process does not yield abundances comparable to the observed $r$-process elements in the solar system because neutron densities are too low.

\section{References}

Birck. J. L.. and G. W. Lugmair (1988). "Nickel and Chromium Isolopes in Allende Inclusions." Earth amd Plame'. Si'i. Le'fr. 90. 131.

Hartmann. D.. S. E. Woosiley. and M. F. El Eid (1988). "Nucleosynthesis in Neutron Rich Supernova Ejecta." Astrophss. J 297. $\$ 37$. 


\section{High-Spatial- Resolution Detectors for Hard-X-Ray Imaging}

\author{
Principal Investigator: \$. Kahn* \\ ( u-Investigator: (). Siegmund* and \\ C. Haile!

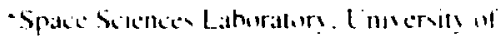 \\ Califumia. Hethele?
}

$\mathrm{T}$

he aim of our study was to

investigate the feasibility of using a high-spatial-resolution image intensitier coupled to an alkali-halide scintillator crystal for hard-x-ray imaging. Computer modeling in support of this effort would determine if the observation of cosmic $x$-ray sources could be done with high enough sensitivity to yield an astrophysically useful instrument.

The design we have adopled is quite different from the one we originally proposed. The original design involved an image intensifier that was available at LLNL. This device. however. proved to have disappointing energy resolution.

We became aware of a phototube that was commercially available and could image a multiphoton input. Its large area $\left(16 \mathrm{~cm}^{2}\right)$ and lack of

We are investigating a new phototube and various geometries for a device that could be used to obtain useful astrophysical data on cosmic hard-x-ray sources.

optical-liber faceplate suggested that it might make a good imaging unit for the $x$-ray imaging spectrometer (XRIS). We evaluated one of these tubes coupled to scintillator crystals and obtained good energy and spatial resolution $(\sim 10 \%$ and $\sim 1.5 \mathrm{~mm}$ at $100 \mathrm{keV}$ ). Thus. the XRIS with an imaging-proportional (IP) counter could serve as the basis for a balloon payload without need for opticalfiber couplers. Although we would have to array many of these tubes. their low cost makes this process feasible.

We performed additional studies on the new phototube to understand the scaling of spatial resolution with crystal thickness and $x$-ray energy. We used crystals both with and without entrance windows. The difference between geometries can be substantial in that each can modify the width of the light cloud reaching the photocathode and. hence. the spatial resolution. We successfully modeled our results for a crystal with a window. Our results for crystals without entrance windows are much better than might be naively expected from our model. We hope to better understand this surprising outcome in the future.

We have also evaluated the science that could be done with XRIS. We used our experimental results as input for the computer model to determine sensitivities of the XRIS payload for a variety of potential cosmic hard- $x$-ray sources. It is now clear that XRIS can be used to study the center of our galaxy and giant clusters of galaxies at photon energies that are greater than those previously possible. 


\title{
Measurement of We have characterized the properties of stepped-index, Optical Fibers to be fused-silica, $U V$-transmitting optical fibers that are candidates Used in Multiobject Spectroscopy for use in a multiobject spectrograph.
}

\author{
Principal Investigator: J. P. Brodic \\ Co-Investigator: C. J. Hailey
}

$\mathrm{T}^{\mathrm{s}}$ he goal of this project is to develop a spectroscopic instrument that will dramatically increase the efficiency of the 120-in. telescope at the UC Lick Observatory. Currently, astronomical spectra are collected one object at a time. A multiobject spectrograph is being developed that will collect light from 100 separate optical fibers located on the focal plane of the telescope and channel the light to a floor-mounted spectrometer $30 \mathrm{~m}$ away. The ability to gather 100 spectra simultaneously will permit: new projects that require large statistical samples of astronomical spectra.

A crucial issue in the development of this instrument is the performance of the optical fibers that channel the light to the spectrograph. The light transmission of these fibers must be high enough to ensure good sensitivity of the instrument. Also important is the focal ratio degradation of the fibers. which is the change in the effective speed of the telescope output beam after light passes through the fibers. Focal ratio degradation results from the presence of microbends in the fibers. stresses on the fiber ends. and facial

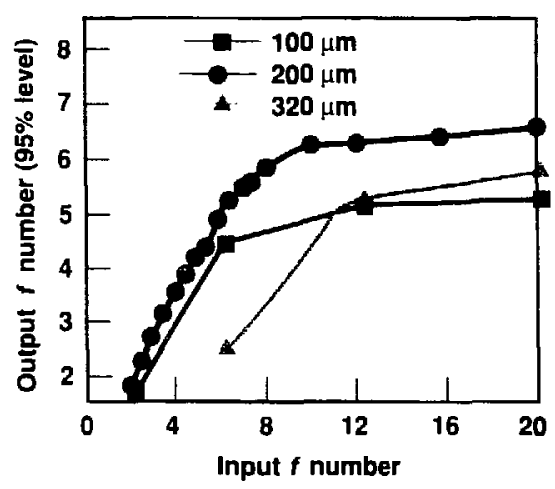

Figure 1. Output for various input $f$ numbers for three fiber diameters. The relatively low value for the $320-\mu \mathrm{m}$ core fiber may be a result of a stressed end mounting. roughness. Thus, the way in which the optical tibers are polished and mounted is very important.

Typical data on focal ratio degradation are shown in Figure 1. The data indicate that the $100-\mu \mathrm{m}$ diam core fibers. which are best matched to the Lick stellar seeing disk, would greatly degrade the beam $f$ number. The data also show that the specially polished and mounted, $200-\mu \mathrm{m}$-diam core fibers will produce an output beam that will not significantly degrade the Lick prime focus input beam (slightly faster than $f / 5$ ).

We have selected and characterized optical fibers which, when properly mounted and polished. are acceptable in terms of fiber focal ratio degradation and optical and UV transmission. Our experiments have produced key data that have enabled us to optimize the design of the multiobject spectrograph. 


\section{Astrophysical Studies of CNO Isotopes}

Principal Investigator: M. Jura* Co-Investigators: D. Dearborn and

1. Hawkins

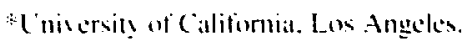

$I^{n}$ n yualitative ternos, it is well established that most of the material heavier than helium was synthesized in stars rather than in the Big Bang. However, quantitative details of the process of nucleosynthesis. and the resultant chemical evolution of the galaxy. are still uncertain. In particular, because carbon. nitrogen. and oxygen are the most abundant elements after hydrogen and helium. and because the carbon-nitrogen-oxygen ( $\mathrm{CNO}$ ) tricycle is so important as an energy source within stars. we have concentrated our efforts on understanding the abundances of these three species.

We used stellar evolution and nucleosynthesis computer codes to calculate ${ }^{12} \mathrm{C} /{ }^{13} \mathrm{C},{ }^{16} \mathrm{O} / /^{17} \mathrm{O}$. and ${ }^{16} \mathrm{O} /{ }^{18} \mathrm{O}$ abundance ratios on the surfaces of stars with masses in the range 0.8 to $25 \mathrm{M}_{5}$. We compared the predicted surface-oxygen ratios in these stars to existing observations to set more stringent limits on the destruction rates of ${ }^{17} \mathrm{O}$ and ${ }^{18} \mathrm{O}$. via the reactions ${ }^{17} \mathrm{O}(\mathrm{p}, \alpha){ }^{14} \mathrm{~N}$ and ${ }^{18} \mathrm{O}(\mathrm{p}, \alpha){ }^{15} \mathrm{~N}$, which are theoretically uncertain by up to two orders of magnitude. In addition. the behavior of our calculated oxygen abundance ratios can be used as a sensitive observational test of the depth of convection in stars whose measured carbon isotope ratios agree

We are combining theory with observations to help explain the history of element production in our galaxy, particularly that of carbon, nitrogen, and oxygen.

with the ${ }^{12} \mathrm{C} / 1 . \mathrm{C}$ values predicted by our models. This serves as evidence that observed oxygen-abundance ratios are the consequence of normial stellar evolution followed by convective mixing that brings material from the star's interior to the surface. and that the star has not suffered additional nonconvective mixing processes. This objective is important because it can lead to a better understanding of which stars undergo more extensive convective mixing of material and are thus the major contributors of processed elements to the interstellar medium.

We are now preparing for publication the results of our calculations of a grid of models of stars with masses in the range 0.8 to $25 \mathrm{M}$. to obtain carbon and oxygen isotope ratios, in particular ${ }^{12} \mathrm{C} /{ }^{1.3} \mathrm{C}$. ${ }^{16} \mathrm{O} /{ }^{17} \mathrm{O}$. and ${ }^{16} \mathrm{O} /{ }^{1 \mathrm{~h}} \mathrm{O}$. In evolved models of stars up to $15 \mathrm{M}_{-}$, we found that after hydrogen exhaustion in the core and a first dredge-up of material. surface ${ }^{12} \mathrm{C} /{ }^{1.3} \mathrm{C}$ ratios are on the order of 22 , which is considerably lower than the solar value of 89 . The enhanced ${ }^{13} \mathrm{C}$ abundance can be understood in terms of an incomplete CNO cycle operating in a thin shell outside the hydrocen-burning core in the main sequence phase. Here. the temperature is hot enough to burn "'C $10^{1:} \mathrm{C}$ hut not $10^{14} \mathrm{~N}$. These predicted carbon isotope ratios are. thus. the conseyuence of normal stellar processing followed by convective mixing.

The ${ }^{16} \mathrm{O} /{ }^{17} \mathrm{O}$ surlace ratios were found to decrease from the solar value of 2600 to 800 . 106. and 6?. for the 1.3-. 2.0-. and 3.()-M. stars. respectively. Implementation of two extreme theoretical destructicin rates of ${ }^{-17} \mathrm{O}$ and ${ }^{18} \mathrm{O}$ in the nuclensynthesis of models evolved through the first dredge-up does not change the ratios predicted above because the convective layer has not had a chance to dig deeper into the star and reach more processed material.

We pushed the computational evolution past helium ignition in the more massive stars. using the two extreme choices of ${ }^{17} \mathrm{O}$ destruction rates. After comparing our calculations with infrared $\mathrm{CO}$ observations of red giant photospheres. we conclude that the higher destruction rate is the more appropriate choice. Our results also suggest that theory and observation can be reconciled only if the conveclion layer in stars of masses less than $3 \mathrm{M}$. attains a depth that is somewhat less than that previously calculated. By periorming a similar analysis. we have found that the lower ${ }^{16} \mathrm{O}$ destruction rate is clearly more consistent with the observalions. 


\section{The Interface of Astrophysics and Particle Physics}

Principal Investigator: J. Silk"

Co-Investigators: D. Dearborn and

(i. Raffelt*

- Iniversil! of Callfomia. Berkeley.

$\mathrm{O}$ ur goal is to explore the interface of astrophysics and particle physics in cosmology. Constraints from the cosmological production of helium and deuterium and from the observed extreme isotropy of cosmic microwave background radiation may have effectively eliminated ordinary baryonic matter as a candidate for pervasive dark matter. Our new approach provides plausible elementary-particle candidates for the dark matter that pervaies our universe and promises to account for the extreme isotropy of cosmic blackbody radiation. now known to be more than 3 parts in 105 on scales ranging from 5 arc-minutes up to 90 deg. It tentatively accounts for the

\section{We are developing an interdisciplinary approach to astrophysical probiems in an attempt to understand the nature of dark matter in the universe.}

origin of the fluctuations from which galaxies and galaxy clusters formed. Our aim is to develop a coordinated. interdisciplinary approach to astrophysical problems. involving input from particle physics. with emphasis on constraining the nature of dark matter.

The theory of stellar evolution. in conjunction with observational data. yields important information on the nature and distribution of particle dark matter in the universe. We can. for example, use low-mass stars as a probe for dark matter in galactic nuclei. the'n review astrophysical axion bounds to understand constraints on the possible interprelation of the cosmic microwave background distortion in terms of late particle decays. Thus. the observed lifetimes of horizontal branch stars yield an upper bound of $3 \times 10^{-511} \mathrm{~cm}^{2}$ for the process $\gamma+{ }^{+} \mathrm{He} \rightarrow{ }^{+} \mathrm{He}+\mathrm{X}^{0}$ involving some hypothetical boson $X^{\circ}$. This result excludes a recent interpretation of the angular distribution of the IMB and Kamioka signals of neutrinos from SN 1987A in terms of the coherent scattering process $\mathrm{X}^{\circ}+{ }^{16} \mathrm{O} \rightarrow$ ${ }^{16} \mathrm{O}+\gamma$.

The observation of a neutrino pulse from SN 1987A constrains the production of light, exotic particles in the protoneutron star. We are investigating recently derived bounds on axion parameters. the strength of right-handed weak currents. Dirac masses of neutrinos. neutrino magnetic-dipole moments, and bounds on the neutrino-majoron coupling. 


\section{Plasma Astrophysics}

Principal lnvestigator: J. Arons* (in-Investigators: K. Klein, A. B. Langdon. C. Max. D. Adsop.* D. Burnard.* Y. CallanI.* I). Hartmann, $\div$ S. Woosley, $\div$ and $A$. Zachary**

( Imerosts of Califormat. Berheles

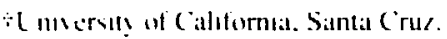

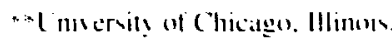

$\mathrm{T}$ he first goal of our rescarch project was to study the basic physics of relativistic shock waves in electron-positron plasmass. with application to the origin of synchrotron emission in supernova remnants powered by pulsars and to the nonthermal emission from jets emanating from active galactic nuclei. Part of this effort was oriented toward modeling the electromagnetic waves created as part of the shock structure because these waves provide the conduil for energy into nonthermal particles. In this work. we made use of an existing LLNL plasma-simulation computer code whose properties are ideally suited to studying the electromagnetic phenomena associated with relativistic shocks.

Our second research goal was to investigate the physics of accretion onto the polar caps of magnetized neutron stars when radiation pressure

\section{We are attempting to understand the origin of nonthermal energy in astrophysical systems.}

is ihe dominant effect controlling the deceleration of plasma. This ffort is directed primarily loward understanding the temporal fluctuations and polarimetric content of the emergent radiation observed in $x$-ray binary stars. These values provide powerful diagnostics into the flow structure and magnetic fields of accreting neutron stars. Our research in this area made use of radiation hydrodynamics and radiation-transfer computer codes that were developed at LLNL for this work.

We have completed a study of the cyclotron-reprocessing efficiency of gamma rays in the outer magnetosphere of a magnetized neutron star under conditions appropriate to sources of gamma-ray bursts. In this work. we attempted to model the optical and ultraviolet emission from isolated. old neutron stars undergoing gamma-ray bursts. All other models for this phenomenon reyuire a surrounding disk or a companion star as the sile of the reprocessing matcrial.

We have also completed a study of the propagation of a low-density beam of ions through a magnetized plasma. The goal of this work was to understand the excitation of largeamplitude hydromagnetic waves upstream from a collisionless shock and to compare this effect with satellite measurements made upstrean of the earth's bow shock.

Finally, we have studied the role of cosmic rays upstream of a supernova remnani's shock wave in the excitation of large-amplitude density 17utuations in the interstellar mediun. In this research, we were interested in a possible explanation for the pockets of strong scintillation observed in the radio flux of pulsars. 


\section{Fractal Dust Grains We are using the discrete-dipole approximation to study \\ Principal In estigator: F.. Wright* Co-Investigators: $C$. Alcoek and absorption and siattering properties of fractal dust grains in the solar system.} l. Hawkins

- Eniversity of Calitomiat Los. Angeles.

A significant proportion of dust particles in the solar system are loose aggregations with low mean density. These structures can best be described using fractal geometry. which is known to be appropriate for particles that grow by slow aggregation. Traditional models of optical and infrared absorption and scattering by interstellar grains have considered only solid particles with simple topologies. The objective in

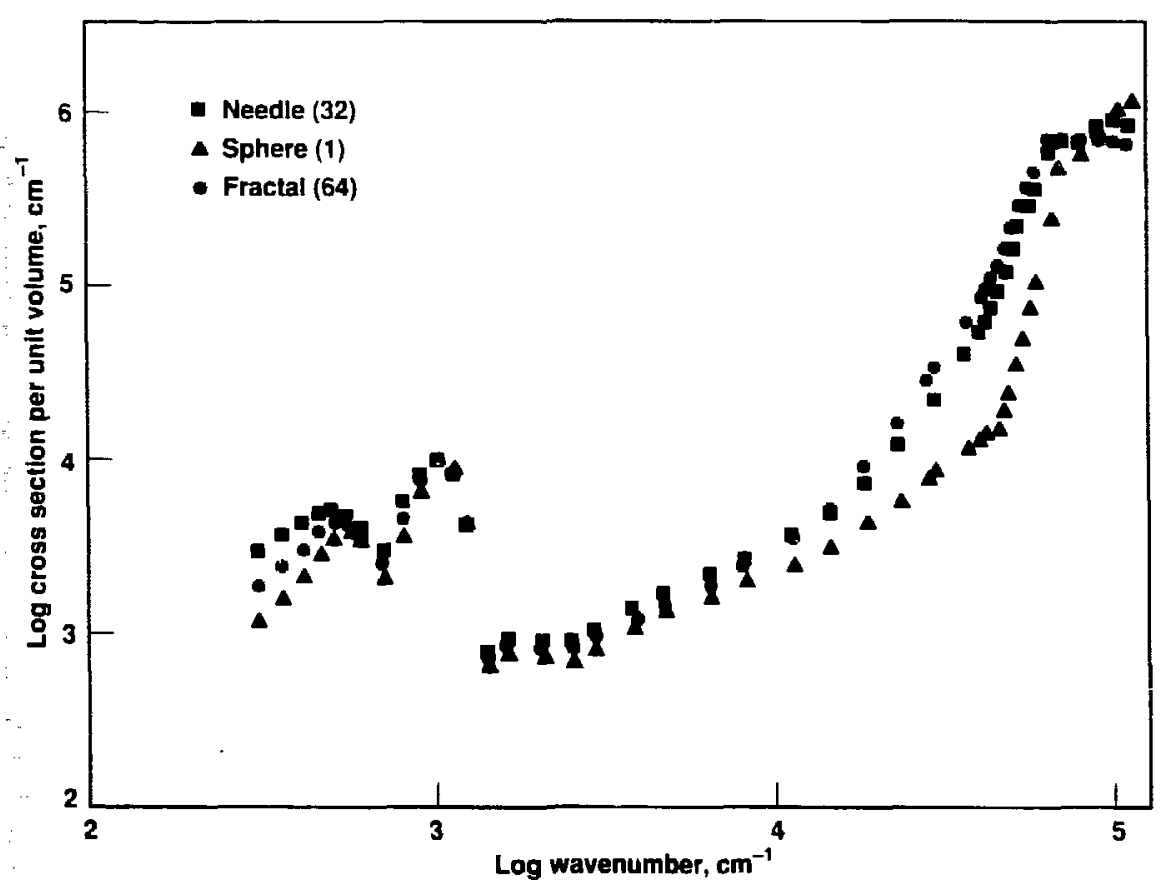

Figure 1. Cross section per unit volume of solid material as a function of wavenumber for grains of three different shapes: needles, spheres, and fractals. Numbers in parentheses are the number of unit cells used in the construction of the grains.

our project was to study the absorption and scattering properties of tractal dust grains. We have now made substantial progress toward this objeclive.

We used the discrete-dipole approximation, in which many small regions of one grain are described using interacting dipoles to model the interaction of the grain with radiation. We have found that fractal grains have much greater cross sections for interaction with radiation than do solid grains with similar masses, as shown in Figure l. This result is potentially of great importance because fractal dust grains may dominate the infrared background radiation in some of the channels of the Cosmic Background Explorer Satellite, which is scheduled for launch in 1989. 


\section{Statistical Mechanics and Phase Equilibria of Ionic and Geophysical Systems at High Pressure}

\author{
Principal Investigator: M. Hukowinshi* \\ (o-lnsebtigators: N. Ross and \\ I.. Stivrude*

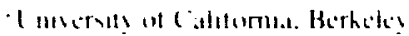

$\mathrm{R}$ ecent discussions of the chemical and thermal evolution of the earth's interior have been intluenced considerably by the realization that. al pressures in excess of those corresponding to depths of about $200 \mathrm{~km}$. the density of magmas might exceed that of crystal phases with which they are in equilibrium. If this concept is true. it would place an upper bound on the depth from which certain magnas can rise to the surface, and it may suggest that there are significant compositional differences between the lower and upper mantles. Evidence for densc liquids comes mainly from shockwave data and is not entirely conclusive. The main purpose of our project is to model liquid silicates and to obtain information on the behavior of these liquids when they

We are using computer simulations to model liquid silicates in an effort to understand their behavior under extreme pressure.

are subjecled lo pressure. Inteled. detailed structural information can be ohtained on! y through computer simulations.

We investigated the effect of pressure on the structure of tetrahedrally bonded liquid $\mathrm{SiO}$, by using Monte Carlo simulations balsed on a covalent potential model of letralledral Si-O bonding. The simulated liquid has aero-pressure density. structure. and compressibility that are in good agreement with experimental observations. The corresponding propertics and known equations of statc of the crystalline phases are also reproduced accurately. The liquid compresses by a continuous rearrangement, of the internicdiaterange order. as evidenced by a tightening of the ring-size distribution around six-membered rings. Elfeclive Si-0 conordinations (1) greater than four were not ubserved even at sol GiPa ol pressure: the first and second coordination shells remain distinet. Hence. a change in local bonding that increalses the number of $\mathrm{Si}-\mathrm{O}$ honds per silicon alom. e.g... a rehybridization of silicon orbitals. seems to be required to achieve coordinations higher than four in liquid $\mathrm{SiO}_{z}$. Even though the coordination number of the model liquid does not exceed four, its density surpasses that of all Latrahedral crystal phases by 60 GPa. $\mathrm{SiO}$, glass has a measured densily $10 \%$ higher than the model liquid at high pressure. suggesting the presence of sixfold coordination in the glass. 


\section{Dy namic High- Pressure Synthesis of High-Temperature Superconductors and Ferromagnets}

\author{
Principal Ins estigator: M. B. Maple* \\ Co-Investigators: W. Vellis, J. Neumeier.* \\ C. Seaman.* and J. Markert*

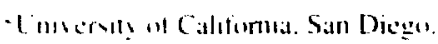

W c' have used high dynamic pressure, yenerated by the

LLNL iwo-stage light-gas gun, to synthesize (Neumeier e't al. 1988) and compact (Nellis 't al.. 1988) superconducting materials. We are attempting to produce superconductors with high critical temperature $(T)$. high critical current density $(J)$. and high upper eritical magnetic field $\left(H_{i 2}\right)$. We have achieved dynamic pressures up to 1 Mbar. temperatures up to a few thousand kelvins. pressure quench rates up to $10^{1-}$ baris. and thermal quench rates up $1010^{4} \mathrm{~K} / \mathrm{s}$.

Our principal goals are to fabricate high-l. conductors by means of shock compaction of the "new high- $T_{\text {c }}$ copper oxides and shock synthesis of new high- $T_{c}$ materials. Shock compaction of powders has the potential to produce high $J_{\text {. }}$. because compressive energy is deposited heterogeneously at grain boundaries, the region limiting $J_{i}$.

We are attempting to fabricate high-critical-current-density conductors by means of shock compaction of new copper oxides and shock synthesis of new high-critical-temperature materials.

All specimenss were prepared and then characterized at UC San Diego hefore and after processing with the LLNL two-stage light-gas gun.

Shock-compacted specimens of $\mathrm{YBa}_{2} \mathrm{Cu}_{3} \mathrm{O}_{7-6}$ and $\mathrm{HoBa}_{2} \mathrm{Cu}_{3} \mathrm{O}_{7}$ powder mixed with 30-and 50 -vol\% silver powder were prepared via the light-gas gun in the pressure range of 3-22 GPa. Subsequent measurements of magnetic susceptibility on specimens compacted from small $(<28-\mu \mathrm{m})$ and large $(>180-\mu \mathrm{m})$ powders showed that bulk superconductivity is retained in this pressure range. with $T$ onsets unchanged at $91 \mathrm{~K}$. but with an apparent broadening of the transition. Measurements of electrical resistivity revealed a change in slope at 60 and/or $90 \mathrm{~K}$ for most samples. We observed a complete resistive transition al $T_{\mathrm{L}}=90 \mathrm{~K}$ only after a specimen was annealed at $890^{\circ} \mathrm{C}$ in oxygen.

We have also prepared samples of the high- $T_{\text {, copper-oxide }}$ superconductors $\mathrm{Bi}_{2} \mathrm{Sr}_{2} \mathrm{CaCu}_{2} \mathrm{O}$ $\left(T_{c}=88 \mathrm{~K}\right)$ and $\mathrm{Tl}_{2} \overline{\mathrm{B}} \mathrm{a}_{2} \mathrm{Ca}_{2} \mathrm{Cu}_{3}^{2} \mathrm{O}_{\text {, }}$ $\left(T^{\circ}=121 \mathrm{~K}\right)$ and have performed preliminary shock compaction experiments on these materials. Our results to date suggest that oxygenation of the intergranular region, either by postprocessing or in situ sources. is necessary to produce high $J$. Once the process for achieving high $J$ is developed using 0.2-g research-size specimens. the process could be scaled up in length using the high-explosive technology available at LLNL.

\section{References}

Nellik. W.J.. M. B. Maple. and T. H. Geballe (1988). "Synthesis of Metastable Superconductors by High Dynamic Pressure," SPIE. Mulitime tional Materials (SPIE. Bellingham. WA ) 878. 2.

Neumeier, J. J.. W. J. Nellis. M. B. Maple. M. S. Torikachvili. K. N. Yang. J. M. Ferreira. L. T. Summers, J. I. Miller. and B. C. Sales 119891 . "Metastable A15 Phisie Nha Si Sỵnthesized bỵ High Dỵnamic Pressure." High Pressume Res. I 1.3) (in press). 


\section{Melting and Other Phase Transitions of Solids at High Pressures}

Principal Investigator: M. Nicol* Co-Investigators: D. Young. M. Ross. and B. Barer*

- L merersily of California. Lon Aneceles

$\mathrm{M}$ elting and solid-solid phase transition:s reflect delicate energy balances between two phases of condensed matter. Thus. predicted pressures and temperatures of phase transitions are sensitive tests of statistical-mechanical models for both phases. Our project couples the expertise available at UC Los Angeles in measuring phase transitions at high pressures in diamond-anvil cells with LLNL expertise in modeling equations of state, especially melting curves of simple solids.

We have worked on several onecomponent systems (including Ar.

We are measuring phase transitions at high pressures in diamond-anvil cells and are modeling equations of state of simple solids.

$\mathrm{N}_{2}, \mathrm{O}_{2}$ ) and are extending this work to mixtures. Near room temperature. we have determined the $\left(\mathrm{O}_{2}\right)_{1}:\left(\mathrm{N}_{2}\right)_{1}$, $P-x$ diagram to more than 10 'GPa. where $x$ is the molar oxygen concentration and $P$ is pressure. We have also made measurements to pressures of $35 \mathrm{GPa}$ for a few compositions. We have discovered a new phase of the $\mathrm{N}_{2}-\mathrm{O}_{2}$ system at pressures above $11 \mathrm{GPa}$, the properties of which emphasize the differences among $\mathrm{O}_{2}-\mathrm{O}_{2}, \mathrm{O}_{2}-\mathrm{N}_{2}$, and $\mathrm{N}_{2}-\mathrm{N}_{2}$ interactions.

Mixtures of $\mathrm{N}_{2}$ and $\mathrm{O}_{2}$ in diamond-anvil cellis are béing characterized by Raman spectra of the vibrons and, when possible. lattice vibrations to determine the room-temperature isotherm of the binary $P-T-x$ phase diagram ( $T$ is temperature). We surveyed samples with compositions of $5.15,25,35$. 50.65 .75 and $90 \mathrm{~mol} \% \mathrm{O}$, to pressures of at least $10 \mathrm{GPa}^{-}$. In addition. we studied several compositions at pressures as high as $34 \mathrm{GPa}$. Below $10 \mathrm{GPa}$, the two components appear to be highly miscible. For $N_{\text {, }}$-rich samples, the vibron spectra of the cubic $\delta-\mathrm{N}$, phase suggest nonrandom mixing. The effects are especially noticeable ahove $11 \mathrm{GPa}$. It appears that $\mathrm{O}_{2}$ molecules preferentially occupy one of the sites and that the preference varies with pressure and/or composition. 


\section{Conductivity of Mantle Rocks at Subsolidus Temperatures}

Principal Investigator: S. Constable* Co-Investigator: A. Duba

"Inutute of Cicophysits and Planetars

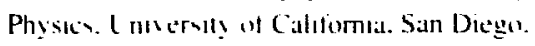

D alta on electrical conductivity of rock at high temperature below the sea floor are needed to interpret electromagnetic sounding data obtained from sea-floor controlled-source sounding (Cox et al., 1988). Dunite is a representative mineral for this purpose. We measured the electrical conductivities of several samples of dunite from Jackson County. North Carolina. having minor $(<10 \%)$ pyroxene and a grain size of approximately $1 \mathrm{~mm}$. Our measurements encompassed the temperature range of 20 to $1200^{\circ} \mathrm{C}$. We controlled the oxygen fugacity $\left(f \mathrm{O}_{2}\right)$ in the measurement environment by passing a $\mathrm{CO}_{2}: \mathrm{CO}$ mix through the conductivity cell.

We have measured the electrical conductivity of dunite, a representative mineral, to assist in the interpretation of data from sea-floor sounding.

The conductivity of dunite is much less than that of other uliramafic rocks reported in the literature and is comparable to single crystals of olivine of similar composition. Although our measurements were not made under pressure. the effect of cracking due to thermal cycling was not evident in the highly reproducible results on reversible conductivity. Some hysteresis, amounting to $0.3 \mathrm{log}$ units at most, appears to be dependent on heating and cooling rates and on $f \mathrm{O}$. This result suggests changes in defect density and type as a function of temperature at fixed gas mix, although reversible reactions between olivine and other phases in the rock and on the grain boundaries might also affect conductivity.
It has been often suggested that values for single-crystal conductivity might be smaller than those for polyerystalline materials because of enhanced conduction along grain boundaries and the effects of phases other than olivine in the upper mantle. Our results do not support this notion.

\section{Reference}

Cox. C. S.. S. C. Constable. A. D. Chave, and S. C. Webb (1988). "Controlled Source Electromagnetic Sounding of the Oceanic Lilhosphere." Nuture' 320. 52. 


\section{Measurement of We have modified an existing apparatus and designed a new Elastic Constants up device to extend the limit of elastic-constant temperature to $2000 \mathrm{~K}$ measurements from 1700 to $2000 \mathrm{~K}$.}

Principal Investigator: T. Goto* (o-Investigator: A. Duba

* Institute of Cieophysicis and Planetary Physics. Universily of Califomia. Los Angeles.

$\mathrm{K}$ nowledge of high-temperature elastic properties of minerals is needed for an understanding of the physics of the deep earth. In this domain, high temperatures are those well above the Debye temperature. which is the temperature above which all thermal vibrations of a crystal lattice are excited. Because Debye temperatures of representative minerals range from 600 to $1100 \mathrm{~K}$. data on elastic constants for temperatures well above $1000 \mathrm{~K}$ are of current geophysical interest.

The object of our project was to extend the limit of elastic-constant temperature measurements from 1700 to $2000 \mathrm{~K}$. For non-iron- containing silicates, our problem was to extend previous measurements by modifying the existing experimental apparatus. For iron-bearing minerals, on the other hand, our problem was to design a new device that could stabilize the partial pressure of oxygen surrounding a sample to a low level as the temperature increased.

Our previous success in obtaining $1700 \mathrm{~K}$ for elasticity measurements was due to separation of transducers from the sample by long polycrystalline corundum buffer rods. The rods allowed the transducer to remain at less than $1000 \mathrm{~K}$ while the specimen attained higher temperatures. By redesigning our buffer rods 10 accommodate some distortion without destroying alignment, we performed experiments on $\mathrm{Al}_{2} \mathrm{O}_{3}$ up to $1825 \mathrm{~K}$ (Goto and Anderson, 1988).

Increasing the temperature to $2000 \mathrm{~K}$ will require buffer rods made of zirconia. In addition, we have designed an apparatus to control the fugacity of our iron-containing sample at higher temperature and are now building this apparatus.

\section{Reference}

Goto, T. , and O. L. Anderson (1988), “An Apparatus for Measuring Elastic Constants of Single Crystals by a Resonance Technique up to $1825 \mathrm{~K}$." $R \mathrm{c}^{\prime} \mathrm{l}$. Sici. Inst. 59. 1405. 


\section{Emission Spectra from Simple Shocked Solids}

Principal Investigator: $\mathrm{M}$. Nicol* Co-Investigators: N.C. Holmes, H.-C. Cynn.* and S. Johnson*

*Lniversity of Califomia. Los Angeles.

$\mathrm{W}$ e are using the expertise available at UC Los Angeles in chemistry and spectroscopy at high pressures as well as that at LLNL in shock-wave generation and diagnostics to investigate the chemistry that occurs during shock compression of simple organic molecules. Our purpose is to understand the equations of state (EOS). transport properties, and chemical kinetics of planetary interiors.

Shock-wave studies of the EOSs of simple molecular compunds ( $\mathrm{CO}$. $\mathrm{CH}_{4}, \mathrm{C}_{6} \mathrm{H}_{6}$. and $\mathrm{N}_{2}$ ) suggest that these materials decompose at high shock pressures and temperatures. More complex organic conijouinds, including high explosives. also decompose during shock compression. Interpretations of the EOS data depend critically on assumptions about the products formed, their individual EOSs, and the rates of formation of the reaction products. Molecular spectroscopy might be used to identify products and intermea:ates of reactions and, in favorable cases, reaction kinetics. Thus, the goal of our project is to test

\section{We are testing the use of molecular and vibrational spectroscopy for analyzing the chemistry of shock decomposition in simple molecular systems.}

the value of molecular electronic and vibrational spectroscopy for analyzing the chemistry of shock decomposition in simple molecular systems.

We have shown that for singleand double-shocked benzene specimens, the emission spectra are simply broad and thermal in character (Nicol et al., 1988). Evidently, most of the reaction products are generated in their ground electronic states. This finding suggests that a technique that probes ground-state populations, such as absorption spectroscopy, may be usefully applied.

We have recently developed a new, double-beam, absorption spectroscopic instrument for use in shock-compression experiments.

This instrument uses optical fibers for sample illumination and detection of the absorption signal. In our previous work on emission spectroscopy, we learned that closedbeam, lensless systems are preferable for shock experiments. We obtain the absorption spectrum with a novel dual-array, linear-diode-array detector. This detector allows simultaneous recording of the light input to the specimen holder and the light that passes twice through the shocked sample. The system can be gated to allow a time resolution of about $50 \mathrm{~ns}$. We also added several photomultiplier detectors in narrowwavelength bands to record the time dependence of the absorption.

Our preliminary results indicate that adequate spectra can be obtained on a single-shot basis in shock experiments on water and benzene. The time dependence of the signals agrees quantitatively with an optical model of the system as the shock moves through the sample. We plan to conduct experiments with this new apparatus in early 1989 to observe Mie scattering from carbon particles formed during shock decomposition of benzene.

\section{Reference}

Nicol, M., S. W. Johnson, and N. C. Holmes (1988). "Shock-Chemistry of Benzene as Revealed by Spectra From and Behind the Shock Front." Shock Waves in Condensed Matter-1987, S. C. Schmidt and N. C. Holmes, Eds. (North-Holland. Amsterdam). p. 99. 


\section{Transition-Metal Oxides and Silicates at Ultrahigh Pressures}

Principal Investigator: R. Jeanloz* Co-Investigators: R. Reichlin, S. Martin, Q. Williams,* and E. Kinittle*

*University of Califomia. Berkeley.

$\mathrm{E}$ xperiments on fayalite $\left(\mathrm{Fe}_{2} \mathrm{SiO}_{4}\right)$ to $30 \mathrm{GPa}$ have suggested that this material might become metallic at a pressure of $80 \mathrm{GPa}$ (Mao and Bell. 1972). Because of the importance of understanding the nature of the $\mathrm{Fe}-\mathrm{O}$ bond at conditions in the earth's deep mantle, we compressed $\mathrm{Fe}_{2} \mathrm{SiO}_{4}$ up to $85 \mathrm{GPa}$. We discovered a new type of metastable glass at high pressures and at $300 \mathrm{~K}$. Crystalline fayalite amorphizes at $41 \pm 5 \mathrm{GPa}$, resulting in a significant change in electrical

After compressing $\mathrm{Fe}_{2} \mathrm{SiO}_{4}$ to pressures up to $85 \mathrm{GPa}$, we have discovered a new type of metastable glass at $300 \mathrm{~K}$ and have documented changes in optical and electrical properties as it is converted continuously to an amorphous state.

properties. Extrapolations of our results indicate that metallization of the glassy phase would not occur until pressures above $300 \mathrm{GPa}$. which are much higher than expected previously.

Because of its highly refractory nature, amorphous $\mathrm{Fe}_{2} \mathrm{SiO}_{4}$ has been produced only once before by conventional techniques (splat quenching). We found from Fouriertransform infrared spectroscopy that the pressure-amorphized fayalite is distinctly differert in structure from the conventional (splat-quenched) glass. Our study is the first to document the changes in optical and electrical properties of a crystal as it is converted continuousiy to an amorphous state. We have demonstrated that novel glasses can be produced by high pressure.

\section{Reference}

Mao, H. K., and P. M. Bell (1972), "Electrical Conductivily and the Red Shift of Absorption in Olivine and Spinel at High Pressure." Scicnce 176. 403. 


\section{Institute for Scientific Computing Research}

N. C. Smiriga
The Institute for Scientific Computing Research (ISCR) supports collaboraltive research in scientitic computing between $I C$ and LLNL. The goals of the lnstitute are to advance the state of the art in computer science and to foster research that strengthens the ties between the related disciplines of computer science and scientific computing.

Through the ISCR. LLNL's expertise in scientitic computing and its computational facilities are made available to University researchers. The Institute also provides professional enrichment for LLNL scientists by encouraging collaborative and interdisciplinary work. Currently. the ISCR interacts mainly with faculty and students from UC Berkeley. UC Davis. and UC Los Angeles.

In FY88, the IR\&D Program provided the ISCR with funding to suppon two postdoctoral fellows and to cover the Institute"s administrative and secretarial costs. The ISCR also received substantial contributions from LLNL's Computation Department. During FY88. the ISCR supported three posidoctoral fellows who were jointly funded by the IR\&D Progran, the Physics Department, and the Computation Department.

Two of the iSCR postdoctoral fellows are performing research in computational fluid dynamics. Computational fluid dynamics is an essential element in many of the computer simulations of physical phenomena performed at the Laboratory. The topics under investigation include vortex methods to solve the incompressible Navier-Stokes equations and numerical simulation of self-similar shock refraction.

The third postdoctoral fellow is working on physics algorithms for massively parallel computers and on computer models of motion detection in vertebrate retina.

The ISCR organized two workshops in FY88. One examined the SISAL language: SISAL is a functional programming language designed to facilitate the writing and debugging of scientific applications on parallel processors. The second workshop had the dual objectives of bringing into focus the various research efforts on artificial neural networks scattered throughout the UC system and identifying research activities within LLNL that could benefit from the emerging technology of artificial neural networks.

Also during FY88, two conference rooms adjacent to the ISCR were renovated; the work was completed in January 1988. Since then, the Institute has been able to host seminars on a regular basis.

The ISCR received $\$ 185,000$ in IR\&D funds for FY 88 . 


\section{Physics Algorithms for Massively Parallel Computers}

\author{
Principal Investigator: M. Colvin \\ Co-Investigators: A. Ladd. D. Frenkel.* \\ C. Sugiyama, and $B$. Nder
}

*Fo MI Instituke of Alomic and Molecular Phyises. The vitherlands.

$\mathrm{T}$ here is much current interest in the use of lattice gas methods for solving the incompressible Navier-Stokes equations. The simplicity and regular structure of these methods makes them ideally suited for massively parallel computers. We first applied lattice gas methods to the simulation of twodimensional Brownian motion. Our approach was to model the relatively slow motion of the solid particles using molecular dynamics and to model the fluid phase with a lattice gas (Ladd et al.. 1988) This algorithm has worked extremely well. At low solid densities. the theoretical results for the drag forces and suspension viscosity are reproduced correctly. Moreover, this algorithm is extremely fast, even on conventional computer architectures: systems with several hundred solid particles could be simulated on a desktop workstation. The results for the two-dimensional suspensions are so encouraging that we are extending the model to three dimensions.

We also applied lattice gas methods to the simulation of diffusion-limited aggregation (DLA). Experimental and theoretical studies have shown that under certain conditions. crystals grow into lowdensity. self-similar structures that can be characterized by a fractal dimension. Mosi DLA simulations

Most computational physics algorithms can be implemented on computers with up to several dozen processors, but these methods are unsuitable for the massively parallel computers (with hundreds or thousands of processors) that will be needed to simulate large-scale chemical or biological systems. We are developing algorithms for a variety of physics problems designed specifically for the massively parallel computers that will be available in the coming years.

\section{$x$}

model only the motions of the aggregating particles and ignore the potentially important hydrodynamic interactions between the growing erystal and the solvent. We developed a lattice gas model that accurately models the interaction of the solvent with the crystal and the aggregating particles and yields

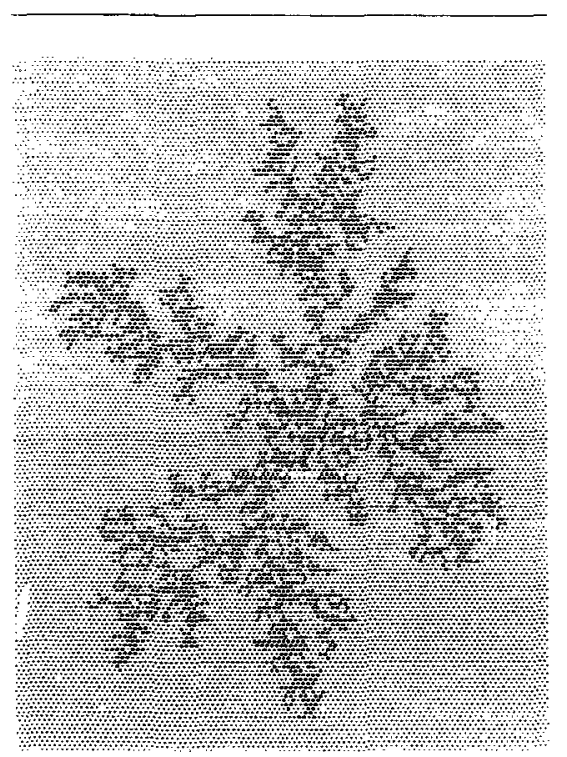

Figure 1. Crystal "grown" using the lattice gas model of diffusionlimited aggregation with simulated hydrodynamic interactions. The fractal dimension of the crystal in this simulation is 1.65 , in good agreement with experimental results. crystals with fractal dimensions in good agreement with experimental results (Figure 1).

We also examined the application of quantum chemical calculations on parallel computers. Although such methods (used for the ab initio calculation of chemical properties of small molecules) have been adapted to parallel computers (Whiteside et al.. 1987), the large data sets and tightly coupled iterative algorithms severely constrain the number of processors that can be used efficiently. To overcome this difficulty, we are studying an altemative method. called quantum Monte Carlo (QMC), involving the stochastic evolution of electron configurations. In QMC, chemical properties are calculated by averaging over many random walks (typically millions). Since these random walks are independent, QMC is naturally adaptable to parallel computers with any plausible number of processors.

\footnotetext{
References

Lidd. A. J. C., M. E. Colvin, and D. Frenkel

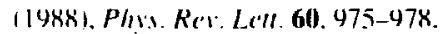

Whiteride, R. A.. J. S. Binkley. M. E. (olvin, and H. F. Schacker, Ill (1987). f. (h'm. Pha 86. 218.5-2193.
} 


\section{Computer Model of Motion Detection in the Vertebrate Retina}

Principal Investigators: M. Colvin and

F. Fieckmain

Co-Investigators: Prof. F. Herblin," (i. Maguire,* P. Lukasiewicz,*" I. Sasinowski." and $\mathrm{T}$. Avelrod

E nivernity of Catlifurnial, Berkele!
A computer modet of the retina of the eye would make it possible to test hypotheses about retina function and would help in the design of synthetic motion-detection systems As the first step toward such a model, we have developed a detailed simulation of the small functional units believed to mediate movement detection in the retina of the Tiger Salamander. andomical and physiological data about the retinil. but we still do now have a complete understanding of how the retina transforms visual data. A detailed computer model of the retina. based on existing data. could provide an important framework for new experimental data and would

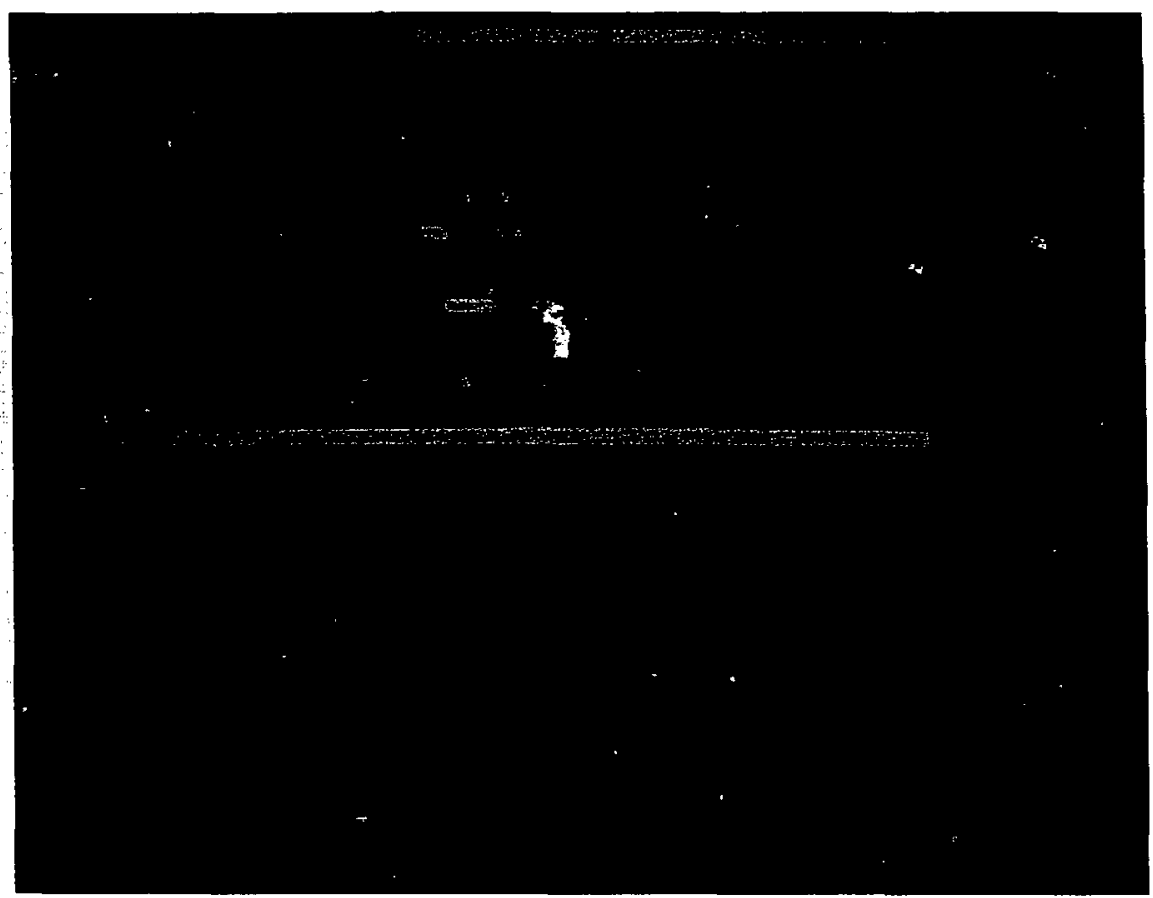

Figure I. Photograph of the computer screen showing our interactive computer model of the motion-detection subunit in the retina. The rectangular and octagonal boxes represent different retinal neurons: their levels of excitation are denoted by the different colors. The excitation levels are also displayed in oscilloscope traces at the bottom of the screen. allow the testing of hypotheses about retina function. Such a computer model would also be very uselul in suggesting design principles for synthetic motion-delection systems.

Our goal is to develop a general computer model of the vertebrate retina. As the first step. we have developed a detailed simulation of the small functional units believed to mediate movement detection in the retina of the Tiger Salamander. These so-called movement-gated subunits consist of three cell types, two of which are responsible for detecting the arrival or departure of the target while the third acts as a lateral inhibitory element. Our present simulation consists of an interactive neural network program that closely mimics the response of each of the various cell types (see Figure 1). The model exhibits behavior that is consistent with known biological datia and acts ats al movement detector with preferred and null-target directions.

We are presently extending our model to simulate an interacting twodimensional arraty of these subunits. Future work will involve a more detailed simulation of the individual neurons and the inclusion of more retinal cell types. 


\section{Advanced Algorithms in Computational Fluid Dynamics}

\author{
Principal Investigator: F.. C;. Puckett \\ Co-Investigators: S. Baden.* P'. ('olella. \\ I. F. Henderson. $\div$ and $M 1$. Weleome \\ L.awrotuc Borkeley Liahuraturs. \\ Berkeles. Cis

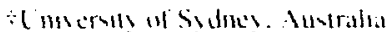

Our work on computational fluid dynamics has focused on two different areas: development of fast vortex methods for viscous incompressible fluid flow, and computation of the refraction of a shock wave at an oblique interface between two inviscid compressible gases.
$\mathrm{M}$ any problems in physics recyuire the modeling of thuid tlous. We may be able to address at number of these by using vortex methods to solve the incompressible Navier-Stokes equations. Vortex methods are particle methods thalt carry information about the vorticity

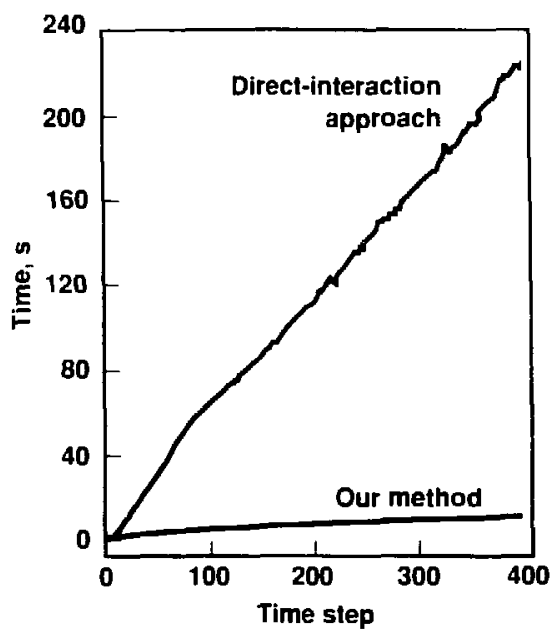

Figure 1. Comparison of computational speed for our hybrid vortex method and a conventional direct-interaction approach for calculating viscous incompressible flow. Our method is at least ten times faster. in the llow being modeled and allow pirticles to be concentrated in regions of high vorticity. Their principal drawback is the amount of computational effort needed to compute the velocity field inducied by the particles.

We have developed a fast vortex method for modeling viscous. incompressible flow in a box. This is the lirst fast implementation of a fully viscous, hybrid vortex method. Vortex sheets are generated to model vorticily production near boundaries. and these subsequently diffuse into the interior of the computational domain. where they are converted into vortex blobs (Chorin. 1973 and 1978). Our approach is a modification of Anderson :s (1986) method of local corrections (MLC). extended to include viscous effects. Compared to traditional implementations of the vortex method. our method is at least ten times faster (Figure 1). This work has established the leasibility of doing large, detailed computations using the hybrid vortex method.

We are also investigating the self-similar refraction of a shock wave by an oblicue interface hetween two galses. Our initial effort wils to compute the calse in which the fluid containing the incident shock has a lower sound speed than the lluid on the other side of the interface (the slow-fast case). We used a version of the adaptive-meshretinement algorithm of Berger and Colellit ( I988). coupled with at multifluid algorithm to handle the interfince between the two galses. We have obtained excellent agreement with the experimental results reported in Abd-el-Fattah and Henderson (1978) and have been able to correlate the experimentally observed wave patterns to the inviscid nonlinear waves in the calculation.

\section{References}

Ahd-cl-Fultah. A. M... and I. F. Henderson (1978), "Shock Waves al a Slow-Fast Gas Interface." I. Fluid Merh. 89. 79-85.

Anderson. C. (1986). "A Method of Lotal Corrections lor Computing the Velocity Ficld Due to at Distribution of Vortex Blohs." f. Comp. Phys 62. 111-123. Berger, M. J.. and P. Colclla a l98x I. Locesl Alaprive Mesh Refine'me'm for Shork Madrolvmamics. I.awrence Lisermore National L.aboratory. Preprint I!CRI. 97196.

Chorin, A. J.1197.31. "Numericial Study of Silughly Viscous Flom." I Flum Moh 57 795.796.

Chorin. A. J. 119781. "Vurtex Sheel Approumatlum ol Benundars Laners." I ( 


\section{Plasma Physics Research Institute}

J. Killeen
The Plasmal Phisios Reseatrch Institute (PPRI) was established in 1987 as a joint LC-LLNL organization. Its purpose is Io strengthen basic and applied research in plasmat science throughout the liniversity. The PPRI makes the facilities and expertise of LLNL more available to campus scholars in tields of interest to the Institute. Research on fundamental issues in plasma physics is its primary focus. The PPRI receives support from the IR\&D Program. from the Department of Applied Science at UC Davis, and from other LLNL programs.

In FY88. the program of the PPRI consisted of three elements:

- The Davis Diverted Tokamak.

- A join LLNL-UC Berkeley particle-simulation project.

- A summer program sponsoring research by a visiting scientist on radiofrequency ( $\mathrm{rf}$ ) heating and current drive in tokaniaks.

The Davis Diverted Tokamak is so named because it employs a magnetic field configured to divert (eliminate) unstable edge plasmas. thus creating a more coherent plasma. This magnetic field is called a divertor. The design of the tokamak was guided by the Tokamak Simulation Code (TSC), provided by Princeton Plasina Physics Laboratory. Our investigations will focus on how the divertor affects the confinement and stability of the plasma.

Our particle-simulation project consists of adding new capabilities to the one-dimensional, relativistic, electrostatic particle code TESS. This code makes it possible to simulate particle confinement in simple and tandemmirтor plasmas. In FY88, we added models that simulate energy diffusion in the plasma and plasma heating by charge-exchange and impact-ionization processes.

The FY88 summer program sponsored the development of a computer code to simulate parametric instabilities in tokamak plasmas penetrated by lower-hybrid of waves.

These projects will be continued in FY89, and several new ones will be started. including the following:

- Theoretical and computational plasma astrophysics (UC Berkeley).

- Statistical dynamics of multi-field models for plasma turbulence (UC San Diego).

- Numerical simulation of rf experiments in the ionosphere (UCLA).

- Basic plasma physics research in inertial confinement fusion (UC Davis).

- Nighttime ionospheric cavitons generated by high-frequency radio waves (UCLA).

In FY88, the PPRI received $\$ 150,000$ in IR\&D funds. 


\section{The Davis Diverted Tokamak}

\author{
Principal Investigators: D. Hwang* \\ Co-Investigators: D. E. Shumaker. \\ K. Mizuno,* (;. Dimonte, B. I. Cohen. \\ b. Flittner,* and T. Hillyer* \\ * Lneruit! of Califurmia. Davin.
}

I n FY88. we made progress on the coristruction and assembly of the Davis Diverted Tokaniak (DDT). The DDT is now ready for experimental operation. We obtained Iwo X-band. lunible (8.6-9.5-GHz) microwave transmitter systems capable of delivering $250 \mathrm{~kW}$ each for up to $2 \mu \mathrm{s}$. We also obtained microwave diagnostic and transport equipment to deliver power into the DDT vacuum chamber. Electrical power has been installed in the laboratory. and we are currently installing the microwave systems. which should be operational by the end of 1988. We designed an initial set of plasma and microwave diagnostics, including electromagnetic loop probes and Langmuir probes: these will be fabricated at UC Davis. We also built a discharge-plasma source to produce the low-density plasma required to match the frequency range of the $X$-band microwave sources.

The use of a magnetic field as a divertor has been shown to enhance the plasma containment properties of a tokamak. However, the introduction of divertors causes:

In the Davis Diverted Tokamak, a magnetic field is used to divert or eliminate unstable edge plasmas, thus creating a more coherent plasma. We are studying how the divertor affects the confinement and stability of the plasma.

axisymmetric plasma instability to become a problem. Up to now this instability has been corrected by using passive conductors and active leedback systems, both of which can be costly. Experimental results in the literature show that the axisymmetric instability is nonlinear and grows on a time scalc corresponding to the $L / R$ time of the plasma ( $L=$ inductance and $R=$ resistance). Recent experiments have shown that lower-hybrid of waves can control the profile of the plasma current and thus modily the resistance and inductance of the plasma.

In FY89. we will conduct experiments using lower-hybrid current drive to remedy the axisymmetric instability. Lowerhybrid current drive has been shown to produce electron distributions that appear to contain an anisotropic high-energy tail. This condition could produce a plasma that is less collisional, and thus lower in resistivity. on the outside. For a given loop voltage. such plasma parameters should lead to a redistribution of the current. with at latrge fraction of the current flowing on the plasmal surface. This change in the current protile will produce a larese change in the plasma inductance.

Our lower-hybrid stabilization experiments will be conducted with a $5(1)-k W$ klystron system. :sed at $800 \mathrm{MH} z$ at the Princelon Plasma Physics Laboratory. The Princeton data show that this system is capable of modifying the plasma current up to an electron density of about $1 \times 10^{13} / \mathrm{cm}^{3}$. This density is ideally suited for the DDT since the operating densily range is about $1 \times 10^{1.3} / \mathrm{cm}^{3}$.

We also plan to use the DDT facility 10 investigate beal-wave current drive. In this type of experiment, two counterstreaming electromagnetic waves mix nonlinearly to generate plasma waves that. in turn. produce directed energetic electrons through Landau damping. This investigation will provide a basis for future microwave tokamal. experiments utilizing millinneter-induction. free-electron lasers. For sake of economy, we will tailor these experiments around our $\mathrm{X}$-band microwave sources, which were available on the surplus market and which produce sulficiently short wavelengths for geometric optics I0 apply. 


\section{Joint LLNL/UCB We are adding new capabilities to the TESS particle- Particle-Simulation simulation code. \\ Project}

Principal Investigator: R. Procassini* Co-Investigators: E. Morse,*

C. K. Birdsall.* .l. Cummings.* and

B. I. Cohen

* Lniversing of Caliturnia. Berkeley.

$\mathrm{T}$

he one-dimensional (axial).

relativistic, electrostatic particle code TESS makes it possible to simulate particle confinement in simple and tandem-mirror plasmas. In FY88. we made a number of advances in the development of TESS. Specifically, we added: - A quasilinear, radiofrequency energy diffusion model for both ioncyclotron resonance plasma heating and relativistic electron-cyclotron resonance plasma heating.
- A neutral-beam injection model that simulates plasma heating via chargeexchange and impact-ionization processes.

The balance of TESS consists of a basic electrostatic particle code. which uses a direct implicit scheme to advance particle trajectories and field quantities. and a Monte Carlo, binary. particle-collision model. The code has been used to investigate the collisional loss processes in an auxiliary-heated, tandem-mirror plasma.
In FY89. we plan to modify TESS 10 allow the kinetic simulation of plasma-surface interactions at the divertor plate of a tokamak. The code will then be capable of studying the effects of recycled plasma on the collector-sheath potential drop and will provide a self-consistent simulation of plate erosion due to sputtering and redeposition of sputtered material. 


\section{Intense Lower-Hybrid Wave Penetration into Magnetized Fusion Plasma}

Principal Inıestigator: M. Porkulah*

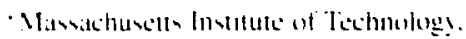
Cambridye. MA.

$\mathrm{T}$ he prospect of achieving intense, pulsed radiofrequency

waves in the $\mathrm{X}$-band regine $(8-10 \mathrm{GH} /)$ with a relativistic klystron creates new possibilities for lower-hybrid wave penetration in high-lemperature. reactor-grade. magnetized fusion plasma. For example. the steady-state version of the International Thermonuclear Experimental Reactor (ITER). which is now being studied by an international group of scientists at Garching. Federal Republic of Gemlany. vields tens of megawatts of lower-hybrid power for driving toroidal currents. Although. to date.

In the summer of 1988, the PPRI sponsored research by a visiting scientist on radiofrequency heating and current drive in tokamaks.

lower-hybrid power has produced the most impressive toroidal currentdrive results by noninductive means. its applicability in reactor-grade plasmas is thought to be restricted to the plasma periphery because of Landau damping at electron temperatures greater than $15 \mathrm{keV}$. Nevertheless. high-intensity. lowerhybrid waves may, in fact. penetrate to the core of the tokamak plasmia by flattening the electron-distribution function. thereby reducing Landau damping.

An important issue connected with this wave penetration is the potential severity of nonlinear effects. such as parametric instabilities. In FY88, the PPRI
Summer Program sponsored the development of a code that simulates such nonlinear phenomena. even in the presence of very intense electric fields (about $200 \mathrm{kV} / \mathrm{cm}$ ). Under these conditions, the commonly used theory of weak parametric instabilities is not satisfied. The results of our calculations have been reported (Killeen, 1988).

\section{Reference}

Killeen. J. (1988). The Plasma Phisics Researdh Instinte'. Anmual Revicus. Lawrence Livernore National Laboratory. internal repon. (Readers wishing to obtain copies of this document should contact the author.) 


\section{Program for Analytical Cytology}

B. H. Mayall
The Program for Analytical Cytologs (PAC) fosters coilaboralive research. pronotes scientitic progress. and facilitates technology transfer in the field of analytical cylology. By means of anatytical cylology. we can quantify the properties of individual cells and investigate the distribution of such properties across a population of cells. rather than merely measuring in a lest tube the average characteristics of many cells. The PAC serves as a scientitic and institutional bridge between LLNL and campuses of the University of California. particularly UC San Francisco. As a result of PAC projects, we are seeing benefits to the biomedical research community. primarily at UC San Francisco, and increasingly at the Berkeley. Davis. and Los Angeles campuses. PAC activities are contributing significantly to the diagnosis. understanding. and treatment of many diseases. and have made UC San Francisco a world leader in clinical applications of analytical cytology.

The PAC uses funding from the UC Regents to award many small grants for innovative and collaborative research projects. LLNL and UC San Francisco provide matching funds primarily to support administration and teaching: additional gifts from industry support postdoctoral fellows. The PAC awards permit researchers to collect preliminary data and to demonstrate the feasibility of the ir investigations. More than one-half of the PAC awards have evolved into ongoing projects. Grants from the National Institutes of Health now support the mature collaborative research projects of proven potential.

Early in FY88. the future of the PAC research grants was uncertain because the University of California defined new guidelines for distributing nuclear science funds. The University initiated the Institutional Collaborative Research Program (INCOR) and invited applicants to compete for INCOR funding: the PAC was one of only four proposals approved for funding. This reflects recognition of past achievements by the PAC. the need for nuclear science funds to continue and strengthen the PAC mini-award program. and the potential for the PAC to make substantial contributions in the future.

A primary scientific interest of the PAC is to advance image cytometry at LLNL and its application at UC campuses. Image cytometry combines optical microscopy and digital image processing in a quantitative approach that permits detailed analysis of large numbers of cells prepared on a glass slide. This technique is emerging as a crucial approach for analytical cytology. and LLNL is pioneering many of the new applications of image cytometry.

In the following short articles, we highlight five PAC efforts during FY88. The first two are based on application of the glycophorin-A (GPA) assay developed at LLNL. This assay is an extraordinarily sensitive test that uses monoclonal antibodies against the $\mathbf{M}$ and $\mathbf{N}$ types of GPA, the two variant types found on the surface of human red blood cells. One project uses this assay to monitor changes associated with the aging of red blood cells. The other uses this assay to monitor mutations induced in cancer patients undergoing chemotherapy with mutagenic drugs. In the third article. LLNL approaches to quantifying the DNA content of tumor cells are applied in human breast cancer to evaluate progression of the disease. to find the stage at which major changes occur in cellular DNA content. and to relate such changes to the clinical course of the disease. The project described in the fourth article uses cylokinetic techniques to analyze the proliferative behavior of human brain tumors and to relate their cellular proliferation to the clinical outcome. In the final project. basic techniques of analytical cytology are used to investigate fundamental mechanisms of the body"s immunologic defenses.

The Program for Analytical Cytology received $\$ 190 .(0)(0)$ in IR\&D funds in FY8X. 


\section{Red Cell Density and Aging}

\author{
Principal Inv estigator: I.. I 'orash* \\ Co-Investigators: R. L anglois, R. Jensen. \\ and M. (lark*
}

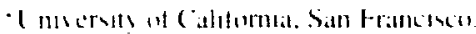

$\mathrm{T}$ he purpose of our project is 10 determine if cellular density increases progressively as red cells age in irive. If density is proven to be an ige-dependent characteristic, then separating red cells by density from whole blood may provide a means to prepare transfusion products depleted of old red cells and enriched with young cells. Such enhanced producis could reduce the frequency of transfusion for patients with chronic anemia and could reduce the toxicity associated with excessive iron accumulation during long-term transfusions.

We have developed a technique in which red cells bearing the glycophorin-A (GPA) antigenic phenotype $N N$ can be identilied when mixed with either GPA MN or GPA MM cells. The $M$ antigen can be detected using a monoclonal antibody directed against the $M$ phenotype. Patients with chronic. stable anemia and either the MM or MN phenotype are transfused with $\mathrm{NN}$ red cells. and the density distribution of these cells is followed as the transfused cells age in vivo. In this way. the effect of in vivo aging on red cell density can be examined. After initial studies with unfractionated red cells, densitydependent cohorts of NN cells are prepared and transfused into $\mathrm{MM}$ or $M N$ recipients to measure the survival and density distribution of low- and high-density cells. If we

\section{We are developing transfusion products enriched with low- density red cells that may increase the transfusion interval for patients with chronic anemia.}

contirm that low-density red cells survive in the circulation longer than the unf ratetionated eclls, then units of such cells will be used for transfusion support of patients with chronic anemia to contirm that the transfusion interval can be increased under clinical conditions.

The specific aims of this project are 10:

- Use monoclonal antibodics directed against the $M$ and $N$ types of GPA to detect small numbers of NN red cells among a larger population of $\mathrm{MN}$ red cells.

- Prepare in vitro mixtures of NN and $\mathrm{MN}$ cells that mimic the proportions of these cell types in an in vivo human transfusion experiment in which NN cells will be transfused into $\mathrm{MN}$ individuals.

- Examine the concentration of $\mathrm{N}$ and $M$ types of GPA on red cells of various densities after densitydependent fractionation (necessary to ascertain whether concentrations of these surface antigens vary with cell density).

This year, we instituted the GPA assay in our laboratory and demonstrated that we could detect $\mathrm{NN}$ cells mixed with $\mathrm{MN}$ cells in a ratio of $1: 2000$. well within the working limits required to perform our proposed experiments. We also showed that we could isolate either high- or low-density NN cohorts. mix them with unfractionated $M N$ red cells. and then detect expected numbers of $\mathrm{NN}$ cells in the correct density fraction after density-gradient centrifugation. Alter adapting the technique for delecting small numbers of NN cells mixed with MM or $\mathrm{MN}$ cells, we prepared antificial mixtures of $\mathrm{MN}$ and $\mathrm{NN}$ cells, separated them into densitydependent fractions, and determined the coefficient of variation for detection of a 1:2000) mixlure of NN and $M N$ cells. This coefficient was less than $5 \%$, an acceptable level.

Our first patient had myelodysplasia with a stable. chronic transfusion requirement. The patient, whose red cell phenotyr ' was $\mathrm{MN}$, was transfused with uritrat icnated $\mathrm{NN}$ cells. We obtained $5-\mathrm{ml}$ blood samples weekly for analysis of density distribution of the transfused $N N$ cells as they aged in vivo. The density distribution of the recipient's autologous NM-positive cells was stable, and we detected the transfused $\mathrm{NN}$-positive cells with adequate precision. We then used red cell iractions enriched with either low- or high-density cells. We are evaluating a new cell-separation system to ensure that it can provide cell fractions that are adequately enriched with low-and high-density cells.

We are now seeking other patients with the correct clinical state to participate in the project. Our work may provide the potential for improved transfusion support of paticnts with chronic anemia and a new means to measure red cell survival. 


\section{Detecting Somatic Cell Mutations Using the Glycophorin-A Assay}

\author{
Principal Investigator: S. Saks* \\ Co-Investigators: W. L. Bigbee. R. H. \\ Jensen, E. C. C'adman.* and H. Jaffe ${ }^{*}$
}

:Lnicervirs of Calitomial. San Franciaco.

$\mathrm{L}$

LNL scientists have recently

developed a new human in vive somatic cell mutation assily based on immunologic detection and flowsorter enumeration of variant red cells that fail to express a nomally present cell-surface antigen. We are applying this assay to blood samples from cancer patients undergoing chemotherapy with mutagenic drugs. Our aim is to validate the genetic basis of the assay by determining whether elevated frequencies of glycophorin-A (GPA) "null" cells can be demonstrated in these individuals.

We screened cancer patients of the Oncology Clinics at UC San Francisco for individuals with the required clinical histories who were undergoing appropriate chemotherapy. We compared the frequency of GPA variant red cells in blood samples from patients treated with several classes of mutagenic chemotherapy with the variant cell frequency observed in normal subjects.

Blood samples from 85 cancer patients were encoded to ensure anonymity in a blind study. Because the GPA assay requires blood of the heterozygous MN type. samples were first serotyped using commercial anti-M and anti- $\mathrm{N}$ sera. Because $52 \%$ of the general population are MN heterozygotes. we expected about one-half of the patients to have

\section{We have found evidence of the in vivo induction of null variant red cells in blood samples from cancer patients undergoing chemotherapy with mutagenic drugs.}

the required MN blood type. Blood samples from 41 patients were typed as $M N$ and run in the assiay: after eliminating patients with incomplete clinical histories or contirmation of recent blood transtusion. the study population was reduced to 30 individuals.

The pattients were diagnosed with a variety of malignancies. including brealst cancer. colon cancer. Hodgkin $\$$ disease. and malignant melanoma. Treatments included a variety of mutagenic agents. such as adriamycin. bleomycin. cis-platinum. and dicarbazine. and sometimes involved other non- or weakly mutagenic agents. In addition to each patient 's current chemotherapy treatment. we obtained other clinical data and collected blood simples at random times before, during. and after chemotherapy:

Red cells from MN samples were labeled with monoclonal antibodies and analyzed on a dual-beam sorter using the IW 1 version of our GPA assay. This version measures the frequency of variant cells that have lost expression of the GPA(M) allele while retaining expression of the sister GPA(N) allele. Data were calculated as the frequency of $\mathrm{N}$ nullvariant cells per million normal cells. which we call the variant frequency.

For statistical analysis. samples were placed into a pretherapy group and four other groups defined by the time a sample was obtained relative to the course of treatment. Table I shows a generally consistent and statistically significant effect of

Table 1. GPA variant frequencies in UC San Francisco patients.

\begin{tabular}{lccccccc} 
& & & \multicolumn{4}{c}{ Variant frequency per million cells } \\
\cline { 5 - 8 } Sample group & Days & Samples & Range & Median & Mean \pm SD & $p^{*}$ \\
Pretherapy & - & 22 & $4-23$ & 11.0 & $11.9 \pm 5.4$ & - \\
Early therapy & $4-93$ & 15 & $2-171$ & 19.0 & $32.1 \pm 41.7$ & 0.004 \\
Late therapy & $120-335$ & 11 & $5-53$ & 36.0 & $31.7 \pm 17.3$ & 0.001 \\
Early post-therapy & $12-101$ & 6 & $29-120$ & 40.0 & $56.5 \pm 34.0$ & $<0.001$ \\
Late post-therapy & $132-4126$ & 6 & $2-26$ & 21.0 & $17.8 \pm 8.7$ & 0.030
\end{tabular}

* Standard deviation.

${ }^{\dagger}$ Mann-Whitney statistic compared to all pretherapy cohorts. 
chemotherapy. despite the heterogencous pattient population. Variant frequencies increased during therapy, realched at maximum of ahoul fivefold over the pretherapy level at or shortly after the end of theralpy. and then declined to near pretherapy kevels within six months. Thus. our study provides clear evidence of the induction in rive of null variant red cells by mutience chemotherapy.

The time of appearance and persistence of induced variants suggests that cells at maximum risk for mulagenic damage by the se agents are the rapidly cycling erythroid precursor population.

We are now studying breast cancer pattients receiving standardiecd treallments with atdriamycin and cyclophosphamide. We also plan on study patients receiving other agents thought to be sem-edl mutigems. Some cancer patients receiving chemolheraps with mutagens are al excess rish of sceondary cancer. mainly atcule leukemia and sympomal. Thus. certain chemotherapeutic agents may induce as circinogentic polential from persistent in vion mutitional damage to hemopoietic stem cells. If in rive mutagenesis is related to cancer risk. then cyuantification of induced in vive, somatic cell mutation using the (iPA assily maly become a predictor of the ultimale risk of developing malignancy.

\section{Keference}

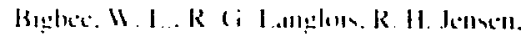

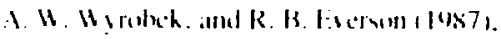

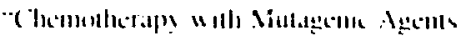

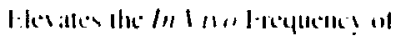

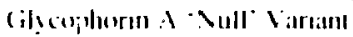

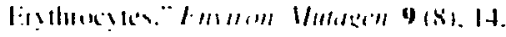




\section{Viability of Primary Human Breast Cancers}

Principal Investigator: H. S. Smith* Co-Investigators: J. W. Ciray, B. H. Mayall. and B.-M. L.jung

* Lnir ervity of California. San Francisco. and Peralta Cancer Research Insiatute. Oakland. CA.

Clniversity of California. San Francisco.

$\mathrm{T}$ he goal of our study was to characterize the properties of hyperdiploid populations found in many breast cancers. Hyperdiploidy refers to cells containing more than 46 chromosomes. the human diploid number. We wanted to challenge suggestions that the diploid cells cultured from breast cancers are nonmalignant in origin because it seemed possible that another isolation technique might readily detect true cancer cells. those with hyperdiploid DNA contents.

Much evidence suggests that the cells responsible for metastatic breast cancer are aneuploid (nondiploid). Hence. the ability to isolate those cells capable of metastatic growth from primary breast cancers is important for both a clinical and a basic understanding of the disease process. However, there is a paradox in that many breast cancers contain a large proportion of cells with hyperdiploid DNA content. In contrast, cells cultured from primary breast cancers are uniformly diploid. . It is essential to understand where :." the process of isolation or culture the aneuploid cells are lost.

We used image cytometric techniques rather than flow systems for our studies because of the limited number of cells available for study. We evaluated specimens for DNA

We have found that hyperdiploid cells usually do not grow in cell culture, whereas diploid breast cancer cells proliferate well. Failure to see hyperdiploid cells cultured from breast cancers is due to their poor viability.

content before and after different isolation procedures. Populations isolated by gentle mechanical dissociation were enriched in hyperdiploid cells, whereas populations isolated from the same breast carcinomas by enzymatic digestion were enriched for diploid populations. We found that the mechanically dissociated material grew poorly in culture. Further studies of this phenomenon revealed that the majority of cells in most mechanically dissociated samples were nonviable by dye exclusion. In contrast. the enzymatically digested material was uniformly viable.

Subsequent experiments revealed that the nonviable cells were not an artifact of sample preparation or of the time delay from commencement of surgery to specimen acquisition in the research laboratory. Tumor cells acquired by fine-needle aspiration cytology prior to surgery and assayed immediately also contained a variable but often sizable proportion of nonviable cells.

We conclude that hyperdiploid cells are not readily cultured from primary breast cancers because few of them are viable. Techniques that enrich for hyperdiploid cells also enrich for nonviable cells, whereas techniques that enrich for viable cells favor diploid populations. Therefore. regardless of the technique used. only a small subpopulation of viable cells is hyperdiploid. Thus, viable aneuploid populations. which have been hypothesized to represent those cancer cells capable of metastatic growth, are actually only a small component of most breast cancers.

\section{References}

Dairkee. S. H.. B. H. Mayall. H. S. Smith. and A. J. Hackell (1987). - A Marker that Predicls Early Recurrence of Breast Cancer“ (letter), Lance' 8532, 514.

Smith. H. S.. B.-M. Ljung. B. H. Mayall. S. S. Sylvester, and A. I. Hackelt (1987). "Ceilular Manifestations of Human Breast Cancer." Cellular and Molecular Biolugs of Experimenol Manmary Cancer.

D. Medina. W. Kidwell. G. Heppner. and E. Anderson. Eds. (Plenum Press. New York. NY).

Smith. H. S.. S. H. Dairkee . B.-M. Ljung. B. H. Mayall. S. S. Sylvester. and A. J. Hacketl (1986). "Clonal Manifestations of Human Breast Cancer." Cellular und Modular Biolousy of Experimentul Mammary Cancer. D. Medine. W. Kedwell. G. Heppner. and E. Anderson. Eds. (Plenum Press. Neu York. NY).

Smith. H. S.. S. R. Wolman. G. Auer, and A. J. Hacket (1986). "Cell Cullure Studies: A Perspective on Matignant Progression of Human Breast Cancer." Breast Camcer: Orisins. Detertiem. and Treatme'nt. M. A. Rich. J. C. Hager. and J. TayglorPapadimitriou. Eds. (Martinus Nijhotf. Buston. MA). pp. $31-49$. 


\section{Human Brain Tumors Classified by Cytometry}

\author{
Principal Investigator: J. Muruvic* \\ Co-Investigators: J. W. Gray and \\ T. Hoshino*
}

*Laversity of California. San Francisco.

B ecause brain tumors grow within a closed cavity. fatality depends critically on the size or rate of tumor growth. Biological determination of the degree of cellular abnormality in primary brain tumors has been important in estimating the prognosis of patients and predicting the effects of drugs and radiation on the tumor. Quantification of the proliferative capacity of tumors with flow cytometry and immunocytochemistry will greatly enhance our ability to predict tumor behavior.

Our objective was to develop an improved bromodeoxyuridine (BrdUrd) staining procedure and multivariate analysis on human specimens and to establish the protocol of BrdUrd administration. The goal was to measure cellular predictors of tumor growth (e.g., rate of DNA synthesis, cell cycle time, growth fraction) and to correlate these findings with serial computed tomography scans.

Sixteen patients with brain tumors were given a 30-60-min intravenous infusion of BrdUrd at $200 \mathrm{mg} / \mathrm{m}^{2}$. Fragments from biopsied tumor specimens were divided into two portions. One portion was dissociated into single cells, stained with fluorescein isothiocyanate (FITC), using antiBrdUrd monoclonal antibody as the first antibody, stained with propidium iodide (for DNA). and then analyzed

\section{For patients with brain tumors, we are developing and evaluating BrdUrd-labeling procedures to measure cellular predictors of tumor growth.}

by flow cytometry. We calculated the labeling index (LI) as the number of FITC-labeled cells expressed as the percentage of total cells analyzed. The other portion was stained with immunoperoxidase using antiBrdUrd monoclonal antibody as the first antibody. We calculated the LI of these tissue sections in two ways: from selected areas in which the labeled cells were evenly distributed, and from the entire tissue section. The LIs obtained by flow cytometry correlated closely with those from entire tissue sections and were usually lower than the LIs from selected areas of tissue sections. The Lls determined by flow cytometry also correlated well with those from selected areas of tissue sections. Thus, the flow-cytometry-derived LI and the tissue-derived LI provide useful information for predicting biological behavior of individual tumors and for designing treatment regimens for patients with brain tumors. Different standards, however, must be used to interpret the LIs obtained by these two methods.

We also analyzed paraffinembedded specimens of brain tumors from 256 patients who had received an intravenous infusion of BrdUrd during craniotomy. We used DNA flow cylometry to determine the modal population. A single Gi peak indicales a unimodal DNA population; two or more Gl peaks indicate a multimodal population. Most pituitary tumors and moderately anaplastic astrocylomas had unimodal DNA populations, whereas a higher percentage of other slowgrowing tumors had multimodal populations. A similarly high percentage of the rapidly growing brain tumors also had multimodal populations. In most tumor groups, however, the percent of tumors with multimodal DNA populations did not correlate with the BrdUrd labeling index or the percent of BrdUrdlabeled cells. Thus, analysis of DNA distribution by flow cytometry may provide information about the degree of heterogeneity and the biological behavior of individual brain tumors, but the results do not necessarily correlate with the rate of tumor growth or the prognosis in individual patients.

\section{References}

Cho, K. G., T. Nagashima. S. Bamwell. and T. Hoshino (1988), "Flow Cylomelric Determination of Model DNA Population in Relalion to Proliferalive Polential of Human Intracranial Neoplasms." I. Newrosury. 68, 588-592.

Nagashima. R.. T. Hoshino. K. G. Cho. M. Senegor. F. Waldman, and K. Nomura (1988). "Comparison of" Bromodeoxyuridine Labeling Indices from Tissue Sections and Flow Cytometry of Brain Tumors." I. Neturosurg. 68. 388-392. 


\section{Molecular Regulation of Complement Activation}

\author{
Principal Investigator: (i. A. Jarvis*
}

Co-Investigators: $R$. Langlois and

J. M. (iriffiss*

* Lniversily of Callifomia. Sin Francreas

$\mathrm{T}$ he primary inmunologic barrier to bacterial infection depends on a Iwo-step process. First. antibodies from the host recognize and attach to antigens on the surface of bacterial. Second. a system of proteins. known as complement. recognizes the antibody-antigen complex and kills the antibody-coated bacteria by lysing its membrane. For infection by the bacteria Noisscria

meningitidis, resistance to disease is correlated with the formation of strain-specific bactericidal activity. The mechanism is antibodydependent, complement-mediated immune lysis. The classical pathway (CP) of complement activation has long been assumed to be the principal effector pathway.

Recently however, two human families with multiple cases of fatal. fulminant (group B. C, and Y) meningococcal infection have been identified. These cases suggest that the altemative complement pathway (ACP) is important for protection against meningococcal disease. In addition. fully encapsulated (group B) meningococci and $\mathrm{K} \mathrm{I}$ Escherichia coli. in the absence of host-acquired immunity. have been found to resist the activity of the ACP. Resistance was dependent on production of an identical $\mathrm{K}$ polysaccharide homopolymer of sialic acid by both organisms.

\section{We are using analytical cytology to investigate complement mechanisms that are of fundamental importance to the body's immunologic defenses against many bacterial infections.}

Our objective was to detine the contribution of the ACP to host defense against gram-negative infection and to understand the ACP regulatory role of $\mathrm{K}$ polysalecharides using $E$. coli and $N$. meningitidis als target cells as models. We hypothesized that production of $\mathrm{K}$ polysaccharides reduces ACP activation with variable degrees of efliciency related to quantitative and structural differences, and that a specific antibody augments ACP activation by either the increased efficiency or extent of ACP activation.

Our specific aims were twofold. First, we attempled to determine whether there are quantitative differences in the capacily of $\mathrm{K}$ polysaccharides of different structural or chemical families to regulate ACP activation. We used flow cytometry to quantify $\mathrm{K}$ polysaccharide expression by and ACP component binding to bacteria. Second, we used flow cytometry to determine the effect of $\mathrm{K}$ polysaccharide antibody on the kinetics of binding ACP components to specilic groups of $N$. meningitidis and $E$. colli.

We used a fluorescein-labeled anti-K polysaccharide monoclone and a FACS II llow cytometer. We found interstratin differences in the quantity ol' $\mathrm{K}$ polysaccharicle produced by various strains of group B N. mo'minzitidis. We also found intrastrain differences in $\mathrm{K}$ polysalccharide production depending on the growth phase of the halcterial cell. Thus. we can group strains based on the quantity of $\mathrm{K}$ polysalccharide they produce. We ilso identified subpopulations of cells that produced exceptionally high amounts of $\mathrm{K}$ polysaccharide. a finding that led us to propose that this group of high-producer cells resists killing by complement in the blood and produces septicemia.

In $N$. gommoloreare, we used a FACS II flow cytometer and a monoclonal antibody directed at a lipo-oligosaccharide (LOS) epitope (antigenic determinant) to define the dynamics of LOS expression over time. LOS is an important molecule for the serum resistance of this organism. We found a reduction in fluorescence (monoclonal binding) in the entire population as growth progressed from 2 to 8 hours in culture. This result indicates that the density of LOS expression was a function of the time of growth and that variable LOS expression at the single-cell level maly affect the outcome of the bacterial-complement interaction.

In other work, we concluded thall the degree to which strains of N. meningitidis are lysed and killed 
in human serum is a function of strain-specific binding of properdin. which is one of the initiators of ACP. Our most recent investigations used flow cytometry to quantify simultaneously $\mathrm{K}$ polysaccharide production by and complement component binding to

N. meningiticlis. We found. for two group $\mathrm{B}$ strains. a correlation between increased $\mathrm{K}$ polysaccharide production and decreased complement $\mathrm{C} 3$ deposition. These investigations confirm the importance of $\mathrm{ACP}$ in defending the host against N. meningitidis infection.

\section{References}

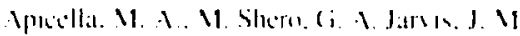
Gritlins, R. F. Mandrell. and H. Situneader 1 1987 . "Phenon! pue Variation in Epilope

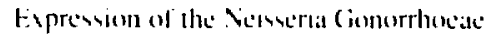

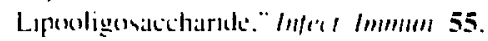
$1755-1761$.

Jarsen. (i. A.. H. Schneider. N1. K. Alherturom. and J. M. Griftion (IUksis. "Stram-Specific. Direceled Binding of Properdin Accounls tor

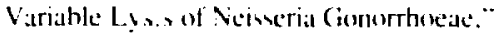

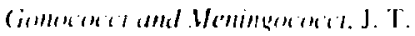
Pontman of al . Fals Martinus Siphutf. Derdircht. The setherlands). 
$I \cdot R \cdot \& \cdot D$

\section{Resource Requirements \& Author Index}

Lawrence Livermore National Laboratory 


\section{FY88 Budget}

\section{Institutional Research and Development Program}

FY88 actual cost, thousands of dollars

\section{Exploratory Research}

Biotechnology

Chemistry and Materials Science

Computation

Earth Sciences

Engineering

Nuclear Chemistry

Physics

Director's Initiatives

Biotechnology

Energy Research

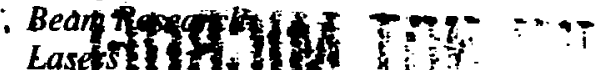

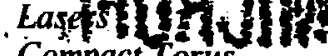

Compact Torus

Supercospty

Individual Awards

26 projects funded in FY88

31 grants projected for FY89

University of California Institutes

Institute of Geophysics and Planetary Physics

Institute for Scientific Computing Research

Plasma Physics Research Institute

Program for Analytical Cytology

\section{IR\&D Administration}

\section{Totals}

\section{Capital Equipment}

Operating Costs
$\$ 5,464$

99

1,003

728

876

498

750

2,010

6,495

710

110

773

2,150

1,252*

1,500

$3,241 \dagger$

1,979

$1,454 * *$

185

150

190

$339+\dagger$

$\$ 180$

$\$ 18,018$

\footnotetext{
-The Compact Torus Director's Initiative received an additional $\$ 11,000$ for capital equipment. for a total of $\$ 1,263,000$.

†Individual researchers were awarded an additional $\$ 112,000$ for capilnl equipment, for a total of $\$ 3,353,000$.

**The Institute of Geophysics and Planetary Physics received an additional \$57,000 for capital equipment, for a total of $\$ 1,511,000$.

†+Cost includes $I R \& D$ Annual Report Fr87, salaries, and administrative expenses.
} 


\section{Author Index}

A Albrition, J. R. 154

Alcock. C. 172. 209

Alder, B. J. 65, 218

Alsop. D. 208

Anderson, J. 194

Angel, S. M. 41

Anspaugh, L. R. 88

Arons, J. 208

Atherton, L. J. 107

Axelrod. T. 202. 219

B

Bacien. S. 220

Baer, B. 212

Baisden. P. A. 59

Balaban, D. 25

Balhorn, R. L. 7, 141, 148

Balooch. M. 161
Band, D. 201

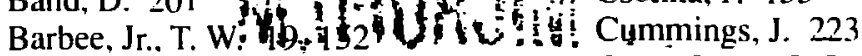

Bardsley, J. N. 79

Bauer. J. 144

Bazan. J. M. 52, 54

Beach, R. J. 112

Bebbe, T. 148

Beeman, J. 168

Bell, W. L. 148

Benett. W. J. 112

Bennett, J. 40

Bigbee, W. L. 227

Birdsall, C. K. 223

Bixler, J. 152

Blaedel, K. L. 47

Bonner, B. 157

Borchers, R. R. 23

Borg, I. Y. 99

Boyd, J. K. 165

Brand, H. 28

Brase, J. 115

Brodie, J. P. 178, 205

Buettner, H. M. 41

Bukowinski. M. 210

Burnard. D. 208

Buscheck, T. A. 38

C

Cadman, E. C. 227

Caffee, M. W. 52

Cameron, K. 195

Campbell, E. M. 77
Carey, P. G. 133

Carman, M. L. 96

Chantrenne. S. 175

Chiao, R. Y. 170

Chu, C. W. 10

Ciarlo, D. K. ' 63

Clark, G. 115

Clark. M. 22,

Coffield, F. 28

Cohen, B. I. 222, 223

Colella, P. 220

Colmenares, C. A. 21

Colvin. M. 218, 219

Connor. M. 21

Constable, S. 213

Cooper, J. F. 107

Corash, L. 226

Covey, C. 82

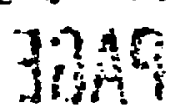

ffypn, H.-C. 215

is:

Dannevik, W. P. 24

Davis, J. 69

Davis, J. I. 117

Davis, P. 47

Dearborn, D. 206, 207

Decman, D. 56

Dermer, C. D. 182

Dibley, L. L. 36

Dietrich, D. D. 152,177

Dimonte, G. 222

Doehne, E. 198

Douglass, S. 167

Drake, T. 196

Droege, M. W. 96

Duba, A. G. 34, 213, 214

Durham, W. 65

Durst, M. 32

E

Eder, D. C. 71

Eeckmian, F. 219

Egan, P. O. 175

Elsholz, W. E. 21

Engelage, J. 56

Evans. C. L. 21
Caplan. M. 165 
F

Falckler. O. 73

Fallabella, S. 167

Felton. J. S. 8

Feo. J. T. 30)

Finkel. R. C. 52. 199

Fitch. J. P. 117.159

Flegal. A. R. 200)

Flittner, D. 22ב2

Fluss. M. J. 10

Franse, J. 47

Frenkel. D. 218

Friedmin, A. 45, 6?

Fry, I. J. 93

Fuller. G. 172

G

Gallant, Y. 208

Garbarini. J. 25

Garcia. E. 93, 97

Garcia-Gonzales. D. 193

Garrison. J. C. 170

Gaver. R. 21

Glassley. W. E. 42. 197

Gledhill, B. 69

Glenn. L. A. 43

Gonis. A. 15

Goodman, D. M. 159

Goto. T. 214

Goulding, F. 168

Grabowski, K. S. 13

Grant, P. M. 59

Gray, J. W. 115, 229, 230

Grieman, W. 25

Griffiss, J. M. 231

H

Hailey, C. J. 178, 204, 205

Haller, E. 168

Hallett, W. 177

Hammer, J. H. 122

Harrar, J. 40

Hartman, C. W. 122

Hartmann, D. 202. 203. 208

Hawkins. I. 206, 209

Henderson, L. F. 220

Hendricks, C. 67

Hernandez. J. 28

Hillyer, T. 222

Holmes, N. C. 215

Holzrichter, J. F. 1

Hornady, R. 155

Hoshino. T. 230
Hough. S. 194

Howell. R. H. 10. 182

liunter. J. 155

Hwang. D. 22ב

I

Irwin. J. J. 197

J

Jackson. K. J. 40. 158

Jiffe. H. 228

Jarvis. G. A. 231

Jean. Y. C. 10

Jeanloz. R. 216

Jensen, R. H. 226, 227

Johnson. S. 215

Jones, K. M. 182

Jura, M. 206

$\mathbf{K}$

Kahn, S. 204

Kasameyer, P. W. 41

Kercher. J. R. 88

Killeen, J. 221

King, W. E. 13

Klein, R. 208

Koniges, A. E. 24

Knapp, R. B. 38

Knauss, K. G. 40

Knittle, E. 216

Krupke, W. F. 112

L

Labov, S. 168

Ladd, A. 218

Lafranchi, E. A. 44

Lager, D. 28

Laming, J. M. 177

Landen, N. 77, 79

Landen, O. L. 173

Landis, D. 168

Langdon, A. B. 208

Langlois. R. 226. 231

Lawrence. T. W. 159

Lea. S. 177

Leich, D. A. 51, 54

Leith. C. E. 24

Liang, E. P. 182

Lindner, M. 54

Ljung. B.-M. 229

London, R. A. 71. 115

Lukasiewicz. P. 219
M

MacCracken. M. 81. 82

Malcdougill. J. D. I99

Madden, N. 168

Magnotta. F. 182

Maguire, G. 219

Malkan. M. 2(1)

Maple, M. B. 211

Marchant. Y. Y. 6

Margolis. S. 198

Markert. J. 211

Marlin, S. 63, 216

Marrus. R. 152

Massie. N. A. 117

Mathews. G. J. 172. 2(1)3

Malthews, D. 115

Maurer. W. 28

Max.C. E. 187. 188.208

Max. N. 141

Maxon, M. S. 71

Mayall, B. H. 225, 229

McClure, E. R. 50

McConaghy. C. F. 163

McKeegan, K. D. 52

McMahan. A. K. 63

McNally, K. C. 190

McWilliams. B. M. 133

Mendelsohn. M. L. 5

Miller, D. E. 161

Mitchell. A. R. 150

Mizuno, K. 222

More, R. M. 77

Morse, E. 45, 223

Mugge, M. 73

Mundinger, D. C. 112

Murovic, J. 230

$\mathbf{N}$

Nathel. H. 170

Nellis, W. J. 64, 211

Nelson, E. 69

Nelson, G. 190, 191, 193

Neumeier. J. 211

Nicol, M. 212, 215

Niemeyer. S. 54, 195, 200)

Nimz. G. 195

Nitao, J. J. 38

O

Orvis. W. J. 16.3 


\section{$\mathbf{P}$}

Pallavicini. M. 146

Palmer. C. E. A. 59

Park, S. S. 96

Patton. H. 194

Penner. J. 81.87

Perry. M. D. 79. 173

Peters, D. 115

Phinney. D. L. 52

Pinkel. D. 115

Pinto. P. 202

Poppe. C. 69

Porkolab. M. 224

Post. R. F. 167

Prior. M. H. 175

Procassini, R. 223

Proctor. I. 69

Prothero, Jr., W. 192

Puckett. E. G. 220

\section{$\mathbf{R}$}

Raffelt, G. 207

Ray. S. 45

Reichlin, R. 63. 157, 216

Reynolds, J. 197

Rosen, M. D. 71, 115

Ross. M. 63, 180, 210,212

Rubin, K. 199

Russ, III. G. P. 52. 54. 198

Russo, R. E. 55

Rutledge, J. 168

Ryerson. F. J. 34. 36, 157

\section{S}

Saks, S. 228

Salmeron, M. 148

Salop. A. 165

Sasinowski, J. 219

Schwartz. L. 33

Scott. W. S. 128

Seaman. C. 211

Searfus, R. 28

See. E. F. 21

Shinn, J. H. 6

Shreve, R. 196

Shumaker. D. E. 222

Siegmund. O. 204

Siekhaus. W. J. 7. 148.161

Sigmon, T. W. 133

Silk, J. 207

Silva, R. J. 55. 59

Silver. E. 168
Silver. J. 177

Simionovici. A. 177

Smiriga, N. G. 217

Smith, G. 157

Smith, H. S. 229

Snyderman. N. J. 171

Solarz, R. W. 112

Spies. R. B. 144

Stearns, D. G. 77

Steck. L. 192

Stewarı, R. E. 178

Stixrude. L. 210

Stöftl, W. 56

Stone, R. R. 165

Stowers, I. F. 50

Struble. G. L. 87

Sugihara, T. T. 9

Sugiyama, G. 218

Sweeney, J. J. 97

Szöke. A. 79. 173

T

Tang. J. 97

Tarter. B. 61

Tatchyn, R. 155

Taylor. R. T. 96

Thomson, T. 154

Thorington. C. 165

Tompson, A. F. B. 38

Toor. A. 155

Torres, R. A. 59

Trebes, J. 115

Turchi, P. E. 10

Turteltaub, K. W. 8

V

Van Arsdall, P. 115

Vanderlaan, M. 91

Vidale, J. 193

W

Wachs, A. L. 10

Walton, O. 196

Ward, R. A. 139, 141

Weiner. K. H. 133

Weisgraber, T, 167

Weiss. M. 75

Welcome. M. 220

Werblin. F. 219

Westenskow. G. A. 100. 155

Whelan, D. 155

Williams. Q. 216
Wilson. B. G. 154

Wilson. T. 148

Winter, N. 180

Wolery, T. J. 40

Wong, J. 17

Woosley, S. 202, 203. 208

Wright. E. 209

Wu.R.S. 191

Wuebbles. D. 81.82

Y

Yee, J. H. 163

Yorkey, T. 115

Young, D. 212

Youing. M. S. 34, 157

Yu. S. S. 100

Z

Zachary. A. 208

Zandt, G. 42, 190, 191, 192, 193

Ziock. K.P. 182

Ziolkowski, R. W. 45 